Patricia Purtschert



Eine Geschichte der weißen Schweiz

transcript] POSTCOLONIAL STUDIES

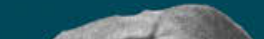


Patricia Purtschert

Kolonialität und Geschlecht im 20. Jahrhundert

Postcolonial Studies | Band 33 
Patricia Purtschert ist Philosophin und Kulturwissenschaftlerin sowie Co-Leiterin des Interdisziplinären Zentrums für Geschlechterforschung an der Universität Bern. 
Patricia Purtschert

\section{Kolonialität und Geschlecht im 20. Jahrhundert}

Eine Geschichte der weißen Schweiz 
Publiziert mit Unterstützung des Schweizerischen Nationalfonds zur Förderung der wissenschaftlichen Forschung

\section{Bibliografische Information der Deutschen Nationalbibliothek}

Die Deutsche Nationalbibliothek verzeichnet diese Publikation in der Deutschen Nationalbibliografie; detaillierte bibliografische Daten sind im Internet über http://dnb.d-nb.de abrufbar.

\section{(c) $(1) \Theta \Theta$}

Dieses Werk ist lizenziert unter der Creative Commons Attribution-NonCommercial-NoDerivs 4.० Lizenz (BY-NC-ND). Diese Lizenz erlaubt die private Nutzung, gestattet aber keine Bearbeitung und keine kommerzielle Nutzung. Weitere Informationen finden Sie unter https://creativecommons.org/licenses/by-nc-nd/4.o/deed.de Um Genehmigungen für Adaptionen, Übersetzungen, Derivate oder Wiederverwendung zu kommerziellen Zwecken einzuholen, wenden Sie sich bitte an rights@transcript-verlag.de

Die Bedingungen der Creative-Commons-Lizenz gelten nur für Originalmaterial. Die Wiederverwendung von Material aus anderen Quellen (gekennzeichnet mit Quellenangabe) wie z.B. Schaubilder, Abbildungen, Fotos und Textauszüge erfordert ggf. weitere Nutzungsgenehmigungen durch den jeweiligen Rechteinhaber.

\section{() 2019 transcript Verlag, Bielefeld}

\section{Umschlaggestaltung: Maria Arndt, Bielefeld}

Umschlagabbildung: Bild 1: Werbung für Lux-Seife (Ausschnitt), Quelle: Schweizer Illustrierte Zeitung 1932(7); Bild 2: Bergsteiger Peter Diener, Quelle: Titelbild Schweizer Illustrierte Zeitung 1960(26)

Lektorat: Petra Schäfter, textetage

Satz: Justine Buri, Bielefeld

Druck: Majuskel Medienproduktion GmbH, Wetzlar

Print-ISBN 978-3-8376-4410-4

PDF-ISBN 978-3-8394-4410-8

https://doi.org/10.14361/9783839444108

Gedruckt auf alterungsbeständigem Papier mit chlorfrei gebleichtem Zellstoff. Besuchen Sie uns im Internet: https://www.transcript-verlag.de Bitte fordern Sie unser Gesamtverzeichnis und andere Broschüren an unter: info@transcript-verlag.de 


\section{Inhalt}

\section{Kolonialität und Geschlecht - Eine Einleitung $\mid 7$}

Paradoxien moderner Macht $\mid 15$

Kolonialität und Moderne 21

Europas >rassenloser Rassismus< | 27

Koloniale Amnesie | 31

Kolonialität, Geschlecht und Sexualität | 35

Moderne Subjektformation und Othering $\mid 40$

Koloniale Komplizenschaft | 50

Kulturelle Dimensionen des Rassismus $\mid 57$

Schweizer Alltagsrassismus und koloniale Unschuld | 62

\section{Kapitel 1}

\section{Weiße Waren: Die Erfindung der Schweizer Hausfrau $\mid 71$}

Vignette: >Total macht aus Braunbären wieder Eisbären | 72

Schweizer Warenrassismus $\mid 77$

Die Erfindung des >weißen N-<: Erster Teil | 88

Eine koloniale Genealogie des >weißen N-<| 96

Das >Senegalesendorf $<$ im Zürcher Zoo | 107

Weiße Männlichkeit und anti-egalitäres Othering | 114

Schweizer Schokolade und die Kommodifizierung

Schwarzer Körper 122

Die Erfindung des >weißen N-<: Zweiter Teil | 132

Warenrassismus und Othering $\mid 138$

Weiße Weiblichkeit in der Werbung 149

Die Schweizer Hausfrau und the white woman's burden $\mid 157$

Kolonialer Zivilisationsneid 164

Schwarzer Neid auf weißes Glück | 174

Konklusion: Weißsein als Versprechen | 179 


\section{Kapitel 2}

Kämpfe im Himalaya: Schweizer Helden in kolonialen Abenteuern | 185

Vignette: Kampf am Everest | 186

Imaginäre Bergtopografien | 194

Die Schweiz und die Berge in Zeiten der Dekolonisierung | 196

Erforschen und Erobern | 204

Tropische Alpen, alpine Tropen | 207

Schweizer >Berg-Othering $<\mid 211$

Der >native informant $<$ und die Grenzen der Kultur | 219

Nationale Freiheit und koloniale Expansion | 228

Koloniale Kämpfe am Himalaya | 234

Die Internationalisierung des Höhenbergsteigens 238

Nepal und die Schweiz: Ein Verhältnis >ungleicher Ähnlichkeit<| 246

Sahibs und Sherpas $\mid 252$

Männlichkeit in der Todeszone | 265

Über >Rassengrenzen< hinweg:

Tenzing Norgay und Raymond Lambert $\mid 276$

Schweizer >Technokolonialismus $<\mid 282$

Konklusion: >Berg-Othering < und Dekolonisation | 297

\section{Nachwort | 303}

Swiss Ways of Othering: Die Hausfrau und der Bergsteiger | 304

Das >hyperreale Europa und die Schweiz | 307

Für ein post-monolithisches Verständnis des Kolonialismus | 310

Weiterführende Überlegungen zur Schweizer Geschichte | 313

Danksagung | 323

Abbildungsverzeichnis | 327

Literatur | 329 


\section{Kolonialität und Geschlecht - Eine Einleitung}

„Da sitzt er, ausgelaugt. Schweigend. Eine flackernde Kerze erleuchtet nur spärlich die Kammer des Zimmermanns im Gastarbeiterheim. Der Euramerikaner aus einer Schweizer Ethnie spricht einen deutschen Dialekt und gibt vor, im Zeitalter von Jet und Web vor Gewalt und Hunger geflohen zu sein. Er hat sich jedoch jene Aura bewahrt, die schon unsere Krankenschwestern und Entwicklungshelfer faszinierte. Nennen wir inn Yacouba, erstens, um seine Identität zu schützen, und zweitens, weil er einen Familiennamen hat, bei dem man sich die Zunge aushaken würde. " ${ }^{1}$

Mit diesen Sätzen beginnt Abdourahman Waberis Persiflage auf die aktuelle Weltordnung, In den Vereinigten Staaten von Afrika. Waberi denkt sich darin eine Welt aus, in der Afrika die unangefochtene ökonomische, kulturelle, technische und politische Vorherrschaft zukommt. Der unerschöpfliche Reichtum des afrikanischen Kontinents wird mit dem Elend der zahlreichen illegalen Migrant*innen kontrastiert, die aus Euramerika auf den Kontinent drängen und an den Rändern der Großstädte in Armut und Verzweiflung leben. Stellvertretend für diese verarmten Massen wird die Geschichte von Yacouba erzählt, einem Schweizer, der »in einer verseuchten Favela der Region Zürich geboren [wurde], wo Kindersterblichkeit und AIDS [...] Rekordwerte erreichen «. ${ }^{2}$

Die afrikanischen Reaktionen auf die Migrationsbewegungen aus Euramerika fallen unterschiedlich aus: Professor Garba Huntingawbe von der Kenyatta School of European and American Studies stellt im Fernsehen die rhetorische Frage, ob Afrika weiterhin das ganze Elend der Welt aufnehmen könne, und fordert die rücksichtslose Abschiebung aller aus-

1 | Waberi 2007, 9.

2 | Waberi 2007, 9. 
ländischen Staatsangehörigen: »Zuerst die Illegalen, dann die Halblegalen, dann die Paralegalen und so weiter und so fort.« ${ }^{3}$ Dagegen hält ein alternatives Netzwerk, dessen Gesicht Dounya Daher von der Universität Langston Hughes in Harar ist. Sie hat sich unter anderem einen Namen gemacht »für ihre Kampagne zugunsten eines Herkunftssiegels [...], das in den Supermärkten von Abidjan für fair gehandelte Bananen aus Nebraska ${ }^{4}$ wirbt. Der Sprecher der Vereinigten Staaten von Afrika schließlich, Seine Exzellenz El Hadj Saidou Touré, erklärt »die Stabilisierung des Friedens in Westeuropa zur absoluten Priorität « ${ }^{5}$ für die afrikanische Staatengemeinschaft.

Während die Mächtigen der Welt, sprich Afrikas, miteinander ringen, zieht der Schweizer Yacouba auf der Suche nach Arbeit und Nahrung durch die Straßen von Asmara, begafft von den Einheimischen: »Wenn er vorübergeht, drehen sich die Fußgänger nach ihm um, erstaunter als Völkerkundler, die im tiefsten Bayern auf einen primitiven Volksstamm stoßen. ${ }^{6}$ Yacouba verschwindet noch vor Ende der ersten Hälfte des Romans. Er wird tot in einer Sackgasse an der Rue Toussaint-Louverture aufgefunden, verblutet mangels medizinischer Hilfe. Lakonisch wird festgehalten: »Die Polizei hat nur wenige Indizien entdeckt, unter anderem seine dreckige Mütze und einen nicht abgeschickten Brief an seine Familie in Zürich. [...] Die ganze Ermittlung hat ein pickeliger Praktikant aus Arusha zusammengestoppelt. «7 Der Zürcher Yacouba, dessen richtigen Namen wir erst spät und nur beiläufig erfahren, bleibt gesichtslos und ohne Konturen. Dass er den Roman eröffnet, ist aber kein Zufall. Denn es sind die um ihr Überleben kämpfenden Figuren aus Euramerika, welche die Geschichte des reichen Afrikas umranken. Überall tauchen sie auf, überfluten und stören die glänzenden Straßenbilder der afrikanischen Hauptstädte. Das Elend Europas bildet die Kulisse für die Geschichte der privilegierten Protagonistin, einer afrikanischen Künstlerin europäischer Herkunft, die sich zwischen Gleichgültigkeit und kurz anhaltenden An-
3 | Waberi 2007, 13.
4 | Waberi 2007, 13.
5 | Waberi 2007, 14.
6 | Waberi 2007, 15.
7 | Waberi 2007, 60. 
fällen von sozialem Engagement zwischen diesen Gestalten aus einer anderen Welt bewegt. ${ }^{8}$

Waberis Roman ist eine eindrückliche Auseinandersetzung mit dem Kolonialismus und der neokolonialen Weltordnung. Mit dem Stilmittel der Umkehrung hält er dem Westen einen Spiegel vor Augen, der zeigt, wie widersinnig, kontingent und dennoch wirkmächtig die Trennung der Welt in eine fortschrittliche und eine rückständige Sphäre ist. Warum aber eröffnet Waberi seine Kritik an der kolonialen Weltordnung mit dem Bild eines verarmten Schweizer Migranten, der in den luxuriösen Straßen von Asmara um sein Leben kämpft und den Subalternen per se verkörpert? Warum lenken die ersten Sätze dieser fulminanten Abrechnung mit dem Kolonialismus die Aufmerksamkeit auf Zürich und nicht auf London, Paris, Amsterdam, Brüssel, Lissabon oder Madrid? Vielleicht weil Waberi es vermeiden will, eine ehemalige Kolonialmacht ins Zentrum zu stellen, weil sein Roman keine einseitige Abrechnung mit einer Metropole darstellt, sondern den gesamten europäisch-nordamerikanischen Machtkomplex in den Blick nehmen will? Denn mit Yacouba hat er eine Figur geschaffen, die mitten ins westeuropäische Selbstbild zielt. Die Schweiz, die er repräsentiert, gilt als Verkörperung einer idealisierten Idee des Westens: als friedliche, demokratische, humanitäre, multikulturelle, global vernetzte und ökonomisch höchst erfolgreiche Nation.

Yacoubas Herkunftsland wird im Roman explizit zum Thema gemacht: »Nach Afrika - oh Zaubername, Sesam-öffne-dich! - hat es Yacouba wegen der Milizen verschlagen, die sein Heimatland in briefmarkengroße Stücke zerschlagen. Dieser Flickenteppich mit Namen Schweiz wird seit vielen Jahrhunderten von ethnischen und sprachlichen Auseinandersetzungen heimgesucht. [...] Von allen Seiten prallen verschiedene Dialekte und Echos von Hass und Verbitterung in ansteckendem Missklang aufeinander, einmal ganz abgesehen davon, dass zwei Drittel der Fläche schneebedeckt, öd und unbewohnbar sind. « In dieser Passage nutzt Waberi die Figur des Zürcher Flüchtlings, um ein bekanntes Bild der Schweiz, gleichzeitig ein beliebtes Selbst- und ein viel zitiertes Fremdbild, satirisch umzukehren. Da ist einmal ihre landschaftliche Beschaffenheit: Waberi verweist darauf, wie die Alpen, die im Diskurs der Aufklärung zum Inbegriff natürlicher Schönheit und Erhabenheit erklärt

8 | Vgl. dazu die Gedanken der Übersetzerin (Meintel 2007, 151f.).

9 | Waberi 2007, $21 f$. 
wurden, aus einer genauso vertretbaren, aber weniger wohlwollenden Perspektive als »schneebedeckt, öd und unbewohnbar« geschildert werden können. So wie die Landschaften Afrikas oftmals als von der Sonnenglut geplagte Wüsteneinöde oder als undurchdringbares Dschungeldickicht beschrieben und als tropisches Gebiet in Gegensatz zu den gemäßigten Zonen Europas gesetzt werden, so zeigt er, lässt sich das verklärte Bild der mythisch schönen Schweizer Bergwelt in sein Gegenteil verkehren. Eindrücklich ist nicht nur die Umwertung der Werte, die dabei vorgenommen wird, sondern auch die Persiflage des hegemonialen Gestus, der dabei zum Ausdruck kommt. Dieser manifestiert sich auch in der Art und Weise, wie Yacouba beschrieben wird. Denn der subalterne Schweizer verfügt über keine Möglichkeit, seine Herkunft, seine Geschichte, seine Flucht oder seine Suche nach einem anderen Leben in eigene Worte $\mathrm{zu}$ fassen und dem dominanten und verkürzten afrikanischen Blick auf Euramerika etwas entgegenzuhalten.

Die Charakterisierung der Schweiz als »ethnischer Flickenteppich « widmet sich einem anderen bekannten Bild dieses Landes: Aufgrund ihrer föderalen politischen Struktur und ihres Umgangs mit der Mehrsprachigkeit wird die Schweiz immer wieder als Vorbild und Maßstab für Staaten angeführt, die zerrissen sind oder sich in der Zerreißprobe befinden. ${ }^{10}$ Dazu lässt sich kritisch anmerken, dass sich die egalitäre Sprachund Kulturpolitik in der Schweiz auf vier und nur vier Sprachen bezieht: Rätoromanisch, Italienisch, Französisch und Deutsch. Englisch, Portugiesisch, Albanisch, Serbisch, Kroatisch oder Spanisch, Sprachen also, die in der Schweiz sehr verbreitet sind, werden im Unterschied zu den vier Landessprachen vom Bundesamt für Statistik als sogenannte »Nichtlandessprachen « aufgeführt. ${ }^{11}$ Dieser eigenartige Begriff beschreibt Spra-

10 | Vgl. etwa die Publikation Swiss Democracy. Possible Solutions to Conflict in Multicultural Societies, die in der dritten Auflage vorliegt (Linder 2010).

11 | Vgl. den Eintrag "Sprachen" des Bundesamts für Statistik, https://www. bfs.admin.ch/bfs/de/home/statistiken/bevoelkerung/sprachen-religionen/spra chen.html (Zugriff am 24. September 2018). Gemäß dieser Darstellung, die sich auf die Strukturerhebung der Eidgenössischen Volkszählung stützt, gibt im Jahr 2016 fast ein Viertel der Bevölkerung, nämlich 24,1 \%, eine 'Nichtlandessprache، als Hauptsprache an. Die häufigsten ,Nichtlandessprachen sind Englisch (5,1\%), Portugiesisch (3,7 \%), Albanisch (3,1 \%), Serbisch/Kroatisch (2,4 \%) und Spa$\operatorname{nisch}(2,3 \%)$. 
chen, die im Land gesprochen werden, nach dem vorherrschenden Verständnis aber nicht zum Land gehören. Damit wird eine Grenze zwischen Sprachen gezogen, die als Bestandteil der Schweiz anerkannt werden, nämlich Deutsch, Französisch, Italienisch und Rätoromanisch, und solchen, die als >fremd und >zugewandert gelten. Allerdings wurde Rätoromanisch erst $1938 \mathrm{im}$ Zuge einer eidgenössischen Volksabstimmung zur vierten Landessprache erklärt. ${ }^{12}$ Dieses Ereignis macht nicht nur die relativ junge Geschichte der Landessprachen und die historische Kontingenz dieser Entscheidung deutlich: Rätoromanisch wurde im Kontext der $>$ Geistigen Landesverteidigung ${ }^{13}$ und als Reaktion auf italienische Ansprüche auf Schweizer Gebiet zu einer offiziellen Sprache gekürt. Die Anerkennung des Rätoromanischen als vierte Landessprache zeigt darüber hinaus auch eine historisch verbriefte Möglichkeit auf, die Anzahl und Bedeutung von Landessprachen $>$ demokratisch ${ }^{14} \mathrm{zu}$ beschließen.

Während also die Schweiz immer wieder als Vorbild für krisenanfällige Staaten verwendet wird, zeigt Waberis satirische Umkehrung, dass Mehrsprachigkeit und kulturelle Vielfalt ihre positive Konnotation erst durch die Situierung im westeuropäischen Kontext erhalten. Im Hinblick auf Afrika jedoch, das die Hintergrundfolie für Waberis Darstellung der Schweiz bildet, mutieren dieselben Unterschiede unter der Hand zur Begründung für die politische Unfähigkeit, einen Nationalstaat zusammenhalten und regieren zu können. Das Vorzeigemodell der multikulturellen Schweiz wird unter diesem Perspektivenwechsel zum >Flickenteppich mit Namen Schweiz

Waberis Satire funktioniert deshalb so gut, weil sie sich über ein Kernstück der modernen Weltsicht mokiert: die Einteilung der Welt in einen friedlichen modernen >Westen (Europa und Nordamerika) und einen

12 | Liver 2012; Valär 2013.

13 | Der Begriff umfasst politische und kulturelle Bewegungen, die mit der Stärkung und Propagierung von sschweizerischen. Werten den Nationalsozialismus, Faschismus und Kommunismus abwehren wollten. Vgl. Jorio 2006.

14 | Demokratisch heißt im vorliegenden Fall, dass alle erwachsenen Männer mit Schweizer Bürgerrecht über die Anerkennung von Rätoromanisch als Landessprache abstimmen konnten. Dies wirft grundlegende Fragen nach dem Verhältnis zwischen den Menschen auf, die in der Schweiz leben, und denjenigen, die über die Gestaltung des gemeinsamen Lebensraums entscheiden können. 
rückständigen und gewaltgeladenen $>$ Rest ${ }^{15}$ (Afrika, Asien, Lateinamerika, die Karibik und Ozeanien). Dass diese hierarchische Zweiteilung auf den Kolonialismus zurückgeht, entspricht mittlerweile einem breit etablierten Konsens der postkolonialen Forschung. Bislang hat sich diese jedoch wenig mit der Bedeutung der Schweiz innerhalb dieses kolonialen Nexus befasst. Was Waberi mit der Figur des Schweizers Yacouba und den stilistischen Mitteln der Literatur so treffend vor Augen führt, weist deshalb ins Zentrum der Fragen, die mich in dieser Arbeit umtreiben: Wie prägte die koloniale Episteme die Herausbildung von Geschichte, Kultur und Gesellschaft in der Schweiz? Wie strukturieren koloniale Denkmuster das Wissen über die Welt und die Fremd- und Selbstwahrnehmung dieses Landes von der Zeit ihrer Entstehung Mitte des 19. Jahrhunderts bis hinein die Gegenwart? ${ }^{16}$

Die Thematisierung der kolonialen Vergangenheit und der postkolonialen Gegenwart der Schweiz liegt noch immer quer zu gängigen Mustern nationaler Selbstdarstellung. Exemplarisch dafür ist die Äußerung des Schweizer Vertreters auf der Weltkonferenz gegen Rassismus in Durban 2001. Er gab im Vorfeld der Veranstaltung zu Protokoll, dass Entschädigungsforderungen für die Schweiz kein Thema seien, »da wir mit Sklaverei, Sklavenhandel und Kolonialismus nichts zu tun hatten «. ${ }^{17}$ Zehn Jahre später betonte die scheidende sozialdemokratische Bundesrätin Micheline Calmy-Rey in ihrer Abschiedsrede, dass die Schweiz »dank ihrer langen Tradition der Demokratie und des Dialogs, ihrer nichtkolonialen Vergangenheit, ihrer Neutralität, der ausgezeichneten Qualität ihrer Diplomatie und der Stabilität ihres politischen Systems « ${ }^{18}$ eine besonders geeignete Partnerin für die internationale Zusammenarbeit in einer globalisierten Welt darstelle. Vor Kurzem hielt sich schließlich Bundesrätin Doris Leuthard während eines offiziellen Besuchs in der Hafenstadt Ouidah in Benin auf, einem ehemaligen Zentrum des Skla-

15 | Hall 1992, 279.

16 | Für eine postkoloniale Auseinandersetzung mit der Gründungsphase der Schweiz vgl. Schär 2016b.

17 | Vgl. Egli, Martina: "Weder Entschuldigung noch Entschädigung", in: Die Weltwoche, 7. Juni 2001. Siehe auch David, Etemad und Schaufelbühl 2005, 8f., sowie zur Rezeptionsgeschichte dieser Äußerung Purtschert 2011a, 2011b und 2011c.

18 | Calmy-Rey 2011 [Hervorhebung PP]. 
venhandels. Bei einem Fernsehinterview gab sie zu Protokoll: »C'est une partie de l'historie du Bénin. Une partie historique qui est une tragédie. Et j'ai dit à Monsieur et Madame la ministre: Je suis contente que la Suisse ne participait jamais ni à ces histoires d'esclavage ni à la colonisation «. ${ }^{19}$ Waberis Satire auf die globale Herrschaftsgeschichte lässt sich als Aufforderung lesen, solche Selbstbilder radikal infrage zu stellen.

Die vorliegende Arbeit kommt dieser Aufforderung nach, indem sie das Selbstverständnis der Schweiz als am europäischen Kolonialismus unbeteiligte Außenseiterin in Zweifel zieht. Sie reiht sich damit in eine junge, aber schnell anwachsende Forschungsliteratur ein, die sich mit der Kolonialgeschichte der Schweiz und ihren Auswirkungen auf die Gegenwart auseinandersetzt. Zu diesem Korpus gehören Forschungsarbeiten, welche die Schweizer Geschichte als Bestandteil einer globalen Vernetzungsgeschichte ausweisen, indem sie die wirtschaftlichen oder wissenschaftlichen Verflechtungen von Schweizer Akteur»innen und Institutionen mit dem Kolonialismus zum Thema machen. ${ }^{20}$ Im Unterschied dazu widmet sich diese Studie den kulturellen, diskursiven und epistemischen Formen des Kolonialismus und führt damit eine Debatte fort, die seit einigen Jahren mit dem Begriff der >postkolonialen Schweiz< verbunden wird. ${ }^{21}$ Sie reflektiert die koloniale Herkunft und Verflochtenheit der Bilder, Vorstellungen und Wahrnehmungen von Selbst und Anderem, Heimischem und Fremdem, die in diesem Land vorherrschend sind und nicht nur politische Diskussionen und wissenschaftliche Studien, sondern - und das ist ein vordringliches Thema meiner Untersuchung auch das populäre Wissen und die Alltagswelt durchdringen.

Eine weitere Erkenntnis begleitet diese Analyse der postkolonialen Schweiz auf Schritt und Tritt: Koloniale Denkstrukturen sind untrennbar mit Geschlechterdiskursen verwoben. Rassifizierte Vorstellungen von Selbst und Anderem ermöglichen auf vielfältige Weise die Durchsetzung

19 | Leuthard, Doris 2017, Visite à Ouidah: La Présidente Suisse Doris Leuthard se prononce sur l'histoire de l'esclavage. https://www.youtube.com/watch?v=0g MgptOuLLo (Zugriff am 24. Oktober 2018).

20 | Vgl. u.a. Schär 2015; Dejung 2013; Zangger 2011; David, Etemad und Schaufelbühl 2005; Fässler 2005. Für einen umfassenden Überblick vgl. Purtschert und Fischer-Tiné 2015.

21 | Vgl. Purtschert 2008a und 2008b; Purtschert, Lüthi und Falk 2012a; Purtschert, Falk und Lüthi 2015. 
dominanter Geschlechter- und Sexualitätsnormen, während diese umgekehrt koloniale Hierarchien denkbar und plausibel machen. Diesen gegenseitigen Verweisungszusammenhang $\mathrm{zu}$ rekonstruieren, ist eine vorrangige Aufgabe dieser Studie. Dabei geht es um nichts weniger als darum zu zeigen, dass Schweizer Geschichte nicht ohne Kolonial- und Geschlechtergeschichte geschrieben werden kann, dass Kolonialgeschichte einer feministischen Analyse und Geschlechtergeschichte einer postkolonialen Perspektive bedarf.

Die vorliegende Einleitung steckt den theoretischen und methodischen Rahmen dieser Studie ab. Dafür wird in einem ersten Schritt eine postkoloniale Perspektive auf die Moderne eröffnet. >Rasse < wird als eine konstitutive Differenzkategorie dieser Epoche kenntlich gemacht, und es wird auf die bedeutsamen Widersprüche im modernen Gleichheitsverständnis verwiesen, die daraus resultieren. Im Anschluss daran steht ein zentraler Umbruch im 20. Jahrhundert im Fokus: Nach dem Zweiten Weltkrieg ereignet sich in Europa eine epistemische Zäsur, welche die gegenwärtige Verwendung und das Verständnis von $>$ Rasse ${ }^{22}$ bis heute kennzeichnet. Sie ist für dieses Buch auch deshalb bedeutsam, weil sich die beiden historischen Untersuchungen, die ich vorstelle, auf die 1930 er und 1950er Jahre beziehen und damit vor und nach diesem Bruch angesiedelt sind. In einem nächsten Schritt werden die strukturelle Ähnlichkeit und die interdependente Verschränkung von Geschlecht und >Rasse als zwei grundlegende Differenzkategorien der Moderne thematisiert. Zudem wird das Konzept des Othering eingeführt, mit dem Prozesse der hierarchischen Differenzproduktion beschrieben werden können.

Der Begriff der >kolonialen Komplizenschaft<, der danach eingeführt wird, ermöglicht es, die Bedeutung des Kolonialismus für diejenigen Länder zu erörtern, die sich - wie die Schweiz - nicht als Kolonialmächte verstanden und dennoch zur westeuropäischen Metropole gehörten. Dabei zeigt sich, dass auch in solchen Ländern ein >koloniales Imaginäres< ausgemacht werden kann, das sich gerade in Alltagszusammenhängen und

22 | Im Folgenden steht der Begriff, Rasse، stets in Anführungszeichen, um eine explizite Distanznahme zu einer Verwendung dieses Begriffs zu markieren, die intrinsische kulturelle, soziale oder biologische Unterschiede zwischen Menschen behauptet. Alternativ spreche ich von 'Rassifizierung، als Bezeichnung für diejenigen Prozesse, mit denen die Sichtbarkeit, Intelligibilität und soziale Wirklichkeit von Rassendifferenzen hergestellt und durchgesetzt werden. 
in populären Formen des Wissens niederschlägt. Daran schließt die methodische Frage an, was es bedeutet, Rassismus mit kulturwissenschaftlichen Mitteln zu untersuchen. Abschließend erfolgt ein Ausblick auf die beiden Untersuchungsfelder der vorliegenden Arbeit: Das erste Kapitel erforscht die Entstehung der wirkmächtigen Figur der Schweizer Hausfrau in den 1930er Jahren. Das zweite Kapitel wendet sich dem idealisierten Bild des Schweizer Bergsteigers in den 1950er Jahren zu und analysiert, inwiefern auch dieses auf einer kolonialen Matrix beruht.

\section{Paradoxien moderner Macht}

Der Postkolonialismus widmet sich der Reflexion historischer Zusammenhänge, die - sofern sie in ihrem ganzen Ausmaß zur Kenntnis genommen werden - das gängige Geschichtsverständnis, das auf einem eurozentrischen Weltbild fußt, radikal erschüttern muss. Denn zum einen zeigt die postkoloniale Forschung, dass die Moderne keine intrinsisch europäische Errungenschaft darstellt. Zum anderen legt sie dar, dass das Zeitalter der Aufklärung nicht mit der Befreiung der Menschen aus ihrer Unmündigkeit gleichgesetzt werden kann. Vielmehr wurde ein großer Teil der Menschheit gerade durch Praktiken, die mit der Aufklärung verbunden sind, in neue und systematische Ausbeutungsverhältnisse gezwungen. Damit werden zwei dominante Narrative infrage gestellt: erstens die historische These, dass alles, was zur Moderne gehört, im Westen entstanden und von da aus in die Welt diffundiert ist, und zweitens die normative These, wonach die Errungenschaften der Moderne die Existenzbedingungen der Menschheit grundsätzlich verbessert haben. Aus einer solchen Perspektive ergeben sich, wie noch zu zeigen sein wird, bedeutsame Allianzen mit anderen herrschaftskritischen Ansätzen, namentlich mit dem Feminismus.

In ihrer Kritik an der eurozentrischen Historiografie zeigen postkoloniale Studien, dass die Geschichte der Moderne in der Regel aus einem europäischen Blickwinkel verfasst wurde und dass (männliche) Europäer in diesen Narrativen als entscheidende Handlungsträger figurierten. Die Aufklärung, der Kapitalismus, die Industrialisierung sowie die Entstehung demokratischer Nationalstaaten, moderner Wissenschaften oder einer bürgerlichen Öffentlichkeit wurden als europäische Errungenschaften beschrieben, die von einem westlichen Zentrum aus in die 
Welt exportiert werden konnten. Dem setzt der Postkolonialismus eine Sichtweise entgegen, der zufolge die Entstehung der Moderne als Effekt von transnationalen und globalen Interaktionen zu verstehen ist. ${ }^{23}$ Diese sind zwar von außerordentlich asymmetrischen Machtkonstellationen gekennzeichnet, lassen sich aber nicht auf aktive Subjekte im Norden und passive Rezipient*innen im Süden zurückführen. ${ }^{24}$

Dadurch wird eine andere Rekonstruktion von Geschichte möglich: Sie kann nun aus der Sicht von Menschen beschrieben werden, die in einer eurozentrischen Geschichtsschreibung lediglich als Objekte einer von Europa vorangetriebenen Entwicklung erscheinen. ${ }^{25}$ Sichtbar werden damit, wie Achille Mbembe ausführt, »die vielfältigen Erfahrungen der Emanzipation und ihrer Grenzen und die Formen, in denen unterdrückte Völker zu historischen Subjekten wurden und damit ihrerseits zur Konstitution einer transnationalen und diasporischen Welt beitrugen $\ll^{26}$. Die postkoloniale Forschung macht die Handlungsspielräume und Errungenschaften kolonialisierter Subjekte sichtbar, erinnert an Widerstandskämpfe und an Aushandlungsprozesse, dokumentiert aber auch die immensen Machtdifferenzen zwischen Kolonien und Metropolen, Missionsgesellschaften und lokalen Gemeinschaften, kolonialen Siedler*innen und indigenen Einwohner*innen. ${ }^{27}$

Denn die Globalisierung ist, und darauf legt die postkoloniale Forschung ihr Augenmerk, unweigerlich verknüpft mit der Herstellung, Durchsetzung und Etablierung enormer Macht- und Gewaltverhältnisse, die etwa durch die Eroberungskriege in Amerika, den transatlantischen Sklavenhandel, die Errichtung europäischer Siedlerkolonien oder Kolonialreiche in Afrika, Asien, Lateinamerika, Ozeanien und der Karibik geschaffen worden sind. Der Blick auf diese gleichzeitig grundlegenden,

23 | Vgl. Gilroy 1993; Chakrabarty 2002; Ghosh und Kennedy 2006.

24 | Vgl. dazu exemplarisch Fischer-Tiné 2013.

25 | Vgl. Conrad, Randeria und Römhild 2013; Bhambra 2007; Manjapra 2014a.

26 | Mbembe 2013, 225.

27 | Die christliche Missionstätigkeit diente der Verbreitung der eigenen Glaubensvorstellungen und der Anwerbung neuer Glaubensgenoss*innen. In der Hochphase der Mission im 19. und frühen 20. Jahrhundert wurde besonders intensiv die sogenannte äußere Mission zur Bekehrung der 'Heiden، in Übersee betrieben. Die missionarischen Aktivitäen waren dabei in das imperiale Projekt eingebunden und auf vielfältige Weise mit inm verflochten. Vgl. Haller-Dirr 2010. 
aber in der vorherrschenden Wahrnehmung oftmals ausgeblendeten oder banalisierten Aspekte der Moderne fördert fundamentale Widersprüche zutage. Denn zur gleichen Zeit, als das bürgerliche Europa den Feudalismus abschaffte und Gleichheit und Freiheit zum Kern eines neuen menschlichen Selbstverständnisses erklärte, wurden große Teile der Menschheit erobert, beherrscht, versklavt, unterworfen und ermordet.

Postkoloniale Denker*innen gehen davon aus, dass sich diese Phänomene nicht unabhängig voneinander gleichsam zufällig parallel ereignet haben, sondern dass sie vielmehr miteinander verwoben sind und sich gegenseitig bedingt haben. So macht Toni Morrison deutlich, dass die amerikanische Unabhängigkeitserklärung und das mit ihr verbundene Freiheitsverständnis aufs Engste mit der Institution der Sklaverei und der Präsenz versklavter Menschen inmitten der amerikanischen Gesellschaft verknüpft waren: »Das Konzept der Freiheit entstand nicht in einem Vakuum. Nichts rückte die Freiheit derart ins Licht wie die Sklaverei - wenn sie sie nicht überhaupt erst erschuf. $\ll^{28}$ Vor einem solchen Hintergrund führt das aufklärerische Versprechen, die menschliche Gleichheit verwirklichen zu wollen, in ein Paradox. Denn Gleichheit wurde als allgemein gültiger Maßstab verkündet und zugleich mit Ausnahmen versehen, die einen Großteil der Menschheit betrafen. Françoise Vergès fragt entsprechend: »Quelle est cette égalité universelle qui ne s'appliquerait qu'à certains individus? Quelle en serait la justification sinon que l'égalité n'est pas un principe universel mais toujours soumis à l'exception? « ${ }^{29}$ Gleichheit wurde mit dem Anspruch der universellen Gültigkeit ausgestattet, de facto aber nur sehr partikulär eingefordert. Genau dieses Versprechen der Allgemeingültigkeit wurde aber, wie zahlreiche Freiheitskämpfe in der Geschichte der Moderne dokumentieren, zum Dreh- und Angelpunkt emanzipatorischer Bewegungen, die mit den Mitteln der Aufklärung gegen die Umsetzung der Aufklärung angehen.

Auf ein ähnliches Paradox zwischen dem Universalismus des Gleichheitsversprechens und seiner partikulären Auslegung weist Joan Scott aus einer feministischen Perspektive hin. ${ }^{30}$ Mit Berufung auf die französische

28 | Morrison 1994, 65. Siehe auch Patterson 1982 zum Verhältnis von Sklaverei und Aufklärung sowie die Studie von Buck-Morss 2011, die Hegels Reflexionen über die menschliche Freiheit zur transatlantischen Sklaverei in Bezug setzt.

29 | Vergès 2005, 115.

30 | Scott 1996. 
Deklaration der Menschenrechte, so Scott, forderten Frauen seit Beginn der bürgerlichen Revolutionen ihren Einschluss in die politische Sphäre und ihr Recht auf Partizipation. Dabei wurden sie kontinuierlich mit einem Paradox konfrontiert, das aus dem Konzept des Menschen folgte, welches den Menschenrechten zugrunde lag. Dieses Konzept definierte das Subjekt der modernen Demokratie als Individuum und setzte Individualität implizit mit Männlichkeit gleich. ${ }^{31}$ Frauen wurden als grundsätzlich abhängige Wesen verstanden und konnten die Kriterien des MenschSeins deshalb immer nur bedingt erfüllen. Wenn Frauen nun den Status des Menschlichen für sich einklagten, sahen sie sich gezwungen, auf eine Geschlechterdifferenz Bezug zu nehmen, die sie gleichzeitig überwinden wollten: »To the extent that it acted for >women<, feminism produced the >sexual difference $<$ it sought to eliminate. This paradox - the need to both accept and to refuse >sexual difference $<-$ was the constitutive condition of feminism. «2 Anders als Männer, die aufgrund ihres Geschlechts als Bürger und politische Subjekte wahrgenommen wurden, sahen sich Frauen dem Widerspruch ausgesetzt, dass sie als Menschen galten, die qua Geschlecht aus dem Verständnis des Menschlichen ausgeschlossen blieben.

Obwohl das Postulat menschlicher Gleichheit auf den ersten Blick als Garant für eine Politik gilt, in der grundlegende Rechte für alle gesichert sind, erweist es sich gerade auch als Ansatzpunkt für Ungleichheit und Ausschluss. In der Dialektik der Aufklärung sprechen Max Horkheimer und Theodor W. Adorno deshalb von der »repressiven Ungleichheit « ${ }^{33}$, die dem modernen Gleichheitsverständnis innewohnt. Der Nationalsozialismus, so die Autoren, führe diese »Entfaltung der Gleichheit des Rechts zum Unrecht durch die Gleichen ${ }^{34}$ vor Augen: Weil es nur für diejenigen gilt, die als >Gleiche< anerkannt werden, begründet das moderne Gleichheitsversprechen den Ausschluss und sogar die Vernichtung von Menschen, die zu Anderen gemacht werden. Wem die Anerkennung als Gleicher verweigert wird, die oder der fällt aus dem Raster des modernen Rechtssystems. Wer oder was als gleich oder ungleich definiert wird, erweist sich somit als eine zentrale Frage moderner Macht, denn die Kriterien, die zur Bestimmung des Gleichen verwendet werden - das

31 | Scott 1996, 5.

32 | Scott 1996, 3f.

33 | Horkheimer und Adorno 2001, 19.

34 | Horkheimer und Adorno 2001, 19. 
zeigen sowohl die feministischen als auch die antikolonialen Kämpfe werden weitgehend von denjenigen festgelegt, welche die gesellschaftliche Macht innehaben. Daraus folgt, so Andrea Maihofer, »dass es von immenser politischer und gesellschaftlicher Bedeutung ist, erstens: wer den Maßstab [der Gleichheit] bestimmt und zweitens: welche inhaltliche Bestimmung der Maßstab erhält « ${ }^{35}$.

Für die Frage, wie ein modernes Verständnis von Gleichheit bestimmt wird, sind Natur und Natürlichkeit entscheidend. Denn die Errichtung gesellschaftlicher Hierarchien in modernen Gesellschaften, die sich der Gleichheit verschreiben, wird durch den Rekurs auf die Natur und die Legitimierung durch die modernen Wissenschaften ermöglicht, die sich zunehmend der Durchdringung und Erforschung dieser Natur widmen. Ab dem 18. Jahrhundert wurde die ungleiche Behandlung von Frauen und Männern vermehrt mit biologischen Differenzen zwischen den Geschlechtern erklärt. ${ }^{36}$ Es entstand eine »qualitative Geschlechterdifferenz ${ }^{37}$, welche die Ungleichheit der Frauen mit wissenschaftlichen Mitteln zu begründen suchte. Wie Londa Schiebinger zeigt, verlief diese Entwicklung parallel zum weitgehenden Ausschluss von Frauen aus Forschungszusammenhängen. ${ }^{38}$ Das Konzept einer »Geschlechterkomplementarität«, das seit dem 18. Jahrhundert in den Wissenschaften entwickelt wurde und sich auch im populären Diskurs durchsetzte, rechtfertigte die paradoxe Klassifizierung der Frau als Mensch, dem kein Recht auf die Menschenrechte zustand: »The doctrine of sexual complementarity, which taught that men and women are not physical and moral equals but complementary opposites, functioned as an important supplement to nascent liberalism, making inequalities seem natural while satisfying the needs of European society for a continued sexual division of labor. « ${ }^{39}$ Die Komplementarität der Geschlechter begründete also nicht nur den Ausschluss der Frauen aus der Polis, sondern auch die moderne Arbeitsteilung, die den Frauen die unbezahlte reproduktive und den Männern die produktive Lohnarbeit zuwies.

35 | Maihofer 2001, 121.

36 | Honegger 1991.

37 | Maihofer 2001, 113.

38 | Schiebinger 1989.

39 | Schiebinger 1993, 39. 
Gleichzeitig mit der zunehmenden Festschreibung der Geschlechterdifferenz durch die Biologie wurden nun auch >Rassendifferenzen< vermehrt durch den Rekurs auf die Natur konstruiert und dadurch, im Zirkelschluss, begründet. Wie Schiebingers Arbeiten zeigen, verlaufen diese beiden Prozesse der Naturalisierung menschlicher Differenzen nicht einfach nur parallel, sondern sind vielmehr miteinander verknüpft. So galt dem schwedischen Naturforscher Carl Linnaeus, der die Grundlagen der modernen Taxonomie schuf, der Bartwuchs als Indiz sowohl für die Geschlechterdifferenz als auch für >Rassenhierarchien «: »Women, black men (to a certain extent), and especially men of the Americas simply lacked that masculine >badge of honor < - the philosopher's beard. $\star^{40}$ Die Körperbehaarung von Männern mutierte zu einem viel debattierten Gegenstand der Naturforschung im ausgehenden 18. Jahrhundert und ihr Fehlen wurde als »Zeichen der Unvollständigkeit« ${ }^{41}$ insbesondere von Frauen und Native Americans erachtet. Auch die Rassenlehre im 19. Jahrhundert, die sich intensiv mit der Vermessung von Knochen beschäftigte, begründete die Mangelhaftigkeit weiblicher Menschen mit den Defiziten von nicht-weißen Menschen und umgekehrt: »Women and Africans were seen as sharing similar deficiencies when measured against a constant norm - the élite European man. Women and black males had narrow, childlike skulls; both were innately impulsive, emotional and imitative. ${ }^{42}$ Diese Beschreibung macht nicht nur deutlich, dass sich Geschlecht und >Rasse gegenseitig konstituieren, sondern zeigt auch die eklatanten Leerstellen auf, die dabei entstehen. Obwohl er den impliziten Maßstab der Forschung bildet, bleibt der weiße Mann als Referenzpunkt des Menschlichen unsichtbar. Unsichtbar bleibt auch die Schwarze Frau, die in der Gleichsetzung von Geschlecht mit weißer Frau und von >Rasseく mit nicht-weißem Mann durch das epistemische Raster fällt.. ${ }^{43}$

40 | Schiebinger 1993, 120.

41 | Schiebinger 1993, 121.

42 | Schiebinger 1993, 158.

43 | Schwarz wird hier und im Folgenden groß geschrieben, wenn der Begriff Personen bezeichnet. Diese Schreibweise betont die Erfahrungen von rassistischer Unterdrückung und antirassistischem Widerstand, die Schwarze Menschen miteinander teilen. Die Großschreibung von Schwarz, so Claudia Unterweger, stelle eine "ermächtigend gemeinte (Selbst-)Bezeichnung einer gesellschaftlich marginalisierten Gruppe dar" und "unterstreicht die widerständige Bedeutung eines 
Die Erforschung menschlicher Körper, die über weite Strecken in der Erfindung körperlicher Unterschiede bestand, war unauflöslich mit der Frage des Politischen verbunden. ${ }^{44}$ Denn mit der abnehmenden Deutungskraft der Religion avancierte die moderne Wissenschaft zunehmend zum Erklärungsmodell für die Ordnung der Welt. Das moderne Demokratieverständnis wurde dabei mit einem Konzept von Natur verknüpft, das sowohl die Gleichheit bürgerlicher weißer Männer als auch die Ungleichheit von Frauen und nicht-weißen Menschen begründen sollte: »Thus the great public dramas of the eighteenth century - the struggles for enfranchisement and the abolition of slavery - exposed the Janus-face of nature destined to plague democratic orders for the next two hundred years: inclusion in the polis rested on notions of natural equalities, while exclusion from it rested on notions of natural differences. $\aleph^{45}$ Der Begriff menschlicher Gleichheit und der Verweis auf die Natur stellten zentrale Elemente eines Regulativs dar, das Zugehörigkeit und Ausschluss in modernen politischen Ordnungen herstellte, mit Differenzen wie Geschlecht, Sexualität, Kultur oder >Rasse< operierte und sich zunehmend auf die wissenschaftlich begründete Naturalisierung dieser Differenzen stützte. Die Begriffe des Menschen und der menschlichen Gleichheit waren damit tief geprägt von einer eurozentrischen und androzentrischen Logik des Ausschlusses. Gleichzeitig eröffneten sie bedeutende Schauplätze für die modernen Kämpfe um Einschluss, Partizipation und Anerkennung.

\section{Kolonialität Und Moderne}

Eine alternative Beschreibung der Moderne, die nicht bei der Gleichheit, sondern bei der Ungleichheit ansetzt und dabei die »colonial underside of European modernity ${ }^{46}$ freizulegen sucht, wurde in jüngerer Zeit im

Wortes, das in seinem ursprünglich rassistischen Sinn umgedeutet wurde" (Unterweger 2016, 215). Wenn es um die Analyse rassistischer Phänomene (wie den sschwarzen Neid، im ersten Kapitel) geht, wird schwarz klein geschrieben.

44 | Die Politik des 18. Jahrhunderts, so Schiebinger, war eine Politik des Körpers (Schiebinger 1993, 9).

45 | Schiebinger 1993, 9f. [Hervorhebung im Original].

46 | Dzenovska 2013, 398. 
Kontext der Dekolonisationstheorie entwickelt. Anibal Quijano datiert die Entstehung der Moderne auf die Eroberung Amerikas. ${ }^{47}$ Damit ging die Errichtung einer ökonomischen Struktur einher, die auf der radikalen Ungleichbehandlung von Menschen beruhte und sich zu einer Grundlage des modernen Kapitalismus entwickelte. Entscheidend für diese Ordnung ist die hierarchische Aufteilung von Menschen in solche, deren Arbeitskraft rücksichtslos ausgebeutet werden konnte, und solche, deren Arbeit in einer (wenn auch ungleichen) Form entlohnt werden musste. Die Herstellung dieser Asymmetrie beruhte, so Quijano, auf der neu aufgekommenen Idee von >Rasse $<$, die sich $\mathrm{zu}$ einem strukturierenden Prinzip moderner Gesellschaften entwickelte. Die Vorstellung biologisch abgestützter >Rassenunterschiede< ermöglichte die Einteilung von Menschen in solche, die als Träger von Rechten konzipiert waren, und solche, denen Rechte beliebig zu- und abgesprochen werden konnten. ${ }^{48}$ Quijano geht mit der postkolonialen Forschung einig, dass sich >Rasse $<$ nicht auf eine biologisch fundierte Verschiedenheit von Menschen bezieht, sondern eine >Fiktion < darstellt, deren Wirkmacht gerade auf der behaupteten Natürlichkeit von >Rassenunterschieden< beruht. ${ }^{49}$ Die eurozentrische Rationalität, die >Rasse $<$ als strukturierendes Moment der Moderne einsetzt, bezeichnet Quijano als »Kolonialität der Macht« (»coloniality of power $)^{50}$. Mit ihrer Hilfe konnten phänotypische Unterschiede und kulturelle Eigenheiten hergestellt oder spezifisch gewichtet und zu Kennzeichen von angeblich natürlichen Hierarchien gemacht werden. Die koloniale Unterwerfung und Ausbeutung von Menschen wurde derart mit einer >natürlichen` Unterlegenheit begründet, die aus der konstruierten Unterschiedlichkeit menschlicher >Rassen< hergeleitet wurde. ${ }^{51}$

Kolonialität als Analysebegriff umfasst neben der (kapitalistischen) Ökonomie insbesondere die koloniale Episteme, die rassifizierte Zuschreibungen als modernes Wissen hervorbrachte und reproduzierte. Von den Vertreter*innen der Dekolonisationstheorien wird es darum als vordringliche Aufgabe erachtet, Wissen zu dekolonisieren. Weil moderne

47 | Quijano 2000.

48 | Quijano 2000, 534.

49 | Der Begriff "fiction of race" wird von Amy Gutmann verwendet (Gutmann 1996). Für die Konstruktion von ,Rasser siehe Appiah und Gutmann 1996.

50 | Quijano 2000.

51 | Quijano 2000, 535. 
Wissensbestände und Wissenspraktiken aber von der eurozentrischen Rationalität durchdrungen sind, ist eine solche Aufgabe nicht einfach zu bewerkstelligen. Es gibt kein (gänzliches) Außerhalb des modernen Wissens, von dem aus die kolonialen Elemente des Wissens untersucht, kritisiert und ersetzt werden könnten. Entsprechend votiert Walter Mignolo für eine Praxis des »epistemic de-linking «52. Damit bezeichnet er die gezielte Unterbrechung der kolonialen Logik mit dem Ziel, die koloniale Matrix der Macht zu verschieben und andere Formen des Denkens vorstellbar zu machen. Ein solches dekolonialisiertes Wissen entsteht zugleich durch das Aufgreifen, Aufwerten und Aktualisieren von widerständischen und alternativen Wissensbeständen, die von den modernen Wissenschaften ignoriert, geringgeschätzt, de-legitimiert, vereinnahmt oder bekämpft worden sind.

Stärker noch als der Postkolonialismus, dessen Bezeichnung die Bedeutung der politischen (im Unterschied zur ökonomischen oder epistemischen) Dekolonisation als Zäsur hervorhebt, betont die These von der Kolonialität der Macht, dass die Arbeit des Dekolonisierens noch weitgehend vor uns liegt. ${ }^{53}$ Ein solches Verständnis ermöglicht es, die koloniale Konstellation als unausgewiesene Grundlage der Moderne sichtbar zu machen und dadurch eine fundamentale Kritik der Moderne als koloniale Formation zu formulieren. ${ }^{54}$ Aufgrund ihres zeitlich und räumlich weit gespannten Begriffs kolonialer Macht wird dekolonialen Ansätzen manchmal vorgeworfen, die zahlreichen Nuancen, Transformationen und lokalen Eigenheiten von Herrschaftsverhältnissen zwischen den Anfängen des Kolonialismus im 16. Jahrhundert und der Gegenwart einzuebnen. ${ }^{55}$ Allerdings lässt der Begriffsrahmen, den die Kolonialität der Macht aufspannt, durchaus eine differenzierte Auseinandersetzung mit historisch und geografisch spezifischen Kontexten zu - eine solche ist nicht zuletzt das Ziel meiner nachfolgenden, historisch situierten Analysen zur Schweiz der 1930er und 1950er Jahre.

52 | Mignolo 2009, 15.

53 | Allerdings gehen auch die Postcolonial Studies von der Kontinuität und Transformation kolonialer Bedingungen unter nachkolonialen Verhältnissen aus. Vgl. dazu Hall 2013.

54 | Kerner 2012, 94.

55 | Vgl. Kerner 2012, 94. 
Wie die Vertreter*innen der Dekolonisierungstheorie geht auch David Goldberg von einem >klassischen Rassismus< aus, der sich seit dem 16. Jahrhundert im Kontext von europäischer Expansion, Kolonialismus und Sklaverei als »self-proclaimed European superiority « ${ }^{56}$ entwickelte. Gleichzeitig betont er, dass die jeweilige Funktionsweise von >Rasse< als »a way (or a set of ways) of being in the world, of living, of meaning-making « ${ }^{57}$ ständigen Veränderungen unterliegt und deshalb nur in regional situierten und historisch differenzierten Analysen untersucht werden kann. Für das Westeuropa nach dem Zweiten Weltkrieg macht Goldberg eine koloniale Konstellation aus, die er als »rassenlosen Rassismus« (»raceless racism $\ll)^{58}$ beschreibt. >Rasse< bleibt dabei ein entscheidendes strukturelles Element europäischer Gesellschaften, unterliegt aber gleichzeitig einem Verbot der Artikulation. Der weitgehende Verzicht auf die Verwendung des Begriffs >Rasse< bedeutet demnach nicht, dass der Rassismus verschwunden ist, sondern, in den Worten von Colette Guillaumin, neu als ein »Phänomen der Zensur « ${ }^{59}$ gedeutet werden muss. Wie kommt es dazu, dass >Rasse< im europäischen Kontext kaum mehr als Ordnungskategorie verwendet wird und dennoch wirkmächtig bleibt?

Nach dem Zweiten Weltkrieg wurde die Shoa zum historischen Referenzpunkt für den Umgang mit >Rasse $<.{ }^{60}$ Die internationale Verurteilung der genozidalen Praxis des Nationalsozialismus führte zu einer offiziellen Abkehr von der Verwendung von Rassenkategorien. Wie Étienne Balibar ausführt, lässt sich dieser entscheidende »epistemologische Bruch « ${ }^{61}$ mit den beiden »Statements on the Question of Race« der UNESCO aus den Jahren 1950 und 1951 verbinden. ${ }^{62}>$ Rasse< als vorherrschendes Konzept zur Erklärung menschlicher Diversität wurde dabei durch den Begriff des Rassismus ersetzt, der auf die verheerende Wirkung dieses Differenzdenkens verweist. Damit wandelte sich auch das anthropologische Verständnis auf entscheidende Weise: Der Mensch wurde neu als Wesen verstanden, das des Rassismus fähig ist, und nicht mehr als eines, das durch

56 | Goldberg 2006, 331.

57 | Goldberg 2006, 334.

58 | Goldberg 2006, 356.

59 | Guillaumin 2000, 36.

60 | Goldberg 2006, 336.

61 | Balibar 2005, 18.

62 | Vgl. UNESCO 1969. 
$>$ Rasse< erklärt werden kann. ${ }^{63}$ Wegweisend für diese epistemische Zäsur war die Vorstellung von >Rasse<als Mythos, die in der ersten UNESCOErklärung zum Ausdruck gebracht wurde, sowie der Vorschlag, den »Rassenbegriff angesichts seines missverständlichen alltagssprachlichen Gebrauchs ganz fallenzulassen und durch den der >ethnischen Gruppen< zu ersetzen ${ }^{64}$.

Diese Formulierungen provozierten viel Widerspruch, nicht zuletzt aus den Reihen der Naturwissenschaften, wo großes Interesse bestand, an einem Begriff menschlicher biologischer >Rassen < festzuhalten. ${ }^{65}$ Auch wenn die Definition von >Rasse< damit ein umstrittener Aushandlungsgegenstand blieb, markierten die UNESCO-Erklärungen einen bedeutsamen Perspektivenwechsel in Wissenschaft, Politik und Gesellschaft, wie Staffan Müller-Wille festhält: »[D]ie Botschaft der Erklärung, soweit sie in den Massenmedien Widerhall fand, [war] klar: Rasse ist ein Mythos, ein Begriff für etwas, das es eigentlich, das heißt wissenschaftlich besehen, nicht wirklich gibt. ${ }^{66}$ In der Schweiz fand in der Nachkriegszeit eine (verspätete) doppelte Distanznahme vom Rassendenken statt: Einerseits schrieb sich die Schweiz in das postrassistische Verständnis Westeuropas ein, indem sie sich der Ablehnung eines nationalsozialistischen Rassenverständnisses anschloss. Andererseits wurde beteuert, die Schweiz habe weder am Kolonialismus noch am Nationalsozialismus partizipiert. Damit setzte sich die paradoxe Vorstellung durch, dass sich die Schweiz Mitte des 20. Jahrhunderts gemeinsam mit Europa von einem Rassismus abwandte, an dem sie angeblich nie beteiligt war. ${ }^{67}$ Diese diskursive Ver-

63 | Balibar 2005, 17.

64 | Keller 1995, 249.

65 | Diese Auseinandersetzungen führten schließlich zur zweiten UNESCO-Erklärung von 1951, in der zentrale Formulierungen abgeschwächt wurden. Vgl. dazu Müller-Wille 2003.

66 | Müller-Wille 2003, 79.

67 | Dass die Schweiz sehr wohl in rassistische Praktiken involviert war, zeigen etwa die Studien von Pascal Germann zur Rassenforschung. Während diese im frühen 20. Jahrhundert in den Kolonialländern mehr und mehr der Kritik durch anti-koloniale Bewegungen ausgesetzt war, entwickelte sich beispielsweise ein an der Universität Zürich angesiedeltes anthropologisches Institut zu einem führenden Forschungszentrum für Rassenforschung: "The Zurich school of anthropology's reputation as a purely scientific school, independent from imperialist powers 
schiebung ereignete sich allerdings erstaunlich spät. So verschwand, wie Pascal Germann ausführt, der nach wie vor gebräuchliche Begriff der »Rassenhygiene« erst um 1970 aus den biowissenschaftlichen und medizinischen Diskursen der Schweiz. ${ }^{68}$

Das neue, international ausgehandelte Verständnis von >Rasse $<$, das sich Mitte des 20. Jahrhunderts durchsetzte, hatte unter anderem zur Folge, dass sich westliche Staaten die Bekämpfung von Rassismus zur Aufgabe machten. ${ }^{69}$ Dem staatlichen anti-rassistischen Engagement lag ein geläutertes Verständnis der Menschenrechte zugrunde, das nicht mehr mit den >Rassenhierarchien< zu vereinbaren war und stattdessen zum wirkmächtigsten Gegenmittel gegen Rassismus avancieren sollte. Die postkoloniale Forschung ist sich mit Guillaumin, Balibar und Goldberg allerdings weitgehend einig, dass mit dem Verschwinden des Begriffs >Rasse< nicht auch gleichzeitig die strukturelle Wirkmacht von Rassismus überwunden war. Stuart Hall spricht von einem »kulturellen Rassismus $\ll^{70}$ und Balibar von einem »Rassismus ohne Rassen ${ }^{71}$, die sich seit Mitte des 20. Jahrhunderts als Reaktion auf diese Transformationen herausgebildet haben.

Beide Autoren situieren dieses Phänomen im Kontext der politischen Dekolonisation sowie der neuen Migrationsbewegungen von den Ex-Kolonien in die Ex-Metropolen. Es handelt sich, wie Balibar schreibt, um einen »Rassismus der >Entkolonisierung $<$, in der sich die Bewegungsrichtung der Bevölkerung zwischen den alten Kolonien und den alten >Mutterländern $<$ umkehrt « ${ }^{72}$. Kennzeichnend für diesen Rassismus ist, dass der Begriff >Rasse< durch neue und scheinbar unverfängliche Konzepte wie Kultur oder Ethnizität ersetzt wurde. Zur Herstellung hierarchisierender Unterschiede zwischen Menschen und Gesellschaften wurden nun

and apolitical, substantially contributed to its international attraction. The reality, however, looked quite different." (Germann 2015, 55). Die Schweizer Rassenforschung entstand in enger Verbundenheit mit kolonialen Forschungsprojekten und wurde international führend beim Entwickeln und Setzen anthropometrischer Messmethoden und Standards. Vgl. auch Germann 2016.

68 | Germann 2016, 413.

69 | Balibar 2005, 23.

70 | Hall 2000a, 11.

71 | Balibar 1990, 28.

72 | Balibar 1990, 28. 
verstärkt differente Kulturen, Herkunftsregionen oder Religionen eingesetzt. Damit ging, wie Balibar betont, eine Verschiebung von der Naturalisierung der >Rasse < zur Naturalisierung des Rassismus einher: »Von der Theorie der Rassen [...] wird der Übergang zu einer Theorie der >ethnischen Beziehungen< [...] vollzogen, die nicht die rassische Zugehörigkeit, sondern das rassistische Verhalten zu einem natürlichen Faktor erklärt. « ${ }^{73}$ Nicht mit Menschen aus sanderen Kulturen< zusammenleben zu wollen, wurde in der Folge als natürliche Abwehrstrategie und ur-menschliche Reaktion auf die >Kulturvermischung gedeutet. Dieser diskursive Konnex liegt einer Vielzahl von Argumenten zugrunde, die gegen die Migration aus sanderen Kulturen< angeführt werden konnten. Die Vorstellung, es gebe >ursprüngliche und authentische Kulturen < und ein anthropologisch begründbares Bedürfnis, die eigene Kultur vor Vermischung und Auflösung zu bewahren, machte den Rassismus zu einem erklärbaren und rationalen Phänomen..$^{74}$ Würde das >natürliche< Begehren respektiert, die eigene Kultur zu erhalten, so lautete nun das zentrale Argument, sähen sich die Menschen auch nicht mehr gezwungen, rassistisch zu agieren.

\section{EUROPAS 'RASSENLOSER RASSISMUS、}

Mit der Vorstellung, das Rassendenken in Europa sei mit dem Ende des Zweiten Weltkriegs überwunden, ging die Idee einher, dass der Begriff >Rasse nur noch im außereuropäischen Raum eine Rolle spiele. »Race is a problem everywhere else but Europe ${ }^{75}{ }^{75}$ schreibt Goldberg kritisch. Man blickte nun skeptisch auf sogenannte >Rassenunruhen< in den USA oder engagierte sich gegen das Apartheidregime in Südafrika. ${ }^{76}$ Innerhalb Europas aber wurde >Rasse< als anachronistischer Begriff verstanden, dem über historische Betrachtungen hinaus keine Bedeutung mehr zukam. Die Darstellung der Shoa als Inbegriff eines mörderischen Rassendenkens und als das Unaussprechliche per se hatte paradoxerweise zur Folge, dass aktuelle Konstellationen des Rassismus (und damit auch des Antisemitismus) nicht mehr benannt werden konnten: »Racial Euro-

73 | Balibar 1990, 30 [Hervorhebung im Original].

74 | Balibar 1990, 30.

75 | Goldberg 2006, 341.

76 | Goldberg 2006, 343. 
peanization has rendered race unmentionable, unspeakable if not as reference to an anti-Semitism of the past that cannot presently be allowed to revive. «77 Was Goldberg als »racial Europeanization « bezeichnet, ist eine diskursive Konstellation, in der >Rasse < wirkmächtig blieb, aber unartikulierbar geworden war. Rassismus wurde in der Folge in erster Linie bei den wenigen Gruppierungen und Zusammenschlüssen ausgemacht, die sich noch explizit einer >Rassen<-Terminologie bedienten. Er mutierte zu einem bei Rechtsextremisten, Neonazis und Neo-Faschisten zu verortenden, relativ isolierten Phänomen, das wenig mit der Verfassung gegenwärtiger europäischer Zivilgesellschaften, Demokratien oder Rechtsstaaten zu tun hatte.

Im Unterschied zu einer solchen Sichtweise macht Goldberg im westeuropäischen Schweigen rund um den Begriff >Rasse < das Unvermögen aus, eigene rassistische Verwicklungen denken zu können: »Racial Europeanization thus concerns itself overwhelmingly with racial avoidance as denial of or at least failure to acknowledge its own racist implication. ${ }^{78}$ Das hat zur Folge, dass rassistische Strukturen und rassistisch motivierte Taten - mit Ausnahme der Aktivitäten von rechtsextremen Akteur*innen, die das >Rasse〈-Vokabular bedienen - nicht als solche benannt werden. Sie gelten als kulturelle Konflikte, die scheinbar keine Geschichte haben, oder als Ausdruck >ur-menschlicher< Probleme von Einheimischen mit Fremden. Für die Schweiz hält Kijan Espahangizi fest, dass »man in den öffentlichen Auseinandersetzungen mit den migrations- und ausländerpolitischen Verschärfungen der letzten Jahrzehnte nicht von Rassismus [spricht], sondern wenn, dann verharmlosend von >Fremdenfeindlichkeit< (als wären Menschen per se fremd und würden nicht gesellschaftlich fremdgemacht) «. ${ }^{79}$ Der Begriff der Fremdenfeindlichkeit wirkt harmloser als derjenige des Rassismus und macht die Kontinuitäten zwischen Kolonialismus, Rassenforschung und der Gegenwart unsichtbar. ${ }^{80}$

Zur neuen diskursiven Konstellation gehört auch, dass >Rasse $<$ und Rassismus zu Phänomenen umgedeutet wurden, die nicht intrinsisch mit Europa und der europäischen Geschichte verbunden, sondern erst in

77 | Goldberg 2006, 339.

78 | Goldberg 2006, 344.

79 | Espahangizi 2015, 11.

80 | Dies bringt eine spezifische Form des "Racial Denial" hervor, wie Stefanie C. Boulila ausführt (2018). 
jüngster Zeit von Migrant*innen nach Europa gebracht worden seien. Die verstärkte Zuwanderung von Menschen aus Ländern außerhalb Europas führe demnach zu sozialen Spannungen in den neuen multikulturellen Gesellschaften der Gegenwart, die sich entlang von ethnischen, kulturellen und zunehmend religiösen Differenzen entladen würden. Menschen, die als rassisch Andere markiert werden, finden sich durch die Logik der >Rassenlosigkeit< in einem Paradox wieder: Sie leben in Gesellschaften, die von sich behaupten, >Rasse < keine Bedeutung zukommen zu lassen. Gleichzeitig werden sie, wie Fatima El-Tayeb aufzeigt, beständig rassifiziert: Sie werden gefragt, woher sie kommen, warum sie die Landessprache sprechen, wann sie in ihr Herkunftsland zurückgehen, sie werden an der Grenze überdurchschnittlich oft kontrolliert und von der Polizei häufiger aufgegriffen. »Europeans possessing the (visual) markers of Otherness thus are eternal newcomers, forever suspended in time, forever >just arriving< defined by a static foreignness overriding both individual experience and historical facts. ${ }^{81}$

Wie sich ein solcher >rassenloser Rassismus auf die gegenwärtige Schweiz auswirkt, zeigt eine Forschungsarbeit von Noémi Michel, die sich mit dem Bildregime der rechtspopulistischen Schweizer Volkspartei (SVP) beschäftigt - seit 2007 auf nationaler Ebene die Partei mit dem größten Anteil von Wähler*innen der Schweiz. ${ }^{82} 2007$ begann die SVP, mit den sogenannten >Schäfchenplakaten < für eine Initiative zu werben, welche die Ausweisung von straffällig gewordenen Ausländer*innen forderte. Am 28. November 2010 wurde die Initiative mit knapp 53 Prozent der Stimmen in einer eidgenössischen Abstimmung angenommen. Das Plakat zeigt ein weißes Schaf, das ein schwarzes Schaf durch einen Tritt aus dem nationalen Territorium (symbolisiert durch die Schweizer Fahne) befördert. Zwei weiße Schafe im Hintergrund sehen der Tat unbewegt zu. Das schwarze Schaf blickt wütend und aggressiv, während die runden Kulleraugen der drei weißen Schafe eine unschuldige Sicht auf die Welt nahelegen. Das Plakat ist mit dem Slogan >Sicherheit schaffen< versehen. Meine gemeinsam mit Barbara Lüthi und Francesca Falk durchgeführte Analyse der Kampagne zeigt, dass Bild und Text gezielt mit der Mehrdeutigkeit der Metapher des schwarzen Schafes spielen: »Einerseits operiert [das Plakat] mit rassistischen Elementen, die klar erkennbar sind,

81 | El-Tayeb 2011, xxv.

82 | Michel 2014. Zur SVP vgl. Skenderovic 2015b. 
andererseits konnte sich die SVP auf die Position zurückziehen, dass hier nur die Redensart [vom >schwarzen Schaf $<$ als einem negativ auffallenden Mitglied einer Gruppe] gemeint sei.« ${ }^{83}$

Noémi Michel bezeichnet die spezifische Ikonografie des Schafes, die sich im Anschluss an die Veröffentlichung des Plakats in den unterschiedlichen Sprachregionen der Schweiz verbreitete und eine große Anzahl von anti-rassistisch motivierten Gegendiskursen bewirkte, als »Moutonologie $\ll^{84}$. Diese ist Ausdruck und Element des Regimes der Rassenlosigkeit in der Schweiz, weil sie es ermöglicht, ständig über >Rasse< zu sprechen, ohne das entsprechende Vokabular bedienen zu müssen. ${ }^{85}$ Im politischen Spiel mit den Schäfchenbildern wird $>$ Rasse $<z u$ einem zentralen Aushandlungsgegenstand, ohne dass dieser artikuliert werden muss. Antirassistischen Stimmen, welche die Kampagne kritisierten, wurde dementsprechend vorgeworfen, Rassismus durch seine Benennung überhaupt erst zu erzeugen: »La contre-lecture de l'UDC [frz. für SVP] a pour effet de nier le racisme imputé à son affiche en déplaçant son origine chez ceux qui énoncent explicitement des référents raciaux. Une telle contre-lecture mobilise les ressort du régime de racelessness qui prévaut en Suisse, elle s'appuie sur le tabou de la référence à la >race ${ }{ }^{86}{ }^{86}$ Die anti-rassistische Kritik, so Michel, werde auf diese Weise als unintelligibles Sprechen markiert und in einem Außen des legitimen Diskurses verortet - ein Außen, das durch den >rassenlosen Rassismus< erst hergestellt worden ist. $^{87}$

Eine weitere bedeutsame Erkenntnis von Michels Studie ist, dass sich auch die anti-rassistischen Stimmen, die sich als Antwort auf die Kampagne formierten, in die diskursive Konstellation des >rassenlosen Rassismus< einschrieben. Sie nahmen nämlich kaum Bezug auf die Schweizer Kolonialgeschichte, die prominente Schweizer Beteiligung an der Rassenforschung oder die aktuelle und historische Bedeutung von >Rasse < in der Schweiz. Die Denunzierung der Kampagne, so Michel, »passe par les références externes au territoire de la Suisse (le nazisme, le fascisme, le

83 | Purtschert, Lüthi und Falk 2012b, 45.

84 | Michel 2014, 218ff.

85 | Michel 2014, 295.

86 | Michel 2014, 267 [Hervorhebung im Original].

87 | Michel 2014, 295. Vgl. dazu auch Purtschert 2012a. 
suprématisme du KKK [Ku-Klux-Klan]) «8 ${ }^{88}$ Die Lokalisierung des Rassismus an einem anderen Ort und in einer anderen Zeit, ein Signum des europäischen Regimes der >Rassenlosigkeit<, kennzeichnet die anti-rassistischen Gegendiskurse in der Schweiz: Auch sie folgen einer Logik der kolonialen Amnesie.

\section{Koloniale Amnesie}

Nach der Dekolonisierung unterblieb eine breit geführte gesellschaftliche Auseinandersetzung mit dem Unrecht, das durch die Kolonisation und den Sklavenhandel verursacht worden ist. Errichtet wurde stattdessen, wie Stuart Hall es nennt, eine Kultur der »kolonialen Amnesie «. ${ }^{89}$ Wie Hall für Großbritannien ausführt, ermöglichte dieses aktive Vergessen der eigenen kolonialen Herrschaft die Entkoppelung aktueller Migrationsbewegungen von der kolonialen Vergangenheit, mit der sie eng verbunden waren:

"Die alten kolonialen Verhältnisse, Sklaverei und die koloniale Herrschaft, die Britannien mehr als 400 Jahre mit dem Imperium verknüpften, markierten die Wege, denen diese Migranten folgten. Aber diese historischen Beziehungen von Abhängigkeit und Unterordnung wurden rekonfiguriert - in der jetzt klassischen postkolonialen Weise -, als sie auf dem heimischen britischen Boden zusammentrafen. Im Gefolge der Dekolonisierung, maskiert durch eine koloniale Amnesie und die systematische Leugnung des Imperiums` (das sich 1960 wie eine Wolke des Unwissens herabsenkte), wurde dieses Zusammentreffen als ein 'Neuanfang, interpretiert. Die meisten Briten schauten auf diese 'Kinder des Imperiums`, als ob sie sich nicht vorstellen könnten, wo 'die ' hergekommen sein könnten, was für eine Beziehung sie um alles in der Welt zu Britannien haben könnten. “90

Mithilfe der kolonialen Amnesie konnten die Migrationsbewegungen aus den ehemaligen Kolonien als neue und überraschende Phänomene gedeutet werden, die scheinbar aus dem Nichts kamen. Entsprechend stand nicht die Verantwortung Europas als ehemaliger Metropole im Zentrum

\footnotetext{
88 | Michel 2014, 251.

89 | Hall 2004a, 199.

90 | Hall 2004a, 199 [Hervorhebung PP].
} 
einer postkolonialen Politik der Migration, sondern unterschiedliche Strategien der Abwehr gegen die sunerwarteten und scheinbar unbekannten Einwanderer.

Goldberg zufolge bezeichnet der Begriff der Amnesie Strategien des Vergessens und Ent-nennens, die den Umgang ehemaliger Kolonialmächte mit ihrer kolonialen Vergangenheit charakterisieren, »the now deafening silence in Europe concerning its colonial legacy «" ${ }^{91}$. Wie El-Tayeb ausführt, wirkt sich das Unsichtbarmachen von kolonialen Verflechtungen insbesondere auf die Lebensbedingungen von rassifizierten Menschen aus. Denn das wiederholte Negieren der (post-)kolonialen Bezüge zwischen den ehemaligen Metropolen und der Welt führt dazu, dass diese Menschen nie als zugehörig gelten. Stattdessen werden sie beständig als Fremde und eben erst Angekommene adressiert: »[E]very acknowledgment of a nonwhite presence always seems to happen for the very first time. ${ }^{92}$

Der Begriff der Amnesie bezeichnet somit eine aktive Praxis des Tilgens von geschichtlichen Verbindungen, die auf den Kolonialismus zurückgehen. ${ }^{93}$ Francesca Falk hat darauf hingewiesen, dass auch die "gesellschaftspolitisch prägende Wirkung der Immigration « ${ }^{94}$ in der Schweizer Geschichtsschreibung stark unterbelichtet geblieben sei. Noch immer ginge man davon aus, dass Migration eine Marginalie der Schweizergeschichte darstelle, obwohl sie ohne die gewichtigen Impulse durch die Migration und die bedeutsamen Beiträge von Migrant*innen nicht denkbar sei. Eine solche »gewollte Entkoppelung « ${ }^{95}$ von National- und Migrationsgeschichte wird auch durch das Vergessen der Kolonialgeschichte ermöglicht: »Sklavenplantagen in der Karibik, die Auslöschung der Mehrheit der indianischen Bevölkerung in den Amerikas und die blutigen Eroberungen im indischen Ozean und im Pazifik« gehörten ebenso zur Schweizergeschichte »wie Morgarten und Marignano [zwei Schlachten um 1315 und 1515, die als zentral für die Entstehung der Schweizer Eidge-

91 | Goldberg 2006, 337.

92 | El-Tayeb 2011, xxiv.

93 | Zu einer Kritik der Verwendung des Amnesiebegriffs in der Kolonialgeschichte vgl. Stoler 2011.

94 | Falk 2015, 156.

95 | Falk 2015, 155. 
nossenschaft gelten], das Fabrikgesetz und das Frauenstimmrecht $«,{ }^{96}$ fordert Bernhard Schär. Wie aber gelingt es, die zahlreichen und eigentlich unübersehbaren Bezüge zwischen der Schweiz und dem Kolonialismus kontinuierlich vergessen zu machen? Während in Großbritannien, Holland, Frankreich oder Deutschland angesichts der eigenen Kolonialgeschichte spezifische Formen des Vergessens entwickelt wurden - >Frankreich war eine gute Kolonialmacht< oder >Deutschland war keine wirkliche Kolonialmacht ${ }^{97}$-, wird der Kolonialismus in der Schweiz in der Regel im Außen verortet: >Kolonial waren die anderen<. Dieser spezifisch schweizerische Modus der Amnesie zeigt sich in aller Deutlichkeit in der Reaktion des Bundesrates aus dem Jahre 2003 auf die parlamentarische Anfrage der Nationalrätin Pia Hollenstein. Sie hatte im Anschluss an die UNOKonferenz gegen Rassismus 2001 die Frage gestellt, welche Vorstellungen von Wiedergutmachung und Entschädigung der Bundesrat zu entwickeln gedenke. ${ }^{98}$ In seiner Antwort vertrat der Bundesrat die Auffassung, »dass die verschiedenen Fragen im Zusammenhang mit dem Sklavenhandel auf internationaler Ebene behandelt werden müssen. Deshalb versucht die Schweiz eine vermittelnde Rolle zwischen afrikanischen Staaten und ehemaligen Kolonialmächten zu spielen, namentlich in der UNO-Menschenrechtskommission «"99. Obwohl Hollensteins Interpellation explizit auf Forschungen Bezug nimmt, welche die Verwicklungen von Schweizer Akteuren in den Sklavenhandel belegen, verschiebt der Bundesrat in seiner Antwort die Position der Schweiz weg von einer involvierten hin zu einer außenstehenden Partei. Damit setzt er das Schweizer Selbstverständnis, wonach immer nur die Anderen kolonial sind, in Szene und verhindert auf diese Weise die Diskussion, die Hollenstein anstoßen will, nämlich die Frage nach der Aufarbeitung der eigenen Verwicklungen in koloniale Machenschaften. Damit nicht genug: Mit der Verortung als vermittelnde Kraft zwischen ehemaligen Kolonien und Kolonialmächten imaginiert der Bundesrat die Schweiz als Akteurin, die wesentlich zur Versöhnung und Verständigung globaler kolonialer Gewalterfahrungen beitragen kann. Dies zeigt, wie die Schweiz als außenstehende, unbeteiligte Kraft konstruiert und gleichzeitig als neutrale Instanz positioniert

96 | Schär 2016b, 6.

97 | Vgl. dazu unsere Ausführungen in Purtschert, Lüthi und Falk 2012b, $21 \mathrm{ff}$.

98 | Hollenstein 2003.

99 | Hollenstein 2003 [Hervorhebung PP]. 
wird. Sie kann durch ihre Vermittlerinnentätigkeit im internationalen Geschehen eine bedeutsame Rolle spielen und damit eine internationale »Verflechtung durch Neutralität « ${ }^{100}$ erwirken. Bedingung für eine solche Selbstpositionierung als außenstehende und vermittelnde Partei ist das Unsichtbarmachen der zahlreichen kolonialen Bezüge, die die Schweizer Geschichte und Gegenwart durchwirken.

Welche Folgen diese postkoloniale Amnesie in der Schweiz zeitigte, dokumentiert Jovita dos Santos Pintos Forschung über Tilo Frey. Die Neuenburgerin wurde zusammen mit zehn anderen Frauen im Oktober 1971 für die Freisinnige Partei in den Nationalrat gewählt. Sie gehörte damit der ersten Generation von Frauen an, die nach der Verabschiedung des allgemeinen Stimm- und Wahlrechts im Februar 1971 ein politisches Amt auf Bundesebene wahrnehmen konnten. Frey, Tochter einer Kamerunerin und eines Schweizers, war zudem die erste Schwarze Nationalrätin der Schweiz. ${ }^{101}$ Allerdings fand die Geschichte der Schwarzen Politikerin weder Eingang in die hegemoniale noch in die alternative Historiografie. Tilo Frey geriet weitgehend in Vergessenheit. »Die Schweizer Parlamentsgeschichte wurde durch dieses >Vergessen $>$ weiß gewaschen « Pinto. ${ }^{102}$ Ereignisse, die einer >weißen< Schweizer Geschichte widersprechen, werden demnach aktiv >vergessen « und »als bedeutungslos erachtet [...], weil keine Bezüge gemacht werden zu einer >kollektiven Erinnerung< und sie somit auch keinen Platz in dieser haben ${ }^{103}$.

Die spezifische koloniale Amnesie, die sich im Vergessen von Tilo Frey zeigt, wird von Pinto mit der Weigerung erklärt, Schweizer Geschichte auch als Geschichte zu verstehen, die von nicht-weißen Akteur*innen gemacht worden ist. Dieses >Weiß-Waschen< schlägt sich in der Verwendung der Figur der wiederkehrenden ersten Begegnung mit den nicht-weißen Anderen nieder, die El-Tayeb als einen zentralen Aspekt des gegenwärtigen europäischen Rassismus beschreibt. ${ }^{104}$ Diese kam im Jahr 2007 zum Einsatz, als der sozialdemokratische Politiker Ricardo Lumengo erfolgreich für den Nationalrat kandidierte und die Medien ausführlich über den >ersten schwarzen Nationalrat< der Schweiz berichteten. In diesen De-

100 | Speich Chassé 2012 [Hervorhebung im Original].

101 | Vgl. dazu auch Jeannin-Jaquet 2008.

102 | Pinto 2014, 119.

103 | Pinto 2014, 111.

104 | Vgl. El-Tayeb 2011, xxiv. 
batten wurde, wie Pinto schreibt, das »rassisierte Selbst-Verständnis der Schweiz als Weißer Raum « ${ }^{105}$ bekräftigt: einerseits durch das Vergessen von Tilo Frey, andererseits durch die Inszenierung der Wahl eines nichtweißen Politikers als Spektakel. Im patriarchalen Kontext der Schweiz ist das >Vergessen-Machen< von Frey allerdings nicht nur auf ihr Nicht-weißSein, sondern auch auf ihre Position als Frau zurückzuführen. Es spiegelt wider, wie Pinto festhält, dass »nationale, >kollektivierte< Erinnerung weiterhin an einem bürgerlichen Geschlechtermodell orientiert ist, in welchem >große Taten an >große Männer gebunden werden « ${ }^{106}$. Frey passt nicht nur als Schwarze Nationalrätin, sondern auch als Frau nicht in das Bild des männlich konnotierten Politikers, dessen Wirken entsprechend erinnert werden kann. Ihre Positionierung an der prekären Schnittstelle von >Rasse < und Geschlecht wirft deshalb die Frage auf, wie die Kolonialität der Macht mit der modernen Geschlechterordnung verbunden ist.

\section{Kolonialität, Geschlecht und Sexualität}

Die Dekolonisierungstheorie, wie sie von Quijano und Mignolo entwickelt wurde, erfuhr eine bedeutsame Weiterentwicklung durch María Lugones. Sie fordert, dass eine Theorie der Kolonialität Geschlecht und Sexualität als grundlegende Dimensionen der Moderne mit bedenken muss. Nicht nur >Rasse < und Klasse sind demnach intrinsisch miteinan der verschränkt. Mit der Moderne entstand auch ein Verständnis von Geschlecht und Sexualität, das untrennbar mit der kolonialen Matrix verwoben ist und diese gleichzeitig mit begründet. ${ }^{107}$ Das koloniale Geschlechtersystem zeichnet sich durch die rigide Aufteilung von Menschen in zwei Geschlechter, das Primat der Heterosexualität sowie die patriarchale Herrschaft von Männern über Frauen aus. ${ }^{108}$ Zudem unterscheidet Lugones zwischen einer >hellen $<$ und einer >dunklen $<$ Seite des modernen kolonialen Geschlechtersystems. Die shelle Seite entspricht der normativen Ausgestaltung der bürgerlichen Geschlechterordnung. Die europäische bürgerliche Frau reproduzierte demnach »race and capi-

105 | Pinto 2014, 120.

106 | Pinto 2014, 119.

107 | Vgl. dazu auch Crenshaw 1989 und McClintock 1995.

108 | Lugones 2007, 193. 
tal through her sexual purity, passivity [...] in the service of the white, European, bourgeois man « ${ }^{109}$. In diesem Modell stellt der bürgerliche (weiße) Mann das Subjekt dar, das autonom über sich selbst verfügt und sich politisch, gesellschaftlich, intellektuell oder künstlerisch verwirklichen kann. Die bürgerliche (weiße) Frau hingegen muss ihr Tun auf den Mann ausrichten. Sie kümmert sich um seine Nachkommenschaft, die Befriedigung seiner körperlichen Bedürfnisse und den emotionalen Rückhalt im privaten Raum der Familie, und verrichtet damit all die Arbeiten, die ihn erst zur Tätigkeit im öffentlichen Raum befähigen.

Diese geschlechtsspezifische Weise, in der Welt zu sein, wurde von Simone de Beauvoir folgendermaßen beschrieben: »In seinem Beruf, seinem politischen Leben erfährt [der Mann] die Veränderung, den Fortschritt, er empfindet sein Aus-sich-Herausgehen in Zeit und Raum. Und wenn er des Umherschweifens müde ist, gründet er ein Heim, läßt sich nieder und verankert sich in der Welt. Abends sammelt er sich zu Hause, wo die Frau über Möbel und Kinder wacht und die gespeicherte Vergangenheit hütet. Sie selbst hat keine andere Aufgabe, als das Leben in seiner reinen und gleichbleibenden Allgemeinheit zu bewahren. ${ }^{110}$ Durch die unbezahlte Arbeit im Haushalt und die Geburt, Pflege und Erziehung der Kinder schaffen Frauen die Grundlage dafür, dass sich Männer beruflichen, politischen und gesellschaftlichen Tätigkeiten widmen können. Sie sichern auf diese Weise die Reproduktion einer kapitalistischen Ökonomie sowie der (weißen) Nation.

Obwohl das hier beschriebene Geschlechterarrangement durch den Kolonialismus für einen Großteil der Menschheit maßgeblich wurde, galten nur wenige Männer und Frauen als Verkörperung der damit verbundenen bürgerlichen Normen. Vielen anderen Menschen wurde kein Platz in der bürgerlichen Geschlechterordnung angeboten, es wurde ihnen vielmehr deutlich gemacht, dass sie sich außerhalb dieser Ordnung befanden. Das idealisierte Geschlechterbild des Bürgertums, bei dem ein rational agierender Mann von einer sorgenden Frau unterstützt wird, das als Maßstab bürgerlicher Zivilisiertheit galt, wurde auf diese Weise auch für die Herstellung und Aufrechterhaltung kolonialer Hierarchien eingesetzt. Diese regulative Funktion von Geschlecht kam schon in der frühen Phase des Kolonialismus zum Einsatz, als die angebliche Unzivilisiertheit

109 | Lugones 2010, 743.

110 | Beauvoir 1994, 521. Vgl. auch Purtschert 2006. 
der Bewohner*innen Amerikas dadurch zum Ausdruck gebracht wurde, dass sie als Hermaphroditen beschrieben und auf Darstellungen mit monströsen Geschlechtsteilen ausgestattet wurden. ${ }^{111}$ Omise'eke Natasha Tinsley zufolge herrschte auf amerikanischen Plantagen später insofern eine »negative Geschlechtergleichheit«, als bei der brutalen Ausbeutung von Sklav*innen in vielen Bereichen kein Unterschied zwischen Männern und Frauen gemacht wurde. ${ }^{112}$ Die angeblich besondere Empfindlichkeit der körperlich schwächeren und gefühlsbetonten Frau, die in der bürgerlichen Welt als Argument für ihre Bevormundung diente, wurde für die Schwarzen Frauen auf Sklavenplantagen nicht ins Feld geführt. Oftmals wurden Frauen, Kinder und Männer unterschiedslos für schwerste Arbeiten eingesetzt, schreibt Angela Davis: »Women were not too >feminine< to work in coal mines, in iron foundries or to be lumberjacks and ditchdiggers. «113 Ins Spiel gebracht wurde die Schutzbedürftigkeit von nicht-weißen Frauen erst, wenn sich damit die Herrschaft über ihre Männer begründen ließ. Die angeblich gewalttätige und >unzivilisierte< Behandlung von einheimischen Frauen durch ihre Männer diente dann der Legitimation von kolonialen Interventionen und missionarischen Eingriffen - eine Logik, die Gayatri Spivak mit dem Diktum »weiße Männer retten braune Frauen vor braunen Männern «114 auf den Punkt gebracht hat.

Auch die Vorstellung einer zivilisierten bürgerlichen Sexualität wurde mithilfe rassifizierter Figuren entwickelt, die an den Extremen zwischen Hypersexualität und Asexualität angesiedelt wurden. ${ }^{115}$ Der rationalen Triebkontrolle des bürgerlichen Mannes wurde dabei die exzessive Sexua-

111 | Lugones 2007, 195.

112 | Tinsley 2008, 209.

113 | Davis 1983, 10.

114 | Spivak 2008, 81. Vgl. auch Levine 2004. Für die Kritik an einem aktuellen Einsatz dieser Logik im westeuropäischen Umgang mit Migration siehe Dietze 2009. In jüngster Zeit wird zudem diskutiert, inwiefern auch der Schutz von LGBTIQ-Personen vor der Gewalt nicht-weißer Anderer für rassistische Zwecke instrumentalisiert wird. Rahul Rao spricht mit Bezug auf Spivaks Diktum von "white gays to save brown gays from brown homophobes“ (Rao 2010, 182), María do Mar Castro Varela und Nikita Dhawan ändern die Formel um in "white queer is trying to save the brown queer from the brown straight" (Castro Varela und Dhawan 2011, 110). Vgl. auch Puar 2007 und für die Schweiz Mesquita und Purtschert 2016.

115 | Lugones 2010, 744. 
lität des Kolonialisierten oder aber seine sexuelle Passivität gegenübergestellt. Entscheidend ist dabei die Auftrennung von Ratio und Körper. Während das weiße männliche Subjekt einen Körper besitzt, der vordringlich im Dienste seines überragenden Geistes steht, werden weiße Frauen und nicht-weiße Menschen auf ihre Körperlichkeit festgeschrieben. Solche rassistischen Figurationen von Sexualität dienten dazu, koloniale Herrschaft und Gewalt zu legitimieren. Für die Karibik hält M. Jacqui Alexander fest: »Black bodies, the economic pivot of slave-plantation economy, were sexualized. Black women's bodies evidenced an unruly sexuality, untamed and wild. Black male sexuality was to be feared as the hypersexualized stalker. ${ }^{116}$ Im (Post-)Sklavenhalterkontext der USA wurde die angeblich unkontrollierte Sexualität Schwarzer Männer zu einer Bedrohung für weiße Frauen stilisiert und häufig angeführt, um Lynchmorde zu legitimieren. ${ }^{117}>$ Rassenhierarchien gründeten aber auch auf der Entmännlichung nicht-weißer Männer. Ihre Feminisierung, so hält Mrinalini Sinha für das Britisch Raj fest, war ein entscheidender Bestandteil kolonialer Regierungspraktiken. ${ }^{118}$ Und David Eng zeigt, dass die nationale Zugehörigkeit und die Handlungsmacht asiatisch-amerikanischer Männer in den USA des 19. und 20. Jahrhunderts über rassifizierte Zuschreibungen von Geschlechter- und Sexualitätsnormen reguliert wurde. So wurde die Männlichkeit und damit der soziale Status asiatisch-amerikanischer Männer infrage gestellt, indem sie verweiblicht und mit Homosexualität in Verbindung gebracht wurden. ${ }^{119}$ Feminisierung und (Homo-)Sexualisierung wurden eingesetzt, um die koloniale Hierarchie zwischen weißen und nicht-weißen Männern herzustellen. Umgekehrt stärkte die Rassifizierung von Weiblichkeit und Homosexualität bestehende homophobe und sexistische Praktiken, die wiederum gegenüber Frauen und Queers zum Einsatz kamen.

Im Unterschied zu Männern wurden rassifizierte Frauen oft als Repräsentantinnen einer animalischen Sexualität oder einer degenerierten Weiblichkeit betrachtet. Weibliche Körper figurierten in der kolonialen Literatur, so Tony Ballantyne und Antoinette Burton, »as a recurrent

116 | Alexander 1994, 12.

117 | Davis 1983, 172ff.

118 | Sinha 1995.

119 | Eng 2001. 
emblem of native savagery and monstrosity « ${ }^{120}$. Nicht-weiße Frauen verkörperten dabei unterschiedliche Formen devianter Sexualität: Sie galten als besonders unterwürfig, als asexuelle oder umgekehrt als besonders verführerische und sexuell verfügbare Wesen, ohne dass sie mit den bürgerlichen Attributen von Weiblichkeit (etwa Verletzbarkeit oder Schutzbedürftigkeit) ausgestattet wurden. Die sexistische Reduktion von Frauen auf ihren Körper, welche die bürgerliche Kultur kennzeichnete, war im kolonialen Kontext besonders ausgeprägt. So macht bell hooks in den Auftritten Schwarzer Frauen im kolonialen Paris des frühen 20. Jahrhunderts, bei denen sich ein (hauptsächlich) weißes Publikum vom »naked image of Otherness « ${ }^{121}$ unterhalten ließ, die fortgesetzte Weigerung aus, Schwarze Frauen als Subjekte anzuerkennen. Darin zeigten sich sexistische Formen der Objektivierung, die auf die Sklaverei zurückgehen, »when the bodies of black women were commodity, available to anyone white who could pay the price «. ${ }^{122}$ Dieser kolonial-weiße sexistische $\mathrm{Zu}$ griff auf die Körper Schwarzer Frauen setze sich auf vielfältige Weise bis in die Gegenwart hinein fort.

Lugones' Aufteilung des modernen Geschlechtersystems in eine helle und eine dunkle Seite zeigt, dass Vorstellungen von Männlichkeit, Weiblichkeit, Heterosexualität, Zweigeschlechtlichkeit und einer >natürlichen Hierarchie zwischen den Geschlechtern einen normativen Rahmen aufspannten, der vielen nicht-europäischen Kulturen im Kontext kolonialer Machtverhältnisse aufgezwungen wurde. ${ }^{123}$ Gleichzeitig diente dieser Rahmen als Regulativ für die Beherrschung kolonialisierter Menschen und für die Herstellung einer weißen zivilisierten Kultur, die in Abgrenzung von diesen anderen, »unzivilisierten« Existenzweisen zustande kam. Lugones' Konzept der »Kolonialität von Geschlecht « ${ }^{124}$ macht damit denkbar, wie >Rasse`, Geschlecht, Sexualität und Klasse miteinander ver-

120 | Ballantyne und Burton 2005b, 405. Dies zeigt etwa die Geschichte der südafrikanischen Sarah Baartman, welche in Europa als 'Hottentoten-Venus ' bezeichnet wurde. Baartman kam 1810 aus der südafrikanischen Kapregion nach London und wurde danach in England und Frankreich auf Völkerschauen ausgestellt. Vgl. Crais and Scully 2009, Ritter 2010.

121 | Hooks 1992, 62.

122 | Hooks 1992, 62.

123 | Vgl. dazu etwa Oyěwùmí 1997 oder Dankwa 2011.

124 | Lugones 2010, 745. 
schränkt und durcheinander artikuliert wurden: Weiße Männlichkeit konstituierte sich durch die Feminisierung nicht-weißer Männer und die Abwertung weißer Frauen, die sich wiederum in der Differenz zu weißen Arbeiterinnen und nicht-weißen Frauen ihrer bürgerlichen Weiblichkeit versichern konnten. Die Konstruktion kolonialer Differenzen war damit, wie Anne McClintock in ihrer Studie über das viktorianische England zeigt, unaufhebbar mit Geschlechter- und Klassenunterschieden verstrickt: »Racial stigmata were systematically, if often contradictorily, drawn on to elaborate minute shadings of difference in which social hierarchies of race, class and gender overlapped.« ${ }^{125}$ Wenn die Wirkmacht dieser sozialen Differenzen auf ihrer gegenseitigen Bezugnahme beruht, wenn, mit anderen Worten, die Bedeutung von >Rasse < durch die (wechselhaften und veränderbaren) Relationen zu Geschlecht, Sexualität und Klasse generiert wird, dann ist es wissenschaftlich erforderlich, diese Differenzen in ihrer Wechselwirkung zu untersuchen.

Eine Analyse der Kolonialität moderner Macht kommt folglich nicht umhin, solche Überschneidungen in den Blick zu nehmen. Dies gilt nicht nur für die Analyse derjenigen Menschen, die als die >Anderen der Moderne < bestimmt worden sind - Frauen, Kolonialisierte oder Angehörige der Unterschichten -, sondern auch für die männlichen und weißen Subjekte, die im kolonialen Zentrum der Macht angesiedelt sind.

\section{Moderne Subjektformation Und Othering}

Aus einer postkolonialen Perspektive erscheint der Kolonialismus nicht mehr nur als Thema der ehemaligen Kolonien, sondern als eines, das die ganze moderne Welt angeht. Diese Einsicht eröffnet eine bedeutsame neue Sicht auf die Gesellschaften, die zur ehemaligen Metropole gehören. In seinem 1955 erschienen Discours sur le colonialisme schreibt Aimé Césaire: »Où veux-je en venir? A cette idée: que nul ne colonise innocemment, que nul non plus ne colonise impunément; qu'une nation qui colonise, qu'une civilisation qui justifie la colonisation - donc la force - est déjà une civilisation malade, une civilisation moralement atteinte, qui, irrésistiblement, de conséquence en conséquence, de reniement en renie-

125 | McClintock 1995, 54. Vgl. auch Kerner 2009. 
ment, appelle son Hitler, je veux dire son châtiment. «126 Die im Kolonialismus ausgeübte Gewalt an den Kolonialisierten, so Césaire, durchdrang die europäische Kolonialmacht im Inneren und schlug auf sie zurück. Dass der Kolonialismus, je nach Spielart, die Kolonialisierten als minderwertige, unterentwickelte, kindliche, animalische Wesen behandelte oder sie gar auf eine Sache reduzierte, blieb demnach nicht ohne Wirkung auf diejenigen Subjekte, die dieses Herrschaftssystem vertraten und durchsetzten. Diese selbstzerstörerische Kraft sah Césaire im Nationalsozialismus am Werk, der die Praktiken, die in den Kolonien entwickelt und zur Anwendung gebracht worden waren, nun auf einen Teil der europäischen Bevölkerung ausrichtete. ${ }^{127}$

Césaires alttestamentliches Vokabular der Strafe, die Europa durch den Nationalsozialismus erfahren haben soll, ist analytisch problematisch und heuristisch wenig hilfreich. Seine Einsicht aber, dass die koloniale Herrschaft für das (Selbst-)Verständnis und die Entwicklung Europas zentral war, beschäftigt die Forschung bis zum heutigen Tag. Sie korrespondiert auch mit Hannah Arendts wenige Jahre vor Césaires Buch veröffentlichter Arbeit zum Totalitarismus, welche die Entstehung des Nationalsozialismus vor dem Hintergrund des Imperialismus erklärt. Der nationalsozialistische Staat perfektionierte gemäß Arendt jene bürokratische Herrschaft, welche in den Kolonien zuvor entwickelt und praktiziert worden war. Sie zeichnete sich dadurch aus, dass sie die Regierung durch die Verwaltung von Menschen ersetzte; ein Schritt, der durch die fehlende Anerkennung der Bürgerrechte in den Kolonien ermöglicht wurde und in der Aberkennung von Bürgerrechten im Nationalsozialismus seine Entsprechung fand. ${ }^{128}$

Césaire thematisiert die konstitutive Bedeutung des Kolonialismus für Europa auch auf der Ebene der Subjektformation. Demnach wendete sich die enthumanisierende Praxis der kolonialen Herrschaft gegen die Kolonialherren selbst. Sie führte dazu, »que le colonisateur, qui, pour se donner bonne conscience, s'habitue à voir dans l'autre la bête, s'entraîne à le traiter en bête, tend objectivement à se transformer lui-même en bête. « ${ }^{129}$ Der Kolonialherr musste, um die Kolonisierung vor sich selbst verantwor-

126 | Césaire 2004, 19.

127 | Césaire 2004, 13.

128 | Arendt 1986, 399.

129 | Césaire 2004, 21 [Hervorhebung im Original]. 
ten und angesichts seiner Tätigkeit ein >gutes Gewissen< aufrechterhalten zu können, im kolonialen Anderen ein Tier erblicken. Die Negation der Menschlichkeit des Anderen blieb aber nicht ohne Folge für den Kolonialherren. Césaire insistiert darauf, dass die kontinuierliche Degradierung des kolonisierten Anderen auch zur Entmenschlichung des kolonialisierenden Subjekts führt. In einer kürzlich erstellten Analyse der weißen Vorherrschaft in den USA kommt Toni Morrison zu einem ähnlichen Schluss. Wenn die Gewalttaten von Weißen gegenüber der nicht-weißen Bevölkerung nicht so schrecklich wären, so Morrison, könnte man den vollständigen Verlust von Menschlichkeit betrauern, der sich darin zeigt. Denn die alltägliche Ausübung von Gewalt gegenüber Schwarzen Menschen in den USA dokumentiere die unendliche Angst weißer Menschen vor dem Verlust ihrer Macht: »These sacrifices, made by supposedly tough white men, who are prepared to abandon their humanity out of fear of black men and women, suggest the true horror of lost status. «130 Ein solcher Blick auf Weißsein ${ }^{131}$ als ein komplexes und wirkmächtiges Element moderner Macht ermöglicht ein Wissen, das einem vorherrschenden Verständnis verschlossen bleibt. Weißsein wird dabei als Norm sichtbar gemacht, die Wissen organisiert, ohne selbst als Moment der Wissensproduktion kenntlich gemacht $\mathrm{zu}$ werden. Demgegenüber steht die in Schwarzen Analysen gewonnene Einsicht, dass rassistische Praktiken und Vorstellungen nicht nur das Leben nicht-weißer, sondern auch dasjenige weißer Menschen prägt, und dass die Praktiken der Ent-menschlichung, die rassistische Gesellschaften durchziehen, auch diejenigen formen, die als weiße Menschen in modernen Gesellschaften leben.

James Baldwin erklärt den Zugang zu diesem alternativen Wissen folgendermaßen: »You cannot lynch me and keep me in ghettos without becoming something monstrous yourselves. And furthermore, you give me a terrifying advantage. You never had to look at me. I had to look at you. I know more about you than you know about me. «132 Baldwins Aus-

130 | Morrison 2016.

131 | Mit der Übersetzung von Whiteness als ,Weißsein ‘ folge ich dem Vorschlag von Eske Wollrad. Der Neologismus ermögliche, so Wollrad, "die Erforschung raum/zeitlich spezifischer Artikulationen deutscher Rassifizierungsprozesse im Gegenüber zu und in Abgrenzung von Rassifizierungsprozessen im angloamerikanischen Raum" (Wollrad 2005, 21f.).

132 | Baldwin 2017, 103. 
sage scheint erst einmal kontra-intuitiv zu sein. Warum sollen weiße Menschen, die mit der Rassenforschung, der Ethnologie, der Anthropologie, der Geschichte, der Soziologie, der statistischen, medizinischen oder bevölkerungspolitischen Durchdringung nicht-weißer Menschen in den USA (und auf der ganzen Welt) ein ganzes Wissensregime um nicht-weiße Menschen herum entwickelt haben, diese niemals angeschaut haben? Die Antwortet ist: weil sie sie nur als Objekte des Wissens untersucht, nicht aber als menschliches Gegenüber betrachtet haben. Darum fehlt ihnen ein Wissen, über das nicht-weiße Menschen verfügen, weil diese sich gezwungenermaßen an einer weißen Kultur ausrichten müssen. In einer Welt, in der Weiße die Maßstäbe für das Menschsein setzen und sich gleichzeitig als Verkörperung dieser humanen Werte verstehen, müssen nicht-weiße Menschen auf Weiße Bezug nehmen, um überhaupt in das Ringen um einen menschlichen Status eintreten zu können. Dadurch aber, und darauf weist Baldwin hin, gewinnen nicht-weiße Menschen ein profundes Wissen über die Ausgestaltung, Funktionsweise und Veränderung des rassistischen Systems, in dem sie leben. Für Individuen, die Rassismus ausgesetzt werden, sind solche Einsichten überlebensnotwendig. Darüber hinaus bilden sie aber auch ein wertvolles kritisches Wissen, das innerhalb eines weiß dominierten Systems unsichtbar bleibt. Denn die Wirkmacht des >Whitening $<$, des Weiß-Machens, beruht gerade darauf, dass es nicht als historisch gewachsenes, kontingentes und in vielerlei Hinsicht widersprüchliches Herrschaftssystem, sondern als natürliche und selbstverständliche Ordnung der Dinge erscheint. Wie aber können die Entstehung und das Wirken eines solchen Systems erklärt werden?

In der Periode der transatlantischen Sklaverei, so Valentin Y. Mudimbe, bildete sich ein westliches Raster der Wahrnehmung heraus, das die Wissensordnungen der Moderne auf entscheidende Weise veränderte. Im Anschluss an die Studien von Michel Foucault diagnostiziert Mudimbe im Verlaufe des 17. Jahrhunderts einen signifikanten Übergang von einem Regime der Ähnlichkeit zu einem Regime der radikalen Differenz. Letzteres setzt ganz wesentlich beim Verhältnis zwischen Selbst und Fremdem an: Das europäische Selbstverständnis gründete fortan nicht mehr auf der Idee, das privilegierte Modell des Menschen zu stellen, von dem kulturell Andere abgeleitet werden können. Es basierte nun auf einer rassifizierten Vorstellung von Identität, die einer radikalen Alterität bedarf: »The African has become not only the Other who is everyone else except me, but rather the key which, in its abnormal differences, specifies the 
identity of the Same. «133 Als Verkörperung des Animalischen und Monströsen erlaubt es die Figur des Afrikaners dem weißen Europäer, sich im Kontrast zu diesem Anderen als zivilisiertes Selbst zu entwerfen. Alterität erscheint dabei stets als Folie für die Herstellung des Selbst. In dieser »order of otherness « ${ }^{134}$ hat das Andere keinen eigenen Ort. Es steht immer schon im Dienste des Einen, der hegemonialen Vorstellung eines europäischen Subjekts, das sich in Abgrenzung vom Anderen entwirft.

Césaires und Mudimbes These, dass das hegemoniale Subjekt konstitutiv auf der Setzung und Negierung eines minderwertig gemachten Anderen beruht, weist augenfällige Parallelen zu feministischen Analysen auf. In ihrem Werk Das andere Geschlecht von 1949 schreibt Simone de Beauvoir, dass die Frau »mit Bezug auf den Mann determiniert und differenziert [wird], er aber nicht mit Bezug auf sie. Sie ist das Unwesentliche gegenüber dem Wesentlichen. Er ist das Subjekt, er ist das Absolute: sie ist das Andere. ${ }^{135}$ Beauvoir beschreibt damit aus einer feministischen Perspektive ein Verhältnis, in dem sich die Identität des Einen, diesmal des Mannes, durch die hierarchische Differenz zur Anderen, hier der Frau, herausbildet. Diese konstitutive Abhängigkeit des Einen von der Anderen bleibt im Hinblick auf den Mann verdeckt: Er erscheint als autonomes Subjekt und als Inbegriff des Menschlichen, während die Frau sich als Repräsentation des Anderen immer nur in Bezug auf den Mann definieren kann. ${ }^{136}$ Während Beauvoirs Beschreibung patriarchaler Subjektformationen viele Parallelen mit Césaires intersubjektiv angelegter Kritik des Kolonialismus aufweist, findet Mudimbes epistemische Kritik des Kolonialismus ein feministisches Gegenstück in der poststrukturalistischen Analyse von Luce Irigaray.

Um die patriarchale Anordnung des Wissens zu beschreiben, verwendet Luce Irigaray den Begriff der »Ökonomie des Gleichen «. ${ }^{137}$ Sie versucht damit die Funktionsweise einer Sprache offenzulegen, die eine

133 | Mudimbe 1988, 12. Vgl. Purtschert 2012c.

134 | Mudimbe 1988, 25.

135 | Beauvoir 1994, 12.

136 | Pointiert beschrieben wurde der Übergang von einer graduellen zu einer komplementären Geschlechterdifferenz von Thomas Laqueur. Er geht davon aus, dass ein Eingeschlechts- durch ein Zweigeschlechtermodell ersetzt worden sei. Vgl. Laqueur 1992.

137 | Vgl. Irigaray 1979, 165. 
androzentrische Weltordnung stützt, also eine Sicht auf die Welt, die von einer männlichen Sichtweise ausgeht und sie gleichzeitig zur einzig möglichen Perspektive erklärt. Das bedeutet, dass Frauen, wie Irigaray schreibt, in einer »Ökonomie des Sinns gefangen sind, die der Selbstaffektion des (männlichen) Subjekts dient « ${ }^{138}$. Das Herstellen und In-Zirkulation-Setzen von Bedeutung orientiert sich implizit und gleichsam unbewusst (also ohne dass es thematisiert, gerechtfertigt oder sichtbar gemacht würde) an einem männlich konnotierten Zentrum. Irigaray zufolge gibt es damit nicht zwei Geschlechter, sondern nur eines, das männliche, welches das weibliche als »Spiegel« benutzt: Die Frau dient dem Mann dazu, sich zu verdoppeln oder zu vervielfältigen, sich im Spiegel der Anderen zu erkennen und zu bestätigen. Sprache funktioniert dabei als Sinnzusammenhang, der immer auf ein Gleiches, nämlich ein männliches Zentrum bezogen bleibt. Césaire und Beauvoir betonen die Hierarchie zwischen dem Kolonialherrn und dem Kolonisierten beziehungsweise zwischen Mann und Frau und untersuchen ihre Effekte für diejenigen, die als zweitrangig, anders, abhängig und unselbstständig gelten. Mudimbe und Irigaray gehen einen Schritt weiter, indem sie zeigen, dass es in diesen modernen Repräsentationsregimes (noch) keinen Ort gibt für das nicht-weiße Subjekt oder die Frau.

In all diesen Ansätzen zeigt sich eine bedeutsame Übereinstimmung, die Viktoria Schmidt-Linsenhoff als kleinsten gemeinsamen Nenner von Feminismus und Postkolonialismus beschreibt, die Kritik nämlich »an einem Identitätsmodell, das umso verbohrter und gewaltförmiger auf Ganzheit und Autonomie besteht, je abhängiger es von seinem konstitutiven Außen ist « ${ }^{139}$. Vor diesem Hintergrund lässt sich die Alteritätsstruktur eines Subjekts herausstellen, das sich in Abgrenzung von Anderen als Inbegriff des Menschlichen setzt, diese fundamentale Relationalität und die mit ihr verbundene Gewalt aber aus seinem Selbstverständnis verbannt.

Um eine solche konstitutive Verflechtung von weißer Subjektformation und kolonialer Alterität zu beschreiben, hat sich seit Mitte der $1980 e r$ Jahre in der postkolonialen Theorie der Begriff des Othering durchgesetzt. Mary Louise Pratt charakterisiert die rassistischen Berichte eines britischen Reisenden in Südafrika aus dem Jahre 1801 als koloniales »Other-

138 | Irigaray 1979, 128.

139 | Schmidt-Linsenhoff 2005, 9. 
ing « ${ }^{140}$. Pratt schreibt: »The people to be othered are homogenized into a collective >they<, which is distilled even further into an iconic she< (the standardized adult male specimen). This abstract $>$ he $</>t h e y<$ is the subject of verbs in a timeless present tense, which characterizes anything she< is or does not as a particular historical event but as an instance of a pregiven custom or trait. ${ }^{141}$ Der Prozess, innerhalb dessen das koloniale Gegenüber zum Anderen gemacht wird, besteht im Wesentlichen darin, dieses Gegenüber nicht als Individuum, sondern als Vertreter eines Kollektives wahrzunehmen. In der Regel wird es von einer männlichen Figur repräsentiert, wodurch die koloniale Frau im patriarchalen Raster der Wahrnehmung unrepräsentierbar und so zum Verschwinden gebracht wird. Zugleich werden die Handlungen von Kolonialisierten als Wiederholung von immer gleichen Ritualen und Traditionen gedeutet und damit außerhalb einer historischen Zeiterfahrung angesiedelt.

Während Pratt in dieser Sequenz das stereotype Festschreiben der Anderen im kolonialen Diskurs und damit gewissermaßen den ersten Teil des Othering beschreibt, geht Gayatri Spivak einen Schritt weiter, indem sie die Rückwirkungen des Othering auf europäische und kolonialisierte Subjekte zum Gegenstand macht. Sie untersucht dazu einen 1815 verfassten Bericht von Geoffrey Birch, einem Mitarbeiter des britischen Gouverneurs in Indien. Spivaks Studie zeigt, dass auch scheinbar unbedeutende Akteure den kolonialen Diskurs reproduzierten und damit zur »kartographischen Transformation ${ }^{142}$ Indiens beitrugen. Für Spivak stellt der `kleine< Kolonialbeamte Birch eine zugleich exemplarische und zufällig gewählte Figur dar, die den Prozess der europäischen Identitätsbildung auf kolonialem Grund vorantrieb: »He [Birch] is actually engaged in consolidating the self of Europe by obliging the native to cathect the space of the Other on his home ground. He is worlding their own world, which is far from mere uninscribed earth, anew, by obliging them to domesticate the alien as Master.« ${ }^{143}$ Spivaks Analyse rückt die Selbstkonstitution des Kolonialbeamten in den Blick: Eigentlich ein unbeholfener Fremder, kann Birch mithilfe des kolonialen Diskurses den Einheimischen zum Anderen machen; im Anschluss daran muss dieser ihm, dem

140 | Pratt 1985, 120.

141 | Pratt 1985, 120.

142 | Spivak 1985, 133.

143 | Spivak 1985, 133 [Hervorhebung im Original]. 
eigentlich Fremden, dabei behilflich sein, sich als Herr zu installieren. Dadurch macht Spivak eine grundlegende Verbindung zwischen Othering und dem kolonialisierten Territorium ersichtlich: Das Beschreiben, Benennen, Ausmessen und In-Besitz-Nehmen des Raumes, in dem andere Menschen leben, bezeichnet sie als ein >worlding the world<, ein gewaltsames >Zur-Welt-Machen $<$ des fremden Ortes, das auf der Vernichtung, Entwertung oder Aneignung bereits bestehender Sinn-, Wissens- und Lebenszusammenhänge beruht.

Dieser Prozess hat entscheidende Auswirkungen auf das Selbstverhältnis von Kolonialisierten. Die Auslöschung der vielfältigen Einschreibungen in ein Land, das dadurch als »leeres Land « ${ }^{144}$ hervorgebracht wird, als Tabula rasa, auf der sich der Text des Kolonialherren als autoritatives Wissen einschreiben kann, zwingt die Einheimischen dazu, sich von nun an durch die Augen des Kolonisators zu betrachten: »[T]he necessary yet contradictory assumption of an uninscribed earth which is the condition of possibility of the worlding of a world generates the force to make the >native< see himself as >other « «" ${ }^{145}$ Während sich der fremde Kolonialbeamte durch das Othering als Vertreter des kolonialen Systems etablieren kann, werden Kolonialisierte gezwungen, sich fortan vermittels der kolonialen Episteme als Andere zu betrachten. Im Kontext der US-amerikanischen Post-Sklavenhaltergesellschaft wurden die Folgen eines solchen Selbstverhältnisses von Du Bois als »double consciousness « beschrieben, als »this sense of always looking at one's self through the eyes of others «, ${ }^{146}$ das eine unaufhebbare Spaltung zwischen dem eigenen (Schwarzen) Selbst und der maßgeblichen (weißen) Kultur zur Folge hatte. Sie beinhaltet aber auch, wie oben mit Bezug auf Morrison und Baldwin gezeigt worden ist, Zugang zu einem bedeutsamen kritischen Wissen über Rassismus und weiße Vorherrschaft.

Die Frage, wie Kolonialismus die Kolonisierenden affizierte und wie er auf die kolonialen Metropolen zurückwirkte, verbindet diese Überlegungen mit zwei weiteren bedeutsamen Forschungsrichtungen: den Critical Whiteness Studies und der New Imperial History. Den Critical Whiteness Studies, die in den 1990 or Jahren in den USA entstanden und an den Einsichten von Aimé Césaire, Frantz Fanon, Audre Lorde, Angela

144 | Vgl. dazu Falk 2011.

145 | Spivak 1985, 133.

146 | Du Bois 2003, 9. Vgl. auch Fanon 1980 und Nandy 1983. 
Davis, James Baldwin oder bell hooks ansetzen, geht es um eine Analyse von >Rasse<, die auch das Weißsein als grundlegenden Aspekt moderner Herrschaftsverhältnisse und rassifizierter Zuschreibungen in den Blick nimmt. ${ }^{147}$ »White people are >raced<, just as men are >gendered « $\ll,{ }^{148}$ schreibt Ruth Frankenberg und weist dabei auf die strukturell ähnlich bedeutsame >Entdeckung< der Männlichkeit in der Geschlechterforschung hin. ${ }^{149}$ Denn ebenso wie Männlichkeit im Patriarchat bleibt Weißsein im kolonialen >Rassenregime die unmarkierte und unsichtbare Norm. Dadurch wird $\gg$ Rasse $<$ zu einem Thema, das nur diejenigen zu betreffen scheint, die als nicht-weiß markiert sind. Obwohl modernen Rassifizierungsprozessen eine weiße Perspektive zugrunde liegt, wird diese in der Regel nicht kenntlich gemacht: Weißsein wird mit Menschsein gleichgesetzt und gilt als nicht weiter erklärungsbedürftig.

Die De-thematisierung von Weißsein hat auch in der Geschichtsschreibung Folgen gezeitigt, wie Harald Fischer-Tiné bemerkt: »Whereas a great awareness of social and cultural constructions of racial identities exists in other fields [...] >whiteness< still often escapes critical examination when it comes to European or imperial history to this day. ${ }^{150}$ Die fehlende Auseinandersetzung mit der weißen Norm, auf der Rassifizierung beruht, läuft Gefahr, wie Isabel Lorey für die feministische Theorie festhält, die Privilegiertheit einer weißen Perspektive aufrechtzuerhalten: »Solange in der feministischen Theorie Rasse oder auch Ethnie nur als Markierung der Anderen verstanden wird, hat sie auch auf diese Weise Teil am Othering. Die Anderen bleiben die Anderen. $\ll^{151}$ Die Critical Whiteness Studies setzen an dieser Stelle ein und zeichnen nach, wie Weißsein als dominante gesellschaftliche und epistemische Position erzeugt und naturalisiert wird. ${ }^{152}$ Die Sichtbarmachung solcher Konstruktionsprozesse ermöglicht es, wie Peggy Piesche und Susan Arndt konstatieren, die »normativen Konturierungen und Rezeptionen des weißen >Eigenen< sowie damit korrespondierende Konstruktionen des rassialisierten >Ande-

147 | Vgl. auch Painter 2010.

148 | Frankenberg 1993, 1.

149 | Vgl. Connell 1999.

150 | Fischer-Tiné 2009, 16.

151 | Lorey 2006, 74.

152 | Vgl. Iso 2008. Zur Einführung der Weißseins-Forschung in der Schweiz siehe Michel und Honegger 2010, Lavanchy 2015 und Rohner 2015. 
ren ${ }^{153}{ }^{153} \mathrm{zu}$ erfassen. Weißseinsforschung untersucht diejenigen Aspekte des Othering, die mit der Herstellung hegemonialer Kulturen und Identitäten verbunden sind. Sie etabliert auf diese Weise, wie Gabriele Dietze es nennt, ein bedeutsames »Paradigma weißer Hegemonie(selbst)kritik « ${ }^{154}$.

Während die Critical Whiteness Studies die Universalität des weißen Subjekts infrage stellen, dekonstruiert die New Imperial History die Vorstellung eines autarken Westens. Sie zeigt, dass die Vorstellung des Westens als Inbegriff von Moderne und Zivilisation seine grundlegende Verflochtenheit mit anderen Teilen der Welt ausblendet. Damit wendet sie sich gegen die Vorstellung, Wissen, Ideen, Technologien, Praktiken und qualifiziertes Personal seien von den Metropolen in die Kolonien exportiert und Rohstoffe, Territorium und physische Arbeitskraft von den Kolonien erworben worden; eine Darstellung, die alle Handlungsmacht dem Westen zuschreibt. Demgegenüber plädiert die New Imperial History dafür, die Wechselbeziehungen und Austauschprozesse zwischen unterschiedlichen Räumen ins Zentrum der Forschung zu rücken. Kolonie und Metropole sind damit, wie Ann Stoler und Frederick Cooper schreiben, nicht mehr getrennte Bereiche, sondern Bestandteile eines zusammenhängenden Analysefeldes. ${ }^{155}$ Mit dieser Neubestimmung stellt die, mit Frantz Fanon gesprochen, >manichäische< Trennung von Kolonie und Metropole ${ }^{156}$ nicht mehr eine Prämisse der Forschung dar, sondern wird selbst zu ihrem Untersuchungsgegenstand.

Aus einer solchen Perspektive kann gefragt werden, wie die Differenzen zwischen Kolonien und Metropolen, zwischen Kolonisierten und Kolonisierenden, zwischen Zivilisation und Wildnis beständig hergestellt, aufrechterhalten, überwacht, neu bestimmt, angefochten oder strategisch eingesetzt wurden. Analysiert werden können weiter die unterschiedlichen Praktiken des Othering, die Kolonisierte zu Anderen machen, denn »the otherness of colonized persons was neither inherent nor stable; his or her difference had to be defined and maintained « ${ }^{157}$. Nicht zufällig gerieten mit der Dekonstruktion einer scharfen Trennlinie zwischen Kolonie und Metropole in den letzten Jahren auch die scheinbaren Außenbereiche

153 | Piesche und Arndt 2011, 193 [Hervorhebung im Original].

154 | Dietze 2006, 220.

155 | Stoler und Cooper 1997, 4.

156 | Fanon 1981.

157 | Stoler und Cooper 1997, 7. 
des Kolonialismus vermehrt ins Blickfeld. Mit der Herstellung eines globalen Analysefeldes und einer neuen Sensibilität für Prozesse, die sich nicht zwangsläufig auf nationalstaatliche Räume eingrenzen lassen, sind die (angeblichen) Rand- und Außenzonen des Kolonialismus verstärkt sichtbar geworden; eine Entwicklung, die für die Diskussion über die Rolle der Schweiz im Kolonialismus von entscheidender Bedeutung ist.

\section{Koloniale Komplizenschaft}

Ein wichtiger Impuls für die Debatte über die kolonialen Ränder ging vom Begriff der »kolonialen Komplizenschaft « ${ }^{158}$ aus, der von nordischen Forscherinnen vor einigen Jahren in die Diskussion eingebracht wurde. Ihr Ausgangspunkt ist die Auseinandersetzung mit der postkolonialen Gegenwart in den nordischen Ländern, wo sich ein rassifizierter segregierter Arbeits- und Wohnungsmarkt, strukturelle Diskriminierung sowie Alltagsrassismus beobachten lassen. ${ }^{159}$ Gleichzeitig herrsche die Meinung vor, die nordischen Länder wiesen nur spärliche Verbindungen zum Kolonialismus auf, dem aus diesem Grunde auch keine bedeutende Rolle für das Verständnis der Gegenwart zukommen könne. ${ }^{160}$

Als Beispiel für die Auswirkung, die eine solche fehlende Anerkennung der eigenen Kolonialgeschichte hat, führen die Autorinnen eine kürzlich lancierte finnische Petition zur Beibehaltung rassistischer Etiketten auf alkoholischen Getränken an. Die Abbildungen gehörten zu einem Set von kolonialen Werbebildern, die sich in ganz Europa finden lassen. Von den Befürworter*innen der Petition wurden sie aber aus dem transnationalen Kontext herausgelöst und als finnisches Kulturgut dargestellt. Die Vorstellung, dass Finnland nicht in das koloniale Projekt involviert gewesen sei, so folgern die Autorinnen, »makes it possible to claim that in the Nordic/Finnish context such images and products are not racist ${ }^{161}$. Dem Begriff der kolonialen Komplizenschaft kommt vor diesem Hintergrund eine heuristische Bedeutung zu: Er stellt die Annahme infrage, es könne ein Außerhalb des kolonialen Systems geben,

158 | Mulinari, Keskinen, Irni und Tuori 2009.

159 | Mulinari, Keskinen, Irni und Tuori, 2.

160 | Mulinari, Keskinen, Irni und Tuori 2009, 1.

161 | Mulinari, Keskinen, Irni und Tuori, 2. 
und rückt mögliche Verstrickungen mit dem Kolonialismus in den Bereich des Denkbaren. Die nordischen Länder, so die Autorinnen, bildeten zwar keine kolonialen Zentren. Dennoch waren sie auf unterschiedliche Weise an der Errichtung und Erhaltung kolonialer Herrschaftsstrukturen beteiligt. ${ }^{162}$

Ulla Vuorela erwähnt drei Beispiele für eine solche koloniale Komplizenschaft. Anhand ihrer eigenen Kindheitserfahrungen im Finnland der 1950er Jahre rekonstruiert die Autorin erstens, wie einem finnischen Kind eine selbstverständliche und unhinterfragte imperiale Perspektive auf die Welt vermittelt wurde: durch britische Kinderbücher, einem an den Narrativen der Metropolen orientierten Geschichtsunterricht oder dem Kolonialwarenladen vor Ort, der exotische Konsumgüter feilgeboten hatte. Zweitens zeigt sie, dass finnische Akteur*innen an der Produktion kolonialen Wissens beteiligt waren. Bis heute blicke man in Finnland mit Stolz auf Anthropologen wie Edvard Westermarck oder Gunnar Landtman, die sich an der frühen Entwicklung des Faches beteiligt und dabei ein Wissen generiert hätten, das auch der kolonialen Administration dienlich gewesen sei. ${ }^{163}$ Drittens beschreibt die Autorin, wie die nordischen Länder ihre Entwicklungszusammenarbeit in den 1980er Jahren an die neoliberalen Auflagen der Weltbank und des internationalen Währungsfonds angepasst hatten. ${ }^{164} \mathrm{Im}$ Falle von Tansania wurden diese Strukturanpassungsprogramme gegen den Widerstand der betroffenen Regierung durchgesetzt und hatten einen massiven Abbau des Bildungs-, Gesundheits- und Sozialsystems im Land zur Folge.

Vuorelas Beispiele machen drei unterschiedliche Facetten kolonialer Komplizenschaft deutlich, die man als kulturelle, wissenschaftliche und politische Dimension der Verflechtung beschreiben könnte. Das erste Beispiel zeigt, dass Europa als transnationaler Raum gedacht werden muss: Vorstellungen westlicher Zivilisation und weißer Superiorität zirkulierten in Form von Texten, Bildern oder Konsumgütern großflächig, auch wenn sie auf unterschiedliche Weise an lokale Kontexte adaptiert wurden. Diese Einsicht lässt sich mit Gewinn auf die Schweiz anwenden. Die von der Autorin gewählten Beispiele, eine kolonial geprägte Kinderliteratur, die Bedeutung des Kolonialwarenhandels und das in der Schule

162 | Mulinari, Keskinen, Irni und Tuori, 9.

163 | Vuorela 2009, 22; 27.

164 | Vuorela 2009, 22; 28. 
vermittelte eurozentrische Geschichtsbild, eignen sich hervorragend, um die transnationale Einbindung der Schweiz in ein koloniales Europa deutlich zu machen. ${ }^{165}$

Vuorales zweite Fallstudie zeigt, dass in Ländern wie Finnland koloniales Wissen nicht nur aufgegriffen und rezipiert, sondern von finnischen Akteur*innen auch aktiv hergestellt wurde. Dass gewisse europäische Länder nicht als Metropole galten, konnte sich für die Forschung sogar als förderlich erweisen. Das verdeutlicht ein Beispiel aus der Schweiz: Das anthropologische Institut der Universität Zürich hatte sich Anfang des 20. Jahrhunderts zu einem Zentrum der internationalen Rassenforschung entwickelt. Hauptsächlich bei der Festlegung von Standards und Techniken der Vermessung nahm das Institut eine weltweit führende Stellung ein; Forschende aus unterschiedlichsten Ländern suchten es zu Ausbildungszwecken auf. ${ }^{166}$ Die Konzentration auf die angeblich unpolitischen technischen Aspekte der Rassenforschung fügte sich dabei hervorragend in die »technokoloniale ${ }^{167}$ Strategie ein, die für die Schweizer Kolonialkultur charakteristisch ist. Die koloniale Außenseiterposition der Schweiz wertet Pascal Germann dabei als Standortvorteil: Während Wissenschaftler*innen aus der Metropole im Verlaufe des 20. Jahrhunderts zunehmend mit dem Vorwurf konfrontiert wurden, mit ihrer Arbeit imperiale Überlegenheitsvorstellungen zu reproduzieren, sahen sich Schweizer Forschende kaum einem solchen Verdacht ausgesetzt: »[R]acial-anthropological research in Switzerland - a country without colonies or imperial ambitions - rarely came under suspicion of being ideologically motivated. «168 Damit kommt eine Analyse der wissenschaftlichen Verflechtungen der Schweiz mit der kolonialen Welt zu einem ähnlichen Schluss wie eine Untersuchung ihrer wirtschaftlichen Verbindungen. Für den Handel hat Richard Behrendt bereits in den 1930er Jahren festgehalten, dass Schweizer Geschäftsleute als »lachende Dritte« von der

165 | Vgl. dazu meine Ausführungen in Purtschert 2008a, 2008b, 2012a sowie in Purtschert und Krüger 2012.

166 | Germann 2015, 55.

167 | Zum Begriff des Technokolonialismus vgl. das Unterkapitel Schweizer 'Technokolonialismus، in Kapitel 2 sowie Purtschert 2016.

168 | Germann 2015, 55. 
kolonialen Infrastruktur profitieren konnten, ohne diese herstellen, aufrechterhalten und verteidigen zu müssen. ${ }^{169}$

Drittens verbindet Vuorela ihre Analyse mit einer kritischen Zeitdiagnose. Demnach setzt sich die Komplizenschaft der nordischen Länder mit den kolonialen Mächten unter neuen, neokolonialen Bedingungen in der Gegenwart fort. Auch bei diesem Aspekt der kolonialen Komplizenschaft liegen mögliche Parallelen mit der Schweiz auf der Hand. So wird seit den späten 196oer Jahren immer wieder diskutiert, inwiefern die Schweiz Nutzen aus einer neokolonialen Weltordnung zog und diese mit ermöglicht, etwa als Drehscheibe für fragwürdige Finanzgeschäfte oder als Sitz international tätiger Konzerne, die in ihren Produktionsstätten im Süden gezielt Arbeits-, Umweltschutz- und Menschenrechtstandards unterlaufen. ${ }^{170}$

Über die kulturellen, wissenschaftlichen und politischen Verstrickungen hinaus dokumentieren Vuorelas Beispiele auch eine imaginäre und affektive Zugehörigkeit zur Metropole. Zentral für okzidentale Identitätsvorstellungen ist ein Begehren nach Zugehörigkeit zu einem weißen Europa, das sich als zivilisiert, modern und fortschrittlich versteht und dieses Verständnis gerade über die Abgrenzung von und die Vorherrschaft über nicht-europäische Gebiete entwickelte.

Wenn Zivilisation und Kolonialität sich gegenseitig bedingen und die Identifikation mit einem zivilisierten Raum für das aufkommende nationale Selbstverständnis im 19. Jahrhundert entscheidend war, mussten auch Länder, die nicht als Kolonialmächte auftraten, um die Zugehörigkeit zur Metropole kämpfen. ${ }^{171}$ Susan Zantop spricht in diesem Zusammenhang von Colonial Fantasies ${ }^{172}$, von »kolonialen Fantasien«, als grundlegendem Element der Nationenbildung in Europa. Sie eröffneten »an arena for creating an imaginary community and constructing a national identity in opposition to the perceived racial, sexual, ethnic or national characteristics of others, Europeans and non-Europeans alike « ${ }^{173}$. In ihrer Arbeit zum vorkolonialen Deutschland vor 1870 kommt Zantop

169 | Behrendt 1932.

170 | Vgl. Purtschert, Lüthi und Falk 2012b sowie Purtschert und Fischer-Tiné $2015 b$.

171 | Mulinari, Keskinen, Irni und Tuori, 2.

172 | Vgl. Zantop 1997.

173 | Zantop 1997, 7. 
zum Schluss, dass der Besitz von Kolonien keineswegs Voraussetzung für das Entstehen und den Einsatz von kolonialen Fantasien war. Im Gegenteil: »It was precisely the lack of actual colonialism that created a pervasive desire for colonial possessions and a sense of entitlement to such possessions in the minds of many Germans. ${ }^{174}$

Auch Kristín Loftsdóttir zeigt in ihren Studien zu Island, wie sehr die Zugehörigkeit zu Europa über koloniale Fantasien hergestellt wurde. Island gehörte 400 Jahre der dänischen Monarchie an, bevor es 1918 unabhängig wurde. Für die nationalistischen Bewegungen im 19. Jahrhundert war die Abgrenzung von den außereuropäischen Kolonien Dänemarks zentral - nicht zuletzt, weil die isländische Bevölkerung in Europa oftmals als halbwild und unzivilisiert wahrgenommen wurde. ${ }^{175}$ Als 1905 im Tivoli-Park in Kopenhagen eine nationale Kolonialausstellung stattfand und Menschen aus dänischen Territorien in Grönland, Island und der Karibik vorgeführt wurden, reagierten isländische Studierende in Kopenhagen mit scharfem Protest. Ansatzpunkt ihrer Kritik war aber nicht das Ausstellen von Menschen per se, sondern die Tatsache, dass Isländer neben Schwarzen und grönländischen Menschen präsentiert und mit diesen in eine Reihe gestellt wurden. »The protest was not so much against the ethics of representation, but rather on the grounds that Icelanders did not belong with the >uncivilized<, that they had been incorrectly categorized, reflecting a deep desire to be recognized as a [...] part of Europe. « ${ }^{176}$

Wie das Beispiel Island zeigt, wirkten Differenzen zu den Kolonien als imaginäres Bindemittel, das Europa zusammenhielt. Darüber hinaus waren koloniale Unterschiede bedeutsam, um die Differenzen innerhalb Europas benennen, klassifizieren und organisieren zu können. Für Finnland hält Vuorela fest, dass die koloniale Komplizenschaft eng verbunden war mit Praktiken der >internen Kolonisation<, etwa mit der im 19. Jahrhundert einsetzenden Vertreibung der Sámi nach Lappland. ${ }^{177}$ Auch die Schweiz bekämpfte >nomadische< Lebensformen im 19. Jahrhundert vehement. Seit den 188oer Jahren wurden Fahrende systematisch kontrolliert, an der Einreise gehindert, in Heime und Zwangsarbeitsanstalten

174 | Zantop 1997, 7.

175 | Loftsdóttir 2010, 10.

176 | Loftsdóttir 2010, 10.

177 | Vuorela 2009, 21. 
gesperrt oder des Landes verwiesen. ${ }^{178}$ Die Ausgrenzung, Verfolgung und Bevormundung sowohl der Sámi als auch von Fahrenden in Westeuropa wurden mithilfe kolonialer Vorstellungen begründet und durchgesetzt. ${ }^{179}$

Dass koloniale Differenzen für die Zugehörigkeit zu Europa nach wie vor eine Rolle spielen, zeigt Dace Dzenovskas Untersuchung zu Lettlands Selbstverständnis in der postsozialistischen Gegenwart. Sie macht in Lettland ein explizites Verlangen aus, sich affirmativ auf die Konstruktion einer eigenen kolonialen Vergangenheit zu beziehen. Tatsächlich hatte das Herzogtum Kurland, dessen Gebiet zum heutigen lettischen Staat gehört, im 17. Jahrhundert unter der Führung Jakob Kettlers die karibische Insel Tobago sowie ein Gebiet am westafrikanischen Gambia-Fluss als sein Besitztum erachtet. Sieben Jahre nach der Gründung dieser kurländischen Kolonien im Jahre 1651 mussten sie an Großbritannien abgetreten werden. ${ }^{180}$ Im heutigen Lettland gilt Kettler als historisch bedeutsame Person und seine kolonialen Unternehmungen werden einer neuen lettischen Nationalgeschichte eingeschrieben. ${ }^{181}$

Warum, so fragt Dzenovska, werden koloniale Aspirationen in den baltischen Staaten zu einem Zeitpunkt virulent, an dem sich Europa von der eigenen Kolonialgeschichte zu distanzieren sucht? Postsozialistische Länder, so ihre Antwort, reagierten auf die Positionierung als »an almostbut-not-quite-European other « ${ }^{182}$ nicht nur, indem sie Diskurse über die freie Marktwirtschaft, Menschenrechte und Demokratie, sondern auch die koloniale Weltsicht Europas übernahmen. Anstatt die lettische Begeisterung für die Kolonialgeschichte als unzeitgemäßes Verhalten derjenigen abzutun, die heillos zu spät gekommen sind, erkennt Dzenovska in ihnen die anhaltende Bedeutung kolonialer Fantasien für die Zugehörigkeit zu Europa. Das lettische Begehren nach einer eigenen kolonialen Vergangenheit mache die koloniale Rückseite der europäischen Moderne sichtbar, »thus undermining [European] attempts at keeping the two separate ${ }^{183}$. Das Ringen Islands als ehemalige dänische Kolonie um Unabhängigkeit und Lettlands postsozialistische Suche nach Anschluss

178 | Falk 2012, 205; Schär und Ziegler 2014.

179 | Schär 2008a, 207.

180 | Dzenovska 2013, 395.

181 | Dzenovska 2013, 395.

182 | Dzenovska 2013, 398.

183 | Dzenovska 2013, 398. 
an einen westeuropäischen kapitalistischen Kontext zeigen, wie sehr das Selbstverständnis >kolonialer Außenseiter`vom Kolonialismus geprägt ist: Beide dokumentieren das Bemühen, die eigene Nation in das koloniale Projekt einzuschreiben, weil es unauflöslich mit Modernität, Zivilisation und Fortschrittlichkeit verknüpft ist.

Auch für die Schweiz des ausgehenden 19. Jahrhunderts war die Differenz zu den Kolonien und die Abgrenzung von jenen Teilen der Welt, in denen die Menschen sich angeblich noch im Zustand der Primitivität befanden, von entscheidender Bedeutung. Das Land war gezeichnet von den Nachwirkungen des Sonderbundskrieges ${ }^{184}$ und den Gräben zwischen Stadt und Land. Aufkommende Arbeiterbewegungen sorgten für Nervosität bei den bürgerlichen Eliten, die gleichzeitig damit beschäftigt waren, über alle Differenzen hinweg ein nationales Selbstverständnis und eine >imagined community ${ }^{185} \mathrm{zu}$ erschaffen. Vorstellungen von Afrika und anderen >exotischen Orten, die insbesondere von den Missionsgesellschaften in Umlauf gebracht wurden, erwiesen sich in dieser Situation als enorm hilfreich für die Imagination der Schweiz. Sie ermöglichten es einerseits, die Bedeutung eines christlichen und zivilisierten Europas herauszustellen, dem die Schweiz angehörte, und andererseits die Schweizer Bevölkerung über alle Binnendifferenzen hinweg als Einheit wahrzunehmen.

Patrick Harries schreibt dazu: »The Swiss, a people deeply divided by differences of language, religion, region and class, saw themselves reflected as a group in opposition to what they saw in Africa, and they found a unity of purpose in the Dark Continent that would bind them both at home and abroad. « ${ }^{186}$ Wirkmächtige Repräsentationen der Schweiz als einer nationalstaatlichen Einheit sind ebenso mit Afrika, dem Heidentum und dem Unzivilisierten verbunden wie mit Europa, dem Christentum und der Zivilisation. Denn die Schweiz als imaginierter Raum gewann ihre Konturen nicht nur mithilfe von Binnendifferenzen innerhalb Westeuro-

184 | 1847 kam es zu einem Bürgerkrieg zwischen den katholisch-konservativen Kantonen der Innerschweiz, die sich zu einem sogenannten "Sonderbund" zusammengeschlossen hatten, und ihrer liberal-radikalen Gegnerschaft. Nach dem Sieg der Letzteren wurde 1848 der Bundesstaat gegründet, aus dem die moderne Schweiz hervorging. Vgl. Roca 2012.

185 | Anderson 1983.

186 | Harries 2007a, 35. 
pas - als neutraler Kleinstaat, alpines Territorium, mehrsprachiges Land oder >Willensnation ${ }^{187}$. Sie konturierte sich auch durch ihre Teilhabe an einer europäischen Metropole, die sich nicht von kolonialer Herrschaft lösen lässt. Entscheidend ist, dass diese Kolonialität der Macht nicht nur wirtschaftliche und politische Relationen strukturierte, sondern auch Wissensordnungen und visuelle Regimes durchdrang.

Patrick Minder spricht deshalb von einem »kolonialen Imaginären« der Schweiz, das keineswegs im Widerspruch zu der Tatsache stand, keine (formale) Kolonialmacht zu sein: »Située au cœur d'une Europe nationaliste qui rêve de grandeur, la Suisse affirme par l'expression de son imaginaire colonial qu'elle partage le même destin et les mêmes desseins que ses voisins. En retrait, en retard et à regret, elle ne réussit pas à réaliser son empire, mais, elle appartient de tout son âme, par la pensée, à la race des colonisateurs. ${ }^{188}$ Eine gewichtige Einsicht der hier angestellten Überlegungen besteht somit darin, dass koloniale Fantasien für die Schweiz im 19. und 20. Jahrhundert zentral sind und dass sie im Wechselspiel mit einer ebenso grundlegenden kolonialen Amnesie kontinuierlich ins Spiel gebracht und wieder ausgelöscht werden. Wie aber kann ein solches koloniales Imaginäres ausfindig gemacht und auf welche Weise kann es erforscht werden?

\section{Kulturelle Dimensionen des Rassismus}

In seinem Buch Culture and Imperialism schlägt Edward Said vor, Kultur als einen grundlegenden Bestandteil der imperialen Weltordnung zu verstehen. Kultur ist dabei die Gesamtheit signifizierender Praktiken, »the arts of description, communication, and representation «, ${ }^{189}$ denen eine gewisse Eigenständigkeit zukommt - etwa in Bezug auf die ökonomische, soziale und politische Sphäre - und die sowohl populäre Elemente als auch gelehrte und wissenschaftliche Äußerungen umfassen. ${ }^{190}$ Obwohl

187 | Die Vorstellung einer Willensnation wurde entwickelt, weil man sich im Falle der Schweiz nicht auf "Homogenitätsbehauptungen (gemeinsame Sprache, einheitliche Kultur, homogenes Volk)“ (Tanner 2015, 20) berufen konnte.

188 | Minder 2011, 405 [Hervorhebung PP].

189 | Said 1994b, xii.

190 | Said 1994b, xii. 
sie eigenen Regeln folgt, ist Kultur mit den anderen Sphären verflochten; sie ist von diesen weder determiniert noch gänzlich unabhängig. Diese Zusammenhänge werden von der geisteswissenschaftlichen Forschung zumeist ausgeblendet, hält Said kritisch fest: »Most professional humanists [...] are unable to make the connection between the prolonged and sordid cruelty of such practices as slavery, colonialist and racial oppression, and imperial subjection on the one hand, and the poetry, fiction, philosophy of the society that engages in these practices on the other. «191 Demgegenüber geht es Said darum, Kultur nicht als abgegrenzten Bereich menschlicher Tätigkeiten zu verstehen, »antiseptically quarantined from its worldly affiliations «, ${ }^{192}$ sondern einen Zugang zu ihr zu entwickeln, der die Eingebundenheit der Kultur in die Welt miteinbedenkt und es umgekehrt ermöglicht, politische und soziale Verhältnisse über die Deutung von Kultur zu erschließen.

Ein solches Verständnis von Kulturanalyse liegt auch der vorliegenden Arbeit zur Bedeutung der Kolonialität in der Schweiz zugrunde. Dabei trifft auch auf den Umgang mit Schweizer Kultur zu, was Toni Morrison im Hinblick auf die US-amerikanische Literatur formulierte: Nicht über die Bedeutung von >Rasse< zu sprechen, gilt als »taktvolle, sogar großmütige liberale Geste ${ }^{193}$. Und sie fügt hinzu: »Durch Schweigen ihre Unsichtbarkeit zu erzwingen bedeutet, dem Schwarzen Körper eine schattenlose Teilhaberschaft an den dominierenden kulturellen Körpern zuzugestehen. « ${ }^{194}$ Diese antrainierte Weigerung, die Bedeutung kolonialer Differenzen zur Kenntnis zu nehmen, gilt es abzulegen, um kulturelle Artefakte und die Bedeutung von Kultur überhaupt neu verstehen zu können.

Wenn auch auf andere Weise als in den orientalistischen Studien, die Gegenstand von Saids Untersuchungen bildeten, oder in der US-amerikanischen Literatur, die Morrison analysierte, wird man auch im Schweizer Alltagskontext auf Schritt und Tritt mit einem kolonialen Erbe konfrontiert, das gleichzeitig omnipräsent ist und eigenartig unkommentiert

191 | Said 1994b, xii-xiv.

192 | Said 1994b, xv.

193 | Morrison 1994, 30.

194 | Morrison 1994, 31. 
bleibt. ${ }^{195}$ Wer einen postkolonial instruierten Blick auf die Berichterstattung in den Zeitungen, die Lehrpläne der Schule, politische Debatten, die Verlautbarungen der Regierung oder die Kinderliteratur wirft, stößt unweigerlich auf koloniale Spuren. In den meisten Fällen werden sie als nicht weiter erklärungsbedürftiger Bestandteil der eigenen Kultur oder als Ausdruck eines Common Sense behandelt, dessen Gültigkeit weder infrage gestellt noch überprüft werden muss. Vor dem Hintergrund postkolonialer Theoriebildung scheint es somit überfällig, postkoloniale Diskursformationen in der Schweiz zum Gegenstand wissenschaftlicher Reflexion zu machen. Wie aber kann dies geschehen?

Anders als Said stelle ich in dieser Studie nicht literarische oder wissenschaftliche Werke, sondern populäre Texte und Bilder in den Fokus. Die Kultur, die den Gegenstand meiner Untersuchung bildet, findet sich im Alltäglichen, Gewöhnlichen und Profanen. Meine Analyse stützt sich dabei auf die Erkenntnis von Philomena Essed und Stuart Hall, wonach westliche Gesellschaften von einem »rassistischen Alltagsbewusstsein « ${ }^{196}$ durchdrungen sind. »We must analyze ambiguous meanings, expose hidden currents, and generally question what seems normal or acceptable fordert Essed angesichts eines Alltagsrassismus, der gleichzeitig enorm wirkmächtig ist und eigenartig unterbelichtet bleibt. ${ }^{197}$ Eine solche Analyse des Alltagsrassismus macht eine Praxis der Kritik erforderlich, die koloniale Prämissen aus ihrem Gewand der Normalität herauslöst, benennt und in eine koloniale Genealogie stellt. Dieses Vorgehen impliziert, dass nicht die Frage nach einer rassistischen Täterschaft im Zentrum steht, sondern die Untersuchung von kolonialen Vorannahmen, die in der eigenen Kultur am Werk sind. Stuart Hall verwendet den Begriff des »impliziten Rassismus «, um »jene scheinbar naturalisierte Repräsentation von Ereignissen im Zusammenhang mit >Rasse < [zu beschreiben] - ob in Form von >Tatsachen $<$ oder >Fiktion< -, in die rassistische Prämissen und Behauptungen als ein Satz unhinterfragter Vorannahmen eingehen «. ${ }^{198}$ Ein solcher der Kultur implizit eingeschriebener und normalisierter Rassismus macht es möglich, rassistische Aussagen zu treffen, ohne dass dies

195 | Siehe Hans Fässlers Reise in Schwarz-Weiss, eine äußerst ergiebige Suche nach Spuren des transatlantischen Sklavenhandels in der Schweiz (Fässler 2005).

196 | Hall 1989, 150. Vgl. Essed 1991.

197 | Essed 1991, 10. Vgl. auch Frankenberg 1993, 242.

198 | Hall 1989, 156 [Hervorhebung im Original]. 
bewusst wahrgenommen oder mit einer Intention verknüpft sein müsste. Die Erforschung des (zumeist) unreflektierten Gebrauchs rassistischer Denkweisen im Alltagskontext macht es deshalb erforderlich, die Bedeutung von Bewusstsein, Intention, Schuld und Absicht erst einmal auszuklammern. Die Frage nach dem simpliziten Rassismus in der eigenen Kultur kann damit auch an Texte und Bilder gerichtet werden, die auf den ersten Blick als unverdächtig gelten und einer politisch neutralen oder gar anti-rassistischen Kultur zugeordnet werden.

Welche Analysemethode erlaubt es, die strukturellen Bedingungen kultureller Äußerungen von den Absichten der Subjekte abzulösen, die diese Äußerungen tätigen oder sie verantworten? Ansatzpunkte für eine Forschung, welche die Verschaltung von Kultur mit sozialen Machtverhältnissen untersucht und die Frage der Intention von Akteur*innen dabei (zunächst einmal) zurückstellt, bietet das Diskursmodell von Michel Foucault. Er versteht unter Diskurs ein »Ensemble diskursiver Ereignisse ${ }^{199}$, die in einer gewissen Regelhaftigkeit miteinander verbunden sind. Die Regeln, die diskursive Aussagen ermöglichen und sie auf eine bestimmte Weise miteinander verknüpfen, gründen in gesellschaftlichen Machtverhältnissen, die wiederum von Diskursen gestützt und reproduziert werden. Foucault schreibt dazu: »Umgekehrt kann nichts als Machtmechanismus funktionieren, wenn es sich nicht in Prozeduren und Mittel-Zweck-Beziehungen entfaltet, welche in Wissenssystemen fundiert sind. Es geht also nicht darum zu beschreiben, was Wissen und was Macht ist und wie das eine das andere unterdrückt oder mißbraucht, sondern es geht darum, einen Nexus von Macht-Wissen zu charakterisieren. $\ll^{200}$

Mithilfe eines solchen Verständnisses von Wissen und Macht als sich gegenseitig konstituierende Kräfte können die Vorannahmen und Grundlagen des Wissens in Bezug zur Organisation und Zirkulation von Macht in einer Gesellschaft gesetzt werden. Diese Arbeit wird von Foucault als Kritik beschrieben: Sie setzt die diskursiven Bedingungen von dem, was sagbar ist und was als richtig und wahr erscheinen kann, ins Verhältnis zu bestehenden Machtverhältnissen. Kritik ist, wie Foucault schreibt, »die Bewegung, in welcher das Subjekt sich das Recht herausnimmt, die Wahrheit auf ihre Machteffekte hin zu befragen und die Macht auf die-

199 | Foucault 1994, 37.

200 | Foucault 1992, 33. 
se Wahrheitsdiskurse hin ${ }^{201}$. Wahrheit ist damit nicht, im platonischen Sinne, ein außenstehender absoluter Referenzpunkt. Was innerhalb eines diskursiven Feldes als richtig oder falsch, wahr oder unwahr erscheint, folgt vielmehr bestimmten Regeln, die von gesellschaftlichen Machtverhältnissen konstituiert werden. ${ }^{202}$ Kritik bedeutet nun, diese Regeln ausfindig zu machen, zu beschreiben und im Zuge dessen auch bestehende Vorstellungen von Wahrheit infrage zu stellen.

Die Praxis der Kritik, die ich im Folgenden erprobe, richtet sich nicht nur auf Texte, sondern auch auf das Visuelle und auf die vielfältigen Relationen zwischen Bildern und Texten. Dabei geht es darum, wie Sigrid Schade und Silke Wenk schreiben, »Praktiken des Sehens, des Interpretierens, des Deutens oder auch des Zu-verstehen-Gebens, der Gesten und Rahmungen des Zeigens und Sehens ${ }^{203}$ als Bestandteil jener Prozesse zu deuten, die das Erkennbare vom Nicht-Erkennbaren, das Sinnbehaftete vom Unsinnigen trennen. Praktiken der Repräsentation werden als Bestandteile diskursiver Regimes behandelt, die Faktizität und Wahrheit hervorbringen, Bereiche des Unbenennbaren und Nicht-Darstellbaren herstellen, aber auch Möglichkeiten des Intervenierens und der Umdeutung beinhalten. Ein solcher Zugang geht der Frage nach, wie Johanna Schaffer schreibt, »wie und in wessen Namen, aufgrund der Autorität welcher sozialer Prozesse welche Wirklichkeit repräsentiert, kurz: effektiv wird - oder eben nicht $^{204}$.

Diese Frage möchte ich im Folgenden auf den Begriff des Menschen und des Menschlichen richten. Wie oben gezeigt wurde, entstanden das moderne Verständnis des Subjekts und der mit ihm verbundene Anspruch auf menschliche Gleichheit, grundlegende Rechte und politische Partizipation in einem kolonialen und patriarchalen Kontext. Der Begriff des Menschen erscheint dabei als eine politisch wirkmächtige Kategorie, über die der Zugang zur Gleichheit verhandelt wird. Gleichzeitig legen diskursive Bedingungen fest, wer auf welche Weise als Mensch erscheinen und anerkannt werden kann. Judith Butler schreibt dazu: »When we ask, what are the conditions of intelligibility by which the human emerges, by which the human is recognized, by which some subject becomes the

201 | Foucault 1992, 15.

202 | Foucault 1978, 51.

203 | Schade und Wenk 2011, 9.

204 | Schaffer 2008, 81. 
subject of human love, we are asking about conditions of intelligibility composed of norms, of practices, that have become presuppositional, without which we cannot think the human at all. ${ }^{205}$ Bestimmte menschliche Körper, Lebensweisen und soziale Organisationsformen werden im bestehenden diskursiven Regime sintelligibel gemacht: Sie werden individuierten Wesen zugeschrieben, die über Handlungsfähigkeit und eine kohärente Identität verfügen. Andere Menschen kommen gar nicht oder nur als Kollektivsubjekte, als passive, vormoderne, sprimitive ‘, halbmenschliche oder entwicklungsbedürftige Wesen in den Blick.

Dabei zeigt sich eine Macht der Darstellung, die svermenschlichend oder >entmenschlichend sein kann. Beides aber hängt unauflöslich zusammen: »[T]o be called unreal, and to have that call, as it were, institutionalized as a form of differential treatment, is to become the other against which the human is made. It is the inhuman, the beyond the human, the less than human, the border that secures the human in its ostensible reality. ${ }^{206}$ Was als menschlich erscheint, gründet in der Logik des Othering auf der Abgrenzung und Verwerfung des Unmenschlichen. Dies hat zur Folge, dass Ausschlüsse nicht einfach durch eine Politik der Inklusion aufgehoben werden können. Vielmehr muss das gesamte System der Repräsentation durchquert und sowohl das eigene wie das Andere infrage gestellt werden, um alternative Vorstellungen des Humanen (zumindest ansatzweise) denkbar zu machen. Eine wegweisende Analyse des Schweizer Alltagsrassismus, die aufzeigt, wie die Grenze zwischen Menschlichem und Unmenschlichem hergestellt wird und welche »epistemische Gewalt « ${ }^{207}$ damit einhergeht, stammt aus der Feder von James Baldwin.

\section{Schweizer Alltagsrassismus Und koloniale UnSChuld}

Baldwin hat sich in den frühen 1950er Jahren mehrmals und für längere Zeit im Walliser Dorf Leukerbad aufgehalten, wo die Familie seines Freundes und Geliebten Lucien Happersberger ein Haus besaß. Seine Erlebnisse vor Ort schrieb er im Essay Stranger in a Village nieder, eine

205 | Butler 2004, 57.

206 | Butler 2004, $217 f$.

207 | Spivak 1985, 130. 
profunde Reflexion auf die unterschiedlichen Ausformungen des Rassismus in Nordamerika und Europa. Baldwin bezeichnet die Ortschaft in den Schweizer Alpen als »white wilderness « ${ }^{208}$. In dieser weißen Wildnis, so Baldwin, arbeiten Männer und Frauen den ganzen Tag; sie tragen Wäsche, Holz, Eimer voller Milch und Wasser. Gleich zu Beginn eröffnet Baldwin somit eine paradoxe Szenerie: Er begibt sich an einen Ort, den er als Wildnis erfährt und an dem die Menschen ein Leben führen, das in vielfacher Hinsicht vormodern anmutet. Die weiße Wildnis spielt auf die verschneite Berglandschaft an - »ice and snow as far as the eye can reach «, sie spiegelt aber auch die Sicht des städtischen und gebildeten Protagonisten auf das harte Leben der Bevölkerung im Bergdorf wider, eine Sicht, die nicht zuletzt vom mythischen Bild der Schweizer Alpen geprägt ist. ${ }^{209}$ Zugleich wird der Protagonist durch die Dominanz eines weißen Selbstverständnisses kontinuierlich damit konfrontiert, als Schwarzer Mensch das Außen der Zivilisation zu repräsentieren. ${ }^{210}$ Denn obwohl alle im Dorf wissen, dass er ein US-amerikanischer Schriftsteller ist, behaupten sie unbeirrt: »Black men come from Africa « ${ }^{211}$ und setzen Afrika mit der Wildnis gleich.

Ein beachtlicher Teil von Baldwins Essay beschreibt die Reaktionen der Menschen in Leukerbad auf seine Anwesenheit im Dorf und die Effekte, die diese zeitigen. Seinen eigenen Zustand beschreibt er dabei erst einmal als Schock, der zu einer emotionalen Erstarrung führte: »It must be admitted that in the beginning I was far too shocked to have any real reaction. $\ll^{212}$ Die Konfrontation mit den spezifischen Formen des Othering, die er in der Schweiz erfährt und die sich von dem ihm bekannten Rassismus in den USA unterscheiden, macht ihn handlungsunfähig. Baldwin schreibt: »If I sat in the sun for more than five minutes some daring creature was certain to come along and gingerly put his fingers on my hair, as though he was afraid of an electric shock, or put his hand on my hand, astonished that the color did not rub off.: ${ }^{213}$ Diese Passage dokumentiert eine Grunderfahrung des Alltagsrassismus. Drei Aspekte

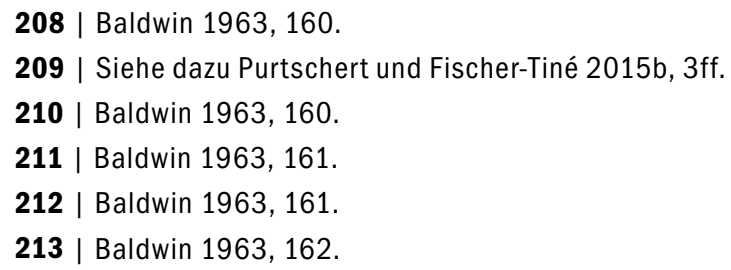


sollen an dieser Stelle hervorgehoben werden: der Zugriff auf Schwarze Körper, die Macht der weißen Norm und die Inszenierung kolonialer Differenz als Spektakel. Alle drei Aspekte finden sich in der kleinen Szene wieder, die Baldwin beschreibt, und alle drei erfassen fundamentale Erfahrungen des Fremd-gemacht-Werdens, denen Schwarze Menschen in der Schweiz bis heute ausgesetzt sind. ${ }^{214}$ So beschreibt Baldwin, dass er sich nicht im öffentlichen Raum bewegen kann, ohne angefasst zu werden. Es scheint ein allgemeines Recht darauf zu geben, seinen Körper zu berühren, seine Haut zu betasten und zu reiben, das Haar zwischen die Finger zu nehmen. Dabei wird eine Grenze überschritten, die gegenüber weißen Menschen in der Regel respektiert wird - wenn auch an dieser Stelle zu fragen wäre, wie sich die rassistische Grenzüberschreitung, die Baldwin beschreibt, zu Übergriffen auf die Körper von Frauen oder Kindern verhält und wie die doppelt betroffenen Körper von Schwarzen Frauen und Kindern in diesem intersektionalen Machtfeld positioniert werden müssten. >Rasse<, so schreibt Saidiya Hartman, erstellt ein hierarchisches System menschlichen Lebens, mithilfe dessen entschieden wird, welche Körper in Waren transformiert werden können und welche nicht. ${ }^{215}$ Diese Kommodifizierung Schwarzer Körper, die dem transatlantischen Sklavenhandel zugrunde lag, schlägt sich im Vorrecht von weißen Menschen nieder, Schwarze Menschen wie Objekte behandeln zu können - ein rassistisches Vorrecht, das auch die Interaktionen in einem Schweizer Bergdorf bestimmt.

Baldwin wird durch die Art und Weise, in der er berührt und sein Aussehen kommentiert wird, am Rand des Menschlichen situiert. Die Fremdheit des Schwarzen Besuchers wird ständig neu hergestellt, indem er betrachtet, angesprochen und betastet wird. Körperliche Merkmale, die different erscheinen, werden mit Attributen in Verbindung gebracht, die an Nichtmenschliches oder an eine sfalsche Menschlichkeit< erinnern: Man befürchtet, von seinem Haar könnten elektrische Schläge ausgehen, als wäre er ein Cyborg an der Schnittstelle von Mensch und Maschine. Und man versucht, seine dunkle Hautfarbe abzuwischen, als ob sich darunter eine andere, hellere, sechtere Haut befinden würde, als ob Schwarzsein eine trügerische Version des Menschlichen ist, unter der die >richtige $<$ zum Vorschein kommen muss. Der Versuch, den Schwar-

214 | Vgl. Pinto 2013, 181.

215 | Hartman 2007, 6. 
zen Besucher an der Grenze des Menschlichen anzusiedeln, richtet sich nicht nur auf sein Äußeres: »[T]here was certainly no element of intentional unkindness, there was yet no suggestion that I was human: I was simply a living wonder. $\aleph^{216}$ Der Schwarze Protagonist wird als lebendiges Kuriosum behandelt, das an unterschiedlichsten Grenzen des Menschlichen angesiedelt ist: an der Grenze zum Übermenschlichen, Teuflischen, Tierischen und Kriminellen - denn Baldwin wird auch bezichtigt, Holz gestohlen zu haben. ${ }^{217}$

Auffallend ist, wie Weißsein als Norm in diesem Schweizer Dorf in den $1950 e r$ Jahren reproduziert wird: Jede dieser Gesten und Äußerungen bestätigt, dass das Menschliche an Attribute gebunden ist, die der Protagonist nicht aufweist: an anderes Haar, an eine andere Haut, an einen anderen Körper. >Rassendifferenz « wird derart nicht nur hergestellt, sondern auch als Spektakel inszeniert. Der Aufenthalt des Schwarzen Schriftstellers wird von den Bewohner*innen des Dorfes zu einer öffentlichen Vorführung erklärt, in der Differenzen ständig neu aufgerufen und in Szene gesetzt werden. Dieses ritualisierte Spektakel hat zur Folge, dass sich der Fremde immer als Fremder fühlt - »I remain as much a stranger today as I was the first day I arrived. « ${ }^{218}$ Seine Fremdheit macht sich an einer Differenz fest, die er zu verkörpern gezwungen ist, indem er »schwarz gemacht ${ }^{219}$ wird. Wann auch immer er sich im Freien aufhält, wird er zum Mittelpunkt eines unfreiwilligen Schauspiels: »[A] wind passed with me - of astonishment, curiosity, amusement, and outrage. ${ }^{220}$ Was die Dorfbewohner*innen - die »natives «221, wie Baldwin sie in seiner Umkehroptik bezeichnet - als Spektakel der Differenz erleben, fühlt sich aufseiten des Schwarzen Besuchers gänzlich anders an. Er erfährt seine Fremdheit als unüberwindlich, die Dorfkultur als kontrollierend und seine eigene Situation als zutiefst einsam. ${ }^{222}$

Zur Macht der Dorfbewohner gehört, dass sie sich als Zugehörige des Westens verstehen, während der Schwarze Protagonist als Repräsentant

216 | Baldwin 1963, 162.

217 | Baldwin 1963, 168.

218 | Baldwin 1963, 161.

219 | Vgl. Pinto 2013, 145.

220 | Baldwin 1963, 161.

221 | Baldwin 1963, 161.

222 | Vgl. Baldwin 1963, 164. 
eines vormodernen Afrikas betrachtet wird: »For this village, even were it incomparably more remote and incredibly more primitive, is the West [...]. These people cannot be, from the point of view of power, strangers anywhere in the world; they have made the modern world, in effect, even if they do not know it. The most illiterate among them is related, in a way that I am not, to Dante, Shakespeare, Michelangelo, Aeschylus, Da Vinci, Rembrandt, and Racine; the cathedral at Chartres says something to them which it cannot say to me, as indeed would New York's Empire State Building, should anyone here ever see it.« ${ }^{223}$ Obwohl James Baldwin aus New York, einer der wichtigsten westlichen Metropolen, stammt und zurzeit in Paris lebt, obwohl er gerade seinen ersten Roman fertigstellt, der ihn zu einem der bedeutendsten Autoren seiner Generation machen wird, bleibt ihm die Identifikation mit einer weißen westlichen Kultur versagt, welche die Bewohner※innen Leukerbads selbstverständlich für sich reklamieren können. ${ }^{224}$

Weiße Superiorität als grundlegende Norm hat der nordamerikanische mit dem europäischen Rassismus gemeinsam. Anders ist aber, so Baldwin, dass diese Norm in Europa mit einer Kultur der >Unschuld< verbunden wird. Diese geht von der Annahme aus, dass die Existenz Schwarzer Menschen für Europa nicht von Bedeutung sei: »in effect, the black man, as a man, did not exist for Europe «. ${ }^{225}$ In den USA hingegen, so Baldwin, sind weiße Menschen gezwungen, sich mit der Tatsache auseinanderzusetzen, dass sie mit Schwarzen Menschen zusammenleben. Diesen relevanten Unterschied macht Baldwin an den historischen Gegebenheiten fest: Weil in der US-amerikanischen Post-Sklavenhaltergesellschaft weiße und Schwarze Menschen eine (wenn auch enorm gewaltvolle) gemeinsame Geschichte in einem (wenn auch immens segregierten)

223 | Baldwin 1963, 165.

224 | Inwiefern das auch für die Dorfbewohnerinnen der Fall ist, müsste aus einer feministischen Perspektive ergründet werden. So weist Simone de Beauvoir darauf hin, dass ein bekannter zeitgenössischer Autor seine abwertenden Bemerkungen gegenüber Frauen dadurch autorisierte, dass er sich in eine Reihe mit den großen Denkern der abendländischen Geschichte stellte: "Bemerkenswert ist, dass er sich durch das zweideutige Wir mit Paulus, Hegel, Lenin und Nietzsche identifiziert und, von deren Größe erhöht, verächtlich auf die Herde Frauen herabblickt, die es wagen, von gleich zu gleich mit inm zu sprechen." (Beauvoir 1994, 21)

225 | Baldwin 1963, 170 [Hervorhebung im Original]. 
gemeinsamen Raum teilen, kann die Präsenz Schwarzer Menschen nicht verleugnet werden. Baldwin verurteilt den Rassismus in Nordamerika aufs Schärfste, er betont aber auch, dass Schwarze Menschen in den USA von weißen Menschen in irgendeiner Form als Gegenüber anerkannt werden müssen.

In Europa hingegen, dessen Kolonialgeschichte in erheblichem Maße außerhalb des eigenen Territoriums stattfand, konnte man das Schwarze Gegenüber vergessen und jede erneute Begegnung mit ihm unter dem Signum von Unschuld und Naivität inszenieren. Im Unterschied zu den weißen Menschen in den USA, so schreibt Baldwin, besäßen die Bewohner*innen von Leukerbad »still [...] the luxury of looking on me as a stranger «226. Eine Schwarze Person, so Baldwin, ringe hingegen in jeder Begegnung mit weißen Europäer*innen darum, nicht als exotische Rarität betrachtet, sondern als Mensch anerkannt zu werden. Dieser Moment sei schwierig und belastend, »for there is a great deal of will power involved in the white man's naïveté «227. Das widersprüchliche Konzept einer Naivität, die im Gewand der Unschuld daherkommt und gleichzeitig Ausdruck von enormer Macht ist, verweist auf die privilegierte Position von weißen Europäer*innen: Sie können ihren rassistischen Umgang mit den Schwarzen Anderen in eine Terminologie des Staunens fassen und als vorurteilslose Faszination für das Fremde beschreiben. Der Schwarze Protagonist erkennt darin die Re-Inszenierung einer kolonialen Praxis, die den objektivierenden weißen Zugriff auf Schwarze Menschen perpetuiert.

Wie ein Echo auf Baldwins »European innocence «228 klingt die »White Innocence ${ }^{229}$, die Gloria Wekker in Auseinandersetzung mit dem postkolonialen Selbstverständnis der Niederlande vor Kurzem in die Diskussion eingebracht hat. Sie bezeichnet damit die widersprüchliche Verfasstheit der postkolonialen holländischen Gesellschaft, die von rassistischen Diskursen und Praktiken durchsetzt ist, deren konstitutive Bedeutung aber negiert wird. »I am intrigued by the ways in which race pops up in unexpected places and moments [...] while the dominant discourse stubbornly maintains that the Netherlands is and always has been colour-blind and

226 | Baldwin 1963, 175.

227 | Baldwin 1963, 166.

228 | Baldwin 1963, 174.

229 | Wekker 2016. 
anti-racist. «230 In einem solchen Zustand >grenzenloser Unschuld könne sich die Gesellschaft wähnen, weil sie die eigene Kolonialgeschichte ausgeblendet, das Selbstbild einer toleranten multikulturellen Gesellschaft in Szene gesetzt und die Schwarze Diaspora und ihre kritischen Wissensbestände marginalisiert habe. Wie Baldwin macht auch Wekker deutlich, dass die koloniale Unschuld auf der Verweigerung der Einsicht beruht, in globale Unrechtsverhältnisse verstrickt zu sein. Über ein halbes Jahrhundert nach Erscheinen von Baldwins Analyse zeigt sie damit, wie aktuell der Topos der Unschuld für eine Auseinandersetzung mit der postkolonialen Gegenwart in Europa noch immer ist.

Dass Baldwin die Wirkmacht des Alltagsrassismus am Beispiel seines Aufenthalts in einem Schweizer Bergdorf herausarbeitete, führt uns zurück zum Beginn dieser Einleitung. Wie Abdourahman Waberi eine helvetische Figur ins Zentrum seiner Kritik an der postkolonialen Weltordnung stellt, so macht auch Baldwin die Schweiz zum Ausgangspunkt für seine Reflexionen über koloniale Unschuld und die ungebrochene Macht der weißen Superiorität in Europa. Beide Analysen verorten die Schweiz in einem kolonialen Raum und bestätigen damit die Annahme, dass sich postkoloniale Forschung mit gutem Grund mit einem Land beschäftigt, das sich selbst als kolonialen Außenseiter versteht. Aus einer queer-feministischen Perspektive lässt sich an beide Texte die Frage richten, wie Geschlecht und Sexualität an der Herstellung einer solchen postkolonialen Kultur beteiligt sind. Und aus einer historischen Warte lässt sich fragen, welche Transformationen eine solche koloniale Matrix insbesondere während der Phase der Dekolonisation Mitte des 20. Jahrhunderts erfahren hat.

Die vorliegende Arbeit versteht sich als Beitrag zu der Debatte darüber, wie die Kolonialität moderner Macht mit kulturellen Repräsentationen in der Schweiz und von der Schweiz verwoben ist und wie die Schweiz dabei, in Anne Lavanchys Worten, als »a white homogeneous nation « ${ }^{231}$ hervorgebracht wird. ${ }^{232} \mathrm{Im}$ Zentrum stehen zwei für das Schweizer Selbstverständnis des 20. Jahrhunderts zentrale Figuren: die Hausfrau und der

230 | Wekker 2014, $159 f$.

231 | Lavanchy 2015, 289. Vgl. dazu auch Cretton 2018.

232 | Meine Ausführungen in den nachfolgenden beiden Teilen stützen sich auf Forschungsergebnisse in Purtschert 2018; Lüthi, Falk und Purtschert 2016; Purtschert 2016; Purtschert, Falk und Lüthi 2015; Purtschert und Fischer-Tiné 2015b; 
Bergsteiger. Beide repräsentieren idealisierte Geschlechtertypen und beide sind unauflöslich verflochten mit der Imagination des Nationalstaates im 20. Jahrhundert. Das Verhältnis dieser stilisierten Figuren zur Nation ist allerdings grundlegend asymmetrisch: Während der Bergführer seit 1900 den idealen Schweizer Staatsbürger symbolisiert, steht die Hausfrau in einem indirekten Verhältnis zum Staat. Sie sorgt für die körperlichen und emotionalen Existenzbedingungen des männlichen Schweizers und gewährleistet als Hausfrau und Mutter die Reproduktion der weißen Nation.

Die Funktion der beiden Figuren ist entsprechend unterschiedlich: Der Alpinist verkörpert die intrinsische Verbindung von Nation und Territorium und stellt ein Identifikationsangebot dar, das sich an männliche Bürger unterschiedlicher Klassen, Konfessionen und Regionen richtet. Insbesondere während der >Geistigen Landesverteidigung k kommt dieser Figur eine integrative und vereinheitlichende Rolle zu. Die Hausfrau hingegen wirkt als normatives Modell für diejenigen Frauen, die seit den 1930er Jahren zunehmend aus der Erwerbsarbeit und der Öffentlichkeit ausgeschlossen und in die häusliche Sphäre zurückgedrängt wurden. Repressive Geschlechtervorstellungen verzahnten sich in dieser Figur mit der Begehrenslogik des Massenkonsums, der den Frauen neue, kapitalistisch kodierte Räume und Sinnhorizonte eröffnen soll.

Meine Arbeit untersucht die koloniale Matrix, die bei der Herstellung dieser beiden für die Schweizer Geschichte zentralen Figuren am Werk ist. Die Studie stellt dabei zwei unterschiedliche Zeitabschnitte in den Fokus: zum einen die 1930er Jahre, als die koloniale Weltsicht in den gängigen Darstellungen noch weitgehend verteidigt wurde, und zum anderen die 1950er Jahre, als im Zuge der weltweiten Dekolonisation und im Anschluss an den Zweiten Weltkrieg neue Standards des globalen Zusammenlebens entwickelt werden mussten.

Die Schweizer Hausfrau, so lässt sich zeigen, gewann in den 1930 er Jahren ihre Konturen als zivilisierte, moderne und fortschrittliche Figur, indem sie gegen verschiedene Bilder rassifizierter Anderer abgesetzt wurde. Zentral für diese Darstellungen war die Entwicklung eines Warenrassismus im späten 19. Jahrhundert, der die Verbreitung kolonialer Bilder mit der Werbung von Konsumartikeln verschaltete. Mit der zunehmen-

Purtschert 2015a und 2015b; Purtschert 2014; Purtschert 2013; Purtschert und Krüger 2012; Purtschert 2012 sowie Purtschert, Lüthi und Falk 2012b. 
den Etablierung des Massenkonsums im frühen 20. Jahrhundert waren breitere soziale Schichten aufgefordert, sich vermehrt über eine zivilisierte bürgerliche Lebensweise zu definieren und Zugang zu ihr zu suchen. Das damit verbundene Versprechen, an einer begehrenswerten weißen Zivilisation teilnehmen zu können, richtete sich in besonderer Weise an Frauen: Denn mit der Reduktion weiblicher Tätigkeiten auf das Private, die in dieser Zeit eingefordert und in vielen Bereichen auch durchgesetzt wurde, ging nicht nur eine faktische Einschränkung des Handlungsspielraumes von Frauen einher, sondern auch das Angebot der affektiven Teilhabe an einer weißen Kultur, die sich gerade im Häuslichen manifestierte. Die weibliche Partizipation an einem imaginären Kolonialismus war deshalb unlösbar mit der Entwicklung und Durchsetzung eines Ideals der weißen Hausfrau verknüpft.

Die Identifikation mit Schweizer Bergsteigern, die in den 1950er Jahren im Himalaya unterwegs waren, ermöglichte es hingegen, althergebrachte koloniale Bilder weißer Männlichkeit zu bedienen, die mit Eroberung, Abenteuer, Mut, Führungs- und Besitzanspruch verbunden waren. Dabei wurden Vorstellungen eines kolonial kodierten >Berg-Othering aufgegriffen, die Mitte des 19. Jahrhunderts aufkamen. Sie dienten der Herstellung einer gemeinsamen nationalen Identität, die die Binnendifferenzen zwischen der städtischen Elite und der ländlichen Bevölkerung überbrücken sollte. Die postulierte Ähnlichkeit zwischen Sherpas und Schweizern, welche die populäre Berichterstattung über das HimalayaBergsteigen Mitte des 20. Jahrhunderts kennzeichnete, griff auf solche Differenzmomente zurück. Das koloniale Imaginäre wurde dabei an globale Transformationen angepasst, ohne dass die weiße Vormacht der Schweizer preisgegeben wurde. Die Beziehungen zwischen europäischen und nicht-europäischen Männern, wie sie in der Berichterstattung über die Bergsteiger am Himalaya gezeigt werden, bedienen ein neues Register von Partnerschaft und Freundschaft, während sie gleichzeitig die koloniale Asymmetrie aufrechterhalten und in ein neues, neokoloniales Register überführen. Sie erweisen sich als wegbereitend für die Stellung, die Schweizer Akteure in der dekolonialen Epoche bis in die Gegenwart einzunehmen suchten: die Rolle der neutralen Vermittler, die behaupten, sich frei von jeglichen kolonialen Verstrickungen in eine globalisierte Welt einzubringen, während sie dabei auf selbstverständlichste Weise ihre weißen Vorrechte reklamieren. 


\section{Kapitel 1}

\section{Weiße Waren: Die Erfindung der Schweizer Hausfrau}

Abbildung 1: Werbung für die Weißwarenwoche im Warenhaus Globus 1933

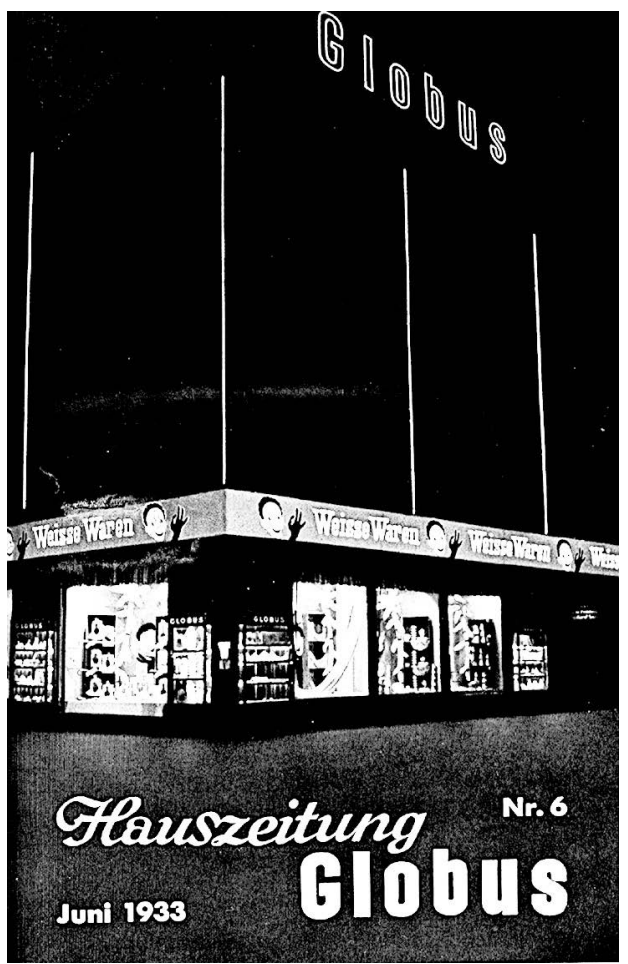

Quelle: Hauszeitung des Warenhauses Globus 1933(6) (Titelbild) 


\section{VIGNETTE: ITOTALı MACHT AUS BRAUNBÄREN WIEDER EISBÄREN}

Abbildung 2: Plakatwerbung der Migros für das Waschmittel >Totak

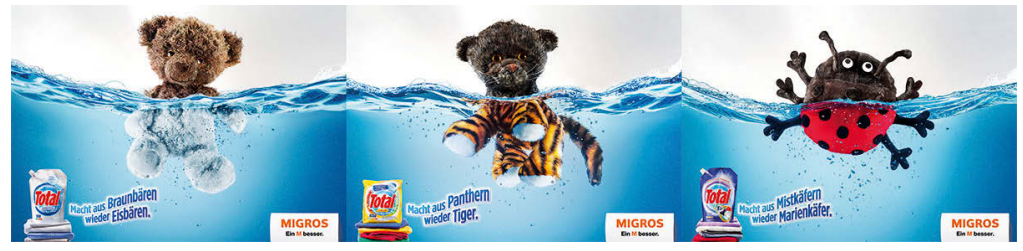

Quelle: https://www.yr-group.ch/advico/neuen-tv-spot-und-plakatkampagnefuer-total-lanciert (Zugriff am 24. September 2018)

Im Herbst 2014 lancierte der Schweizer Großhandelskonzern Migros eine Werbekampagne für sein Waschmittel >Totak, die drei Plakate und einen Werbefilm umfasste. Auf den Plakaten (vgl. Abbildung 2) ist jeweils ein Plüschtier zu sehen, dessen Körper sich im Wasser befindet, während der Kopf herausschaut. Unterhalb und oberhalb der Wasseroberfläche ist die Färbung der Tiere jeweils anders: Der Kopf, der aus dem Wasser ragt, ist braun, der Rumpf, der sich im Wasser befindet, weiß oder farbig. Der Text macht deutlich, dass die Farbveränderung auf das Waschmittel zurückgeht: »Total macht aus Braunbären wieder Eisbären«, heißt es da, »Total macht aus Panthern wieder Tiger« und »Total macht aus Mistkäfern wieder Marienkäfer«. Der Reinigungsprozess, so die Botschaft, stelle die ursprüngliche Zuordnung der Tiere wieder her. Denn wenn der vermeintliche Mistkäfer sich durch die Säuberung als Marienkäfer entpuppt, dann war er vorher eben kein Mistkäfer, sondern ein dreckiger Marienkäfer.

Abgebildet sind allerdings Plüschtiere mit einem regelmäßig braun gefärbten Fell, das keine Spuren von Schmutz, keine Flecken und keine verklebten Stellen aufweist. Mit anderen Worten: Gezeigt wird kein dreckiges, sondern ein dunkles Tier. Text und Bild stehen demnach in einer Spannung: Im Satz >Macht aus Braunbären wieder Eisbären< suggeriert das Wort >wieder<, dass der Bär zuvor weiß war und danach schmutzig wurde; eine Assoziation, die durch den >Mist< im Wort >Mistkäfer verstärkt wird. Das Bild hingegen zeigt einen Bären, der nicht dreckig, sondern braun ist, und damit einer anderen Subspezies angehört als der Eisbär. Die Farbänderung ist damit widersprüchlich: Dass ein dreckiges Plüschtier von Schmutz befreit werden soll, ist im Kontext einer Wasch- 
mittelwerbung eine verständliche Aussage. Warum aber soll aus einem Braunbären mit Vorteil ein Eisbär gemacht werden?

Bei dieser Widersprüchlichkeit setzte ein Protest an, der in Form eines offenen Briefes von fünf Aktivist*innen aus Genf geschrieben und von über 80 Personen unterzeichnet wurde. Das Schreiben hält fest, dass das Inserat eine Verbindung zwischen Reinheit und Weißsein, brauner Farbe und Schmutzigkeit herstelle. Diese Parallelisierung sei problematisch, weil sie auf ein rassistisches Archiv, eine kollektiv geteilte Ansammlung rassistischer Vorstellungen, verweise: Menschen afrikanischer Herkunft seien oftmals mit Schmutz und Unreinheit in Verbindung gebracht worden. Dem Brief angefügt waren mehrere historische Beispiele mit Werbungen für Seifen und Waschmittel, deren Wirkkraft durch das Weiß-Waschen einer Schwarzen Person demonstriert werden sollte. Das Schreiben forderte die sofortige Einstellung der Kampagne.

Nach einem Treffen mit den Initiator*innen ließ Migros über die Presse verlauten, dass die Werbung nicht zurückgezogen und auch keine Entschuldigung ausgesprochen werde. Ein Teddybär sei kein Mensch, ließ der Sprecher des Konzerns verlauten, und die Aktion stehe in Einklang mit dem Verhaltenskodex des Betriebs. ${ }^{1}$ Im März 2015 gewann die Werbung den ersten Preis beim Swiss Poster Award 2014. Von den Medien auf die Kontroverse um das Inserat angesprochen, meinte der Jury-Präsident Christian Brändle: »Dieses Plakat für eine Rassismusdebatte $\mathrm{zu}$ nutzen, ist schlicht missbräuchlich und kontraproduktiv. $\aleph^{2}$ Noch deutlicher wurde er in einem Beitrag der Zeitung Le Matin: »Le racisme est une chose épouvantable mais ces accusations sont hors de propos. Ces gens doivent se taire! « ${ }^{3}$ Auch die Neue Zürcher Zeitung, die im Dezember über den Fall berichtete, nahm die Forderungen aus Genf nicht ernst. Sie bezeichnete den Vorfall als »Sturm im Wasserglas [...], mit etwas Waschmittel versetzt; das beworbene Produkt

1 | 0.V.: "Bärli-Werbung empört Anti-Rassismus-Aktivisten", in: 20 Minuten, 2. Dezember 2014.

2 | Christian Brändle, zitiert nach o.V.: "Christian Brändle: ,Dieses Plakat für eine Rassismusdebatte zu nutzen, ist schlicht missbräuchlich ...'“, in: Klein-Report, 18. März 2015.

3 | Christian Brändle, zitiert nach Pomey, Raphaël: "Pub polémique de Migros élue affiche de l'année», in: Le Matin, 13. März 2015. 
trägt übrigens den Zusatz >Sensitive««" Während sich der Journalist der Neuen Zürcher Zeitung über die Kampagne lustig machte, indem er behauptete, deren Initiatiator*innen wären überempfindlich, unterstellte ihnen der Jury-Präsident des Swiss Poster Award gar eine missbräuchliche Absicht, die der Sache des Antirassismus schaden würde.

Einer der Autoren des Protestbriefes, der schweizerisch-kamerunische Schriftsteller Max Lobe, veröffentlichte auf seinem Blog einen Beitrag, der in überarbeiteter Form in der Zeitung Le Courrier erschien. Darin beschreibt Lobe eine Situation, in der ein Mann mit seinem fünfjährigen Neffen an besagtem Plakat vorbeilief. Das Kind fragte den Onkel, warum das Plüschtier auf dem Bild seine Farbe verliere. »Voilà la question qui tue«, heißt es da. »Que raconter à un gamin noir d'à peine cinq ans face à une telle affiche? Dois-je lui dire que l'ourson est blanchi parce qu'il est sale alors que je sais que son Pipou à lui, quoiqu'il soit brun, est toujours bien entretenu et propre? Dois-je lui dire que l'ourson est blanchi parce que la couleur brune ou noire est une couleur de saleté et que la couleur blanche est une couleur de propreté? « ${ }^{5}$ Der Mann fand sich durch die Begegnung mit dem Plakat ungewollt in einem ethischen Dilemma wieder. In einer Welt, die von Rassismus durchdrungen ist, musste er einem Schwarzen Kind erklären, warum ein brauner Bär mit Vorteil zu einem weißen Bären gemacht wird. Das Oszillieren der Werbung zwischen einem dreckigen und einem genuin braunen Lebewesen verbindet sich in Lobes Text mit einer langen Geschichte des Rassismus, in der nicht-weiße Haut mit physischer und moralischer Unreinheit in Verbindung gebracht wurde. Der Protagonist sah sich vor dem Plakat in die unmögliche Position versetzt, einem Schwarzen Kind die Pointe eines rassistischen Scherzes zu erklären. Das ist die Frage, die >tötet<: Sie zielt mit kindlicher Neugier auf eine verletzende Logik. Lobe veranschaulicht mit seinem Text die Zumutung, im öffentlichen Raum einer Darstellung ausgesetzt zu sein, welche die Zeichen einer rassistischen Geschichte mobilisiert und in Szene setzt, während sie vonseiten der weißen Mehrheitsgesellschaft als unterhaltsame und kindgerechte Werbung gelesen und verteidigt wird. ${ }^{6}$

4 | Bühler, Urs: "Angeschwärzte Weißwäsche», in: Neue Zürcher Zeitung vom 3. Dezember 2015.

5 | Lobe, Max: „Non, mon ourson ne deviandra pas blanc! «, in: Le Courrier, 5. November 2014.

6 | Vgl. dazu Purtschert (im Erscheinen). 
Auffallend ist die große Diskrepanz bei der Wahrnehmung dieser Werbung. Während ein weißer Journalist und ein weißer Werbefachmann die Meinung vertraten, dass die Frage des Rassismus bei dieser Werbung nicht einmal gestellt werden dürfe, forderte ein Schwarzer Autor, dass die Frage des Rassismus aufgeworfen werden müsse, weil die Werbekampagne Zeichen in den öffentlichen Raum stellt, die für nicht-weiße Menschen verletzende Wirkungen zeitigen. Auch das Argument der Migros, es handle sich bei den Abbildungen um Tiere und nicht um Menschen, wurde von den Protestierenden vor einem anderen Hintergrund gelesen. Während die Verwendung von Tieren für den Großhandelskonzern sicherstellte, dass die Bilder nicht auf Menschen bezogen werden konnten, sah sich die Gegenseite an aktuelle rassistische Praktiken erinnert. In einem Boykottaufruf gegen die Migros erinnerte die anti-rassistische Gruppierung Carrefour de refléxion et d'action contre le racisme anti-noir (CRAN) daran, dass die Substitution von Menschen durch Tiere gerade in aktuellen politischen Debatten dazu diene, sich rassistisch äußern zu können, ohne sich dem Vorwurf des Rassismus aussetzen zu müssen. ${ }^{7}$ Das Schreiben verwies dabei auf die berüchtigte >Schäfchenkampagne < der SVP von $2007 .{ }^{8}$ Auch wenn die Migros keine rassistische Botschaft intendierte, so wurde argumentiert, agierte der Konzern in einem diskursiven Feld, in dem semiotische Verschiebungen zwischen Mensch und Tier rassistisch aufgeladen sind.

Für meine Arbeit sind zwei Beobachtungen bedeutsam. Die eine betrifft den gänzlich unterschiedlichen Umgang mit der kolonialen Vergangenheit. In der Argumentation der Migros und anderer Exponent*innen gibt es keinen Bezug auf ein koloniales Archiv. Entsprechend können sie die Zeichen nicht deuten, die Verbindungen nicht herstellen und die Referenzen nicht erkennen, die den anti-rassistischen Aktivist*innen ins Auge springen. Deren Ausführungen zeigen wiederum, dass sich Schwarze Menschen in der Schweiz auch deshalb mit der rassistischen Geschichte beschäftigen, weil sie im Alltag von ihr heimgesucht werden.

7 | CRAN: "Le Cran appelle au Boycott des magasins de la Migros! «, 6. Januar 2014, www.cran.ch/04_PageCentrale/2_Communiques/2015/CRAN_CP_Boycott_ Migros_06Jan2015.pdf (Zugriff am 24. September 2018).

8 | Vgl. dazu meine Ausführungen in der Einleitung sowie Michel 2015. 
Abbildung 3: Filmstill aus der Migros-Werbung für das Waschmittel ,Totak aus dem Jahr 2014

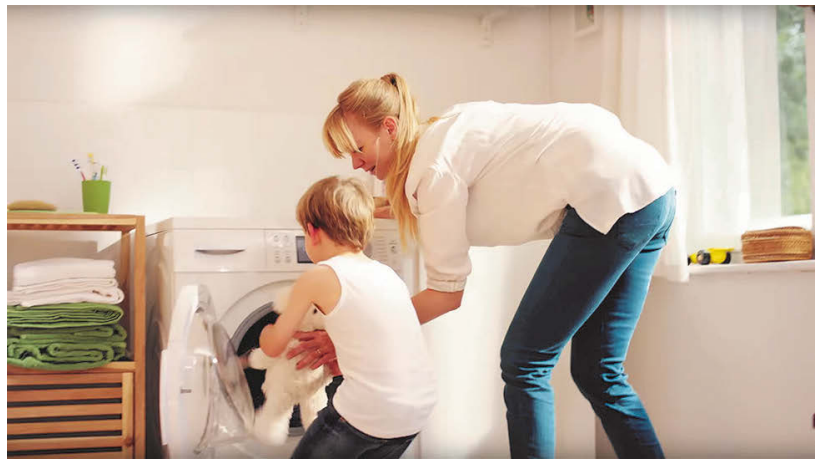

Quelle: https://www.yr-group.ch/advico/neuen-tv-spot-undplakatkampagne-fuer-total-lanciert (Zugriff am 11. Februar 2019)

Ein zweiter Punkt betrifft einen Aspekt, der in der Debatte keine Erwähnung fand: die Inszenierung von Weißsein. Er zeigt sich besonders im kurzen Werbefilm, der die Kampagne begleitete (vgl. Abbildung 3). Dieser beginnt mit Bildern eines weißen Jungen, der in einem lauschigen grünen Garten spielt. Kurz darauf tritt eine Frau ins Bild, die seine Mutter zu sein scheint. Sie hat lange blonde Haare und trägt einen weißen Pullover. Locker einen weißen Wäschekorb in die Seite gestemmt, geht sie durch den grünen Garten zum spielenden Kind und schlägt ihm vor, sein verdrecktes Plüschtier zu waschen. Das tun sie daraufhin gemeinsam - in einer blitzblanken hellen Waschküche mit weißen Vorhängen und einer neuen weißen Waschmaschine.

Im Werbespot des Schweizer Großhandelskonzerns dreht sich alles um die Farbe weiß: weiße Haut, (weiß-)blonde Haare, weiße Räume, weiße Kleider. In einer bedeutsamen Szene zum Schluss breitet sich das Waschmittel auf dem braunen Fell des Bären aus, das, wie in der Großaufnahme sichtbar wird, genau wie dasjenige der Tiere auf dem Plakat nicht dreckig, sondern von gleichmäßig brauner Farbe ist. Das Mittel bleicht das dunkle Fell rasend schnell, bringt das Braun vollständig zum Verschwinden und macht das Fell lupenrein und gleichmäßig weiß. Dass die Huldigung an die gute Hausfrau und Mutter in Weiß gehalten wird, dass das Glück der weißen Frau sich zwischen dem Garten des Einfamilienhauses und der Waschküche abspielt, dass sie die neuste Technik und die besten Produk- 
te verwendet, um ihren Haushalt zu führen, und dass die Differenz zum nicht-weißen Anderen erst vorgeführt und dann zum Verschwinden gebracht wird - das hat, wie die folgenden Ausführungen zeigen, eine lange Geschichte.

\section{SchWeizer Warenrassismus}

Im Frühjahr 1933 erschien im Zürcher Tages-Anzeiger ein Inserat (vgl. Abbildung 4), das fast die Hälfte der Zeitungsseite einnahm. Zu sehen ist eine Gestalt mit nackten Füßen in einem weißen Leinenkleid, die auf einem Schemel sitzt und auf einen Zierkaktus blickt. Ausgestattet ist die Figur mit den Merkmalen, die der zeitgenössische koloniale Diskurs Schwarzen Menschen zuschreibt: krause Haare, breite Lippen, eine fliehende Stirn, eine flache Nase und - mit Ausnahme des weißen Gesichts - Schwarze Haut. Den überdimensionierten Kopf, welcher der Figur ein kindliches Aussehen verleiht, auf die Hand gestützt, die Lider fast geschlossen, die Stirn in Falten gelegt, scheint die Person in schwermütige Gedanken versunken zu sein. Worüber denkt sie nach?

Der Text hilft der Leserin auf die Sprünge: Unter dem Bild ist in großen Lettern »... wehmütige Gedanken an Suraja ...« zu lesen und darunter steht in kleinerer Schrift: »Da sitzt er nun - unser weisser $\mathrm{N}[. .$.$] - und denkt an$ seine ferne Ehehälfte. Täglich sieht er nämlich im Globus diese überwältigende Auswahl an praktischen Bedarfs-Artikeln, täglich grüssen ihn aus allen Abteilungen Weisse Waren in Hülle und Fülle. Und seine Suraja sitzt in einem stillen Dorf tief in Afrika und kann von all diesen Herrlichkeiten nichts profitieren. Der Neid überkommt ihn - den weissen N[...] - wenn er die vielen sparsamen Hausfrauen sieht, die mit Kauf-Freude durch den Globus gehen und sich all das besorgen, was sie für Haus und Hof, für Küche und Keller, für Kind und Kegel brauchen. Nur seiner Suraja entgehen all diese Vorteile ... sie ist halt zu weit weg vom Globus.« Die Anzeige befindet sich, umgeben von Kleininseraten, auf einer Werbeseite der Tageszeitung. Sie war, so heißt es in der Hauszeitung des Warenhauses Globus, welches das Inserat geschaltet hatte, beim Publikum auf große Resonanz gestoßen. ${ }^{9}$

9 | Henauer, W., "Die Geschichte des weissen N[...]", in: Hauszeitung Globus 1933(6). 
Abbildung 4: Wehmütige Gedanken an Suraja, Inserat für das Warenhaus Globus 1933

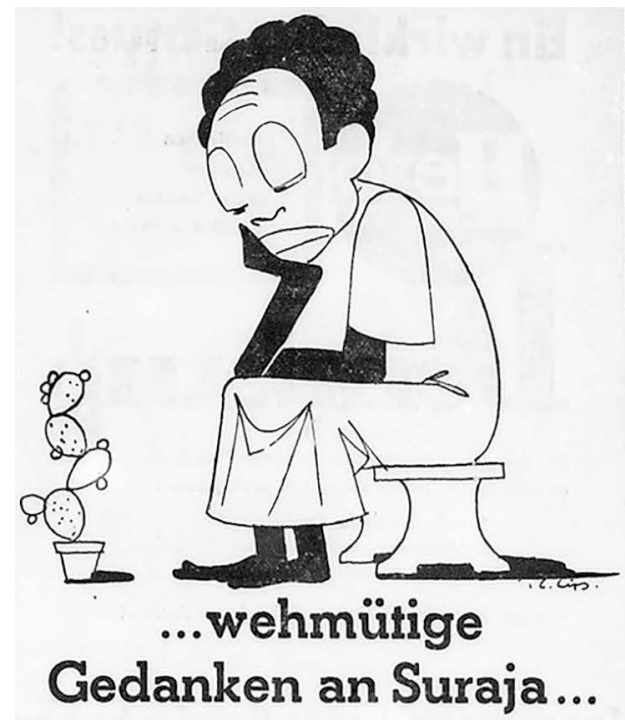

Da sitzt er nun - unser weisser Neger - und denkt an seine ferne Ehehälfte. Täglich sieht or rämlich im Globus diese überwältigende Auswahl an praktischen Bedarfs-Artikeln, täglich grüssen ihn aus allen Abteilungen

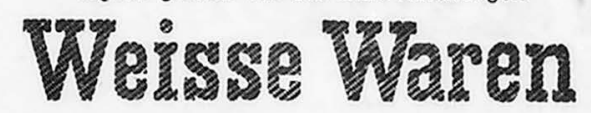

in Hülle und Fülle. Und seine Suraja sitzt in einem stillen Dorf tief in Afrika und kann von all diesen Herrlichkeiten nichts profitie. ren. Der Neid überkommt ihn - den weissen Neger - wenn er die vielen sparsamen Hausfrauen sieht, die mit Kauf-Freude durch den Globus gohen und sich all das besorgen, was sie für Haus und Hof, für Küche und Keller, für Kind und Kegel brauchen. Nur seiner Suraja entgehen all diese Vorteile... sie ist halt zu weit weg vom



Quelle: Zürcher Tages-Anzeiger, 28. April 1933 
Wer ist >unser weißer $\mathrm{N}-<^{10}$, wieso sitzt er voller Heimweh vor einem Kaktus und warum überkommt ihn der Neid beim Anblick Schweizer Hausfrauen? Was hat diese Figur in einer Schweizer Tageszeitung zu suchen? Wer ist Suraja? Und warum wird gerade dieses Inserat verwendet, um Schweizer Hausfrauen dazu zu bewegen, >weiße Waren $>$ zu kaufen?

Die Figur des >weißen N-<, die zwischen 1933 und 1935 in der deutschsprachigen Schweiz als Werbeträger zum Einsatz kam, stellt im Folgenden den Ausgangspunkt für eine Reflexion über den Zusammenhang von Konsum, Kolonialität, Weißsein und dem Ideal der Schweizer Hausfrau dar. Wegleitend dafür ist das Konzept des Warenrassismus, das Anne McClintock entwickelt hat. Sie zeigt damit, wie die neu entstehende Konsumkultur im spätviktorianischen Großbritannien die großflächige Zirkulation kolonialer Vorstellungen, Konzepte und Bilder befördert hatte. ${ }^{11}$ Dieser Zusammenhang erfordert es, so die Autorin, von einem neuen Typus des Rassismus zu sprechen, den sie als >commodity racism<, als Warenrassismus, bezeichnet. In der letzten Dekade des 19. Jahrhunderts fand demnach eine signifikante Verschiebung vom wissenschaftlichen Rassismus, der vor allem in gelehrten und elitären Zirkeln verbreitet war, zum Warenrassismus statt. Letzterer erreichte durch die aufkommende Konsumkultur breite Schichten der Bevölkerung und verknüpfte bestehende Vorstellungen von Waren, Besitz, Genuss, Status, Zivilisation, >Rasse<, Moderne, Geschlecht und Sexualität auf neue Weise. ${ }^{12}$ Diskursi-

10 | Das N-Wort wird im Folgenden als 'N angeführt und in Zitaten als ,N[...] wiedergegeben, um die rassistische Verletzung, die es beinhaltet, abzuschwächen und eine Distanz zum rassistischen Gebrauch dieses Begriffs zu markieren. Das N-Wort sollte, so führt Grada Kilomba aus, "alle südlich der Sahara lebenden Afrikanerlnnen kategorisieren und wurde während der europäischen Expansion erfunden. Das $\mathrm{N}$-Wort ist also in der Geschichte der Versklavung und Kolonisierung situiert, d.h. es ist ein Begriff, welcher mit Brutalität, Verwundung und Schmerz einhergeht". (Kilomba 2009 , o.S.)

11 Schon die Anfänge der Konsumgesellschaft Ende des 17. Jahrhunderts gehen mit der Verbreitung von Kolonialgütern einher, insbesondere mit Tee und Kaffee, indischen Stoffen, chinesischem Porzellan und Zucker (Stearns 2010, 16).

12 | Für die Geschichte der Konsumgesellschaft siehe König 2000 und für einen Überblick über die Forschung zur Konsumkultur Lury 2011 und Cohen 2003. Für die Veränderung der Situation der Arbeiterschaft in Europa durch die Kolonialware Zucker siehe Mintz 1987. 
ve Konstellationen, die auf den Kolonialismus und den transatlantischen Sklavenhandel zurückgingen, wurden dabei in ein neues Verhältnis zu einer kapitalistischen Ordnung gesetzt, die sich durch den aufkommenden Massenkonsum und neue Formen der Werbung auszeichnete.

Damit änderte sich auch die Art und Weise, wie sich koloniales Wissen entwickeln, durchsetzen und verbreiten konnte. Beim wissenschaftlichen Rassismus waren es ethnologische, medizinische oder naturwissenschaftliche Zeitschriften, Reiseberichte oder Ethnografien, beim Warenrassismus hingegen Werbung, Zeitschriften, Völkerschauen und Ausstellungen, die koloniale Bilder, Fantasien und Denkmuster in einem populärkulturellen Kontext vermittelten und für die breite Bevölkerung zugänglich machten. ${ }^{13}$

Die explosionsartige Verbreitung von Plakaten, Druckschriften und Werbematerialen Ende des 19. Jahrhunderts ging auch auf revolutionäre technische Veränderungen zurück: Obwohl es die Chromolithografie, den Mehrfarbensteindruck, bereits seit 1830 gegeben hatte, konnten Fünf-Farb-Drucke aus ökonomischen Gründen erst ab den 188oer Jahren im großen Stil hergestellt und für Werbezwecke verwendet werden. ${ }^{14}$ Werbebilder begannen nun in großer Anzahl in der Gesellschaft zu zirkulieren: Sie klebten an Wänden und Plakatsäulen, erschienen in Schaufenstern und auf Werbetafeln, kursierten als Beilage und Inserate in Zeitungen und Zeitschriften, zierten Zigarettenschachteln und Nahrungsverpackungen und wurden zu Sammelobjekten von Kindern und Erwachsenen. ${ }^{15}$ Mit den neuen Möglichkeiten der Werbung setzte sich auch das Branding durch, die Bindung von Alltagsgegenständen an die Namen der Herstellerfirmen. Gleichzeitig wurden Produkte verstärkt mit gesellschaftlich dominanten Normen und Idealen aufgeladen: »Ehemals triviale Gebrauchsgegenstände, deren Herstellerfirma kaum bekannt und auch von geringem Interesse war, wurden also durch das Zeichensystem der Werbung zu bedeutungsvollen >Trägern der Zivilisation< stilisiert. « ${ }^{16}$

McClintocks These von der Entstehung und Bedeutung des Warenrassismus wird besser nicht als strenge Zäsur gelesen. Unzweifelhaft veränderten sich koloniale Repräsentationsformen mit dem modernen Massenkonsum. Allerdings entstanden populäre Formen des Rassis-

13 | McClintock 1995, 33.

14 | Ciarlo 2011, $3 f$.

15 | Ciarlo 2011, 3.

16 | Wolter 2005, 51. 
mus nicht erst damit. Der Massenkonsum ermöglichte es vielmehr, bestehende rassistische Vorstellungen und Bilder auf neue Weise zu popularisieren und dabei auch zu transformieren. Für die Schweiz waren die Missionsgesellschaften, die einen großen Teil der Bevölkerung in ihre Aktivitäten einbinden konnten, bereits Mitte des 19. Jahrhunderts wichtige Multiplikatorinnen von kolonialen Bildern und Ansichten. Weit über die bürgerliche Oberschicht hinaus boten sie christlichen Akteur*innen die Gelegenheit, sich mit der >Zivilisationsmission $<$ zu verbinden und an ihr mitzuwirken. Der Warenrassismus stützte sich auf dieses bestehende koloniale Vorwissen und konfigurierte es auf neue Weise.

Im Folgenden verwende ich das Konzept des Warenrassismus, um einem bislang wenig beachteten Aspekt der Schweizer Geschichtsschreibung auf die Spur zu kommen: der intersektionalen Verflechtung von Geschlecht und >Rasse < in der Schweiz des 20. Jahrhunderts. Meine Nachforschungen setzen in der Zwischenkriegszeit an und fokussieren die breite gesellschaftliche Durchsetzung bürgerlicher Normen und Praktiken. Die seit dem späten 18. Jahrhundert entstehende bürgerliche Geschlechterordnung wurde dabei verstärkt als Ideal für alle Gesellschaftsschichten propagiert. Ihre Grundlage ist die Aufteilung der Tätigkeitsbereiche von Mann und Frau in einen öffentlichen und einen privaten Raum und die Vorstellung, dass sich diese (hierarchisch strukturierten) Bereiche komplementär ergänzen. Wie Karin Hausen ausführt, geht damit die Vorstellung geschlechtsspezifischer Dispositionen einher, die diese Aufteilung begründen und legitimieren. Es wird »mit den um die Merkmalsgruppen Aktivität-Rationalität für den Mann und Passivität-Emotionalität für die Frau gruppierten Eigenschaften der Mann eindeutig und explizit für die Welt und die Frau für das häusliche Leben qualifiziert« ${ }^{17}$.

Parallel zur Einführung und ontologischen Begründung eines komplementären Geschlechtermodells wurde die Kindheit gänzlich neu wahrgenommen und sozial gestaltet. ${ }^{18}$ Kinder, die vorher als kleine Erwachsene betrachtet und entsprechend behandelt wurden, galten nun als eigene Wesen, die einer spezifischen Sorge- und Erziehungspraxis bedurften. Wie Gisela Bock und Barbara Duden festhalten, war diese Entwicklung unauflösbar verbunden mit der Entstehung neuer Aufgaben für Frauen: »Es entstand die Kindheit und mit ihr die Mehr-Arbeit der Frauen

17 | Hausen 1976, 377.

18 | Ariès 1978. 
in der Kinderstube. $\ll^{19}$ Die psychische, soziale und intellektuelle Entwicklung der neuen Generation galt nun als eine bedeutsame Aufgabe, die der natürlichen Berufung der Frau entspricht. Bock und Duden sprechen von einer Propagandabewegung riesigen Ausmaßes, die im 19. Jahrhundert in Gang gebracht worden ist, »um die Mutterrolle als >natürliche Bestimmung < der Frauen durchzusetzen $\ll^{20}$.

Die um 1800 entwickelten Idealvorstellungen von Familie korrespondierten anfänglich (wenn überhaupt) allenfalls im gebildeten Bürgertum mit realen Lebensverhältnissen. ${ }^{21}$ Im Zuge des 19. Jahrhunderts fanden sie aber, nicht zuletzt durch geschlechtsspezifische Bildungssysteme, verstärkt Eingang in andere Bevölkerungsschichten. Der moderne Begriff der Familie wurde im 19. und 20. Jahrhundert über das städtische Bürgertum hinaus zunehmend für die gesamte Bevölkerung bedeutsam. ${ }^{22}$ Damit verbunden war die Entwicklung und Durchsetzung eines Ideals der Hausfrau, das über alle Schichten hinweg zum normativen Bezugspunkt wurde. Damit begann ein Prozess, »in dem sowohl aus der Hausherrin wie aus dem Hausmädchen eine Hausfrau wird, die im eigenen Heim unbezahlte Hausarbeit aus Liebe verrichtet. Dieser Prozeß läßt sich beschreiben als eine Angleichung, Nivellierung, Homogenisierung der Situation von Frauen ganz unterschiedlicher Position in Bezug auf die Hausarbeit.« $^{23}$

Aufgrund der enormen »Ausstrahlungskraft des bürgerlichen Familienideals $\ll^{24}$ auf alle Familienverhältnisse und seiner weiten Verbreitung wurde die Arbeit von Frauen neu bestimmt. Zwar hatten sie sich schon vorher um die Besorgung des Haushalts gekümmert. Was damals aber als materielle Existenzsicherung und unvermeidbare Tätigkeit galt, wurde neu mit affirmativen Werten und Affekten aufgeladen. Wie Elisabeth Joris und Heidi Witzig schreiben, bestand die Arbeit der Hausfrau nun auch darin, eine besondere Atmosphäre für die anderen Familienmitglieder zu schaffen und ihre Selbstverwirklichung in der Aufopferung zu finden: »Die Erfüllung dieser Aufgabe war nicht Pflicht, sondern Quelle der Freude, war Ausfluss des eigentlichen Wesens der Frau. Hausarbeit war

19 | Bock und Duden 1977, 134.

20 | Bock und Duden 1977, 135.

21 Hausen 1976, 383.

22 | Bock und Duden 1977, 122. Vgl. auch Rosenbaum 1982.

23 | Bock und Duden 1977, 157 [Hervorhebung im Original].

24 | Rosenbaum 1982, 477. 
nicht Arbeit, sondern Liebe, Aufopferung, Aufgehen in den Bedürfnissen der Familie. ${ }^{25}$ Dieses Ideal der guten Hausfrau setzte sich als gesellschaftliche Norm in den 1930er Jahren weitgehend durch. Ab den 1950er Jahren, als eine größere Anzahl von Familien es sich ökonomisch leisten konnte, auf eines der Einkommen zu verzichten und so den Status einer nicht erwerbstätigen Hausfrau zu schaffen, schlug es sich auch vermehrt in der strukturellen Organisation der Gesellschaft nieder. Obwohl nach wie vor eine bedeutende Zahl von Familien auf zwei Einkommen angewiesen war, wurde das Hausfrauen-Ideal prägend für das Geschlechterund Familienverständnis der Schweiz im 20. Jahrhundert. ${ }^{26}$

Die Durchsetzung des bürgerlichen Familienmodells wurde auch durch die Transformation der sozialen und ökonomischen Dimensionen ermöglicht. Dazu gehörte der Aufbau einer betrieblichen Sozialpolitik, die Brigitta Bernet und Jakob Tanner als Führungsstrategie beschreiben, die »seit dem Ersten Weltkrieg das Rückgrat des Industriekapitalismus und des >Schweizer Unternehmertums « ${ }^{27}$ bildete. Im Zuge dieser sozialen Rationalisierung wurde die Rolle der Hausfrau stark befördert. So kamen die seit dem ausgehenden 19. Jahrhundert propagierten und von Firmen erstellten Wohnsiedlungen »dem Streben der Arbeiterfamilien nach bürgerlichen Verhältnissen - eigene vier Wände, ein Stück Gartenland, Intimität, die Frau als Hüterin der Häuslichkeit - entgegen « ${ }^{28}$. Weil die außerhäusliche Tätigkeit von Frauen als Ausnahme dargestellt wurde, sahen sich Arbeiterinnen allerdings mit widersprüchlichen Anforderungen konfrontiert, die aus ihrer Erwerbsarbeit auf der einen und den vorherrschenden Weiblichkeitsnormen auf der anderen Seite resultierten. Im Gegensatz dazu wurde Männern, und damit auch Arbeitern, die weniger konfliktreiche Rolle des Familienernährers angeboten. ${ }^{29}$ Die einschneidenden emotionalen, sozialen und individuellen Veränderungen im Leben von Frauen (und Männern), die mit dem Modell des bürgerlichen Haushalts einhergingen, wurden von Diskursen unterstützt, in denen die kleinfamiliäre Arbeitsteilung als natür-

25 | Joris und Witzig 1986, 31.

26 | "Das Hausfrauenideal setzte sich nur langsam durch: 1870 waren über $50 \%$ der (über 15-jährigen) Erwerbstätigen Frauen, nach dem 1. Weltkrieg bis Mitte der 1970er Jahre sank ihr Anteil aber stetig. "(Blattmann 2011, o.S.)

27 | Bernet und Tanner 2015, 9.

28 | Joris und Witzig 1986, 85.

29 | Joris 2015. 
lich und normativ richtig beschrieben wurde. Dies wirkte sich auch auf das Demokratieverständnis in der Schweiz aus, wo die Forderungen nach dem Frauenstimmrecht in den 1930 er Jahren wieder leiser wurden und der Ausschluss von Frauen mit einem gewissen Stolz zum Merkmal der Schweizer Demokratie erklärt und »zu einem Gütesiegel der heilen Schweiz « ${ }^{30}$ stilisiert wurde, wie Brigitte Studer schreibt.

Diese gesellschaftliche Entwicklung ist eng verflochten mit der »Einengung der demokratischen Spielregeln $\aleph^{31}$ in der Schweiz der 1930er Jahre. Die Machtübernehme der Nationalsozialisten in Deutschland 1933 und die internationale Bedrohungslage führten zu einem rechtskonservativen $\gg$ Rückzug ins Innere ${ }^{32}$, der fortan politische und gesellschaftliche Aushandlungsprozesse dominierte. Dies zeigte sich insbesondere im Umgang mit denjenigen, die als Fremde wahrgenommen wurden. Entscheidende Änderungen hatte das »Bundesgesetz über Aufenthalt und Niederlassung der Ausländer« zur Folge, das 1931 verabschiedet wurde und 1934 in Kraft trat. ${ }^{33}$ Es ermöglichte der Politik, die Zuwanderung zu regulieren und den wirtschaftlichen und bevölkerungspolitischen Erfordernissen anzupassen, etwa durch die Einführung eines sogenannten >Saisonnierstatuts<, einer eng begrenzten und streng geregelten Aufenthaltsgenehmigung. Der Ausländeranteil in der Schweiz wurde fortan nicht mehr primär über die Einbürgerung gesteuert, wie dies vor dem Ersten Weltkrieg der Fall war, sondern über die Zuerkennung und den Entzug von temporären Aufenthaltsbewilligungen. Wo Einbürgerungen vorgenommen wurden, orientierten sie sich verstärkt am Kriterium der Assimilation, womit die Unterscheidung zwischen assimilierbaren und nicht-assimilierbaren Personen an Bedeutung gewann. ${ }^{34}$ Für Studer markiert die Einführung dieses Gesetzes den Abschluss eines Prozesses, den

30 | Studer 2014b, 546.

31 Mattioli 1995, 11.

32 | Zala 2014, 503.

33 | Bundesgesetz über Aufenthalt und Niederlassung der Ausländer vom 26. März 1931, Bundesblatt 1931, Band 1, S. 425-434, online abrufbar unter https://www.amtsdruckschriften.bar.admin.ch/start.do (Zugriff am 24. September 2018).

34 | Kury 2003, 185. 
sie als »Schaffung und Etablierung eines zentralen bevölkerungspolitischen Kontroll- und Regulierungsdispositivs « ${ }^{35}$ beschreibt.

Grundlegend für diese Entwicklung ist die Entstehung und Durchsetzung des sogenannten >Überfremdungsdiskurses<, der sich seit dem Ersten Weltkrieg »wirkmächtig zu formieren $\aleph^{36}$ begann. Mit dem Begriff der >Überfremdung « wurde die Vorstellung einer geistigen, kulturellen, wirtschaftlichen und politischen Bedrohung der Schweiz und des Schweizerischen durch die Migration aus dem Ausland beschrieben. Obwohl der Ausländeranteil in der Schweiz zwischen 1910 und 1930 stark zurückging, wurde die >Überfremdung zu einem zentralen Topos öffentlicher Debatten. Wie Damir Skenderovic festhält, hatten diese Debatten eine enorm restriktive Migrations- und Einbürgerungspolitik zur Folge: »Die Einbürgerung setzte nun die kulturelle Assimilation voraus und galt somit nicht mehr als Mittel der Integrationspolitik, sondern als Zeichen

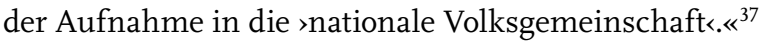

Der Überfremdungsdiskurs naturalisierte ein rassistisches, antisemitisches und fremdenfeindliches Verständnis von Staatszugehörigkeit, das sich zunehmend institutionell und gesetzlich verankern konnte. ${ }^{38}$ Der diskursive Vorteil des Überfremdungsbegriffs bestand darin, dass er mehrdeutig und flexibel eingesetzt werden konnte; Patrick Kury zufolge zielte er in der Zwischenkriegszeit insbesondere auf Jüd*innen ab. ${ }^{39} \mathrm{Al}-$ lerdings bediente der Überfremdungsdiskurs in seiner Ausrichtung auf >Unzivilisierte<, >Slaven< oder >Orientalen< von Anfang an auch koloniale Register, wie Harald Fischer-Tiné dargelegt hat. ${ }^{40}$

\section{5 | Studer 2008, 99.}

36 | Kury 2003, 211. Der Begriff der ,Überfremdung، wurde von Carl Alfred Schmid in der Schrift "Die Fremdenfrage" 1900 zum ersten Mal verwendet. Vgl. Argast 2007, 270.

37 | Skenderovic 2015a. In den 1930er Jahren wurden diese fremdenfeindlichen Diskurse politisch von der neu entstandenen Frontenbewegung aufgenommen sowie durch die an den Schweizer Universitäten prominent vertretene Rassenforschung gestärkt. Siehe dazu auch Germann 2016.

38 | Bereits im Ersten Weltkrieg fand der Begriff Eingang in die Amtssprache; sein rasanter Aufstieg wird insbesondere mit der Schaffung der Fremdenpolizei 1917 in Zusammenhang gebracht. VgI. Kury 2003, 211; Skenderovic $2015 \mathrm{a}$.

39 | Kury 2003, 212.

40 | Fischer-Tiné 2015, 244. 
Die politische Exklusion sowohl von Frauen durch deren Bindung an das Häusliche wie auch von Fremden durch den Überfremdungsdiskurs sind in der Schweizer Geschichtsforschung gut dokumentiert. Mein Ansinnen ist es im Folgenden, diese Befunde durch eine postkoloniale Perspektive zu ergänzen und dabei neue Forschungsfragen aufzuwerfen.

Folgt man Wulf Hund, Michael Pickering und Anandi Ramamurthy, dann beinhaltete der Warenrassismus ein Versprechen, das für die gesellschaftliche Kohäsion eingesetzt wurde: Das Weiß-Machen sollte Inklusion herstellen. Werbung stellte demnach klassenübergreifende Identifikationsangebote bereit, die mithilfe kolonialer Differenzmechanismen soziale Unruhen verhindern sollten: »Hereby commodity racism contributed to the social stabilisation of a capitalist society, which was substantially in trouble after the formation of the working class. $\ll^{41}$ Auch wenn viele der vermarkteten Produkte für Arbeiter*innen unerschwinglich blieben, bot die Werbung im öffentlichen Raum die Möglichkeit, sich mit einer imaginären weißen $>$ Rasse $<\mathrm{zu}$ identifizieren, die Zivilisation, Fortschritt und Überlegenheit verkörperte. Der Warenrassismus konnte auf diese Weise ein Zugehörigkeitsgefühl vermitteln, das von bestehenden Klassendifferenzen ablenken und sie transzendieren sollte. Er bot »whiteness as promise of belonging (and antidote against social discontent) « ${ }^{42}$.

Meine These ist, dass sich im Warenrassismus im Hinblick auf die Frauen ein ähnliches Versprechen und ein vergleichbares >Gegengift gegen soziale Unzufriedenheit< ausmachen lässt. Der koloniale Kontext der Werbung ermöglichte die Herstellung eines semiotischen Überschusses, mit dessen Hilfe die Verbannung der Frauen ins Haus, die fortgesetzte Verweigerung oder erneute Beschneidung ihres Bewegungs- und Aktivitätsradius und ihre augenfällige politische, rechtliche und soziale Ungleichbehandlung in ein anderes Licht gerückt werden konnte: Die Tätigkeit der Hausfrau wurde mit der Teilhabe an einer überlegenen weißen Zivilisation verbunden. Um diese These zu belegen, ist der Rückgriff auf McClintocks Begriff des »Haushaltskults« (»cult of domesticity«) $)^{43}$ hilfreich, der beschreibt, wie Metropole und Kolonie über das Häusliche miteinander verschränkt wurden. Einerseits versuchten Kolonialregierung und Missionen, europäische Geschlechternormen, Familienmodelle und

41 | Hund, Pickering und Ramamurthy 2013, 15.

42 | Hund, Pickering und Ramamurthy 2013, 15.

43 | McClintock 1995, 5 und 209, siehe auch Comaroff und Comaroff 2013. 
Häuslichkeitsvorstellungen in den Kolonien durchzusetzen. Die sittliche Führung des Haushaltes wurde damit zu einem wirkmächtigen Element der Zivilisierungsmission. Andererseits war $>$ Rasse $<$ konstitutiv für die Herstellung eines viktorianischen Kults der Häuslichkeit in den Metropolen, der als kultivierter imperialer Stil inszeniert und als Ausdruck eines zivilisierten weißen Europas zur Schau gestellt wurde. McClintock verdichtet diese Wechselwirkung in der Formel: »[D]omestic space became racialized, colonial space became domesticated. ${ }^{44}$

Für die interne Organisation der britischen Gesellschaft erwies sich der koloniale Haushaltskult in zweierlei Hinsicht als bedeutsam. Erstens diente er der Erfassung, Kontrolle und Disziplinierung von Subjekten, die als deviant galten. Die >Wilden< und >Primitiven< der Metropole konnten anhand kolonialer Kategorisierungen und Praktiken gemessen, eingeteilt und überwacht werden: »[T]he idea of racial deviance was evoked to police the >degenerate< classes - the militant working class, the Irish, Jews, feminists, gays and lesbians, prostitutes, criminals, alcoholics and the insane. $\ll^{45}$ Zweitens war der koloniale Haushaltskult konstitutiv für die Herstellung einer neu entstehenden bürgerlichen Mittelschicht, deren Selbstverständnis auch auf ihrer Abgrenzung von den Kolonialisierten gründete.

McClintocks Untersuchung zeitigt weitreichende Konsequenzen für eine Gesellschaftsanalyse, weil sie den Bereich des Häuslichen aus dem Windschatten der öffentlichen Angelegenheiten holt und zu einem zentralen Schauplatz für die Geschichtsschreibung macht. Das Private ist demnach nicht ein >Hinterhof^der öffentlichen Sphäre, der die Versorgung, Pflege und Regeneration der männlichen Akteure sicherstellte. Vielmehr fanden hegemoniale Vorstellungen der modernen imperialen Lebensweise durch die Stilisierung des bürgerlichen Haushalts ihren Weg in die Öffentlichkeit: »In the process, the Victorian middle-class home became a space for the display of imperial spectacle and the reinvention of race, while the colonies - in particular Africa - became a theatre for exhibiting the Victorian cult of domesticity and the reinvention of gender. $\aleph^{46} \mathrm{McClin}$ tock beschreibt damit einen gegenseitigen Verweisungszusammenhang zwischen Kolonie und Metropole, in welchem dem gepflegten modernen

44 | McClintock 1995, 36. Zur viktorianischen Geschlechterpolitik vgl. Griffin 2014; Hall, McClelland und Rendall 2000; Ittmann 1995.

45 | McClintock 1995, 43.

46 | McClintock 1995, 34. 
Heim eine Scharnierfunktion zukam: Während die (afrikanische) Kolonie zum Schauplatz eines bürgerlichen Haushaltskults wurde, der den >rückständigen < Anderen beigebracht werden musste, mutierte der weiße, mittelständische Haushalt in Großbritannien zum Ausstellungsraum für das imperiale Projekt. Lässt sich dieser wegweisende Befund von McClintock auch auf die Schweiz beziehen und ermöglicht er es, die Globus-Kampagne mit dem >weißen $\mathrm{N}-<$ in ein neues Licht zu rücken?

\section{Die Erfindung des iweissen N-८: Erster Teil}

Die in neuer Weise an die Frauen delegierten Aufgaben - die Schaffung einer spezifisch häuslichen Atmosphäre und die Sinnfindung in der Sorge um die Familie - entstanden im Kontext einer kolonialen Weltordnung. Wie wirkte sich diese Tatsache auf die Entwicklung der neuen Geschlechterordnung aus? Ausgehend von dieser Frage werden im Folgenden populäre und hegemoniale Medien untersucht, in denen die zeitgenössischen Normen von Weiblichkeit und Familie in der deutschsprachigen Schweiz der 1930er Jahre zum Zirkulieren gebracht wurden: Werbung, Illustrierte, Missionszeitschriften, Zeitungsartikel und Reiseliteratur.

Mein Fokus liegt dabei in erster Linie auf Bildern, Beschreibungen und Repräsentationen von Afrika, das als gänzlich Anderes der europäischen Kultur und von Kultur überhaupt fungierte. Afrika, so schreibt Mbembe, sei zum Inbegriff einer radikalen Andersheit geworden, der dem Westen als Kontrastfolie für seine globale Eigenständigkeit und Vorrangstellung diente. »Africa as an idea, a concept, has historically served, and continues to serve, as a polemical argument for the West's desperate desire to assert its difference from the rest of the world. $\ll^{47}$ Das galt auch für die Schweiz: Dichotome Vorstellungen von Afrika und Europa, Schwarz- und Weißsein, Zivilisation und Wildheit, Fortschritt und Stillstand sowie Christentum und Heidentum waren in der populären Kultur der Schweiz omnipräsent. In seiner Analyse von kolonialen Bildern zwischen 1880 und 1939 kommt Patrick Minder zu dem Schluss, dass Repräsentationen von Afrika und afrikanischen Menschen in der Schweiz weitaus häufiger zu finden waren also solche von Bewohner*innen anderer Kolonialgebiete. ${ }^{48}$ Meine Aus-

47 | Mbembe 2001, 2.

48 | Minder 2011, 405. Vgl. dazu auch Joris: "Verdichtete sich für die Schweizer 
führungen setzen deshalb nicht zufällig bei einer Figur an, die mit Afrika in Verbindung gebracht wurde: dem >weißen $\mathrm{N}-<$. Dieser bereits erwähnte Werbeträger eines Schweizer Warenhauses in den 1930er Jahren wird im Folgenden als Kreuzungspunkt unterschiedlicher Diskursstränge untersucht und dient dabei zugleich als Anschauungsbeispiel für die Präsenz und Bedeutung einer kolonialen Wissensordnung für die Schweizer Alltagskultur der Zwischenkriegszeit.

Die Einführung der neuen Werbefigur, des >weißen $\mathrm{N}$-<, wurde als Ereignis inszeniert: Im April 1933 erschien im Zürcher Tages-Anzeiger an drei aufeinanderfolgenden Tagen eine insgesamt fünfteilige Inserate-Serie, deren Zweck und Urheberschaft zunächst unklar blieb. Protagonist des ersten Inserates (vgl. Abbildung 5, Teil 1) ist ein >Reklamechef<, der unter großem Druck steht, sich etwas einfallen zu lassen - noch weiß die Leserschaft nicht, wofür. Das Bild zeigt ihn als einen weißen Mann im Anzug, mit hoher Stirn, nach hinten gekämmtem Haarschopf und Brille, den Kopf nachdenklich auf die Hand gestützt, aufgeregt im Kreis herumgehend. Über seinem Kopf türmen sich Fragezeichen.



Quelle: Zürcher Tages-Anzeiger, 18. April 1933

Zentrale des sozialdemokratischen Grütlivereins zu Beginn des 20. Jahrhunderts die Zurückgebliebenheit im Bild des Wallis als 'Afrika', so sahen zur selben Zeit die Einheimischen in den Tunnelarbeitern 'Afrikaner - das Fremde schlechthin." (Joris 2016, 39). 
Der beigefügte Text klärt die Leser*innen über den Grund für seine schwierige Situation auf: »... ja, ja, ... auch Reklame-Chefs können ihre guten Einfälle nicht aus dem Aermel schütteln! Sie sehen es an diesem hier, wie er verzweifelt nach Ideen sucht, nach Ideen für einen bedeutsamen Sonder-Verkauf! « ${ }^{49}$

Während die Leserschaft erfährt, was beworben werden soll, bleibt unklar, von wem das Inserat stammt. Das ändert sich auch nicht durch das zweite Inserat (vgl. Abbildung 5, Teil 2) auf derselben Seite unten rechts, das erneut den Werbefachmann zeigt. Er sitzt nun an einem mit Blättern übersäten Tisch und spricht sichtlich aufgeregt in einen Telefonhörer. Ein Kabel verbindet seinen Schreibtisch mit einer Palme in der Wüste, in deren Mitte ein Telefon klingelt. »Hallo! ... geben Sie mir bitte Afrika « ruft der Werbeleiter in den Hörer. Und weiter: »Ein rettender Einfall: Zu was gibt es ein Telephon ... und zu was ein afrikanisches Ferien-Land, wo sich einer herumtreibt, der bestimmt gute Ideen hat! ... Na? Kommt er denn nicht ans Telephon? «50 Aus postkolonialer Perspektive ist bemerkenswert, wie die Handlungsmacht in dieser Ankündigung verteilt wird:

Der Werbeleiter verlangt zwar >Afrika<, wie sich aber gleich herausstellt, verspricht er sich den >rettenden Einfall nicht von einer afrikanischen Person, sondern von jemandem, der sich als Tourist in Afrika aufhält und damit eine kommodifizierte Perspektive auf den Kontinent einnimmt.

Am nächsten Tag erscheinen erneut zwei Globus-Inserate auf einer Werbeseite des Zürcher Tages-Anzeigers (vgl. Abbildung 6). Im ersten erfahren die Leser*innen endlich, wen der Werbechef zu erreichen sucht: Es ist Globi, der blaue Papagei. ${ }^{51}$ Er ist seit 1932 ein beliebter Werbeträger des Warenhauses Globus und richtet sich besonders an Kinder. ${ }^{52}$ Auf dem Inserat sitzt er vergnügt auf einer Wolke über der Palme, den Tele-

49 | Inserat im Tages-Anzeiger, 18. April 1933.

50 | Inserat im Tages-Anzeiger, 18. April 1933.

51 | Der rweiße $\mathrm{N}$-r wurde ein halbes Jahr nach der Erfindung des blauen Papageien Globi als Werbeträger lanciert. Letzterer entwickelte sich zu einer der beliebtesten Figuren der Deutschschweizer Kinderliteratur (vgl. Purtschert und Krüger 2012). Zwischen 1933 und 1935 wurden verschiedene Inserate mit dem ,weißen $\mathrm{N}$-ı geschaltet und eine Bildergeschichte veröffentlicht, in der er als Globis Helfer agiert. Danach verschwand der 'weiße $\mathrm{N}-4$.

52 | Vgl. dazu Bellwald 2003 sowie Purtschert und Krüger 2012. 
fonhörer ans Ohr gepresst. Vor dem Baum steht eine Schwarze Figur in einem weißen Kleid, das wie ein Kinder- oder Puppenkleid geschnitten ist, und schaut mit großen Augen $\mathrm{zu}$ ihm hoch. Eine zweite Schwarze Gestalt kommt angerannt, die Hände eigenartig abgewinkelt, als würde sie gleichzeitig rennen und tanzen. Globi spricht folgende Worte in den Hörer: »JJ.JA! HIER GLOBI. Moment bitte! Muss erst absitzen und ausschnaufen. ${ }^{53}$ Im nächsten Bild sitzt er gemütlich in der Krone der Palme, mittlerweile von neun Menschen umringt, die alle kindliche Züge aufweisen. Acht dieser Figuren sind Schwarz und tragen weiße Kleider, während die Person in der Mitte komplementär zu den anderen gestaltet ist: Sie trägt ein schwarzes Kleid und hat einen weißen Hinterkopf und weiße Arme und Beine.

Abbildung 6: Serie von Werbeinseraten für das Warenhaus Globus 1933 (Teil 3 und 4)

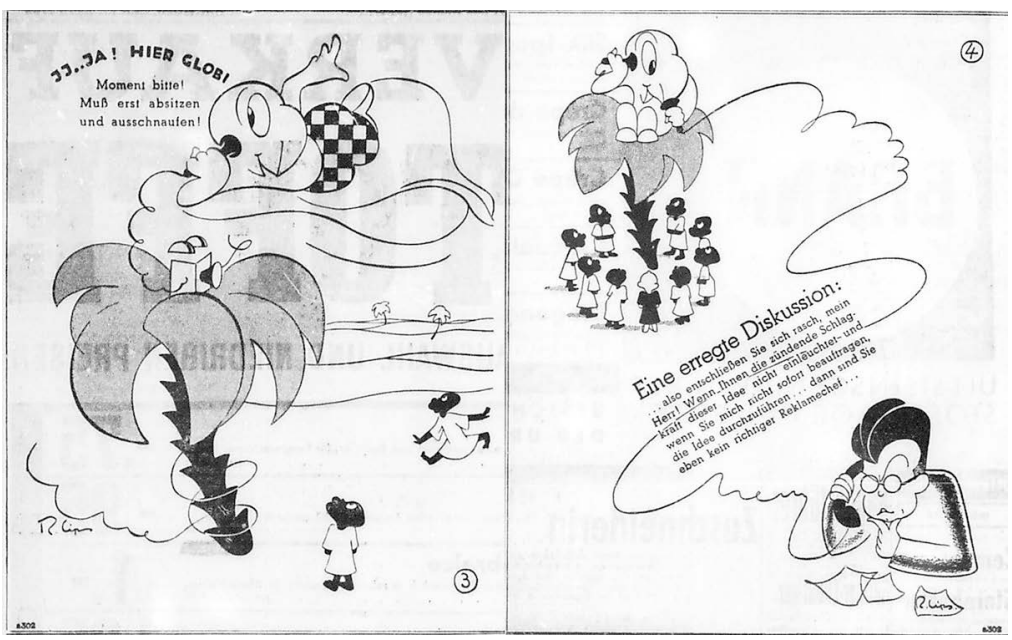

Quelle: Zürcher Tages-Anzeiger, 19. April 1933

Unten rechts im Bild ist der Reklamechef erkennbar, der über den Telefondraht mit Globi in Verbindung steht. Sein grüblerischer Ausdruck kontrastiert mit Globis Heiterkeit. Zwischen den beiden Figuren steht folgender Text: »Eine erregte Diskussion: ... also entschließen Sie sich rasch, 
mein Herr! Wenn Ihnen die zündende Schlagkraft dieser Idee nicht einleuchtet und wenn Sie mich nicht sofort beauftragen, die Idee durchzuführen ... dann sind Sie eben kein richtiger Reklamechef! ... ${ }^{54}$ Diese Worte scheinen von Globi zu stammen. Er verfügt über eine Werbeidee, von der er, im Unterschied zum Reklamechef, überzeugt ist. Selbstbewusst wirft er ihm mangelnde Professionalität vor, sollte er sich nicht auf seinen Vorschlag einlassen.

Obwohl mit diesen beiden Inseraten Entscheidendes im Unklaren belassen und somit die Spannung aufrechterhalten wurde, wussten die informierten Leser*innen durch Globis Auftritt, dass die Inserate vom Warenhaus Globus stammten. Vielleicht erkannten sie im aufgeregten >Werbechef sogar Ignatius Karl Schiele, der 1931 im Zuge der neuen Corporate Identity-Strategie des Unternehmens als Werbeleiter eingestellt wurde. ${ }^{55}$ Der Bezug zu Afrika, der im zweiten Inserat (vgl. Abbildung 5, Teil 2) ins Spiel gebracht wurde, verstärkte sich in diesen beiden Bildern und damit auch die Vermutung, die angekündigte Werbung werde mit dem Kontinent zu tun haben. Bezeichnend ist erneut die Aufstellung der Akteur*innen und die Verteilung von Handlungsmacht: Die Aktivität und Kreativität Globis wie auch des Werbechefs und die Bedeutsamkeit der Handlungen dieser beiden in der Schweiz lokalisierten Figuren kontrastiert mit den Schwarzen Figuren, die lediglich stumm starren und staunen.

Am nächsten Tag wurde das Rätsel gelöst und die neue Werbe-Idee von Globus mit einem fünften Inserat bekannt gemacht. Auf diese Weise wurde die Leserschaft der Zeitung in einen Findungsprozess eingebunden, der als Seriengeschichte aufgebaut war und eine entsprechende Spannung erzeugte. Dieses Vorgehen ist exemplarisch für eine Werbung, die zunehmend selbstreferentiell wurde und sich vom Artikel ablöste, den sie vertreiben sollte. ${ }^{56}$ Seit der Zwischenkriegszeit versuchte die Werbung verstärkt, psychologische Kenntnisse einzubeziehen, um Kaufwünsche zu aktivieren und zu modellieren. ${ }^{57}$ Zur Hervorbringung eines neuen Typus von Konsument*innen gehörte, dass seit den 1920er Jahren verstärkt auch psychologische Erkenntnisse übernommen wurden, die das »ab-

54 | Inserat im Tages-Anzeiger, 19. April 1933.

55 | Pfenninger 2007, 29.

56 | Haas 1995, 73.

57 | Tanner und Studer 2012, 688. Vgl. Brändli Blumenbach 2000. 
satz- und werbewirtschaftliche Nachdenken über menschliche Bedürfnisse, Antriebe und Motivationen ${ }^{58}{ }^{5} \mathrm{z}$ einem Bestandteil der Werbung machten. Diese Entwicklung war stark auf Frauen ausgerichtet, die einen Großteil der Einkäufe vornahmen: Die Kundschaft des Globus bestand in dieser Zeit zu 95 Prozent aus Konsumentinnen, die vornehmlich dem Mittelstand zugerechnet wurden. ${ }^{59}$

Die Bedeutung der Werbung für die Warenhäuser lag auch im spannungsreichen politischen Kontext der 1930er Jahre begründet. 30 Jahre zuvor, um 1900, hatten sich in Schweizer Städten verschiedene Warenhäuser nach US-amerikanischem und französischem Vorbild etabliert. ${ }^{60}$ Sie zeichneten sich dadurch aus, dass die Preise festgelegt und mit einem Preisschild angezeigt waren, dass nur gegen Bargeld verkauft und dass unterschiedlichste Waren geführt wurden. ${ }^{61}$ Im Vergleich mit dem althergebrachten Einzelhandel waren die Warenhäuser offen für neue Organisationsformen und Werbemethoden, die vornehmlich aus den USA kamen. ${ }^{62}$ Als reale Erneurer sowie als Sinnbild für einen einschneidenden Strukturwandel fanden sich Warenhäuser in der Schweiz seit ihrer Verbreitung dem Vorwurf ausgesetzt, den Einzelhandel zu bedrohen.

Diese Spannungen verstärkten sich in der Weltwirtschaftskrise von 1929, welche die Schweiz zu Beginn der 1930er Jahre mit Verzögerung erreichte. ${ }^{63}$ Viele Kampagnen verknüpften die angebliche Gefahr, die von

$\mathbf{5 8}$ | Brändli Blumenbach 2000, 102.

59 | Pfenninger 2007, $27 f$.

60 | Denneberg 1937, $47 f f$.

61 | Denneberg 1937, 56. Aus postkolonialer Sicht interessant ist, dass die Warenhäuser zu Beginn auch als Basare bezeichnet wurden. So lautete der usprüngliche Name des Globus bei seiner Gründung 1892 "J. Webers Bazar" (Pfenninger 2007, 17).

62 | So rät beispielsweise eine Anleitung zur ızeitgemäßen Gestaltung، der Schaufenster von 1930 dem Einzelhandel eindringlich, den Schaufenstern ebenso viel Aufmerksamkeit zukommen zu lassen, wie dies die Warenhäuser taten. Vgl. Baumann 1930.

63 | Die Arbeitslosenzahlen stiegen von 8.000 Personen im Jahr 1929 auf 54.000 im Jahr 1932 und erreichten mit 93.000 Arbeitslosen im Jahr 1936 den höchsten Stand; dies entsprach 5 \% der erwerbstätigen Bevölkerung (Reich 2007, 24f.). Als Rezession wird die Zeit zwischen 1931 und 1936 angegeben (vgl. Zala 2014, 504). 
den Warenhäusern ausging, mit antisemitischen und fremdenfeindlichen Inhalten und zielten auf Geschäfte wie Nordmann, Loeb oder Maus, die sich im Besitz von jüdischen oder ausländischen Familien befanden. ${ }^{64}$

Diese Debatten führten schließlich zum Erlass eines Bundesbeschlusses über das »Verbot der Eröffnung und Erweiterung von Warenhäusern, Kaufhäusern, Einheitspreis- und Filialgeschäften«, der von 1933 bis 1945 in Kraft war und die Geschäftsmöglichkeiten der Warenhäuser massiv einschränkte. ${ }^{65}$ Die Kontroverse um die Warenhäuser fand zudem vor dem Hintergrund einer weitgehenden Nationalisierung der Ökonomie statt. Wie Mario König zeigt, setzte dieser Prozess nach dem Ersten Weltkrieg ein und war eng mit der politischen Überfremdungsdebatte verflochten. Die Angst vor der ökonomischen Dominanz ausländischer Firmen und der Ruf nach einer >Rückbesinnung < auf die eigene Wirtschaftskraft führten zu einer Reihe von Gesetzesänderungen und zu Kampagnen wie den seit 1917 stattfindenden >Schweizer Wochen<, welche die Bevölkerung zum Kauf von Schweizer Produkten aufriefen. ${ }^{66}$ Brisant und für die postkoloniale Wirtschaftsgeschichte der Schweiz bedeutsam ist, dass der international orientierte und auf offene Märkte setzende Bereich der Exportwirtschaft und der Finanzdienstleistungen trotz des Trends zur nationalen Abschottung aufrechterhalten wurde. König hält dazu fest: »Von der Politik war damit ein Balanceakt gefordert: Offenheit für die einen, Schutz für die anderen. ${ }^{67}$

Damit entstand eine Wirtschaftsstruktur, die bis in die Gegenwart hinein fortwirkt und durch ein entscheidendes Paradox geprägt ist: Einerseits etablierte sich die Schweiz mithilfe entsprechender gesetzlicher Regelungen und der Unterstützung wirtschaftsliberaler politischer Kräfte erfolgreich als global bedeutsamer Finanzplatz und exportorientierter Industriestandort. Andererseits wurde das Bild einer autonomen und selbstgenügsamen Volkwirtschaft geschaffen und gepflegt, das vor dem schädli-

64 | Liebeskind Sauthier 2013. Siehe auch Kamis-Müller 2000, 158-167.

65 | Pfenninger 2007, 35. Die wirtschaftliche Bedeutung der Warenhäuser, so schreibt David Reich, wurde in dieser Zeit überschätzt: "Wichtiger war deren symbolische Bedeutung als leuchtende، Boten eines sich anbahnenden Strukturwandels im Detailhandel, der bei den traditionellen Kleinhändlern Existenzängste auslöste." (Reich 2007, 22) Der Anteil am Umsatz des Schweizer Einzelhandels lag unter $4 \%$. Vgl. Pfenninger 2007, 35.

66 | König 2004, 131, $134 f f$.

67 | König 2004, 134. 
chen Einfluss fremder Kräfte bewahrt werden musste; eine Vorstellung, die stark von rassistischen und fremdenfeindlichen Diskursen genährt wurde. Die Werbeaktion mit dem $>$ weißen $\mathrm{N}-<$ entstand somit in einer Zeit, als sich die Warenhäuser großem gesellschaftlichen und ökonomischen Druck ausgesetzt sahen. Die sichtliche Verzweiflung des Reklamechefs kann vor diesem Hintergrund nicht nur als individuelle Schaffenskrise gelesen werden, sondern auch als Kommentar zur aktuellen Lage der Kaufhäuser.

Warum aber wurde Afrika als Kulisse gewählt, um die Globus-Werbung in Szene zu setzen? Für die Beantwortung dieser Frage erweist sich ein Blick in einige Illustrierte dieser Jahre als aufschlussreich. Die Begeisterung für einen modernen, technisch avancierten Lebensstil durchdrang die populären Zeitschriften der 1930er Jahre, die dieses Lebensgefühl gleichzeitig darstellen und hervorrufen sollten. Illustrierte waren neben dem Radio das prägende Massenmedium der Zwischenkriegszeit. Sie dienten dazu, die Klassengrenzen aufzuweichen und die Herausbildung einer »schichtunspezifischen Populärkultur « ${ }^{68} \mathrm{zu}$ begünstigen. Für die Darstellung des modernen, fortschrittlichen Lebensgefühls, das Illustrierte vermittelten, waren koloniale Bilder entscheidend. Die tropischen Wälder, die Wüsten und Steppen mit ihren sprimitiv lebenden Bewohner*innen lieferten die Kulisse, vor der sich das moderne Europa kontrastreich abheben konnte. Zugleich befeuerten diese Bilder den kolonialen Tatendrang: In der außereuropäischen Welt, so ihre Botschaft, gab es noch immer unbetretene Gebiete zu entdecken, zu kartografieren, zu erobern, zu besiedeln, zu beschreiben, zu entwickeln und zu zivilisieren. ${ }^{69}$

Die ambivalente Beziehung zu den angeblich unzivilisierten und halbzivilisierten Gegenden der Welt, die zugleich abstoßend und anziehend wirkten, über die gestaunt und gelacht werden konnte, die aber auch eine große Sehnsucht nach einer gänzlich anderen Welt wachhielten, prägte die Populärkultur. So fanden sich in den Illustrierten der frühen 1930er Jahre zahlreiche Berichte von Reisen in unbekannte Welten: »Erlebnis bei den wilden Lobi-N[...]n « ${ }^{70}$, Bei den Fetischanbetern der Guineaküste $\ll^{71}$, »Städte, die noch kein Weisser sah $\aleph^{72}$ oder »Bei den Nachkommen

68 | Tanner und Studer 2012.

69 | Vgl. dazu meine Ausführungen im zweiten Kapitel.

70 | Schweizer Illustrierte Zeitung 1934(37).

71 | Schweizer Illustrierte Zeitung 1930(26).

72 | Zürcher Illustrierte 1932(15). 
der Kannibalen «73. Häufig widmeten sich Berichte dem abenteuerlichen, erfolgreichen oder aufopfernden Leben von Schweizer*innen im außereuropäischen Kontext: »Besuch auf einer Schweizer Kaffee-Plantage auf Sumatra ${ }^{74}$, »50-jähriges Jubiläum der Schweizerkolonie in Süd-Chile « ${ }^{75}$, »Schweizerische Sägerei im afrikanischen Gebirgs-Urwald « ${ }^{76}$, »Helvetia in Indien $\aleph^{77}$ oder $\gg$ Gummi, Kokos, Moskitos und Jass. Auf einer Schweizerplantage in den Philippinen $\ll^{78}$. Beliebt waren auch Artikel, die von menschlichen >Kuriositäten in der außereuropäischen Welt berichteten: »Völkerrassen in der >afrikanischen Schweiz< [Abessinien] «79 oder »Philosophen aus Grönland « ${ }^{80}$. Übertitelt mit der rhetorischen Frage »Wären das auch Ihre Leibgerichte?«, zeigt ein Artikel Bilder der »Wanderheuschrecke, eine[r] Kafferndelikatesse« oder »Eingeborene Sumatras beim Braten eines Hundes auf offenem Feuer «1 ${ }^{81}$. Die Beschäftigung mit fremden und exotischen Welten, die gleichzeitig lockten, verwirrten, abschreckten und unterhielten, war Teil der Schweizer Alltagskultur.

\section{Eine koloniale Genealogie des iWeissen N-^}

Vor diesem Hintergrund lässt sich neu darüber nachdenken, warum sich die Globus-Kampagne von 1933 auf Afrika bezog. Auffallend ist, dass das letzte Inserat (vgl. Abbildung 7) eine afrikanische Kulisse für das verwendet, was als Werbetheater für die Weißwarenwoche bezeichnet werden könnte. McClintocks Metapher von Afrika als Schaubühne für den bürgerlichen Haushaltskult wird darin gleichsam in Szene gesetzt: Zu sehen ist eine Bühne mit einer >afrikanischen< Wüstenlandschaft als Hintergrund. Am linken Rand steht der Globus-Werbeleiter an einem Mikrofon und liest sichtlich aufgeregt einen Text vor. Aus dem Souffleurkasten

73 | Schweizer Illustrierte Zeitung 1932(8).

74 | Schweizer Illustrierte Zeitung 1934(15).

75 | Schweizer Illustrierte Zeitung 1934(21).

76 | Schweizer Illustrierte Zeitung 1933(8).

77 | Schweizer Illustrierte Zeitung 1933(24).

78 | Schweizer Illustrierte Zeitung 1930(20).

79 | Schweizer Illustrierte Zeitung 1933(6).

80 | Schweizer Illustrierte Zeitung 1933(19).

81 | Schweizer Illustrierte Zeitung 1930(30). 
zwischen Bühne und Zuschauerraum guckt Globis lachendes Gesicht. Obwohl er nicht auf der Bühne steht, suggeriert seine Anwesenheit als Einsager, dass er die Fäden in der Hand hält. Auf der Bühnenmitte steht ein Mensch auf einem geflochtenen Stuhl. Er hat schwarze Hände, Füße und Haare und einen weißen Kopf. Stilisiert nach dem Bild eines kleinen Kindes, mit einwärts gedrehten Füßen, einem überdimensional großen Haupt und in ein weißes Hemd gekleidet, steht er, sichtlich verlegen, mit hochgezogener Schulter da und steckt sich den Zeigefinger in den Mund.

Abbildung 7: Serie von Werbeinseraten

für das Warenhaus Globus 1933 (Teil 5)

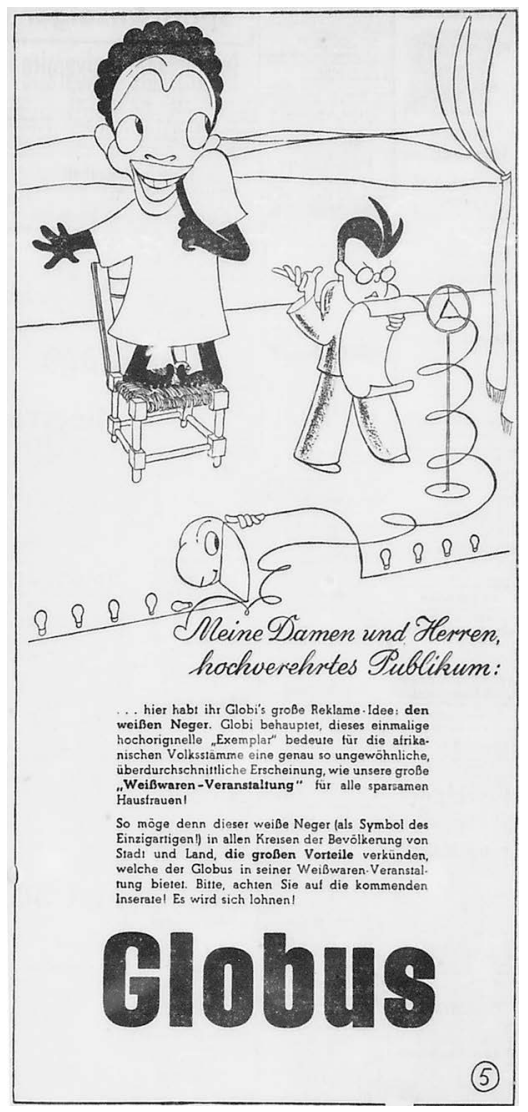

Quelle: Zürcher Tages-Anzeiger, 20. April 1933 
Unter dem Bild sind die Worte des Werbeleiters abgedruckt: »Meine Damen und Herren, hochverehrtes Publikum: ... hier habt ihr Globi's große Reklame: den weißen N[...]. Globi behauptet, dieses einmalige hochoriginelle >Exemplar bedeutet für die afrikanischen Volksstämme eine genau so ungewöhnliche, überdurchschnittliche Erscheinung, wie unsere große >Weißwaren-Veranstaltung für alle sparsamen Hausfrauen! So möge denn dieser weiße N[...] (als Symbol des Einzigartigen) in allen Kreisen der Bevölkerung von Stadt und Land, die großen Vorteile verkünden, welche der Globus in seiner Weißwaren-Veranstaltung bietet. Bitte, achten Sie auf die kommenden Inserate! Es wird sich lohnen!« Die Rede enthüllt die zuvor angekündigte Werbeidee: Der >weiße $\mathrm{N}-<$, der auf dem vierten Bild der Inserateserie vor der Palme stand (damals allerdings noch mit weißen Füßen und Händen), ist das neue Motiv der anstehenden WeißwarenWochen. Ein >weißer N-< in einem weißen Kleid, der für weiße Wäsche wirbt, indem er kindlich, unbeholfen, verloren, aber auch schelmisch und verspielt in den Theatersaal blickt.

Das Kennzeichen des >weißen $\mathrm{N}$ - $<$ sei, so der Werbechef, seine Einzigartigkeit: Er stoße nicht nur als Afrikaner in der Schweiz, sondern auch als >Weißer in Afrika auf Erstaunen. Die Hauszeitung des Globus, eine neu eingeführte Publikation für die Mitarbeitenden des Warenhauses, berichtete ebenfalls über die Entstehungsgeschichte des >weißen $\mathrm{N}-<$. Werbeleiter Schiele erzählte darin, wie er versucht hatte, den Zeichner Robert Lips anzuspornen: »Wir brauchen ein neues Reklame-Motiv für unsern großen Weißwaren-Verkauf. Es muss aber etwas Neuartiges, etwas noch nie Dagewesenes, etwas geradezu Revolutionäres sein. $^{82}$ Auf der Suche nach einer zündenden Idee untersuchten sie die Figuren, mit denen im nahen Ausland für Weißwaren geworben wird:

"In diesem Zusammenhang gelangte man auch zur N[...]-Figur, die hauptsächlich in Deutschland und Frankreich Verwendung fand. 'Sehen Sie, Herr Lips', sagte Herr Schiele, ' [...] Der N[...] zum Beispiel könnte hervorragend sein, wenn Sie es verstünden, dieses Motiv zeichnerisch oder ideell neuartig zu gestalten. Ich denke

82 | Henauer, W.: "Die Geschichte des weissen N[...]", in: Globus Hauszeitung 1933(6). 
an irgendeine Verrücktheit, über die sich jedermann aufhält, an einen bewussten Blödsinn, wie wenn man sagen würde: trockenes Wasser oder weißer N[...]. «" ${ }^{83}$

Diese Aussage zeigt, dass koloniale Bilder in Europa über nationale Grenzen hinweg zirkulierten: Der $>\mathrm{N}-<$ wurde auch in anderen Ländern mit >weißen Waren< in Verbindung gebracht, insbesondere in Frankreich, einer der größten kolonialen Metropolen, und Deutschland, bis zum Ersten Weltkrieg ebenfalls eine bedeutsame Kolonialmacht. ${ }^{84}$ Schiele wollte das bekannte koloniale Motiv des >N-< nun durch eine unerwartete Pointe in einen Blickfang verwandeln. Seine Idee, einen >bewussten Blödsinn wie einen >weißen $\mathrm{N}-<$ zu kreieren, nahm Zeichner Lips mit Begeisterung auf. Die Vorstellung, dass mit dem >weißen $\mathrm{N}$-< etwas Überraschendes und Einzigartiges in die Welt tritt, verweist auf die Innovation als zentrales Element zeitgenössischer Werbung, die mit überraschenden und unterhaltenden Sujets aufwarten soll.

Unterzieht man die Erzählung der Globus-Werbeabteilung einer postkolonialen Lektüre, zeigt sich allerdings ein anderes Bild. Was als eigenwillige Darbietung und überraschende Erfindung vorgeführt wurde, der >weiße N-८, gründete demnach auf einem geschickten Spiel mit Versatzstücken bekannter kolonialer Muster. In diesem Inserat wurde, mit anderen Worten, keine >ungewöhnliche, überdurchschnittliche Erscheinung kreiert, wie dies der Werbetext behauptet, sondern ein koloniales Theater aufgeführt, mit dem das Publikum bestens bekannt war. Die Serialität im Unterschied zur Einzigartigkeit - dieser Darstellung zeigt sich daran, dass die Zeichnungen des >weißen $\mathrm{N}$-< zahlreiche Attribute beinhalten, die typisch sind für die Kolonialwerbung im frühen 20. Jahrhundert. Dazu gehört das Einbeziehen und die Überzeichnung sogenannter >Rassenmerkmale<, aber auch die im Verhältnis zum Körper überdimensionierte Größe des Kopfes, die dazu führt, dass die Figur eine unbestimmte Position zwischen Kind und Erwachsenem einnimmt, »neither adult nor child, but a curios man-child ${ }^{85}$. Auffallend ist auch die starke Betonung der Lippen, die wie ein eigenes Körperteil vom Gesicht abgegrenzt sind

83 | Henauer, W.: "Die Geschichte des weissen N[...]", in: Globus Hauszeitung 1933(6).

84 | Ein Beispiel eines ,weiße $\mathrm{N}-$ - in der viktorianischen Werbung findet sich bei McClintock 1995, $220 f$.

85 | Ciarlo 2011, 285. 
und oftmals den ganzen unteren Teil des Gesichts verdecken. Übergroße Lippen wurden in den amerikanischen Minstrel Shows eingesetzt, deren Visualisierungen von $>$ Rasse $<$ die westeuropäische Werbung seit 1900 stark beeinflussten. ${ }^{86}$

Wie aber lässt sich die spezifische Kombination von weißer Haut und rassifizierter schwarzer Physiognomie erklären? Der >weiße $\mathrm{N}$-< verweist auf das Phänomen des Albinismus, dem im kolonialen Kontext große Aufmerksamkeit zukam. In Völkerschauen wurden Schwarze Menschen mit heller oder fehlender Pigmentierung als spezielle Attraktionen vermarktet: so zum Beispiel Amanoua Kpapo aus Accra, die zu Beginn des 20. Jahrhunderts in Westeuropa als >weiße N-< ausgestellt wurde. ${ }^{87} 1903$ trat sie im Rahmen einer `Togotruppe < auch in mehreren Schweizer Städten auf. ${ }^{88}$ Auf Werbe-Plakaten wird Kpapo als leuchtend helle Gestalt dargestellt, von der sich eine Schwarze Menschenmenge angstvoll abwendet. ${ }^{89}$ So wie vom Globus-Werbeleiter behauptet wurde, der >weiße $\mathrm{N}$-< sei für Schwarze Menschen eine ebenso >ungewöhnliche, überdurchschnittliche Erscheinung wie für Schweizer Betrachter*innen, wurde die Einzigartigkeit der >weißen Schwarzen< auch auf dem Werbeplakat dadurch hervorgehoben, dass sie im exotischen Afrika selbst als Exotin erscheint.

Gemäß Charles Martin entstand der Schwarze Albino gemeinsam mit der dichotomen Ausdifferenzierung von weißer und schwarzer Haut als bedeutsames $>$ Rassenmerkmak im 17. Jahrhundert: $\gg$ With whiteness invented and beatified, the albino body of the white African emerges as a possible challenge, an obstacle to this new binary of black and white. «"

86 | Ciarlo 2011, 24. Für die erste Dekade des 20. Jahrhundert stellt Ciarlo eine massive Verbreitung rassifizierter Darstellungen in Deutschland fest: "By the First World War, the conventions of racialization were so widely established in consumer culture that it is nearly impossible to find images of blacks that do not deploy them. I have found only a handful of black figures in the Trademark Registration Rolls that eschew racializing techniques after 1910." (Ciarlo 2011, 291; Hervorhebung im Original) Obwohl sich diese Dynamik teilweise mit der deutschen Kolonialpolitik erklären lässt, können für die Schweiz ähnliche Tendenzen vermutet werden.

87 | Brändle 2007, 49, 59 und 200.

88 | Kpapo war 1903 in Zürich, Genf, Lausanne, Bern, Aarau, Solothurn, Bern, Fribourg, Payern und Vevey zu sehen. Brändle 2007, 210.

89 | Brändle 2007, 67f.

90 | Martin 2002, 5. 
Das Vorkommen des Albinismus in nicht-weißen Bevölkerungen verband sich dabei mit der Vorstellung einer rassischen Grenzüberschreitung. Weiße Nicht-Weiße brachten die Ordnung eines Regimes durcheinander, für das die Hautfarbe zentral ist. Sie berührten damit die Trope des Passing - der Möglichkeit, dass Schwarze Menschen nicht als solche erkannt wurden und als weiß durchgehen konnten. Insbesondere in Gesellschaften, in denen weiße und Schwarze Menschen zusammenlebten, verband sich damit die Angst, dass >Rasse< als gesellschaftliches Regulativ unterwandert werden und eine »unaccountable blackness « ${ }^{91}$ auch Körpern innewohnen konnte, die als weiß galten. Populäre Darstellungen von >weißen $\mathrm{N}-\prec$ nahmen solche Ängste vor rassischer Vermischung auf und dienten dazu, diese zu bannen. Denn trotz weißer Haut waren solche Figuren mithilfe anderer rassifizierter Merkmale unübersehbar als NichtWeiße kenntlich gemacht. Sie erschienen als eigenartige, komische, burleske oder bizarre Figuren, welche die >Rassengrenzen< trotz ihrer Übertretung nicht auflösten, sondern stabilisierten.

Dass sich ein weißer Schwarzer angeblich mit Sicherheit als Nicht-Weißer erkennen ließ, wurde auch in einer wissenschaftlichen Abhandlung über den Albinismus thematisiert, die Fritz Sarasin 1936 im Schweizerischen Archiv für Volkskunde veröffentlicht hatte. Nicht nur behauptete Sarasin, andere phänotypische Merkmale als die Hautfarbe würden sicherstellen, dass jemand (von einem weißen Wissenschaftler) eindeutig als Vertreter*innen der >farbigen Rasse< erkannt werden könne. Darüber hinaus bezeichnete Sarasin die Kombination von unterschiedlichen >Rassenmerkmalen< als hässlich und befremdend: Die »ästhetische Beurteilung der Albinos farbiger Rassen durch Europäer [...] fällt fast ausnahmslos sehr ungünstig aus. Es ist vornehmlich die Kombination der an Europäer erinnernden weißen Haut- und hellen Haarfarbe mit den Gesichtszügen der eingeborenen Rassen, welche fremdartig und abstoßend wirkt. « ${ }^{92}$ Diese Vorstellung war auch in Bezug auf die sogenannte >Rassenmischung< vorherrschend. ${ }^{93}$ In Sarasins Zusammenstellung der

91 | Martin 2002, 156.

92 | Sarasin 1936, 206.

93 | Der Schweizer Rassenforscher Otto Schlaginhaufen warnte 1916 angesichts der Präsenz nicht-weißer Soldaten im Europa des Ersten Weltkriegs: "Die durch die Einführung der farbigen Hilfstruppen hervorgerufenen Mischungen zwischen Weißen und Farbigen sind eine Beeinträchtigung der Eigenschaften des europäi- 
Forschungsliteratur zum Albinismus finden sich aber auch Beispiele, die den Vorrang der weißen vor der schwarzen Hautfarbe belegen sollen. Im Basuto-Land, so heißt es etwa, würden Albinos wegen ihrer weißen Farbe geschätzt und europäisch gekleidet. »Albino-Frauen verheiraten sich leicht, weil sie den Weißen gleichen und sind mehr Stück Vieh wert als normal gefärbte Frauen. «94 Mehr als über die beschriebene Tradition geben solche Passagen Auskunft über die Prämisse einer weißen Superiorität, die Sarasins Studie zugrunde liegt.

Der >weiße N-<der Globus-Werbung rief aber nicht nur Assoziationen zum Albino auf. Ein genauer Blick auf die Figur zeigt, dass lediglich ihr Kopf weiß, Arme und Beine hingegen schwarz sind. Dieses Bild eines partiell weißen Schwarzen spielt auf einen weiteren kolonialen Topos an, denjenigen der >Mohrenwäsche $<$. Die Vorstellung eines Schwarzen Menschen, dessen Hautfarbe abgewaschen wird, tauchte im 19. Jahrhundert in Märchen auf und wurde in Völkerschauen theatralisch inszeniert. ${ }^{95}$ Die Mohrenwäsche, so Nana Badenberg, sei »Ausdruck eines kulturell verfestigten Stereotyps, in dem sich auf suggestive Weise hygienische und moralische Denkfiguren verbinden: Was schwarz ist, gilt als schmutzig; die Redewendung >einen Mohren weiß waschen< bezeichnet das aussichtslose Unterfangen, einen offenkundig Schuldigen entlasten zu wollen « ${ }^{96}$. Dieses Motiv trat in vielfältiger Verknüpfung mit dem Warenrassismus auf: In der Blütezeit des Kolonialismus setzten »Rasierschaum, Zahnpasta oder Putzmittel - all jene Produkte, die glänzendes Weiß versprachen, [...] auf die Werbewirksamkeit Schwarzer «"

Besonders beliebt war dabei das Spiel mit schwarzer Haut, die weiß gewaschen werden sollte. In diesen Darstellungen stand ein Ansinnen der Zivilisationsmission, nämlich Schwarzen Menschen Hygiene beizubringen, pars pro toto für den Anspruch, sie mit der Zivilisation vertraut zu machen. Die Werbung setzte auf dieses Motiv, um die Kraft ihres Produkts vor Augen zu führen: Eine niederländische Seifenwerbung von

schen Menschen, ein Raub am Erbgut der weißen Rasse." (Schlaginhaufen, zitiert nach Keller 2006, 53).

94 | Sarasin 1936, $218 f$.

95 | Badenberg erwähnt das Beispiel einer inszenierten Mohrenwäsche im Leipziger Zoo 1894 (Badenberg 2004, 173).

96 | Badenberg 2004, 174.

97 | Badenberg 2004, 177. 
1892 zeigte beispielsweise ein Schwarzes Kind, das sich erfolgreich das Gesicht weiß schrubbte. ${ }^{98}$ Auch in der Schweiz kursierten solche Bilder. Ein Plakat der Savonnerie nationale de Genève, das um 1900 entstand, zeigt einen lachenden Schwarzen Mann, der seine Arme und Hände in einem Waschzuber weiß gescheuert hat. Schwarze Tinte tropft von seinem linken Arm. Umringt ist er von einer Gruppe weißer Menschen, darunter ein Mann und zwei Frauen in Schweizer Tracht, die ihm lachend zuschauen. ${ }^{99}$ Allerdings sorgte die Inszenierung der Unmöglichkeit, Schwarze Menschen gänzlich weiß zu machen, nicht nur für Gelächter, sie führte auch die Grenzen der Zivilisationsmission vor Augen: Schwarze Menschen konnten demnach nur partiell weiß gewaschen werden, andere rassifizierte Körpermerkmale behielten sie bei. Im übertragenen Sinn wurde damit auch eine Grenze der Assimilation an die europäische Kultur symbolisiert. Die Angleichung an die weiße Kultur erscheint in solchen Bildern als begehrenswertes Ziel, das nicht-weiße Menschen anstreben, aber nie gänzlich erreichen konnten.

Während die partielle Übertretung der rassifizierten Grenze in der Mohrenwäsche der Belustigung der weißen Betrachter*innen diente, symbolisierte die Überschreitung in die Gegenrichtung eine Drohung. Eske Wollrad verweist auf ein bekanntes deutsches Kinderbuch von 1877 , in dem ein schmutziges weißes Kind nicht mehr sauber gemacht werden konnte und von den anderen Kindern schließlich als >Mohrenkind beschimpft wurde. Verschmutzung wird bei dieser Geschichte mit dem Verlust von Weißsein verbunden. Wollrad schreibt dazu: »Bedeutsam ist diese Art von Literatur [...], weil sie die Instabilität von Weißsein bebildert und die Konditionen benennt, unter denen die LeserInnen Weiß bleiben. ${ }^{100}$ Die Lektion, dass man des Weißseins verlustig gehen konnte, wenn dieses nicht durch ein vorgegebenes Verhalten wie Reinlichkeit, Arbeitsamkeit und Zurückhaltung aufrechterhalten und >verdient< wurde, richtete sich in besonderem Maße an die ärmeren Schichten der weißen Gesellschaft.

98 | Badenberg 2004, 178.

99 | Das Plakat ist von Edouard-Louis Baud und trägt den Titel "Savonnerie nationale Genève", ungefähr 1900, Plakatsammlung der Schule für Gestaltung Basel, Nr. 4244. Ich danke dem Collectif Afro-Swiss für den Hinweis und Patrick Minder für die Angaben zum Plakat.

100 | Wollrad 2005, 78. 
Zurück zur Globus-Werbung: Die Farbe Weiß verband den >weißen $\mathrm{N}-<$ auch mit der Ware, die er bewarb, und mit der Veranstaltung, auf die er aufmerksam machen sollte, die Weißwarenwoche. Wie die Hauszeitung des Globus ausführte, verwies diese Bezeichnung darauf, dass Wäsche vor der Einführung waschechter Farben weiß gewesen war. Zudem wurden andere weiße Haushaltswaren unter die Weißwarenwoche subsumiert. ${ }^{101}$ Auf den Globus-Werbebildern finden sich neben Bett- und Haushaltstextilien denn auch weißes Geschirr und Unterwäsche. Weiße Wäsche war symbolisch hoch bedeutsam: Sie galt als Zeichen für einen vorbildlich geführten Haushalt, der den hygienischen Standards der Zeit entsprach. ${ }^{102}$ Die Globus-Hauszeitung strich dies entsprechend heraus. Obwohl farbige Wäsche mittlerweile erhältlich sei, so heißt es da, werde weiß »stets, was Wäsche-Artikel betrifft, in Bezug auf Hygiene an erster Stelle bleiben « ${ }^{103}$. Diese Formulierung enthält einen kolonialen Subtext, der Weißsein, Sauberkeit und Reinheit verbindet und sie Schwarzsein, Schmutzigkeit und Unreinheit gegenüberstellt.

>Rasse und Hygiene überschneiden sich im kolonialen Diskurs des Fin de Siècle auf entscheidende Weise: Die Disziplinierung kolonialer Subjekte wurde mit der Notwendigkeit begründet, ihnen eine hygienische Lebensführung beibringen zu müssen. Nicht von ungefähr, so schreibt McClintock, war Seife ein Leitsymbol des Kolonialismus: »Soap flourished not only because it created and filled a spectacular gap in the domestic market but also because, as a cheap and portable domestic commodity, it could persuasively mediate the Victorian poetics of racial hygiene and imperial progress. ${ }^{104}$ Die Bedeutung von Schmutz und Reinheit verband sich mit einer aufklärerischen Farbmetaphorik, die kolonial aufgeladen war, wie Frantz Fanon zeigt: »In Europa wird das Böse durch das Schwarze dargestellt. [...] Der Henker ist der schwarze Mann, Satan ist schwarz, man spricht von Finsternis, und wenn man schmutzig ist, ist man schwarz - gleichviel, ob es sich um körperlichen oder moralischen Schmutz handelt. [...] Das Schwarze, das Dunkle, der Schatten, die Finsternis, die Nacht, die Labyrinthe der Erde, die abyssischen Tiefen,

101 | 0.V.: "Die ,weisse Woche، im Globus Chur", in: Globus Hauszeitung 1933(6).

102 | Zur biopolitischen Bedeutung der Hygiene im 19. Jahrhundert vgl. Sarasin 2001.

103 | 0.V.: "Die ,weisse Wocher im Globus Chur", in: Globus Hauszeitung 1933(6).

104 | McClintock 1995, 209. Vgl. dazu auch Opitz 1986, 43. 
jemanden anschwärzen; und auf der anderen Seite: der klare Blick der Unschuld, die weiße Taube des Friedens, das feenhafte, paradiesische Licht. «105 In ihrer kulturwissenschaftlichen Arbeit zur Farbsymbolik zeigt Jana Husmann-Kastein, wie die aufklärerische Assoziation des europäischen Vernunftsubjekts mit Helligkeit im Verlaufe des 19. Jahrhundert in eine anthropologische und >wissenschaftliche< Kategorie des Weißseins transformiert wurde. ${ }^{106}$

In der doppelten Bedeutung von Moral und Hygiene fungierte Reinheit in der Schweiz der 1930er Jahre auch als zentraler Topos des Antisemitismus, hält Jakob Tanner fest: »Die jüdische Kultur wurde nicht nur verbal mit >Schmutz<, >Vergiftung<, >Gestank $<$ und ergo mit Amoral konnotiert; vielmehr machte sich zunehmend ein affektiv-emotionaler Komplex bemerkbar, der [...] in wortwörtlichen Berührungsängsten und Distanzierungsbedürfnissen resultierte.«107 Jüd※innen wurden als besonders körperlich und gleichzeitig als Fremdkörper imaginiert und damit als »Antithese zur eigenen, sauberen Physis, zur homogenen Nation, zur $>$ reinen, virilen und weißen Rasse $\ll^{108}$. Die Konstruktion sinterner Anderer < - wie Juden und Fahrende - und >externer Anderer < - wie Schwarze Menschen - stellten unterschiedliche, aber miteinander verbundene $>$ Rassenphantasmen < dar. Vor diesem Hintergrund stellt sich die Frage, ob die Werbekampagne mit dem $>$ weißen $\mathrm{N}-\prec$ nicht auch eine Verschiebung des antisemitischen und fremdenfeindlichen Diskurses bezweckte, der die Betreiber der Warenhäuser in den 1930er Jahre beschäftigte.

Die Inszenierung der $>$ Weißwarenwoche $<$ kann derart als Antwort auf den antisemitisch aufgeladenen Vorwurf gelesen werden, Warenhäuser tätigten moralisch unsaubere und für die Nation schädliche Geschäfte. Für eine solche Deutung sprechen mehrere Punkte: Erstens inszenierte sich das Warenhaus durch die >Weißwarenwochen< als bedeutsamer Ort für die Pflege der Nation. Es ermöglichte der modernen Schweizer Hausfrau, ihren Haushalt hygienisch zu führen und dadurch das Weißsein von Heim und Nation zu gewährleisten. Zweitens wurde mit dem >weißen $\mathrm{N}$-< ein Spektakel des Exotischen inszeniert, das von derjenigen Figur des bedrohlichen Fremden ablenken konnte, der die Überfremdungsdiskur-

105 | Fanon 1980, $118 f$.

106 | Husmann-Kastein 2006, 45.

107 | Tanner 1997, 331.

108 | Tanner 1997, 331. 
se dominierte. Im Gegensatz zu den antisemitischen Darstellungen des >Juden<, der das Spiel der Assimilation beherrschte und sich (beinahe) unerkannt in der Nation festsetzen konnte, stellte der >weiße $\mathrm{N}$-< eine Figur des Fremden dar, die komisch, lustig, unterhaltsam und durch ihre rassische Überzeichnung immer als fremd erkennbar war.

Wie Francesca Falk zeigt, galt der Jude in dieser Zeit als gefährlicher »Grenzverwischer«, als das »konturlose, polymorphe und grenzüberschreitende Andere ${ }^{109}$ schlechthin. Im Kontrast dazu half eine Figur wie diejenige des >weißen $\mathrm{N}$-< dabei, die Stabilität von rassisch aufgeladenen Nationengrenzen vor Augen zu führen. Im Falle des >weißen N-く wird dies bestärkt durch das Narrativ eines afrikanischen Fremden, der von Schweizer Akteuren für Werbezwecke in die Schweiz verschleppt wurde. Die Erzählung von Globi, der aus seinen Ferien einen Schwarzen Menschen mitbringt, weckte Assoziationen zum transatlantischen Sklavenhandel und zu zeitgenössischen Völkerschauen und rief Bilder von passiven, ausgelieferten, Schwarzen Migrierenden und von aktiven, mächtigen, weißen Sklavenhändlern und Impresarios auf. Die Vorstellung einer weißen Kontrolle über die nicht-weiße Einwanderung, die damit erzeugt wird, steht in auffälligem Kontrast zum antisemitisch aufgeladenen Phantasma von Migration im zeitgenössischen Überfremdungsdiskurs, wonach Fremde, die oftmals nicht als fremd erkennbar sind, in die Schweiz einwandern, sich erfolgreich am gesellschaftlichen und vor allem wirtschaftlichen Leben beteiligen und derart die Nation $\mathrm{zu}$ unterwandern und von Innen zu zerstören drohen. Damit stellt sich in der Tat die Frage, ob dem >weißen $\mathrm{N}-<$ in einem Diskurs, in dem sich kolonialrassistische und antisemitische Bilder wirkungsvoll verknüpfen ließen, nicht auch eine Beschwichtigungsfunktion zukam: Er sollte die Assoziation zwischen Warenhausbesitzern und dem gefährlichen Fremden auflösen und die Bedeutsamkeit der Warenhäuser für die Herstellung einer weißen, hygienischen Nation versinnbildlichen, in der das Fremde kontrolliert und für die eigenen Zwecke eingesetzt werden konnte.

109 | Falk 2008, 118. Der Ausdruck , Grenzverwischer, geht auf Otto Weininger zurück, der diesen (pejorativen) Begriff für Juden verwendet hat (Falk 2008, 52). In ihrer Arbeit zeigt Falk bedeutsame Überschneidungen zwischen der Figur des Juden und des Homosexuellen in den Filmen von Veit Harlan auf, die beide als Grenzverwischer dargestellt wurden. 


\section{Das ISenegalesendorf` IM Zürcher Zoo}

In seiner Studie über die >Erfindung ‘ Afrikas arbeitet Valentin Mudimbe heraus, wie im Laufe des 17. Jahrhunderts eine eurozentrische Logik der Ähnlichkeit durch eine koloniale Logik des Gleichen ersetzt worden ist, die das europäische Selbst radikal vom afrikanischen Anderen unterschied. ${ }^{110}$ Afrikaner*innen galten demnach nicht mehr als minderwertige Versionen des Europäers, wie dies zuvor der Fall gewesen war, sondern repräsentierten nun die >primitiven ten Menschen. Sie erschienen als das ganz Andere, das Monströse und Bestialische und markierten so die Grenze des Menschlichen, als deren Verkörperung der Europäer galt. Ende des 19. Jahrhunderts nahm die von Mudimbe beschriebene >Logik des Gleichen $<$ unter dem Einfluss der Rassenforschung und des Sozialdarwinismus neue Formen an: Auf der Suche nach dem missing link zwischen Affen und Menschen wurden im letzten Drittel des 19. Jahrhunderts sogenannte >Primitive< zu bevorzugten Untersuchungsobjekten der anthropologischen Forschung. Sie galten, wie Marianne Sommer schreibt, als »lebende Fossile « ${ }^{111}$, die einen frühen Zustand des zivilisierten Menschen darstellen und dazu dienen sollten, die evolutionäre Lücke zwischen Affen und Menschen zu schließen.

Die Ausstellungen von exotisierten Menschen, die seit Ende des 19. Jahrhunderts auch in Zoologischen Gärten veranstaltet wurden, waren Schauplätze für diese Untersuchungen zum Ursprung des Menschen. In ihnen trafen sich Schauspiel und Forschung, Spektakel und Wissenschaft: Völkerschauen wurden derart zu einer wichtigen Schnittstelle zwischen wissenschaftlichem und populärem Rassismus. ${ }^{112}$ Impresarios und Wissenschaftler profitierten in einer ersten Zeit gegenseitig voneinander - Letztere erhielten Zugang zu begehrten Forschungsobjekten, ohne weite, teure und gefährliche Reisen unternehmen zu müssen, während Erstere Profit aus dem Ruf der Völkerschauen schlugen, eine Stätte für Forschung und Bildung zu sein. Dieses Verständnis wirkte sich auch in der Schweiz aus: So gewährte der Basler Zoo Ende des 19. Jahrhunderts allen Schulklassen verbilligten Eintritt zu den Völkerschauen. ${ }^{113}$

110 | Mudimbe 1988.

111 | Sommer 2007, 155.

112 | Blanchard, Bancel und Lemaire 2008. Vgl. auch Purtschert 2014.

113 | Staehelin 1993, 114. 
Die Kooperation zwischen Impresarios und Wissenschaftlern nahm allerdings ein baldiges Ende. Den Wissenschaftlern wurde zunehmend deutlich, dass die angebliche Authentizität der Wilden auf Inszenierungen beruhte, die sich stärker an populären Bildern von exotischen Menschen orientierten als an der Herkunft der ausgestellten Personen. Anne Dreesbach spricht diesbezüglich von einem »Stereotypenkreislauf «114: Die Werbung für die Shows aktivierte bereits bekannte Stereotype, die in den Aufführungen wiederum bestätigt und re-inszeniert wurden.

Völkerschauen dürften eine wichtige Inspiration für die Figur des >weißen N-< gewesen sein. Das zeigt sich in der Art und Weise, in der dessen Reise in die Schweiz beschrieben wurde. Seine Mobilität war - anders als diejenige von weißen Missionaren, Kaufleuten oder Kolonisatoren, deren Geschichten dem Schweizer Publikum vertraut waren - nicht Ausdruck von Handlungsfähigkeit und einem selbstbestimmten Zugriff auf die Welt. ${ }^{115}$ Die Gründe für seine Reise nach Europa blieben dem Schweizer Publikum ebenso unzugänglich wie diejenige der Menschen, die zur Zeit der Erfindung des >weißen $\mathrm{N}$ - in den Völkerschauen ausgestellt wurden. Wie die Verhandlungen zwischen dem Globus-Werbeleiter und Globi zeigen, wurde auch bei der Werbung für die Weißwarenwochen nur die Initiative der Schweizer Akteure erkennbar, die den >weißen $\mathrm{N}-<$ als Attraktion ins Land holten. Er ist damit - ähnlich wie die exotischen Tiere, Pflanzen und auch Menschen, die in die Schweiz gebracht und zur Ergötzung und Belehrung des einheimischen Publikums ausgestellt wurden - Objekt in einem kolonialen Regime, das die Welt als Ausstellung begreift. ${ }^{116}$ Timothy Mitchell beschreibt die von ihm analysierten Ausstellungen im Europa des 19. Jahrhundert als Versuch, die Welt als exotisches Spektakel zu verstehen. ${ }^{117}$ Anders als von den Ausstellungsmachern behauptet, ging es dabei kaum um die Vermittlung von Wissen über das Leben fremder Menschen, sondern vielmehr um die Inszenierung und Bestätigung einer bereits bekannten eurozentrischen Perspektive auf die Welt. Sie wurde den weißen Betrachter*innen als Raum vorgestellt, der mit Versprechungen, Verheißungen und materiellen Lockungen gefüllt war, als ein Sammelsurium von Kuriositäten, Rohstoffen, Wissensobjek-

114 | Dreesbach 2012.

115 | Für eine der seltenen Ausnahmen vgl. Brändle 2007.

116 | Mitchell 2013.

117 | Mitchell 2013, 442. 
ten, als Abenteuerspielplatz und unerforschtes Territorium, das kartografiert, beschrieben und klassifiziert werden wollte.

Dieses Verständnis der >Welt als Ausstellung< war auch in der Schweiz präsent. Zum einen nahm das Land an diversen Weltausstellungen teil und reihte sich damit in die Liste der Nationen ein, die diese Anlässe als Bühne nutzten, »auf denen die Industrienationen ihre Leistungsfähigkeit maßen «, ${ }_{118}$ und zwar in expliziter Abgrenzung zu den ausgestellten >Wilden<. Auch wenn die Schweiz, anders als die Kolonialmächte, für ihre Selbstdarstellungen auf den Weltausstellungen keine außereuropäischen Menschen einsetzte, inszenierte sie sich durch ihre Teilnahme an diesen Anlässen dennoch, wie Christof Dejung schreibt, als »Teil der europäischen Zivilisation und benutzte das koloniale Andere als identitätsstiftende Kontrastfolie «119. Explizit manifestierte sich dieses nationale Othering im Rahmen der Landesausstellung 1896 in Genf, wo ein >Village noire< mit senegalesischen Bewohner*innen errichtet wurde. ${ }^{120}$ Populärer und wissenschaftlicher Rassismus, Spektakel und Wissenschaft gingen dabei ineinander über: So dozierte ein Anthropologe im Kontext der Ausstellung vor einem vollen Saal über die >nigritische Rasse<. 15 afrikanische Frauen, Männer und Kinder wurden dem Genfer Publikum vorgeführt und die angebliche Besonderheit ihrer Haut, ihrer Köpfe, ihrer Füße, ihres Gang, ihres Haars und ihrer Nasen dabei eingehend erörtert. ${ }^{121}$

Obwohl die erfolgreichste Zeit der Völkerschauen zum Zeitpunkt der Erfindung des >weißen $\mathrm{N}-<1933$ bereits vorüber war, fanden noch mehrere solche Veranstaltungen mit Bezug zu Afrika statt: So wurde 1925 in Lausanne und später in Zürich-Altstetten ein >afrikanisches Dorf < mit 70 Personen aus der Region des heutigen Guinea und dem Senegal errichtet. Der Zirkus Knie zeigte 1928 in seinem Seitenzelt die Show >Ägypten und seine Rätsel und 1929 eine Völkerschau mit indischen und afrikanischen Menschen. 1930 wurde im Zürcher Zoo während sechs Wochen ein >Senegalesendorf< aufgebaut, in dem $6_{5}$ Frauen, Männer und Kinder ausgestellt wurden. ${ }^{122}$ Sie mussten dabei den >Alltag < in einer senegalesischen Dorfgemeinschaft spielen. Das Zoo-Publikum konnte den Bewoh-

118 | Dejung 2012, 338.

119 | Dejung 2012, 347.

120 | Minder 2008, 330.

121 | Minder 2008, 334.

122 | Brändle 2013, 242. 
ner*innen beim Seidenweben, Teppich knüpfen, Holz schnitzen, Gold schmieden, Schneidern, Kochen und Essen zusehen und die Kinder in der Koranschule beobachten. Als ein Höhepunkt der Ausstellung galt die muslimische Hochzeit eines Paares, die öffentlich zelebriert wurde; über 7.000 Schaulustige sicherten sich eine Eintrittskarte für diesen Anlass. ${ }^{123}$

Einiges spricht dafür, dass die populäre Ausstellung des >Senegalesendorfs< im Zürcher Zoo von 1930 eine Vorlage für die Figur des >weißen $\mathrm{N}-<$ geliefert hatte. So spielt sein weißer Rock auf die Bekleidung der Männer in der Ausstellung an, von denen einige einen hellen Boubou getragen hatten. Und der Name seiner Frau, Suraja, verweist auf den muslimischen Hintergrund des >Senegalesendorfs $<$ Z Zudem gewinnt der Einsatz des >weißen $\mathrm{N}-<$ an Plausibilität, wenn wir einen Blick auf die Berichterstattung über die Völkerschau werfen. Sie zeigt, wie das safrikanische Familienleben< in der Schweiz zum Anlass genommen wurde, exotisierte Vorstellungen von Sexualität, Erotik, Familie und Reproduktion zu produzieren und sie als Hintergrundfolie für eine Kritik der Schweizer Geschlechterverhältnisse zu verwenden. Im nachfolgenden Close Reading eines Zeitungsberichts von 1930 werden drei Aspekte herausgestellt, die auch für die Figur des >weißen $\mathrm{N}-<$ von Bedeutung sind: die Herstellung weißer Männlichkeit vermittels nicht-weißer Anderer, das koloniale Othering als Korrektiv für das Unbehagen in der eigenen Kultur und die Fantasie einer weißen Verfügungsmacht über Schwarze Intimität.

Am 9. März 1930 erschien ein Bericht mit dem Titel »Senegalesen im Zoo « in der Neuen Zürcher Zeitung, in dem unter anderem folgende längere Passage zu lesen ist: »Der Chef der 65köpfigen Schar gab bei der Führung Erläuterungen und schenkte den Herren der Presse, weil er weiß, was sich in Europa gehört, geschnitzte Brieföffner zum Andenken und zur zarten Bestechung. Er steht als Kaufmann im Pass und ist so etwas wie ein technischer Kapitän und magischer Obern[...] in einer Person. Ein Hüne mit zwei Zentnern Schokolade und viel Gutmütigkeit. Wie viel Fruchtbarkeit ist nicht um diesen Marabu [sic!]. Ein Teil der Frauen steht fünf Minuten vor der Mutterschaft, zwei tragen ihre Neugeborenen hinten im Rückentuch; diese schwarzen Menschenäffchen schlafen selig in der Körperwärme ihrer Mutter [...]. Es ist eine fruchtbare Familie und etwas Trächtiges und Stallhaftes liegt im Ganzen. Die Jungfrauen haben ein lustiges Geäugel, stellen weiße Zahnreihen bloß und kichern, wenn 
man sie ansieht, als ob sie von unsern Blicken gekitzelt worden wären. Ich kann mir nicht helfen, aber diese schwarzen Mütter sind mütterhafter als die weißen Mütter; sie stehen schwer, wie beladene Fruchtbäume auf dem Boden, blicken immer mit großen, rollenden Augen über den Platz, und in ihrem umständlichen, aber oft farbig wundervollen Kleidergewölk kann sich ein halbes Dutzend schwarzer Rangen verbergen. «124

Der Beobachter der Völkerschau, ein vom >Senegalesendorf offensichtlich bewegter Journalist der Neuen Zürcher Zeitung, organisierte seine Wahrnehmung entlang patriarchaler Parameter. Ausgangspunkt und Zentrum seiner Analyse ist ein älterer Mann, den er als religiösen und sozialen Vorsteher der Gemeinschaft bezeichnet: der Marabut. Im Unterschied zu den weiblichen Figuren wird ihm eine berufliche Identität und eine Führungsrolle zugeschrieben. Von ihm erfahren wir, dass er einen Pass besitzt und damit am aktuellen Mobilitätsregime teilnehmen kann. Allerdings wird seine Identität nur mit den Insignien moderner Männlichkeit ausgestattet, um diese in einem zweiten Schritt wieder infrage zu stellen. Denn sein Auftritt vor den weißen Journalisten erscheint fragwürdig: Zwar verschenkt er mit dem Brieföffner ein brauchbares Andenken und zudem eines, das entgegen den stereotypen Vorstellungen von Afrika auf einen vertrauten Umgang mit der Schriftkultur hinweist. Aber der Journalist sieht darin kein eigenständiges Handeln als Geschäftsmann, sondern unterstellt ein Nachahmen dessen, was sich in Europa gehört.

Der Vorsteher der Gruppe wird, mit Homi Bhabha gesprochen, als mimic man gezeichnet, als eine Figur, welche die Konventionen und Normen der Moderne immer nur unvollständig verkörpern kann. Bhabha beschreibt den mimic man im Kontext des British Raj als »Ergebnis einer makelbehafteten kolonialen Mimesis, in der Anglisiertsein ganz ausdrücklich bedeutet, nicht Engländer zu sein « ${ }^{125}$. Der mimic man ist nie ganz assimiliert, ihm haftet immer der Makel des Nachahmens, der Kopie, des verfehlten Originals an. Beim senegalesischen Marabut bedeutet das: Er stattet die Journalisten mit Informationen aus, verfügt über einen Pass mit einem eingetragenen bürgerlichen Beruf, er verschenkt Andenken an die anwesenden Pressevertreter und bedient sich somit eines Verhaltensrepertoires, das auch ein weißer Mann an den Tag legen würde. Seine Darstellung als moderner Geschäftsmann wird aber beständig in

124 | N. N., "Senegalesen im Zoo", in: Neue Zürcher Zeitung, 9. März 1930.

125 | Bhabha 2007, 129 [Hervorhebung im Original]. 
Zweifel gezogen: Man wird darüber informiert, dass er >weiß, was sich in Europa gehört<. Und man erfährt, dass der Brieföffner der >zarten Bestechung < diene, ohne dass ausgesprochen würde, zu welchem Zweck diese Bestechung erfolgt.

Diese Textstelle zeigt, dass der Schreiber ein Vorwissen über die koloniale Mimikry bei den Leser*innen voraussetzt, mit dessen Hilfe solche Anspielungen eingeordnet werden sollen. In der Beschreibung der Schwarzen Menschen wechselt der Text zwischen den Registern des modernen Menschen, des >Primitiven $<$, des Kindes und des Tieres. Diese Hin- und Herbewegungen sind Bestandteile einer kolonialen Episteme, mit denen die Leserschaft vertraut war. So war die Vorstellung, rassifizierte Andere würden sich mithilfe des Nachahmens in die eigene Kultur einpassen, ein wichtiges Phantasma des zeitgenössischen Antisemitismus. In einem dreiteiligen Artikel, der im Herbst 1933 in den Schweizer Monatsheften erschien, die damals zunehmend als Plattform für die frontistische Bewegung dienten, ${ }^{126}$ wird der konvertierte Jude als mimic man beschrieben: »Oft ist der Übertritt in das Christentum nur der Eintritt in die gute Gesellschaft, die berühmte Mimikry, mit der der Jude mit einzigartiger Geschicklichkeit in fremde Häute schlüpft, um sich äussere Vorteile durch die Vermischung und Glaubenswechsel zu erkaufen.«127

Die Assimilation des Juden an die christliche Kultur bleibt gemäß dieser Beschreibung ebenfalls unvollständig, aber im Unterschied zum Schwarzen Menschen kann er sich die fremde Kultur erfolgreich zu eigen machen und für seine Zwecke instrumentalisieren. Während der Versuch der Schwarzen Person, sich die Kulturtechniken der Zivilisation anzu-

126 | Vgl. Tanner 2015, 221. Politisch kaum einflussreich, lag die Bedeutung der heterogenen und durch Fusionen und Spaltungen gezeichneten Frontenbewegung in ihrer Agitation gegen die Demokratie und die Wirtschaftspolitik und in ihrem unverhüllten Antisemitismus (Zala 2014, 506). Ein Einblick in die Zürcher Illustrierte nach dem ,Frontenfrühling، 1933 zeigt, dass die Frontenbewegung in einer breiteren Öffentlichkeit mit Interesse zur Kenntnis genommen wurde. Unter dem Titel "Neue politische Bewegungen" berichtet der Artikel vom "politischen Erneuerungseifer", der "breite Bevölkerungsschichten" erfasst haben soll, um sogleich klarzustellen, dass "weder zum Staunen noch zum Erschrecken" Grund vorliege, da das Politisieren den Schweizern seit Jahrhunderten im Blut liege (o.V.: "Neue politische Bewegungen in der Schweiz", in: Zürcher Illustrierte 1933[27]). 127 | Wyss 1933a, 279. 
eignen, in der Beschreibung der Neuen Zürcher Zeitung lächerlich wirkt, wird die Mimikry des Juden in den Schweizer Monatsheften als gelungen und damit gefährlich eingeschätzt. Der Ausschluss des Schwarzen Menschen und des Juden wird in beiden Texten mithilfe einer fiktiven Grenze vollzogen, die sie von einer angeblich originären Kultur, >Rasse $<$ und Religion abtrennen. Die beiden Variationen des mimic man unterscheiden sich aber in einem signifikanten Punkt: Während der Marabut eine gutmütige und lachhafte Figur abgibt, gerade weil seine Nachahmung als so durchschaubar gilt, wird dem Juden, der sich auf die Mimikry versteht, die Möglichkeit der erfolgreichen Täuschung und damit eine ungleich größere Macht zugeschrieben: Er wird als >innerer Feind< konstruiert, der gerade darum bedrohlich ist, weil er im Unterschied zum Schwarzen Menschen als Schweizer >durchgehen< kann. Wie oben gezeigt, fungieren der Jude und der $>\mathrm{N}-<$ damit als komplementäre und aufeinander bezogene Figuren des Fremden. So dient die clowneske Darstellung Schwarzer Assimilation, die als lachhaft dargestellt wird, nicht zuletzt als Kontrastfolie für die angebliche Gefahr, die von jüdischen Menschen ausgehen soll. Auf diese Weise durchkreuzen und bekräftigen sich kolonialrassistische und antisemitische Diskurse in der Schweiz der 1930er Jahre.

Das weitgehende Scheitern einer >Schwarzen Mimesis < zeigt sich auch in der Beschreibung des Marabut als >technischer Kapitän und magischer Obern-く. Ihm wird damit innerhalb seiner Gruppe eine Führungsrolle auf weltlicher und spiritueller Ebene zugeschrieben. Der Begriff des $>$ magischen Obern-< baut aber zugleich Distanz zu einem europäischen Verständnis von Religion auf: Die Magie verweist auf eine minderwertige und >primitive< Religiosität, die es verunmöglicht, den Marabut mit einem christlichen Pfarrer oder Priester zu vergleichen; gleichzeitig wird durch die Koppelung von Magie und muslimischer Religion die Überlegenheit des Christentums gegenüber dem Islam behauptet. Zudem wird die soziale Führungsposition des Marabut nicht im Rahmen des europäischen Vokabulars eingeordnet - er ist kein Vorsteher, kein Oberhaupt oder Leiter, sondern einzig ein $>$ Obern- $<$, der Oberste der $>\mathrm{N}-<$.

Die karikierende Beschreibung der Führungsrolle wird im nächsten Satz durch den Fokus auf seinen Körper verstärkt: Nachdem die weltliche und religiöse Autorität des Marabut destruiert worden ist, wird nun sein Körper als Kuriosum vorgestellt. Er sei riesig wie ein Hüne - der Begriff stammt von den Hunnen ab und verweist auf eine andere Figur der Wilden, die als >Europas Andere 
Schokolade und viel Gutmütigkeit<. Seine Größe wird nicht als Zeichen von Autorität interpretiert, die Beschreibung seines Körpers als Schokolade dient vielmehr einer kolonialen Strategie der De-Autorisierung. Die Assoziation von Schwarzen Menschen und Kakao war zu dieser Zeit omnipräsent - Schweizer Schokoladenfirmen verwendeten häufig Abbildungen von Schwarzen Menschen für ihre Werbung. ${ }^{128}$

Die Verbindung von Schwarzen Körpern und Konsumwaren steht in der Linie eines Denkens, das auf die transatlantische Sklaverei zurückgeht und Schwarze Menschen als Objekte einer frühkapitalistischen Wirtschaftslogik betrachtet. Dieser verdinglichte Blick auf den Schwarzen Anderen verbindet sich mit den Gütern des Kolonialwarenhandels, der auf der Arbeit von Sklav*innen gründet: Baumwolle, Kaffee, Kakao, Zucker. ${ }^{129}$ Dass der Schwarze Andere als Schokoladenfigur beschrieben wird, verweist aber auch auf den Schauplatz der Beschreibung. Der weiße Schweizer Reporter begegnete dem senegalesischen Marabut im Zürcher Zoo, wo letzterer gegen Eintrittsgeld besichtigt werden konnte. Der Blick des Journalisten konstituiert sich durch eine materielle und zugleich symbolische Ökonomie, die auf einem kommodifizierten Umgang mit dem Schwarzen Anderen fußt. Dazu gehört die Fantasie, ihn konsumieren zu können wie die Schokolade, die er angeblich verkörpert; dies ist ein Topos, der uns später nochmals begegnen wird.

\section{Weisse MännlichKeIt UNd ANTI-EgALItÄRES Othering}

Mit der Vorstellung der Konsumierbarkeit seines Schwarzen Gegenübers im Zoo gehen diverse erotische und sexuelle Fantasien einher, die vom Autor in die Szene eingearbeitet werden. Dabei kommt eine zweite bedeutsame Funktion des Marabut zum Tragen: Er stellt nicht nur eine Karikatur moderner Männlichkeit dar, von der sich der Journalist mit einem Statusgewinn abgrenzen konnte. Er agiert zugleich als virile Grenzfigur,

128 | Vgl. dazu das Unterkapitel Schweizer Schokolade und die Kommodifizierung Schwarzer Körper.

129 | Sowohl die Bedeutung als auch das Ausmaß und die Zirkulation von Kolonialwaren wurden für die Schweiz noch nicht untersucht. Für eine allgemeine Darstellung vgl. Pfeisinger und Schennach 1989. Für die untrennbare Verwobenheit von Konsumkultur und Kolonialismus argumentiert auch Lury 2011, $108 \mathrm{ff}$. 
die dem Schreiber den Zugang zu einem verloren geglaubten patriarchalen Ideal ermöglicht. Afrika dient dem Schweizer Journalisten dabei als Kontrastfolie für eine Sphäre, die der modernen Welt scheinbar entgegensteht, indem sie das Magische, Wilde, Natürliche und Animalische verkörpert. Mit der Passage $>$ Wie viel Fruchtbarkeit ist nicht um diesen Marabu. Ein Teil der Frauen steht fünf Minuten vor der Mutterschaft, zwei tragen ihre Neugeborenen hinten im Rückentuch < ruft der Text eine koloniale Fantasie auf, die mit McClintock den »Porno-Tropics « ${ }^{130}$ zugeordnet werden kann, jener kolonialen Tradition, gemäß der unbekannte Gebiete und ihre Bewohner*innen im Register erotischer und sexueller Fantasien imaginiert werden.

Die Aussage eröffnet einen Raum sexueller Spekulationen, die dadurch genährt werden, dass schwangere Frauen und junge Mütter zu der Gruppe gehören, welcher der Marabut vorsteht. Damit klingt die Möglichkeit an, dass er selbst sexuell über diese Frauen verfügen könne, dass er mitunter der Erzeuger dieser geborenen und ungeborenen Kinder sei. Die Fantasie vom sexuell allmächtigen Patriarchen taucht nicht zufällig auf; sie findet sich auch in wichtigen zeitgenössischen Abhandlungen zur menschlichen Entwicklung. In seinem 1912 erschienenen Werk Totem und Tabu bezieht sich Sigmund Freud auf Charles Darwins Begriff der Urhorde. Im menschlichen Urzustand soll der Mensch in einer Gruppe gelebt haben, so heißt es da, der ein »gewalttätiger, eifersüchtiger Vater [vorsteht], der alle Weibchen für sich behält und die heranwachsenden Söhne vertreibt « ${ }^{131}$. Wie Marianne Sommer festhält, schreibt der Autor dieser Vorstellung eine prominente Bedeutung für die menschliche Entwicklung zu: »Freud assumed that the Darwinian primeval horde had really existed, and that actual events had led to the initial acquisition of the Oedipus complex that then became part of our phylogenetic heritage. « ${ }^{132}$

In seiner 1930 erschienenen Schrift Das Unbehagen in der Kultur nimmt Freud diese These erneut auf. ${ }^{133}$ Die Figur des >Primitiven<, der über alle Frauen verfügt, erscheint dabei als ambivalent: Einerseits verkörpert er die Angst der Söhne vor der Übermacht des Vaters - eine Übermacht, die durch die Gründung des Staates beziehungsweise durch die

130 | McClintock 1995, 21.

131 | Freud 1999b, 171.

132 | Sommer 2005, 248.

133 | Freud 1999d, 458ff. 
Formulierung einer übergeordneten Moral und ihrer inner-psychischen Vertretung im Über-Ich gebannt werden konnte. Gleichzeitig verkörpert der Patriarch die Fantasie männlicher Allmacht und erinnert damit schmerzlich an die Grenzen des Machtstrebens, die dem Mann in einer auf Gleichheit gründenden modernen Gesellschaft gesetzt sind. Sie äußern sich im melancholischen Verhältnis zu den sozialen Beschränkungen, die ihm den Schutz vor der Aggression Anderer garantieren. Vor dem Hintergrund dieser Spielart des Othering erscheint der Marabut nun nicht als lächerliche Imitation eines westlichen Subjekts, sondern als Projektions- und Identifikationsfigur für eine (angeblich) eingebüßte patriarchale (All-)Macht. Die Figur macht damit auch deutlich, wie sich Hypervirilität und Entmännlichung in rassistischen Diskursen verschränken: Der Marabut ist ein lächerlicher Geschäftsmann, der das moderne Verhalten nur imitieren kann, und gleichzeitig ist er ein eindrücklicher Patriarch, der eine anachronistische und >primitive< Version männlicher Macht repräsentiert.

Steht der Marabut mit einem Bein in der Moderne, so erscheinen die Frauen - und mit ihnen die Kinder - als Repräsentant*innen einer natürlichen Sinnlichkeit, Sexualität und Mütterlichkeit. Mit ihnen wird die Grenze zum Tier virulent, was sich schon dadurch zeigt, dass etwas >Trächtiges und Stallhaftes< in der Luft liegen soll. Weiter werden die Kleinkinder als >schwarze Menschenäffchen bezeichnet, die auf dem Rücken ihrer Mütter schlafen. Die Betonung des Körperlichen kennzeichnet auch die Beschreibung der Schwarzen Frauen: Sie blicken mit >großen, rollenden Augen ihren Kleidern. Der selbstverständliche Zugriff auf Schwarze Intimität, den diese Zeilen dokumentieren, zeigt sich exemplarisch in der Beschreibung eines Blickwechsels der Journalisten mit den jungen Frauen. »Die Jungfrauen haben ein lustiges Geäugel, stellen weiße Zahnreihen bloß und kichern, wenn man sie ansieht, als ob sie von unsern Blicken gekitzelt worden wären. « ${ }^{134}$ Das Lachen und >Geäugel< der jungen Frauen scheint eine erotische Atmosphäre zu evozieren, die einerseits aktiv von den Schwarzen Frauen erzeugt wird, aber gleichzeitig auf die erotische Ausstrahlung der weißen Journalisten zurückverweist, welche die Frauen mit ihren Blicken >kitzeln<.

134 | O.V.: "Senegalesen im Zoo", in: Neue Zürcher Zeitung, 9. März 1930. 
Der Schreibende imaginiert sich damit in der Position des Beobachters, der von den jungen Schwarzen Frauen - scheinbar zu seinem Erstaunen - zum Subjekt eines von ihnen initiierten Begehrens gemacht wird: Sie kichern, als ob sie gekitzelt worden wären, und lassen die Blicke der Journalisten damit retrospektiv als taktil erscheinen. Diese eigenartige Vertauschung von Aktivität und Passivität ereignete sich in einer Situation, die von umgekehrten Machtverhältnissen gekennzeichnet war, nämlich der Begegnung weißer Journalisten, die sich frei bewegen konnten, mit Schwarzen Frauen, die im Zürcher Zoo ausgestellt wurden. Indem er ihnen eine aktive Rolle bei der Herstellung dieser Szene zuschreibt, verdeckt der Journalist den Umstand, dass er seinen Artikel mit einem erotischen Subtext in der >pornotropischen Tradition unterlegt. Ausgeblendet bleiben in dieser Darstellung auch andere Lesarten des Kicherns, die auf ein Unbehagen der jungen Frauen hinweisen könnten oder auch darauf, dass diese sich über das Starren der weißen Männer lustig machten. Der Journalist imaginiert sich stattdessen als Zentrum eines Schwarzen weiblichen Begehrens, was ihn nicht zuletzt in die Nähe zum Schwarzen Patriarchen und seinem scheinbar selbstverständlichen Zugriff auf die Frauen rückt.

Die Selbstgenese eines Subjekts, das von der exotisierten Anderen begehrt wird, und damit bin ich beim zweiten Punkt meiner Lektüre, diente nicht nur der Selbstbestätigung weißer Männlichkeit. Sie initiierte darüber hinaus eine harsche Kritik an den einheimischen Frauen und den aktuellen Geschlechterverhältnissen. Im Artikel heißt es dazu: »Herr Dr. $X$. stellt uns eine Braut vor und ruft auch den Bräutigam herbei. Die Braut in ihrer würdigen Toga zeigt die Zähne, und der Bräutigam nimmts hin, dass man ihre Intimität der Presse zeigt. Aber die Braut ist herrlich, sie grinst jung aus voller Seele heraus, wie ein Tierchen, das sich genommen und dem Manne zugeteilt weiss, zu dessen Ehre sie einmal fruchtbar sein wird. Unsere Jungfern pflegen sich bei solchen Vorstellungen stolz zu blähen, als ob sie's wären, die Besitz genommen hätten.« ${ }^{135}$

Diese Passage ist beachtenswert, weil sie die Machtverhältnisse gleichzeitig festhält und desartikuliert. Beschrieben wird eine Szene im Zürcher Zoo: ein weißer >Herr Doktor<, der den anwesenden Journalisten eine Schwarze Frau vorführt. Sie zeigt die Zähne und grinst >wie ein Tierchen<. Tatsächlich wird sie im Kontext des Zoos wie ein Tier vorgeführt.

135 | O.V.: "Senegalesen im Zoo", in: Neue Zürcher Zeitung, 9. März 1930. 
Die Frau bleibt in dieser Passage gänzlich stimm- und sprachlos. Die einzige Regung, die beschrieben wird, ist eine instinktive Bejahung der Tatsache, dass sie nun >dem Mann zugeteilt< ist und ihm ihre reproduktive Fähigkeit zur Verfügung stellen wird. Anders der Mann: Obwohl nicht er vorgeführt wird, sondern seine Frau, wird ihm zugestanden, Widerstand leisten oder sich wehren zu dürfen. Er aber nimmt es mit Gelassenheit, >dass man ihre Intimität der Presse zeigt<, er verzichtet also auf das Recht, seine Frau zu verteidigen, das ihm vermittels einer patriarchalen Besitzlogik zugeschrieben wird. Auch hier lässt sich mit Blick auf den Zwangscharakter der Szenerie fragen: Wie hätte er sich gegen das Vorführen der Frau wehren können? War seine >Gelassenheit< vielleicht Ausdruck von Selbstbeherrschung, weil er verhindern wollte, dass sich die Demonstration länger hinzog? Oder von Verzweiflung, weil er nicht wusste, wie er sich hätte wehren können?

Die Senegalesin führte in den Augen des Journalisten eine Weiblichkeit vor, deren Dasein sich darauf beschränkte, ihrem zukünftigen Mann zu gehören und für ihn fruchtbar sein zu wollen. Durch sie wird das Bild einer natürlichen weiblichen Hingabe an die menschliche Reproduktion und an die sexuellen Bedürfnisse des Ehemannes gezeichnet. Indem der Journalist ihr Verhalten mit seinem Unbehagen an den aktuellen Geschlechterverhältnissen verknüpft, erfüllt die Schwarze Frau eine spezifische Funktion des Othering. Sie ermöglichte seine Kritik an der modernen weißen Frau zu einem Zeitpunkt, an dem die Emanzipationsbestrebungen und Partizipationsansprüche von Frauen in der Schweiz mit Wucht bekämpft und bald auch schon erfolgreich in die Schranken gewiesen wurden. ${ }^{136}$ Im Unterschied zur Schwarzen Frau, die ihre sexuellen und reproduktiven Pflichten gegenüber ihrem Mann angeblich übernahm, ohne damit eigene Absichten zu verfolgen, benahmen sich die hiesigen jungen Frauen so, als könnten sie die patriarchale Besitzlogik auf den Kopf stellen und Mann und/oder künftige Kinder als ihren Besitz verstehen: »Unsere Jungfern pflegen sich bei solchen Vorstellungen stolz zu blähen, als ob sie's wären, die Besitz genommen hätten.« ${ }^{137}$

Das >natürliche< Verhalten der Schwarzen Frauen wirkte sich aus dieser Sicht positiv auf die Männer aus: Dass die beiden Schwarzen Männer derart entspannt waren, schienen sie der selbstverständlichen Hingabe

136 | Vgl. Joris und Witzig 1986, 74.

137 | 0.V.: "Senegalesen im Zoo", in: Neue Zürcher Zeitung, 9. März 1930. 
der Frauen zu verdanken. Der junge Bräutigam blieb gelassen, als seine Braut der Presse vorgeführt wurde. Und der Marabut wirkte, obwohl Vorsteher einer großen Gemeinschaft, gutmütig. Für den modernen Schweizer Mann, aus dessen Sicht der Text geschrieben ist, war der Marabut zwar kein ernst zu nehmendes oder gar gleichwertiges Gegenüber. Dennoch eignete sich seine >primitiveく Männlichkeit dazu, ihn als Projektionsfläche für weiße, männliche und heteronormative Fantasien zu verwenden, die den befürchteten Verlust einer >natürlichen < patriarchalen Geschlechterordnung sichtbar machten.

Der Artikel zum >Senegalesendorf< im Zürcher Zoo ist nicht der einzige, der ein solches anti-egalitäres Othering belegt. Zwei Jahre später erschien in den Schweizer Monatsheften ein Artikel mit dem Titel »Die >faulen< N[...] « von Karl Lang, einem Vordenker der bereits erwähnten Frontenbewegung in der Schweiz. ${ }^{138}$ In diesem Artikel entwickelt Lang eine kulturpessimistische Degenerationsthese, die er mit einer Geschlechtertheorie verschränkt. Demnach gebe es einen >männlichen< Lebensrhythmus. Dieser sei unregelmäßig und verbinde anstrengende Aktivitäten mit Ruhepausen, wie es etwa bei der Tätigkeit eines Jägers der Fall sei. ${ }^{139}$ Parallel dazu existiere ein >weiblicher Rhythmus, der regelmäßig und durchgängig sei wie die Arbeit der Frau im Garten und auf dem Felde. Im Unterschied zu Europa, so Lang, sei dieser Rhythmus in Afrika durch die natürliche Lebensführung erhalten geblieben. »Am laufenden Band zerstampfen die N[...]innen ihre Körner zu Mehl ${ }^{140}$ schreibt er, während die Männer zwischen anstrengender Arbeit und Muße abwechselten: »So arbeitet der natürliche Mann. Bald heftig, bald gar nicht. « ${ }^{141}$

Seine Theorie der geschlechtsspezifischen Lebensrhythmen untermauerte Lang mit der >natürlichen ₹ Funktionsweise des sexuellen Triebs: So wie seine Sexualität beschaffen sei, so wolle der Mensch auch arbeiten. Die Lust des Mannes unterliege Schwankungen. Die Frau hingegen sei ständig für den Geschlechtsakt bereit: »Sie, in der immer eine gedämpfte Erotik wellt, die sie zur Liebe befähigt zu jeder Zeit, sie arbeitet gerne beständig, im Gleichtakt, regelmäßig. Von morgens bis abends. ${ }^{142} \mathrm{Im} \mathrm{Ge}-$

138 | Lang 1932. Zu Lang vgl. Wolf 2008.

139 | Lang 1932, 624.

140 | Lang 1932, 624.

141 | Lang 1932, 624.

142 | Lang 1932, 624. 
schlechterbild von Lang korrespondiert damit eine ständige sexuelle Verfügbarkeit der Frau für den Mann mit der kontinuierlichen Disponibilität ihrer Arbeitskraft. Übertragen auf die bürgerliche Kultur des 20. Jahrhunderts heißt das nichts anderes, als dass die Frau ihre Aufgaben im Haushalt, in der Kindererziehung und als Gattin rund um die Uhr erfüllen und gleichzeitig den sexuellen Bedürfnissen des Mannes immer zur Verfügung stehen soll. Langs Problem ist nun, dass die kapitalistische Arbeitswelt es dem Mann nicht mehr ermöglicht, seinem natürlichen Rhythmus nachzugehen: »Die Maschine hat dem Mann den weiblichen Rhythmus aufgezwungen. Und daran ist er erkrankt.« ${ }^{143} \mathrm{Er}$ diagnostiziert eine Verweiblichung des Mannes im Zuge des kapitalistischen Arbeitslebens; eine Beurteilung, die er unter Rekurs auf den $>\mathrm{N}$ - $<$ als Repräsentanten einer gesunden Männlichkeit vornehmen kann.

Ohne an dieser Stelle weiter auf Langs Zeitdiagnose und seine Verankerung im frontistischen Vokabular der 1930er Jahre eingehen zu können, zeigt sein Artikel im Vergleich mit demjenigen zum ১Senegalesendorf< in der Neuen Zürcher Zeitung, dass die Figur rassifizierter Anderer über politische Differenzen hinweg als Kontrastfolie für Gesellschaftsanalysen verwendet wurde, die dazu dienten, die Kritik an egalitären Tendenzen zu befördern. Beide Artikel legitimierten durch den Bezug auf die angeblich 'gesünderen< Naturmenschen eine komplementäre und hierarchische Geschlechterdifferenz, die ihrerseits ein Produkt des Bürgertums war. Indem sie die afrikanische Geschlechterdifferenz als >natürlich < bezeichneten, naturalisierten sie zudem die Ungleichheit zwischen afrikanischen und europäischen Menschen. Erstere verkörperten einen Zustand der Natürlichkeit, der außerhalb von Moderne, Technik, Kapitalismus und Zivilisation angesiedelt wurde. Damit wurden auch historische Entwicklungen und aktuelle Transformationen von Geschlechterrollen in Afrika sowie gesellschaftliche Aushandlungen von Geschlechterarrangements zwischen afrikanischen Frauen und Männern undenkbar gemacht.

In diese Texte eingeschrieben sind somit mehrere, miteinander verschränkte koloniale Fantasien: erstens die Fantasie einer Weiblichkeit, die sich ganz ihren reproduktiven Tätigkeiten hingibt, zweitens die Fantasie einer erotischen Grundstimmung, die auf einer ständigen sexuellen Verfügbarkeit der Frauen basiert, sowie drittens die Fantasie einer entspannten Männlichkeit, die weder um die Befriedigung von sexuellen Be- 
dürfnissen noch um die Sicherung der eigenen Fortpflanzung bangen muss. Alle drei Aspekte konturieren ex negativo die Position einer weißen Männlichkeit, die ihr Unbehagen mit der modernen Geschlechterordnung zum Ausdruck bringt und die erneute Einhegung weißer Frauen in einen angeblich natürlichen Aufgabenbereich fordert. Sie kann als Teil eines Krisendiskurses verstanden werden, der mit der Jahrhundertwende aufkam. In ihm waren, wie Caroline Arni ausführt, Geschlechterverhältnisse und der Zustand von Kultur untrennbar miteinander verschränkt. Behauptet wurde nämlich, dass »Ehe und das Geschlechterverhältnis, ja gar die Weiblichkeit und die Männlichkeit zusammen mit der ganzen modernen Kultur tief in der Krise steckten, dass die Befindlichkeit der Geschlechter Symptom einer Kulturkrise und die Kulturkrise Symptom einer Geschlechterkrise ${ }^{144}$ sei.

Wie die beiden Artikel zeigen, wurde diese Krise der Geschlechterverhältnisse auch über die Figur der Schwarzen Anderen verhandelt und mehr noch: über das koloniale Othering teilweise erst verhandelbar gemacht. Grundlage für eine solche >projektive Selbstreflexion< war die Konstruktion eines weißen und männlichen Selbst, das davon ausging, dass es die intimen Bezüge der exotisierten Anderen deuten und verstehen konnte, dass ihm diese Intimität zur Verfügung stand, dass es sich in sie hineinbegeben, sie studieren, sich von ihr stimulieren lassen und die Anderen mit seinen skitzelnden Blicken traktieren konnte. Es gründete auf der Prämisse, dass zum Schwarzen Körper ein anderes Verhältnis von Nähe und Distanz eingenommen werden konnte als zum weißen Körper. Im Umgang mit ihm war ein Regime der Distanzlosigkeit am Werk: Was in der Schweiz als privat galt und in der neu entstehenden Architektur der Kleinfamilie fremden Blicken entzogen werden sollte - Familienleben, Fortpflanzung und Erotik -, wurde im `Senegalesendorf^als öffentliches Spektakel organisiert, an dem sich weiße Betrachter*innen nach Bedarf ergötzen konnten.

Dass sich die Inszenierung weißer Verfügungsmacht über Schwarze Körper auch in der Werbung zeigte, macht ein Exkurs in die Schokoladenwerbung der 1930er Jahre deutlich. Denn auch das industrielle Produkt, das in dieser Zeit zu einem identitätsstiftenden Element der Nation avancierte, ist zutiefst mit dem kolonialen Imaginären der Schweiz verbunden. 


\section{SCHWEIZER Schokolade UNd die KommodifizieRUNG SCHWARZER KÖRPER}

Die Erfindung der Milchschokolade erfolgte 1870 und fällt zeitlich mit der Hochphase des europäischen Kolonialismus zusammen. Ist diese Gleichzeitigkeit für die Geschichte der Schweizer Schokolade von Bedeutung, können beide Ereignisse auf sinnvolle Weise miteinander in Verbindung gebracht werden? Wenige Jahrzehnte nach der Einführung der Milchschokolade, um 1900, erfuhr die Schweizer Schokoladenindustrie einen regelrechten Boom. Bereits 1905 stand die Schokolade in der Rangliste der wichtigsten Schweizer Exportgüter auf dem sechsten Platz. ${ }^{145}$ In diesem Zeitraum etablierte sich auch der Begriff der >Schweizer Schokolade< ${ }^{146}$ Mit der Durchsetzung der Milchschokolade als national bedeutsamem Produkt, schreibt Roman Rossfeld, änderte sich entsprechend die Bildersprache der Werbung: »Hatten früher Firmenansichten und exotische Motive in der Werbung vorgeherrscht, warb die schweizerische Schokoladenindustrie nach 1900 hauptsächlich mit verschneiten Berggipfeln, Milchkühen und dem guten Image der Alpenmilch. ${ }^{147}$ Schokolade wurde in dieser Phase nationalistisch aufgeladen und mit einer idealisierten Bergwelt, einem »Heidi-Land « ${ }^{148}$, verknüpft. Die Stilisierung einer heilen Alpenwelt bediente folkloristische Bilder der Schweiz, die ein gemeinsames Imaginäres schufen, und wirkte Gefühlen des Verlusts und dem Unbehagen an der Moderne entgegen, die Industrialisierung und Urbanisierung mit sich brachten. ${ }^{149}$ Auch außerhalb der Schweiz wurde das Bild einer kleinen heilen Bergwelt im Herzen Europas und eines Lebens im Rhythmus und im Einklang mit der Natur bedient; eine Vorstellung, die beispielsweise im Village Suisse an der Weltausstellung 1900 in Paris mit großem Aufwand und viel Erfolg inszeniert worden war. ${ }^{150}$

Mit der Transformation der Schokolade vom Luxusartikel zur Massenware um 1900 und ihrer damit einhergehenden Nationalisierung wichen

145 | Rossfeld 2007, 89f.

146 | Rossfeld 2012, 58. Programmatisch dazu etwa die kleine Studie von Tobler 1917.

147 | Rossfeld 2007, 116.

148 | Rossfeld 2012, 63.

149 | Rossfeld 2012, 67.

150 | Rossfeld 2012, 66. 
die exotischen Motive aber nicht allesamt »den Alpen, der Reinheit der Natur, dem Rütli oder Wilhelm Tell $\ll^{151}$, wie Rossfeld schreibt. Meine Recherchen belegen vielmehr, dass das exotische Othering weiterhin einen wichtigen Bestandteil der Schokoladenwerbung ausmachte. ${ }^{152}$ So war etwa die »komische « ${ }^{153}$ Kolonialwerbung in der Schweizer Schokoladenindustrie außerordentlich beliebt: 1929 publizierte das Unternehmen Tobler ein Werbeplakat mit zwei karnevalesken Schwarzen Gestalten, 1930 warb die Schokoladenfirma Suchard mit einem kulleräugigen Schwarzen Diener in Livree und in den $1960 e r$ Jahren verwendete die MaestraniSchokolade musizierende Schwarze Strichfiguren, die in ähnlicher Form bis vor wenigen Jahren auch die Packungen der Sugus-Fruchtbonbons von Suchard zierten. ${ }^{154}$

Neben komischen wurden in der Werbung auch >pornotropische< Elemente eingesetzt. Wie Wolter schreibt, gehörte die erotische Reklame zu den häufigsten Formen der Kolonialwerbung: »Der Genuss des Kakaos soll, so verspricht die Werbung [...], mit dem >Genuss der Frau<, dem sexuellen Akt, vergleichbar sein. Die Frau ist der Kakao! «155 Mit dieser Überblendung von sexuellem und kulinarischem Genuss arbeitete ein Inserat der Schweizer Schokoladenfirma Tobler aus dem Jahre 1932 (vgl. Abbildung 8), das eine schlanke Schwarze Frau an einem Strand zeigt, die einen Korb auf dem Kopf trägt. ${ }^{156}$ Ihre Darstellung folgt einem stilisierten Bild von Weiblichkeit: Die Figur trägt einen hellen Wickelrock, helle Halsketten und Armringe und ist barbusig. Üppige tropische Vegetation rahmt die Szene ein. Am Horizont zeichnen sich die weißen Segel eines Schiffes ab. »Ein Hauch der Tropen ist in jeder Tafel Tobler Mocca eingeschlossen « steht am rechten unteren Bildrand in schnörkeliger Schrift geschrieben.

Das Bild lässt sich als eine Urszene der Schokoladenproduktion deuten, als Moment nämlich, an dem die tropische Kakaobohnen in die Hände des europäischen Händlers gelangen. Der aufs Meer gerichtete Blick der Schwarzen Frau evoziert, dass sie der Ankunft des weißen Händlers

151 | Rossfeld 2012, 77. Siehe auch Rossfeld 2007, 436.

152 | Vgl. dazu auch Bendix 1993.

153 | Wolter 2005, 78.

154 | Vgl. Purtschert 2008b.

155 | Wolter 2005, 74.

156 | Inserat in der Schweizer Illustrierten Zeitung 1932(47). 
entgegensieht. Der koloniale Handel wird derart mit einer heteronormativen Liebesszene überblendet: Die Schwarze Frau kann als einheimische Geliebte gelesen werden, die auf die Ankunft des weißen Seemannes wartet. Die harte Arbeit auf den Schokoladenplantagen bleibt in der ästhetisierten Darstellung ausgeblendet: Der weiße Händler scheint die Schokoladenbohnen am Ufer in einer harmonischen Szene in Empfang zu nehmen, ohne in Berührung mit Plantagen oder Kolonialherrschaft zu kommen.

Abbildung 8: Inserat für Tobler-Schokolade 1932

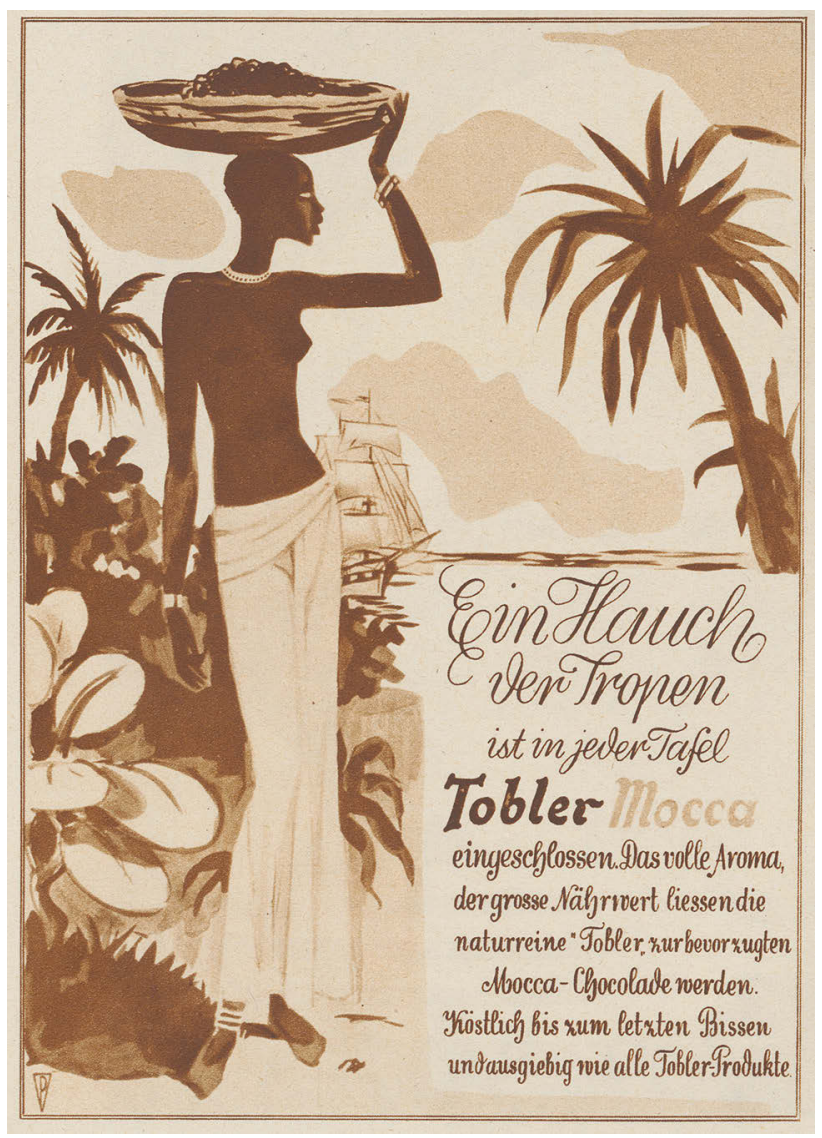

Quelle: Schweizer Illustrierte Zeitung 1932(47) 
Die Macht-, Gewalt- und Besitzverhältnisse, die den Kakaohandel unter dem Kolonialismus kennzeichnen, werden damit unsichtbar gemacht. Der Schwarze weibliche Körper, das koloniale Territorium und die materiellen Rohstoffe der Kolonie überlappen sich stattdessen in dieser symbolischen Ordnung der >Porno-Tropics $<$. Die Kolonie wird zum Ort, der den weißen Abenteurer mit Erotik und materiellem Reichtum lockt. Wie McClintock zeigt, wurde das eroberte Land in der Kolonialliteratur oftmals als Frau imaginiert, die in Besitz genommen und sexuell gefügig gemacht werden konnte. ${ }^{157}$ Betrachtet man die Werbung vor diesem Hintergrund, lässt sich die Schwarze Frau als Symbol für kolonialisiertes Territorium entziffern, das sich und seine Produkte dem weißen, männlich kodierten Westen bereitwillig darbietet.

Mit der Trennung zwischen der Produktion von Rohstoffen und ihrer Veredelung wird zudem die geschlechterspezifisch aufgeladene Differenz zwischen Moderne und Vormoderne, Kultur und Natur aufgerufen. Die Firma Tobler repräsentiert in dieser Darstellung die Schweizer Fabrikanten, die aus dem Rohstoff ein modernes Nahrungsmittel machen. Die Schwarze Frau steht für die Authentizität des exotischen Produkts, als »testifier of authenticity « ${ }^{158}$. Gleichzeitig gewährleistet sie die Kontinuität der Exotik zwischen dem Ort der Herstellung und dem Ort des Konsums: »Ein Hauch der Tropen « finde sich in jeder Schokolade, heißt es in der Werbung, weshalb deren Genuss »köstlich bis zum letzten Bissen« sei. Impliziert wird damit, dass mit der Schokolade auch die exotische Atmosphäre und die erotische Stimmung der Tropen konsumiert werden können. Warenrassismus ist somit nicht nur eine kulturelle Form der Legitimation und Durchsetzung imperialer Macht, wie McClintock dies für Großbritannien herausgearbeitet hat. Er beinhaltet auch die Möglichkeit, Teilhabe am Imperium zu versinnbildlichen: Schweizer Schokolade steht zu Beginn des 20. Jahrhunderts auch für den schweizerischen Zugang zur imperialen Welt mit ihren ökonomischen Profiten und exotischen Genüssen.

Die Firma Tobler publizierte wenige Jahre später ein Plakat (vgl. Abbildung 9), das für Rumschokolade warb und ebenfalls eine Schwarze Frau mit einem Korb auf dem Kopf zeigte. Dieses Mal handelte es sich nicht um eine Zeichnung, sondern um eine kolorierte Fotografie. Der Bezug zum Rohstoff, der Schokolade, bleibt diffuser, weil nicht ersichtlich ist,

157 | McClintock 1995, 21.

158 | Ciarlo 2011, 280. 
ob die Frau Kakaobohnen in ihrem Korb trägt und ob sie überhaupt in der Kakaoproduktion tätig ist. Dafür wird die erotische Dimension der Werbung stärker hervorgehoben: So kann die Bezeichnung >Nur für Erwachsene $<$, die auf den Alkoholgehalt der Schokolade aufmerksam macht, als sexuelle Anspielung gelesen werden.

Abbildung 9: Plakatwerbung für Tobler-Schokolade 1935

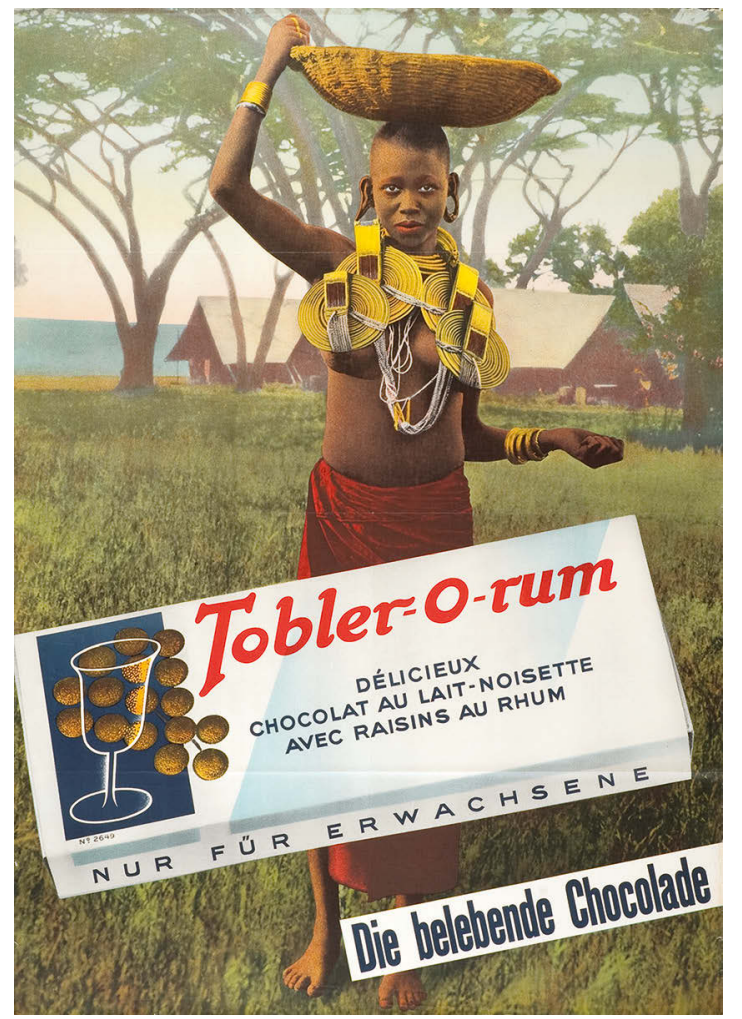

Quelle: Museum für Gestaltung Zürich, Plakatsammlung, ZHdK

Damit operiert auch dieses Plakat in einem heteronormativen und androzentrischen Rahmen: Dem weißen heterosexuellen Mann wird gemeinsam mit der >belebenden Schokolade< eine Schwarze Frau mit nacktem Oberkörper dargeboten. Die rot kolorierten Lippen der Frau können so gedeutet werden, dass sie sich nach >westlichem Standard ‘ für den weißen Betrachter schön gemacht hat. Gleichzeitig weisen der für westliche Ver- 
hältnisse außergewöhnliche und ausladende Schmuck und die gepiercten und in die Länge gezogenen Ohrläppchen auf Schönheitsvorstellungen hin, die nicht westlichen Weiblichkeitsnormen entsprechen und damit exotische Darstellungen aufrufen, die gleichzeitig verwundern und kurios erscheinen mögen. In diesem Zusammenhang ist es wichtig festzuhalten, dass sich gleichzeitig mit der Einordnung dieses Bildes in ein westliches Sichtregime eine große Wissenslücke auftut: Wir wissen nicht, welche Schönheitsnormen und Bekleidungspraktiken im kulturellen Kontext, in dem diese Frau lebte, relevant waren. Mit der Feststellung, dass ihr Aussehen in der Schweiz der 1930er Jahre als exotisch und kurios galt, muss gleichzeitig die wichtige Einsicht einhergehen, dass ihre Kleidung, ihr Schmuck oder ihre Körperhaltung Bedeutungen haben, über die wir nichts erfahren können. ${ }^{159}$ Und mehr noch: Wir wissen gerade darum so wenig darüber, weil das koloniale Bildregime und das gewaltvolle Othering, das ihm innewohnt, den Zugang zum Verständnis und zum Wissen von Anderen auf vielfache Weise verstellt.

Dazu kommt, dass der Ausdruck der afrikanischen Frau schwer zu lesen ist; die >belebende Wirkung< der Szene entsteht nicht dadurch, dass ihr Blick aktives Interesse signalisiert. Er scheint eher verhalten, abwartend und vielleicht sogar verängstigt $\mathrm{zu}$ sein und enthält keine der bekannten Zeichen, die als Interesse an einem erotischen Spiel gelesen werden können. Warum wird dieses Bild dennoch für eine Werbung eingesetzt, die zum Konsum verführen soll? Ein anderes Beispiel aus der Schokoladenwerbung wirft ähnliche Fragen auf.

Das Inserat der Firma Lindt (vgl. Abbildung 10), das 1933 publiziert worden war, zeigt die Fotografie einer Schwarzen Frau mit einem kleinen Kind. Das Bild ist in Brauntönen gehalten und korrespondiert mit dem Text, in dem es heißt: »Lindt Chocolade. Rassig, braun und süss und fein wie dies kleine N[...]lein.« Weiter unten steht in kleiner Schrift: »Zum Anbeissen.« Was aber heißt >rassig〈? Der Duden listet den Begriff rassig als Ableitung von >Rasse< auf und führt folgende Beispiele an: »Rasse haben/ sein (salopp; rassig sein: die Frau, das Pferd, der Wein hat/ist Rasse) « ${ }^{160}$. Wie Andrew Andriana Boussoulas bemerkt, schließt sich an diese Definition die Frage an, wer sich in der Position befindet, Frauen zu bewer-

159 | Vgl. dazu die kritischen Bemerkungen von Kerstin Brandes (2007).

160 | Duden 2015. 
ten, Zuchtpferde einzuschätzen oder sich einen edlen Wein zu gönnen. ${ }^{161}$ Dabei fungiert Männlichkeit und »Weißsein sprachlich als unmarkierter Marker, wenn der aus der unsichtbaren Norm des weißen Blicks heraus als >r[assig] / geanderte Mensch als erotisch, anregend, emotional, unkontrollierbar, gefährlich-attraktiv und eben deswegen auch als nicht gleichwertig markiert wird « ${ }^{162}$. Der offensiv sexualisierte und kolonial konnotierte Gebrauch des Begriffs, wie er von Boussoulas beschrieben wird, installiert einen begehrenden männlichen-heterosexuellen Blick auf eine Frau, deren Verführungskraft mit ihrer >südlichen< Herkunft und ihrem rassifizierten Aussehen verbunden wird.

Abbildung 10: Inserat für Lindt-Schokolade 1933

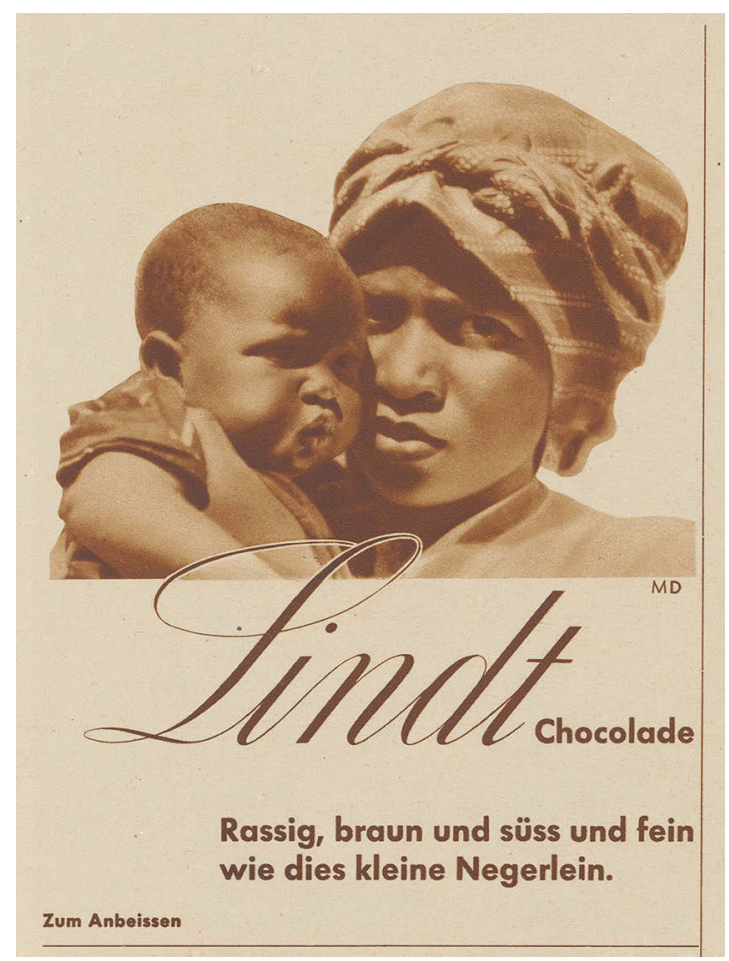

Quelle: Schweizer Illustrierte Zeitung 1933(45)

161 | Boussoulas 2011, 665.

162 | Boussoulas 2011, 665. 
Wie aber lässt sich diese Auslegung mit der Werbung für die Lindt-Schokolade in Verbindung bringen? Denn da wird nicht die Frau, sondern das Schwarze Kind als >rassig, braun, süss und fein < beschrieben, und es wird mit der Schokolade gleichgesetzt, indem es als >zum Anbeißen< bezeichnet wird. Die Werbung ruft bestimmte Assoziationen zwischen >rassig<, >braun<, >süß < und >fein auf, die alle sowohl auf die Schokolade als auch auf das Schwarze Kind verweisen. Dabei wird mit der Doppeldeutigkeit des Begriffs gespielt: Die Schokolade ist >rassig<, weil sie gut schmeckt, das Kind hingegen gilt als >rassig<, weil es als Mitglied einer anderen >Ras$\mathrm{se}<$ markiert ist, die als interessant, aufregend und exotisch gilt.

Die Schokolade wurde durch die Herkunft ihres Rohstoffes aus Westafrika mit Schwarzen Menschen in Verbindung gebracht; als koloniales Konsumprodukt verband sie sich zudem mit der Verfügungsmacht über Schwarze Körper. Denn das Vereinnahmen, Konsumieren und Sich-Einverleiben von Schwarzen Anderen ist eine Prämisse des Warenrassismus. Damit zeigen diese Schokoladenwerbungen ein Verhältnis zum rassifizierten Anderen auf, das von bell hooks als »consumer cannibalism « ${ }^{163}$ beschrieben worden ist. Hooks stellt mit dieser Formulierung eine bedeutsame Umkehrung von bekannten rassifizierten Praktiken her: Das Verspeisen von Menschenfleisch, in der kolonialen Logik den >Primitiven zugeschrieben, wird zu einem bedeutsamen Modus kolonialer Macht. Denn das exotisierte Andere wird in der kolonialen Logik immer wieder mit dem Begehren nach etwas verbunden, was der weißen Kultur fehlt: dem Ursprünglichen, Körperlichen, Sinnlichen, Unverdorbenen oder Naturhaften. >Consumer cannibalism< bezeichnet die vielfältigen Techniken des Einverleibens exotisierter Anderer in der Konsumkultur, die dieses Begehren befriedigen sollen. Sie gründen auf der Fantasie, sich dasjenige, was die Anderen verkörpern, durch deren Verzehr aneignen zu können. Sexualität spielt in diesem kolonial-kannibalistischen Szenario eine bedeutsame Rolle. Die rassifizierten und vergeschlechtlichten Körper von Anderen werden dabei zum Mittel, die einem einzigen Zweck dienen: das Vergnügen und den Genuss machtvoller Subjekte möglich zu machen. ${ }^{164}$

Genauso wie das Inserat der Firma Tobler folgt auch die Anzeige der Firma Lindt der Logik des >consumer cannibalism`. Der Text spielt mit

163 | hooks 1992, 31.

164 | hooks 1992, 23. 
der Vorstellung, das kleine Kind könne gegessen werden wie Schokolade, weil es so süß ist. Es greift die Formulierung auf, wonach man jemanden >zum Fressen gern hat< oder >zum Anbeißen findet<. Die Werbung spielt mit dieser, oft auf Kinder angewandten Redewendung, verschiebt sie aber in mehrerlei Hinsicht: Was in der Regel als Ausdruck einer nahen oder intimen Beziehung gilt (>das Kind ist zum Anbeißen<), äußert sich an dieser Stelle als Zugriff auf unbekannte Schwarze Körper. Zudem erhält die Vorstellung des Zubeißens und Essens durch die Gleichsetzung von Schwarzen Körpern, Schokolade und der Ausbeutungslogik des Kolonialismus eine gewaltvolle Assoziation mit kolonialer Macht. Schließlich gibt die Fotografie in keiner Weise eine verspielte Atmosphäre wieder, wie sie die Redewendung aufruft. Es zeigt kein Baby, das mit der Betrachterin spielen möchte und um ihr Interesse ringt, sondern ein Kind, dessen Gesicht zur Seite gewandt und dessen Gemütszustand schwer zu ergründen ist. Die Mutter scheint das Kind zu beruhigen; gleichzeitig hält sie den Blick auf die Betrachterin oder den Betrachter gerichtet, als wolle sie diese kontrollieren und auf Distanz halten. Es liegt nahe, dieses Bild im Kontext der Sklaverei zu lesen. Wenn der weiße Blick auf das Kind dazu auffordert, dieses als >rassig, braun und süß und fein< zu betrachten, als kommodifizierbar, als verzehrbar, als Konsumobjekt, dann kann der Ausdruck der Mutter als eine Reaktion gedeutet werden, die ebenfalls im Kontext der Sklaverei verortbar ist. Ihr Blick ist nicht auffordernd oder freundlich, er ist aber auch nicht bestimmt oder abweisend, wie man es von einer Person erwarten könnte, die sich gegen den Zugriff auf ihr Kind wehren kann. Sie scheint ihrem Kind beistehen zu wollen, ohne es gänzlich beschützen zu können. So mag der eingeschränkte Handlungsspielraum einer versklavten Person ausgesehen haben oder derjenige einer >Senegalesin < im Zürcher Zoo, die sich und ihre Kinder den weißen Schaulustigen vorführen musste.

Eine derartige Werbung legt damit sowohl den selbstverständlichen Zugriff auf Schwarze (und in besonderem Maße auf weibliche und kindliche) Körper nahe als auch das Übertreten und Ignorieren von Zeichen, die Widerstand, Distanznahme oder Desinteresse signalisieren. Darin zeigt sich ein affektiver Mechanismus, den ich als >sistierte Empathie< bezeichnen möchte. Entscheidend dafür ist, dass die fehlende Einladung oder Kooperation aufseiten der Schwarzen Frau und des Kindes der Werbebotschaft keinen Abbruch zu tun scheint. Wie der verhaltene Blick der Schwarzen Frau auf der Werbung für >Tobler-o-Rumく, so stellt auch der 
abweisende Blick der Mutter auf der Lindt-Reklame keinen Grund dar, die Schwarzen Körper nicht in eine weiße Logik des Konsumierens, Genießens und Verzehrens einzubinden. Die Möglichkeit Schwarzen weiblichen Widerstands gegen die Kommodifizierung ist auf diesen Bildern zwar anwesend, die Inserate fordern aber gleichzeitig zur aktiven Negierung dieser Zeichen auf. Denn die Schwarzen Körper können nur mit Genuss in Verbindung gebracht werden, wenn die Betrachter*innen die sichtbaren Zeichen von Widerstand übergehen. Die subjektive Handlungsmacht der Frauen und des Kindes, die durch deren Blicke und Gesten unübersehbar ins Bild ragt, muss ausgelöscht werden, damit die Werbung funktioniert und sinnlichen Genuss versprechen kann. Die beiden Beispiele verdeutlichen, wie sich weiße Verfügungsmacht über Schwarze Körper trotz solcher und gegen solche Zeichen der Distanznahme artikulieren kann. Ein wichtiger Aspekt des weißen Blickregimes ist damit die Sistierung der Empathie bei der Betrachtung nicht-weißer Frauen, nicht-weißer Kinder, nicht-weißer Menschen.

Diese Dokumente geben, so meine These, Aufschluss über Praktiken eines weißen Blicks um 1930 und über die Art und Weise, wie das Schauen auf Schwarze Körper eingeübt und praktiziert werden musste, damit das >Senegalesendorf im Zürcher Zoo als unterhaltsames und lehrreiches Spektakel erlebt und die Schokoladenwerbung als Aufforderung zum Genuss gelesen werden konnte. Die Beispiele zeigen aber auch, dass die koloniale Herkunft der Schokolade und ihre Nationalisierung in der Bildsprache der Werbung nach 1900 nicht voneinander entkoppelt, sondern im Gegenteil auf neue Weise miteinander verschränkt wurden. Die $>$ Rasse< der Anderen, ihre Würzigkeit und Süße, ihre Erotik, Sinnlichkeit und Konsumierbarkeit wurden mit einem Produkt verbunden, das den Schweizer Kolonialhandel verkörperte. Für McClintock stellte die Seife das Paradebeispiel für ein Konsumgut dar, das die Zivilisationsmission Großbritanniens verkörperte und als »allegory of imperial progress « ${ }^{165}$ gelesen werden konnte. Was die Seife für Großbritannien, ist die Schokolade für die Schweiz, so könnte man behaupten. Sie fungiert als Allegorie der Teilhabe am kolonialen Wirtschafts- und Genussregime und dokumentiert gleichzeitig mit einem Produkt, in dem die einheimische Milch mit dem fremden Kakao eine Legierung eingeht, die spezifische und einzigartige Position der Schweiz im kolonialen Projekt.

165 | McClintock 1995, 214. 


\section{Die Erfindung Des iweissen N- - : Zweiter Teil}

Wenn Geschlecht mit Kolonialität verflochten ist und wenn die Erfindung der modernen Kleinfamilie, der Hausfrau und des Häuslichen sich damit auch in der Schweiz nicht von einem kolonialen Diskurs trennen lassen, wenn der >weiße $\mathrm{N}$-< eine spezifische Aussage in einem solchen diskursiven Feld darstellt - was lässt sich dann über die geschlechtliche Positionierung dieser Figur sagen? Als Erstes lässt sich festhalten, dass die kategoriale Zuordnung variiert: Das Bild, mit dem dieses Kapitel eröffnet wurde, zeigt einen melancholischen Ehemann (vgl. Abbildung 4), das Inserat, das den >weißen $\mathrm{N}-<$ auf einer Theaterbühne zeigt, führt eine kindliche Figur vor (vgl. Abbildung 7). In den meisten Anzeigen aber erscheint der >weiße $\mathrm{N}-<$ als Schwarzer Bediensteter und nimmt damit eine transnational kursierende Figur mit einer langen kolonialen Tradition auf. Denn die Figur des exotisierten Dieners, der >morgenländische< und >afrikanische< Motive in sich vereint, wurde um 1900 oftmals für die Vermarktung europäischer Konsumgüter eingesetzt. ${ }^{166}$

Was den >weißen $\mathrm{N}-<$ des Globus kennzeichnet, ist somit seine schillernde Position zwischen Kind und Erwachsenem, Frau und Mann, Fremdem und Vertrautem, Dienstpersonal und Familienmitglied. Diese Grenzüberschreitungen nehmen koloniale Vorstellungen von nicht-europäischen und insbesondere afrikanischen Menschen auf, die in Missionsund Kolonialdarstellungen häufig als kindlich und erziehungsbedürftig beschrieben wurden. Wie die Analyse zum >Senegalesendorf in Zürich gezeigt hat, wurden afrikanische Menschen zudem mit dem Bereich der Familie, des Haushalts und des Privaten in Verbindung gebracht, während sie gleichzeitig außerhalb der Sphäre des Urbanen, der Industrialisierung und der modernen politischen Ordnung angesiedelt wurden.

John und Jean Comaroff beschreiben die »Dialektik des Häuslichen «, ${ }^{167}$ wonach »die konkreten Formen des Häuslichen und die herrschende Gesellschaftsordnung, in die sie eingebettet sind, wechselseitig voneinander abhängen ${ }^{168}$ als entscheidendes Moment in der Formation der Moderne. Mit der Vermittlung einer modernen Kultur des Häuslichen in den Kolonien wurden die Voraussetzungen für eine weiße Hegemonie und für eine

166 | Wolter 2005, 68.

167 | Comaroff und Comaroff 2013, 295.

168 | Comaroff und Comaroff 2013, 296. 
kapitalistische Gesellschaftsordnung gelegt. Kulturimperialismus konnte sich am wirkungsvollsten »entlang der Konturen des Alltagslebens « ${ }^{169}$ entfalten. Das hieß zum einen, dass die Zivilisationsmission über die Ideologie der Kleinfamilie, die Vermittlung bürgerlicher Geschlechternormen sowie die Durchsetzung einer Architektur erfolgte, die zwischen privatem und öffentlichen Raum unterschied. Es bedeutete aber auch, dass moderne Vorstellungen des Häuslichen in der Metropole über den Bezug zum angeblich vormodernen Außen in den Kolonien hergestellt wurden.

Dieser zweite Aspekt soll im Folgenden anhand einer Werbung aus dem Jahr 1935 erörtert werden (vgl. Abbildung 11): Die Reklame, die in der Jugendzeitschrift des Globus-Warenhauses erschien, beinhaltet einen Text, der u-förmig von elf Bildern umringt wird. Auf allen ist der >weiße $\mathrm{N}-<$ abgebildet. Das erste Bild oben links zeigt ihn als Verkäufer, der weiße Wäsche an die Frau zu bringen sucht - die rechte Hand zur sogenannten Qualitätsgeste erhoben, seit 1932 das Kennzeichen von Globus. ${ }^{170} \mathrm{Im}$ untersten, größten Bild, das eine zentrale Stelle einnimmt, sitzt der >weiße $\mathrm{N}-<$ lachend an einem Tisch mit vier Kindern, die vermutlich (darauf lässt der dunkle Inhalt der Tassen schließen) Kakao trinken.

Der Eindruck, dass eine Mutter hier mit ihren Kindern zu Tische sitzt, wird verstärkt durch die Figur des Globi, der pfeifeschmauchend am rechten Rand auftaucht. Seine Darstellung gleicht der eines patriarchalen Familienvaters: Er befindet sich außerhalb des Familienkreises und hält die Hände hinter dem Rücken verschränkt. Seine Position suggeriert, dass er sich nicht um die Bitten der Kinder kümmern, keinen ausgeleerten Kakao aufwischen und auch keine Querelen am Tisch schlichten wird. Vielmehr blickt er aus sicherer Distanz zufrieden auf die Kinderschar und das geordnete Familienleben, das vom $>$ weißen $\mathrm{N}$ - organisiert wird. Dieser sitzt mit fröhlicher Miene gemeinsam mit den artigen Kindern in einer Runde um einen mit einem fleckenlosen weißen Tuch bedeckten Tisch.

169 | Comaroff und Comaroff 2013, 295.

170 | Pfenninger 2007, 30. 
Abbildung 11: Inserat für das Warenhaus Globus 1935

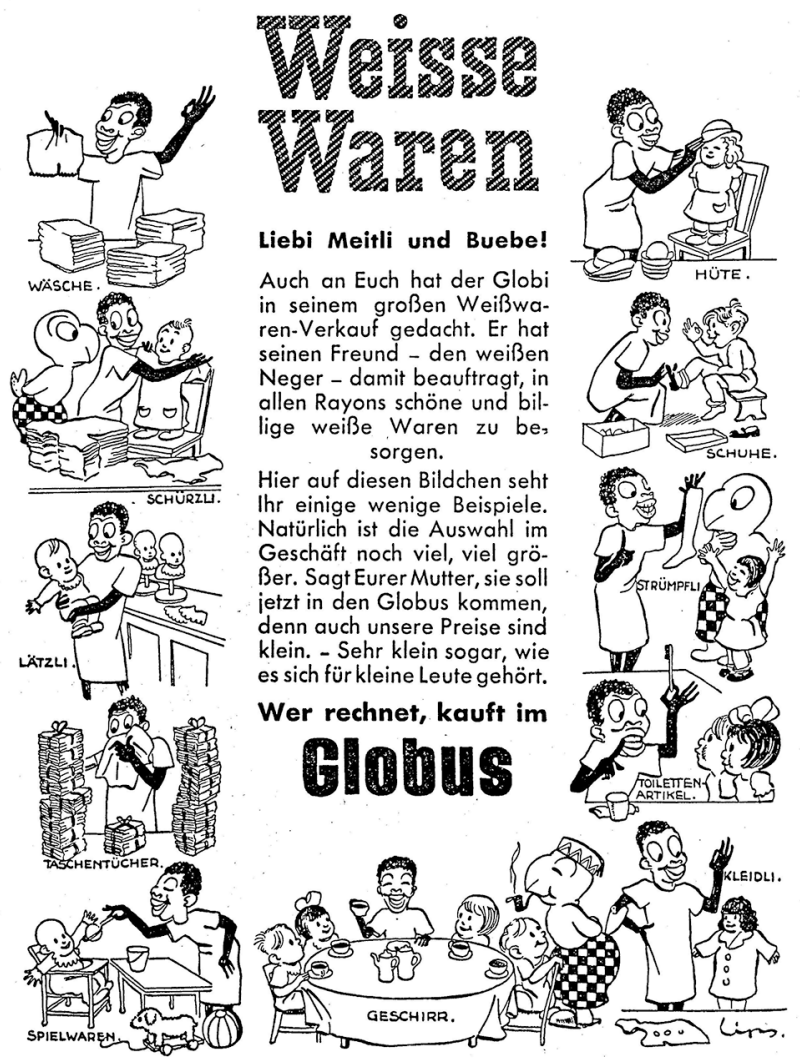

Quelle: Der Globi. Jugend-Schrift der Magazine zum Globus, 1935(1)

Die Lippen des >weißen $\mathrm{N}-<$, die auf diesem Bild noch stärker überzeichnet sind als auf anderen Abbildungen, und die hohen geschwungenen Augenbrauen verleihen ihm einen weiblichen Ausdruck. Seine feminine Rolle ist bereits im oben erwähnten ersten Bild (vgl. Abbildung 12) angelegt, in dem er Weißwaren anpreist. Damit übernimmt er eine typische weibliche Tätigkeit, denn das Verkaufspersonal in den Warenhäusern bestand in erster Linie aus Frauen. ${ }^{171}$ Zudem hält der >weiße N-< auf dieser Abbildung eine weiße Unterhose in der Hand und damit ein

171 | Vgl. dazu König, Siegrist und Vetterli 1985, $238 f f$. 
Kleidungsstück, das ihn in Berührung mit bürgerlicher Intimität bringt: Die Abbildung eines weißen männlichen Verkäufers, der eine Unterhose anbietet, würde eine undenkbare Umkehrung der Geschlechterrollen und ihrer Zuteilungen zum privaten und öffentlichen Raum darstellen. Der >weiße N-< wird an dieser Stelle mit weiblichen Figuren überblendet, die zum Kontext der neuen Mittelschicht gehören: die Verkäuferin, das Kindermädchen, die Mutter, die Haus- und Ehefrau. Während >Rassen<und Geschlechtergrenzen dadurch partiell aufgelöst werden, bleiben entscheidende Schranken bestehen. Das männliche Geschlecht des >weißen $\mathrm{N}-<$ stellt sicher, dass er keine Mutter sein kann, und die weißen Kinder mit ihrem glatten und zumeist hellen Haar lassen keinen Zweifel daran, dass sie nicht Schwarzer Abstammung sind. Der >weiße $\mathrm{N}$-< fungiert als Haushaltshilfe und Kinderfrau und kann als solche die weiße Hausfrau vertreten, nicht aber ihren Platz einnehmen.

Abbildung 12: Inserat für das Warenhaus Globus 1935 (Ausschnitt 1)
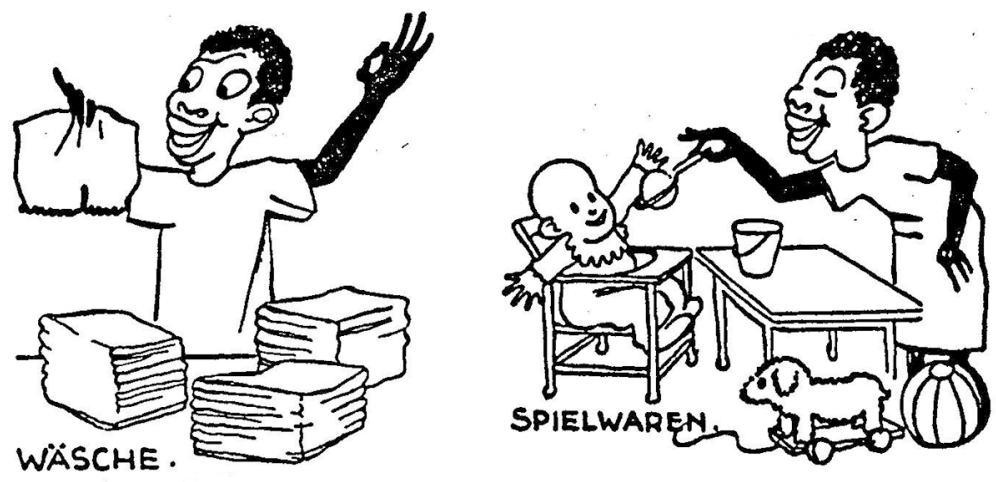

Quelle: Der Globi. Jugend-Schrift der Magazine zum Globus, 1935(1)

Der >weiße $\mathrm{N}$-く übernimmt damit auf diesen Bildern die Arbeit der Schweizer Mittelstandsfrau, und zwar sowohl ihre Lohnarbeit als Verkäuferin wie auch ihre Tätigkeit als Hausfrau. Auf einer Abbildung spielt er mit einem Kleinkind, das in einem Kinderstuhl sitzt (vgl. Abbildung 12). Während sich diese Szene in der Spielwarenabteilung des Warenhauses ereignen könnte, wo ein engagierter Verkäufer das Kind einer Kundin unterhält (nicht zuletzt mit dem Ziel, die Eltern für den Kauf des Spielzeugs zu gewinnen), könnte sie ebenso gut in einem privaten Heim statt- 
finden. Auch hier wird der >weiße N-< mit weiblichen Attributen ausgestattet, die sich neben den oben erwähnten Gesichtszügen besonders stark in seiner Körperhaltung ausdrücken. Das weiße Hemd, das in anderen Darstellungen des >weißen $\mathrm{N}-<$ an ein Kinderkleid erinnert, wird hier zum körperbetonten Kostüm. Das Halten der Rassel mit Daumen und Zeigefinger, die dem Kind zugeneigte Haltung, die devot an die Hüfte gelegte linke Hand erinnern an zeitgenössische Idealbilder der Mutter, die in ihrer Tätigkeit aufgeht und gleichzeitig Eleganz verkörpert, indem sie Elemente bürgerlicher Weiblichkeit inkorporiert.

An wen richtet sich das Inserat, wen soll der >weiße $\mathrm{N}$-< ansprechen, erreichen und von der Verkaufsaktion überzeugen? Der Text in der Mitte der Seite wendet sich an die Kinder, die >Meitli und Buebe<, Mädchen und Knaben. Globi habe den >weißen N-<, heißt es da, beauftragt, schöne und billige Waren für die Weißwarenwochen zu besorgen. In der Tat zeigen sich die Kinder auf den Bildern begeistert vom Angebot, das ihnen unterbreitet wird: Sie freuen sich über passende Schuhe, jubeln über weiße Strümpfe, interessieren sich für eine Zahnbürste oder für Kinderspielzeug. Gleichzeitig macht der Text deutlich, dass die Kinder zwischen dem Warenhaus und den Hausfrauen vermitteln sollen, an die sich die Werbung primär richtet: »Sagt Eurer Mutter, sie soll jetzt in den Globus kommen, denn auch unsere Preise sind klein.« Mit der Kombination von attraktiver, funktionaler, qualitativ hochstehender - die sogenannte >Qualitätshand < des Globus wird zweimal vom >weißen $\mathrm{N}$-< und einmal von einem Kind angezeigt - und preisgünstiger Ware ruft der Globus ein Bild der Hausfrau auf, die als Konsumentin gleichzeitig den Preis und die Qualität im Blick hat.

Jakob Tanner und Brigitte Studer haben darauf hingewiesen, wie Sparen und Konsumieren in den 1930er Jahren das Bild der Hausfrau bestimmten: »Sparmentalität - das >Markenzeichen < der >Schweizer Hausfrau< - und Konsumorientierung - das Zeichen für familiären Erfolg - gingen eine widersprüchliche, jedoch synergetische Verbindung ein. « ${ }^{172}$ Während die häusliche Produktion von Nahrung und Kleidern zurückging, wurde die >Konsumarbeit< bedeutsamer: »Die Hausfrau musste sich ständig einen Überblick über das immer umfangreicher werdende Marktangebot verschaffen, um zum Beispiel das Produkt mit dem besten Preis-Leistungs-Verhältnis zu finden «, ${ }^{173}$ hält Anna Bähler fest.

172 | Tanner und Studer 2012, 644.

173 | Bähler 1996, 177. 
Die weiße Schweizer Hausfrau kann damit gleichzeitig als Adressatin und unsichtbarer Bezugspunkt des Inserats entziffert werden: Sie bleibt absent, obwohl sie die eigentliche Empfängerin der Werbebotschaft darstellt. Der >weiße N-< taucht als Substitut auf, der ihre Rolle als Verkäuferin, vor allem aber als gute Mutter und Ehefrau wahrnimmt und ihr damit den Blick auf die ihr zugewiesene gesellschaftliche Rolle ermöglicht. Diese Ersetzung wird durch die koloniale Differenz gleichzeitig ermöglicht und beschränkt: Die Präsenz der Schwarzen Dienerfigur erhöht den Status der weißen Hausfrau, ohne ihn zu bedrohen; denn der >weiße N-< kann ihren Platz als weiße Mutter von weißen Kindern nie einnehmen.

Mit dieser Bedeutungsverschiebung löst sich auch die Grenze zwischen Verkäufer und Bedienstetem auf. Der >weiße N-< preist nicht nur die Ware an, sondern übernimmt zugleich die Arbeit, die mit dieser Ware verbunden ist und die die Domäne der Schweizer Hausfrau kennzeichnet. Er hält das Kleinkind auf dem Arm, er bespielt es, er hilft den Kindern bei der Körperpflege. Seine zunehmende Einhegung in den Bereich des Häuslichen gipfelt im zentralen Bild (vgl. Abbildung 13), in dem das Warenhaus ausgeblendet wird und der >weiße $\mathrm{N}$-< in der Position der Hausfrau erscheint, welche die Kinder betreut und ernährt, die Zufriedenheit des Hausherrn gewährleistet und eine geordnete häusliche Atmosphäre herstellt.

Abbildung 13: Inserat für das Warenhaus Globus 1935 (Ausschnitt 2)

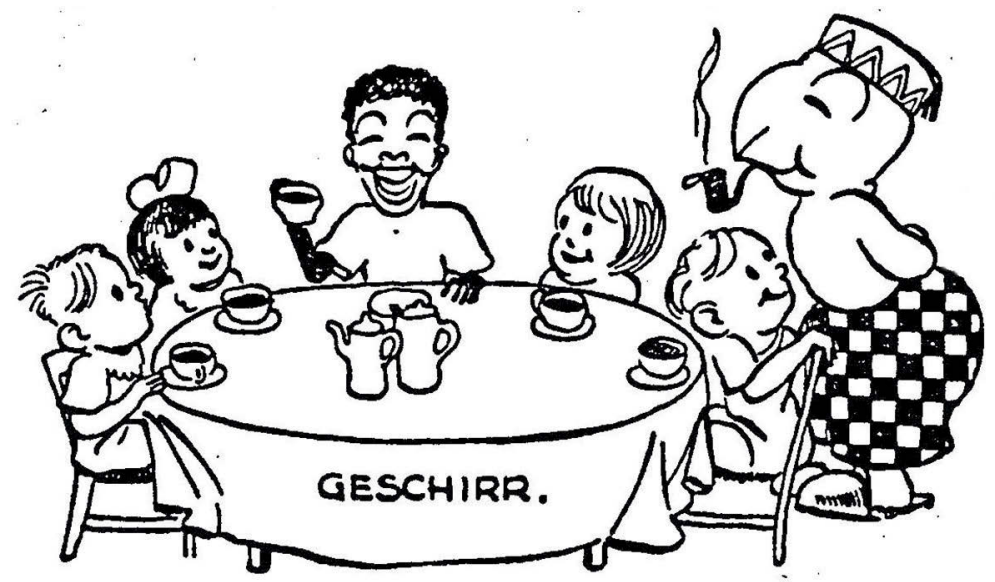

Quelle: Der Globi. Jugend-Schrift der Magazine zum Globus, 1935(1) 
Als ihr Platzhalter ermöglicht es der >weiße N-< der Schweizer Hausfrau, sich für einen Moment aus dem häuslichen Alltag herauszunehmen und sich mithilfe einer kolonialen Fantasie in die Perspektive einer kolonialen Hausherrin mit Dienstboten zu versetzen. Paradoxerweise wird diese Fantasie zu einem historischen Zeitpunkt aufgerufen, an dem sich die Zahl von Hausangestellten drastisch verringerte und sich »der Übergang von der Hausherrin zur Hausfrau, von der Aufsicht über bezahlte Hausarbeit anderer zur eigenen unbezahlten Hausarbeit « ${ }^{174}$ vollzog, wie Gisela Bock und Barbara Duden konstatieren. Das vorherige Dienstmädchen konnte nun selbst die Position der bürgerlichen Hausvorsteherin anstreben - als Hausfrau ohne Bedienstete allerdings.

Die Botschaft der Werbung besagte demnach, dass die Waren des Globus der Hausfrau einen guten Dienst erweisen, weil sie auch die Bediensteten ersetzen könnten. Die kommodifizierte Figur des Schwarzen Dieners, der mittels der kolonialen Ikonografie zwischen Mensch und Produkt angesiedelt wird, macht die virulente Schnittstelle zwischen neuen Dienstleistungsprodukten und der verfallenden Bedienstetenkultur sichtbar. Koloniale Fantasien ermöglichen es in dieser Umbruchphase, der Hausfrau imaginär den sozialen Status einer Hausherrin zuzuweisen. Das partielle Weißsein des >weißen N-<lässt sich vor diesem Hintergrund als unvollständige und nicht vervollständigbare Annäherung an die Schweizer Hausfrau lesen, deren Status über die Differenz zum rassifizierten Anderen attraktiv und begehrenswert erscheint. Die komische und bizarre Werbefigur des Globus hält der Schweizer Hausfrau einen durch die >Rassendifferenz « verzerrten Spiegel hin, in dem sie sich nicht als Bedienstete, sondern als Hausherrin, nicht als mimic man, sondern als gute Hausfrau, nicht als feminisierter Mann, sondern als wahrhafte Frau, nicht als weißer Schwarzer, sondern als authentische Weiße erkennen kann.

\section{WARENRASSISMUS UND OtherING}

Gemäß McClintock kann die intime Verknüpfung von Massenkonsum und Imperialismus im Fin de Siècle nicht getrennt werden von der Neuerfindung des Häuslichen und der Hausfrau, denn »the mass-marketing

174 | Bock und Duden 1977, 155. 
of empire as a global system was intimately wedded to the Western reinvention of domesticity, so that imperialism cannot be understood without a theory of domestic space ${ }^{175}$. Diese Einsicht gilt es auch umzukehren: Die Durchsetzung bürgerlicher Normen durch den Massenkonsum bedurfte der Bezugnahme auf das imperiale Projekt. Die Schweiz ist ein interessantes Beispiel für die Untersuchung dieses Zusammenhangs, weil die Einschränkung der Frauen auf die häusliche und private Sphäre hier sowohl in normativer als auch in praktischer Hinsicht besonders weitreichend war. ${ }^{176}$

Wie Arni festhält, wurde das Ideal der >modernen Familie um 1900 zum normativ verbindlichen Modell des Zusammenlebens, »ein Modell, das sich auszeichnet durch eine Konzentration auf die Paarbeziehung und das Kind, durch eine ausgeprägt geschlechterpolarisierte familiale Ordnung sowie durch eine privatistische Abgrenzung von der Außenwelt und zugleich eine zunehmende Unterwerfung unter sozialpolitische Steuerung « ${ }^{177}$. Die wirkmächtige Figur der modernen Familie legitimierte unterschiedliche Machtverhältnisse, die gleichzeitig konstitutiv in sie eingelassen waren: die neu kodierten patriarchalen Herrschaftsbezüge zwischen den Familienmitgliedern, die im Schweizerischen Zivilgesetzbuch von $1907^{178}$ ihren rechtlichen Niederschlag fanden, die zunehmende biopolitische Regulierung der Bevölkerung durch Staat, Kantone und Gemeinden und Wohltätigkeitsinstitutionen, die neuen affektiven Verbindungen, die zwischen den Klassen vermittels der Konsumgesellschaft hergestellt wurden und eine maßgeblich durch die Wissenschaft unterstützte Ontologisierung einer komplementären und hierarchischen Zweigeschlechtlichkeit. Damit wurde die Hausfrau Teil des nationalen Projekts: »Mit der Schaffung der >Schweizer Hausfrau<, die sich durch besondere Sparsamkeit, Bescheidenheit und was der nationalen Tugenden noch mehr waren, auszeichnen sollte, wurde die >Schweizer Frau<

175 | McClintock 1995, 17.

176 | Blattmann 1998, 28.

177 | Arni 2004, 13. Zur Vorgeschichte dieser Entwicklung siehe Mesmer 1988.

178 | Schweizerisches Zivilgesetzbuch vom 1. Dezember 1907, in Kraft getreten am 1. Januar 1912, Bundesblatt 1907, Band 6, S. 589-890, online abrufbar unter https://www.amtsdruckschriften.bar.admin.ch/start.do (Zugriff am 24. September 2018). 
nachhaltig in die nationale Ideologie eingebunden. ${ }^{179}$ Wie wir noch sehen werden, diente das Leitbild bürgerlicher Weiblichkeit in der Schweiz gleichzeitig seit Mitte des 19. Jahrhunderts auch »zur Disziplinierung der Unterschichten und zu deren Einbindung in den schweizerischen Nationalstaat ${ }^{180}$.

Der Tätigkeitsbereich von Frauen wurde in den 1930er Jahren ideell und faktisch enorm eingeschränkt, etwa durch die Vorgabe, dass verheiratete Frauen nicht erwerbstätig sein sollten. ${ }^{181}$ Die heftig geführten Debatten zum >Doppelverdienertum<, die um 1930 einsetzten, bewirkten eine zunehmende Ablehnung der Erwerbstätigkeit von verheirateten Frauen. ${ }^{182}$ Trotz vieler Proteste und Einwände setzte sich dieses Dispositiv weitgehend durch und führte zu einer »Zementierung der rollengeteilten, hierarchisch organisierten Familie als dem Kern des bürgerlichen Staates (als einer Männergemeinschaft) « ${ }^{183}$. Diese Norm der nicht-erwerbstätigen Hausfrau und Mutter, die im Haushalt ihre wahre Bestimmung findet, wurde in der Zwischenkriegszeit hegemonial.

Das Ideal der tüchtigen, einfachen und fleißigen Hausfrau prägte nun auch Bewegungen, die zuvor dissidente Positionen eingenommen hatten. Joris schreibt: »Auf diese Linie schweizerischen Frauseins schwenkten im Laufe der dreißiger Jahre alle bedeutenden Frauenorganisationen ein, selbst Sozialdemokratinnen, die noch vor kurzem auf das Recht auf Arbeit gepocht hatten. ${ }^{184}$ Gleichzeitig wurden die Kämpfe um die ökonomischen und politischen Rechte von Frauen in den 1930er Jahren unter dem Einfluss der Wirtschaftskrise, der zunehmend rechtskonservativen Ausrichtung der Politik und der >Geistigen Landesverteidigung z zurückgedrängt. Die Diskussion um die außerhäusliche Erwerbsarbeit der Frau

179 | Blattmann 1998, 28.

180 | Joris 1990, 100.

181 | Studer 2001a, 79.

182 | Ziegler 1996; Studer 2001b.

183 | Ziegler 1996, 100.

184 | Joris 1990, 114. Diese Entwicklung ist nicht zu trennen von der Reorganisation der Sozialdemokratie in der Schweiz, die ab den 1930er-Jahren den Diskurs der 'Geistigen Landesverteidigung، zu übernehmen begann. 1935 strich die sozialdemokratische Partei die Diktatur des Prolatariats aus inrem Programm und ebnete damit den Weg in eine Koalitionsregierung mit den bürgerlichen Kräften (Degen 2013). 
und ihre politische Gleichstellung verschwand zusehends, und damit auch die Forderung nach dem Frauenstimmrecht oder gleichem Lohn für gleiche Arbeit. ${ }^{185}$ Umgekehrt gewann, so Joris und Witzig, »der Gedanke wieder an Bedeutung, die Schaffung einer Familienatmosphäre sei eher Berufung als Beruf. Der Schutz der Privatsphäre und der familiären Intimität war für die Frauen der Mittelschicht vorrangig « ${ }^{186}$. Das Modell der $»$ Nur-Hausfrau ${ }^{187}$ wurde zwar erst mit der Hochkonjunktur ab den 195oer Jahren für eine größere Anzahl von Frauen Realität. In den 1930er Jahren entstand aber das, was man mit McClintock den >modernen Schweizer Haushaltskult< nennen könnte.

Paradoxerweise fand das Zelebrieren des Privaten, Familiären und Intimen in hohem Maße in der Öffentlichkeit statt. Gerade die Werbung, die Hauswände und Plakatsäulen mit häuslichen Szenen im Großformat vollpflasterte - Männer, die sich rasieren, Kinder, die gebadet werden, Hausfrauen beim Putzen -, spielte mit der Durchlässigkeit der Grenzen zwischen privatem und öffentlichem Raum. ${ }^{188}$ Diese Prozesse überschnitten sich mit der im ausgehenden 19. Jahrhundert einsetzendenden Assoziierung von Frauen mit Konsum. ${ }^{189}$ Das aufstrebende Marketing der Zwischenkriegszeit wurde, wie Tanner und Studer zeigen, stark an Konsumentinnen ausgerichtet: „Gagnez la femme etablierte sich als Motiv der sich herausbildenden Konsumgesellschaft.« ${ }^{190}$ Gleichzeitig wurde der Massenkonsum zu einem wichtigen Transmissionsriemen für die Verbreitung eines Ideals von Weiblichkeit, die sich ganz dem Heim und den Kindern verschreibt.

Die Werbung adressierte die neue Hausfrau aber nicht nur als Hüterin des Häuslichen, sondern auch als Vertreterin einer imperialen Weltordnung. Der moderne Haushaltskult der Zwischenkriegszeit verband sich dabei mit dem Versprechen, Teil einer zivilisierten und fortschrittlichen Welt zu sein. Wie Beispiele aus der Werbung der 1930er Jahre zeigen, denen ich mich im Folgenden zuwende, wurde die Schweizer Hausfrau als Bestandteil einer Kultur des Weißseins imaginiert, in der sich weiße

\footnotetext{
185 | Joris und Witzig 1986, 74.

186 | Joris und Witzig 1986, 74.

187 | Joris und Witzig 1986, 75.

188 | McClintock 1995, 209.

189 | Tanner und Studer 2012, 643.

190 | Tanner und Studer 2012, 644 [Hervorhebung im Original].
} 
Wäsche, ein mustergültiger Haushalt und der makellose helle Teint der Haut auf signifikante Weise verschränkten und dabei Vorstellungen einer fortschrittlichen weißen Nation sichtbar machten, die erfolgreich in die imperiale Metropole eingebunden war. Werbung verhandelte demnach nicht nur komplementäre und hierarchische Geschlechternormen, sondern auch Weißsein als implizite Norm des Schweizer Haushaltskults.

Abbildung 14: Inserat der Firma Electrolux 1933

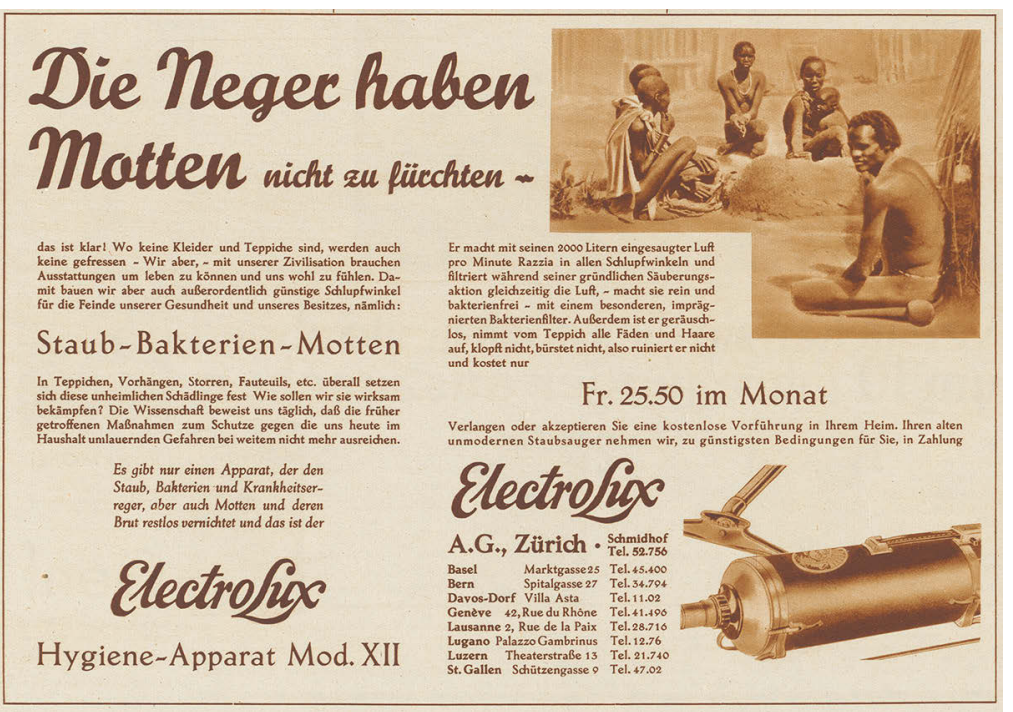

Quelle: Schweizer Illustrierte Zeitung 1933(22)

Ein wichtiger Bestandteil des kolonialen Haushaltskults war die Figur der >primitiven< Anderen, durch deren Rückständigkeit die Fortschrittlichkeit der modernen Hausfrau herausgestellt werden konnte. Diese Form des Othering findet sich in einer Staubsauger-Werbung der Firma Electrolux aus dem Jahre 1933 (vgl. Abbildung 14). Sie zeigt rechts eine Fotografie, auf der fünf Schwarze Erwachsene und ein Kleinkind zu sehen sind, nackt oder wenig bekleidet und auf dem Erdboden sitzend. Am rechten Bildrand zeichnen sich Wand und Dach einer Strohhütte ab. Im Inserat steht in großen Lettern: »Die N[...] haben Motten«, gefolgt von einem kleiner gedruckten Teilsatz »nicht zu fürchten - «. Der Titel spielt demnach mit der Vorstellung, Schwarze Menschen würden mit Motten leben, eine Anspielung auf die rassistische Verbindung von Schwarzsein und Schmutz. 
Erst ein genauerer Blick zeigt, dass dem nicht so ist: Die abgebildeten Menschen haben gerade keine Motten. Denn weiter heißt es in kleiner Schrift: »das ist klar! Wo keine Kleider und Teppiche sind, werden auch keine gefressen - Wir aber, - mit unserer Zivilisation brauchen Ausstattungen um leben zu können und uns wohl zu fühlen. Damit bauen wir aber auch außerordentlich günstige Schlupfwinkel für die Feinde unserer Gesundheit und unseres Besitzes, nämlich: Staub - Bakterien - Motten.«

Die Funktion Schwarzer Menschen in diesem Inserat ist eine zweifache: Zum einen sind sie der Blickfang für die Werbung. Ihr Bild soll die Neugier der Leserschaft wecken und der reißerische Titel mit der unerwarteten Wendung im kleingedruckten Satzteil soll sie zum Lachen bringen - ein Lachen, das eine rassistische Weltsicht abruft und bestätigt. Gleichzeitig symbolisieren sie eine Gegenwelt zum häuslichen Dasein der Zivilisation. Sie machen deutlich, dass ein Leben ohne Motten bedeuten würde, keine Kleider und Teppiche zu besitzen. Die Motten werden damit zum Zeichen eines zivilisierten Daseins, das sich von der >primitiven Lebensweise der Wilden abhebt. Der mühsame Kampf gegen diese Eindringlinge erhält dadurch eine neue Bedeutung: Dass Motten Teppiche zerfressen, verweist auf den Status von Menschen, die in einer Wohnung und nicht in der Wildnis leben. Motten richten sich gegen >Gesundheit und Besitz<, aber gerade darum belegt ihr Vorhandensein eine bürgerliche Existenz, die ein modern kodiertes Verständnis von Gesundheit und Besitz impliziert. Angesichts der fast nackten, dünnen, ärmlichen Schwarzen Menschen kann die weiße Hausfrau die Vorstellung getrost zurückweisen, dass sie ein Leben ohne Motten, Staub und Staubsauger führen möchte.

Mit dem Staubsauger, der die Motten erfolgreich bekämpfen soll, kommt eine weitere bedeutsame Dimension des kolonialen Othering ins Spiel. Das Gerät weist auf den technischen Fortschritt hin, der die Tätigkeit im Haushalt zunehmend durchdrang. Wie Joris festhält, wurde die Hausarbeit in der Zwischenkriegszeit durch Rationalisierungsbewegungen erfasst, die aus der betrieblichen Arbeit stammten. ${ }^{191}$ Obwohl Haushaltsgeräte erst in der Hochkonjunktur der 1950 or und $1960 e r$ Jahren im größeren Stil Eingang in Schweizer Haushalte fanden, wurden sie in den 1930er Jahren bereits eifrig beworben. Neben den erhöhten Ansprüchen an die Hygiene und dem Mangel an Dienstbot*innen reagierte diese Ent-

191 | Joris 2015. 
wicklung auch auf das »Bedürfnis, die Hausarbeit der bürgerlichen Frau durch den prestigeträchtigen Besitz eines elektrischen Geräts aufzuwerten ${ }^{192}$.

Die Vorstellung des technischen Fortschrittes verband die Haushalte mit national bedeutsamen Projekten wie dem Bau von Wasserkraftwerken oder der Elektrifizierung der Eisenbahn. ${ }^{193}$ Der Staubsauger war damit weit mehr als ein Hilfsmittel im Haushalt, er stellte auch eine Verbindung zum Bild einer technisch avancierten Nation her. Diese Relation verstärkte sich durch die Assoziation des Staubsaugens mit der Wissenschaft. Im Inserat heißt es: »Die Wissenschaft beweist uns täglich, dass die früher getroffenen Maßnahmen zum Schutz gegen die uns heute im Haushalt umlauernden Gefahren bei weitem nicht mehr ausreichen.« Diese Aussage bindet die Hausfrau nicht nur in eine Welt der technischen Innovationen, sondern auch der wissenschaftlichen Wahrheit ein. Gleichzeitig wird mit diesem Satz eine weitere Differenz angesprochen, die nicht die >Primitiven $<$ ohne Teppich von den Zivilisierten mit Teppich unterscheidet, sondern die moderne Hausfrau mit einer fortschrittlichen, sprich technisch und wissenschaftlich abgestützten Haushaltsführung von der Vorfahrin mit ihren unzureichenden sfrüher getroffenen Maßnahmen< unterscheidet. Damit wird die Schweizer Hausfrau im Inserat durch eine doppelte Differenz als moderne Frau konstituiert: in Abgrenzung zu den zeitgenössischen >Primitiven<, die eine räumliche Differenz, und zu ihren eigenen Vorfahren, die eine zeitliche Differenz aufrufen.

Die moderne Reinigungsarbeit, so vermittelt das Inserat, ist darum effizient und hygienisch, weil sie durch Technik ermöglicht und durch wissenschaftliche Erkenntnis begleitet wird. Wie ich im zweiten Kapitel dieser Arbeit diskutiere, bestand seit dem späten 19. Jahrhundert ein enger Zusammenhang zwischen Schweizer Selbstbildern und technischem Fortschritt. ${ }^{194}$ Die Staubsauger-Reklame zeigt, dass dieser >Techno-Kolonialismus a auch für den Bereich des Haushalts bedeutsam war: Die Fortschrittlichkeit der Schweizer Hausfrau maß sich daran, dass sie sich, im Unterschied zu den >primitiven Anderen, der modernen Technik bedienen konnte.

192 | Bähler 1996, 177.

193 | Pasquier 2006.

194 | Vgl. dazu das Unterkapitel Schweizer ,Technokolonialismus<. 
Dass der technische Fortschritt der Nation im Haushalt zum Ausdruck gebracht und mit kolonialen Anderen kontrastiert wurde, verdeutlicht ein Artikel zur Schweizer Wasserversorgung, der im Jahre 1932 in der Schweizer Illustrierten Zeitung erschien. ${ }^{195} \mathrm{Zu}$ Beginn stellt der Bericht die selbstverständliche Verfügbarkeit von sauberem Wasser im eigenen Heim infrage: »Wer denkt groß daran, dass das kristallklare Wasser in Küche und Baderaum eine herrliche Gabe der Natur ist, um die wir in breiten Erdstrichen benieden werden? Nur wer schon einmal die wasserarmen Gebiete Italiens, Spaniens oder Nordafrikas betreten hat, weiß das kostbare Nass unserer Alpenzone nach Gebühr zu schätzen.« ${ }^{196}$ Wasser taucht in dieser Darstellung erst einmal als natürliche Ressource auf, die mit den Alpen in Verbindung gebracht und dann den trockenen Landschaften Italiens, Spaniens und Nordafrikas gegenübergestellt wird. Man müsse diese anderen Gebiete betreten haben, man müsse gleichsam die wasserarmen Landschaften des Südens vor Augen gehabt haben, um den Reichtum der Schweiz erkennen zu können, so legt die auf dem Othering basierende Logik des Artikels nahe.

Es sind aber nicht nur die natürlichen Ressourcen, welche die Schweiz zu einem Wasserparadies machen. Es ist, so heißt es weiter, die Technik, welche die Gewinnung von Trinkwasser und seine Verteilung ermögliche. Es »sei vorausgeschickt«, hält der Text fest, bevor er sich den Details der Wasserklärung zuwendet, »dass uns die Fortschritte der Technik alle nötigen Mittel verschafft haben, um Wasser selbst unter Überwindung größter Hindernisse an die einzelnen Verbrauchsstellen heranzuführen. Die gewaltigen Errungenschaften der Neuzeit ermöglichen ferner die Zubereitung jedes beliebigen Wassers als Trinkwasser. ${ }^{197}$ Es ist also die Kombination natürlicher Ressourcen in den Alpen mit den fortschrittlichsten Techniken, die das Schweizer Wasser zu einem hygienischen und überall erhältlichen Gut macht. Ähnlich wie die Gotthardbahn für eine Schweiz steht, die erfolgreich imposante Berglandschaften mit technischen Innovationen verbindet, symbolisiert das Trinkwasser an dieser Stelle die gelungene Fusion zwischen Natur und Technik im Kontext einer Schweiz, die für beides steht.

195 | 0.V.: "Wasser im Haushaltu, in: Schweizer Illustrierte Zeitung 1932(6).

196 | 0.V.: "Wasser im Haushalt", in: Schweizer Illustrierte Zeitung 1932(6).

197 | 0.V.: "Wasser im Haushalt", in: Schweizer Illustrierte Zeitung 1932(6). 
Bedeutsam ist, dass der Artikel explizit die Schweizer Hausfrau adressiert. Sie ist die glückliche Nutznießerin der modernen Wassertechnik, wie der Artikel zum Schluss konstatiert: »In jedem Falle aber ist die Beschaffung unseres Trinkwassers ein technisches Kunstwerk, das alle Aufmerksamkeit unserer Hausfrauen verdient, zumal wenn man sie in die Lage unserer Vorfahren zurückversetzt, welche mit so primitiven Brunnenanlagen versehen waren, dass sie sehr häufig als Herde gefährlicher Epidemien erkannt werden mussten. ${ }^{198}$ Die Technik der Trinkwasserversorgung schützt die Hausfrau und ihre Familie vor Verschmutzung und damit vor Krankheiten. Aus einer biopolitischen Perspektive lässt sich dieser Text als geschlechterspezifische Subjektivierungsanleitung lesen, in der das Herstellen von Nation und Familie unter der Perspektive der Hygiene zusammengeführt wird. Die idealisierte Schweizerin wird dabei, anders als der Schweizer (wie wir im zweiten Kapitel sehen werden), nicht als verkörperte Verbindung von imposanter Bergwelt und technischem Können betrachtet, sondern als Rezipientin und Konsumentin dieser Verbindung. Sie ist nicht die Schöpferin des >technischen Kunstwerksく, sondern die Nutzerin, deren Wirkstätte, der Haushalt, im Kontext von nationalem Territorium (die Berge und ihr Wasserreichtum), technischem Fortschritt (die Wasserreinigung und -distribution) und biopolitischer Regulierung (die hygienische Lebensführung und Pflege der Familie) verortet wird. Als differenzielles Moment dieser Verbindung dienen die im ersten Satz aufgerufenen Bewohner*innen der trockenen Gebiete dieser Erde, die bei der Illustration des Artikels wiederkehren.

Der Text ist mit zwei Fotografien bebildert (vgl. Abbildung 15), welche die Nutzung des Wassers im Alltag veranschaulichen. Das linke Bild zeigt eine weiße Frau, die an einem Spülbecken in der Küche steht und Wasser aus dem Hahn in ein gläsernes Trinkglas laufen lässt. An der Wand hängen ein Kalender und eine Kuchenform aus Metall. Sie trägt eine Bluse mit adrett aufgekrempeltem Rand und eine Schürze, das typische Kleidungsstück der Hausfrau, die ihre Kleidung vor den Spuren der Küchenarbeit, vor Mehl- oder Fettflecken schützen will. Das Haar trägt sie modisch frisiert in mehreren großen Wellen. Ihr Gesichtsausdruck wirkt ruhig und konzentriert. Die Lichtführung leuchtet Gesicht und Hände der Frau, die im Zentrum des Bildes sind, hell aus. Das zweite Bild zeigt eine Schwarze Frau, die einen Krug an einem Wasserhahn im

198 | O.V.: "Wasser im Haushalt», in: Schweizer Illustrierte Zeitung 1932(6). 
Freien füllt. Daneben stehen neun weitere große Wasserbehälter. Ebenso wie eine jüngere Frau, die hinter ihr steht und ihr zuschaut, trägt sie ein Wickeltuch, das über ihrer linken Körperhälfte liegt und ihre rechte Schulter frei lässt. Ihre Füße sind nackt.

Abbildung 15: Illustration des Artikels »Wasser im Haushalt« 1932

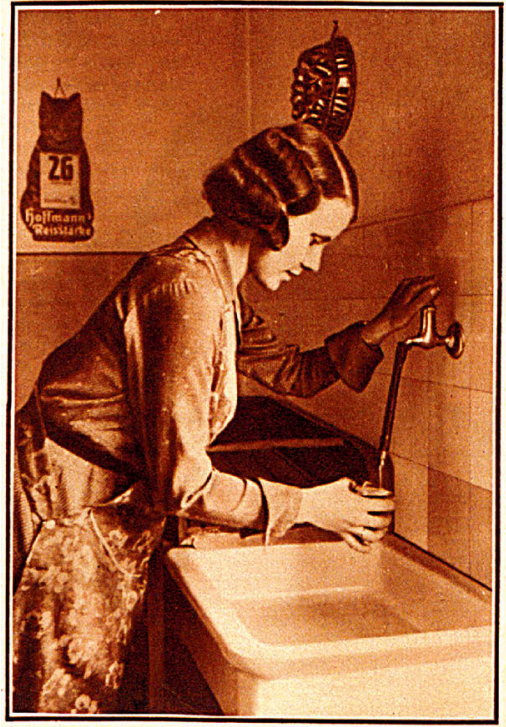

Go felbjtberitänolid unb bequem bezieben woir in uniern șüden Das quellfrilde Trintwafler, und erft, wenn wir im Süben wailierarme (5ebiete Durd)ibanbern, tommt uns dum Betwu[st [ein, wie toftbar diejes $\mathfrak{N a f}$ ift. (Whot. E. Eteimie, 3ultid.)

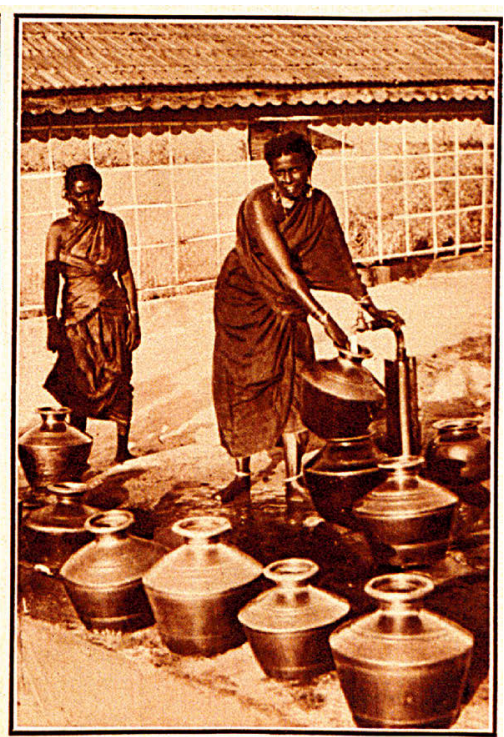

Sm Drient ift eine folde פafferteitung Durd Mobr unb \$ałnen felten. Meift wirb Das Waffer aus 3iebbrumnen emporgegogen. Dft genug ift es (Afmutig und sum Trinten unbraudbar. Eine Qeitung, mie fie

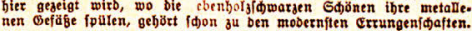

Quelle: Schweizer Illustrierte Zeitung 1932(6)

Im Hintergrund ist die Wand eines einfachen einstöckigen Hauses erkennbar. Die Frau blickt direkt in die Kamera und lächelt zurückhaltend. Obwohl die Protagonistinnen auf beiden Fotos dieselben Tätigkeiten ausführen, arbeiten die Bilder mit einer Gegenüberstellung: die Frau in der Küche und die Frau draußen, das durchsichtige Glas und der schwere dunkle Krug, die modische Kleidung und das Wickeltuch, der zeitgemäße Haushalt mit seiner modernen Infrastruktur und das einfache Haus, das eine rudimentäre Ausstattung nahelegt.

Die Bildlegende treibt die in den Bildern angelegte Dichotomisierung weiter. Die Bildunterschrift des zweiten Fotos lautet: »Im Orient ist eine solche Wasserleitung durch Rohr und Hahnen selten. Meist wird das 
Wasser aus Ziehbrunnen emporgezogen. Oft genug ist es schmutzig und zum Trinken unbrauchbar. Eine Leitung, wie sie hier gezeigt wird, wo die ebenholzschwarzen Schönen ihre metallenen Gefässe spülen, gehört schon zu den modernsten Errungenschaften.«Hygiene, Sauberkeit und Gesundheit sind das zentrale Moment, das die Welt der weißen und diejenige der Schwarzen Frau voneinander unterscheidet. Zudem wird auch an dieser Stelle die Schwarze Frau über den Topos der Hygiene mit der Vorfahrin der weißen Frau verbunden: Die »primitiven Brunnenanlagen [...] als Herde gefährlicher Epidemien« der historischen Schweizerinnen wecken Assoziationen mit den Ziehbrunnen im Orient, deren Wasser oft »schmutzig und zum Trinken unbrauchbar« sei.

Der eingeschränkte Zugang zu einer Technologie an einem unbekannten, ärmlichen und exotisierten Ort (der Text spricht vom Orient, während das Bild eine ostafrikanische Szene zu zeigen scheint) macht ersichtlich, wie >selbstverständlich und bequem < der Umgang mit Wasser ist, über den die moderne Schweizer Hausfrau verfügt. Erst die Differenz zur Frau im >Orient< lässt die Schweizer Hausfrau als begünstigt erscheinen: Ihre Küche mit dem Kalender und der Kuchenform an der Wand kann in eine moderne Zeitrechnung eingeordnet werden und sich so von der Lebenswelt der Schwarzen Frau absetzen, die unentschieden zwischen Draußen und Drinnen, Vormoderne und Moderne changiert. Sie lebt nicht im Freien, wie die Schwarzen Menschen in der Electrolux-Werbung (vgl. Abbildung 14), aber ihr Haus ist simpel und der Zugang zu einer rudimentären Technik zwingt sie dazu, Handlungen im Freien zu verrichten, welche die Schweizer Hausfrau im Inneren des Hauses ausführen kann.

Die Unterscheidung von Innen und Außen ist dabei höchst bedeutsam, denn die Herstellung eines privaten sinneren<, vom öffentlichen >äußeren abgegrenzten Raum ist zentral für die moderne Geschlechterordnung. Bedeutsam ist auch die Herstellung von Weißsein durch das Othering: Die Bezeichnung der einen Frau als >ebenholzschwarz< führt eine Differenz zum hell ausgeleuchteten Gesicht der anderen Frau ein, die weiß erscheint, ohne als weiß bezeichnet werden zu müssen. Das Othering der nicht-weißen Frau macht ersichtlich, dass die Stilisierung der modernen Schweizer Hausfrau ganz wesentlich im Register des Weißseins erfolgte. 


\section{Weisse Weiblichkeit in der Werbung}

Die Deutschschweizer Illustrierten der frühen 1930er Jahre enthielten unzählige Werbeanzeigen für Parfüm, Seife, Zahnpasta, Sonnencreme, Shampoos, Enthaarungscreme und Kosmetika. Auffallend helle Haut wechselte sich dabei ab mit einem sonnengebräunten Teint. Während perlweiße Haut meist mit Luxus und Häuslichkeit in Verbindung gebracht wurde, stand die gebräunte weiße Haut für einen gesunden bürgerlichen Lebensstil, zu dem Freizeit, Sport und frische Luft gehörten. Viele Inserate für Sonnenschutzmittel zeigten Frauen beim Skifahren oder Tennisspielen und versprachen eine "gesunde sonnengebräunte und doch samtweiche Haut «199 oder eine »wundervoll bronzene Hauttönung « ${ }^{200}$. Während braune Haut in gewissen Kontexten auf Arbeiterinnen, Bäuerinnen oder rassifizierte Figuren wie Fahrende verwies, erschien sie im Kontext der Werbung als Spielart eines bürgerlichen Weißseins.

Viele Anzeigen verbanden die helle Haut einer Frau mit Stil und Eleganz, während andere den braunen Teint mit geröteten Wangen als Ausdruck von Vitalität propagierten. Diese Ansicht korrespondierte mit zeitgenössischen Vorstellungen einer gesunden Lebensführung, die der sportlichen Betätigung an der frischen Luft eine wichtige Rolle für die >Volksgesundheit< einräumten. Bereits seit dem Fin de Siècle galt die gebräunte Haut als Zeichen von Erholung, Gesundheit und einer privilegierten Lebensweise. ${ }^{201}$ Unter dem Nationalsozialismus wurde die Bräunung der Haut verstärkt mit der >Rassenfrage< verknüpft. So wurde, wie Niklaus Ingold zeigt, im Umfeld des Nudisten Hans Surén heftig über die Frage debattiert, ob der sonnengebräunte Teint als Merkmal des >germanischen Volkskörpers< gelten konnte oder ob die Praktiken des Sonnenbadens zur (gefährlichen) Aufweichung der >Rassengrenzen < führten. ${ }^{202}$

Die Unterscheidung zwischen einer weißen Haut, die sich bräunen kann, und einer nicht-weißen Haut ist 1935 auch Thema auf der Kinderseite der Zürcher Illustrierten Zeitung. Der Artikel stellt das Schulmädchen Susettli vor, das afrikanischer Herkunft ist. Im Folgenden wird ausführlich

199 | Inserat in der Zürcher Illustrierten, 1932(29).

200 | Inserat in der Zürcher Illustrierten, 1932(20).

201 | Ingold 2015, 184.

202 | Ingold 2015, 207. 
beschrieben, wie es sich durch seine Hautfarbe von den Mitschülerinnen unterscheidet: »Nur im Sommer, da ist der Unterschied zwischen ihm und den andern am kleinsten. Da sitzen die meisten Kinder sonnengebräunt in den Bänken. Nur die Stubenhocker und Bücherwürmer sehen noch richtig aus wie $>$ Weiße $<.{ }^{203}$ Im Sommer vermindert sich demnach der Unterschied zwischen den weißen Kindern und dem Schwarzen Kind, ohne dass er deswegen verschwindet. Dass die einen Kinder ihre Hautfarbe nicht ändern und noch immer aussehen wie >Weißeく, wird kritisch konnotiert; ihr Weißsein entspricht der bleichen Haut der Stubenhocker, denen die frische Luft fehlt. Entscheidend aber ist die Unveränderlichkeit der Schwarzen gegenüber der weißen Haut: Susettli bleibt in dieser Darstellung immer gleich Schwarz, während sich die Haut der weißen Kinder mit der Sonneneinstrahlung verändert und den Jahreszeiten anpasst. Die Schwarze Hautfarbe ist die andere Hautfarbe; sie stellt den statischen Referenzpunkt zum wechselnden Teint der weißen Kinder dar, die gerade durch diesen Kontrast auf differenzierte Weise weiß gemacht werden können.

Auch ein Inserat von 1935 (vgl. Abbildung 16) zeigt, wie koloniales Othering eingesetzt wird, um weiße Weiblichkeit herzustellen. Es wirbt für die Kosmetikreihe Khasana und zeigt das Konterfei einer lächelnden weißen Frau, hinter der das ernsthaft dreinblickende Gesicht eines dunkelhäutigen Mannes erkennbar ist. ${ }^{204}$ Mehrere Kennzeichen, insbesondere der Federschmuck und sein stark bemaltes Gesicht, weisen ihn als >Indianer< aus, eine zeitgenössische Figur des exotisierten Fremden. ${ }^{205}$ »Kriegsbemalung?« steht in dicken Lettern unter dem Bild. Der Text erläutert: »Die sollte der Kulturmensch den wilden Völkern überlassen. Die Zeiten, in denen sich Frauen und Mädchen auffallend Lippen und Wangen bemalten, sind auch vorüber. Stattdessen frischen sie heute ihre Gesichtsfarbe mit Khasana-Superb-Creme unauffällig auf, die natürliches Rot aus den Wangen hervorzaubert.« Die Werbung richtet sich an den Kulturmenschen, allerdings - das wird im zweiten Satz deutlich - an den weiblichen Kulturmenschen, nämlich an Frauen und Mädchen. Der offene und kecke Blick der Frau im Vordergrund scheint die Betrachterin zu adressieren und $\mathrm{zu}$ besagen: >So kannst du aussehen, wenn du dich mit Khasana schminkst<. Dieses Spiel wird aber unterbrochen durch den Titel

203 | O.V.: "Kleine Welt«, in: Zürcher Illustrierte 1935(38).

204 | Inserat in der Schweizer Illustrierten Zeitung 1935(42).

205 | Vgl. Grabbe 2012 und Coulthard 2014. 
>Kriegsbemalung und den düsteren Blick des Mannes, der sich aus dem Hintergrund dazwischenschiebt.

Abbildung 16: Inserat für Khasana-Kosmetik 1935

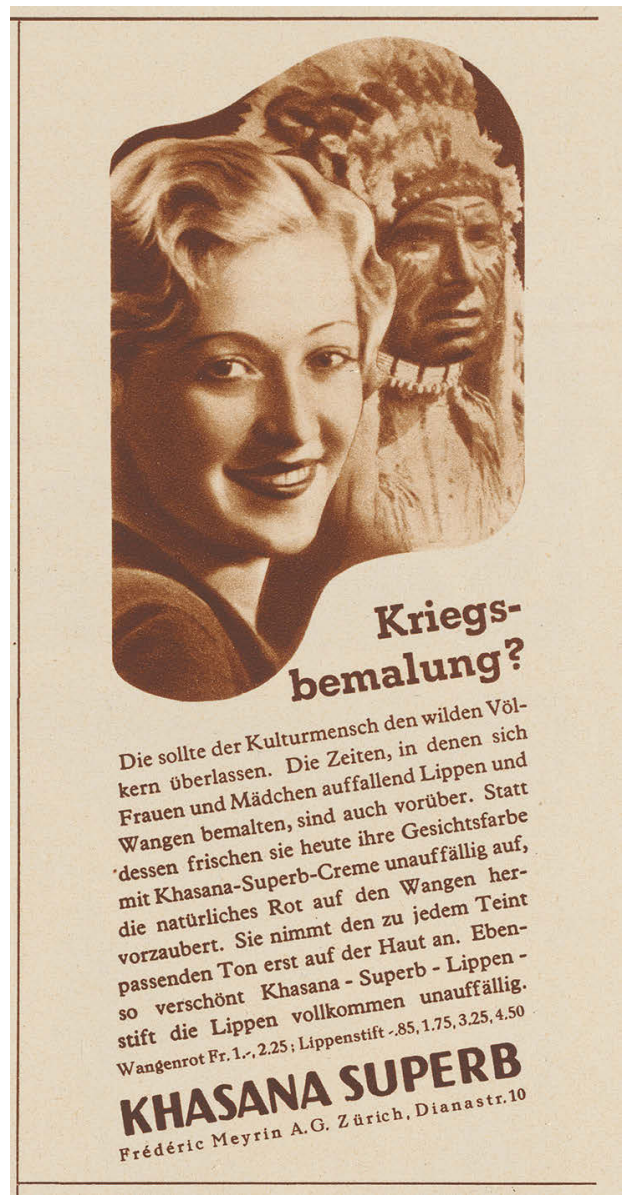

Quelle: Schweizer Illustrierte Zeitung 1935(42)

Im Unterschied zum Kulturmenschen steht der >Indianer< für die Zugehörigkeit zu den >wilden Völkern<. Wie der Text deutlich macht, zeichnet ihn gerade sein artifizielles Aussehen aus: das Tragen von Schmuck und die auffällige Kriegsbemalung. Ziel des weiblichen Kulturmenschen ist im Gegensatz dazu die kunstvolle Herstellung eines natürlichen Aussehens. Die wei- 
ße Frau >frischt $<$ ihre Gesichtsfarbe mit einem Produkt auf, das ihre Wangen >natürlich< rötet. Damit wird eine Dialektik von Natur und Kultur angesprochen, gemäß der die weiße Frau eine sittliche, gezähmte und ästhetisch ansprechende Natur in der Kultur repräsentieren kann. Der Wilde - ernst, kriegerisch, maskenhaft - versinnbildlicht diesen Prozess als Kontrastfigur. Nicht weil er sich nicht zu schmücken weiß, befindet er sich im Zustand der Wildheit, sondern weil sein Schmuck als solcher erkennbar wird.

Damit unterstützt der >Indianer< das Weiß-Machen der Frau in doppelter Weise: Zum einen verunmöglicht es seine angeblich rote Haut, Weißsein durch rote Wangen zu betonen. Zweitens karikiert er als Mann, der sich schminkt, die hegemoniale Geschlechterordnung: Nicht die männliche Kriegsbemalung, sondern die weibliche Kosmetik charakterisiert den Kulturzustand. Die Schönheit der weißen Frau wiederum richtet sich an eine imaginäre Perspektive, die dem Inserat eingeschrieben ist, ohne dass sie explizit zum Vorschein kommt. Sie kann in Anlehnung an Stuart Hall als >weißes Auge< bezeichnet werden, das zugleich abwesend und alles beherrschend ist, »der ungenannte Standort, von dem aus all diese >Beobachtungen gemacht werden und von dem aus sie alleine einen Sinn ergeben. [...] Das >weiße Auge < befindet sich stets außerhalb des Rahmens - aber es sieht und ordnet alles, was darin ist. ${ }^{206}$ Erst durch den Einbezug dieses unsichtbaren, aber strukturierenden Auges fügen sich die verschiedenen, miteinander verflochtenen Differenzierungsprozesse sinnvoll zusammen: Da ist zum einen das adrette Lächeln der weißen Frau. Es ist auf den weißen Mann ausgerichtet, der durch den weiblichen Blick in seiner privilegierten Position in der heteronormativen Ordnung bestätigt wird. Dass sie sich vom Wilden ab- und dem weißen Mann zuwendet, kann als Zeichen dafür gelesen werden, dass sie für die Fortsetzung einer weißen Genealogie einsteht und damit auch die Zukunft einer weißen Nation garantiert. Damit wird im Bild auch die koloniale Angst gebannt, die weiße Frau könnte der erotischen Anziehungskraft des Wilden verfallen.

Während der Wilde in der Khasana-Werbung eine Abgrenzung vom Zustand des >Primitiven $<$ ermöglicht, der gerade durch die Umkehrung der Geschlechterordnung verkörpert wird, schließen andere Werbeanzeigen an die Figur des edlen Wilden an. So präsentiert die 1935 publizierte Zahnpastawerbung der Firma Siko (vgl. Abbildung 17) das Bild einer Schwarzen Frau mit auffallend großen weißen Zähnen: »Man sagt: >Ein

$206 \mid$ Hall 1989, 159. 
$\mathrm{N}[. .$. gebiss ...< und macht damit ein Kompliment ... denkt natürlich dabei an das Lächeln der Joséphine ... oder Marianne Anderson. Jetzt hat man anerkannt, dass die exotischen Völker ihre blendend weißen Zähne einem gewissen Früchte-Salz zu verdanken haben: dem Weinstein, der alle Mund-Mikroben vernichtet und das Email der Zähne unterhält.« ${ }^{207}$ Die Werbung stellt zuallererst klar, dass der Begriff des $>N$-gebisses< als Kompliment gelesen werden muss, obwohl $>\mathrm{N}-<$ in der kolonialen Kultur auf minderwertige Menschen verweist und das >Gebiss $<$ auf Tiere.

Die Attraktivität der Zähne von Schwarzen Menschen wird mit den beiden berühmten und gefeierten Künstlerinnen Josephine Baker und Marian Anderson unterstrichen, deren Lächeln dem Publikum bekannt ist. Wie Nancy Nenno zeigt, wurde Baker im Berlin der Weimarer Jahre als Darstellerin des >Primitiven $<$, von »Leben, Natur und Wollust ${ }^{208}$ und damit als Gegenfigur zur Zivilisation gelesen. ${ }^{209}$ Schwarze Künstlerinnen verkörperten einen kunstvoll inszenierten Exotismus, der etwa in Bakers berühmtem Bananentanz zum Ausdruck kam. ${ }^{210}$ Gleichzeitig repräsentierte Baker auch die moderne und elegant gekleidete US-Amerikanerin und wurde mit der Verbreitung des Jazz in Europa in Verbindung gebracht. ${ }^{211}$ Diese Mehrdeutigkeiten ermöglichten, mit Baker und Anderson einerseits Berühmtheit und Eleganz ins Spiel zu bringen - viele Kosmetikwerbungen bezogen sich auf bekannte Schauspielerinnen und Sängerinnen. Andererseits erlaubten diese rassifizierten Figuren, einen Bezug zur angeblich robusten Gesundheit und zum scheinbar ursprünglichen Wissen >exotischer Völker< herzustellen. Im Unterschied zu der vorangehend besprochenen Khasana-

207 | Inserat in der Schweizer Illustrierten Zeitung 1935(45).

208 | Nenno 1999, 143. In der Forschung wird betont, dass Baker an dieser Stilisierung beteiligt war. VgI. Nenno 1999, 151f.; Sweeney 2004, $37 \mathrm{ff}$.

209 | Dieses in den 1920er-Jahren gefeierte 'Spektakel des Primitiven ‘ wird bei der Rückkehr von Baker nach Berlin 1928 unter dem wachsenden Einfluss der Nationalsozialisten als entartet angegriffen. In dieser Zeit stand Baker verstärkt für die "die Doppelfunktion des Primitiven als lebensspendend und bedrohlich“ (Nenno 1999, 152). Anders sah die Situation in Frankreich aus: Petrine Archer-Straw liest Bakers Transformation von Animalität zu Eleganz als Legitimation des französischen Kolonialismus (Archer-Straw 2000, 133).

210 | Nenno 1999, $136 \mathrm{f}$.

211 | Nenno 1999, 148f. 
Reklame (vgl. Abbildung 16) weist dieses Inserat auf die Dekadenz und die Zerfallstendenzen moderner Lebensführung hin.

Abbildung 17: Inserat für Siko-Zahnpasta 1935

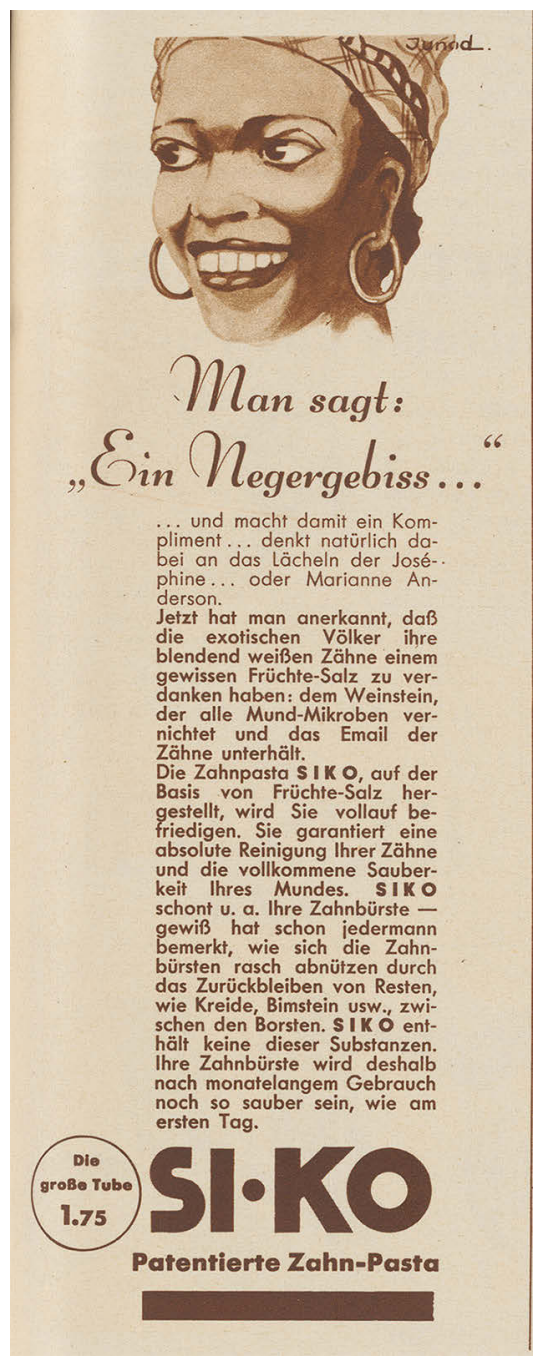

Quelle: Schweizer Illustrierte Zeitung 1935(45) 
Dass gerade die Zähne zum Zeichen des Kulturpessimismus mutierten, ist kein Zufall. Bernhard Schär stellt in seiner Untersuchung zur Zahnmedizin in der Schweiz fest, dass Zahnkrankheiten in der Zwischenkriegszeit als Bestandteil der sozialen Frage galten und zu einem Gegenstand von biopolitischen Abhandlungen und Interventionen gemacht wurden. ${ }^{212}$ Insbesondere Karies wurde als Symptom für eine ungesunde Lebensweise betrachtet, die wiederum auf den mit der Zivilisation einhergehenden Werte- und Sittenverfall zurückgeführt wurde. ${ }^{213}$ Die Siko-Werbung setzte bei dieser kulturpessimistischen Einschätzung an und propagierte die dialektische Überführung einer natürlichen Gesundheitspflege in die moderne Kultur. Angepriesen wird die Entwicklung einer Zahnpasta, die auf Weinstein (Kalziumsalz) basiert und damit auf ein >primitives Wissen< zurückgreift, das dem zivilisierten Menschen abhanden gekommen war und das er sich im Kontext der Moderne erst wieder aneignen muss. Schwarze Frauen wie Josephine Baker und Marian Anderson fungieren als Figuren, die diesen Prozess denkbar machen: Ihre rassifizierten Körper erscheinen als naturbelassene Relikte inmitten einer modernen und urbanen Kultur.

Im Kontext dieser postkolonialen Analysen können nun auch Inserate kritisch betrachtet werden, deren koloniale Bezüge nicht auf den ersten Blick ersichtlich sind. Das lässt sich anhand eines Inserats der Oltener Seifenfabrik Sunlight AG aus dem Jahre 1932 aufzeigen (vgl. Abbildung 18). Abgebildet ist eine junge Frau, die als »Mädchen in Weiss« bezeichnet und, wie es heißt, von »allen bewundert wurde«. Der Grund dafür wird sogleich erwähnt: »Das Kleid war aber auch wunderbar weiss.« Die Fotografie zeigt eine junge Frau in einem einfachen, hellen Kleid auf einem Sofa sitzend, den Blick leicht nach unten geneigt, modisch frisiert, mit einer Perlenkette. Sie wirkt wie eine scheuere Version der Frau in der Khasana-Werbung (Abbildung 16) und eine jüngere Variante der abgebildeten Hausfrau im Bericht zur Wassergewinnung (Abbildung 15).

Der Text besagt: »Es ist nicht immer die Frau mit einem pikanten Gesicht, die Blicke auf sich zieht. Sehr oft ist es das Kleid, das sie trägt auch das einfachste Kleid - aber dann sieht es eben so duftig und frisch aus, wie man es eben nur mit LUX fertig bringt.« Der Schlüssel zu gesellschaftlicher Anerkennung liegt gemäß dieser Formulierung in einer

212 | Schär 2008b, 102.

213 | Schär 2008b, $103 f$. 
anziehenden, modischen, zugleich aber unbescholtenen und bescheidenen Weiblichkeit: Eine Frau, die ihr Kleid richtig wäscht, die Frische und Wohlgeruch ausstrahlt, erhält gesellschaftliche Anerkennung. Das >weiße Kleid< wird hier zum Zeichen für die Hygiene, den Fleiß und die hauswirtschaftliche Expertise der jungen Frau. Weiß fungiert aber auch als Inbegriff von Schönheit, Reinheit und als Hinweis auf Keuschheit und Jungfräulichkeit. Zugleich korrespondiert die Haut der Frau mit ihrem Kleid: Das weiße Kleid und der weiße Teint ihres Gesichts werden durch den dunklen Hintergrund und ihr dunkles Haar hervorgehoben.

\section{Abbildung 18: Inserat für Lux-Seife 1932}

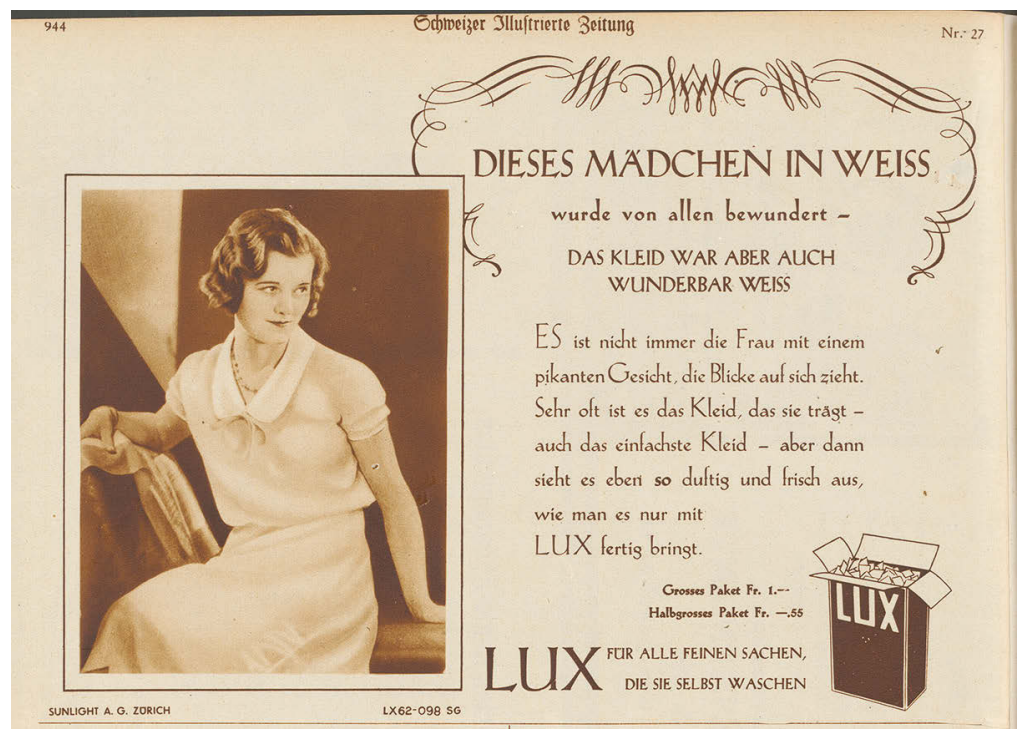

Quelle: Schweizer Illustrierte Zeitung 1932(27)

In einer typischen Verschränkung von Konsumlogik und Sittlichkeitsideal erscheint Weißsein an dieser Stelle als etwas, das begehrenswert ist und performativ erworben werden kann: Durch eine sowohl modische und konsumorientierte als auch eine sparsame und pflichtbewusste Lebensführung gelingt es, zum >Mädchen in Weiß zu werden.

In der Ausrichtung dieses Inserats auf einkommensschwächere Frauen, die sich Seife leisten können und den Einschluss in die ehrbare Gesellschaft durch Heirat erträumen sollen, zeigt sich die Dissemination 
weißer Bürgerlichkeit und die strategische Legierung von Reinheit, Hygiene, Demut, Weißsein und dem Ideal der Hausfrau. Deutlich wird dabei, dass bürgerliche Normen in diesem Prozess umgeschrieben wurden. Die Hausfrau der Mittelschicht konnte sich, anders als die Angehörige des Großbürgertums, nicht auf Bedienstete verlassen und musste mit einem kleinen Haushaltsetat zurechtkommen. ${ }^{214}$ Dafür lockte das bürgerliche Leben mit dem Versprechen der Inklusion: Der soziale Aufstieg wird denkbar. Adrettes Aussehen und gesellschaftliche Aufmerksamkeit, so suggeriert das Inserat, waren nicht mehr nur denjenigen Frauen zugänglich, die über teure Kleider verfügten. Weißsein konnte, so die Botschaft, durch die Verkörperung von Weiblichkeitsnormen wie Reinlichkeit, Gepflegtheit und Bescheidenheit errungen werden. Intelligibel gemacht wurden diese Ideale, wie meine vorhergehenden Analysen zeigten, mithilfe kolonialer Differenzen zum unzivilisierten und unhygienischen Anderen, die dem Weißsein erst die nötigen semantischen Konturen verleihen.

\section{Die Schweizer Hausfrau UND ITHE WHITE WOMAN'S BURDEN}

Das koloniale Othering, das mit der zunehmenden Orientierung der Bevölkerung an einem bürgerlichen Geschlechtermodell einherging, wurde in der Schweiz des 19. Jahrhunderts noch in erster Linie über die Mission vermittelt. Zeitschriften, Kalender und Sammelbilder der Mission, so Harries, waren formativ für den Schweizer Haushalt Ende des 19. Jahrhunderts: »Missionary propaganda brought Africa directly into the intimate recesses of Swiss homes. ${ }^{215}$ Sowohl in privaten als auch in öffentlichen Bereichen wurde Afrika als Folie verwendet, vor deren Hintergrund die Schweizer Gesellschaft ihre Fortschrittlichkeit messen und ihre innere Zerrissenheit überdecken konnte. »Vor allem der >kleine Weiße< konnte das Gefühl haben, ein Mensch zu sein, wenn er die Unterschiede zwischen ihm und dem N[...] kultivierte«, schreibt Mbembe. ${ }^{216}$ Die >Ras-

214 | Vgl. Joris 1990.

215 | Harries 2007a, 4.

216 | Mbembe 2014, 79. 
senlogik lag damit quer zur sozialen und ökonomischen Strukturierung europäischer Gesellschaften.

So gelang es der Basler Mission durch die Einführung der sogenannten >Halbbatzenkollekte<, eine große Zahl von Arbeitern und insbesondere von Arbeiterinnen für das Unternehmen der Mission zu gewinnen. Die proletarischen Beiträge deckten in der zweiten Hälfte des 19. Jahrhunderts regelmäßig ein Viertel der Gesamtausgaben des Missionswerkes ab. ${ }^{217}$ Mit spezifischen, auf die Unterschicht abzielenden Sammelstrategien wurde die Differenz zwischen Gebenden und Nehmenden, Zivilisierten und Unzivilisierten, Christen und Heiden auch in der Arbeiterschaft verankert. Schär schreibt dazu: »Lohnabhängige Fabrikarbeiter sollten zu >Miteigentümern an der Erdoberfläche und damit in den globalen Herrschaftsanspruch eingebunden werden, den die europäische bürgerliche Elite im Zuge des Imperialismus des 19. Jahrhunderts durchsetzte. ${ }^{218}$ Damit wurden nicht nur »cultural conditions for the normalization of imperialism ${ }^{219}$ geschaffen, wie Harries treffend formuliert. Eine solche koloniale Matrix war auch, wie ich im Folgenden zeige, eine wichtige Bedingung für die Durchsetzung der »Nur-Hausfrau ${ }^{220}$ in der Schweizer Gesellschaft.

Zuvor jedoch ist es hilfreich, auf McClintock These zurückzukommen, wonach der häusliche Raum um 1900 rassifiziert und der koloniale Bereich domestiziert wurde. ${ }^{221}$ Wie sah dieser Prozess im Kontext der Schweiz aus? Auf den zweiten Aspekt dieser Dialektik, die Transformation der Kolonie durch die Geschlechternormen der Metropole, kann ich an dieser Stelle nur ein Schlaglicht werfen: Im Zuge der Institutionalisierung ihrer Schulausbildung hatte die Basler Mission um 1860 begonnen, >Mädchenanstalten $<$ zu schaffen und damit die Ausbildung von Mädchen und jungen Frauen in den Missionsgebieten zu kanonisieren. Ulrike Sill bemerkt dazu: »On the Gold Coast, as in Europe, the boarding schools represented a new female space. In their background was the Basel aim of introducing domesticity as a female sphere within the paradigm of

217 | Schär 2015, 75. Vgl. auch Prodolliet 1987.

218 | Schär 2015, 76.

219 | Harries 2007a, 4.

220 | Joris und Witzig 1986, 75.

221 | McClintock 1995, 36. 
modern middle-class femininity.«222 Sill zeigt, wie sich lokale Konzepte und Praktiken an der Goldküste durch den Einfluss der Basler Mission veränderten. Während die Produktion der Bekleidung vor dem späten 19. Jahrhundert eine männliche Domäne war, trugen die Mädchenanstalten, in denen jungen Frauen Nähen und Stricken beigebracht wurde und die Herstellung von Kleidung als >Frauensache < galt, wesentlich zu ihrer Umdeutung als frauenspezifischem Bereich bei. ${ }^{223}$ Sills Arbeit macht deutlich, dass es hierzu komplexer Aushandlungsprozesse zwischen den beteiligten Akteur*innen vor Ort bedurfte - die Entwicklung der Mädchenbildung und ihrer Auswirkungen auf das gesellschaftliche Leben an der Goldküste kann keineswegs als einseitige Durchsetzung von europäischen Normen im afrikanischen Kontext interpretiert werden.

Für die Analyse der Missionsarbeit in der Schweiz gilt es demgegenüber festzuhalten, dass die Herstellung der guten Hausfrau im kolonialen Zusammenhang weitgehend unter Ausblendung dieser Aushandlungsprozesse vor Ort als »theater for exhibiting the [...] cult of domesticity and the reinvention of gender ${ }^{224}$ dargestellt wurde. Dies kann an einem Beispiel aus dem Jahre 1935 veranschaulicht werden. Es handelt sich um einen Bericht aus dem Heidenboten, der Monatszeitschrift der Basler Mission, der von der Missionslehrerin Helene Schlatter zur Mädchenschule in Agogo an der damaligen Goldküste verfasst worden war. Sie vergleicht darin das ordentliche Heim eines ledigen mit dem unordentlichen Haushalt eines verheirateten Lehrers:

"Das Dorf Agogo besitzt eine fünfklassige Schule. Drei christliche Lehrer unterrichten an ihr. Einer derselben ist unverheiratet. So oft wir bei inm eintreten, erfreut uns die große Ordnung im Zimmer, das Tischlein trägt eine saubere Decke, ein Glas mit frischen Blumen steht darauf, die Stühle sind ordentlich, die Bilder an den Wänden hängen gerade, der Hof ist rein gehalten und in einem Beet sind Blumen gezogen. Der Lehrer selbst ist immer sauber und ganz im Anzug, auch wenn man unangemeldet kommt. Ganz anders, wenn wir zum verheirateten Lehrer kommen. Im Hof grüßen uns die beschmutzten Wände, an Drähten hängen unordentliche Tücher und Lappen, die Stühle im Zimmer sind zerbrochen, der Boden mit einer zerrissenen Matte bedeckt. Die junge Frau sitzt auf der Veranda, sie tut

222 | Sill 2010, 287.

223 | Sill 2010, 309ff.

224 | McClintock 1995, 34. 
nichts, immer hat sie zu klagen. Sie hat in Accra eine Schule besucht, Englisch gelernt, aber nicht den Haushalt. ${ }^{225}$

In dieser Darstellung bleibt unklar, wer den Haushalt des ledigen Lehrers besorgt - ist es eine Bedienstete, eine Verwandte oder er selber? Die Beschreibung zielt darauf ab, das Verhalten der Ehefrau des anderen Lehrers zu kritisieren. Obwohl sie eine Schule besucht hatte, lernte sie dabei nicht das, was die Autorin für relevant hält, nämlich die erfolgreiche Führung eines Haushalts. Wie diese auszusehen hat, vermittelt der Text durch die Entgegensetzung der beiden häuslichen Sphären: Die eine ist aufgeräumt und sauber, die andere unordentlich und schmutzig. Deutlich wird dabei auch, wie sehr der ordentliche Haushalt an Attributen eines kleinbürgerlichen und pietistischen Lebensstils gemessen wird: An den Wänden hängen Bilder, und zwar gerade. Auf dem Tisch liegt eine Decke und darauf stehen frische Blumen, die vermutlich im eigenen Garten gezogen worden sind. Die Hausfrau darf nicht klagen und nicht auf der Veranda herumsitzen. Sie hat zu arbeiten und soll dabei guter Dinge sein.

Wie die erfolgreiche Ausbildung einer jungen Frau aussehen kann, beschreibt die Autorin anhand eines weiteren Beispiels: »Da ist Florence, die ganz junge Frau eines Lehrers. Er wünschte sie erzogen >nach bewährter Basler Art<. Scheu und unwissend kam sie zu uns, aber in unheimlichen Wutanfällen schimpft sie hin und wieder, was das Zeug hält. Bald wusch und bügelte sie meine Wäsche, flickte und kochte ganz nett und war mir so eine rechte Hilfe. Heute ist Florence eine glückliche Mutter und sorgsame Hausfrau. ${ }^{226}$ Der Artikel zeigt: Die Beteiligung von Schweizer Missionarinnen am Aufbau eines funktionierenden Schulwesens in Westafrika bestand unter anderem darin, die häusliche Absicherung der Männer, die als Lehrer arbeiteten, zu gewährleisten. Westafrikanische Frauen sollten nach dem Vorbild der Schweiz erzogen werden, deren Arbeitsmarkt den Frauen den Zugang zu qualifizierten und gesellschaftlich anerkannten Arbeiten weitgehend verschloss und ihnen den Platz an der Seite eines Mannes zuwies. Schlatters Text blendet die Frage gänzlich aus, wie Frauen und Männer an der Goldküste ihre Haushaltsführung zu gestalten pflegten oder wie Subsistenzwirtschaft, Erwerbsarbeit und Hausarbeit gemeinhin aufgeteilt waren respektive sich überschnitten.

225 | Schlatter 1935, 25.

226 | Schlatter 1935, 24-25. 
Die Konflikte und Kämpfe um die kulturelle Deutungsmacht über Geschlechternormen, die Sill rekonstruiert, bleiben in diesem Text ausgeklammert und begegnen uns einzig in der Haltung der Lehrersgattin, die sich der guten Haushaltsführung verweigert und sunzufrieden< auf der Veranda sitzt, sowie in den >unheimlichen Wutanfällen der Haushaltsschülerin. Neben den beiden Frauenfiguren - die nachlässige, unerzogene Gattin und die anfänglich aufbrausende und schließlich brave und arbeitsame Ehefrau - sticht die Kooperation mit dem Schwarzen christlichen Mann ins Auge, der seine Frau der Missionarin mit dem Wunsch übergibt, sie nach der >bewährten Basler Art< zu erziehen. Die weiße weibliche Pädagogik scheint sich an dieser Stelle erfolgreich mit dem einheimischen christlichen Patriarchat zu verbinden. In der Tat soll Florence, nachdem sie von der Schweizer Missionarin in die Pflicht genommen wurde, eine glückliche Mutter und sorgsame Hausfrau geworden sein.

Der Artikel im Heidenboten kann mit gutem Grund als Missionspropaganda gelesen werden, die kaum Informationen über die einheimischen Frauen (und Männer) vermittelt. Für die Schweiz bedeutsam ist aber, dass solche Texte eine frauenspezifische imperiale Perspektive eröffneten, indem sie die Tätigkeit der Hausfrau in einen globalen Kontext stellten und ihr eine wichtige Mission zuschrieben. Wie Michael Mann festhält, kann die mission civilisatrice, die sich im französischen Kolonialismus als Motto der Herrschaft in Wort und Tat niedergeschlagen hatte, gewinnbringend auf andere koloniale Kontexte übertragen werden. ${ }^{227}$ Das gilt auch für das vorliegende Beispiel: Die weiße Missionarin und mit ihr ihre Leserin in der Schweiz imaginiert sich als bedeutsame Vertreterin einer Zivilisationsmission, deren Aufgabe in der erfolgreichen Integration aller Frauen in die bürgerliche Geschlechterordnung bestand. Durch die aktive Beteiligung an der Zivilisationsmission tat sich für weiße Frauen ein bedeutsamer Handlungsspielraum auf. Es gelingt ihnen, wie Simone Prodolliet schreibt, als »Machtausübende $\ll^{228}$ darin Anerkennung zu erlangen: »Die Frauen nutzten den ihnen zugeschriebenen Bereich als willkommene Möglichkeit, sich neben der eher eingeschränkten Domäne von Haushalt und Kinderstube ein befriedigendes Arbeitsfeld zu verschaffen. $\ll^{229}$ Weiße Frauen verstan-

227 | Mann 2004, 24.

228 | Prodolliet 1987, 10.

229 | Prodolliet 1987, 160. 
den sich als Trägerinnen der »white women's burden ${ }^{230}$, betraut mit der global bedeutsamen Aufgabe, nicht-weiße Frauen in die richtige Haushaltsführung einzuweihen und sie zu guten Hausfrauen zu erziehen.

In den 1930er Jahren war die Vermittlung von Wissen und Praktiken im Bereich des Haushalts ein wichtiges Handlungsfeld bürgerlicher Frauen. Dies galt sowohl mit Bezug auf die Mission außerhalb Europas wie auch für die sozialen Aktivitäten bürgerlicher Frauen innerhalb der Schweiz. Mit der normativen Stärkung des bürgerlichen Geschlechterund Familienmodells ging für diese Frauen nicht nur eine Einschränkung der Rechte und des Bewegungsraumes einher. Richtet sich der Blick auf die Unterschiede zwischen Frauen in der Schweiz, wird deutlich, dass diese Entwicklung die Stellung bürgerlicher Frauen gegenüber anderen Frauen gefestigt hatte: Sie wurden zu den prädestinierten Erzieherinnen derjenigen Frauen, die noch in die bürgerliche Lebensweise eingeführt werden mussten. Mit anderen Worten: Die Position von Bürgersfrauen, die sich bereits als Missionarsfrauen und Missionsangehörige, als Fabrikantengattinnen, Mäzeninnen und Wohltäterinnen in führenden Positionen hervorgetan hatten, wurde durch die Professionalisierung der Hausarbeit und die Einschränkung der Frauenarbeit in anderen Bereichen zu Beginn des 20. Jahrhunderts erneut gestärkt.

Bereits seit Mitte des 19. Jahrhunderts, so Ute Frevert, reihten sich die bürgerlichen Frauenvereine in die Gruppe der Akteur*innen ein, die sich um die Zivilisierung der Arbeiterbevölkerung und insbesondere der Arbeiterfrauen kümmerten. Dabei ging es nicht nur um die Linderung von Armut und Elend, sondern auch um die Verbreitung bürgerlicher Normen, Verhaltensweisen und Tugenden. ${ }^{231}$ Bürgerlichen Frauen eröffnete sich damit ein »neues, gesellschaftlich geachtetes und politisch gewürdigtes Tätigkeits- und Berufsfeld « ${ }^{232}$. Den Frauenvereinen zur Hebung der Sittlichkeit, die sich im 19. Jahrhundert etwa gegen die Prostitution einsetzten, kam im neu entstehenden biopolitische Regime eine wichtige Rolle zu: Sie führten >Umerziehungsanstalten`wie etwa Heime für >gefalleneく ledige Mütter und ihre Kinder, die bestehende Lücken im

230 | Unter diesem Titel untersucht Antoinette Burton in einem vielbeachteten Artikel die Verwicklung britischer Feministinnen in das imperiale Projekt (Burton 1990).

231 | Frevert 1986, 100.

232 | Frevert 1986, 100. 
öffentlichen Fürsorgesystem füllten, und beteiligten sich damit direkt an der Errichtung neuer sozialer Auffang- und Kontrollsysteme. ${ }^{233} \mathrm{Um}$ gekehrt ermöglichte das soziale Engagement den bürgerlichen Frauen, Einfluss auf politische und gesellschaftliche Veränderungen zu nehmen und Frauen der sogenannten Unterschicht gegenüber eine übergeordnete Position einzunehmen. Joris betont, dass die »offene oder unterschwellige Diffamierung der Unterschichtsfrauen als Unwissende oder Erziehungsbedürftige ${ }^{234}$ gleichsam in die Norm der guten Hausfrau eingeschrieben wurde. Die Aufgabe, Arbeiterinnen zu guten Hausfrauen zu machen, wurde von vielen bürgerlichen Frauen »bereitwillig übernommen, bot sich ihnen doch ein gesellschaftlich und staatlich tolerierter Einstieg in die Öffentlichkeit « ${ }^{235}$. Der Auftrag zur Zivilisierung von Frauen durch Hausarbeit in den außereuropäischen Missionen fand sein Pendant im Erziehungsauftrag im Inneren der Gesellschaft.

Für die Etablierung dieser doppelten Herrschaftsverhältnisse sind die 1930er Jahre bedeutsam, weil sich in dieser Zeit die »vollkommene Identifizierung der >Schweizer Frau $<$ mit der $>$ Hausfrau $\ll{ }^{236}$ vollzog. Einen wichtigen Aspekt dieser Entwicklung stellte die Durchsetzung einer obligatorischen Hauswirtschaftskunde dar. Mit der »Ausdehnung des hauswirtschaftlichen Unterrichts auf alle Frauen«, die seit Ende des 19. Jahrhunderts gefordert wurde, sollte »ein einheitliches, von bürgerlichen Vorstellungen geprägtes Bild schweizerischen Hausfrauentums propagiert werden ${ }^{237}$. Dieses war nicht zuletzt eine Antwort auf die wachsende Arbeiter*innenbewegung. Exponentinnen der 1933 gegründeten Schweizerischen Arbeitsgemeinschaft für den Hausdienst erachteten die Erziehung mittelloser Frauen >zur Tüchtigkeit< als wirksames Mittel gegen die Armut. Die Forderung nach einer verpflichtenden hauswirtschaftlichen Ausbildung entwickelte sich damit zur »Zwangsmassnahme gegen Armengenössige und Randständische « ${ }^{238}$. Die Erziehung von armen und

\footnotetext{
233 | Mesmer 1988, 165.

234 | Joris 1990, 116.

235 | Stalder 1984, 377.

236 | Joris 1990, 115.

237 | Joris 1990, 107.

238 | Joris 1990, 115. Als rarmengenössig، wurde in der Schweiz bezeichnet, wer aufgrund von Armut Anspruch auf Unterstützung (in der Regel durch die Heimatgemeinde) erheben konnte.
} 
nicht-konformen durch bürgerliche Frauen ermöglichte letzteren, eine relevante Rolle in der Herstellung eines Staats einzunehmen, der auf einer Geschlechtersegregation basierte, die Frauen von der direkten politischen Partizipation weitgehend ausschloss.

Es ist eine offene Forschungsfrage, welche Bedeutung den kolonialen Differenzen für die Etablierung, Durchsetzung und Stabilisierung von Herrschaftsverhältnissen zwischen bürgerlichen und nicht-bürgerlichen Frauen in der Schweiz zukam. Zu vermuten ist, dass >Rasse < in diesen Debatten in unterschiedlichen Funktionen zum Einsatz kam, etwa indem Weißsein als gemeinsamer, klassenübergreifender Horizont konstruiert wurde, während die Rassifizierung von Arbeiterinnen, mittellosen und bedürftigen Frauen gleichzeitig dazu diente, soziale Unterschiede herzustellen und sichtbar zu machen. Oder auch, indem der mögliche Ausschluss aus der weißen >Rasse< auch in der Schweiz als Droh- und Sanktionsmittel gegenüber Frauen diente, die als deviant und renitent eingestuft wurden.

\section{KOLONIALER ZiviLisATIONSNEID}

Die halbnackten $>\mathrm{N}$-< in der Electrolux-Werbung (vgl. Abbildung 14), der $>$ Wilde $<$ in der Khasana-Werbung (vgl. Abbildung 15) oder die >Orientalin< im Artikel über das Wasser (vgl. Abbildung 16) bilden eine Schranke zum Unzivilisierten, Vor-Modernen und unvollständig Modernen, die für die Schweizer Hausfrau bedeutsam ist. Diese rassifizierten Anderen fungieren als Außen und als Grenze der Zivilisation: Sie definieren die Position der weißen Frau innerhalb der Kultur, indem sie die Wildheit verkörpern. Anders funktioniert die kulturpessimistische Bezugnahme auf >primitive< Andere: Die Schweizerin erhält nicht die blendend weißen Zähne der Schwarzen Frau, aber sie kann sich eines Produkts bedienen, das ihr durch eine kulturelle Praxis (das Zähneputzen), die auf natürliches Wissen (den Einsatz von Weinstein) zurückgreift, zu einer gesunden Lebensführung verhilft.

In der Werbung begegnet uns eine weitere rassifizierte Konstellation, die auf einem anderen Spiel von Abgrenzung und Identifizierung gründet und die ich im Folgenden als >kolonialen Zivilisationsneid< bezeichnen möchte. Inszeniert wird dabei der neidvolle Blick von >Primitiven < auf die moderne Welt der Hausfrau. Diesem Neid begegnen wir im Inserat, in 
dem der >weiße N-< an Suraja denkt (vgl. Abbildung 4). Er, der im Unterschied zu seiner Frau in der Werbekampagne keinen Namen erhält, wird in diesem Inserat als Ehemann dargestellt, der seine Frau in der gemeinsamen Heimat Afrika zurückgelassen hat. Er befindet sich im Warenhaus und sieht, wie es im Text heißt, täglich die >überwältigende Auswahl an praktischen Bedarfs-Artikeln«, die während der Aktionswochen des Warenhauses Globus in >Hülle und Fülle< angeboten werden. Während die ssparsamen Hausfrauen in der Schweiz all das kaufen können, was sie für einen gut ausgestatteten Haushalt benötigen, entgeht seiner Frau diese Möglichkeit: Sie >sitzt in einem stillen Dorf tief in Afrika und kann von all diesen Herrlichkeiten nichts profitieren<.

Bild und Text vermitteln damit widersprüchliche Gefühle. Genauer: Im Text ereignet sich ein affektiver Bruch zwischen der Wehmut, die durch das Bild gestützt wird, und dem Neid. Denn die fett gedruckten ersten Zeilen $>$... wehmütige Gedanken an Suraja ...< passen zur Gestalt auf dem Bild, die Trauer und Sehnsucht ausdrückt. Diese Vorstellung wird verstärkt durch den nächsten Satz: >Da sitzt er nun [...] und denkt an seine ferne Ehehälfte.< Nahegelegt wird also, dass sich ein Mann, der in der Ferne weilt, nach seiner Frau sehnt. Der Begriff der >Ehehälfte« bringt die Vorstellung mit sich, dass der Betroffene ohne seine Partnerin nur eine shalbe< Person ist. Das Bild beruft sich so auf eine Konzeption der Liebes-Ehe, in der Frau und Mann ergänzend eine Einheit bilden. ${ }^{239}$ Die Beziehung des Schwarzen Mannes zu seiner Frau wird damit in den Kontext eines bürgerlichen, romantischen Liebesideals gestellt. Allerdings wird diese Assoziation im nächsten Satz wieder aufgelöst. Überwältigt ist der Protagonist, so erfahren wir, nicht von der Sehnsucht, die sich aus einer romantischen Liebe speist, sondern vom Anblick der Produkte, zu denen seine Frau keinen Zugang hat. Damit wird er aus der bürgerlichen Liebesvorstellung herausgeschrieben, die den >Zivilisierten« vorbehalten bleibt. Die Vorstellung, dass die Liebe, die im heteronormativen und patriarchalen Arrangement der bürgerlichen Ehe zum Ausdruck kommt, ein Resultat der Zivilisation ist, gehört zur kolonialen Geschichte der Affekte. Wie Jin Haritaworn festhält, gilt Liebe im kolonialen Kontext als Gefühl, zu dem nur zivilisierte Wesen fähig sind: »Racialised and colonised populations are incapable of learning how to love reasonably because they are incapable of escaping their >naturak bodily instincts and impulses such as

239 | Schiebinger 1989, 233. 
hate and anger. $\aleph^{240}$ Dieser Einsatz von niederen Gefühlen, die die höher entwickelten verunmöglichen, findet sich auch im vorliegenden Inserat. Denn es ist nicht die Liebe, sondern der Neid, der vom Mann Besitz ergreift: >Der Neid überkommt ihn - den >weißen $\mathrm{N}-<-$ wenn er die vielen sparsamen Hausfrauen sieht, die mit Kauf-Freude durch den Globus gehen.<

Und Suraja? Die >wehmütigen Gedanken Provinzialität, ihre Immobilität und ihre Unfähigkeit, ein Leben wie die Schweizer Hausfrauen zu führen. Das Konsumieren wird in dieser Darstellung zu einer Aktivität, die eine zivilisierte Weiblichkeit im Unterschied zu Suraja auszeichnet: Ihr sentgehen all diese Vorteile ... sie ist halt zu weit weg vom Globus<. Dieser letzte Satz des Inserats spielt mit der Doppeldeutigkeit des Warenhausnamens. Einerseits befindet sich Suraja, die in einem afrikanischen Dorf wohnt, außerhalb des Einzugsgebietes des Schweizer Warenhauses Globus mit seinen Filialen in der deutschsprachigen Schweiz. Andererseits zeigt die Formulierung an, dass sie sich zu weit weg vom Globus, der Weltkugel oder der globalisierten Welt befindet. Die Vorstellung eines sstillen Dorfs tief in Afrika< abseits des Weltgeschehens beruft sich auf die verbreitete Vorstellung, Afrika sei nicht Teil der modernen, industrialisierten, urbanen und kapitalistischen Welt. ${ }^{24}$ Als Figur zwischen den Welten, die beides kennt - das Schweizer Warenhaus und das stille Dorf in Afrika -, wird der >weiße N-< zum Zeugen für die entscheidende Differenz, die sich im Konsum manifestiert: >Täglich sieht er nämlich < die >überwältigende Auswahk im Warenhaus, die für seine Frau unerreichbar ist.

Das partielle Weißsein des $>$ weißen $\mathrm{N}-\prec$ kann so auch mit seinem Kontakt zur >weißen Welt< in Verbindung gebracht werden - eine weiße Welt, die auf ihn abgefärbt und sein Selbstverständnis durchdrungen hat. Der $>$ weiße $\mathrm{N}-<$ lässt sich in dieser Lesart mit dem Zustand assoziieren, der

240 | Haritaworn 2015, 90.

241 | Eine prominente Variante dieser Vorstellung geht auf den deutschen Philosophen G.W.F. Hegel zurück, der Afrika in seinen Vorlesungen zur Philosophie der Geschichte zum Ort der Geschichtslosigkeit erklärt. Als Ort, an dem Geist und Welt noch ununterschieden sind, kommt Afrika dabei eine paradoxe Bedeutung zu: Als Verortung der Geschichtslosigkeit ist es auch Bedingung der Möglichkeit, den Anfang von Geschichte zu denken. Siehe dazu Purtschert 2006, 47ff. und Purtschert 2010a. 
von Frantz Fanon als »schwarze Haut, weiße Masken ${ }^{242}$ bezeichnet wird. Damit beschreibt er das Ringen Schwarzer Menschen um einen Platz in einer kolonialen Welt, in der Menschsein mit Weißsein gleichgesetzt wird. Dem Schwarzen Subjekt bleibt nichts anderes übrig, als sich an den Maßstäben des Weißseins zu messen: »Für den Schwarzen gibt es nur ein Schicksal. Und es ist weiß. [...] alle seine Anstrengungen zielen darauf ab, eine weiße Existenz zu verwirklichen. « ${ }^{243}$

Die Figur des >weißen N-< verdeutlicht diese dilemmatische Repräsentation von nicht-weißen Menschen in der imperialen Kultur: Er verkörpert einen Schwarzen Mann, der den Zugang zur weißen Welt für sich und seine Frau begehrt. Gleichzeitig wird der >weiße N-< zum Symbol für die Unerfüllbarkeit dieses Begehrens. Seine Wehmut und sein Neid zeigen die Unmöglichkeit auf, tatsächlich in die Grammatik des Weißseins einzutreten: weiß zu werden, der weißen Welt anzugehören, als weiß >durchzugehen<. Diese Undurchlässigkeit der >Rassengrenze< wird auch durch den Kaktus symbolisiert, auf dem sein wehmütiger Blick ruht und der daran erinnert, dass der $>$ weiße $\mathrm{N}-<$ mit dem dornigen und entbehrungsreichen Leben, mit der Dürre, der Natur und der Kargheit der afrikanischen Heimat verbunden bleibt. Gleichzeitig steht der Kaktus für den asymmetrischen Zugriff auf die jeweils andere Kultur: Als exotische Topfpflanze kann er im Warenhaus verkauft und ins koloniale Spektakel des Schweizer Heims eingegliedert werden.

Ein anderes Beispiel dafür, wie das fiktive schwarze Begehren nach einer weißen Welt in der Werbung eingesetzt wird, findet sich in einem Inserat der Firma Henkel für das Waschmittel Persil aus dem Jahr 1934 (vgl. Abbildung 19). Es zeigt die Fotografie eines Schwarzen Kleinkindes, unter der steht: »Ist das wirklich wahr, dass es mit PERSIL so einfach geht? Dann werde ich einmal bei euch in Europa Waschfrau - bei uns in Afrika macht das Waschen schrecklich viel Arbeit.« Die Werbung verspricht weiße und weiche Wäsche für das Baby - »Für Baby-Wäsche nichts anderes als PERSIL! « - und spricht damit junge Mütter an. Umso erstaunlicher ist es, dass das Begehren nach der weißen Zivilisation hier von einem Schwarzen Kleinkind verkörpert wird, dem eigentlich, ebenso wie dem weißen Baby, die frisch gewaschene >Baby-Wäsche< zugute kommen könnte.

242 | Fanon 1980.

243 | Fanon 1980, 145. 
Abbildung 19: Inserat für Persil-Waschmittel 1934

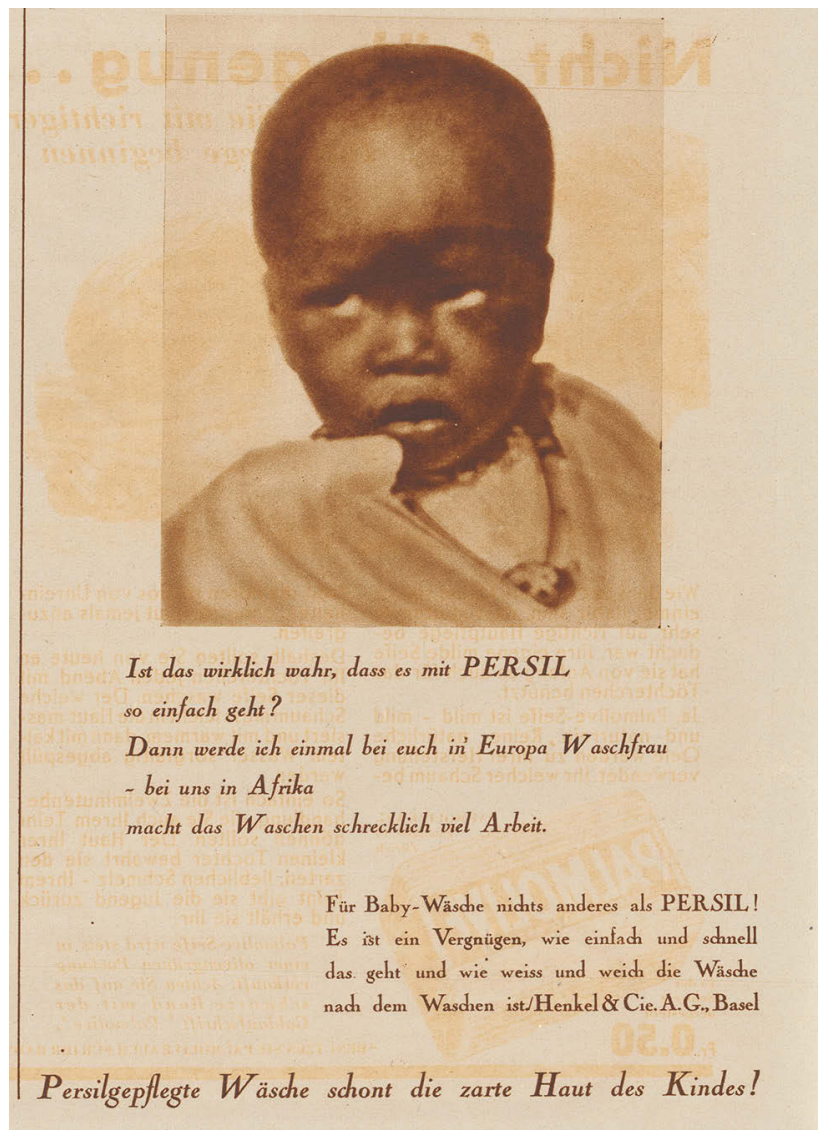

Quelle: Schweizer Illustrierte Zeitung 1934(42)

Das Schwarze Kind wird nicht wie das weiße als pflegebedürftiges Wesen dargestellt, dem nur die besten Produkte zustehen (und das damit, über die Mutter, Adressat der Werbung ist), sondern als zukünftige Arbeitskraft im Dienste von Weißen. Damit wird auch deutlich, dass mit der >zarten Haut des Kindes<, das der >weißen und weichen< Wäsche bedarf, die weiße Haut des weißen Kindes gemeint ist. Der Wunsch des Schwarzen Kindes richtet sich nicht auf die Annehmlichkeit des Produkts, sondern auf die Annehmlichkeit der Arbeit: Es imaginiert sich, obwohl nur wenige Jahre alt, als Waschfrau in Europa. Diese Werbung operiert, wie 
diejenige mit der fernen Suraja, mit der Herstellung einer affektiven Dimension des Haushaltskults. Das Begehren der kolonialen Anderen nach der Konsumwelt Europas ruft auf der Seite der weißen Hausfrau ein Gefühl der Überlegenheit und eine Vorstellung des Glücks hervor, die sich aus dem imaginierten Zivilisationsneid der anderen speisen.

Eine solche kindliche Sehnsucht nach Weißsein, mit der diese Werbung spielt, findet sich auch im bereits erwähnten Bericht auf der Kinderseite der Zürcher Illustrierten von 1935. Der Artikel erzählt die Geschichte des Mädchens >Susettli< aus >Afrika<, das in der Schweiz lebt, damit es »unsere guten Schulen besuche und einmal etwas Rechtes werde $\ll^{244}$. Von dem Mädchen wird berichtete, dass es nicht gerne > N[...]li< genannt wird: »Am liebsten möchte es wie seine Mitschülerinnen aussehen. Manchmal glaubt es fest daran, dass seine Haut mit der Zeit heller werde. Und wenn es im Spiegel merkt, dass es immer noch gleich dunkel geblieben ist, dann wascht und wascht es sich mit Seife. $\ll^{245}$ Der Artikel endet mit der Bemerkung, dass alle, der Lehrer und die Mitschüler*innen, das Kind gerne mögen und »niemand denkt, dass es weniger wert sei, weil es statt einer weissen eine dunkle Hautfarbe mit auf die Welt bekommen hat ${ }^{246}$. Anders als beim >weißen $\mathrm{N}-<$, der die Teilhabe an der Konsumgesellschaft begehrt, wird die Konstruktion eines intrinsischen Begehrens, weiß zu sein, bei Susettli mit dem Wunsch nach Bildung verknüpft, mit der Möglichkeit, in der Schweiz (im Unterschied zu >Afrika - über die genaue Herkunft des Kindes erfahren wir nichts) >etwas Rechtes werden $<$ zu können. Diese Vorstellung knüpft an den Missionsdiskursen an, welche die Dissemination von Bildung und Wissen in die Welt als europäische Aufgabe erachten, für die gerade Schweizer*innen prädestiniert sind.

Der kurze Text gibt einen Einblick in das Leben eines Schwarzen Kindes in der Schweiz der 1930er Jahre. Im Zentrum seiner eindrücklichen Beschreibung steht ein unartikulierter Widerspruch: Zum einen wird erzählt, dass das Mädchen mit dem N-Wort gerufen wird, und dass es dies als unangenehm erlebt. Zugleich versichert der Autor, dass weder Lehrer noch Schulkinder die Hautfarbe zum Anlass nähmen, das Schwarze Kind mit weniger Wertschätzung zu behandeln. Susettlis Wunsch, weiß zu sein, und ihre verzweifelten Versuche, sich weiß zu waschen - die

244 | O.V.: "Kleine Welt", in: Zürcher Illustrierte 1935(38).

245 | O.V.: "Kleine Welt", in: Zürcher Illustrierte 1935(38).

246 | O.V.: "Kleine Welt», in: Zürcher Illustrierte 1935(38). 
>Mohrenwäsche<, der sie sich angeblich selbst unterzieht -, werden damit als ihr inneres Bedürfnis konstruiert. Der Text erzeugt die Fiktion eines Schwarzen Kindes, das sich nichts lieber wünscht, als weiß zu sein, und naturalisiert auf diese Weise seine Sehnsucht nach Weißsein. Die Erfahrungen von Rassismus und Ausgrenzung, die Susettli macht, schimmern zwar im Text durch, werden aber nicht mit ihrem Unwohlsein in Verbindung gebracht. Dass Susettli weiß sein möchte, wird fraglos vorausgesetzt.

In ihrem Buch The Melancholy of Race untersucht Anne Anlin Cheng, wie Rassifizierung in den USA mit dem Begehren nach der weißen Kultur verbunden wird. Sie beschreibt dabei, wie die Bevorzugung des Weißseins gesellschaftlich konstruiert und in der rassifizierten Psyche verankert wird: »White preference [...] travel [sic!] a tortuous, melancholic path of alienation, resistance, aggression, and then, finally, the domestication of that aggression as >love $<{ }^{247}$ Das Schwarze Mädchen, so führt sie am Beispiel eines Romans von Toni Morrison aus, muss nicht nur das weiße Ideal von Weiblichkeit internalisieren, sondern auch die Vorstellung eines Schwarzen Selbst, das vom unerfüllbaren Begehren nach der weißen Weiblichkeit getrieben ist. ${ }^{248}$ Wie Fanon beschreibt Cheng damit die komplexen psychischen Prozesse, die rassifizierte Subjekte durchlaufen müssen, um das Begehren nach Weißsein integrieren zu können, das der weißen Kultur als selbstverständlich gilt. Umgekehrt zeigt Cheng, dass die Konstruktion nicht-weißer Anderer als melancholische Subjekte zur »racial imaginary of white people ${ }^{249}$ gehört: Im Kontext der USA geschieht dies etwa durch die Romantisierung des schwermütigen Sklaven oder des Native American, der bedachtsam und tiefgründig die Zerstörung seiner eigenen Kultur kommentiert. ${ }^{250}$ Die Figur der Melancholie dient dabei zwei Aspekten: Zum einen symbolisiert sie, weil sie sämt-

247 | Cheng 2000, $17 f$.

248 | Cheng 2000, 18.

249 | Dyer 1997, 1.

250 | Cheng deutet racial melancholia، an dieser Stelle als Symptom der weißen Kultur, das die rassifizierten Anderen gleichzeitig verinnerlicht und ausschließt (Cheng 2000, 10). Die Projektion der Melancholie auf den rassifizierten Anderen unterscheidet sich damit von der postkolonialen und imperialen Melancholie, wie sie von Paul Gilroy als "Britain's inability to mourn its loss of empire" beschrieben worden ist (Gilroy 2005, 102). 
liche Anzeichen von individuellem und kollektivem Widerstand tilgt, die Unterwerfung der nicht-weißen Psyche unter den weißen Herrschaftsanspruch. Zum anderen hilft sie dabei, das Unrecht kolonialer Herrschaft unsichtbar zu machen, indem sie deren Folgen zum schicksalhaften Lauf der Dinge erklärt.

Wie lässt sich nun neben Wehmut und Melancholie der Affekt des Neids deuten, der in den erwähnten Quellen eine gewichtige Rolle spielt? Das Begehren der kolonialen Anderen nach der Konsumwelt Europas soll, so meine bereits erwähnte These, auf der Seite der weißen Hausfrau einen Zustand der Erfüllung evozieren, der sich aus dem imaginierten Zivilisationsneid der anderen ableitet. Um diesen Zusammenhängen auf die Spur zu kommen, ist es hilfreich, eine andere historisch bedeutsame Figur des Neids in den Blick zu nehmen, mit der sich die feministische Theorie ausgiebig beschäftigt hat: den Penisneid. In den »Drei Abhandlungen zur Sexualtheorie« verwendet Sigmund Freud den Begriff des Penisneids, um die Position des Mädchens zu charakterisieren. Demnach erkennt bereits das kleine Mädchen, dass der Penis das eigentliche und damit einzige Genital ist, und anerkennt damit seine Mangelhaftigkeit ${ }^{251}$ (ohne dass diese begründet würde, wie Irigaray zeigt ${ }^{252}$ ). In den »Vorlesungen zur Einführung in die Psychoanalyse« beschreibt Freud später, wie die sexuelle Entwicklung des Mädchens, das in dem Moment zum Mädchen wird, in dem es seine »Penislosigkeit « ${ }^{253}$ entdeckt, vom Wunsch nach dem Penis geprägt bleibt. Im Spiel mit der Puppe lernt das Kind, sein Begehren nach dem Penis in den Wunsch nach einem Kind zu transformieren.

Bedeutsam ist, dass mit dieser Übersetzung die Inkorporierung des Mangels in die Subjektivierung des Kindes einhergeht: Das Mädchen lebt von nun an mit dem Wissen, dass es den Penis immer nur indirekt, über den Mann, besitzen kann. Diese unauflösbare Verflechtung von Erfüllung und Aufschiebung des Peniswunsches zeigt sich im Szenario des größten Glücks, das die Freud'sche Theorie der Frau bereitstellt: in der Geburt eines Sohnes. »Das Glück ist groß, wenn dieser Kinderwunsch

$251 \mid$ "Es ist sofort bereit, [das Genitale des Knaben] anzuerkennen, und es unterliegt dem Penisneide, der in dem für die Folge wichtigen Wunsch, auch ein Bub zu sein, gipfelt." (Freud 1999a, 96)

252 | Vgl. Irigaray 1980.

253 | Freud 1999c, 136. 
später einmal seine reale Erfüllung findet, ganz besonders aber, wenn das Kind ein Knäblein ist, das den ersehnten Penis mitbringt. ${ }^{254}$ Aus dieser spezifisch weiblichen Verfasstheit, die auf den unerfüllbaren Wunsch nach dem Penis zurückgeht, leitet Freud eine generelle weibliche Disposition zum Neid ab: »Nicht dass diese Eigenschaften bei Männern vermisst würden oder dass sie bei Frauen keine andere Wurzel hätten als den Penisneid, aber wir sind geneigt, das Mehr bei den Frauen diesem letzteren Einfluss zuzuschreiben. ${ }^{255}$

Feministische Kritikerinnen antworteten auf Freuds Theorie des Penisneids mit seiner gesellschaftlichen und historischen Kontextualisierung. Demnach erhalte, wie Simone de Beauvoir schreibt, »der kindliche Peniswunsch im Leben der erwachsenen Frau nur dann Bedeutung, wenn sie ihre Weiblichkeit als Verstümmelung empfindet: dann möchte sie sich das männliche Glied, das alle Privilegien der Virilität verkörpert, aneignen « ${ }^{256}$. Beauvoirs Beschreibung schwankt in existenzialistischer Manier zwischen dem Plädoyer für eine entschiedene Ablehnung des Penisneids (die erwachsene Frau hat die Möglichkeit, ihre Weiblichkeit nicht als Verstümmelung zu empfinden) und einer Analyse der gesellschaftlichen Bedeutung männlicher Herrschaft (der Penis repräsentiert die männlichen Privilegien, mit denen sich Frauen unweigerlich konfrontiert sehen).

20 Jahre später arbeitete Betty Friedan diesen zweiten Aspekt, den strukturellen Charakter des Penisneids, weiter aus. Wenn Freuds biologische Begründung des Penisneids auf kulturelle Bedingungen zurückgeführt wird, so schreibt sie, lässt sich der Penisneid als rationale Reaktion von Frauen auf ihre Ungleichbehandlung deuten: »Victorian culture gave women many reasons to envy men: the same conditions, in fact, that the feminists fought against. $\ll^{257}$ Nochmals ein Jahrzehnt später legt Luce Irigaray eine mimetische Lektüre von Freuds Sexualtheorie der Frau vor, die deren patriarchale Zirkelschlüsse in minutiöser dekonstruktiver Kleinarbeit aufzeigt.

Für die vorliegende Studie ist Irigarays Feststellung bedeutsam, wonach die Einführung des Penisneids gewisse Entlastungen im psycho-

254 | Freud 1999c, 137.

255 | Freud 1999c, 134.

256 | Beauvoir 1994, 882. Für die feministische Diskussion des Neids vgl. Burke 1998 und Gallop 2006.

257 | Friedan 2010, 92. 
analytischen Rahmengefüge zur Folge hat. Dazu gehöre die männliche Furcht, »das Geschlecht der Frau zerstört, es kastriert zu haben «. ${ }^{258}$ Diese Furcht wiederum ist verknüpft mit Schuldgefühlen und der Angst, »daß sie, als mütterliches Substitut, das gleiche mit seinem Penis-Körper machen könnte, ebenfalls aus Hunger oder zur Vergeltung « ${ }^{259}$. Irigaray unterzieht an dieser Stelle die psychoanalytische Theorie einer psychoanalytischen Lektüre. Die Figur des Penisneids beruht demnach auf einer Abwehr der Gefühle, welche die patriarchale Herrschaft hervorbringt: Furcht, Schuld und Angst. Furcht davor, die andere zerstört zu haben, Schuldgefühle, die aus der eigenen gewaltvollen Herrschaft erwachsen, und die Angst vor einer Umkehrung der Verhältnisse, davor also, selbst zur Frau gemacht und damit verstümmelt zu werden.

Beauvoir und Friedan deuten den Neid somit als rationale Reaktion von Frauen auf die Positionierung in einer patriarchalen Ordnung, die ihnen qua Geschlecht den Zugang zu entscheidenden öffentlichen Positionen abspricht. ${ }^{260}$ Irigaray geht einen Schritt weiter, indem sie die Entstehung des Penisneids nicht bei den Frauen verortet, sondern diesen als Manöver der patriarchalen Kultur beschreibt. Der Neid der Anderen wird dann zu einer »Projektionsmöglichkeit ${ }^{261}$ für die verdrängten Gefühle von Schuld und Angst, die mit der patriarchalen Herrschaft einhergehen.

\section{Schwarzer Neid aUf Weisses Glück}

Wenn wir diese feministischen Lektüren auf einen postkolonialen Kontext übertragen, dann wird der Zivilisationsneid lesbar nicht als Neid derjenigen, die von der Zivilisation ausgeschlossen sind oder sich nur an ihren Rändern aufhalten dürfen, sondern als Fiktion derjenigen, die sich

258 | Irigaray 1980, 72.

259 | Irigaray 1980, 72 [Hervorhebung im Original].

260 | Die feministische Auseinandersetzung mit dem Neid nimmt damit eine andere Gestalt an als diejenige, die inn in kulturkritischer Tradition in einer eigenartigen Ambivalenz als kulturbildende Kraft und als gewichtigen Grund für die degenerierenden Tendenzen der Kultur betrachtet. Vgl. etwa Nietzsche, der das Ressentiment mit Schwächung, Verweiblichung und Verweichlichung gleichsetzt (Nietzsche 1999). Vgl. dazu auch Purtschert 2006.

261 | Irigaray 1980, 72. 
beneidet wissen wollen. Damit lässt sich der koloniale Zivilisationsneid als weiße Fantasie entziffern, der ganz bestimmte Aufgaben zukommen. Er kann zum einen als Entlastungsbewegung interpretiert werden, welche die Position der weißen Frau stärkt und mit >zivilisatorischem Kapital bestückt. Eine erste solche Bewegung findet sich in der Konsumkultur. So wie Freud behauptet, der Penisneid lasse sich mit der Geburt eines Sohnes partiell auflösen, so kann die Konsumgesellschaft als Angebot an die Frauen für eine indirekte Teilhabe an gesellschaftlicher Macht gelesen werden. Der Frau blieb es zu Beginn des 20. Jahrhundert zwar weitgehend verwehrt, sich an der Entwicklung, Planung und Regierung der Gesellschaft und des Staates zu beteiligen. Die weiblich konnotierte Sphäre der Verwertung, Pflege und Reproduktion aber wurde im Kontext der Konsumkultur entscheidend aufgewertet.

Einkaufen, so schreibt Janeen Baxter, »includes both purchasing goods for immediate consumption, such as groceries and other household goods, as well as consumption as a means of identity formation and a symbolic indicator of lifestyle, class position, and status « ${ }^{262}$. In den 1930 er Jahren entstand eine neue Konsumkultur, welche die Konsumentinnen und ihre Bedürfnisse aktiv einzubeziehen suchte. Damit wurde die Vorstellung einer Konsumentin hervorgebracht, welche die Entwicklung von Produkten mit beeinflussen konnte. Aufkommende Konsumbewegungen entwickelten zudem Formen der politischen Partizipation: »[F]emale consumer activists were turning consumption into a new realm of politics. ${ }^{263}$ Die Position als Konsumentin eröffnete derart einen limitierten Zugang zu einer männlich dominierten Öffentlichkeit: »[I]n their capacity as >consumers<, women claimed the responsibility and right to intervene in masculine territories such as work, trade unionism, and local and national politics. ${ }^{264}$ Für die Schweiz besonders bedeutsam war der >Bieler Milchkrieg<von 1930/31. Er wurde von dem neu gegründeten Hausfrauenverein Biel geführt, der die Verteuerung von Milch bekämpfte und die Wiedereinführung der Hauslieferung forderte. ${ }^{265}$ Wenige Jahre später, 1935, schlossen sich die Hausfrauenvereine in einem nationalen Verband zusammen. Unter dessen Initiative wurde 1948 an der ETH

262 | Baxter 2011, 472 [Hervorhebung PP].

263 | Cohen 2003, 36.

264 | Sassatelli 2011, 633.

265 | Joris 1990, 113. Vgl. auch Ziegler 1998. 
Zürich ein Schweizerisches Institut für Hauswirtschaft gegründet. Joris hält dazu fest: »Mit der Schaffung dieser Institution bestätigte sich die öffentliche Anerkennung des gesamtgesellschaftlichen Nutzens der Hausarbeit, der bereits mit dem Einbezug von Frauenvereinen in die Sicherung der Kriegsernährung im Rahmen der Landesverteidigung bezeugt worden war.« ${ }^{266}$ Mit der Konsumgesellschaft entstand ein halböffentlicher Bereich, der es Frauen erlaubte, über Umwege und in sehr begrenztem Umfang politisch aktiv zu werden, Zugang zu wissenschaftlichen Tätigkeiten und zur Berufsbildung zu finden und sich gleichzeitig am Aufbau der Nation zu beteiligen.

Wie ich in diesem Kapitel eingehend diskutiert habe, lassen sich die Vorstellungen von Glück, Aufstieg und Partizipation, die mit Konsum verbunden wurden, nicht von der kolonialen Rahmung der Konsumkultur ablösen. Figuren wie der >weiße N-<, der voller Neid auf die weiße Schweizer Hausfrau blickt, lassen deren Position als erstrebenswert erscheinen. Der in der Werbung imaginierte Neid des Schwarzen Anderen entzündet sich am Konsum von >Weißen Waren $<$ und bestärkt damit die Vorstellung, dass Weißsein, Sauberkeit, Hygiene und der Zugang zum Massenkonsum wünschenswert und gleichzeitig ein Vorrecht der weißen Welt sind. In seiner Ausrichtung auf die aufstrebende Mittelschichtsfrau konstruiert dieses Narrativ eine Sphäre begehrenswerten Weißseins, die nicht auf die Oberschicht reduziert bleibt. Nicht der luxuriöse Lebensstil der Großindustriellen weckte den Neid des >weißen N-<, sondern die Verwendung von >praktischen Bedarfs-Artikeln nicht die schwerreiche Bürgersfrau beneidet er, sondern die >vielen sparsamen Hausfrauen<.

Damit wird eine Idee von Weißsein als »promise of belonging ${ }^{267} \mathrm{er}$ zeugt, welche die ökonomische Dimension des Konsums mit dem gesellschaftlichen Prozess der Verbürgerlichung und der kolonialen Ordnung verknüpft. Der Neid operiert an dieser Stelle als imaginierter Affekt des kolonialen Anderen, der wiederum die Gefühlswelt der weißen Hausfrau konturiert: Es ist der Neid des >weißen N-<, der die >Kauf-Freude < der sparsamen Hausfrauen, also das Glück, das sich mit dem Konsum einstellen

266 | Joris 2015.

267 | Hund, Pickering und Ramamurthy 2013, 15. 
soll, sichtbar werden lässt. ${ }^{268}$ Dabei wird das Register der Pflicht - die Hausfrau muss sparsam sein und den Haushalt mit dem Notwendigen versorgen - mit dem des Glücks und der Erfüllung verschaltet. Genau diese Verbindung stiftet der neidische Blick des Schwarzen Anderen, der auf diese Weise dazu beiträgt, die Figur der glücklichen Hausfrau hervorzubringen. Wie Sara Ahmed in The Promise of Happiness schreibt, ermöglicht es diese Figur, die unbezahlte und gesellschaftlich kaum anerkannte Arbeit von Frauen unsichtbar zu machen: »The happy housewife is a fantasy figure that erases the signs of labor under the sign of happiness. ${ }^{269}$

Und welche Rolle kommt der Schwarzen Frau dabei zu? Der >weiße $\mathrm{N}-<$ beneidet die Schweizer Hausfrau im Namen seiner Ehefrau, die in Afrika verortet wird und selbst nicht in Erscheinung tritt. Sie nimmt eine Position am Rande des Sichtbaren ein und kann nur mittels ihres Ehemannes in den Diskurs eintreten. Er verbalisiert an ihrer Stelle den Neid auf die Zivilisiertheit der weißen Frau - einen Neid, den sie, >zu weit weg vom Globus<, wahrscheinlich nicht einmal selbst empfinden kann. Was McClintock für das viktorianische Großbritannien festgehalten hat, gilt auch hier, dass nämlich Schwarze Frauen in der Werbung kaum als Konsumentinnen in Erscheinung traten, »for, in imperial lore, they lag too far behind men to be agents of history ${ }^{270}$. Sie blieben aber nicht nur unsichtbar, sondern nahmen als Gegenbild zur weißen Konsumentin eine bedeutungsstiftende Funktion ein. Die Schwarze Frau steht als nicht greifbare Platzhalterin für das Außen der zivilisierten Welt, die den Ort der weißen Frau zugleich intelligibel und begehrenswert macht.

Wenn wir schließlich Irigarays Verständnis des Neides als Strategie der Entlastung hinzuziehen, dann lässt sich die eigenartige Kombination von Bild und Text in Abbildung 4 neu interpretieren. Der >weiße $\mathrm{N}-<$ fühlt einen Neid, der sich bildlich als Trauer und Melancholie niederschlägt. Er betrauert, dass Suraja >von all diesen Herrlichkeiten nichts profitieren kann<, und bestätigt durch die melancholische Anerkennung ihres Aus-

268 | Eine andere rassifizierte Figur des Neids ist der 'black envy', wie er von Susan Gubar unter anderem mit Bezug auf Norman Mailers ,White Negro، (Mailer 1957) ausgearbeitet worden ist. Damit beschreibt sie die Mystifizierung Schwarzer Männlichkeit durch Weiße, die seit Mitte des 20. Jahrhunderts im US-amerikanischen Kontext verbreitet ist (Gubar 1997, 175).

269 | Ahmed 2010, 50.

270 | McClintock 1995, 223. 
schlusses die weiße bürgerliche und heteronormative Ordnung, zu der sie nicht gehört. Er nimmt die Trennung der Welt in eine zivilisierte und eine unzivilisierte Sphäre hin (obwohl er paradoxerweise zwischen diesen Welten angesiedelt werden muss, um deren Trennung zu erkennen) und damit auch das Verdikt, dass Suraja >halt zu weit weg vom Globus ist<. So wie Freud den weiblichen Penisneid naturalisiert, indem er ihm eine biologische Faktizität unterstellt und damit alle Fragen nach den historischen, sozialen und erkenntnistheoretischen Prämissen dieser Figur aushebelt, kann der Zivilisationsneid des >weißen N-<als Ontologisierung der imperialen Ordnung gelesen werden.

Es ist aufschlussreich, an dieser Stelle auf eine andere Figur des Neides einzugehen, die von Fanon 30 Jahre nach Erscheinen der Globus-Werbung entworfen wurde. In Die Verdammten dieser Erde hält er fest: »Der Blick, den der Kolonisierte auf die Stadt des Kolonialherrn wirft, ist ein Blick geilen Neides. Besitzträume. Aller Arten von Besitz: sich an den Tisch des Kolonialherrn setzen, im Bett des Kolonialherrn schlafen, wenn möglich mit seiner Frau. Der Kolonisierte ist ein Neider. ${ }^{271}$ Fanon beschreibt den Neid in dieser Passage auf ganz andere Weise. Es ist nicht der Neid desjenigen, der sich wehmütig in die Ordnung der Dinge einfügt und sie als gegeben hinnimmt, sondern der Neid desjenigen, der den Platz seines Herren einnehmen will und alles daransetzt, dass ihm dies eines Tages gelingt.

Irigaray schreibt, dass die Freud'sche Figur des Penisneids die Ängste einhegen hilft, welche die männliche Herrschaft mit sich bringt. Zu diesen Ängsten gehört die Vorstellung, »daß sie, als mütterliches Substitut, das gleiche mit seinem Penis-Körper machen könnte, ebenfalls aus Hunger oder zur Vergeltung «. ${ }^{272}$ Hunger und Vergeltung sind gleichfalls zwei Schreckgespenste des Kolonialismus: Dass sich die Unterdrückten im Kampf um ihr Überleben oder aus Rache gegen die Kolonialherren wenden könnten, ist eine Angst, aus der sich Fanons Bild des Neides speist. Der Kolonialisierte blickt voll triebhaftem Begehren auf die Stadt des Kolonialherren und will alles besitzen, was ihm die koloniale Ordnung vorenthält: den Tisch, das Bett, die Frau. Wie der >weiße $\mathrm{N}-<$ richtet auch Fanons Kolonialisierter den Neid auf den Bereich des Häuslichen, aber nicht, um wehmütig feststellen zu müssen, dass ihm ein solches Leben

271 | Fanon 1981, 33.

272 | Irigaray 1980, 72 [Hervorhebung im Original]. 
nicht zusteht, sondern mit dem Zweck, sich ein solches Leben gewaltsam anzueignen. Er verkörpert die Bedrohung durch ein kolonisiertes Subjekt, das nichts anderes im Sinn hat, als die koloniale Ordnung gewaltsam umzustoßen, den Kolonialherren zu beseitigen und sich an seine Stelle zu setzen.

Sowohl der Kolonialherr als auch der Kolonialisierte sind, so kritisiert Oyèrónkẹ́ Oyěwùmí, in diesem Bild des kolonialen Kampfes männlich konnotiert. Was wäre, fragt sie, »wenn es sich beim Einheimischen um eine Frau handelte, was in der Tat oft zutraf? Wie kommen das Neidgefühl und das Begehren, den Kolonialherren abzulösen, [da] zum Ausdruck? Haben Frauen überhaupt solche Gefühle?« ${ }^{273}$ Oyěwùmí weist auf eine bedeutsame Leerstelle von Fanons Analyse hin, die in androzentrischen Prämissen befangen bleibt. Während weißen Frauen ein sexualisierter Objektstatus im Kampf zwischen Männern zugewiesen wird, kommt die Schwarze Frau gar nicht erst in den Blick. Das Bild vom kolonialen Neider macht die Schwarze Frau unsichtbar und degradiert die weiße Frau zum patriarchalen Statussymbol.

Die Begrenztheit von Fanons Analyse liegt somit darin, dass er in einem patriarchalen Deutungsrahmen verharrt und dabei rassistische Stereotype Schwarzer Männlichkeit fortschreibt. Für die Auseinandersetzung mit der Figur des >weißen N-< ist Fanons Darstellung aber darum hilfreich, weil er ein bedeutsames Phantasma des Kolonialpatriarchats vor Augen führt. Denn durch die Figur von Fanons kolonialem Neider lässt sich die weiße Angst vor dem Schwarzen Aufstand erklären. Sie speist sich aus der Vorstellung eines Kolonisierten, der sich mit der Herrschaft nicht abfindet und nur darauf wartet, die Verhältnisse umzustürzen. »Der Kolonisierte ist ein Verfolgter, der ständig davon träumt, Verfolger zu werden. ${ }^{274}$ Der stärkste Ausdruck dieses Begehrens, selbst zum Herren zu werden, zeigt sich im Wunsch, sich dessen Frau zu bemächtigen. In der >pornotropischen< Logik des Imperialismus, in der sich koloniale Eroberung und gewalttätige Sexualisierung verbinden, spielte die Vorstellung des bedrohlichen Schwarzen Mannes eine zentrale Rolle. Sie wurde zum Symbol von Aufstand, Bedrohung und unerlaubter Grenzüberschreitung. Wie Angela Davis zeigt, wurden in der Post-Sklaverei-Gesellschaft der USA Lynchmorde mit dem Vorwurf der sexuellen Gewalt von Schwar-

273 | Oyěwùmí 1997, 219.

274 | Fanon 1981, 44. 
zen Männern an weißen Frauen begründet, während die Vergewaltigung Schwarzer Frauen durch weiße Männer als deren stillschweigend zu akzeptierendes Vorrecht galt. ${ }^{275}$

Fanons kolonialer Neider und der melancholische >weiße $\mathrm{N}$-< markieren den affektiven Abgrund zwischen Zähmung und Enthemmung, Beherrschung und Widerstand, der für das Kolonialpatriarchat ausschlaggebend ist. Dabei stellt die gänzlich ungefährliche Figur des melancholischen >weißen $\mathrm{N}-<$, der die globalen Ungleichheiten lediglich schwermütig zur Kenntnis nimmt, gleichsam eine Antithese zum revolutionären Subjekt Fanons dar, dessen Neid den kolonialen Umsturz antreibt. Vor dem Hintergrund des revolutionären und gewaltbereiten Neids von Fanons Kolonisiertem lässt sich der ergebene Zivilisationsneid des >weißen $\mathrm{N}-<$ tatsächlich als Mechanismus lesen, der, mit Irigaray gesprochen, dem kolonialen System zu Entlastung verhilft. Er dient dann dazu, die kolonialen Aufstände, dekolonialen Aufbrüche und das Wissen von den fundamentalen globalen Ungleichheiten auszuklammern, auf denen die Konsumkultur und ihr Glücksversprechen beruhten.

\section{KonkLUsion: Weisssein als Versprechen}

In seiner umfassenden Studie zur Kolonialwerbung in Deutschland um 1900 stellt Ciarlo fest: »A common commodity culture of Germany could be built, in part, on a series of powerful images - images that invited viewers - everyday Germans - into the position of colonial master, receiving the goods of the world. « ${ }^{276}$ Dass die alltägliche Selbstwahrnehmung in Deutschland im Fin de Siècle auf einem über die Konsumkultur vermittelten kolonialen Imaginären beruhte, ist eine Einsicht, die mit Gewinn auch auf die Schweiz angewendet werden kann. Allerdings sind für eine solche Studie geschlechtsspezifische Perspektiven unentbehrlich. Die Ge-

275 | Vgl. Davis 1983, 172ff. Bilder des ischwarzen Vergewaltigersı zirkulierten auch in der Schweiz. So wird 1930 in der Schweizer Illustrierten Zeitung das Bild eines Schwarzen Mannes gedruckt, der von einem Weißen an einer Kette geführt wird. Die Bildunterschrift informiert darüber, dass sich der Mann in Texas an einer "weißen Frau vergangen " habe und daraufhin einer "furchtbaren Lynchjustiz" zum Opfer gefallen war (Schweizer Illustrierte Zeitung 1930[23]).

276 | Ciarlo 2011, 306. 
schlechterdifferenz prägte nicht nur den kolonial kodierten Massenkonsum, sondern dieser wurde umgekehrt auch zu einem wichtigen Vehikel, mit dem Geschlechterdifferenz produziert werden konnte. In der Absicht, diese Prozesse nachzuzeichnen, wurde in diesem Teil der vorliegenden Studie die Herstellung des Ideals der Hausfrau rekonstruiert, die sich in den 193oer Jahren als normatives Geschlechtermodell für Frauen in der Schweiz weitgehend durchgesetzt hatte. Es ist, mit bedeutsamen Variationen, bis heute wirkmächtig geblieben.

Mit unübertroffen spitzer Feder beschreibt Iris von Roten Ende der 1950er Jahre die Situation der Schweizer Hausfrau als »Hausarrest « ${ }^{277}$. Und sie fasst die Leere in Worte, die sich bei der Frau abends nach getaner Arbeit einstellte, während der Gatte im Wirtshaus unter Freunden weilte: »An Sommerabenden schauen sie beim Eindunkeln mit dumpfer Sehnsucht nach dem Leben >draußen zum Fenster hinaus. Sie kommen sich vor wie ausgekoppelte Eisenbahnwagen auf einem Nebengeleise. « ${ }^{278}$ Diese kritische Darstellung wirft Fragen auf: Wie konnte die Normierung der Frau als Hausfrau hegemonial werden? Was ermöglichte die zunehmende Einwilligung und den abnehmenden Widerstand von Frauen, die mit dem modernen Hausfrauenkult doch in ein System gepresst wurden, das ihre politischen, sozialen und ökonomischen Rechte weitgehend beschnitt?

Zum einen eröffnete die Position als Konsumentin der Hausfrau einen limitierten Zugang zu öffentlichen Räumen und politischen Diskussionen. Zum anderen stärkte die Ausweitung des bürgerlichen Lebensmodells die Position von bürgerlichen Frauen: Sie konnten eine Vorreiter- und Erzieherinnenrolle gegenüber denjenigen Frauen einnehmen, die noch zur Hausfrau erzogen werden mussten. In den Missionsgebieten gehörten die sheidnischen< Frauen und in der eigenen Gesellschaft Arbeiterinnen, Frauen in ländlichen Kontexten und in Berggebieten, insbesondere aber arme und >gefallene< Frauen dazu. Eine dritte Facette sind die materiellen, sozialen und affektiven Dimensionen, die durch die Konsumkultur gestiftet wurden: Der Gang zum Warenhaus, das Einkaufen, der Austausch mit anderen Konsumentinnen, der Erwerb und die Benutzung von Konsumartikeln im Spannungsfeld von Sparsamkeit und Luxus veränderten die Lebenswelt von Frauen und sollten sie mit Sinn erfüllen.

277 | Von Roten 1991, 23.

278 | Von Roten 1991, 462. 
Eine postkoloniale Perspektive fügt, wie ich gezeigt habe, dieser Analyse einen bedeutsamen weiteren Aspekt hinzu. Die >dumpfe Sehnsucht< der Hausfrau, die am Fenster steht und nach draußen blickt, wurde nämlich auch durch eine imperiale Weltsicht gerahmt. Ihre Sehnsucht nach der Außenwelt wurde von einer kolonialen Alltagskultur modelliert und genährt. Ihr Fenster wurde zu einer Öffnung auf eine Welt hin, die durch koloniale Abenteuer lockte, ihr die Bürde der weißen Frau auferlegte und ihr durch den imaginierten Neid der >Unzivilisierten< einen erfüllten Blick zurück auf die eigene Lebenswelt ermöglichte.

Im Rückgriff auf die postkoloniale Forschung und die Whiteness Studies ging es in diesem Kapitel darum zu zeigen, dass mit der Verbreitung bürgerlicher Normen nicht nur das Ideal der Schweizer Hausfrau generell, sondern spezifisch das der weißen Schweizer Hausfrau propagiert und durchgesetzt wurde. Dieser Fokus ist wichtig, weil er eine konstitutive und in der Forschung zur Schweiz bislang vernachlässigte Dimension der Vergeschlechtlichung zeigt - nämlich deren Verwobenheit mit >Rasse < - und weil damit zentrale Aspekte weiblicher Selbstverhältnisse erfasst werden können. Frauen sollen nicht nur in ihrer tüchtigen Sorge für Andere, in der Führung eines gut organisierten, ordentlichen, wirtschaftlichen und ehrbaren Haushalts aufgehen, sondern auch in ihrer Aufgabe als weibliches Rollenmodell für die koloniale Zivilisationsmission und als Vorsteherinnen einer weiß-gemachten Nation.

In einer Konsumkultur, die sich an die Frauen einer wachsenden Mittelschicht wandte, funktionierte Weißsein damit, wie in Anlehnung an Hund, Pickering und Ramamurthy ausgeführt wurde, als Gegengift gegen soziale Unruhen und als Zusicherung, dazugehören zu dürfen. ${ }^{279}$ Das Versprechen, einer weißen, fortschrittlichen und moralisch überlegenen Zivilisation anzugehören, vermochte die Unzufriedenheit von Frauen zu dämpfen, deren Aktivitätsradius aufgrund ihres Geschlechts radikal eingeschränkt wurde. Tatsächlich war der Modus des Versprechens in der bürgerlichen Geschlechterordnung eng mit der weiblichen Lebensform verbunden. Während der Mann gemäß dem bürgerlichen Narrativ aktiv und gestaltend in die Welt treten sollte, orientierte sich die Hausfrau an den diversen Versprechen, die den Horizont ihres Wirkungsfeldes einrahmten. 
Das Ideal der Hausfrau, die ihr Glück im Dasein für Andere findet, war und ist noch immer mit einem gesellschaftlich inszenierten Versprechen verknüpft, das die Asymmetrien, die Ungleichheiten, die Ausschlüsse und Machtverhältnisse sowie die enorme Arbeit verdeckt, die Frauen durch die Übernahme reproduktiver Tätigkeiten leisten. Das Versprechen des Weißseins ermöglichte es der Hausfrau darüber hinaus, sich als Bestandteil und Stütze der Zivilisation und als Vorsteherin eines attraktiven, modernen, technisch fortschrittlichen Haushalts zu imaginieren, der ihr den Neid der kolonialen Anderen sicherte. Ihre Teilhabe an einer weißen Kultur, die Einbindung in eine globale Zivilisationsmission, die Unterstützung und indirekte Teilnahme an der Entdeckung und Beherrschung der Welt, der aufkommende Tourismus oder auch fiktive Reisen in exotische Länder durch Reiseberichte, Völkerschauen oder Filme sollten der in ihrem Bewegungsradius limitierten Hausfrau Zugang zu einer unermesslich weiten und begehrenswerten Welt verschaffen.

Wie diese Überlegungen zeigen, gehört der Neid der Anderen zu einer brisanten affektiven Konstellation, die historisch dazu verwendet wurde, koloniale, patriarchale und heteronormative Prämissen des gesellschaftlichen Lebens hervorzubringen und zu stützen. Weiße Fantasien von schwarzem Neid haben eine bedeutsame Rolle gespielt, als es in den 1930er Jahren darum ging, die politischen und sozialen Forderungen der Frauenbewegung zurückzuweisen und mit der weißen Hausfrau eine Figur zu schaffen, welche die faktisch massiv eingeschränkte politische, ökonomische und soziale Handlungsfähigkeit von Frauen gleichwohl begehrenswert erscheinen lassen sollte. Dabei tritt aber auch ein deutlicher Unterschied zwischen dem Freud'schen Penisneid und dem Zivilisationsneid zutage: Während Ersterer die Vormachtstellung weißer Männer in der bürgerlichen Geschlechterordnung naturalisiert, wird Letzterer dazu eingesetzt, die Unterordnung weißer Frauen durch, wie Gabriele Dietze es nennt, eine »okzidentalistische Dividende ${ }^{280}$ sicherzustellen. Obwohl selbst patriarchalen Herrschaftsverhältnissen unterworfen, konnten sich weiße Frauen in den imperialen Metropolen gegenüber orientalisierten und rassifizierten Frauen (und Männern) dennoch als überlegen imaginieren und aus diesem Verhältnis eine Führungsrolle und ein Gefühl der Superiorität ableiten. Um zu verstehen, wie die zunehmend restriktiven Anforderungen an Frauen im frühen 20. Jahrhundert durchgesetzt wer-

280 | Dietze 2009, 35. 
den konnten, muss darum auch deren wirkmächtige intellektuelle und affektive Einbindung in ein koloniales Imaginäres bedacht werden. 



\section{Kapitel 2}

\section{Kämpfe im Himalaya: Schweizer Helden in kolonialen Abenteuern}

Abbildung 20: Titelbild zum Artikel

»Der Schweizer Sieg am Dhaulagiri«1960

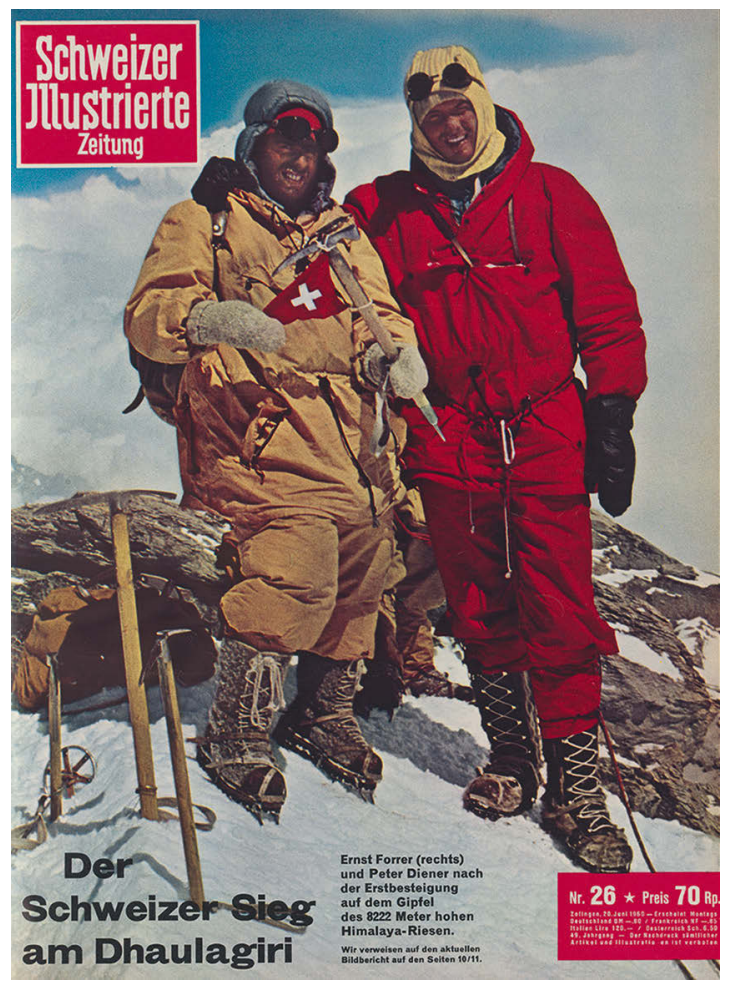

Quelle: Schweizer Illustrierte Zeitung 1960(26) 


\section{Vignette: Kampf am Everest}

Am Samstag, den 27. April 2013, kletterten der Schweizer Ueli Steck, der Italiener Simone Moro und der Engländer Jonathan Griffith in Richtung Gipfel des Mount Everest. ${ }^{1}$ Die drei Extrembergsteiger ließen das Lager zwei, das über dem berüchtigten Khumbu-Eisfall lag, hinter sich und bewegten sich auf das Lager drei zu, das sich auf über 7.000 Metern befindet. Um ihre Zelte zu erreichen, mussten sie die Lhotse-Flanke durchsteigen, eine steile und eisige Rampe, die zum Südsattel zwischen den beiden Achttausendern Everest und Lhotse führt. Zur gleichen Zeit befand sich eine Gruppe von Sherpas auf dieser Strecke. Sie waren dabei, Fixseile für die Tourist*innen anzubringen, die schon bald in großer Zahl das sogenannte >Tal der Stille< zwischen Lhotse und Everest bevölkern und das kurze jährliche Wetterfenster im Mai vor dem Beginn des Monsuns nutzen würden, um den Mount Everest zu besteigen.

Diese jährlichen Vorbereitungsarbeiten der Sherpas sind anstrengend und überaus gefährlich. Aus diesem Grund war auf einem Treffen mit den Expeditionsleitern im Frühling vereinbart worden, dass niemand an der Lhotse-Flanke klettern würde, während die Sherpas die Strecke präparierten. Steck, Moro und Griffith, die als Extrembergsteiger nicht zu den kommerziellen Touren-Anbietern gehörten, hatten an dem Treffen nicht teilgenommen. ${ }^{2}$ An besagtem Tag kletterten sie ungefähr 50 Meter neben den Fixseilen im Alpinstil, das heißt ohne die Seile zu benutzen, bis sie die Höhe ihres Lagers erreicht hatten.

Über die nachfolgenden Ereignisse kursieren unterschiedliche Versionen. Gesichert ist, dass es zu einer Auseinandersetzung zwischen den Sherpas und den europäischen Bergsteigern kam, als diese die Fixseile überquerten. Der Führer der Sherpas, Mingma Tenzing Sherpa, der wenige Meter über der Kreuzungsstelle arbeitete, behauptete, die Bergsteiger hätten Eis losgetreten, das auf einen Arbeiter gefallen sei. Dem widerspra-

1 | Die Zusammenfassung der Ereignisse folgt im Wesentlichen der Darstellung von Paumgarten, Nick: "The Manic Mountain. Ueli Steck and the Clash on Everest", in: The New Yorker, 3. Juni 2013. Download unter: www.newyorker.com/magazine/2013/06/03/the-manic-mountain (Zugriff am 24. September 2018). Vgl. dazu auch Steck 2016.

2 Steck behauptet denn auch, er habe nichts von dieser Vereinbarung gewusst. Vgl. Steck 2016, 29. 
chen die europäischen Alpinisten, denen zufolge Mingma sie zurechtgewiesen und im Wortwechsel die Hand mit seiner Eisaxt gehoben haben soll. Von beiden Seiten bestätigt wurde jedenfalls, dass Moro im weiteren Verlauf Mingma auf Nepali anschrie und ihn als >machikne < bezeichnete, was als >motherfucker übersetzt wird. Die Sherpas brachen nach diesem Vorfall ihre Arbeit ab und verließen die Wand. Steck und Moro übernahmen danach ohne Absprache die Arbeit der Sherpas in der Hoffnung, die Situation beruhigen zu können, und verlegten die restlichen 260 Meter Fixseil selbst. Alle drei stiegen dann zum Lager zwei ab, um, wie sie sagten, die Situation zu klären.

Im Lager kam es daraufhin zu einem Handgemenge zwischen mehreren Sherpas und den europäischen Bergsteigern. Ein größerer Stein wurde auf das Zelt geworfen, in das sich Steck geflüchtet hatte. Die amerikanische Bergsteigerin Melissa Arnot, zwei Sherpas und ein westlicher Bergführer blockierten daraufhin den Weg zum Zelt. Als aus dem Base Camp die Information kam, dass Steck, Moro und Griffith über eine Genehmigung verfügten (was von einigen Sherpas bezweifelt worden war), verzog sich die Menge. Die drei europäischen Bergsteiger beendeten ihre geplante Tour vorzeitig und stiegen ins Basislager ab. Am nächsten Tag gingen die Schlagzeilen über diesen Vorfall um die Welt.

Da mit Ueli Steck, der vier Jahre später in derselben Region tödlich verunglückte, ein Schweizer in die Ereignisse involviert war, wurde die Auseinandersetzung am Everest in der Schweizer Presse ausführlich kommentiert. Dabei wurde Verständnis für die Lage der Sherpas geäußert, die auch immer wieder mit Schweizer Bergführern und Tourismusunternehmern verglichen wurden. »Die Sherpas haben gemerkt, dass sich mit dem Everest Geld verdienen lässt.< Die Lohtse-Flanke [sic!] gehöre heute den Sherpas, wie der Hörnligrat zum Matterhorn den Zermatter Bergführern gehört«, wird der Alpinist und Höhenmediziner Oswald Oelz im Tages-Anzeiger zitiert. ${ }^{3}$ Vergleichbar argumentiert auch der Kommunikationswissenschaftler Kurt Luger im nationalen Radiosender SRF 4. Er weist die These zurück, wonach es sich bei der Auseinandersetzung um einen Kultur-Konflikt gehandelt habe, indem er auf die Ähnlichkeit zwischen Nepal und der Schweiz rekurriert: Sherpas seien wie die Bewohner in den alpinen Tourismusgebieten von ihren Gästen ab-

3 | Zitiert nach Petroni, Bruno: "Ueli Steck bricht Everest-Expedition ab", in: Tages-Anzeiger, 1. Mai 2013. 
hängig. Darum könne nicht von einem Hass auf den Westen als Ursache des Konflikts gesprochen werden. Dem fügt er hinzu: Hass würde auch der Lebensphilosophie von Sherpas widersprechen, denn »wir reden von Buddhisten, die nicht aus dem Haus gehen, ohne sich dafür zu entschuldigen, dass sie Blumen zertreten oder Ameisen eliminieren $\aleph^{4}$.

Ganz anders sah dies Steck: Im Westen herrsche noch immer das Bild des friedlichen Bergvolkes vor, kritisierte er. ${ }^{5}$ Dass dies nicht der Realität entspreche, führt er anhand des Phänomens der Selbstjustiz in Nepal aus, das ein »kulturelles Problem $\aleph^{6}$ darstelle. In einem Land mit einer funktionierenden Justiz wie der Schweiz hingegen, so Steck, hätten seine Angreifer mit einer Strafverfolgung rechnen müssen: »Wenn das in der Schweiz passiert wäre, müssten alle ins Gefängnis. «7 In der Fernseh-Nachrichtensendung 1ovorı führte er zudem aus, dass vier oder fünf Personen die Drahtzieher der >Angriffe < auf die Europäer waren. »Die anderen haben sie angestachelt, wie sie das gemacht haben, wir wissen, wie das funktioniert in Nepal, das ist relativ einfach, wenn man da ein wenig etwas erzählt, dass die Sherpas eine Aggression entwickeln. ${ }^{8}$ Zum Bild von leicht erhitzbaren Männern passte auch der Begriff des Mobs, der in der Berichterstattung die Runde machte und auch in der abschließenden Erklärung der drei europäischen Bergsteiger verwendet wurde. ${ }^{9}$ Ein »Mob wütender Sherpas machte regelrecht Jagd auf Steck und Moro«, titelt das

4 | SRF 4 News: "Geht es um einen Konflikt der Kulturen?", www.srf.ch/play/radio/ popupaudioplayer?id=1f667262-e880-4d30-8b6e-945fe7398189 (Zugriff am 24. September 2018).

5 | Zitiert nach Krebs, Adrian: "Ueli Steck und seine Kollegen wurden mit dem Tod bedroht", in: Neue Zürcher Zeitung, 1. Mai 2013.

6 | Boyadjian, Rupen: "Wenn das in der Schweiz passiert wäre, müssten alle ins Gefängnis“, in: Tages-Anzeiger, 2. Mai 2013.

7 | Ebd.

8 | SRF News: "Ueli Steck: 80 bis 100 Sherpas standen vermummt vor meinen [sic!] Zeltı", 6. Mai 2013, www.srf.ch/news/panorama/ueli-steck-80-bis-100sherpas-standen-vermummt-vor-meinen-zelt (Zugriff am 24. September 2018).

9 | Griffith, Jonathan, Ueli Steck und Simone Moro: „Abschliessende Erklärung zur Everest-Schlägerei“, http://kletterszene.com/news/abschliessende-erklarungvon-jonathan-griffith-ueli-steck-und-simone-moro-zur-everest-schlagerei (Zugriff am 24. September 2018). 
Internetportal des Schweizer Radio und Fernsehen SRF. ${ }^{10}$ Und in der Boulevardzeitung Blick beschreibt Moro, was es bedeutet, einem >Mob< gegenüberzustehen: »Wir waren wie in einer anderen Welt. Eine gefährliche, unberechenbare Welt. «11 Das Schweizer Fernsehen hält fest: »Die Sherpas wollten nur noch eines: Blut sehen. ${ }^{12}$

Auffallend ist weiter, welche Bedeutung der amerikanischen Bergsteigerin Melissa Arnot in der Berichterstattung zukam. Die Gratiszeitung 20 Minuten titelte: »Das ist Stecks schöne Retterin $\ll,{ }^{13}$ und der Blick sprach vom »blonden Schutzengel von Ueli Steck« ${ }^{14}$. Viele Artikel betonten Arnots Mut und schrieben es ihrem Einfluss zu, dass die Europäer mit dem Leben davongekommen waren. Die Bergsteigerin habe sich »unerschrocken« zwischen die Männer gestellt, heißt es in 20 Minuten: »Sie ergriff die Hände eines der Sherpas, um die Situation zu beruhigen. >Ich wollte keine Heldin sein<, sagte sie dem Newsportal [abs News], >aber ich war sicher, dass mich die Sherpas nicht angreifen würden, einfach deshalb, weil ich eine Frau bin. ${ }^{15}$ Zum Bild der aggressiven Sherpas kam die Vorstellung von braunen Männern, die es nicht wagen würden, gegenüber einer weißen Frau Gewalt anzuwenden.

10 | SRF Fortsetzung folgt: "Zwischen alpinistischen Höhepunkten und menschlichen Abgründen«, 16. April 2015, www.srf.ch/sendungen/fortsetzung-folgt/ zwischen-alpinistischen-hoehepunkten-und-menschlichen-abgruenden (Zugriff am 24. September 2018).

11 | Müller, Myrte: "Ueli Steck mit Stein verletzt! ", in: Blick, 28. April 2013.

12 | SRF News: "Ueli Steck: 80 bis 100 Sherpas standen vermummt vor meinen [sic!] Zelt‘", 6. Mai 2013, www.srf.ch/news/panorama/ueli-steck-80-bis-100sherpas-standen-vermummt-vor-meinen-zelt (Zugriff am 24. September 2018).

13 | O.V., "Das ist Stecks schöne Retterin «, in: 20 Minuten, 1. Mai 2013.

14 | O.V., "Der blonde Schutzengel von Ueli Steck", in: Blick, 1. Mai 2013.

15 | O.V., "Das ist Stecks schöne Retterin“, in: 20 Minuten, 1. Mai 2013. 
Abbildung 21: Filmstill aus dem Dokumentarfilm High Tension 2013

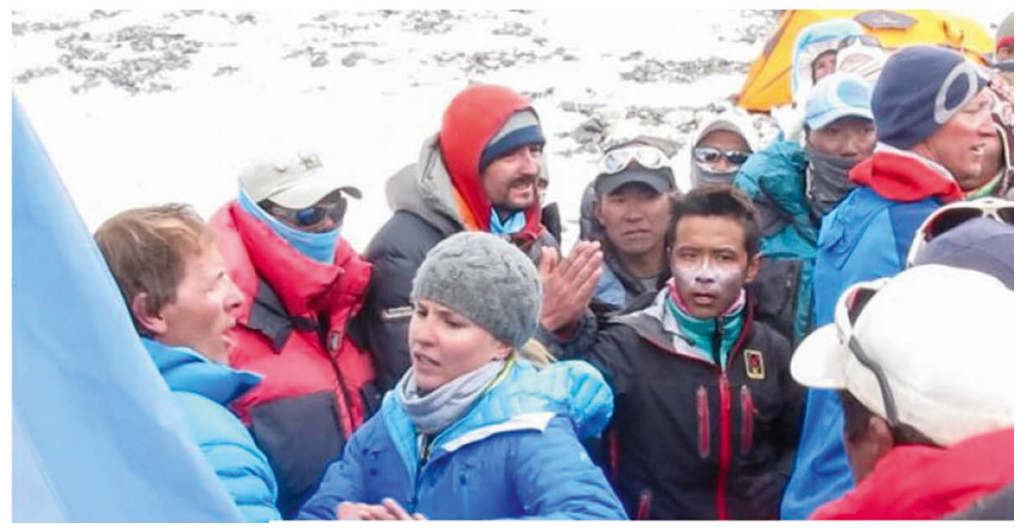

Quelle: Reel Rock 8 (2013). Dokumentarfilm High Tension, USA, Nepal

Ein Ausschnitt aus dem Dokumentarfilm High Tension, der auch im Schweizer Fernsehen gezeigt wurde, legt eine andere Deutung des Vorfalles nahe (vgl. Abbildung 21). Die Szene zeigt einen Sherpa neben Arnot, der sich an der Schlichtung beteiligt. In der Filmszene ist zu sehen, wie er mehrere Personen zurückhält, die nach vorne drängen. Die Szene aus dem Dokumentarfilm wurde in einen Fernsehbericht des SRF eingespielt. Der Kommentar erwähnte den beteiligten Sherpa nicht: »Mitten im Getümmel versucht eine Frau zu schlichten: die amerikanische Bergsteigerin Melissa Arnot. ${ }^{16}$ Auch die Moderatorin ging im darauffolgenden Gespräch mit Steck nur auf Arnots Rolle ein. Steck wiederum bestätigte im Gespräch die Vorstellung, Arnot alleine hätte die Situation beruhigt: Ohne ihre Vermittlung hätte es schlecht für ihn ausgesehen, meinte er. In der abschließenden Erklärung von Griffith, Steck und Moro ist von einem einheimischen Bergsteiger die Rede, Pang Nuru Sherpa, der die Eskalation zu verhindern half. Gedankt wird aber nur den beiden weißen Personen: »Gemeinsam standen Melissa Arnot, ein leitender westlicher Bergführer und Pang Nuru Sherpa vor dem Zelt und verwehrten jedem den Zutritt. Während (ungefähr) 20 Minuten stand der Mob vor dem Zelt und verlangte, Ueli solle herauskommen und sie sagten, dass mindestens

16 | SRF Fortsetzung folgt: "Ueli Steck - Der schnellste Mann am Berg“, 17. April 2015, www.srf.ch/sendungen/fortsetzung-folgt/staffel-2015/ueli-steck-derschnellste-mann-am-berg (Zugriff am 18. September 2018). 
einer von uns hier und jetzt umgebracht werde und man sich später um die anderen kümmern werde. Ueli verdankt sein Leben Melissa und dem leitenden Bergführer, die trotz der grossen Gefahr, in der sie sich selber befanden, nicht nachgaben. ${ }^{17}$ Der Weigerung, die schlichtende Rolle von Pang Nuru und anderen anzuerkennen, kommt dabei eine narrative Funktion zu: Sie ermöglichte es den europäischen Bergsteigern, die Sherpas als kulturell einheitliche Gruppe darzustellen und das Verhalten einzelner Personen damit als irrationale und gewalttätige Charakterzüge eines ganzen Kollektivs zu beschreiben.

Steck musste von den Schweizer Medien viel Kritik einstecken, er erhielt aber auch eine beachtliche Plattform, um über seine Erfahrungen zu sprechen. Seine Gefühle, Überlegungen und Fragen beschäftigten die Schweizer Öffentlichkeit über Monate. Mehrmals kam das mögliche Ende von Stecks glänzender Bergsteigerkarriere zur Sprache: »Ueli Steck stellt Bergsteiger-Dasein in Frage ${ }^{18}{ }^{18}$ hieß es in der Neuen Zürcher Zeitung, »Sherpas zerstörten meinen Everest-Traum « ${ }^{19}$ titelte auch die öffentlich-rechtliche Nachrichtenplattform Swissinfo. Unter dem Titel »Ich höre auf, das ist ziemlich klar«, berichtete Steck der Schweizer Illustrierten, der Vorfall am Everest habe ihn kaputtgemacht: »Psychisch geht es mir noch schlechter als im Sommer. Ich spüre ein riesiges Loch, eine tiefe Leere in mir ${ }^{20}{ }^{20}$ gab Steck zu Protokoll. Der Platz, den die Darstellungen der europäischen Bergsteiger in den Medien einnahmen, kontrastierte mit der Absenz der Sherpas, deren Stimmen in der Berichterstattung kaum

17 | Griffith, Jonathan, Ueli Steckund Simone Moro: „Abschliessende Erklärungzur Everest-Schlägerei“, http://kletterszene.com/news/abschliessende-erklarungvon-jonathan-griffith-ueli-steck-und-simone-moro-zur-everest-schlagerei (Zugriff am 18. September 2018). In seinem Buch dankt Steck Melissa Arnot und Marty Schmidt, aber nicht Pang Nuru, obwohl er erwähnt, dass dieser nicht einverstanden war mit dem Angriff auf die europäischen Bergsteiger (Steck 2016, 22 und 29f.)

18 | Kucera, Andrea: "Ueli Steck stellt Bergsteiger-Dasein in Frage", in: Neue Zürcher Zeitung, 7. Mai 2013.

19 | Bierling, Billi: "Sherpas zerstörten meinen Everest-Traum", in: Swissinfo, 30. April 2013, www.swissinfo.ch/ger/ueli-steck-_-sherpas-zerstoerten-meineneverest-traum-/35683270 (Zugriff am 24. September 2018).

20 | Zitiert nach Knecht, Natascha: "Ich höre auf, das ist ziemlich klar", in: Schweizer Illustrierte, 17. Dezember 2015. 
zu hören waren. Eines der wenigen zugänglichen Interviews, in dem ein beteiligter Nepalese, Tashi Sherpa, das Wort ergriff, erschien in der USamerikanischen Zeitschrift Live Bravely Outside Magazin. Der Sherpa erzählte: »I have read in blogs that claimed one hundred Sherpas attacked them [the Europeans], that they were trying to kill them, and they had to flee for their lives. That's false. [...] In reality, we were helpless. There was no one who spoke on our behalf. There were so many journalists in Base Camp. They were constantly blogging and updating on the brawl. But not a single journalist or blogger approached us. They were simply not interested on [sic!] us. Even the government-appointed liaison officer didn't bother to talk to us. ${ }^{21}$ Tashi Sherpas Darstellung von Journalist*innen, die ihre Geschichten in unmittelbarer Nähe der betroffenen Sherpas im Base Camp schrieben, ohne mit ihnen das Gespräch zu suchen, zeigt die eingeschränkte Perspektive der Berichterstattung auf: Subalternes Wissen ist nicht dadurch gekennzeichnet, dass es nicht vorhanden ist, sondern dass es nicht wahrgenommen wird.

In den Schweizer Medien wird die Situation der Sherpas auffallend oft mit derjenigen von Schweizer Tourismusanbietern und Bergführern verglichen. Dabei wird ein Verständnis für ihre Situation eingefordert, indem auf ihre (vermeintliche) >Verspätung < hingewiesen wird: Die Sherpas entwickelten sich gemäß dieser Darstellung allmählich zu den Touristikfachleuten, welche die Schweizer schon lange sind. Der Topos der Ähnlichkeit zwischen Schweizern und Nepalesen hat, wie im Folgenden gezeigt wird, eine lange Geschichte, die eng mit der Entstehung des modernen Alpinismus im 19. Jahrhundert und mit dem Höhenbergsteigen im 20. Jahrhundert verbunden ist. Die Vorstellung einer Ähnlichkeit von schweizerischen und nepalesischen Tourismusanbietern wird zudem kontinuierlich durchkreuzt von unterschiedlichen (und nicht selten widersprüchlichen) orientalistischen Bildern: vom friedfertigen Buddhisten, vom gewalttätigen Mob, vom Leben im Zustand der Rechtlosigkeit. Dazu gehörte auch die Vorstellung, dass sich die entfesselten Einheimischen von einer weißen Frau widerstandslos in die Schranken

21 | Zitiert nach Adhikari, Deepak: "The Everest Brawl: A Sherpas' Tale", www. outsideonline.com/1929351/everest-brawl-sherpas-tale (Zugriff am 24. September 2018). 
weisen lassen. ${ }^{22}$ Diese stereotypen Bilder der Sherpas sind Bestandteil einer eurozentrischen Wissensordnung, die nicht nur die Darstellung der erwähnten Auseinandersetzung bestimmt, sondern, wie im Folgenden dargelegt wird, unauflöslich mit der Geschichte des Bergsteigens verbunden ist.

Aufschlussreich ist schließlich die Darstellung von Ueli Steck, dessen Erfahrungen am Everest über Monate hinweg in den Medien diskutiert wurden. Gezeichnet wurde dabei das Bild eines sensiblen und hoch talentierten Bergsteigers auf dem Zenit seiner Karriere, der durch die Konfrontation mit aggressiven Sherpas in eine tiefe Lebenskrise gestürzt worden war. Das Vokabular von Heldenhaftigkeit und Krise, von aufrichtiger Männlichkeit und harten Kämpfen mit sich und einer feindseligen Umwelt steht ebenfalls in einer kolonialen Genealogie. Seit den $1920 e r$ Jahren war der Himalaya ein Schauplatz weißer heroischer Männlichkeit, die gerade im Kampf und in der Krise zum Ausdruck kam.

Schließlich kann die heftige Reaktion auf den Konflikt am Everest auch in Bezug auf eine Zäsur in der Ikonografie postkolonialer Freundschaft gelesen werden, für die Schweizer $>$ Sahibs ${ }^{23}$ und nepalesische Sherpas seit der Schweizer Everest-Expedition von 1952 standen. Die geschilderten Ereignisse am Everest brechen mit einem bekannten Bild, das den Schweizer Bergsteiger als Freund und Vertrauten der Sherpas zeigte. In seiner Darstellung der Vorkommnisse war Steck denn auch sehr darauf bedacht, dieses Bild wiederherzustellen. So schreibt er:

"Ich bemühte mich, mir die positiven Erlebnisse aus dem Jahr 2012 in Erinnerung zu rufen, als ich mit Tenji [Tenjing Sherpa, ein nepalesischer Kletterpartner von Steck] den Gipfel erreicht hatte. [...] Wir waren - als ebenbürtige Kletterpartner, nicht als ,Träger und ,Kunde - parallel zu dem Sherpa-Team aufgestiegen, das die Gipfeletappe fixierte. Dieses Bild, wie ich gemeinsam mit einem Sherpa zufrieden

22 | "Gegenüber einer Frau tätlich zu werden, das wäre gegen die Ehre der Sherpas gegangen “, schreibt Steck $(2016,22)$.

23 | Der Begriff ,Sahib، stammt aus dem Arabischen und bezeichnet eine höfliche Anrede. Während der britischen Kolonialherrschaft in Südasien wurde er insbesondere für die Kolonialherren benutzt. Die weibliche Entsprechung war 'Memsahib،. 
auf dem höchsten Punkt der Erde sitze, wollte ich mir bewahren, nicht das der gewaltbereiten Menge in Lager $2 .{ }^{24}$

Die Vorstellungen, die Steck an dieser Stelle aufruft, denen zufolge Sherpa und Schweizer Bergsteiger sich auf Augenhöhe begegnen, die historische Beziehung zwischen Assistent und Auftraggeber transzendieren und den Aufenthalt auf dem höchsten Berg der Welt >gemeinsam >zufrieden< erleben, haben eine (post-)koloniale Geschichte. Ihre Rekonstruktion macht deutlich, warum die Bilder von gewaltbereiten Sherpas nicht einfach eine Störung der seit Langem bestehenden harmonischen Freundschaft zwischen Schweizern und Nepalesen anzeigen. Sie können vielmehr als Verweis auf ein koloniales Archiv gelesen werden, in dem beide Vorstellungen - die von Sherpas als Freunden und als fremde und befremdliche Andere - abgelegt sind. Dem Bild einer ebenbürtigen Freundschaft kam dabei eine zentrale Bedeutung zu, als sich Europa im Zuge der Dekolonisation gezwungen sah, die Beziehungen zu den ehemaligen Kolonialisierten anders $\mathrm{zu}$ imaginieren. Ausgehandelt wurde dabei, wie die nachfolgende Untersuchung zeigt, auch eine spezifisch schweizerische Version weißer Männlichkeit, die sich vorteilhaft in einer nachkolonialen Welt positionieren konnte.

\section{IMAGINÄRE BERGTOPOGRAFIEN}

Albert Eggler, der Leiter des schweizerischen Expeditionsteams, dem 1956 die Erstbesteigung des Lhotse und die Zweitbesteigung des benachbarten Everest gelang, beschreibt seine Anreise mithilfe eines historischen Vergleichs: »Mit dem Eintritt in die Bergwelt von Thyangboche mochten wir gewissermassen einer Bergsteigergruppe aus dem Jahr 1856 vergleichbar gewesen sein, die Zermatt hinter sich gelassen hat und nun im Weiler Zmutt vorübergehend Quartier bezieht. ${ }^{25}$ Eggler ruft mit diesen Zeilen das >Goldene Zeitalter des Alpinismus tion im Himalaya als Wiederholung eines hundert Jahre zurückliegenden Versuchs, die höchsten Gipfel der Westalpen zu erklimmen. Berge, Landschaften und Ortschaften werden dabei überblendet: Die kleine An-

24 | Steck 2016, 31.

25 | Eggler 1956, 66. 
siedlung Zmutt, die Bergsteiger erreichen, nachdem sie in Zermatt aufgebrochen sind, steht für das nepalesische Dorf Thyangboche. Zermatt korrespondiert, obwohl der Name unerwähnt bleibt, mit Namche Bazar, der letzten größeren Ortschaft auf dem Weg zum höchsten Berg der Welt. Die Expedition zum Lhotse und Everest wird auf einer imaginären Landkarte des Wallis nachgezeichnet und als Aufstieg zum Matterhorn verständlich gemacht.

Egglers Vergleich ist alles andere als selbstverständlich. Zum einen sind die Größendimensionen der Berge in den beiden Regionen vollkommen unterschiedlich: Das Matterhorn mit seinen 4.478 Meter ist nur etwa halb so hoch wie der Everest mit 8.848 Metern. Entsprechend ist die Besteigung des Matterhorns im alpinen Stil an einem einzigen Tag möglich, Expeditionen auf die höchsten Berge der Welt machen es hingegen erforderlich, mehrere Nächte unterwegs zu verbringen - erst im Basislager und dann in den verschiedenen Camps am Berg. Im Unterschied zum kontinuierlichen Aufstieg in den Alpen werden die Gipfel des Himalaya aus Gründen der Akklimatisation und für die Erstellung der diversen Routen und Camps bis zum Gipfel in einer fortwährenden Auf- und Abbewegung durchstiegen. Zudem stellt der Everest andere Anforderungen an Bergsteiger*innen als das Matterhorn. Ein Großteil des Aufstiegs erfolgt in Schnee und Eis, während die Besteigung des Matterhorns eine klassische Felskletterei erforderlich macht. Zudem sind die politischen und historischen Kontexte, in welche die beiden Gebirgsmassive eingelassen sind, gänzlich verschieden.

Wie also kommt Eggler dazu, die Besteigung der beiden Berge zu vergleichen? Er schreibt: »Die Parallelen liegen vor allem darin, dass auch wir für den Nachschub auf den Rücken der Einheimischen angewiesen waren und auch unsere Ziele über den bergsteigerischen Drang der eingesessenen Bevölkerung hinausgingen. Auch wir waren wohl in den Augen der Leute, die in den Gebäuden der Klostersiedlungen ihr karges Leben fristeten, mit ebenso unermesslichen irdischen Gütern gesegnet, wie man es vor hundert Jahren von den bergsteigenden Lords in den Alpentälern geglaubt haben mochte. ${ }^{26}$ Egglers Vergleich fokussiert auf das Verhältnis der Bergsteiger zu den Einheimischen und dabei vor allem auf die Abhängigkeit von der lokalen Arbeitskraft: Auch wenn die Himalaya-Expeditionen oftmals durch mehrere hundert und die alpinen 
Unternehmungen lediglich durch eine vergleichsweise geringe Anzahl von Personen begleitet wurden - ohne den Einsatz von Träger*innen hätten die Vorräte, das Expeditionsmaterial und die Instrumente weder in dem einen noch in dem anderen Fall an ihre Bestimmungsorte gebracht werden können.

Auffallend ist, dass die Einheimischen in Egglers Beschreibung als physische Arbeitskräfte Erwähnung finden, nicht aber als Vermittler*innen von Wissen im Hinblick auf Orientierung, Gelände, Geologie, Flora und Fauna, Ernährung und Gesundheit, obwohl sie diese Informationen mit großer Sicherheit ebenfalls geliefert hatten. Das Ausblenden dieser Wissensdimension mag mit der teilnahmslosen Haltung zusammenhängen, die den Einheimischen unterstellt wird: Denn sie sollen, im Unterschied zu den westlichen Bergsteigern, kaum über alpinistische Ambitionen verfügen. Beschäftigt mit dem Überleben in einer kargen Gegend, entlockt ihnen der materielle Reichtum der eindringenden Fremden Staunen und vielleicht die ersten Anzeichen eines Interesses für ein Leben, das über die pure Reproduktion der eigenen Lebensbedingungen hinausgeht - ein Leben, das Wissenschaft, Entdeckung, Erforschung miteinschließt und das mit einem Wort als >modern den kann. Egglers Beschreibung der nepalesischen Bevölkerung könnte nahtlos in die bekannte koloniale Literatur eingereiht werden, welche die rassifizierten Anderen in der Vormoderne lokalisiert. ${ }^{27}$ Was Egglers Text von dieser Literatur unterscheidet und ihn für eine Reflexion über die postkoloniale Schweiz interessant macht, ist das Spiel von Ähnlichkeit und Differenz, das zwischen der schweizerischen und der nepalesischen Bergbevölkerung eröffnet wird und Einsichten in die koloniale Verortung von Schweizer Identitätsdiskursen ermöglicht.

\section{Die Schweiz Und die Berge in Zeiten Der Dekolonisierung}

»Der Kampf um den Mount Everest« titelte die Schweizer Illustrierte Zeitung vom 9. Dezember 1952. »Mit Spannung und größtem Interesse, aber auch mit innerlicher Anteilnahme wurden nicht nur in der Schweiz, sondern in der ganzen Welt die kühnen Bemühungen der schweizerischen

27 | Vgl. Said 1994a, Fabian 1983, Spivak 1999. 
Mount-Everest-Expedition verfolgt«, steht unter dem großformatigen Farbporträt des Genfer Bergsteigers Raymond Lambert. Beim Wettrennen um die Erstbesteigung der höchsten Berge der Welt nahmen Schweizer Bergsteiger einen führenden Platz ein. Zwei der 14 Achttausender der Erde, der Lhotse und der Dhaulagiri, wurden 1956 und 1960 von Expeditionsteams unter Schweizer Leitung zum ersten Mal erklommen. Und 1952 standen Raymond Lambert und Tenzing Norgay, der spätere Erstbesteiger des Everest, weniger als 300 Meter unter dem Gipfel des höchsten Berges der Welt. Diese Aktivitäten stießen in der Schweizer Bevölkerung auf große Resonanz: Zeitungs- und Radioberichte, Zeitschriftenartikel, Bücher und Filme dokumentierten die Versuche, bei diesem Wettrennen an der Spitze mit dabei zu sein. Ausgehandelt wurde dabei, so meine These, auch die Position der Schweiz in einer Welt, die im Begriff stand, sich durch die Dekolonisierung nachhaltig zu verändern.

Der Himalaya wurde damit Teil einer Vorstellungswelt, in der die Schweiz als Nationalstaat eng mit den Bergen verflochten war. Diese Verbindung hat eine lange Geschichte und gilt unter anderem als zentral für die Gründungsmythen und nationalen Identitätsvorstellungen, die im Anschluss an 1848, insbesondere aber im späten 19. Jahrhundert entwickelt wurden. ${ }^{28}$ Entsprechend viel Aufmerksamkeit wurde in dieser Zeit dem Bergsteigen entgegengebracht. Zum einen führte es in Gegenden, die noch als sunberührte Natur galten. Zum anderen stellte der Alpinismus einen Bereich dar, in dem die Grenze des Menschenmöglichen durch die rasante Verbesserung von Klettertechnik und Ausrüstung in kurzer Zeit enorm erweitert werden konnte. Dadurch bildete er idealtypisch die Möglichkeiten technischen Fortschritts ab. Ferner verfügte das Bergsteigen in der Schweiz über die Qualität, Binnendifferenzen zwischen Stadt und Land zu überbrücken. Das früher eher negativ besetzte Bild des Bergführers, so Andrea Hungerbühler, entwickelte sich um $1900 \mathrm{zu}$ einem idealisierten Bild Schweizer Männlichkeit, zu einer Zeit also, als der Alpenmythos zu einem etablierten Bestandteil des nationalen Selbstverständnisses mutierte. ${ }^{29}$

Der Beruf des Bergführers war zu dieser Zeit noch nicht alt: Während des >Goldenen Zeitalters < des Alpinismus Mitte des 19. Jahrhunderts standen einheimische Männer oftmals als Träger oder Führer im Diens-

28 | Vgl. Mathieu und Boscani Leoni 2005a.

29 | Zimmer 1998, 657. 
te bürgerlicher Bergsteiger*innen, die vornehmlich aus Großbritannien, Deutschland oder der Schweiz stammten. Um 1850 entstanden die ersten Berufsverbände. ${ }^{30}$ Das Bild des Bergführers war in dieser Zeit aber keineswegs nur positiv konnotiert und viele Tourist*innen berichteten von Konflikten oder Schwierigkeiten mit Bergführern: »Überlieferte Klagen beziehen sich etwa auf fehlende Kenntnis des Gebirges, Unzuverlässigkeit, mangelnden Anstand, überhöhte Preise, Vertragsbruch, Prellerei und immer wieder auf den übermässigen Alkoholkonsum. « ${ }^{31}$

Dieses Bild verbesserte sich erst um 1900.32 Einen Beitrag dazu leisteten unter anderem populäre Biografien, in denen Bergführer als »prototypische Schweizer « ${ }^{33}$ dargestellt wurden. Eigenschaften wie Frömmigkeit, Tugendhaftigkeit, Patriotismus, Einfachheit, Ehrlichkeit, Mut und Treue wurden in diesen Schriften erfolgreich mit der Figur des Bergführers verknüpft und als schweizerisch und männlich kodiert. ${ }^{34}$ Hochkonjunktur hatte diese Figur während der Zeit der >Geistigen Landesverteidigungく, die sich in den $1930 e r$ Jahren herausbildete. Im Zweiten Weltkrieg schließlich kam die Bergsemantik aufgrund ihrer flexiblen und ambivalenten Verwendungsweise vielfach zum Einsatz. Bekannte Beispiele dafür sind General Guisans Réduit-Strategie oder Bundesrat Etters Stilisierung des Gotthards zum Inbegriff der Freiheit. ${ }^{35}$ Schweizer Bergführerbiografien reihten sich aber auch in eine transnationale Literatur zum Bergsteigen ein, die in den westlichen Ländern zirkulierte. Diese Werke, so Julie Rak, verbanden eine militarisierte Perspektive mit der kolonialen Geste des Eroberns: »The classic texts of mountaineering feature the intense symbolism of a militarized push to the empire's vertical limits. $\aleph^{36}$ Den Le-

30 | Wirz 2007, $105 f$.

31 | Hungerbühler 2013a, 76.

32 | Hungerbühler 2013a, 83.

33 | Hungerbühler 2009, 123.

34 | Hungerbühler 2009, $123 f$.

35 | Vgl. Sarasin 2003; Sarasin und Wecker 1998; Altermatt, Bosshard-Pfluger und Tanner 1998; Marchal 1992; Marchal und Mattioli 1992; Anker 1986. Als Réduit wird die ab 1940 verwendete Strategie bezeichnet, die Armee in erster Linie auf die Verteidigung des schweizerischen Alpenraumes auszurichten (vgl. Senn 2010).

36 | Rak 2007, 114. 
ser*innen solcher Texte sei dabei beigebracht worden, was es bedeute, ein heroischer Mann zu sein. ${ }^{37}$

Wie Männlichkeit, Nation und Alpinismus im Schweizer Kontext miteinander verknüpft wurden, lässt sich anhand des Buches Pioniere der Alpen zeigen, das 1946 von der Schweizerischen Stiftung für Alpine Forschung (SSAF) herausgegeben wurde. Dem Klappentext zufolge richtete es sich »nicht nur an die Alpinisten, sondern auch an die Allgemeinheit, auch an die Jugend - und vor allem an alle, die die Liebe zur Heimat im Herzen tragen. Sie werden erfahren, wieviel unser Land dieser Auslese aus einer Schar hervorragender, wenn auch einfacher und bescheidener Männer aus dem Volke zu verdanken hat. [...] Wer die Lebensgeschichte dieser Führerpioniere liest, der wird vielleicht mit einem leisen Staunen entdecken, wieviel hervorragende >männliche Eigenschaften $>$ im besten Sinne des Wortes diese Söhne des Hochgebirges ihr eigen nannten. Charakteren aller Art wird er begegnen; in den Melodien ihres Lebens tönt es sehr verschieden; aber die vorklingenden Noten sind: Mut, Freude an der Tat, Liebe zur Heimat und Pflichtgefühl.« ${ }^{38}$

Die alpinistischen Leistungen der ersten Bergführergenerationen waren, so macht der Text deutlich, für die Bewohner*innen des ganzen Landes von Belang. Das Buch sei daher für all diejenigen gedacht, die eine >Liebe zur Heimat< empfinden. Die eigene emotionale Bindung an die Nation solle durch die Lektüre mit einem spezifischen Wissen ergänzt werden: dem Wissen um die Bedeutung der Bergführer für das Ansehen der Schweiz. Wichtig ist, dass diese Bergführer als außergewöhnliche Gestalten und einfache Vertreter des Volkes dargestellt werden, als >hervorragende, wenn auch einfache und bescheidene Männer<. Sie unterschieden sich damit von denjenigen Figuren der Elite, die in der Schweiz politisch und ökonomisch den Takt angaben. Ihre herausragende Position wird konstitutiv mit ihrer Männlichkeit verbunden: Sie sind >Söhne des Hochgebirgesく, die männlichen Abkömmlinge einer Landschaft, die zum Inbegriff der Schweiz stilisiert wird. Die Gleichsetzung ihrer positiven Eigenschaften mit dem Adjektiv >männlich< zeigt und performiert zugleich die Idealisierung von Männlichkeit im Kontext der Nation. Gleichzeitig binden die Begriffe Mut und Tatkraft den Bergführer zurück an Idealvorstellungen des autonomen Subjekts. Der Alpinist verbindet sich

37 | Rak 2007, 114.

38 | Egger 1946, o.S. (Klappentext). 
als Sinnbild der Schweizer Nation damit wirkmächtig mit dem Bild des Bergsteigers »as the epitome of the autonomous individual ${ }^{39}$, das auf die Erfindung des Alpinismus im 19. Jahrhundert zurückgeht.

Der Bergführer repräsentiert eine moderne Männlichkeit, die unerschrocken vorgeht und durch eine ausgeprägte Handlungsautonomie gekennzeichnet ist. Damit wird eine Verbindung zu einem Männlichkeitsideal hergestellt, das konstitutiv für die Moderne ist und von Seyla Benhabib als Ideal eines »freischwebenden Selbst « ${ }^{40}$ bezeichnet wurde. Diese Vorstellung eines vernunftbegabten und primär autonom agierenden Subjekts blendet mannigfaltige Aspekte menschlicher Abhängigkeit und damit die Tatsache aus, »dass das Denken, Fühlen und Handeln des Einzelnen historisch bestimmt und gesellschaftlich bedingt ist « ${ }^{41}$, wie Andrea Maihofer ausführt. Dass der Bergführer dieses Ideal verkörpert, liegt keineswegs in der Natur der Sache: Das Bergsteigen ließe sich mit ebenso guten Gründen als Exempel für die Unhintergehbarkeit des Kollektivs heranziehen. Denn die Bergführer berieten sich mit den Trägern und mit den Gästen, sicherten sich gegenseitig mit Seilen oder besprachen mit Einheimischen, darunter auch vielen Frauen, am Fuße des Berges die aktuelle Wettersituation oder mögliche Routen. Bergführerbiografien beschreiben diese wichtigen Momente aber nicht oder nur am Rande. Vielmehr wird die Fähigkeit der Bergführer hervorgehoben, die Gäste selbstständig durch die Wirren der Bergwelt zu geleiten und in gefährlichen Situationen rational zu bleiben, um dann selbstbestimmt und mit kühlem Kopf die richtige Entscheidung zu treffen.

Erst die Ausblendung der sozialen Lebenswelt, in die die Bergführer eingebunden sind, macht es möglich, diesen Erzählungen das Narrativ eines >freischwebenden Selbst zugrunde zu legen. Wenn überhaupt, werden Mütter oder Partnerinnen in den Biografien oftmals ganz zum Schluss erwähnt. Wir erfahren allenfalls, ob Ehefrauen nach einem Unfalltod als Witwe Unterstützung benötigten und wie viele Kinder sie dem Bergpionier geboren hatten. Von Töchtern ist selten die Rede und von den Söhnen da, wo diese in die Bergsteigerspuren der Väter getreten sind. Schwestern werden kaum erwähnt, während die Brüder oftmals in eine männliche Bergführer-Genealogie eingereiht werden.

39 | Slemon 2008, 236.

40 | Benhabib 1995, 79. Vgl. auch Maihofer 1995, 153.

41 | Maihofer 1995, 153. 
Welche Rolle kommt den Frauen in solchen idealisierten Darstellungen der Bergführer zu? Sie erscheinen nicht als Subjekte, die durch ihre Arbeit und ihre Präsenz das Leben der Bergführer begleitet und mit ermöglicht haben. Vielmehr symbolisieren sie entweder als zurückgelassene Witwen das Opfer, das den Mut der Pioniere und das Risiko ihres Tuns apostrophiert, ${ }^{42}$ sowie den Großmut der >Herren<, die den verwitweten Frauen nach einem tödlichen Bergunfall (manchmal) eine Pension entrichten ließen, ${ }^{43}$ oder sie verkörpern die materielle Bedingung der Reproduktion einer männlichen Bergführer-Dynastie.

In ihrer feministischen Kritik an philosophischen Subjekttheorien beschreibt Luce Irigaray, wie sich die materielle und symbolische Reproduktion des männlichen Selbst überlagern. Um die androzentrische >Logik des Einen< aufrechtzuerhalten, muss sich das Subjekt durch Andere vervielfältigen. Diesen Anderen kommt keine Eigenständigkeit zu, sie können lediglich in ihrer Funktion für die männliche Selbstreproduktion erscheinen. »Ihm [dem Subjekt] gegenüber bleibt jedes Außen immer Bedingung der Möglichkeit des Bildes von sich und der Reproduktion seiner selbst. [...] Ein Anderer nur deshalb, weil er lediglich im Dienst des Subjekts selbst steht, dem er seine Oberfläche präsentiert, unschuldig und unwissend über sich selbst.« ${ }^{44}$ Diese Beschreibung entspricht weitgehend der Art und Weise, wie Frauen, Mütter, Schwestern und Kinder in der Bergsteigerliteratur des 20. Jahrhunderts behandelt werden. Im Buch Pioniere der Alpen von 1946 werden Frauen beispielsweise aus dem Text herausgeschrieben oder nur am Rande erwähnt, manchmal als sichtbare (»Im Jahre 1883 heiratete er Maria Cunfermann von Scheid und hatte zehn Kinder, meist Mädchen, wovon er vier, bevor sie aufgezogen waren, wieder verlor. $«^{45}$ ) und manchmal als unsichtbare Bedingung männlicher Reproduktion (»Burgener hatte fünf Kinder, darunter waren mehrere Söhne gleich ihm Bergführer « ${ }^{46}$ ). Indem sie derart in die Subjektkonzepte der bürgerlichen Aufklärung eingeschrieben wurden, konnten die Bergführerfiguren als Vertreter der Schweiz und der Moderne erschei-

42 | Vgl. meine Ausführungen zum Zusammenhang von Tod, Trauer und der Position der Ehefrau in Purtschert 2006, $77 \mathrm{ff}$.

43 | Vgl. Egger 1946, 176.

44 | Irigaray 1980, 172 [Hervorhebung im Original].

45 | Egger 1946, 318f.

46 | Egger 1946, 279. 
nen beziehungsweise dazu beitragen, die Schweiz als modernen Raum erkennbar werden zu lassen. Ihr Subjektstatus beruhte dabei auf der Ausblendung der Abhängigkeit von Anderen, insbesondere von Frauen, die in solchen Darstellungen nur als dienstbare und abhängige Figuren, nicht aber selbst als Subjekte in Erscheinung treten können.

In der Figur des Bergführers fanden also mehrere bedeutungsvolle Aspekte zusammen: Sie knüpfte an die Männlichkeitsbilder der bürgerlichen Moderne an und verband diese mit einer nationalistisch geprägten Version des Bürgers. Die >Liebe zur Heimat<, die der Klappentext von Pioniere der Alpen betont, stellte sicher, dass es sich um eine Person handelt, die sich ihrem Land intrinsisch verbunden sieht. Und das Aufrufen seines Pflichtgefühls machte deutlich, dass der freiheitsliebende und in den Bergen autonom agierende Mann gleichzeitig bereit war, sich in das Kollektiv der (männlichen) Staatsbürgerschaft einzureihen und darin seine vaterländischen Aufgaben zu erfüllen - es verhindert, mit anderen Worten, dass er in die Nähe des Revolutionärs und Aufständischen rücken konnte. Seine Verwegenheit und sein Freiheitsdrang waren auf den Kampf mit den Naturelementen am Berg beschränkt. Als Geschäftsmann, Familienoberhaupt und Staatsbürger jedoch hielt er die gesellschaftlichen Regeln auf vorbildliche Weise ein. Gleichzeitig unterschied sich der Bergführer vom politisch einflussreichen Bürger der städtischen Elite, deren Produkt er weitgehend war. Als Ausdruck eines bodenständigen und willensstarken Berglers bediente er die romantischen Naturfantasien der Städter*innen, die seit dem späten 18. Jahrhundert die modernen Fortschrittsnarrative als Teil eines zivilisationskritischen Gegendiskurses begleiteten. ${ }^{47}$

In der Forschung sind die Zusammenhänge zwischen der Schweizer Nation, den Bergen und modernen Männlichkeitsidealen ausführlich untersucht worden. ${ }^{48}$ Kaum thematisiert wurde aber bisher, dass die Figur des Bergführers Mitte des 20. Jahrhunderts nicht nur für den inneren Zusammenhalt der Schweiz und ihre Verteidigung gegen feindliche Kräfte innerhalb Europas stand, sondern auch für den kolonialen Aufbruch in bislang unbekannte Gebiete. Von Bernhard Schär stammt der wichtige Hinweis, dass dieselbe europäische Elite, welche die Idee eines freiheitsliebenden Hirten- und Bauernvolkes in den Alpen hervorgebracht hatte, gleichzeitig koloniale Vorstellungen von außereuropäischen Anderen ent-

47 | Vgl. Zimmer 1998, 647.

48 | Vgl. insbesondere Wirz 2007 und Hungerbühler 2013a. 
wickelte, die ein ländliches, ’primitives`, auf Subsistenz gründendes und noch nicht zur Freiheit gereiftes Dasein verkörpern sollten. ${ }^{49}$ Welches andere Wissen gewinnen wir aus der Einsicht, dass die diskursive Herstellung der Alpen und der Kolonien intrinsisch miteinander verbunden ist, und wie lässt sich dies anhand der Darstellung des Bergsteigens und des Bergsteigers als Inbegriff des Schweizer Bürgers aufzeigen?

Einen Hinweis auf den Zusammenhang zwischen nationalistischem Alpendiskurs und Kolonialismus liefert der Titel des oben besprochenen Werkes: In Pioniere der Alpen geht es um >Pioniere < und damit um Männer, die für die Entdeckung und Erforschung von bislang Unbekanntem stehen. Eines von vier Kapiteln ist den sogenannten >Auslandsführern< gewidmet, die im späten 19. und frühen 20. Jahrhundert im Kaukasus, in den Anden, im Himalaya oder in den Bergen Neuseelands unterwegs waren. In der Einleitung zu diesem Kapitel wird festgehalten, dass die Exploration der höchsten Berge auf britische Initiative zurückgeht. Die Durchführung dieses Unterfangens sei aber ohne die Schweizer Bergführer undenkbar gewesen, heißt es weiter, denn »als die Engländer sich neuen Tummelplätzen zuwandten, [...] wagten sie es nicht, in die noch ganz unbekannten Gebirge ohne ihre bewährten Schweizer Führer einzudringen, die damit ihren Anteil an der Erforschung der außereuropäischen Hochgebirge, besonders im Anfang, reichlich verdient haben « ${ }^{50}$. Schweizer Bergführer, so lautet die Erzählung an dieser Stelle, begleiteten die Vertreter der größten imperialen Macht, Großbritannien, auf die höchsten Berge der Welt und beteiligten sich damit an Unternehmungen, die sich auf koloniale Praktiken stützten und von imperialer Symbolik durchdrungen waren. Mehr noch, die Assistenz der Schweizer wurde als notwendige Bedingung dafür gesehen, dass die Briten überhaupt den Schritt in die unbekannten Gebirge der Welt wagen konnten. Diese Darstellung belegt die These, die der vorliegenden Arbeit zugrunde liegt: Die Popularität von Bergführerfiguren in der Schweiz des 20. Jahrhunderts beruhte auf der Möglichkeit, sie - und damit die Schweiz - in die europäische Abenteuer- und Entdeckerkultur zu integrieren und koloniale Fantasien damit nachhaltig in der Populärkultur zu verankern.

49 | Schär 2012, 316.

50 | Egger 1946, 337. 


\section{Erforschen Und Erobern}

Wie aber hängen Bergsteigen und koloniale Expansion zusammen? Die konstitutive Beziehung zwischen Alpinismus und Kolonialismus geht auf die Geschichte der Expeditionen zurück. Wie Robert Stafford zeigt, sind Entdeckungsfahrten seit dem 16. Jahrhundert mit den imperialistischen Projekten europäischer Mächte verbunden, und seit dem späten 18. Jahrhundert machen sie einen unhintergehbaren Bestandteil des imperialen Selbstverständnisses aus. ${ }^{51}$ Auch wenn viele Forschende davon ausgingen, nicht in koloniale Geschäfte involviert zu sein, war ihre Tätigkeit de facto nicht davon zu trennen. Entdeckungsfahrten im imperialen Kontext hingen eng mit den ausbeuterischen Praktiken des Kolonialismus zusammen, weil Informationen gefunden und zusammengetragen wurden, die der Legitimierung imperialer Herrschaft dienten. »The concentration of scientific and commercial data in Europe helped tip the balance of power against the indigenous peoples of other continents, whose control over their destinies could be eroded as surely by map coordinates and museum specimens as by steamships, bullets, and treaties of cession. ${ }^{52}$ Stafford stellt mit dieser Darstellung die kategorische Trennung zwischen Wissenschaft und Politik infrage und macht deutlich, dass letztere im Kontext des Kolonialismus immer auch eine >Politik mit anderen Mitteln $<$ war.

Dieses kolonial geprägte Verständnis von Entdecken und Erforschen lag auch dem außereuropäischen Bergsteigen Mitte des 20. Jahrhunderts zugrunde. Das Aufspüren und Erschließen von Neuland, der Kampf mit der Wildnis und den Grenzen des menschlichen beziehungsweise männlichen Körpers, die Verbesserung, Entwicklung und Erprobung technischer Hilfsmittel wie Zelte, Schlafsäcke und Sauerstoffgeräte, die Erforschung von Geologie, Flora und Fauna bislang unbekannter Gebiete und die Begegnungen mit Einheimischen und ihren scheinbar exotischen Sitten und Bräuchen kennzeichneten die Bergsteige-Expeditionen Mitte des 20. Jahrhunderts in die asiatischen, amerikanischen und afrikanischen Gebirge.

Entsprechend sah sich die Schweizerische Stiftung für Alpine Forschungen (SSAF), die ab 1939 mehrere wichtige und groß angelegte Expedi-

51 | Stafford 1999, 294.

52 | Stafford 1999, 302. 
tionen durchführte, im Dienste der Forscher und Bergsteiger. ${ }^{53}$ Sie verband die bergsteigerische Erschließung neuer Gebiete mit geologischen, botanischen, zoologischen und ethnologischen Untersuchungen sowie der Kartografierung bislang (im Westen) unbekannter Regionen. Auch in der medialen Öffentlichkeit wurde die enge Verbindung von bergsteigerischem Entdecken und wissenschaftlichem Erforschen immer wieder betont. In einem Artikel in der Neuen Zürcher Zeitung hieß es zur ersten Everest-Expedition von 1952: »Jedesmal, wenn ein weißer Fleck von der Erdkarte getilgt werden soll, teilt sich die Menschheit in zwei Lager: die einen warten fast fiebernd auf Berichte über Opfer, Schatzfunde oder unbekannte Bestien; den andern genügt der Wagemut, mit dem eine Handvoll Forscher den Geist der alten Pioniere wachhält, um zur fortschreitenden Erschließung des Erdballs ein Stücklein Erkenntnis beizutragen. ${ }^{54}$ Obwohl die Menschheit gemäß dieser Darstellung geteilt ist, verbindet sie eine kolonial geprägte Perspektive auf die Welt (was impliziert, dass kolonisierte Menschen, die diese koloniale Perspektive nicht einnehmen können, nicht zur Menschheit gehören). Die einen interessiert der abenteuerliche Teil, die Schätze und Ungeheuer - in den 1950er Jahren halten Spekulationen über den Yeti die Bevölkerung in Atem; die Schweizer Expeditionen versprechen sich nicht zuletzt spektakuläre Bilder und Informationen über den sabominable snow man $<-$, die anderen stellen die Erforschung der Welt in den Vordergrund. Beiden gemeinsam ist die Prämisse der notwendigen >Tilgung der weißen Flecken<, eine Vorstellung, die sich, wie Lisa Bloom schreibt, mit der Legitimation kolonialer Macht verbindet: »Marking them [spaces] as blank was a discursive strategy that produced the rationale to justify the process of filling them in by the West. $\aleph^{55}$ Das Bergsteigen im Himalaya wurde in der Schweiz der frühen Nachkriegszeit mit einem kolonialen Gestus der Entdeckung und des Ausgriffs verknüpft - paradoxerweise zu einem Zeitpunkt, an dem die Dekolonisationsbewegungen in Asien und Afrika erfolgreich das Blatt zu wenden begannen.

53 | SSAF 1972, 147. Die Stiftung nennt sich heute Schweizerische Stiftung für Alpine Forschung, siehe www. alpineresearch.ch (Zugriff am 24. September 2018). 54 | Gurtner, Othmar: "Mount-Everest-Expedition 1952", in: Neue Zürcher Zeitung, 20. Juni 1952.

55 | Bloom 1993, 2. 
Der koloniale Blick auf die Anderen lässt sich etwa in der Berichterstattung über Nepal ausmachen, wo die Schweizer Everest-Expeditionen von 1952 ihren Anfang nahmen. Wegen seiner langjährigen Abschottung war über das Königreich wenig bekannt. ${ }^{56}$ Nepal war keine Kolonie und galt wegen seiner Isolationspolitik, mit der es auch auf den britischen Kolonialismus reagierte, als eines der wenigen Länder, das scheinbar noch >unentdeckt< war. Mit anderen Worten: Gerade weil es keinem Kolonialisierungsversuch zum Opfer gefallen war und damit noch das Unbekannte, Natürliche und Ursprüngliche zu beherbergen schien, dominierte in den 1950er Jahren paradoxerweise eine koloniale Perspektive auf Nepal. Das Land wurde, wie Sara Elmer schreibt, von Schweizer Protagonist*innen der Anthropologie und Entwicklungshilfe »als weißer Fleck auf der Landkarte betrachtet, der noch entdeckt und erforscht werden konnte ${ }^{57}$.

In der Berichterstattung dominierte deshalb die Auffassung, dass $>$ neue< Erkenntnisse über ein >unbekanntes< Land gewonnen werden sollten. So berichtete das Expeditionsmitglied André Roch in der Neuen Zürcher Zeitung vom 17. Mai 1952: »Während der Nepaler den Typus zwischen Hindu und Chinesen verkörpert, ist der Tibetaner durchaus Mongole. Er ist dunkelhäutiger und man ist ungewiss, ob alles Dunkle Haut ist. ${ }^{58}$ Roch stellte nicht nur Hypothesen über rassische Unterschiede an, die in Nepal angeblich anzutreffen waren, sondern brachte auch die rassistische Vorstellung ins Spiel, wonach dunkle Hautfarbe auf eine unhygienische Lebensweise zurückgeführt werden könne. ${ }^{59}$ Auch intertextuelle Anleihen an die westliche Abenteuerliteratur waren in diesen Berichten omnipräsent. Roch schreibt, die Dorfbewohner hätten »chinesische Züge mit hängenden Schnäuzen, ganz wie in Sven Hedins Büchern « ${ }^{60}$. Auffallend ist, welchen zentralen Stellenwert die Diskussion über die physischen Merkmale der Einheimischen und ihre Ausdifferenzierung in

56 | Vgl. Whelpton 2005, Des Chene 2007.

57 | Elmer 2012, 261.

58 | Roch, André: "Die Mount-Everest-Expedition von 1952. Fortgesetzter Anmarsch «, in: Neue Zürcher Zeitung, 17. Mai 1952.

59 | Vgl. dazu meine Ausführungen zur rassistischen Verbindung von Weißsein und Reinheit auf der einen und Schwarzsein und Unreinheit auf der anderen Seite im ersten Kapitel der Arbeit.

60 | Roch, André: "Die Mount-Everest-Expedition von 1952. Fortgesetzter Anmarsch“, in: Neue Zürcher Zeitung, 17. Mai 1952. 
unterschiedliche rassifizierte Gruppen einnahm, die oftmals auf orientalistischen Stereotypen gründeten. ${ }^{61}$ Von den Sherpas heißt es im französischen Erinnerungsband zur Everest-Expedition von 1952, sie seien »de race mongole, petits, gais, serviables et dévoués jusqu'au sacrifice $\ll^{62}$.

Über solche populären Anleihen an die Rassentheorien hinaus waren rassenanthropologische Forschungen auch offizieller Bestandteil der Schweizer Everest-Expedition von 1952. Neben dem Geologen Augustin Lombard und dem Botaniker Albert Zimmermann gehörte die Ethnologin Marguerite Lobsiger-Dellenbach zum wissenschaftlichen Personal der Frühjahrsexpedition. Sie hatte lange Zeit als Assistentin des einflussreichen Genfer Anthropologen Eugène Pittard gearbeitet und wurde 1952 Direktorin des Ethnographischen Museums in Genf. Im Zuge der Schweizer Expedition vermaß sie in Nepal 51 Männer und 24 Frauen. Für jede Person notierte sie die Größe im Stehen und Sitzen, zwei Kopfmaße, drei Gesichtsmaße, die Größe und Breite der Nase, Haut- und Augenfarbe sowie die Textur und Farbe der Haare. ${ }^{63}$ Dass ihre Forschung Teil der Schweizer Everest-Expedition war, verdeutlicht, dass Rassenforschung über das Ende des Zweiten Weltkriegs hinaus in der Schweiz nicht nur praktiziert wurde, sondern auch weiterhin auf großes Interesse stieß. ${ }^{64}$

\section{Tropische Alpen, Alpine Tropen}

Neuere Untersuchungen zeigen, dass die Erforschung von Kolonien und Alpen keineswegs getrennt vonstatten ging. Mit Bezug auf Ann Stolers und Frederick Coopers wegweisende Forderung, Kolonien und Metropole in einem gemeinsamen Analyserahmen zu untersuchen, schlägt Schär deshalb vor, Alpen und Tropen als intrinsisch miteinander verbundene Gegenstände der modernen Wissenschaften zu behandeln. ${ }^{65}$ Nahegelegt wird dies durch die gleichzeitige Erschließung beider Räume, was dazu führte, dass das Wissen über die Tropen der Erforschung der Alpen zugrunde gelegt wurde und umgekehrt. Harries legt anhand der Mission

61 | Vgl. Said 1994a.

62 | Roch 1952, 17.

63 | Lobsiger-Dellenbach 1953, 100.

64 | Vgl. dazu Germann 2013, Keller 1995 und Keller 2006.

65 | Schär 2015b, 31. 
dar, dass Schweizer Forschende kulturelle Konventionen des Sehens, Untersuchens, Unterscheidens und Zuordnens mitbrachten, die von ihrem Leben in und ihren Auseinandersetzungen mit der alpinen Landschaft geprägt waren: »In particular, they [the missionaries] carried to Africa the European images, themes and attitudes employed to describe the Alps as a primitive wilderness. ${ }^{66}$ Umgekehrt gründete die Analyse der Schweizer Naturgeschichte, wie Schär nachweist, auf einem kolonialen Vokabular und den materiellen Grundlagen einer imperialen Raub- und Sammelkultur. ${ }^{67}$ So entwickelte Oswald Heer, Professor für Botanik am damaligen Eidgenössischen Polytechnikum (der heutigen ETH Zürich), in seinem 1865 veröffentlichten Hauptwerk Die Urwelt der Schweiz eine breit rezipierte Theorie über die geologische und botanische Vergangenheit des Landes. Er ging davon aus, dass die Schweiz ursprünglich durch eine tropische Vegetation und ein warmes und feuchtes Klima gekennzeichnet gewesen war. Allmählich wurde dieses Klima zunehmend temperierter, sodass höher entwickelte Pflanzen und Tiere entstehen konnten. Mit der Eiszeit nahm die tropische Phase ein Ende und wich einem gemäßigten Klima, welches die Besiedlung durch Menschen möglich machte. ${ }^{68}$

Die These einer Evolution von einer tropischen zu einer gemäßigten Schweiz ist Resultat der kolonialen Prämissen, die Heers Forschung zugrunde lagen: Er verglich Pflanzen- und Tierfossilien aus den Alpen mit Objekten, die in den neu eingerichteten naturhistorischen Museen zu finden waren und größtenteils aus kolonialen Kontexten stammten. Diese asynchrone Anordnung von Gegenständen aus unterschiedlichen Zeiträumen - den versteinerten Überresten aus den Alpen und den zeitgenössischen Tier- und Pflanzenfunden aus den Tropen - bildete eine unreflektierte koloniale Grundlage von Heers wissenschaftlichen Studien. Die zeitliche Differenz, die in der Versuchsanordnung angelegt war, mutierte unter der Hand zu einem Strukturmoment des Narrativs vom naturgeschichtlichen Ursprung der Schweiz. Demnach ließen sich in den Tropen diejenigen natürlichen Bedingungen finden, die am Beginn der Schweizer Naturgeschichte standen. Mithilfe dieser Ungleichzeitigkeit konnte

66 | Harries 2007b, 219.

67 | Schär 2015b.

68 | Schär 2015b, 38. 
eine Vorstellung der Tropen konstruiert werden, die scheinbar Einblicke in die Anfänge der eigenen Entwicklung zu geben vermochte.

Eine solche koloniale Ineinanderfaltung von Raum und Zeit war kein Spezifikum von Heers Wissenschaft. Die »Ungleichheit zwischen jenen Menschen, deren Geschichte rekonstruiert wird, und jenen, die dieser Rekonstruktion als Fossilien dienen «, ${ }^{69}$ stellt gemäß Sommer ein grundlegendes Element der Anthropologie dar. Wie Schär argumentiert, basierten solche Vergleichsanordnungen auf einer Zeitstruktur, die von Johannes Fabian im Hinblick auf die moderne Anthropologie als »Verweigerung der Gleichzeitigkeit ${ }^{70}$ beschrieben wurde: »After all, Heer's narrative implied that the contemporary stropics $<$ had remained static and unchanged since the beginning of times. ${ }^{71}$ McClintock spricht vom »anachronistischen Raum $\ll^{72}$ als einer wichtigen imperialen Denkfigur des späten 19. Jahrhunderts, die neben wissenschaftlichen auch populäre Diskursfelder prägte: »According to this trope, colonized people - like women and the working class in the metropolis - do not inhabit history proper but exist in a permanently anterior time within the geographic space of the modern empire as anachronistic humans, atavistic, irrational, bereft of human agency - the living embodiment of the archaic >primitive $<. \ll^{73}$

Die stropische Wendung z zum modernen Selbst ist, wie ich an anderer Stelle dargelegt habe, konstitutiv für die Konstituierung des europäischen Subjekts im 19. Jahrhundert. Der Begriff verweist dabei auf die Doppeldeutigkeit der Tropen, »denn die Gegend am geographischen Wendekreis stellt die Bedingung der sprachlichen Wendung dar, über die der Mensch der gemäßigten Zone mit seiner verlorenen Vergangenheit in Beziehung tritt ${ }^{74}$. Am Beispiel von Friedrich Nietzsche lässt sich zeigen, dass diese Rückwendung des eigenen Blicks vermittels des tropischen Anderen auf sein eigenes historisches Selbst eine prominente Form moderner Selbstkritik begründete. Die Tropen repräsentierten demnach nicht nur das

69 | Sommer 2010, 65. Sommers Artikel thematisiert gegenwärtige Konstellationen und Transformationen dieser Versuchsanordnung in der Humanpopulationsgenetik.

70 | Fabian 1983.

71 | Schär 2015b, 39.

72 | McClintock 1995, 30.

73 | McClintock 1995, 30.

74 | Purtschert 2006, 176 [Hervorhebung im Original]. 
>primitive< Vergangene als Überwundenes, sondern auch das, was der gemäßigten Zone abhanden gekommen war und als Verlust betrauert werden konnte. ${ }^{75}$ Diese Zivilisationskritik zirkuliert auch im Schweizer Kontext. Mit dem Verschwinden eines angeblich simplen und naturnahen Lebens in den Alpen, das von den Transformationen einer industrialisierten Gesellschaft eingeholt und zerstört wurde, standen die Kolonien zunehmend für eine positiv konnotierte Ursprünglichkeit. Harries zufolge kam Missionsgesellschaften bei der Verbreitung solcher Bilder eine wichtige Rolle $\mathrm{zu}$, denn »a nostalgia for a more secure, harmonious world governed by simple values and everyday traditions pervaded much of the missionary literature on Africa $\ll^{76}$.

Der anachronistische Raum - zu dem nicht nur Menschen und Kulturen gehörten, sondern auch >primitive< Geografien, Landschaften, Flora und Fauna - stellte eine koloniale Bedingung für das Fortschrittsdenken und, spezifischer noch, für die evolutionären Erklärungsmodelle des 19 . und 20. Jahrhunderts dar. Fortschritt wurde demnach von ausgewählten Subjekten und Landschaften verkörpert, während andere an beliebigen Orten auf der Fortschrittsskala oder gar an deren Nullpunkt platziert werden konnten. ${ }^{77}$ McClintock hat aufgezeigt, dass diese Differenzierungen die europäischen Nationalstaaten auch in ihrem Inneren durchzogen und auf diese Weise interne Räume schufen, die als >ursprünglichく, >natürlich , oder >primitiv markiert waren: das Private im Unterschied zum Öffentlichen, die Lebensräume von Arbeiter*innen, Prostituierten, Fahrenden, Armen oder der ländlichen Bevölkerung. ${ }^{78}$

Die Anordnung von Menschen an unterschiedlichen Punkten auf einer historischen Achse des Fortschritts war nicht statisch. Sie beruhte auf dem beweglichen Einsatz von Differenzierungsprozessen und deren kontinuierlicher Anpassung an die jeweiligen Machtformationen. Auch das lässt sich am Beispiel der Alpenbevölkerung aufzeigen. So besteht, wie Schär es nennt, eine >koloniale Pointeく der volkskundlichen Forschung in der Schweiz darin, dass die sprimitiven< Traditionen, die im frühen 20. Jahrhundert in der alpinen Bevölkerung ausgemacht wurden,

75 | Purtschert 2006, 176.

76 | Harries 2007a, 50.

77 | Vgl. dazu Sommer 2015, 46ff.

78 | Vgl. McClintock 1995. 
lediglich »Überreste aus früheren Kulturzuständen « ${ }^{79}$ darstellen sollten. Im Unterschied dazu wurden ähnliche Funde in den Tropen nicht als Relikte einer lange vergangenen Kulturstufe, sondern als Beweis für den >primitiven< Gesamtzustand einer Kultur ausgelegt. ${ }^{80}$

Angefügt werden kann, dass die koloniale Pointe je nach Ausgangslage variiert wurde. Die Alpen, und damit kommt die Beweglichkeit differentieller Zuschreibungen ins Spiel, galten zwar im Vergleich zu den Tropen als höher entwickelt und entgingen so der Gefahr, als >primitive< Zone eingestuft zu werden. Durch ihre Verbindung mit frühen Stufen der Menschheitsgeschichte wurde die alpine Bevölkerung aber gleichzeitig als partiell zurückgeblieben und entwicklungsbedürftig ausgewiesen. Damit konnte ein >Berg-Othering in Gang gesetzt werden, das bis in die Gegenwart hinein wirkmächtig ist: Im Verhältnis zur Landschaft und den Bewohner*innen der Tropen gehörten die Alpen und ihre Bevölkerung zur zivilisierten Welt Europas. Im Vergleich aber zu den urbanen Zentren Europas rückten sie in die Nähe des >Primitiven«. Praktiken und Lebensformen der alpinen Bevölkerung konnten als rückständig klassifiziert und zum Einsatzfeld für soziale Regulierungen gemacht werden, die den Übergang der Bergbevölkerung von der Vormoderne in die Moderne sicherstellen sollten. Mit dem Bezug auf das koloniale Vokabular gerieten die Alpen in ein komplexes Spiel von Nähe und Distanz zum >Primitiven<, mit dessen Hilfe innerstaatliche Hierarchien im 19. und 20. Jahrhundert hergestellt und legitimiert werden konnten. ${ }^{81}$

\section{SCHWEIZER /BERG-0THERINGr}

Die koloniale Verbindung von Entdecken und Erforschen wirkte auch auf Europa und die Schweiz zurück, wie sich bei der Entstehung des modernen Alpinismus im 19. Jahrhundert zeigt. Aus der Perspektive der britischen Bergsteiger*innen wurden die Alpen als >weißer Fleck auf der Landkarte beschrieben und als unbekannte, wilde und ursprüngliche

79 | Schär 2015a, 319.

80 | Schär 2015a, 320.

81 | Vgl. dazu Schärs Ausführungen zur wissenschaftlichen Untersuchung der Zähne und der Einführung der Zahnpflege im Goms der 1920er-Jahre; Schär 2008b und Schär 2007, 34. 
Landschaft imaginiert, die in kolonialer Manier erobert, erkundet, in Besitz genommen, vermessen und benannt werden konnte. Eine imperiale Rhetorik, bei der es darum ging, als erster Mensch den Fuß auf ein bislang unbetretenes Stück Land zu setzen, dominierte das Wettrennen um die Erstbesteigung der höchsten Alpengipfel. Der von den Briten initiierte moderne Alpinismus bot, wie Peter Hansen argumentiert, Männern der Mittelschicht die Gelegenheit, ihre kolonialen Ambitionen inmitten Europas auszuleben: »Middle-class mountaineers adopted the languages of exploration and adventure from contemporary explorers in the Arctic and Africa to describe their climbing. ${ }^{82}$

Als die Alpen von den Briten im 19. Jahrhundert zum »playground of Europe « ${ }^{83}$ erklärt wurden, stieß das auf Widerstand seitens der bürgerlichen Elite in der Schweiz. Wie Tanja Wirz ausführt, war die >Rückeroberung< der Schweizer Alpen von den Briten ein Auslöser, der zur Gründung des Schweizer Alpenclubs (SAC) 1863 führte: »Die imperialistische Botschaft der englischen Bergsteiger blieb nicht ungehört: Im damaligen politischen Klima interpretierten Schweizer Bergsteiger dies als Besetzung eines Gebietes, das zur Nation Schweiz gehörte und deshalb symbolisch rückerobert werden musste. Ein zentrales Motiv bei der Gründung des SAC war deshalb der Wunsch nach konkreter Aneignung der als >Geburtsort< der Schweiz gedeuteten imaginären Alpen im Wettstreit mit anderen Nationen. ${ }^{84}$ Die Briten waren nicht die ersten, welche die Schweizer Alpen einem imperialen Zugriff unterwarfen. Die städtischen Eliten, die sich 1863 zur Gründung des SAC versammelten, hatten längst ihre eigene kolonial konnotierte Perspektive auf die Berge entwickelt.

Das lässt sich anhand eines Schreibens des Berner Chemieprofessors Rudolf Theodor Simler zeigen, das dieser am 20. Oktober 1862 an neun bekannte >Bergsteiger und Alpenfreunde der Schweiz« verschickt hatte. In diesem Schreiben, das als Gründungsdokument des SAC in die Geschichte einging, hielt Simler seine Befürchtung fest, der 1857 gegründete britische Alpenclub könne eine dominante Größe bei der bergsteigerischen und wissenschaftlichen Erschließung der Schweizer Alpen werden: »Es ist Ihnen nicht unbekannt, dass der >englische Alpenclub< in Folge seiner Organisation den schweizerischen Touristen starke Concur-

82 | Hansen 1995, 304.

83 | Vgl. Stephen 1936.

84 | Wirz 2007, 124. 
renz macht, und es könnte bald dahin kommen, dass, wenn das Publicum in der Schweiz über die Regionen des ewigen Schnee's und Eises, über die Zugänglichkeit der Gletscher und Felsengipfel sich aufklären will, es $\mathrm{zu}$ den Beschreibungen des englischen Alpenclubs greifen muss. Eine solche Sachlage schien uns bemühend, ja sogar beschämend.«85

Simler befürchtete also, dass die organisierte Form des Bergsteigens durch einen eigens dafür gegründeten Club zu einem Wissensmonopol der Briten führen könnte. Die Vorstellung, dass das kartografische, geografische und alpinistische Wissen über ein Territorium, das zum Schweizer Nationalstaat gehörte, von einer anderen Nation erhoben, verwaltet und zur Verfügung gestellt würde, fand er >beschämend<. Keine Nebensächlichkeit war dabei, dass diese andere Nation die größte imperiale Macht der Zeit darstellte und einen bedeutsamen Teil der Erdoberfläche als ihr Herrschaftsgebiet reklamierte. Wenn Simler die britische Dominanz in den Schweizer Alpen als >beschämend bezeichnet, dann schwang nicht zuletzt eine Abgrenzung von den Kolonien und ein Verständnis von Scham mit, das darauf beruhte, wie eine Kolonie behandelt werden zu können.

Simler setzte sein Schreiben mit einer Darstellung der alpinen Entdeckungsgeschichte fort. Er betonte, dass Schweizer von Beginn an eine bedeutende Rolle darin gespielt hatten:

"Auf den Schweizern ruht zwar immer das Verdienst, die ersten gewesen zu sein, welche auf die unvergleichlichen Schönheiten der Alpen- und Gletschernatur aufmerksam machten, welche sie zugleich wissenschaftlich explorirten - wir brauchen nur zu erinnern an: Conrad Gessner, Josias Simler, J. J. Scheuchzer, H. B. de Saussure, Escher v. d. Linth, Hugi, Agassiz, Desor, G. Studer, M. Ulrich, J. Weilenmann -, aber heute, unter veränderten Verhältnissen, wäre es wünschenswerth, wenn man sich einigte zu einer grösseren Gesellschaft, um so zum Theil planmässig die letzten Verstecke der Eisregionen und die noch unbestiegenen Gipfel in Angriff zu nehmen und später durch anmuthige und belehrende Schilderungen die gesammelten Erfahrungen dem Publicum zu übergeben." ${ }^{86}$

In dieser Passage geht Simler nicht auf die Bedeutung britischer Bergsteiger im >Goldenen Zeitalter des Alpinismus

85 | Simler 2013, 54. Siehe auch Senger 1945, 170.

86 | Simler 2013, 54. 
Erstbesteigungen initiiert und gemeinsam mit lokalen Führern durchgeführt hatten. Er schreibt Schweizer Forschenden die ästhetische und wissenschaftliche >Entdeckung der Alpen zu und sieht diese Tradition durch die jüngsten Entwicklungen bedroht - eine Bedrohung, die sich mit der Gründung eines Schweizer Alpenclubs abwenden ließe. Vor dem Hintergrund einer symbolischen Besetzung der Alpen durch die Briten kann Simlers Brief als Gegendiskurs verstanden werden, der einer britischen Hegemonie dezidiert widersprach: Erstens, so Simler, hatten nicht die Briten, sondern die Schweizer die Erforschung der Alpen begonnen und die größten Beiträge dazu geleistet. Damit müssten die Schweizer die imaginäre Vorherrschaft über die Alpen nicht von den Briten zurückerobern, sondern einzig deren drohende Konkurrenz abwehren. Zweitens, und das ist der bedeutsamste Punkt, legt Simler denselben imperialen Blick auf die Alpen an den Tag, der auch die britische Praxis kennzeichnet: Der neu zu gründende Schweizer Alpenclub soll die letzten >unerreichten Orte< entdecken, die letzten >unbestiegenen Gipfel< erklimmen und bislang >unbekannte Gebiete< erforschen.

Simler brachte in diesen Zeilen eine koloniale Perspektive auf die Berge in Anschlag, die ihn als Mitglied einer europäischen Bildungselite auswies, und verband diese mit einer Nationalisierung des Territoriums. ${ }^{87}$ Über die einwöchige Expedition zum Tödi, die am 9. August 1863 unter der Leitung von Simler stattgefunden hatte und die als erste Unternehmung des neu gegründeten SAC gilt, schreibt Andrea Porrini: »In der Tat wurde die Unternehmung als eine patriotische und wissenschaftliche Kolonisierung eines Niemandslandes gesehen, als welches das Hochgebirge damals galt, jener Teil des Landesterritoriums, den der junge Bundesrat noch nicht so unter Kontrolle hatte. $\ll^{88}$ Zur Verteidigung des Herrschaftsanspruchs über die Alpen, der sich der SAC verschrieb, gehörte die Sicherung der Definitionsmacht über dieses Territorium, etwa durch die Benennung von Gebieten, die Standardisierung von Namen, Praktiken der Vermessung, das Aufbereiten und den Vertrieb von kartografischen Informationen sowie den Bau von Wegen und Unterkünften. Bis zu einem gewissen Grad sicherte sich der SAC auch die Kontrolle über die Mobilität in diesem Gebiet, indem er den Zutritt zum Club und zu seinen Hütten

87 | Vgl. dazu Schär 2015a.

88 | Porrini 2013, 50. 
regulierte. ${ }^{89}$ Vor dem Hintergrund der imperialen Praxis des Entdeckens kann die Position des SAC als symbolischer Souveränitätsanspruch gedeutet werden, der die Abgrenzung gegenüber den kolonialisierten Territorien Außereuropas implizierte und gleichzeitig die städtische Vorherrschaft gegenüber den ländlichen Gebieten in der Schweiz zum Ausdruck bringen sollte.

In einer Zeit, in der die wissenschaftliche Erforschung eines Gebietes, seiner Naturgeschichte, seiner Geologie und seiner >Völker< eine entscheidende Komponente imperialer Macht darstellte, markierte Simlers Aufruf zur Erforschung des eigenen Territoriums die Zurückweisung eines imperialen Anspruchs vonseiten britischer Bergsteiger und Forscher. Simlers Position ist aber mehrdeutig, denn die bürgerliche Elite, die sich im SAC versammelte, hatte mehr mit den britischen Bergsteigern und Wissenschaftlern gemein als mit den bäuerlichen Alpenbewohner*innen. Simlers Schreiben signalisierte daher mindestens ebenso sehr einen Gestus der kolonialen Besitznahme wie einen Moment der Selbstverteidigung. Sein Schreiben besagte nicht: >Wir sind die Wilden<, sondern vielmehr: >Diese Wildnis gehört zu unserem Herrschaftsgebiet<.

Die bürgerliche Elite der Schweiz betrachtete den alpinen Raum unter einer imperialen Perspektive als weißen Fleck auf der Landkarte, als Untersuchungsobjekt und als Herausforderung für die Modernisierung des Landes. Dieser Herausforderung begegnete man mit Projekten wie dem Bau der Eisenbahn oder der flächendeckenden Vermessung der Schweiz, wie sie vom Bundesamt für Topographie vorgenommen wurde. ${ }^{90}$ Gleichzeitig wurden Bewohner*innen der Alpen und insbesondere Bergführer aber auch zunehmend als Sinnbild für die Schweiz eingesetzt. Die Vorstellung von den Bergen als einem Ort natürlicher Schönheit und Erhabenheit verschränkte sich ab Mitte des 19. Jahrhunderts zunehmend mit einem nationalistischen Diskurs, der den Alpen eine zentrale Rolle für die Imagination des jungen helvetischen Staates zuwies. So entstand zwischen 1870 und 1945 ein Alpendiskurs, der über Klassen- und Sprachgrenzen hinaus wirkmächtig war und sich dadurch auszeichnete, dass Landschaft und Nation miteinander verflochten wurden. ${ }^{91}$ Wie Oliver Zimmer zeigt, wurde die Ausgestaltung einer nationalen Identität durch

89 | Wirz 2007, 125.

90 | Vgl. Gugerli und Speich 2002.

91 | Zimmer 1998, 645. 
diese >Naturalisierung der Nation< fortan auf die Natur zurückgeführt: $»[N]$ ature - or in the Swiss case, the Alps - [was] [...] depicted as a force capable of determining national identity and giving it a compact, homogeneous, unified form. $\ll^{92}$ In dieser Zeit verfestigte und verbreitete sich die Vorstellung, die Eigenheiten der Schweizer Nation und ihrer Bevölkerung seien durch die territoriale Beschaffenheit des Landes bedingt.

Leitbegriffe des nationalen Selbstverständnisses, insbesondere die sprichwörtliche Freiheit, die der Mythos des Wilhelm Tell und der Rütlischwur illustrierten, wurden aus der alpinen Landschaft abgeleitet, wie Wirz schreibt: »In den Jahren 1870 bis 1940 wurde es zum Allgemeinplatz, dass die Schweiz mit all ihren Merkmalen geradezu zwangsläufig aus der alpinen Landschaft hervorgegangen sei; Demokratie, Freiheit, Unabhängigkeit und was der schweizerischen Ideale mehr sind, waren demnach in den engen Bergtälern gleichsam gewachsen. « ${ }^{93}$ Die Verbindung zwischen den Alpen und der Nation wurde in diesen Narrativen kausal dargestellt, als naturwüchsiges Wesen der Nation, das sich aus ihrer landschaftlichen Beschaffenheit ergab und in ihr wurzelte.

Die Wahl der Alpen als zentralem Signifikanten der Nation liegt jedoch keineswegs auf der Hand: Wie Zimmer ausführt, war die Schweiz 1910 nach England das am stärksten industrialisierte Land. Zudem wohnte nur ein Bruchteil der Bevölkerung in den Alpen. ${ }^{94}$ Die fortschreitende Industrialisierung und Modernisierung der Schweiz ließ die Berge aber als faszinierende Gegenwelt erscheinen, deren Bewohner*innen im Kontrast zum zivilisierten und von sich selbst entfremdeten Menschen Einfachheit, Ehrlichkeit und Reinheit verkörperten. ${ }^{95}$ Der Bezug auf die Landschaft als Ursprung des schweizerischen Wesens macht es zudem möglich, dem in Europa dominanten sethno-linguistischen Nationalismus<, der von einer gemeinsamen Sprache und Kultur als Grundlage der Nation ausging und insbesondere in Deutschland und Italien vorherrschend war, etwas Überzeugendes entgegenzusetzen. ${ }^{96}$

Die Berge erwiesen sich noch in weiterer Hinsicht als Glücksgriff für die mythische Grundlegung des jungen Nationalstaates. So konnte die

92 | Zimmer 1998, 645.

93 | Wirz 2007, 91 [Hervorhebung im Original].

94 | Zimmer 1998, 660.

95 | Vgl. Zimmer 1998, 647.

96 | Zimmer 1998, 649, 659. 
katholische Innerschweiz, die im Sonderbundskrieg von 1947 unterlegen war, als Geburtsstätte der mythischen Schweiz symbolisch in die Nation eingebunden werden. Zudem wurden jene Bilder von der Schweiz als >Bergparadies < bedient, die auch im wirtschaftlich zunehmend wichtigen Fremdenverkehr an Bedeutung gewannen. ${ }^{97}$ Folkloristische Anlässe sowie das Bergsteigen und Wandern stifteten physische, affektive und intellektuelle Verbindungen zwischen der Bevölkerung und einer Landschaft, welche die Nation verkörpern sollte. Die Alpen wurden als erfahr- und begehbarer Raum gestaltet, »in dem rituell nationale Identität gestiftet wird: Beim Wandern durch die nationale Erinnerungslandschaft schrieben sich Schweizerinnen und Schweizer die Heimat gleichsam in ihre Körper ein « ${ }^{98}$, stellt Wirz fest.

Der nationale Diskurs wies damit einerseits einen identifikatorischen Bezug zu den Bergen auf, zeichnete sich aber andererseits durch eine imperiale Sicht auf eben diese Berge aus. Diese Spannung zwischen Herrschaft über alpine Lebenswelt und Identifikation mit ihr habe ich oben mit dem Begriff des >Berg-Othering <eschrieben. Auch die Elite, die sich 1863 zum SAC zusammenschloss, lässt sich in dieser dialektischen Struktur verorten: Die Gründungsfiguren des SAC verkörperten keineswegs die alpine und ländliche Schweiz. Sie entstammten allesamt wohlhabenden bürgerlichen Familien aus größtenteils städtischen Kontexten. Von den 35 Personen, die sich am 19. April 1863 in Olten zur Gründung trafen, lebten 22 in den drei Deutschschweizer Städten Basel, Zürich und Bern, und sie bezeichneten sich als Unternehmer, Akademiker, Beamter, Anwalt, Pfarrer oder Kaufmann. ${ }^{99}$ Kein Bauer, kein Bergführer, kein Hotelier und kein Arbeiter war Teil der illustren Runde. Und dennoch bezogen sie sich auf die Alpen, um ihr Selbstverständnis als Schweizer und Bergsteiger $\mathrm{zu}$ artikulieren.

Die ländliche Bevölkerung stand dem SAC wegen seiner bürgerlichen Situierung skeptisch gegenüber. Dies führte unter anderem zu Spannungen mit dem Bergführerwesen, das der SAC gleich nach seiner Gründung besser regulieren und organisieren wollte. ${ }^{100}$ Wie Andrea Hungerbühler ausführt, wurde in diesen Konflikten auch der soziale Status beider Sei-

97 | Wirz 2007, 92.

98 | Wirz 2007, 93.

99 | Schmid und Anker 2013, 55.

100 | Hungerbühler 2013b. 
ten ausgehandelt: »Den häufig akademisch gebildeten, bürgerlichen, in Städten ansässigen >Herren $<$ des SAC standen - zumindest bis zum Zweiten Weltkrieg - die meist aus bäuerlichen oder handwerklichem Milieu und aus Berggebieten stammenden Bergführer gegenüber. Die soziale Hierarchie schlug sich auf Seite der >Herren< in einer Haltung der Überlegenheit nieder, die sowohl belehrende wie fürsorgliche Züge annehmen konnte. «101 Die Art und Weise, in der das Verhältnis zu den Bergen als Symbol der Nation hergestellt wurde, war damit stark von Klasse und Geschlecht geprägt. So wurde das Bergsteigen um 1900 vor allem von bürgerlichen Männern praktiziert. Tanja Wirz zufolge nutzten sie die Alpen dabei als >liminalen Raum<, der es ihnen ermöglichte, die körperlichen und psychischen Grenzen zu überschreiten, die ihnen durch das Leben im urbanen Raum gesetzt wurden. ${ }^{102}$ Das Bergsteigen diente zudem dazu, homosoziale Bindungen zu kultivieren und Konkurrenzverhalten einzuüben - beides entscheidende Elemente einer erfolgreichen Männlichkeit in einer kapitalistischen Wirtschaftsordnung.

Das >Berg-Othering< ermöglichte es, eine kolonial kodierte Differenz zwischen bürgerlich-städtischer und bäuerlich-ländlicher Männlichkeit aufrechtzuerhalten und gleichzeitig ein Angebot zur wechselseitigen Identifikation zu unterbreiten: Der seinfache< Mann sollte sich im Bild des bodenständigen Berglers repräsentiert und in die Nation integriert sehen. Im Zuge der > Geistigen Landesverteidigung< etablierte sich auf dieser Grundlage ein integrativer Alpendiskurs, der die Grenzen von Klassen und Regionen, nicht aber die Geschlechtergrenzen transzendieren sollte, denn die »grosse Verbrüderung quer durch die politischen Lager fand [...] auch über die Vorstellung statt, alle Schweizer seien Bergkameraden « ${ }^{103}$. Während den Frauen eine komplementäre Rolle zu Hause oder in der Berghütte zugewiesen wurde, verband der sogenannte Aktivdienst, der militärische Einsatz der wehrpflichtigen Bürger, der zu einem Großteil im Gebirge absolviert wurde, die unternehmerische und politische Elite mit allen anderen wehrfähigen Männern.

Nation wurde somit nicht nur über den männlichen Körper, sondern auch vermittels männlicher Körperschaften dargestellt. Zentral dafür war das Konzept der Brüderlichkeit, das es ermöglichte, Männer über soziale

101 | Hungerbühler 2013b, 83.

102 | Wirz 2007.

103 | Wirz 2007, 359. 
Unterschiede hinweg als Gleiche zu inkorporieren: »Das Ideal der Brüderlichkeit sollte [...] soziale Schranken zumindest gedanklich niederreißen, Staatenlenker und Staatsdiener als im selben Staatsboot sitzend imaginieren. ${ }^{104}$ Frauen blieben von diesen Repräsentationen ausgeschlossen, weil sie als immer schon abhängige Wesen galten, die sich nicht als autonome Subjekte zu einer Gemeinschaft zusammenschließen konnten. ${ }^{105}$ Bereiche, die eine Nähe zum Militär aufwiesen und in denen sich Männer klassenübergreifend gemeinsam betätigten, erwiesen sich als besonders geeignet für die androzentrischen Darstellungen der Nation. Ein wichtiger Schauplatz für die nationale Repräsentation wurde deshalb der Sport, bei dem sich starke und disziplinierte Männerkörper im Verbund betätigen konnten. Wie Svenja Goltermann am Beispiel der Turnbewegung im Deutschland des späten 19. Jahrhunderts zeigt, bildete die Leistungsfähigkeit der männlichen Körper nicht nur deren Virilität ab: »An ihnen mass sich auch das Potential der $>$ Nation $\ll . \ll{ }^{106}$ In der Schweiz wurde die Verbindung zwischen dem männlichen Körper, der Kameradschaft und der Nation insbesondere durch den Alpinismus gestiftet - als »brotherhood of the rope ${ }^{107}$.

\section{Der inative informantı Und die Grenzen der Kultur}

Die zunehmende Bedeutung der Alpen für die nationale Repräsentation der Schweiz war, so meine These, in eine koloniale Semantik eingelassen - ein Aspekt, der in der bestehenden Forschung kaum reflektiert wird und den ich im Folgenden anhand der Bergsteigerliteratur vertiefe. Bergführer verkörperten demnach schweizerische Werte nicht nur vermittels androzentrischer Vorstellungen, wie die Geschlechtergeschichte überzeugend dargelegt hat. ${ }^{108}$ Vielmehr war deren pionierhafte Männlichkeit auch unauflöslich mit kolonialen Diskursen verflochten. Dies lässt sich exemplarisch an der 1937 erschienenen Lebensgeschichte des Saas Feer

104 | Kreisky 2011, 34.

105 | Pratt 1990, 51. Vgl. auch McClintock 1993, 62.

106 | Goltermann 1998, 114.

107 | Slemon 2008. Vgl. dazu auch die Ausführungen im Unterkapitel Über ,Rassengrenzen , hinweg: Tenzing Norgay und Raymond Lambert.

108 | Vgl. Wirz 2007. 
Bergführers Matthias Zurbriggen aufzeigen, »unbestrittener König aller Auslandsführer «, ${ }^{109}$ der als Erstbesteiger des Aconcaguas, des höchsten Berges Amerikas, gilt. Schon der Titel seines Buches, Von den Alpen zu den Anden, macht deutlich, dass sich der alpinistische Drang Zurbriggens nicht auf das nationale Territorium beschränken ließ. Als junger Mann stand er zudem im Dienst eines Schweizer Kolonisten in Algier, für den er als Jagdgehilfe tätig war. ${ }^{110}$ Ein Blick in Zurbriggens Schilderung einer britischen Expedition in den Himalaya im Jahr 1882, an der er teilgenommen hatte, fördert die hinreichend bekannten kolonialen Bilder zutage. So rückt er etwa die Einheimischen in die Nähe von Tieren: »Die Menschen nähren sich von Bananen und anderen Früchten, Lebensmitteln, die eigentlich besser für Tiere als für Menschen passen. «111

Nahm der Schweizer Bergführer damit dieselbe koloniale Perspektive ein wie seine westlichen Auftraggeber? Verschwindet im außereuropäischen Gebiet die Differenz zwischen bürgerlichen Herren und alpinen Bergführern, indem sich beide Europa zuordnen und damit als Inbegriff von Zivilisation verstehen? An dieser Stelle ist es hilfreich, Hansens Überlegungen zum Bergsteigen einzubeziehen: Er versteht das Bergsteigen als spezifische moderne Tätigkeit, die immer eine Relation zur Vormoderne herstellt. Diese Beziehung manifestiert sich nicht nur in der Differenz zwischen dem Entdecker und einer als urtümlich charakterisierten Landschaft, die entdeckt werden soll. Sie strukturiert auch, wie Hansen ausführt, die Beziehung zwischen Bergsteiger und Assistent: »Petrarch accompanied by his brother and servants, or Leslie Stephen by Melchior Anderegg, or even Edmund Hillary by Tenzing Norgay on Mount Everest, are each a case in point. The apparent nonmodernity of such partners in ascent is then taken as a sign of the modernity of the modern man. ${ }^{112}$ Gemäß Hansen konstituiert sich die Position des Bergsteigers als Pionier der Moderne erst durch die Hierarchie zwischen einem aufgeklärten Subjekt und seinem vormodernen Assistenten - eine Beziehung, die konstitutiv für die Seilschaft am Berg ist.

Wie lässt sich aus diesem Blickwinkel die Positionierung des Schweizer Bergführers im außereuropäischen Gebirge charakterisieren? Zum

109 | Egger 1946, 344.

110 | Zurbriggen 1937, 15ff.; Egger 1946, 355.

111 | Zurbriggen 1937, 42.

112 | Hansen 2013, 16. 
einen fällt auf, dass er gegenüber den Einheimischen in die Rolle des >modernen Mannes gerät. Einheimische wurden selten und zumeist in herabsetzender Weise erwähnt. Wo sie als Mitarbeiter der Expedition überhaupt in den Blick gerieten, wurde kein Zweifel daran gelassen, dass ihnen die helvetischen Gehilfen überlegen waren. Die Differenzen, die zwischen den Schweizer Bergführern und den lokalen Assistenten aufgemacht wurden, ordnen erstere, obwohl ebenfalls in britischer Anstellung, der Gruppe der Sahibs zu. ${ }^{113}$ Mehr noch, die Fähigkeit des weißen Schweizers, gegenüber nicht-weißen Einheimischen eine übergeordnete Position einzunehmen, wurde als Leistung hervorgehoben: Von Andreas Maurer, der 1880 mit einer Expedition nach Sikkim reiste, heißt es, er habe es vermocht, »den Befehl über eine große Zahl halbwilder Eingeborener zu führen «114. Den Schweizer Bergführern wurde eine privilegierte Stellung zugesprochen, die man mit Dietze als »okzidentalistische Dividende ${ }^{115}$ beschreiben kann. Obwohl sie in einem hierarchischen Verhältnis zu den Expeditionsleitern standen, stellte ihr Weißsein sicher, dass sich die Schweizer Bergführer gegenüber den einheimischen Männern als überlegen positionieren konnten.

Dennoch erwiesen sich die Beziehungen zwischen dem smodernen Mann< und seinem >vormodernen Assistenten< im Kontext der ersten außereuropäischen Expeditionen als komplexer, als sie es im Alpenraum waren, weil nicht zwei, sondern drei Positionen aufeinandertrafen: die lokalen Assistenten, die Schweizer Bergführer und die europäischen (oftmals britischen oder französischen) Expeditionsleiter. Während die Schweizer Bergführer gegenüber den Einheimischen als Vertreter der Moderne galten, die auf selbstverständliche Weise eine koloniale Perspektive auf Land und Leute einnahmen, verschob sich diese Zuordnung in Bezug auf das Verhältnis zwischen Expeditionsleitern und Bergführern. Das Verhältnis zwischen bürgerlichen britischen Herren und bäuerlichen schweizerischen Assistenten war ebenfalls geprägt von der Differenzierung zwischen einem modernen Menschen, der wissen, erforschen, ergründen und entdecken will, und seinem vormodernen Gehilfen, der diesen Drang nur ansatzweise teilt.

113 | Vgl. z.B. Zurbriggen 1937, $57 f$.

114 | Egger 1946, 235.

115 | Dietze 2009, 35. 
So wird in der Bergsteigerliteratur immer wieder beschrieben, dass die Schweizer Bergsteiger von starkem Heimweh geplagt waren und den Aufenthalt in >fremden < Gegenden als schwierig empfanden. Egger zitiert den Engländer Freshfield, der meint, die Bergführer seien stets bereit gewesen, »den gewohnten Gefahren der Schneewelt [...] entgegenzutreten, aber die Aussicht, fremden Völkern, Ländern und Meeren zu begegnen, erregt ihren Verdacht «116. Als typisch wird das Verhalten des Schweizer Bergführers Heinrich Zurflüh geschildert, dem gemeinsam mit dem berühmten englischen Bergsteiger Albert Mummery eine spektakuläre Erstbesteigung im Kaukasus gelang: »Auf dem Hinweg erklärte er [Zurflüh] beständig: `Es gefällt mir nicht!< Und auch nach erfolgter Besteigung war das wiederholte $>$ Es gefällt mir nicht! $<[. .$.$] der Grund der plötzli-$ chen Abreise, denn Mummery konnte gegen diese Abneigung nicht mehr aufkommen. «117

Trotz hervorragender alpinistischer Leistungen erwies sich Zurflüh als unfähig, sich in der Fremde zurechtzufinden. Sein Heimweh war stärker als der Wunsch, neue Gebiete zu entdecken und sich dem Unbekannten zu stellen, den er im Unterschied zu seinem britischen Auftraggeber nicht zu hegen schien. Schweizer Bergführer, denen diese Abenteuerlust zugeschrieben wurde, unterschieden sich wiederum von den britischen >Herren< durch den fehlenden akademischen Wissensdurst. So heißt es etwa von Ulrich Kaufmann: »Phantasievoll, abenteuerliebend und reiselustig, verschwand er gewöhnlich anfangs des Winters aus Grindelwald, machte als Steward auf einem französischen Ozeandampfer große Reisen nach Indien, Australien, Südamerika und Nordafrika, wobei er oft tief ins Innere vorstieß, und kehrte dann, sprachgewandt und erlebnisreich, im Frühling wieder ins Hotel [den Familienbetrieb in Grindelwald] zurück.« ${ }^{118}$ Kaufmann wies zwar den Drang auf, fremde Länder zu bereisen, seine bodenständige Art unterschied sich aber von der bürgerlichen Praxis des Entdeckens. Entsprechend brachte er von seinen Reisen denn auch $>$ Erlebnisse $<$ und nicht (wissenschaftliche) Erkenntnisse mit.

Die ambivalente Positionierung des Bergführers zwischen Moderne und Vormoderne, zwischen der eingeschränkten Position der >Eingeborenen und der kultivierten Haltung der kolonialen Pioniere, zwischen

116 | Egger 1946, 338.

117 | Egger 1946, 341.

118 | Egger 1946, 348-351. 
der naturverbundenen Lebensweise der >Primitiven $<$ und der dekadenten Männlichkeit des Bürgertums stellte eine geschickte und hilfreiche Fiktion der bürgerlichen Elite in der Schweiz dar. Sie ermöglichte ein Spiel der Des/Identifikation mit dieser Figur, die sich durch eine große Beweglichkeit auszeichnete, sowohl in Bezug auf differente Positionen innerhalb der Schweiz als auch gegenüber europäischen Mächten und den postkolonialen Anderen. Dieser Aspekt wird im Folgenden mit Bezug auf Carl Egger verdeutlicht, dem Autor von Pioniere der Alpen.

Egger hob sich deutlich von den Bergführern ab, die er in seinem Buch beschrieb. Er war ein reformierter Kaufmann, der sein ganzes Leben in Basel verbrachte, und kann als ein typischer mittelständischer und urbaner Vertreter aus dem >Flachland <eschrieben werden, der eine große Passion für das Bergsteigen und Skifahren hegte. Er realisierte 36 Erstbegehungen in den Schweizer Alpen und neun Erstbesteigungen im Kaukasus, bei denen er sich insbesondere der kartografischen Erkundung dieser Gebiete widmete. Zudem war er Schriftsteller und Maler. ${ }^{119}$ Neben seiner Herkunft aus einem städtischen bürgerlichen Kontext war auch die Art und Weise, in der er das Bergsteigen betrieb, typisch für seine Klassenzugehörigkeit. Er dokumentierte seine Bergfahrten ausführlich in Büchern und Berichten und betätigte sich auf seinen Touren als Wissenschaftler und Kartograf. Eggers großes Verdienst sei es gewesen, so schreibt die SSAF, das »Dschailükmassiv erforscht zu haben; er hat eine Skizze seiner Orographie verfertigt, seine Geschichte studiert und die Namen festgelegt $\ll^{120}$.

Das Verhältnis zwischen Egger und den Bergführern war geprägt von den Differenzen zwischen Stadt und Land, zwischen den Klassen sowie zwischen Metropole und Kolonie. Dies zeigt sich in seinen Ausführungen über Melchior Anderegg, einem der prominentesten Schweizer Bergführer des 19. Jahrhunderts: »Melchiors Geschick, sich im Spaltengewirr durchzufinden, ist oft mit einem Indianer-Instinkt verglichen worden. ${ }^{121}$ Diese Beschreibung des Bergführers unterscheidet sich in dreifacher Hinsicht von derjenigen eines bürgerlichen Bergsteigers: Weder würde man Letzteren nur mit dem Vornamen bezeichnen, noch seine Kenntnisse auf den Instinkt zurückführen, noch ihn mit nicht-weißen indigenen Men-

119 | Schmidt-0tt 2005. Vgl. dazu auch seine Biografie in SSAF 1948.

120 | SSAF 1948, 70.

121 | Egger 1946, 83. 
schen gleichsetzen. Drei klassische Register der Moderne werden in dieser kurzen Beschreibung in Anschlag gebracht: der soziale Status (durch die Erwähnung des Vornamens statt des Nachnamens), die Bedeutung der Rationalität (durch die Erwähnung des Instinkts als Gegenbegriff zur Vernunft) sowie Rassifizierung (durch den Vergleich des Bergführers mit nicht-weißen Menschen). Dieser eine kurze Satz macht deutlich, wie sich die Differenz zwischen Moderne und Vormoderne in die Beziehung zwischen dem bürgerlichen Autoren und dem alpinen Protagonisten einschreibt.

Egger verortete sich selbst fraglos im Kontext jener europäischen Elite, die das außereuropäische Bergsteigen als neue Arena für das Erobern, Beschreiben, Erforschen, Entdecken und Beherrschen verstand, als »masculine testing grounds ${ }^{122}$. Das verdeutlicht ein Blick auf sein Werk Die Eroberung des Kaukasus von 1932, in dem Egger Texte von bedeutenden europäischen Bergsteigern versammelte. ${ }^{123}$ Wie schon der Haupttitel des Buches, so bringt auch Eggers eigener Beitrag mit dem Titel »Die Belagerung des Dschailük«zum Ausdruck, wie sehr sein Denken über das Bergsteigen von einem militärischen Verständnis von Kampf und Krieg geprägt war. Insbesondere die Erstbesteigung eines Berges wurde in der Regel als kriegerische Handlung beschrieben: Der Berg musste belagert, bekämpft und besiegt werden.

Für die Schweizer Bergsteigerliteratur bezeichnend ist, dass Egger nicht nur die exotische Szenerie des Kaukasus schilderte, sondern sie in ein Ähnlichkeitsverhältnis zur Schweiz setzte: »Prächtiger Wald, Blumenwiesen, weidende Kuhherden, dazu weiße Spitzen im Hintergrund und ein Sommerhimmel voll Schönwetterwolken empfingen uns da oben [...]. Ganz schweizerisch wurde einem bei dieser Landschaft zu Mute, sie hätte ebenso gut im Wallis oder Tessin stehen können. [...] Dann aber tauchte plötzlich der lehmbeworfene Weidenkamin eines Koschs auf und wir befanden uns wieder im Kaukasus vor der Wohnung unseres Eseltreibers und machten Bekanntschaft mit seiner zahlreichen Sippe; sogar der jüngste Spross hängte sich völlig unbekleidet an den Rock der Mutter und betrachtete die Fremden mit großen Augen. « ${ }^{124}$ Egger verortet sich in dieser Erzählung erst in einer vertrauten Berglandschaft. Die Pflan-

122 | Bloom 2010, 31.

123 | Egger 1932a.

124 | Egger 1932b, 145-146. 
zen, Tiere, die Berge und das Wetter erinnern ihn an alpine Gebiete der Schweiz, das Wallis oder das Tessin. Was die Landschaft als different, exotisch und anders ausweist, sind die Menschen und ihre Kultur: Es ist die >primitive< Bauweise der Häuser (>lehmbeworfener Weidenkamin`), die einfache Tätigkeit (>Eseltreiber $<$ ), die Bedeutung der Großfamilie (>zahlreiche Sippe<), die Nacktheit (unbekleidetes Kind) und die Unkenntnis moderner Menschen (staunendes Kind).

Mit dieser Beschreibung setzt Egger das >Berg-Othering< in Gang, das für die Positionierung des Schweizer Bürgertums bedeutsam ist: Vor dem Hintergrund der helvetischen >Naturalisierung der Nation $<$ kann er sich, anders als ein Engländer, in den Bergen als Quasi-Einheimischer positionieren. Das Wieder-Erkennen im Anderen schlägt allerdings da um, wo sich Egger den Bewohner*innen des Kaukasus gegenübersieht. Sie verkörpern eine vormoderne Existenzweise, im Gegensatz zu der Egger als Vertreter der Moderne erscheinen muss.

Die Differenz zwischen einem vormodernen Anderen und dem modernen Selbst bringt Egger wirkmächtig ins Spiel, wenn er beschreibt, wie er auf dem Gipfel des Dschailük steht:

"Wenn uns unsere Diener oft zweifelnd befragten: ,Warum besteigen Sie eigentlich alle diese Berge? so hätten wir innen hier wieder eine deutliche Antwort geben können. Die Rundsicht sprach für sich. Neben den alten Bekannten [...] fügte sich daran der Ueberblick über ein völlig neues Gletschergebiet in nächster Nähe [...]. All dies nun getaucht in wundervoll leuchtende Farben und Lichtspiele, vom erhabensten Standpunkt aus genossen, konnte das nicht allein schon für alle Mühen entschädigen? Dazu kam aber noch die Erkenntnis des Zusammenhangs der Täler und Bergketten, der Gletscher- und Vulkanbildung und wieder des Auf- und Abbaues der Höhen, die Ahnung des gewaltigen tektonischen Ringens, das sich da im Laufe der Jahrtausende abgespielt hat. Und endlich die Freude am Erfolg. Schon allein das körperliche Wohlgefühl des Schwebens im All, des Erhöhtseins und Losgelöstseins von Zeit und Stoff, dann aber auch das rein moralische der Lösung einer Aufgabe und der Ueberwindung von Schwierigkeiten. Aber wie konnten wir all das unseren einfachen Leuten begreiflich machen? « ${ }^{125}$

>Aber wie konnten wir all das unseren einfachen Leuten begreiflich machen?<: Die einheimischen Diener, die Egger nicht auf den Gipfel folgen

125 | Egger 1932b, 150. 
können, werden an dieser Stelle zum stummen Gegenüber in einem Gespräch, das Egger mit sich selbst führt. Dieses Gespräch stellt die komplexe Antwort auf eine einfache Frage der Diener dar, die diese jedoch nicht verstehen können. Wie kann man ihnen, so fragt Egger, die entscheidenden Kategorien der Moderne begreiflich machen, die sich alle in der Erfahrung des Bergsteigens treffen: die Rundsicht und Übersicht, insbesondere über bislang unbekannte Gebiete, die ästhetische Erfahrung der Erhabenheit, welche sich beim Anblick dieser Landschaft einstellt, die wissenschaftliche Erkenntnis, welche sich durch den Blick auf diese Landschaft gewinnen lässt, die Einsicht in ihre Entstehungsgeschichte und schließlich der Erfolg der Besteigung, der nicht nur als körperliche, sondern in erster Linie als moralische Leistung verstanden werden will?

Es ist aufschlussreich, die Anlage dieses Textes mithilfe von Spivaks Lektüre von Immanuel Kants Schriften zu analysieren. ${ }^{126}$ Kants Theorie des Erhabenen, so bemerkt Spivak, bedarf einer Figur des >native informant $<$ des >eingeborenen Informanten<, welche die Position des aufgeklärten Subjekts konturiert und intelligibel macht. Im ersten Teil von Kants dritter Kritik erscheint diese Gegenfigur zur Moderne als >roher Mensch<: »In der Tat wird ohne Entwicklung sittlicher Ideen das, was wir, durch Kultur vorbereitet, erhaben nennen, dem rohen Menschen bloß abschreckend vorkommen «, ${ }^{127}$ schreibt Kant. Im Gegensatz zum kultivierten Menschen erweist sich der rohe Mensch als unfähig, das Erhabene zu erkennen. Getrieben vom Drang zu überleben, kann er der Macht und Zerstörungskraft der Natur nur mit Angst begegnen. Dieses dumpfe und angstvolle Erleben der Natur ist die Folie, auf der die kultivierte Erfahrung des zivilisierten Menschen zur Geltung gebracht werden kann. Das Erhabene bleibt dem zivilisierten Menschen vorbehalten, es ist aber gerade der rohe Mensch, der den Bezug zu diesem Erhabenen erst denkbar macht.

Wer aber, fragt Spivak, ist der rohe Mensch? Die Figur des snative informant<, so meint sie, kehre im zweiten Teil der Kritik wieder. Kant hält darin an einer Stelle fest, dass der Zweck des Menschen nicht erkennbar wird, »wenn man etwa die Neuholländer oder Feuerländer in Gedanken hat « ${ }^{128}$. Die indigenen Bewohner*innen Patagoniens und Australiens markieren an dieser Stelle als scheinbar kulturlose Wesen die Grenzen

126 | Spivak 1999; vgl. dazu Purtschert 2012b.

127 | Kant 2006, 134.

128 | Kant 2006, 286. 
des Menschlichen und machen damit die grundlegende Bedeutung ersichtlich, die der Kultur für die Definition des Menschlichen zukommt. Aus einer postkolonialen Perspektive zeigt diese Stelle, dass die Grenze des Menschlichen bei Kant über die >Rassendifferenz` figuriert wird: Der >rohe Mensch< aus der Ästhetik, so Spivak, erhält in der Teleologie einen Namen und eine Zuordnung, er wird als koloniale Figur lesbar. ${ }^{129}$ Mithilfe des >native informant konturiert Kant die Umrisse des Menschlichen und naturalisiert damit die imperialistischen Prämissen der Kultur: »We find here the axiomatics of imperialism as a natural argument to indicate the limits of the cognition of (cultural) man. ${ }^{130}$

Vor dem Hintergrund dieser Analyse lässt sich der Diener in Eggers Beschreibung als aufklärerischer Einsatz des rohen Menschen lesen. Er macht Eggers moderne Erfahrung der Natur denkbar und verhilft ihm dazu, sie in ihre ästhetische, wissenschaftliche, körperliche und moralische Dimension aufzufächern. Obwohl der Diener derjenige ist, der die Frage nach dem Sinn des Bergsteigens aufwirft, gilt Eggers Antwort nicht ihm, sondern einem modernen Menschen, der seine Ausführungen versteht. Das zeigt der letzte Satz der Passage, der ein >wir< einführt, das der Beschränktheit der einfachen Leute etwas ratlos gegenübersteht: »Aber wie konnten wir all das unseren einfachen Leuten begreiflich machen? « Dieses >wir bezeugt Eggers Verortung inmitten der europäischen Bergsteigerelite. Die Differenz zwischen den verständnislosen Dienern als Verkörperung des Vormodernen und den bürgerlichen Bergsteigern macht deren Modernität intelligibel und konstituiert damit erst die Stimme, die sich dann in paternalistischer Weise oder erzieherischer Absicht den einfachen Menschen zuwenden kann. ${ }^{131}$

Wie diese Überlegungen zeigen, standen die Berge über die bekannte Vorstellung hinaus, Schutzwall und Festung, »symbol of protection against external threats « ${ }^{132} \mathrm{zu}$ sein, auch für die Schweizer Beteiligung an den kolonialen Eroberungsmissionen - eine Beteiligung, die gleichsam als Mitgliedsausweis für die zivilisierte Welt galt. Die spezifische Verbindung zwischen Nation und Bergen wurde Mitte des 20. Jahrhundert zudem ins Feld geführt, um den Führungsanspruch der Schweizer Berg-

129 | Spivak 1999, 26.

130 | Spivak 1999, 26.

131 | Hansen 2013, 16.

132 | Zimmer 1998, 653. 
steiger im symbolisch bedeutsamen Kampf um die höchsten Gipfel der Welt zu belegen.

\section{Nationale Freiheit und koloniale Expansion}

Die Hinwendung von Schweizer Bergsteigern zu den >Bergen der Welt<, wie eine Bücherreihe der Schweizerischen Stiftung für Alpine Forschung (SSAF) betitelt wurde, fiel zusammen mit der zunehmenden Erschließung des Alpenraumes. Diesen Zusammenhang belegt ein Aufruf, den das Initiativkomittee zur Gründung des SSAF im Dezember 1938 dem Organ des SAC, Die Alpen, beilegen ließ. Er war von führenden Köpfen in Wirtschaft und Politik unterzeichnet, darunter der bekannte Geologieprofessor Arnold Heim und der freisinnige Ständerat Robert Schöpfer. ${ }^{133}$ Der Aufruf zur Vereinsgründung kann als Dokument gelesen werden, das die >Naturalisierung der Nation< kurz vor Ausbruch des Zweiten Weltkriegs zum Ausdruck bringt. Dabei zeigt sich, dass die wesenhafte Verbindung, die zwischen den Alpen und der Schweizer Nation hergestellt wurde, nicht notwendigerweise auf einer Kongruenz von Nation und nationalem Territorium beruhte. Die Berge als territoriale Grundlage der Schweiz legitimierten vielmehr einen kolonial unterfütterten Expansionsanspruch auf die >Berge der Welt<.

Der Aufruf des neu gegründeten Initiativkomittees beginnt mit den Worten: »Die Berge haben nicht nur der schweizerischen Landschaft ihre ewige Prägung gegeben, sie haben auch das Wesen des schweizerischen Menschen geformt. « ${ }^{134}$ Obwohl ein Großteil der Schweizer Bevölkerung nicht in den Alpen wohnhaft ist, behauptet diese Aussage einen intrinsischen Zusammenhang zwischen den Bergen, der Nation und der Bevölkerung. Den Menschen sei etwas von der »Strenge und Herbheit [der Berge], aber auch von ihrer Schönheit und Grösse« in die Seele geschrieben, heißt es weiter. ${ }^{135}$ Und: »Vor allem ist es der Abglanz ihrer Selbstherrlichkeit, der in der Brust des Schweizers als unbändiges Freiheitsgefühl lebt. ${ }^{136}$

133 | SSAF 1972, $5 f$.

134 | Komitee zur Gründung des SSAF, zitiert nach SSAF 1972, 4.

135 | Komitee zur Gründung des SSAF, zitiert nach SSAF 1972, 4.

136 | Komitee zur Gründung des SSAF, zitiert nach SSAF 1972, 4. 
Die stärkste und bedeutsamste Wirkung, welche die Berge auf das Wesen der in ihnen lebenden Menschen haben, ist demnach ihr Bedürfnis nach Freiheit. Dieses Bedürfnis äußert sich, wie es weiter heißt, im politischen Willen zur Souveränität, der sich in der Geschichte der Schweiz niedergeschlagen hat und ihr Fortbestehen auch in schwierigen Zeiten ermöglichen soll: »Dieses Freiheitsgefühl gibt sich als urwüchsiger Wille zur Selbstbestimmung kund, und dieser Wille ist unser Führer durchs Leben. Er hat unsere Geschichte geformt, er sei in Zeiten von Not und Gefahr Garant unserer Zukunft.« ${ }^{137}$ Die Freiheit als sine qua non der Schweiz bleibe aber nur erhalten, so der Aufruf weiter, wenn der Kontakt zu ihrem landschaftlichen Ursprung in den Bergen gewährleistet bleibe: »Auf den Bergen wohnt die Freiheit. Solange wir mit dem ungebrochenen Naturleben unserer Bergwelt Fühlung behalten, werden wir als Volk nicht altern, wird schweizerische Tatkraft nicht erlahmen. «138 Weil die Freiheit als Essenz des Schweizer Wesens in den Bergen lokalisiert ist, erweist es sich als vital für die Nation, die Verbindung zum Gebirge aufrechtzuerhalten. Diese Relation aber stellt der Bergsteiger her: »Darum kommt den Bergsteigern und Bergführern eine besondere Sendung zu. Sie sind Mittler, indem sie den frischen Hauch der Berge in die Täler und ins werktätige Leben tragen. «139 Bergsteiger und Bergführer haben eine national bedeutsame Aufgabe. Sie vermitteln zwischen den Bergen, aus denen das Streben nach Freiheit stammt, und dem Tal, in dem sich die Menschen vom freiheitlichen Ursprung der Alpen zu entfernen drohen.

Allerdings, und an dieser Stelle lässt sich der eindringliche Aufruf des Komitees mit Gewinn durch eine postkoloniale Linse lesen, verkörpern die Schweizer Alpen den Raum der Freiheit kaum mehr. Die Ausdifferenzierung zwischen städtischem und ländlichem Gebiet in der Schweiz, die Jon Mathieu auf die im 18. und 19. Jahrhundert stark wachsende »Differenz der Nutzungsintensität zwischen dem Alpenraum und seinem Umland ${ }^{140}$ zurückführt, verliert ihre metaphorische Überzeugungskraft. Das Bild der zunehmend touristisch und verkehrstechnisch erschlossenen Alpen reibt sich mit der Vorstellung eines unbegrenzten, von Men-

137 | Komitee zur Gründung des SSAF, zitiert nach SSAF 1972, 4.

138 | Komitee zur Gründung des SSAF, zitiert nach SSAF 1972, 4.

139 | Komitee zur Gründung des SSAF, zitiert nach SSAF 1972, 4.

140 | Mathieu 2005, 72. 
schenhand kaum berührten und als sakral stilisierten Raumes. ${ }^{141}$ Das alpinistische Bedürfnis nach Entdeckung unbekannter Gebiete kann sich zunehmend weniger innerhalb des nationalstaatlichen Territoriums entfalten und verlangt nach neuen Räumen: »Pioniergeist erfüllt die besten unserer Bergsteiger und Bergführer. Aber richtiger Pioniergeist verlangt nach neuen Aufgaben. Die bergsteigerische Erschließung der Alpen ist beendet. Der Blick richtet sich über diese hinaus nach den fernen unerschlossenen Gebirgen der Erde. Dort harren noch bergsteigerische Aufgaben im besten Sinne des Wortes der Lösung, dort kann sich eine tatenfrohe Jugend erproben. ${ }^{142}$

Das für die Schweiz unabdingbare Freiheitsgefühl, das zwingend an den physischen Kontakt mit den Bergen gekoppelt ist, muss in Zukunft durch Abenteuer in fernen Ländern genährt werden. Damit wird das Überleben der Schweiz als freiheitlicher Nation an die bergsteigerische Expansion gekoppelt. Denn wenn das Wohlergehen der Schweiz auf dem ständigen Kontakt zu einer ungebändigten Bergwelt beruht, die es in den Alpen kaum noch gibt, dann ist der Ausgriff auf weniger erschlossene Berge unumgänglich für die Sicherung der Nation. Das Gründungspapier der SSAF bindet somit die Expeditionstätigkeit in außereuropäische Gebiete an ein nationales Interesse zurück. Die koloniale Figur des Ausgriffs verbindet sich hier konstitutiv mit dem Schweizer Selbstverständnis als freiheitsliebende Nation.

Es gibt aber auch externe Gründe, die für eine Schweizer Beteiligung am Höhenbergsteigen sprechen. Der Aufruf zur Gründung des SSAF lokalisiert diese in der Konkurrenz durch andere westeuropäische Länder: »Jahr für Jahr senden Engländer, Italiener, Deutsche, Franzosen ihre Besten zur Erschließung noch nie bestiegener Berge. Nur die Schweiz, das ausgesprochene Bergsteigerland, steht abseits und untätig da. Das darf nicht so bleiben. Heute mehr als je dürfen wir bei der Lösung der letzten und größten bergsteigerischen Ziele nicht bloß Zuschauer sein, sondern müssen in edlem Wettstreit unsere besten und tüchtigsten Kräfte

141 J Jon Mathieu und Simona Boscani Leoni weisen darauf hin, dass die Alpen ab dem 18. Jahrhundert zunehmend sakralisiert wurden, "also genau zu einem Zeitpunkt, als man anderweitig von Säkularisierung sprach “ (Mathieu und Boscani Leoni 2005b, 18).

142 | Komitee zur Gründung des SSAF, zitiert nach SSAF 1972, 4. 
aktiv einsetzen.« ${ }^{143}$ Dass die für ihre alpinistischen Leistungen bekannte Schweiz sich nicht an der Erschließung außereuropäischer Berge beteiligt, wird an dieser Stelle zum Zeichen von Schwäche. Es scheint, als ob die >schweizerische Tatkraft $<$ in der Tat zu >erlahmen< droht, wenn das Land sich nicht den noch unentdeckten >Bergen der Welt< zuwendet. Der Ausgriff auf weniger erschlossene Berge sichert die Zugehörigkeit zu einem Europa, das sich im Wettrennen um die höchsten Gipfel der Welt misst. Dabei geht es um nichts weniger als um eine eigenständige Mobilisierung der kolonialen Fantasien, welche die symbolträchtige Eroberung der höchsten Gipfel der Welt freisetzen. In augenfälligem Kontrast zu den bekannten Vorstellungen von den Bergen als defensivem Rückzugsort einer bedrohten Nation zeigt sich, dass die Berge auch für einen globalen Führungsanspruch der Schweiz im außereuropäischen Höhenbergsteigen stehen.

Es blieb nicht bei leeren Worten: Der Aufruf des Initiativkomitees führte zur Gründung einer bis heute existierenden Stiftung, die zwischen 1939 und 1956 elf wissenschaftliche und alpinistische Expeditionen im Himalaya, in Karakorum, in Tibesti und in Baffinland durchführte. ${ }^{144}$ In der Stiftung kamen führende Männer aus Politik, Wissenschaft, Militär und Wirtschaft zusammen. ${ }^{145}$ Obwohl keine staatliche Institution, war die SSAF über ihre Mitglieder bestens mit den tonangebenden Kreisen in der Schweiz vernetzt und konnte bei der Organisation ihrer Expeditionen nicht selten auf großzügige Unterstützung durch die Schweizer Diplomatie zählen. ${ }^{146}$

Dass das Schweizer Höhenbergsteigen materiell und symbolisch durch die Bedingungen der Kolonialität gerahmt wird, zeigt sich auch in der Darstellung von Edouard Wyss-Dunant, dem Leiter der FrühlingsExpedition auf den Everest von 1952. Wyss-Dunant war in mehrfacher Hinsicht ein idealer Protagonist für eine Schweizer Expedition: Als bilingualer Sohn eines Vaters aus der deutschsprachigen und einer Mutter aus der französischsprachigen Schweiz verband er die beiden größten

143 | Komitee zur Gründung des SSAF, zitiert nach SSAF 1972, 4.

144 | SSAF 1972, o.S. [Inhaltsverzeichnis].

145 | Vgl. die Porträts der frühen Mitglieder in SSAF 1972.

146 | Vgl. etwa die Rolle, die der Schweizer Gesandte in Neu-Delhi für die nepalesische Genehmigung der Schweizerischen Everest-Expeditionen 1952 spielte (Feuz 1953, 42). 
Sprachregionen des Landes. Zudem repräsentierte er die bürgerliche Elite auf exemplarische Weise: Er war ein angesehener Arzt mit einer eigenen Praxis, der sich zugleich in der medizinischen Forschung betätigte, ein begabter Musiker, ein passionierter Bergsteiger und ein langjähriges Mitglied des Berner Akademischen Alpenclubs. Mit seinen 55 Jahren und seinem staatsmännischen Auftreten entsprach er zudem dem Bild eines reifen Mannes, der ein solches national bedeutsames Unterfangen erfolgreich in die Hand nehmen konnte. In seiner Bergsteigerkarriere hatte er sich ausgiebig mit der Entdeckung >unbekannter< Berge beschäftigt und seine Erfahrungen, wie es sich gehört, ausführlich zu Papier gebracht: Er beteiligte sich an Expeditionen in Mexiko (1936), Ostafrika (1937), Grönland (1938), Tibesti (1946) und im Himalaya (1947 und 1952) und veröffentlichte mehrere Bücher dazu. ${ }^{147}$ Nicht zuletzt erinnerte sein Nachname an Henry Dunant, den international bekannten Schweizer Gründer des Roten Kreuzes (der in Algerien Kolonialgeschäfte getätigt hatte). ${ }^{148}$

Der Reporter der Schweizer Illustrierten Zeitung, der Wyss-Dunant im Vorfeld der Everest-Expedition porträtierte, suchte ihn nicht an seinem Wohnort Genf auf, sondern in seiner, wie er schreibt, >zweiten Heimat< in Marokko, damals ein französisches Protektorat. Begleitet von einer Fotografie, die den Schweizer in einer nordafrikanischen Hochebene zeigt, berichtete der Reporter von seinem Besuch auf Wyss-Dunants »stimmungsvollsten marokkanischen Gutshof« mit dem Namen »Domaine de Beau Séjour « ${ }^{149}$. Gemeinsam mit seiner Frau, lokalen Angestellten und einem Schweizer Verwalter bewirtschaftete Wyss-Dunant seit zwölf Jahren mehrere hundert Hektar Land in Marokko; er betätigte sich, mit anderen Worten, als Kolonialist in einem französisch besetzen Gebiet. Vier Monate des Jahres verbrachte er jeweils in Genf und acht Monate auf seinem nordafrikanischen Landsitz.

Im Artikel wird Wyss-Dunant als »sportlich aussehender, schlanker Mann, ganz nach der Art eines Gutsherrn gekleidet « ${ }^{150}$ beschrieben. Seinen Hof habe er gleichsam aus dem Nichts geschaffen, er habe »Haus,

147 | Hunt 1984, 262.

148 | Vgl. Pous 1979.

149 | Almásy, Paul: "Die Verantwortung für die Führung ist unteilbar. Besuch beim Leiter der Mount-Everest-Expedition 1952, Dr. Wyss-Dunant, auf seinem marokkanischen Hof“, in: Schweizer Illustrierte Zeitung, 12. Februar 1952.

$\mathbf{1 5 0}$ | Ebd. 
Hof, Bäume und Acker selbst aus dem Brachland hervorgezaubert « ${ }^{151}$. Diese Beschreibung greift den kolonialen Mythos des >leeren Landes der von einem unberührten, unbesiedelten und unproduktiven Territorium ausgeht, das erst durch die Arbeit des weißen Kolonialisten urbar gemacht und kultiviert wurde. Ein Gespräch mit dem Arzt, so heißt es weiter im Bericht, macht deutlich, warum »sein schönes Genfer Heim ihm nicht alles bedeuten kann - mag auch dort die herrliche heimatliche Bergwelt gleichsam direkt vor seinen Fenstern liegen. Denn dieser Arzt und Forscher ist seinem ganzen Wesen nach auf die weite, freie Natur angewiesen: aus ihr alleine schöpft er seine Freuden und seine Ambitionen. Was er jedoch in der Natur sucht und liebt, sind nicht die üblichen touristischen Schönheiten, sondern das Endlose, das Unerfassbare und Unbekannte. Er liebt nicht nur die schneebedeckten Gipfel, auch die afrikanische Wüste und die unerforschten, ewigen Eisfelder des Hohen Nordens faszinieren ihn. Der afrikanische Raum ist für Dr. Wyss-Dunant unentbehrlich geworden. ${ }^{152}$

Diese Beschreibung des Expeditionsleiters liest sich wie eine individuelle Verkörperung der >schweizerischen Wesensart<, die 13 Jahre zuvor im Gründungsdokument der SSAF festgehalten wurde. Wyss-Dunant bedeuten demnach die Berge der Schweizer Heimat viel, aber sie reichen nicht aus, um sein forschendes und freiheitliches Wesen auszufüllen. Er benötigt die >weite, freie Natur<, die ihn - in klassisch aufklärerischer Manier - mit dem Endlosen, dem Unfassbaren und Unbekannten konfrontieren. Eine solche sakral aufgeladene Natur findet er aber nicht nur in den Alpen, sondern auch am Nordpol und vor allem in Nordafrika. Letzteres ist Wyss-Dunant darum >unentbehrlich< geworden; er bedarf dieses Bezugs zu Afrika, um sein menschliches Wesen im Angesicht der Natur frei entfalten zu können.

Es ist beachtlich, dass in dieser Darstellung Wyss-Dunants an keiner Stelle ein Widerspruch zwischen seinem Leben in Marokko und seiner national und international bedeutsamen Rolle als Leiter der Schweizerischen Everest-Expedition ausgemacht werden kann. Im Gegenteil: WyssDunants Liebe zu den Bergen der Heimat wird durch seine Faszination für die wilden Zonen der Welt und seinen Landbesitz in Nordafrika bekräftigt. Seine Darstellung als erfolgreicher Kolonist, der vermutlich bestens

$151 \mid$ Ebd.

152 | Ebd. 
in französische Netzwerke integriert war, macht ihn zu einem Schweizer, der im internationalen Kontext bestehen kann. ${ }^{153}$ Daher ist es kein Zufall, dass die Geschichte des marokkanischen Gutshofs die Berichterstattung $\mathrm{zu}$ jener Verhandlung rahmt, welche die Everest-Expedition von 1952 definitiv zu einer >Schweizerischen< Unternehmung machen sollte: Unter dem Titel »Die Verantwortung für die Führung ist unteilbar« berichtet der Artikel vom Beschluss der Schweizer, nach erfolglosen Verhandlungen mit britischen Partnern über eine gemeinsame Unternehmung die Expedition im Alleingang durchzuführen - eine Entscheidung, von der gleich noch die Rede sein wird.

\section{Koloniale Kämpfe am Himalaya}

Weltweit gibt es 14 Berggipfel, die über 8.000 Meter hoch sind. Sie alle liegen im Himalayagebirge. Im Jahre 1950 erreichte eine französische Expedition erstmals den Gipfel eines Achttausenders, der Annapurna. 14 Jahre später fand mit der Besteigung des Shishapangma im Jahre 1964 durch eine chinesische Expedition das Wettrennen um die Erstbesteigung der höchsten Gipfel der Welt seinen Abschluss. Dazwischen liegt das, was man in Anlehnung an das >Goldene Zeitalter des Alpinismus< hundert Jahre zuvor das >Goldene Zeitalter des Himalaya-Bergsteigens< nennen könnte. Schweizer Expeditionen gelang es, zwei der 14 AchttausenderGipfel als erste zu erreichen: den Lhotse im Jahre 1956 und den Dhaulagiri im Jahre 1960. Die Aufbruchsstimmung dieser Jahre und die symbolische Bedeutung des Bergsteigens lässt sich unschwer daran ablesen, dass der höchste Berg der Welt, der Mount Everest, als >dritter Pol< bezeichnet wurde. ${ }^{154}$ Diese Bezeichnung nimmt Bezug auf die Bedeutung der Arktis und Antarktis, die seit Mitte des 19. Jahrhunderts als die größten verbliebenen unentdeckten Räume auf der Landkarte gegolten hatten. ${ }^{155}$

153 | Auf den Versuch, Wyss-Dunant als Bestandteil einer kosmopolitischen Gesellschaft darzustellen, deutet auch die Autorschaft des Berichts hin: Er wurde vom bekannten Fotografen und Reisereporter Paul Almásy verfasst.

154 | Der Begriff geht auf Marcel Kurz zurück und wurde durch das gleichnamige Buch von Günter Oskar Dyhrenfurth bekannt gemacht (Dyhrenfurth 1952, 7).

155 | Bloom 1993, 3. 
Das 1952 unter dem Titel Zum dritten Pol: Die Achttausender der Erde erschienene einflussreiche Buch des deutsch-schweizerischen Himalayaforschers Günter Oskar Dyhrenfurth brachte die Verschränkung von kolonialen Blickweisen mit dem nahenden Ende des Kolonialismus und dem Himalaya gleich auf der ersten Seite auf den Punkt:

"Nord- und Südpol sind ihres geheimnisvollen Schleiers beraubt, Ozeanflüge sind zu einer Alltäglichkeit des modernen Verkehrs geworden, Afrika, einst der dunkle Kontinent, ist wohlbekannt, sogar das Innere der tropischen Rieseninsel NeuGuinea ist jetzt erschlossen. Darum mußte der Kampf um den Himalaya aus dem engen Kreise der Fach-Gelehrten und Bergsteiger allmählich herauswachsen. Dieses Ringen um die höchsten Gipfel der Welt ist zu einer Menschheitssache geworden, zu einer Aufgabe, der man sich nicht entziehen kann, trotz aller Opfer, die dieser Kampf kostet. “156

Dyhrenfurths Beschreibung beinhaltet unterschiedliche Elemente einer kolonialen Weltsicht: Er geht davon aus, dass es ein notwendiges Unterfangen für den menschlichen Fortschritt darstellt, weiße Flecken auf der Weltkarte zum Verschwinden zu bringen. Die kriegerische Metaphorik des Kampfes sowie die militärische Semantik teilt Dyhrenfurths Text mit zahlreichen zeitgenössischen Abhandlungen zum Bergsteigen. Dies gilt auch für die Darstellung des Hochgebirges als geheimnisvollem Ort, welcher der menschlichen Entdeckung harrt und die Fortsetzung einer heroischen Entdecker-Geschichte verspricht. Das >Ringen um die höchsten Gipfel der Welt< wird dabei als >Menschheitssache< beschrieben. Durch die geschlechterneutrale Formulierung, die unsichtbar macht, dass nur Männer gemeint sind, erscheint das Höhenbergsteigen zwar als Aufgabe, die alle angeht. Implizit wird es aber als Aktivität für eine verschwindend kleine weiße männliche Elite konfiguriert.

Dass es beim Wettrennen um die Erstbesteigung vornehmlich um eine Konkurrenz zwischen westlichen Mächten geht, zeigt ein Artikel, der am 10. Dezember 1952 im deutschen Magazin Der Spiegel erschien: »Die Engländer und die Schweizer kämpfen um die Erstbesteigung des 8.888 [sic!] Meter hohen Mount Everest. Die Amerikaner streben den 8.611 Meter hohen Chogori an. Der Nanga Parbat aber blieb den Deutschen vorbe- 
halten. ${ }^{157}$ Die höchsten Berge der Welt werden gemäß dieser Darstellung in kolonialer Manier unter westlichen Mächten aufgeteilt. Obwohl sich auch russische, chinesische, japanische und argentinische Bergsteiger am Gipfel-Wettrennen beteiligten und einheimische Sherpas an beinahe allen Himalaya-Expeditionen teilnahmen, fokussierte die europäische Berichterstattung auf die westlichen Teilnehmer. John Hunt, der Leiter der erfolgreichen britischen Everest-Expedition von 1953, schreibt dazu: »It was as if an agreement existed in those years, by which it was tacitly understood that certain of the big peaks were the special concern of climbers of a particular nation. ${ }^{158}$

Warum aber wird der Everest als Kampfzone zwischen Briten und Schweizern bezeichnet? Tatsächlich galt die Erstbesteigung des Everest in Westeuropa über lange Zeit als britisches Unterfangen. Gordon Stewart führt diesen Anspruch auf die Kartografierung des britischen Herrschaftsgebietes zurück: »[Everest] had, since 1841, when it had been named after Sir George Everest, head of the Indian Survey [die von der British East India Company initiierte und seit dem 18. Jahrhundert betriebene kartografische Vermessung Indiens], been considered a >British < mountain. ${ }^{159}$ Die Benennung des Everest nach einem britischen Kolonial-Offizier verwies auf die symbolische Besetzung des markanten Berges durch die Briten. Auf nepalesisch wird der Berg heute Sagarmāthā genannt, auf tibetisch wird er als Qomolangma bezeichnet. Der tibetische Name war den Briten während des Indian Survey vermutlich bekannt, sie ignorierten ihn aber zugunsten ihrer Namensgebung. ${ }^{160}$

Signifikant für den kolonial kodierten Everest ist die Diskrepanz zwischen imaginierten Besitzverhältnissen und politisch-territorialen

157 | O.V.: „Mordlustig und drohend «, in: Der Spiegel, 10. Dezember 1952.

158 | John Hunt, zitiert nach Slemon 2000, 68.

159 | Stewart 1980, 36. Vgl. dazu auch Slemon 2000, 53.

160 | Der tibetische Name wurde bereits im 18. Jahrhundert auf einer französischen Karte verwendet. Unsworth folgert daraus, dass er den Briten hätte bekannt sein müssen. Der Name Sagarmāthā hingegen sei eine Erfindung der nepalesischen Regierung aus jüngerer Zeit. VgI. Unsworth 1989, 548 und 550. Ich verwende im Folgenden die Bezeichnung 'Mount Everest nicht, weil ich den britischen Namen für vorrangig halte, sondern weil es um die Geschichte eines Berges geht, der im westlichen Kontext unter diesem Namen zu einem Objekt kolonialer Fantasien wurde. 
Konstellationen: Der Berg gehörte nie zum British Raj, dem britischen Kolonialgebiet auf dem indischen Subkontinent, genauso wenig wie die beiden Zugangsrouten, die über Tibet und Nepal führen. Wie Hansen zeigt, stellte der >britische Everest< ein brüchiges eurozentrisches Konstrukt dar. So führte der Start des Stummfilms The Epic of Everest von 1924 in britischen Kinos zu einem Zerwürfnis zwischen London und dem Dalai Lama. ${ }^{161}$ Die tibetanische Regierung hatte sich vergeblich gegen die Vorführung von Filmszenen mit tanzenden Lamas ausgesprochen, weil es sich dabei um heilige Zeremonien handelte. ${ }^{162} \mathrm{Ab} 1925$ stellte Tibet keine Genehmigungen für britische Expeditionen mehr aus. ${ }^{163}$ Trotz solcher Hindernisse, die der britischen Kolonialmacht den Zugang zum höchsten Berg der Welt erschwerten, wurde im Westen die Vorstellung vom Everest als einem britischen Berg gepflegt. So bezeichnete Sir Percy Cox, Sekretär des Mount Everest Committee, einer gemeinsam von der Royal Geographic Society und dem britischen Alpine Club gegründeten Gesellschaft mit dem Ziel, den höchsten Gipfel der Welt zu erreichen, einen Erfolg am Everest in den 1930er Jahren als nationale Angelegenheit, während es einer »nationalen Erniedrigung« (»humiliation«) gleichkäme, würde einer Expedition aus einem anderen Land die erste Besteigung gelingen. ${ }^{164}$

Mit dem nahenden Ende des britischen Imperiums und dem wachsenden Interesse anderer Nationen am Himalaya ließ sich Londons Anspruch auf den Everest auch im westeuropäischen Kontext nicht mehr aufrechterhalten. ${ }^{165}$ Neben dem schwindenden Einfluss Großbritanniens in Asien führten die Okkupation Tibets durch China und die Beendigung der nepalesischen Isolationspolitik zu Beginn der 1950er Jahre zu einer gänzlich neuen Ausgangslage: Der Everest konnte zum ersten Mal auf der im Westen wenig bekannten Südroute angegangen werden. 1952 erhielt die SSAF von Nepal überraschenderweise eine ganzjährige Bewilligung zur Besteigung des Everest und führte in der Folge eine Frühlings- und eine Herbstexpedition durch.

Dem neu entfachten Wettlauf um den höchsten Berg der Welt wurde mit der Erstbesteigung des Everest 1953 durch einen indisch-nepale-

161 | Hansen 1996, 713.

162 | Hansen 1996, 712.

163 | Hansen 1996, 736.

164 | Percy Cox, zitiert nach Stewart 1995, 184.

165 | Dyhrenfurth 1952, 62. 
sischen und einen neuseeländischen Bergsteiger unter britischer Flagge ein Ende gesetzt. Ein Erfolg am Everest war zwar unsicherer gewesen als je zuvor, dennoch wurde er in Großbritannien schließlich als Erfüllung eines beharrlich angestrebten Ziels dargestellt und gefeiert. Hilfreich war dabei nicht zuletzt der Zufall: Die Nachricht vom Gelingen der erfolgreichen Besteigung des Everest erreichte London am Morgen der Krönung Elizabeths II. Gerade weil das Ende des britischen Imperiums und die ökonomischen Probleme Großbritanniens unübersehbar waren, konnte der Erstbesteigung des Everests eine vitale Bedeutung für das nationale Selbstverständnis zugeschrieben werden. Stewart deutet die britische Berichterstattung denn auch als »primarily the story of a lingering farewell to empire ${ }^{166}$.

Vor dem Hintergrund seiner imperialen Geschichte scheint die Bedeutung, die Großbritannien dem Everest beimaß, verständlich. ${ }^{167} \mathrm{Wie}$ aber können die Schweizer Expeditionen und das sie begleitende mediale Interesse eingeordnet werden? Warum begaben sich Bergsteiger eines Landes, das nie offiziell über Kolonien verfügt hatte, in ein Wettrennen mit der erodierenden größten Kolonialmacht zum symbolisch hoch aufgeladenen >dritten Pol< der Erde?

\section{Die Internationalisierung Des Höhenbergsteigens}

Die Konkurrenz zwischen schweizerischen und britischen Bergsteigern machte sich schon zu Beginn der Everest-Exploration bemerkbar. Als die Briten in den 1920er Jahren begannen, den höchsten Berg der Welt zu erkunden, verzichteten sie auf die Hilfe der bewährten Schweizer Berg-

166 | Stewart 1995, 189.

167 | In den 1990er Jahren wurde die politische Bedeutung der Everest-Erstbesteigung allerdings Gegenstand einer wissenschaftlichen Kontroverse. Während Stewart behauptet, der Erfolg am Everest habe es Großbritannien ermöglicht, erneut imperiale Werte zu zelebrieren (Stewart 1995, 172), betont Hansen die konkurrierende Inanspruchnahme des Gipfelerfolgs durch Nepal, Indien, Neuseeland und Großbritannien. Die britische Interpretation des Ereignisses deutet er im Unterschied zu Stewart als Versuch, Großbritannien auf ein post-imperiales Leben im Commonwealth vorzubereiten (Hansen 1997). 
führer. ${ }^{168}$ Der Anspruch, die Besteigung des höchsten Bergs der Welt als britische Tat feiern zu können, hätte durch eine Kooperation mit Schweizer Bergsteigern in Zweifel gezogen werden können. ${ }^{169}$

Ein Bericht von Ernst Feuz aus dem Jahre 1953 zeigt zudem, dass die Idee einer Schweizer Everest-Expedition so alt ist wie die Gründung der SSAF, denn bereits 1939 und 1940 kam es zu mehreren informellen Treffen mit führenden Köpfen der britischen Bergsteigerszene. Ein internes Schreiben der SSAF zu Händen des Präsidenten hält fest, dass sich die Vertreter des britischen Everest Committee und der Royal Geographic Society gegenüber der Idee einer Schweizerischen Everest-Expedition offen zeigten. Es wurden sechs Gründe erläutert, die aus Sicht der Briten dafür sprachen, die Schweizer ziehen zu lassen, und es lohnt sich, das Memorandum der SSAF dazu ausführlich zu zitieren: »1. Der englische Sportmannsgeist gibt unter keinen Umständen zu, dass der >Alpine Club< den Mount Everest für sich allein gepachtet hat. 2. Ein Vergleich zwischen einer englischen und einer ausländischen (schweizerischen) Expedition am Mount Everest wäre interessant und wünschenswert. 3. Eine solche Bewilligung, von den Engländern uns Schweizern erteilt, würde dem >fair play< des Engländers hoch in Anrechnung kommen. 4. Man erinnert sich wohl der von den zähen, unentwegten alten Engländern gemeinsam mit unsern berühmten Bergführern geleisteten Pionierarbeit, durch welche die Alpen erobert und erschlossen wurden. Niemand hätte damals je den Gedanken gehabt, dass das Matterhorn zum Beispiel nur für Engländer bestimmt wäre. 5. Das gute Einvernehmen der alten Bergpioniere aller Länder, das einst zum guten Ton gehörte und heute zum Teil verfälscht wurde, muss wieder hergestellt werden. 6. Die Berge sind das internationale Spielfeld, wo sich die Jugend aller Länder noch gegenseitig anspornen und schätzen lernen kann, getragen von einem Geiste, der sich mit der Geschichte der Eiger-Nordwand-Kämpfe nicht vereinbaren lässt. «170

Es ist bemerkenswert, was diese Darstellung unterschlägt, nämlich die Tatsache, dass die Briten faktisch keineswegs über die Möglichkeit verfügten, den Schweizern >eine Bewilligung zu erteilen<. Dennoch wur-

168 | Hansen 1999, 221.

169 | Gemäß einer 1950 veröffentlichten Zusammenstellung aller HimalayaExpeditionen hörten britische Parteien bereits vor dem Ersten Weltkrieg damit auf, Schweizer Bergführer in den Himalaya mitzunehmen (Kurz 1950).

170 | Feuz 1953, 40f. 
den die Verhandlungen über den Everest so geführt, als befände sich dieser in britischem Besitz und als könnten die beiden führenden Bergsteigerclubs über den Zugang zum Berg bestimmen. Das macht deutlich, wie sehr der Everest innerhalb Europas als besetztes Territorium wahrgenommen und behandelt wurde, auch wenn sich das mit der Realität vor Ort keineswegs deckte. ${ }^{171}$

Gleichzeitig wurde der Alpinismus mit einer Geisteshaltung des Wettkampfs verbunden, gemäß der sich alle miteinander messen konnten. Die Vorstellung von den Bergen als >internationalem Spielfeld grenzt sich dabei ab von den >Eiger-Nordwand-Kämpfen « und von einer Vereinnahmung des Alpinismus für nationale Zwecke, wie dies im Faschismus der Fall war. Das Memorandum bezieht sich dabei explizit auf die erfolgreiche Durchsteigung der Eiger-Nordwand, die als letztes ungelöstes großes Problem des Alpinismus gegolten hatte, durch zwei deutsche und zwei österreichische Bergsteiger im Juli 1938. Das Ereignis wurde vom nationalsozialistischen Regime als Symbol für den erfolgreichen >Anschluss Österreichs an Deutschland und als Beweis für die »Überlegenheit der deutschen Herrenrasse $«{ }^{172}$ gedeutet. Die ablehnende Haltung gegenüber der politischen Verwendung bergsteigerischer Erfolge, die das Memorandum festhält, belegt die Distanznahme von einem Nationalismus faschistischer Prägung. Die nationalistische Verengung des Alpinismus in den Kriegsjahren sollte einer internationalen Ausrichtung des Bergsteigens weichen, welche die westliche Welt neu zusammenband. So erwähnt das Vorwort zu den Bergen der Welt von 1953 die >Entnationalisierung< des Bergsteigens als ein vordringliches Anliegen. ${ }^{173}$ Der Autor schlägt vor, das Schweizerkreuz im Logo der SSAF im Sinne des roten Kreuzes als internationales Zeichen zu werten, als »ein dem Alpensinn in Forschung und Bergsteigen geweihtes e pluribus unum«, als Zeichen dafür also, dass >aus vielen eines< werden kann. ${ }^{174}$

Das Memorandum der SSAF changiert zwischen Nationalismus und Internationalismus und drückt damit eine Ambivalenz aus, die für diese Phase kennzeichnend ist: Die Internationalisierung des Alpinismus nach dem Zweiten Weltkrieg bedeutete nämlich nicht, dass nationale

171 | Vgl. Hansen 1996.

172 | Amstädter 2000, 223.

173 | Gurtner 1953, 5.

174 | Gurtner 1953, 5 [Hervorhebung im Original]. 
Zugehörigkeiten keine Rolle mehr spielten, sondern dass der Alpinismus als freundschaftliches Kräftemessen zwischen national verfassten Expeditionen verstanden wurde. Und auch an dieser Stelle sind die unartikulierten Prämissen des Textes bedeutsam: Obwohl die >Jugend allgemein erwähnt wird, ist lediglich die männliche Jugend gemeint. Die Gleichzeitigkeit von Konkurrenz und Kooperation, die mit der Rhetorik des Wettkampfs einhergeht, verweist auf eine hegemoniale Männlichkeit, die auf Kampf beruht, dabei aber, wie Pierre Bourdieu ausführt, »von den anderen Männern bestätigt und durch die anerkannte Zugehörigkeit zur Gruppe der >wahren Männer beglaubigt werden $\ll^{175}$ muss.

Ferner ist der Internationalismus, von dem an dieser Stelle die Rede ist, ein Internationalismus westlicher Prägung. Mit dem Vergleich von Everest und Matterhorn hätte nämlich die Frage aufgeworfen werden können, inwiefern den nepalesischen und tibetanischen Bergsteigern dasselbe Recht zugestanden werden müsste wie den Schweizern, sich gegen die Vereinnahmung der Berge auf ihrem Territorium zu wehren. Der Text adressiert diese Frage aber nicht. Die Tatsache, dass der Everest den Briten nicht gehörte, wird nur als Argument dafür verwendet, eine Besteigung durch die Schweizer zuzulassen. Das Konzept des Internationalismus, das für die frühe Nachkriegszeit wegweisend wurde, brach nicht mit einer kolonialen Weltsicht; es speiste sich aus der Abwehr gegen die faschistische und nationalsozialistische Vereinnahmung alpinistischer Leistungen sowie aus ihrer drohenden Instrumentalisierung durch kommunistische Nationen.

Der neue westliche Internationalismus formierte sich nämlich auch als Antwort auf die kommunistische Welt und den sich abzeichnenden Kalten Krieg, der sich in den 1950 er Jahren zu einem Ringen um "global alliances and political ideas « ${ }^{176}$ entwickelte. Ein Zeitungsartikel, der am 7. Oktober 1952 in der New York Times veröffentlicht wurde, hält fest, dass nach der Übernahme Tibets durch China nun das Gerücht von einer russischen Expedition auf den Everest-Gipfel die Runde machte, »possibly on the theory that a Communist can climb faster and farther than a representative of the decadent capitalistic systems ${ }^{177}{ }^{177}$ Gleichzeitig wird berichtet, dass sich momentan eine Schweizer Expedition am Berg be-

175 | Bourdieu 2005, 94.

176 | Westad 2010, 4.

177 | O.V.: "A New Assault on Everest«, in: New York Times, 7. Oktober 1952. 
finde: »If they [the Swiss] win the summit no possible practical good can come of it. Yet through all the free countries, millions of men will probably feel a sense of elation in this triumph of human will over stubborn nature. ${ }^{178}$ Diese Zeilen zeigen, dass die zunehmend antagonistisch aufgeladene Konstellation des Kalten Krieges auch auf die Szenerie am Everest übertragen wurde. Mit ironischem Unterton wird bemerkt, dass die russische Expedition vermutlich nur dem Ziel diene, den kapitalistischen Menschen als dekadenten Schwächling zu entlarven. Die Besteigung des Everest wird so als Überblendung zweier Kämpfe dargestellt: des Kampfes zwischen Mensch und Natur einerseits und zwischen sozialistischer und kapitalistischer Weltsicht andererseits. Demnach würden Millionen von Menschen von einem Gefühl des Stolzes ereilt, wenn es den Schweizer Bergsteigern gelänge, die Natur mit ihrem menschlichen Willen zu bezwingen. Mit diesem >Sieg < sollten sich aber nur die Bürger der >freien Länder identifizieren können. In der >unfreien< Welt hinter dem Eisernen Vorhang, wo das Kollektiv und nicht das Individuum zählte, schien es nicht möglich, das Ringen zwischen Mensch und Natur zu verstehen, das sich am höchsten Berg der Welt abspielte. Die propagierte Internationalität des Bergsteigens hatte somit klare Grenzen: Die Protagonisten dieses kameradschaftlichen Kräftemessens waren Männer, die westliche Nationen und das kapitalistische System vertraten. Die selbstverständliche Identifizierung der Schweizer Bergsteiger mit dem westlichen Block durch die New York Times spiegelt dabei die gängige Außenperspektive auf die Schweiz wider. Der von der Regierung unternommene »diskursive Spagat zwischen einer >universellen Neutralitätspolitik und einer westlich konnotierten, antikommunistischen >Gesinnungsfreiheit « ${ }^{179} \mathrm{er}-$ möglichte die Einbindung in den westlichen Block, ohne dass die Schweiz ihren Exzeptionalismus, die Annahme ihrer Sonderstellung, preisgeben musste. Wie Hans Ulrich Jost ausführt, wurde die Neutralität einmal mehr bemüht, um die Integration in den westlichen Block mit der helvetischen Sonderstellung vereinbaren zu können: »Hatte man für den Völkerbund die Neutralität >differenziert<, unter dem Dritten Reich dann aus der öffentlichen Diskussion entfernt, so stellt man sie jetzt unter die Dialektik von >technisch< versus >politisch<. ${ }^{180}$ Insbesondere wirtschaftspolitische

178 | O.V.: "A New Assault on Everest", in: New York Times, 7. Oktober 1952.

179 | Bott, Schaufelbuehl und Zala 2011, 8.

180 | Jost 1998, 201. 
Entscheidungen wurden mit dem Argument legitimiert, es handle sich um technische und nicht um politische Formen des Handels und der $\mathrm{Zu}$ sammenarbeit. Ich werde auf diese entscheidende Differenz und ihre Bedeutung für die postkoloniale Geschichtsschreibung der Schweiz zurückkommen. Für die Phase des Kalten Kriegs ist innenpolitisch relevant, dass auf die Deutungsmuster der >Geistigen Landesverteidigung zurückgegriffen wurde. Die ihr inhärenten Bedrohungsszenarien wurden dabei dem Rahmen des Kalten Kriegs angepasst, was zu entscheidenden inhaltlichen Verschiebungen führte. ${ }^{181}$ Die >Geistige Landesverteidigung<, die in den 1930er Jahren gegen den Faschismus und für die Begründung eines Sozialstaates zum Einsatz kam, wurde nun gegen den Kommunismus und den (Sozial-)Staat angeführt, der neu unter dem ständigen Verdacht stand, Vorbote eines drohenden Staatssozialismus zu sein. ${ }^{182}$

Im Rahmen dieser Re-Nationalisierung im Kontext des Kalten Kriegs wurde das Himalaya-Bergsteigen in der Schweizer Berichterstattung weiterhin auch als nationale Angelegenheit behandelt. ${ }^{183}$ Nach der ersten Besteigung des Lhotse und der zweiten des Everest durch eine Schweizer Expedition schickte Bundesrat Philipp Etter ein Telegramm an die SSAF, in dem er der Equipe im Namen des gesamten Bundesrats seinen Dank aussprach. Sie habe »durch ihre mutige und erfolgreiche Tat, durch die Bezwingung des Mount Everest und Lhotse, unserem Lande hohe Ehre eingelegt und den alten Ruf des schweizerischen Alpinismus durch eine glänzende Leistung neu gekrönt « ${ }^{184}$. In seiner Ansprache beim Empfang der Expeditionsteilnehmer im Zürcher Grandhotel Dolder am 8. Juli 1956 verglich der Zentralpräsident des SAC die Leistung der Schweizer Bergsteiger mit derjenigen von »Pioniere[n] wie Kolumbus, Nansen,

181 | Imhof 2010, 82.

182 | Tanner 1999, 117. Vgl. auch Marti 2015.

183 | Dieses Ansinnen wurde auch ironisch kommentiert. Der Nebelspalter schreibt dazu: "Der Wettstreit um die Gipfel dieser Erde dauert an. Wir Schweizer stürmen mutig voran. Weil die Ausländer unsere Berge zuerst bestiegen, halten wir uns jetzt am Mount Everest schadlos ... falls er sich nicht an uns schadlos hält! Hoch wehe das weisse Kreuz im roten Feld über den fünf Kontinenten. Vorerst ruht es zwar noch gut verpackt im Rucksack." (o.V.: "Kleines Sportlexikon", in: Der Nebelspalter 1952(49)).

184 | Philipp Etter, zitiert nach M. Oe.: "Gute Rückkehr der Schweizerischen Himalaya-Expedition 1956", in: Die Alpen 1956(8). 
Amundsen, Scott und Lindberg« und betonte, auch ein Bergsteiger sei ein »Wegbereiter, sein Streben kraftvoll und männlich « ${ }^{185}$. Auch die internationale Berichterstattung kommentierte die nationale Vereinnahmung der Unternehmung. Von der Frühlings-Expedition auf den Everest berichtete die britische Times nicht ohne ironischen Unterton: »Each box was proudly labelled >Everest $<$, and stamped with a design of a Swiss cross and a coil of alpine rope. ${ }^{186}$

Neben diesem Zelebrieren der Himalaya-Expeditionen als nationale Heldentaten gab es auch Versuche, den Nationalismus zu einem Thema der Anderen zu erklären. Wyss-Dunant, der Leiter der Frühlings-Expedition von 1952, stellte die Schweizer Bergsteiger als Wissenschaftler und Sportler dar, die sich außerhalb eines politischen Feldes mit einer kolonialen Genealogie befanden: »)Für uns Schweizer<, erklärte Dr. Wyss-Dunant, >handelt es sich bei der Himalaja-Expedition um eine rein sportliche und viel mehr um eine wissenschaftliche Leistung, für unsere englischen Freunde dagegen bedeutet die Eroberung des Mount Everest, des höchsten Berges der Welt, eine nationale Angelegenheit. « ${ }^{187}$ Der Everest wurde von der britischen Kolonialpolitik seit Dekaden zum Schaustück imperialer Eroberungskraft stilisiert. Von dieser Geschichte distanzierte sich Wyss-Dunant mit einer für die Schweiz typischen Berufung auf ihre angebliche Parteilosigkeit.

Ein aufsehenerregender Versuch, die alte Konkurrenz mit Großbritannien in eine Kooperation zu überführen, misslang im Jahre 1952. Als die Schweizer von Nepal den Zuschlag für die Besteigung des Everest erhielten, suchten sie das Gespräch mit dem britischen Mount Everest Committee. Die Idee einer gemeinsam durchgeführten Expedition scheiterte allerdings an der Frage der Führung. Die SSAF beharrte darauf, den Schweizer Edouard Wyss-Dunant als Leiter einzusetzen, während das Mount Everest Committee dem Briten Eric Shipton die Leitung über-

185 | Wenck, Robert: "Ansprache beim Empfang der Himalaya-Expedition", in: Die Alpen 1956(8).

186 | 0.V.: "Swiss Expedition to Everest. Start for Base To-Day“, in: The Times, 29. März 1952.

187 | Zitiert nach Almásy, Paul: „Die Verantwortung für die Führung ist unteilbar. Besuch beim Leiter der Mount-Everest-Expedition 1952, Dr. Wyss-Dunant, auf seinem marokkanischen Hof", in: Schweizer Illustrierte Zeitung, 12. Februar 1952. 
geben wollte. ${ }^{188}$ Ebenso bemerkenswert wie die gegenseitige Weigerung, sich von einer Person der anderen Nationalität führen zu lassen, war die Bereitschaft zum Informationsaustausch: Shipton teilte die Ergebnisse seiner Erkundigungsexpedition in Nepal von 1951 bereitwillig mit den Schweizern. Und Letztere versorgten die nächste britische Expedition ein Jahr später mit wegweisenden Informationen.

Die eigenartige Mischung aus nationaler Abgrenzung und internationaler Kooperation schlug sich auch im Buch Forerunners to Everest nieder. Als der französische Bericht der Schweizer Everest-Expeditionen 1954 in englischer Übersetzung erschien, wurde ihm ein Vorwort des Leiters der erfolgreichen Erstbesteigung des Everest von 1953 vorangestellt. John Hunt würdigte die Vorarbeit, welche die Schweizer ein Jahr zuvor am Everest geleistet hatten. Zugleich versuchte er, die Geschichte aus britischer Sicht geradezurücken: »This book is entitled Forerunners to Everest. I feel sure that my Swiss friends will agree with me that there were many forerunners to Everest. The story started in 1921, and before the Swiss went to try their skill and luck a large number of British and Sherpa mountaineers had made sustained and gallant attempts to reach the top. ${ }^{189}$ Hunt forderte, den Begriff der Wegbereiter und die damit verknüpfte Anerkennung wegen ihrer entscheidenden Vorarbeit am Everest auf die ältere, im wesentlichen britische Geschichte der Everest-Expeditionen auszuweiten. Seine Ausführungen beinhalten eine deutliche Kritik am Versuch der Schweizer, ihre Bedeutung für das Gelingen der Everest-Erstbesteigung herauszustreichen. Das war aber nicht alles. Hunts Bemerkung kann auch als Vorschlag dafür gelesen werden, die Everest-Besteigung von nun an als Produkt einer gemeinsamen Geschichte zu interpretieren, in der explizit auch die Sherpas ihren Platz erhalten sollten.

188 | Roch, André: "Die Mount-Everest-Expedition von 1952. Unsere Erfolgsaussichten“, in: Neue Zürcher Zeitung, 2. April 1953.

189 | Hunt 1954, o.S. 


\section{Nepal UNd die SchWeiz: Ein Verhältnis IUNgleicher ÄhnLichKeIt`}

»Mit dem Eintritt in die Bergwelt von Thyangboche mochten wir gewissermaßen einer Bergsteigergruppe aus dem Jahr 1856 vergleichbar gewesen sein, die Zermatt hinter sich gelassen hat und nun im Weiler Zmutt vorübergehend Quartier bezieht. ${ }^{190}$ Diese zu Beginn dieses Kapitels schon einmal zitierte Passage aus Egglers Buch veranschaulicht die diskursive Praxis, den Himalaya mit den Alpen räumlich und zeitlich zu überblenden. Eggler ging nämlich nicht davon aus, dass seine Expeditionsgruppe zum ersten Mal einen Berggipfel im Himalaya erklomm und damit teilweise unbekanntes Gebiet betrat. Die Expedition wurde als historische Wiederholung einer Situation imaginiert, welche die Schweizer aus einer anderen Zeit in einer anderen Rolle kannten. ${ }^{191}$ Waren sie bei der Besteigung der Alpengipfel die Einheimischen, die sich als Handlanger und Gehilfen der britischen (und anderer) Bergsteiger betätigten, so sahen sie sich nun in der Rolle derjenigen, die von den Diensten der Einheimischen Gebrauch machten, angeblich über den größeren >bergsteigerischen Drang verfügten und im Unterscheid zu ihren rückständigen Begleitern die >modernity of the modern man ${ }^{192}$ verkörperten. Wie im Folgenden gezeigt wird, ist das Othering zwischen den weißen Schweizer Bergsteigern und den rassifizierten Sherpas, das in diesen Zeilen zum Ausdruck kommt, konstitutiv für ein hegemoniales Schweizer Selbstverständnis der Nachkriegszeit.

Vorauszuschicken ist, dass die Orientalisierung von Sherpas in der gesamten westlichen Bergsteigerliteratur ausgemacht werden kann. Wie Sherry Ortner festhält, verbanden sich dabei nicht selten herabsetzende Bilder von Anderen mit der Faszination für diese: »By Orientalism here I mean not only a kind of racist >othering ‘, but also at the same time a yearning for solidarity and even identity with the other. $«{ }^{193}$ Im Kontext der Schweiz beruhte das Oszillieren zwischen Identifikation und Des-Identifikation mit

190 | Eggler 1956, 66.

191 | Nicht nur das historisch differenzierte Othering, sondern auch die Überblendung der eigenen mit der fremden Landschaft verweist dabei auf eine koloniale Praxis. Vgl. dazu Stafford 1999, 315.

192 | Hansen 2013, 16.

193 | Ortner 1997, 139. 
den Sherpas auf der Idee einer kulturübergreifenden Ähnlichkeit, die aus der Natur abgeleitet wurde. Dreh- und Angelpunkt dieser Vorstellung war das gemeinsame Leben in den Bergen, das geteilte Erfahrungen und sogar eine wesenhafte Ähnlichkeit hervorbringen sollte. Gleichzeitig wurden die Sherpas außerhalb oder an der Schwelle zur Moderne verortet. Sie ermöglichten es den Schweizer Bergsteigern auf diese Weise, im orientalisierten Anderen die eigene Vorgeschichte zu erkennen und sich durch diese reflexive Drehung in der europäischen Alpinismusgeschichte neu zu situieren. Zudem diente das koloniale Othering der Sherpas dazu, hegemoniale Vorstellungen von nationaler Zugehörigkeit und moderner Männlichkeit in der frühen Nachkriegszeit zu entwickeln, in einer Zeit also, in der die westliche Vormachtstellung immer weniger mithilfe klassischer imperialer Kategorien behauptet und durchgesetzt werden konnte. Fluchtpunkt der folgenden Analyse ist deshalb die Frage, inwiefern sich Empathie und Wieder-Erkennen bei der Beschreibung der Sherpas diskursiv mit kolonialen Grenzziehungen verschränkten und welche Vorstellungen weißer Schweizer Männlichkeit sie damit möglich machten.

Auch das Othering der Sherpas gründete auf der >Naturalisierung der Nation<, auf der Prämisse also, dass sich die Beschaffenheit der Landschaft im Wesen eines Volkes abbilde. Aus dieser Maxime ließ sich eine Gleichartigkeit zwischen der Bevölkerung ähnlich strukturierter Territorien, sprich: eine Verwandtschaft von $>$ Berg-Nationen $<$ behaupten. ${ }^{194}$ Schon in einem 1931 erschienen Bericht von Hettie Dyhrenfurth wurde Nepal als »freie Schweiz des Himalaja ${ }^{195}$ geschildert. Und viele Schweizer Expeditionsberichte beschrieben ein unmittelbares Wieder-Erkennen von Landschaft, Flora und Lebensweise. In einem Bildband der SSAF zu den Himalaya-Expeditionen von 1952 heißt es exemplarisch: »Dieses ruhevolle Herbstbild zeigt eine alpin vertraute Landschaft, ein Tal nahe der Baumgrenze, mit Steineichen, Erlen und Föhren. Selbst die Bauweise der Holzhäuser ist uns vertraut, als wäre dieses Bild beispielsweise im Bergell, statt zwischen Arun und Dudh Kosi, aufgenommen worden. $\ll^{196}$

194 | Eine ähnliche diskursive Strategie beschreibt Lukas Zürcher bei der Schweizer Mission im Ruanda der 1940er-Jahre: "Wo Berge, Seen und Kühe sind, da sind auch Rechtschaffenheit und Anstand nicht weit, lautete die Formel." (Zürcher 2014, 100)

195 | Dyhrenfurth 1931, o.S.

196 | SSAF 1953a, Kommentar zum Bild 21, o.S. 
Für Marguerite Lobsiger-Dellenbach, die als Ethnologin die Frühlings-Expedition $195^{2}$ zum Everest begleitet hatte, waren auch Mehrsprachigkeit und die Koexistenz unterschiedlicher Konfessionen verbindende Elemente zwischen Nepal und der Schweiz: »Le Népal, si pareil à la Suisse par certains côtés, pays de montagnes, entouré de grandes puissances, parlant plusieurs langues, possédant des confessions diverses. ${ }^{197}$ In einem Artikel der Neuen Zürcher Zeitung von 1952 heißt es ferner: »Es ist ein besonderes Anliegen der Stiftung [SSAF], durch praktische Forschungsergebnisse und Einsatz von geographischen Pionierleistungen die von Seiten der Schweiz in dem irgendwie verwandten Bergstaat Nepal begonnene wirtschaftliche Erschließungsarbeit kulturell zu bereichern. « ${ }^{198}$ Auch an dieser Stelle wird der Schweizer Einsatz in Nepal mit einer >verwandtschaftlichen< Beziehung zwischen den Ländern begründet. Auf was aber nimmt die >wirtschaftliche Erschließungsarbeit< Bezug?

Wie Elmer schreibt, war Nepal in den 1950er Jahren das Land, in dem »die Schweiz ihre ersten Gehversuche und Experimente mit der bilateralen Hilfe wagen durfte ${ }^{199}$. Die Schweiz reagierte damit auf den wachsenden außenpolitischen Druck, sich im Bereich der Entwicklungshilfe vorteilhaft zu positionieren. Ein solches Engagement sollte dazu verhelfen, auf die breite Kritik an der Schweizer Neutralitätspolitik zu reagieren und den isolierten Status der Schweiz nach dem Zweiten Weltkrieg aufzubrechen. ${ }^{200}$ Zum Schlagwort entwickelte sich bald schon der Begriff der >technischen Hilfe an unterentwickelte Länder<, der politische Abstinenz versprach und damit die Neutralitätsmaxime nicht zu gefährden schien. ${ }^{201}$ Vertreter der Privatwirtschaft, verschiedener Bundesbehörden und der Eidgenössischen Technischen Hochschule (ETH) in Zürich gründeten 1950 eine >Koordinationskommission für technische Hilfe<, welche die Schweizer Entwicklungshilfe in Gang bringen sollte. ${ }^{202}$

Die Wahl eines ersten Ziellandes für die Entwicklungshilfe fiel auf Nepal, weil der in London akkreditierte nepalesische Botschafter Bim Bahadur

197 | Lobsiger-Dellenbach 1952, 44.

198 | SSAF: "Die Mount-Everest-Expedition 1952", in: Neue Zürcher Zeitung, 29. März 1952.

199 | Elmer 2012, 245.

200 | Vgl. dazu Speich Chassé 2012.

201 | Elmer 2012, 249.

202 | Elmer 2012, 250. 
Pande einen positiven Bericht über die Schweiz verfasst hatte. Dies veranlasste die nepalesische Regierung 1948, ein Gesuch zur Unterstützung durch technische Experten an die Schweiz zu richten. ${ }^{203}$ Wie die Bergsteiger zeigten sich auch Schweizer Entwicklungshelfer*innen voller Enthusiasmus über die Aussicht, ein scheinbar unbekanntes Land entdecken, beraten und auf dem Weg in die Modernisierung begleiten zu können. »Moreover, as Switzerland was only a minor player in international politics and never had formal colonies, Nepal also seemed to offer it the chance to >be first< and do the real >pioneering work $<$ for once. ${ }^{204}$ Nicht nur koloniale Sichtweisen (wie diejenige des Pioniers) prägten das neu entstehende Feld der Entwicklungshilfe, es wurde von Schweizer Akteur*innen überdies mit großen (kolonial anmutenden) Ambitionen besetzt.

Unter der Leitung der ETH wurde das Swiss Nepal Forward Team gegründet, das die Eignung Nepals als Partnerland für die Schweizer Entwicklungsarbeit abklären sollte. Auch bei dieser Gelegenheit wurde hervorgehoben, dass sich die Schweiz wegen ihres gebirgigen Charakters als Partnerin für Nepal geradezu anbiete. ${ }^{205}$ Die Gemeinsamkeit der beiden kleinen Bergnationen wurde in der Folge immer wieder betont, schreibt Elmer: »Freilich wird mit der Begründung der Hilfsbedürftigkeit gleichzeitig auf die frappanten Unterschiede in Reichtum und Lebensstandard hingewiesen: Man sieht sich ähnlich, aber keinesfalls gleich.« ${ }^{206}$ Diese >ungleiche Ähnlichkeit beruhte auf einer kolonialen Differenz und bildete, wie ich im Folgenden argumentiere, eine ideale Basis für die Positionierung der Schweiz im neuen Internationalismus des »Commonwealth Spirit « ${ }^{207}$, der sich insbesondere in einer paternalistisch geprägten Entwicklungshilfe manifestierte. Die behauptete Asymmetrie zwischen dem modernen Alpenland Schweiz und dem vormodernen Bergstaat Nepal führte dazu, dass die aktive Rolle Nepals bei der Lancierung der Schweizer Entwicklungshilfe weitgehend ausgelöscht werden konnte. So sprach die Neue Zürcher Zeitung von einer »von Seiten der Schweiz [...] begonnene[n] wirtschaftliche[n] Erschließungs-

203 | Elmer 2012, 252.

204 | Elmer 2014, 208.

205 | Elmer 2012, 254.

206 | Elmer 2012, 254.

207 | Ward 2001. 
arbeit « ${ }^{208}$. Damit wurde die Initiative des nepalesischen Botschafters und der nepalesischen Regierung unsichtbar gemacht - zugunsten eines Narrativs, dem zufolge es die Schweiz war, welche die wirtschaftlichen Beziehungen zu Nepal in die Wege geleitet hatte.

Eine vergleichbare Verschiebung der Initiative von asiatischen auf schweizerische Schlüsselfiguren ist in der Entstehungsgeschichte des Himalayan Institute of Mountaineering (HMI) zu finden, einer prestigeträchtigen Ausbildungsstätte für Bergführer, die vom Erstbesteiger des Mount Everest, Tenzing Norgay, geleitet wurde. In seiner Autobiografie ist zu lesen, sein Freund Robi Mitra habe dem obersten Minister von Westbengalen, Bidhan Chandra Roy, die Gründung einer solchen Institution vorgeschlagen. Der damalige Premierminister Jawaharlal Nehru nahm sich später des Projekts an und eröffnete die Schule im November $1954 .^{209}$ Im Vorfeld kontaktierte Norgay die SSAF und bat sie um Mitarbeit bei der Schulung von zukünftigen Ausbildern der Sherpas: »Da wir für diese Gründung der allerbesten fachmännischen Ratschläge bedurften, nahmen wir mit der Schweizer Stiftung für alpine Forschung Kontakt auf. Arnold Glatthard, der Leiter der Schule in Rosenlaui, kam nach Indien, um mit uns zu arbeiten. ${ }^{210}$

Was von Norgay als Kooperation beschrieben wurde, die von den asiatischen Partnern initiiert worden war, fand seinen Weg in die Schweizer Öffentlichkeit im sich neu formierenden Vokabular der Entwicklungshilfe. Die Schweizer Presse zeichnete Bilder von einfachen und kräftigen Männern aus dem Himalaya, die in der Schweiz mit alpinistischer Technik und dem entsprechenden Material vertraut gemacht wurden. Im SAC-Organ Die Alpen hieß es, die Männer aus dem Karakorum und dem Himalaya seien »particulièrement robustes, toutefois il leur manque la technique alpine ainsi que le matériel nécessaire pour cette formation « ${ }^{211}$. Die Zeitschrift Sport berichtete von den Ausbildungskursen, die unter der Leitung von Glatthard im Berner Oberland stattfanden und an denen

208 | SSAF: "Die Mount-Everest-Expedition 1952", in: Neue Zürcher Zeitung, 29. März 1952 [Hervorhebung PP].

209 | Vgl. die Website des HMI, https://hmidarjeeling.com/about-hmi/originand-growth/(Zugriff am 24. September 2018).

210 | Norgay und UIIman 1955, 278.

211 | SSAF: "Les sherpas poursuivent leur formation de guide en Suisse avec succès", in: Die Alpen 1954(9). 
mehrere Sherpas teilnahmen: »Nun sind also acht solche Naturburschen in den Händen von A. Glatthard im Rosenlaui. Dort knetet und formt er sie mit großer Geduld und Erfahrung. « ${ }^{212}$ Glatthard wird im Artikel als entscheidender Akteur beschrieben, der Naturmenschen zu kulturellen Wesen machte. Dazu muss er sich, wie der Autor betont, in die Position eines Elternteils versetzen, der seinem Kind etwas beibringt: »Ich hatte Gelegenheit, die Ausbildung der Sherpas [...] zu verfolgen und heute muss ich sagen, Glatthards System, >Wie lehr ich's meinem Kind, ohne dass es etwas merkt<, hat mich begeistert. «213

Die Vorstellung von Schweizer Bergführern, die über das relevante praktische und theoretische Wissen des Bergsteigens verfügten und die sympathischen, aber ungebildeten Sherpas in dieses Wissen einführten, dominierte die Berichterstattung. Die Illustrierte Sie + Er zeigte Fotos von der ersten Skifahrt Tenzing Norgays unter der Überschrift »Der Bezwinger des Mount Everest als >Ski-Säugling «²14. Norgay erwähnt in seiner Autobiografie, dass es bei seinem Aufenthalt im Wallis zu Missstimmungen gekommen sei, weil man ihm die nötige Anerkennung versagt habe. »Leider kam es anfangs zu einer kleinen Trübung, denn ich fühlte mich etwas wie ein unerfahrener Neuling behandelt. « ${ }^{215}$ Die Zusammenarbeit mit Glatthards Kletterschule beschrieb er positiv, verwendete dabei aber ein ganz anderes Vokabular als die Schweizer Medien. Das begann damit, dass er in Indien keine >Naturburschen<, sondern eine Gruppe bewährter Männer mit großer bergsteigerischer Erfahrung ausgewählt hatte, die sich in der Schweiz weiterbilden sollten. »Wir zogen alle nach Rosenlaui, wo wir mit der Schule Arnold Glatthards mehrere Wochen zusammenarbeiteten. « ${ }^{216}$ Während in Norgays Schilderungen die Kooperation im Zentrum stand, fokussierten die Schweizer Medien auf eine Hierarchie zwischen Schweizer Ausbildern und nepalesischen Auszubildenden, die

212 | Zimmermann, Werner: "Ausbildung der Sherpas im Rosenlaui“, in: Sport, 8. August 1954.

213 | Zimmermann, Werner: "Ausbildung der Sherpas im Rosenlaui“, in: Sport, 8. August 1954.

214 | O.V.: "Der Bezwinger des Mount Everest als 'Ski-Säugling“", in: Sie + Er, 31. Dezember 1953.

215 | Norgay und UlIman 1955, 221.

216 | Norgay und UlIman 1955, 322. 
sich mit unterschiedlichen kolonial besetzten Kategorien verband: Natur - Kultur und Eltern - Kind.

Diese paternalistische Perspektive schlug sich auch in der geschichtlichen Tradierung der Ereignisse nieder: Im Historischen Lexikon der Schweiz sind Glatthard und die SSAF nicht als Kooperationspartner der indischen Regierung und von Tenzing Norgay, sondern (fälschlicherweise) als Gründer des Instituts verewigt. Dem Eintrag unter Glatthards Namen zufolge wurde Norgay, der seit 1935 an Expeditionen im Himalaya teilnahm und als einer der erfahrensten Höhenbergsteiger seiner Zeit galt, erst von Glatthard zum Bergführer ausgebildet: »Ab 1954 bildete G[latthard] ind. und nepales. Sherpas zu Bergführern aus, darunter Tenzing Norgay, einen der Erstbesteiger des Mount Everest. Im Auftrag der Schweiz. Stiftung für alpine Forschung gründete er 1953 das Himalajan Mountaineering Institute in Darjeeling (Indien).« ${ }^{217}$

\section{SahibS UNd Sherpas}

Die Prämisse einer >ungleichen Ähnlichkeit zwischen Nepal und der Schweiz zog sich durch die Schweizer Berichterstattung zu den EverestExpeditionen. Das lässt sich anhand eines Artikels zeigen, der am 28. Mai 1952 in der Neuen Zürcher Zeitung und drei Tage später im Tages-Anzeiger publiziert wurde und den Titel »Die Sahibs und ihre Sherpas« trägt. Er erschien während der ersten der beiden Schweizer Everest-Expeditionen und beginnt folgendermaßen: »Als Ergebnis des langen Anmarsches sind zwei wichtige Dinge festzuhalten: die Sohlen sind horniger, die Nacken zäher geworden, der Magen verträgt sich mit rösch [knusprig] gebackenen Chapati, und die Bärte sprießen; der Berg ist erreicht; zwei Dutzend Männer, die Sahibs und ihre Sherpas, beginnen mit seiner Belagerung. Er wird sie in den kommenden Wochen zu einer Schicksalsgemeinschaft schmieden. ${ }^{218}$

Der Text beschreibt als erstes die Verwilderung der Schweizer Bergsteiger: Ihre Füße sind von dem tagelangen Marsch von Katmandu zum Basislager mit Hornhaut überzogen, die Rückenmuskeln sind unter den

217 | Bernet 2006.

218 | Gurtner, Othmar: "Die Sahibs und ihre Sherpas", in: Tages-Anzeiger, 31. Mai 1952. 
schweren Lasten gewachsen und die Gewöhnung an das fremde Essen ist gelungen. ${ }^{219}$ Zudem sind die sprießenden Bärte ein sichtbares Zeichen dafür, dass sich die Männer außerhalb der zivilisierten Sphäre befinden, in der sie sich täglich rasieren können. Die Schweizer Bergsteiger vollziehen rituell jene Vertauschung von Kultur und Natur, die für die koloniale Zone bedeutsam ist. In ihrer Studie zum deutschen Kolonialismus zeigt Katharina Walgenbach, wie sich die dichotome Zuschreibung von Männlichkeit und Kultur einerseits sowie Weiblichkeit und Natur andererseits in der Kolonie umkehrte: »Der Mann wurde nun in den [sic!] Bereich der Natur verortet: Seine Aggression, Kraft und sein Herrschaftswille waren wichtige Attribute, die der Eroberung >fremder< Länder dienen sollte.« ${ }^{220}$ Unrasierte Gesichter lassen sich als Symbol für den Abenteurer in der Wildnis und für den Eintritt des urbanen Mannes in die ländliche Zone lesen - auch Schweizer Bergführer wurden Mitte des 20. Jahrhunderts, im Unterschied zur städtischen Elite, meistens mit Bart abgebildet. Zahlreiche Bilder der Everest-Expeditionen zeigen (in Absetzung zu den stets bartlosen Sherpas) oftmals bärtige weiße Bergsteiger. »Mit Rucksack, Schirm und Wochenbärten « titelte die Illustrierte Sie + Er ihren Bericht über die Everest-Lhotse-Expedition von $1956 .{ }^{221}$ Die Bilder zur Rückkehr der Schweizer Expeditionsteilnehmer, aufgenommen auf dem Flughafen oder bei offiziellen Empfängen, zeigten hingegen Männer mit rasierten Gesichtern in Anzug und Krawatte und kennzeichneten auf diese Weise deren Wieder-Eintritt in die zivilisierte Zone.

Diese Taxonomie des Männlichen strukturierte auch die Beziehungen zwischen Sherpas und Schweizer Bergsteigern: Erstere erschienen als Assistenten, die den heldenhaften Kampf der weißen Männer in der Wildnis unterstützten. Diese asymmetrische Beziehung drückt sich in einem Bild aus, das in Egglers Buch über die Schweizer Everest-Lhotse-Expedition von 1956 veröffentlicht wurde (vgl. Abbildung 22). Es zeigt den Bergsteiger Hans Rudolf von Gunten mit zwei Sherpas namens Annullu und Pasang Phutar. Von Gunten steht erhöht und wirkt wesentlich größer als die beiden Nepalesen. Er scheint ihnen den weiteren Routenverlauf zu er-

219 | Der Fußmarsch von Katmandu zum Basislager dauerte 24 Tage. Vgl. WyssDunant 1952, 12.

220 | Walgenbach 2005, 262.

221 | Riboud, Marc: "Mit Rucksack, Schirm und Wochenbärten“, in: Sie + Er, 29. Juni 1956. 
klären. Die Sherpas sind ihm zugewandt, während sein Gesicht verdeckt bleibt. Die Bildlegende besagt: »Verständigung von Guntens mit Annullu und Pasang Phutar. Seine jede Sprachgrenze überwindende Gebärde hieß eindeutig: >Higher we go!««

Abbildung 22: Hans Rudolfvon Gunten mit Annullu und Pasang Phutar auf der Everest-Lhotse-Expedition

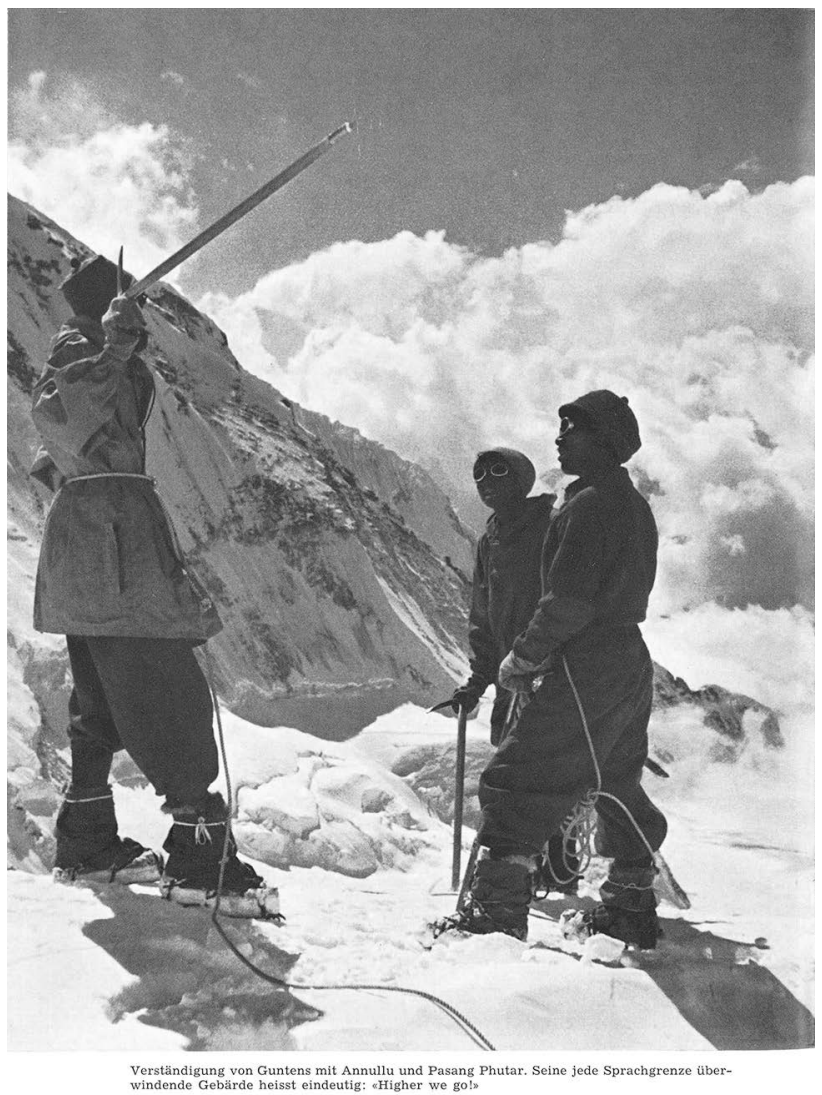

Quelle: Eggler 1956, 152

Der Text verbindet damit die grenzüberschreitende Verständigung mit einer klaren Aufteilung der Tätigkeiten: Der Schweizer Alpinist bestimmt die Route, er spricht, er plant und er symbolisiert den Drang nach oben. Die nepalesischen Sherpas lassen sich belehren, sie hören zu, befolgen 
die Anweisungen und unterstützen den Schweizer in seinem Unterfangen. Diese Hierarchie drückt sich auch in der Darstellung der technischen Hilfsmittel aus: Von Gunten scheint die Seilschaft anzuführen. Sein Pickel zeigt nach oben Richtung Gipfel, während diejenigen der Sherpas in den Schnee gesteckt sind, bereit für die nächsten Schritte.

Ein anderes Bild (vgl. Abbildung 23), das sich in einem Bildband zu den Everest-Expeditionen von 1952 findet, verweist auf eine weitere konstitutive Dimension der Beziehung zwischen Sherpas und Sahibs. Es zeigt den Sherpa Dawa Thondup, der im Vordergrund des Bildes steht und eine Flüssigkeit von einem größeren in einen kleineren Behälter gießt. Links hinten ist Raymond Lambert erkennbar, der auf das Nebelmeer blickt, das sich unter den Bergsteigern ausbreitet. Die abgeschnittenen Füße lassen den Sherpa, im Unterschied zum breitbeinig im Schnee stehenden Schweizer, gedrungen wirken. Der Text informiert darüber, dass Dawa Thondup gerade einen Orangensaft für Lambert zubereitet. ${ }^{222}$ Der Sherpa wird als derjenige dargestellt, der für die reproduktiven Arbeiten zuständig ist. Sein Blick richtet sich auf die Nahrung für den Schweizer Alpinisten, während dessen Blick in die Weite schweift. Der Schweizer ist der Schönheit der Landschaft zugewandt und beschäftigt sich mit der Planung ihrer Erschließung. Im frauenlosen Raum zwischen Basislager und Gipfel sichern die Sherpas das physische Überleben der Expeditionsteilnehmer. Zugleich werden sie dadurch aus dem Bereich der aktiven, heldenhaften und tätigen Männlichkeit verbannt.

Im oben erwähnten Artikel aus der Neuen Zürcher Zeitung wird die spezifische Beziehung zwischen nepalesischen und schweizerischen Bergsteigern aus deren Rollen in der Geschichte der Bergsteigens abgeleitet:

"Das Zusammenleben einheimischer Talleute mit fremden Bergforschern muss uns an die Pionierzeit der Alpenerschliessung erinnern. Doch darf man nicht daraus schließen, im fernen Himalajagebirge füge sich noch einmal jenes romantische Zusammenklingen von 'Herr und Führer, werde der neo-klassische Alpinismus geboren. Die beiderseitigen Voraussetzungen sind zu verschieden, der dortige Eingeborene hat trotz seiner Naturnähe noch nicht den Bergsinn und das bergsteigerische Können erreicht, wie es vor hundert Jahren in den Alpen das große Geschlecht der ersten Bergführergeneration auszeichnete; und die /Herrenı sind 
dort nicht mehr ähnlich den alpinen Pionieren, die durch Energie ausglichen, was innen an Bergerfahrung abging, sondern sie verkörpern vielmehr eine Spitzenklasse westalpinen Bergsteigertums mit einer enormen Erfahrung im Himalaja und in der besonderen Technik der bergsteigerischen Expedition." ${ }^{223}$

\section{Abbildung 23: Dawa Thondup und Raymond Lambert am Everest}

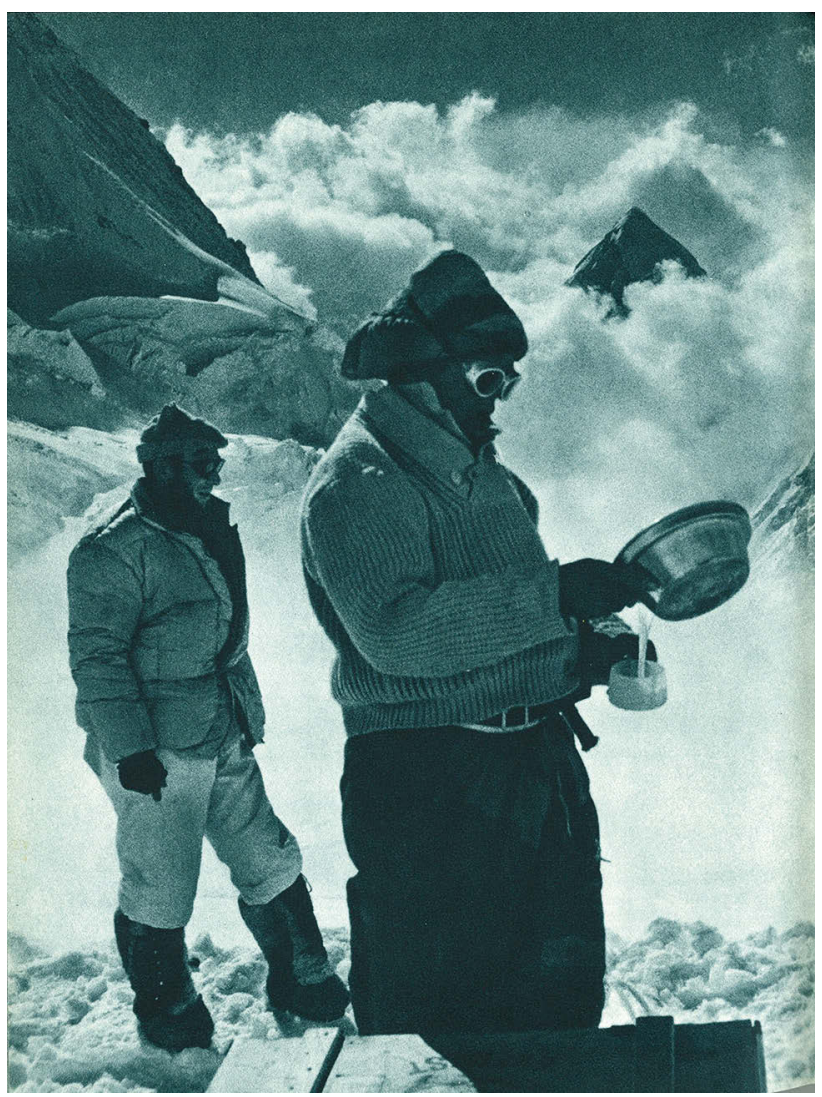

Quelle: Roch 1952, 88

Diese Ausführungen situieren die >ungleiche Ähnlichkeit< von Schweizern und Nepalesen nun im Kontext der Alpinismusgeschichte. Die

223 | Gurtner, Othmar: „Die Sahibs und ihre Sherpas“, in: Tages-Anzeiger, 31. Mai 1952. 
Asymmetrie der Darstellung manifestiert sich bereits mit der Wortwahl: Der Sherpa wird als >Eingeborener beschrieben, beim Schweizer Alpinisten ist vom >Bergführer< die Rede. Was beide gemeinsam haben, ist ihre Naturnähe. Was sie trennt, sind die technischen Kenntnisse und der >Bergsinn< der Schweizer, eine Mischung aus Wissen und Intuition im Umgang mit dem Gebirge. Damit wird die Grenze erneut da gezogen, wo sich das reine Überleben vom zivilisierten Leben scheidet. Sowohl die Sherpas als auch die Schweizer Bergführer leben naturverbunden, aber nur Letztere verfügen über intellektuelle Fähigkeiten und praktische Kenntnisse, die ihren Umgang mit den Bergen als eine moderne Praxis kennzeichnen. Die Differenz, die an dieser Stelle hergestellt wird, beruht auf der klassisch kolonialen Unterscheidung zwischen dem natürlichen und dem modernen Menschen.

Gleichzeitig zieht der Text eine Trennlinie zwischen den britischen Bergsteigern in den Alpen und den Schweizern im Himalaya ein: Erstere hätten durch Energie das wettgemacht, was ihnen an Erfahrung fehlte. Letztere aber verkörperten >eine Spitzenklasse westalpinen Bergsteigertums mit einer enormen Erfahrung im Himalaja<. Diese doppelte Bezugnahme auf Schweizer und Briten zeigt, wie die Everest-Expeditionen dazu verwendet wurden, die Geschichte des Alpinismus umzudeuten. Erfahrung und Können lagen demnach sowohl in den Alpen als auch fast hundert Jahre später im Himalaya aufseiten der Schweizer Bergführer. Diese Darstellung verweist zum einen die Briten an ihren Platz, weil sich deren >Energie< darauf beschränkte, die Bergtouren zu initiieren. Und sie macht zum anderen die Sherpas zu Assistenten, weil die Schweizer durch ihre senorme Erfahrung im Himalaja und in der besonderen Technik der bergsteigerischen Expedition « nicht auf deren Wissen oder Können angewiesen waren, sondern in erster Linie auf ihre physische Hilfe als Träger.

Die bergsteigerische Entdeckung der Alpen wird so in die Erzählungen der Everest-Abenteuer eingeschrieben, dass den Schweizer Bergsteigern eine überragende Position in beiden entscheidenden Epochen des modernen Alpinismus zukommt. Die britischen Herren waren zwar energisch, aber nicht erfahren am Berg. Und die Sherpas waren vertraut mit den Bergen, verfügten aber nicht über das Wissen und die Technik des Bergsteigens. ${ }^{224}$ Damit wird der Schluss nahegelegt, dass die Schwei-

224 | Diese Perspektive war vorherrschend; es gab aber auch einzelne Stimmen, die eine stärkere Gleichbehandlung von Sherpas und europäischen Bergführern 
zer Mitte des 19. Jahrhunderts die besseren Sherpas waren und dass sie hundert Jahre später die besseren Sahibs sind.

Der Einsatz von Sherpas wird im Artikel weiter ausgeführt. Da heißt es: »Jetzt stehen die Sherpas am Berg und teilen Leid und Freud mit ihren Sahibs. Sie sind Kammerdiener, Lastenträger, Feuerschlager, Zeltbauer, Schneewater und Wettertrotzer. Kurz, sie fügen sich mit ihren äußerst zuverlässigen Eigenschaften in das Kader der Sahibs so glücklich ein, dass wirklich von einer vollwertigen Bergkameradschaft gesprochen werden kann.« Bezeichnend ist an dieser Stelle wiederum die Verbindung von Egalität und Hierarchie: Es wird von einer >vollwertigen Bergkameradschaft< gesprochen und gleichzeitig werden physische und Hilfsarbeiten klar den Sherpas zugeschrieben: Sie müssen Lasten tragen und Feuer machen. Darüber hinaus sind sie als $>$ Kammerdiener $<$ um das physische Wohlergehen der Schweizer besorgt, die das Kader stellen und sich bedienen lassen. Der Widerspruch, dass die Bergkameradschaft einerseits >vollwertig< ist, andererseits aber auf einer sozialen Hierarchie beruht, ist als solcher nicht erkennbar, weil ihm eine koloniale Matrix zugrunde liegt, die das Gefälle zwischen weißen und nicht-weißen Männern normalisiert. Das >Berg-Othering< stellt eine Ähnlichkeit zwischen Schweizern und Nepalesen her, welche die koloniale Differenz unter neuen Bedingungen bestätigt.

Eine der diskursiven Strategien, die es ermöglichte, die Modernität der Sherpas in die Kolonialität der Macht einzupassen, war diejenige der Mimikry. Im Expeditionsbericht zur Everest-Expedition von 1952 erzählte René Dittert, wie die Schweizer ihre Sherpas, unter ihnen Tenzing Norgay, in Katmandu trafen: »At that moment, in their European-style clothes, they looked awkward, for they were not city sparrows and would

einforderten. So machte sich etwa Marcel Kurz 1953 zu einem Fürsprecher für die Anerkennung der Sherpas, indem er sich auf die Geschichte der Schweizer Bergführer berief: Das Desinteresse an den Sherpas, so Kurz, erinnere "etwas an die Geringschätzung der ersten Alpenreisenden für die 'Schweizer Bauern`, die sie durch ihre ,Eisberge ، führten. Erst neuerdings beginnt sich der Europäer ein wenig für seine Diener zu interessieren, und man gibt sich jetzt sogar Mühe, ihre Namen angemessen aufzuzeichnen. Vom historischen und ethischen Standpunkt aus ist es ebenso richtig, die Rolle der Himalaya-Sherpas zu kennen, wie die Bedeutung der Führer für die Eroberung der Alpen." (Kurz 1953, 1) 
only become themselves above $16^{\prime} \circ 00$ feet. « $^{225}$ Dittert konnte den >europäischen Kleidungsstik und das urbane Umfeld nicht mit seinem Bild der Sherpas in Einklang bringen: Für ihn sahen sie in den modernen Kleidern tollpatschig und unbeholfen aus. Für Dittert gehörten die Sherpas in die Berge - im Unterschied zu den Schweizer Bergsteigern, denen er das Recht zugestand, sich zwischen urbanen und ländlichen Räumen hinund herzubewegen. Aus seiner Sicht waren die Schweizer in Katmandu weniger fremd als ihre nepalesischen Kollegen.

Formulierungen wie etwa die Rede von der >Schicksalsgemeinschaft $<$, welche die Sherpas und die Sahibs am Everest gebildet hätten, verweisen aber auch auf den Versuch, die Beziehung zwischen beiden vermehrt in Begriffen der Kooperation zu erfassen. Der Präsident der SSAF, Karl Weber, hob in seiner Rede nach der erfolgreichen Everest-Lhotse-Expedition von 1956 vor 400 geladenen Gästen hervor, dass die Expedition als ein Gemeinschaftswerk verstanden werden müsse. In seinen Dank explizit eingeschlossen waren »unsere stets hilfsbereiten, freundlichen Sherpas, ohne deren Hilfe und Können jeglicher Erfolg in den Regionen der Achttausender versagt sein müsste $\ll^{226}$.

Das Himalaya-Bergsteigen wurde damit zu einer Bühne, auf der ein neuer Modus der Partnerschaft mit den Sherpas und neue Formen der Anerkennung von postkolonialen Anderen eingeübt werden konnten. Ein Bildbericht zu den Sherpas, der im Juni 1952 in der Illustrierten Sie + Er erschien, endete entsprechend mit den Worten: »Und man ahnt in diesen Dörfern, auf die der Abendschein von Eisriesen niederleuchtet, dass die Zusammenarbeit mit den Schweizern kein Kriegszug im Sinne der leidigen Weltgeschichte ist, sondern ein Zusammengehen mutiger Männer, die einem großen Ziel entgegenstreben. Darum vereinigt sich das ganze Land Solo Khumbu [der Gegend um den Mount Everest] in Gebet und Wunsch mit dem Schicksal der Mount-Everest-Expedition. Fürwahr, die hohen Berge schlagen hier eine Brücke des Verstehens. $\ll^{227}$

Diese Zeilen verweisen auf den Prozess der Dekolonisation, der die Weltkarte radikal verändern wird. Die Einwohner*innen des Himalaya-

225 | Dittert, Chevalley und Lambert 1954, 17.

226 | Karl Weber, zitiert nach M. Oe.: "Gute Rückkehr der Schweizerischen Himalaya-Expedition 1956", in: Die Alpen 1956(8).

227 | Roch, André: "Sahibs und ihre Sherpas im Banne des Mount Everest", in: Sie + Er 1952(23). 
tals beginnen demnach zu verstehen, dass die Schweizer nicht aus kolonialem Machtstreben heraus agieren, dass sie keinen >Kriegszug im Sinne der leidigen Weltgeschichte< im Sinn haben. Ins Zentrum gerückt wird ein gemeinsames Ziel, dem die Männer über >Rassen<- und Nationengrenzen hinweg entgegenstrebten. Dass mit den Schweizern eine Praxis der Zusammenarbeit auf den Plan trat, die mit dem kolonialen Machtstreben bricht, wird den Schilderungen gemäß in den Dörfern des Solo Khumbu sgeahnt<, und durch Gebete und gute Wünsche für die Everest-Expedition aktiv hergestellt. Durch Bezüge zur Religion (Beten), zu Emotionen (Wünschen) und einem Vor-Wissen (Ahnen) werden den nepalesischen Bergbewohner*innen vor-rationale Formen der Erkenntnis zugesprochen. Gleichzeitig zeigen sie sich interessiert an einer >Brücke des Verstehens $<$ die Schweizer und Nepalesen mithilfe der Berge zwischen beiden Nationen bauen sollen. Es ist eindrücklich zu sehen, welches Verständnis von Dekolonisation sich in diesen wenigen Zeilen spiegelt: Die Arbeit des Verstehens müssen die postkolonialen Anderen leisten, nicht die Vertreter der Metropole. Sie werden durch Othering-Prozesse als Subjekte dargestellt, die erst langsam ahnen, lernen und verstehen, dass nach den Zeiten kolonialer Gewalt nun eine gemeinsame Zukunft ansteht. Die Schweizer hingegen scheinen diese Lektion längst gelernt zu haben: Die Brücke des Verstehens steht bereits, die Einheimischen müssen sie nur noch betreten. Ein solches Bild verkehrt das Ereignis der Dekolonisation gänzlich: Die postkolonialen Anderen, die in zahlreichen Kämpfen an unterschiedlichsten Orten der Welt ihre politische Unabhängigkeit einfordern und erringen, erscheinen darin nicht als Initiator*innen dieses global bedeutsamen Umbruchs, sondern als unaufgeklärtes Publikum, dem die jüngsten historischen Geschehnisse erläutert und ihre Folgen für die Gegenwart nahegebracht werden müssen. Dem Schweizer Publikum wiederum muss nichts erklärt werden, es kann sich wiedererkennen in den mutigen Bergsteigern in Nepal, welche die Botschaft einer neuen gemeinsamen Zukunft in die Welt tragen. In dieser kurzen Passage zeigen sich die Prämissen einer weißen Perspektive, die selbst noch dann autoritär über Wissensformen und Handlungsanweisungen verfügt, wenn es um die Auflösung der eigenen Herrschaft geht. Stattdessen wird eine Transformation von Machtverhältnissen vorgeschlagen, die etliche ihrer entscheidenden Elemente unangetastet lässt: Insbesondere die Hierarchie zwischen europäischen Subjekten und ihren Partnern in Verbindung mit einem durchschlagenden Androzentrismus wird dabei 
weitergeführt. Dass die Kolonialität der Macht diskursiv erhalten bleibt, zeigt sich nicht zuletzt daran, dass die Spuren und Manifestationen kolonialer Gewalt unsichtbar gemacht werden. Fragen der Erinnerung, der Restitution oder des Aufarbeitens kolonialen Unrechts werden in solchen verharmlosenden Darstellungen eines neuen nachkolonialen Zeitalters gänzlich undenkbar gemacht.

Die Berichterstattung über die Everest-Expeditionen, so meine These, spielt eine bedeutsame Rolle bei der Entwicklung eines nachkolonialen Selbstverständnisses: Die Schweizer brechen gemeinsam mit den ihnen ähnelnden nepalesischen Anderen in die verbliebenen großen Abenteuer der Menschheit auf. Erneut ist das Bild des prädestinierten Schweizer Helfers ein männliches: Nicht zufällig spricht der Artikel vom >Zusammengehen mutiger Männer, die einem großen Ziel entgegenstreben<. Die Frauen sind nicht mutig, sondern adrett, und sie säumen den Weg der Männer: »Die Frauen stehen im Sonntagsstaat, wenn ihre Brüder oder Männer als Träger mit einer Karawane durchziehen «, ${ }^{228}$ heißt es im Text. Diese Aussage widerspricht einem Bild im Artikel, das zwei Trägerinnen mit schweren Lasten auf einer Brücke zeigt. Es entspricht aber der Rolle, die den Frauen in der Schweizer Berichterstattung zu den Himalaya-Expeditionen zugewiesen wurde und die darin bestand, den abenteuerlichen Unternehmungen der Männer einen Rahmen zu geben.

Die Vorstellung, dass Männer gemeinsam große Ziele verwirklichen, während Frauen sie mit allen Mitteln unterstützen, spiegelt das vorherrschende Geschlechterverständnis in der Schweiz der frühen Nachkriegszeit wider. Wie in den meisten westlichen Staaten wird in den 1950 er Jahren einem Weiblichkeitsmythos gehuldigt, der Joris zufolge »alle Erwartungen ein[mittelt]: weder jugendlich noch ältlich, zugleich brav und elegant, anziehend und sittsam, kurz: Tüchtigkeit, perfekt gepaart mit Fröhlichkeit und Gepflegtheit «229. Dieses Bild beruhte auf einem asymmetrischen heterosexuellen Arrangement, das dem Mann die Rolle des erwerbstätigen Ernährers und der Frau die Aufgabe der unbezahlten Hausfrau und Mutter zuweist. Was das heißt, hat Iris von Roten 1958 in aller Deutlichkeit beschrieben: »Lebenslängliche Kocherei, unvermeidliches Putzen und Pützeln und die Tretmühle ständigen Reparierens

228 | Roch, André: "Sahibs und ihre Sherpas im Banne des Mount Everest", in: $\mathrm{Sie}+\operatorname{Er} 1952(23)$.

229 | Joris 2012, 107. 
bilden die Zwangsarbeit, die im sogenannten Beruf als Frau und Mutter geleistet werden muß. Wie jede Zwangsarbeit, ist sie nicht bezahlt. « ${ }^{230}$ Die boomende Konsumkultur versprach der Hausfrau in den 1950er Jahren zwar, sich im Haushalt kreativ verwirklichen zu können. Tatsächlich aber wurden die beruflichen Möglichkeiten von Frauen stark eingeschränkt und das Stimm- und Wahlrecht wurde ihnen gänzlich verwehrt.

Als Argument für die Fortsetzung der Männerdemokratie wurde insbesondere die (von der Geschichtswissenschaft mittlerweile widerlegte) These angeführt, die Schweiz habe sich wegen ihrer Armee erfolgreich gegen eine Besatzung durch die nationalsozialistischen und faschistischen Nachbarn gewehrt. Der Grenzschutz wurde als bedeutsamer Akt der Landesverteidigung stilisiert und zugleich als Ort, an dem sich die Männer »mit ihren Geschlechtsgenossen aller Klassen und Schichten in den Strohlagern verbrüderten « ${ }^{231}$, wie Regula Stämpfli festhält: »Nicht die zahlreichen gewaschenen Socken und Hemden, die Soldatenpäckli und -weihnachten wurden in der Erinnerung (und damit in der Geschichte) aufbewahrt, sondern der hehre Geist des Militärdienstes«. ${ }^{232}$ Mütter, Schwestern und Gattinnen, aber auch alle andere Frauen wurden aus der Erinnerung an die verbindenden Erlebnisse der Grenzbesetzung ausgeschlossen. Damit bestärkten die gängigen Narrative zum Zweiten Weltkrieg die Vorstellung der Schweiz als Männerdemokratie: »Damit erhielt die Denkfigur Auftrieb, das Schweizer Stimmrecht sei historisch ein Korrelat der Wehrpflicht.« ${ }^{233}$ Diese Verbindung von militärischer Pflicht und staatsbürgerlichem Recht erhielt nach dem Zweiten Weltkrieg, als »normative Männlichkeit vermehrt mit Soldatentum assoziiert « ${ }^{234}$ wurde, neuen Aufwind. Der zunehmende Antikommunismus stützte diese Perspektive: Er führte die Forderung nach dem Frauenstimmrecht auf emanzipatorische Ideen zurück, die durch den kommunistischen Osten

230 | Von Roten 1991, 429.

231 | Stämpfli 2003, 215.

232 | Stämpfli 2003, 215f. Die ,Soldatenweihnachtı wurde in der Schweiz während des Zweiten Weltkriegs eingeführt, als viele Männer während der Festtage nicht nach Hause durften und im Rahmen des Militärs Weihnachten feiern mussten. Privatpersonen und Firmen spendeten den Soldaten oftmals großzügig Geschenke.

233 | Studer 2014a, 184.

234 | Studer 2014a, 183. 
Einzug in die Schweiz hielten und zum Schutze der Nation bekämpft werden mussten. ${ }^{235}$ Entstanden ist dabei die Vorstellung eines Sonderfalls Schweiz, »zu deren Grundpfeilern die Gleichsetzung von Wehrpflicht mit Staatsbürgerschaft ebenso gehörte wie das fehlende Stimmrecht der Frauen ${ }^{236}$. Die Weigerung, Frauen das Recht auf politische Partizipation zuzugestehen, wurde als Schweizer Eigenart verstanden - ein Argument, das gegen interne und externe Kritik zu immunisieren vermochte. Die »diskursiv beschworene Identität zwischen Bürger und Wehrmann « ${ }^{237}$ ermöglichte es vielmehr, die Schweizer Demokratie trotz ihres eklatanten Bruchs mit dem demokratischen Anspruch auf politische Partizipation als realisiert und sogar als vorbildlich zu betrachten.

Der Ausschluss der Frauen aus der Demokratie, der in der Schweiz im Unterschied zu vielen anderen Staaten über den Zweiten Weltkrieg hinaus fortbestand, wurde auch durch populäre Darstellungen des Bergsteigens gestützt. Militärische Männlichkeit wurde nämlich seit dem Zweiten Weltkrieg wieder eng an den Gebirgssoldaten gekoppelt. Die >Geistige Landesverteidigungく, so Wirz, »stellte den Gotthardpass und andere Bergübergänge ins Zentrum und mit ihnen die zu Protoschweizern erklärten Säumer, Hirten und Bergführer.« ${ }^{238}$ Dazu kam die Verschränkung von Militär und Zivilgesellschaft, die sich etwa darin ausdrückte, dass die Armee mit dem populären Schweizer Alpenclub rege Beziehungen unterhielt. Beide arbeiteten bei der Erstellung von Landeskarten zusammen, der SAC bot nach 1938 Aus- und Weiterbildungskurse im Gebirge für das Militär an und viele Männer, die ihren Militärdienst in den Alpen verbrachten, traten später dem Alpenclub bei. ${ }^{239} 1946$ wurde General Henri Guisan zum Dank für die von ihm geschaffene Idee des Réduits die Ehrenmitgliedschaft des SAC verliehen. ${ }^{240}$

235 | Joris 2012, 116. Übersehen wurde dabei, dass die Männerdemokratie längst vonseiten der Frauen und auch vieler Männer innerhalb der Schweiz infrage gestellt wurde. So formierte sich 1957 breiter Widerstand gegen den obligatorischen Einsatz von Frauen im Zivilschutz, was mit der Losung "Keine neuen Pflichten ohne Rechte“ bekämpft wurde (Joris 2012, 116). Vgl. auch Amlinger 2017.

236 | Joris 2012, 116.

237 | Stämpfli 2003, 226.

238 | Wirz 2007, 358.

239 | Hungerbühler 2013a, 59.

240 | Hungerbühler 2013a, 59. 
Darstellungen von Schweizer Bergsteigern als ideale Verkörperungen des »Bürger-Soldaten ${ }^{241}$, um eine Formulierung von Brigitte Studer aufzugreifen, wurden aber nicht nur im alpinen Raum generiert. Vielmehr bereiteten die Erstbesteigungen der höchsten Berge der Welt eine Bühne, auf denen diese militärische Männlichkeit vorgeführt und popularisiert werden konnte. So ist ein Inserat der Schweizer Illustrierten Zeitung von 1952 mit dem bellizistischen Titel »Der Kampf um den Mount Everest beginnt!« überschrieben. ${ }^{242}$ Die Berichterstattung der Zeitschrift ermögliche es der Leserschaft, heißt es weiter, »jede Phase des gigantischen Kampfes einer Elite schweizerischer Bergsteiger« zu erleben. Solche Darstellungen schaffen militärisch konnotierte Bilder von Schweizer Helden, die in fernen Ländern für Ruhm und Ehre der Nation kämpfen. Und auch die andere Seite der komplementären Geschlechterordnung wird repräsentiert, wenn auch viel weniger oft: Die wenigen Expeditionsberichte, in denen Schweizer Frauen Erwähnung finden, zeigen sie als zuarbeitende und unterstützende Familienmitglieder, die ihr Leben in den Dienst von Anderen stellen. So berichtet der Artikel »Ihre Gatten und Söhne sind im Himalaja« darüber, wie Ehefrauen und Mütter von Expeditionsteilnehmern zu Hause auf die geliebten Männer warteten. Marguerite Gross, verheiratet mit dem Bergsteiger Gustave Gross, erzählt: »Zuerst dachte ich: Jetzt darf er wirklich nicht weg - denn ich erwarte mein viertes Kind auf Februar 1953. Dann dachte ich an ihn und seine Berge; nimmt man ihm die Berge weg, dann nimmt man ihm gleich das ganze Leben. ${ }^{243}$ Gross' Aussage illustriert die selbstlose Aufopferung, die als ideale Haltung der Schweizer Ehefrau galt. Obwohl sie drei Kinder hat und ein viertes erwartet, zeigt sie sich nach kurzem Zögern bereit, über viele Wochen hinweg auf die Unterstützung ihres Mannes zu verzichten, weil sie seine Lebensziele über ihre Wünsche stellen kann. Sogar ihre eigenen Bedürfnisse, die sie in der Folge umstandslos zurückstellt, beziehen sich auf die Unterstützung als schwangere Mutter und Hausfrau, kurz: auf die Reproduktionsarbeit, die sie bereits für ihn leistet. Die Vorstellung, dass sie eigene, von der Familie unabhängige Lebenspläne oder Interessen entwickeln und verfolgen könnte, kann in dieser Darstellung gar nicht in den Bereich

241 | Studer 2014a, 180.

242 | Inserat in: Sie + Er 1952(11).

243 | O.V. "Ihre Gatten und Söhne sind im Himalaja», in: Sie + Er 1952(48), 27. November 1952, 2. 
des Denkbaren rücken. Sie wird als Person beschrieben, die ihr Leben in jeder Hinsicht auf das Leben der Anderen ausrichtet. Der Artikel endet mit den Zeilen: »Berge, Militär und Wein - dies ist im Bas-Valais ehrwürdige Tradition, von der Bergführer Gross ein Stück in den Himalaja mitgenommen hat. Und noch etwas gehört zum Wallis, von dem Frau Gross allerdings nichts sagt: mutige Frauen.« Der Mut des Bergsteigers, der im fernen Hochgebirge sein Leben aufs Spiel setzt, korrespondiert mit dem Mut der Bergsteiger-Ehefrau, der darin besteht, dass sie ihn ziehen lässt und die enorme Arbeit zu Hause klaglos ohne ihn schultert. Solche Schilderungen sind Bestandteil einer diskursiven Praxis, die Männlichkeit mit Innovation und Mobilität verknüpft, während Weiblichkeit mit einem statischen Dasein und der Tätigkeit des Erhaltens verbunden wird. Dabei ist es kein Zufall, dass die ländliche Frau aus dem alpinen Raum diese Rolle idealtypisch verkörpert und nicht etwa die Städterin, die bereits die Unruhe und Entfremdung des modernen Lebens kennt. Damit wird die Vorstellung genährt, Männer würden sich aktiv und im öffentlichen Raum an der Herstellung der Nation beteiligen, während Frauen für die Reproduktion von Familie und Privatsphäre sorgten - eine Vorstellung, die mit der männlichen Norm des Staatsbürgers korrespondierte und den Ausschluss der Frauen aus der politischen Sphäre nachhaltig ins populäre Imaginäre einzugravieren vermochte.

\section{MÄNNLICHKEIt IN DER TOdeSZONE}

Nicht nur die Akteure, auch die Landschaft und das Bergsteigen selbst sind in den Diskursen des modernen Alpinismus tiefgehend vergeschlechtlicht. Wie Tanja Wirz zeigt, wurde das alpine Hochgebirge ab 1880 von bürgerlichen Männern aus der Elite als Rückzugsort genutzt, an dem sie Naturnähe, Wildheit, Abenteuer und Homosozialität pflegen konnten. ${ }^{244}$ Obwohl ihnen sowohl bürgerliche Frauen als auch Arbeiter*innen diesen Raum zunehmend streitig machten, wurden die Alpen in der Bergsteigerliteratur lange als idealisierter Ort dargestellt, an dem bürgerliche und patriotische Werte unter Männern zelebriert werden konnten. »Die Idee, es handle sich dabei [beim Hochgebirge] gewissermassen um ein Archiv aller hergebrachten Traditionen und Werte, in das man sich zum >Auftan- 
ken $<$ zurückziehen könne, wurde im alpinistischen Diskurs seit langem gepflegt «, ${ }^{245}$ schreibt Wirz. Auch die Expeditionen außerhalb Europas wurden bis zu den 1970er Jahren vorwiegend als männliche Tätigkeit erachtet. Das Höhenbergsteigen im Himalaya, so Ortner, »built on male styles of interaction derived from other all-male institutions, especially the army, and [...] it was always in part about masculinity and manhood « ${ }^{246}$. Die Berge wurden zu einem Ort, an dem hegemoniale Männlichkeiten trainiert, erlernt und perfektioniert werden konnten.

Diese androzentrische Perspektive schlägt sich auch im Vokabular der Bergsteigerliteratur nieder. Im Bericht der Schweizer Expedition von 1952, der es zum ersten Mal gelang, den Khumbu-Eisfall zu durchqueren und das Tal zwischen Everest und Lhotse zu betreten, schreibt René Dittert über eine Erkundungstour: »But scarceley [sic!] were we on virgin ground than the battle began again; it was to last the whole day.« ${ }^{247}$ Die Südroute zum Everest wird als jungfräuliches Terrain imaginiert, das mit kriegerischen Mitteln in einem harten Kampf erobert werden musste. Die Erstbegehung wird als Unterwerfungsritus beschrieben, der die Natur erobern und allen nachfolgenden Menschen/Männern zugänglich machen soll: »For it is a strange fact, but one that has always proved true, that where one man has imposed his domination over the elements another man can pass. The way is open, because the forces of nature have waited for man to prove himself master before submitting. « ${ }^{248}$ Diese Vorstellung einer Natur, die gleichzeitig übermächtig ist und darauf wartet, von Menschen/Männern unterworfen und dominiert zu werden, ist nicht nur tief verwoben mit Vorstellungen (hetero-)sexualisierter Gewalt, sondern auch mit einer kolonialen Perspektive auf die noch zu erobernde Welt. Wie McClintock zeigt, kommt der Vorstellung einer feminisierten Landschaft, die von einem männlichen Invasor penetriert, defloriert und mit seinem Namen markiert wird, eine bedeutsame Rolle bei der Imagination kolonialer Eroberungen zu: »By flamboyantly naming >new< lands, male imperials mark them as their own, guaranteeing thereby, or so they believe, a privileged relation to origins. $\ll^{249}$ Auch am Everest wurde das

245 | Wirz 2007, 357.

246 | Ortner 1999, 127.

247 | Dittert, Chevalley und Lambert 1954, 61.

248 | Dittert, Chevalley und Lambert 1954, 40.

249 | McClintock 1995, 29. 
unbekannte Terrain von den westlichen Bergsteigern sprachlich in Besitz genommen: Eine markante Felsstelle im Aufstieg zum Nordsattel des Everest wurde von den mehrheitlich genferischen Bergsteigern Eperon des Genevois (Genfer Sporn) getauft - eine Bezeichnung, die immer noch Verwendung findet.

Die Verwobenheit von kolonialen Entdeckungsnarrativen und modernem Geschlechterdiskurs schlägt sich auch in der Darstellung der Sherpas nieder, denen oftmals die Rolle der unterstützenden Frau zugewiesen wird. Über die Rückkehr ins Camp nach einer Erkundungstour schreibt Dittert: »This two-day struggle had worn us out and the Sherpas saw it. How friendly and kind they were as they unroped us, untied our crampons and boots, and brought us tea! « ${ }^{250}$ Die physische Stärke der Schweizer Bergsteiger kontrastiert in dieser Passage mit der affektiven und umsorgenden Arbeit der Sherpas, die in der westlichen Geschlechterordnung den Frauen zugeschrieben wird. Hegemoniale Vorstellungen von Männlichkeit gründen nicht nur auf dem Ausschluss von Frauen. Wie Andrea Maihofer festhält, dienen sie auch der »Errichtung von Hierarchien zwischen Männern « ${ }^{251}$, beispielsweise durch die Feminisierung der sozial schwächeren Männer.

Die Vorstellung des Himalaya-Bergsteigens als männlicher Tätigkeit, die bis heute dominiert, kann mit guten Gründen infrage gestellt werden. Am langen Zustieg der Expeditionen waren in der Regel zahlreiche einheimische Trägerinnen beteiligt, die sich teilweise über die Basislager hinausbewegten. Für das Schweizer Himalaya-Bergsteigen spielte Annelies Lohner, spätere Sutter, eine herausragende Rolle. Auf ihre Initiative hin wurde 1947 eine SSAF-Expedition ins Gangotri-Massiv im indischen Garhwal zusammengestellt, an der sie gemeinsam mit vier männlichen Bergsteigern auch selbst teilnahm. ${ }^{252}$ Zwei Jahre später war sie an einer weiteren SSAF-Expedition im Gebiet des Kangchendzönga im östlichen Himalaya beteiligt. ${ }^{253}$ Auch an den frühen Himalaya-Expeditionen nahmen europäische Bergsteigerinnen teil. Hettie Dyhrenfurth erreichte

250 | Dittert, Chevalley und Lambert 1954, 62.

251 | Maihofer 2002, 85.

252 | Vgl. www.alpinfo.ch/rueckblick/de/expeditionen/himalaya47.html (Zugriff am 24. September 2018) sowie der Expeditionsbericht mit mehren Texten von Lohner (SSAF 1947).

253 | Vgl. ebd. 
1934 durch die Besteigung des Sia Kangri (Queen Mary Peak) die Höhenmarke von 7.500 Metern und hielt für die nächsten 20 Jahre den Höhenrekord der Frauen. Er wurde erst 1954 von Claude Kogan übertroffen. ${ }^{254}$

Die Französin Kogan war in den 1950er Jahren eine Ausnahmefigur im männlich geprägten Höhenbergsteigen. Gemeinsam mit dem Schweizer Raymond Lambert versuchte sie 1954, den Cho Oyu zu besteigen. ${ }^{255}$ 1959 starb sie bei einer von ihr organisierten Expedition auf denselben Berg, die aus neun europäischen Bergsteigerinnen, drei Sherpanis sowie mehreren männlichen Sherpas bestand. ${ }^{256}$ Auch Loulou Boulaz, die vermutlich beste Schweizer Bergsteigerin des 20. Jahrhunderts, ${ }^{257}$ war mit von der Partie. Dass die Expedition sowohl von den europäischen Teilnehmerinnen als auch von der Presse als >Frauenexpedition < bezeichnet wurde, verdeutlicht zweierlei: Erstens galt das Bergsteigen unausgesprochen als männlich, niemand nahm je den Begriff >Männerexpedition< in den Mund. ${ }^{258}$ Und zweitens verweist die Bezeichnung auf die geschlechtlich hybride Positionierung der Sherpas, die ebenfalls Teil der Expedition waren. Sie gehörten als Helfer und Assistenten nicht zu den wahren Akteur*innen am Berg. Das Ausblenden der männlichen Sherpas im Begriff der >Frauenexpedition $<$ zeigt darüber hinaus deren prekären Status als nicht-weiße Männer an. Weißsein erscheint als implizite Bedingung einer Männlichkeit, die >richtig < und damit auch repräsentierbar ist.

Obwohl sich also einheimische und ausländische Frauen bereits in einer frühen Phase am Himalaya-Bergsteigen beteiligten, waren die Expeditionen Mitte des 20. Jahrhunderts diskursiv auf die Herstellung und Stabilisierung einer eurozentrischen Männlichkeit angelegt. Diese Ausrichtung bildete sich auch in der Berichterstattung zum Höhenbergsteigen ab, die sich in der Regel in drei Abschnitte gliedert: Im ersten Teil wird die Anreise und der tagelange Zustieg zum Basislager geschildert. Diese Sequenz dient oftmals der exotischen Rahmung der Expedition: Fremdes Essen und Trinken, unbekannte Rituale, Gebetspraktiken, Fa-

254 | Nickel 2007, $133 f$.

255 | Lambert und Kogan 1955.

256 | Vgl. Reznicek 1967, 84ff.

257 | 1937 gelang es Boulaz und Pierre Bonnant beinahe, als erste Seilschaft die Eiger-Nordwand zu durchsteigen. Vgl. Wirz 2007, 272 und Purtschert 2010b, 351f. 258 | Zur Geschichte von 'Frauenexpeditionen، am Himalaya vgl. Gugglberger 2016. 
milien- und Verwandtschaftsformen und die Bräuche und Eigenheiten der Einheimischen werden ausführlich beschrieben und in Szene gesetzt. Der Text ist voller Anleihen an die Abenteuer- und ethnologische Literatur, beinhaltet oftmals popularisierte Elemente der Rassenforschung und nimmt auch auf Frauen und Kinder Bezug.

Auf die Schilderung des erfolgreichen Anmarsches zum Basislager folgt diejenige des Aufstiegs. Erzählstil und Gegenstand der Narration verändern sich dabei gänzlich: Widmete sich der erste Teil der farbenfrohen Darstellung einer pittoresken Gegend und exotischer Bräuche, dominiert im zweiten ein technisches Vokabular und eine sakral aufgeladene Sprache. Ersteres wird eingesetzt, um das Material, die Route oder die Wahl der Lagerplätze zu beschreiben und alpinistische Fort- und Rückschritte zu erörtern. Mit Letzterem wird die (Über-)Macht der Natur und damit das Schaudern und die Ehrfurcht zum Ausdruck gebracht, die den modernen Menschen erfassen, wenn er sich auf eine Weise der Natur aussetzt, die ihn mit den Grenzen menschlicher Macht konfrontiert. Ein dritter Teil wendet sich schließlich der dramatischen Schlussphase des Aufstiegs zu, die zumeist als Kampf mit den Elementen dargeboten wird, als menschliche Probe am Rande der Kräfte, als Ringen mit sich selbst und der Natur um Sieg (das Erreichen des Gipfels) oder Niederlage (die Umkehr oder gar der Tod). Diese narrative Klimax spielt sich in der sogenannten Todeszone ab. Sie beginnt auf 7.000 Metern Höhe und findet damit an einem Ort statt, an dem menschliches Überleben nur während einer sehr kurzen Zeitspanne möglich ist, weil die erforderliche Sauerstoffsättigung des Blutes nicht lange aufrechterhalten werden kann. In dieser Extremzone aus Schnee und Eis, die den Menschen an die Grenzen seiner physischen und psychischen Kräfte bringt, wird weiße Männlichkeit in den 1950er Jahren auf neue Weise in Szene gesetzt.

So etwa im Film Mount Everest 1952, der während der Schweizer Herbst-Expedition gedreht wurde. Er inszeniert das Basislager als Schwellenort zwischen dem ersten und dem zweiten Teil des Aufstiegs. Die Männer lassen dabei die menschliche Welt zurück, um sich in Schnee und Eis einer Grunderfahrung des Menschlichen zu stellen. Männlichkeit dient in diesen Erzählungen, wie Frohlick schreibt, als unmarkierter Platzhalter für das Menschliche: »Gendered bodies disappear from view even as the space is aggressively masculinized.« ${ }^{259}$ Das zeigt sich beim Verlassen 
des Basislagers, das die Kommentarstimme mit folgenden Worten begleitet: »Wir haben das majestätische Reich des Himalaja betreten. Hier ist die Natur feindselig, das Leben grausam, hier muss der Mensch den Entscheid über sein Schicksal den Göttern überlassen. ${ }^{260}$ Der Übergang in die Bergwelt nimmt den Menschen aus der Sicherheit einer sozialen Welt und setzt ihn einer Natur aus, die sich feindlich gegen ihn richten kann. Es scheint, als ob die Stimme aus dem Off, welche die Bilder kommentiert, an dieser Stelle die buddhistische Perspektive übernimmt, die ansonsten den Einheimischen zugeschrieben wird, denn es ist von >Göttern im Plural die Rede, die nun über das menschliche Los bestimmen. Die Bergsteiger sind nicht nur der Natur ausgesetzt, sondern auch einer sakralen Macht, welche die christliche Taxonomie zu durchdringen und zu übersteigen scheint. Der Kommentar spricht vom »abenteuerlichen Eindringen des Menschen in eine geheiligte Stätte, die noch gestern der Schlupfwinkel der abergläubigsten Vorstellungen war « ${ }^{261}$. Die christlich positionierten weißen Bergsteiger werden als diejenigen beschrieben, die den Aberglauben verjagen und gleichzeitig von seinem Zauber affiziert werden.

Der behauptete Universalismus der menschlichen Erfahrungen, die in der Todeszone gemacht werden, verdeckt, dass sich diese in einer rein männlichen Sphäre abspielen, die auf dem radikalen Ausschluss der Frauen gründet. Dass die Männer ohne den Schutz von Kultur, Gesellschaft und Politik einer überwältigenden Natur gegenüberstehen, verdeutlichen die Texte nicht nur durch die ständige Referenz auf Götter, Geister, Visionen und gewaltige Energien. Sie stellen auch einen Gegensatz her zwischen einer weißen, lebensfeindlichen und einer grünen, lieblichen Welt, welche die Männer hinter sich gelassen haben:

"Seltsame Vision, menschliche Energie, Größe des Bergs. Auf den hohen Gipfel des Nuptse stürzt sich heulend der wilde Nordwestwind und wirbelt den Schnee auf. Er verfolgt uns ohne Unterbruch. Verschwunden ist alle Lieblichkeit, alle Abwechslung, alles Grün. Die Träger sind in die Ebene zurückgekehrt. Wir sind allein mit den Sherpas, in einer Welt von Eis und Schnee. Zusammen mit dieser rauen

260 | Film "Mount Everest 1952", Archiv Alpines Museum der Schweiz (gesehen am 30. September 2012).

261 | Ebd. 
Einsamkeit beginnt etwas Wesentliches, Absolutes, und Angst und Kampfbegeisterung zugleich erfüllen unsere Herzen. ${ }^{262}$

Umgeben von einer feindlichen Natur und fernab einer menschlichen Welt können die Männer paradoxerweise mit dem eigentlich Menschlichen in Kontakt treten und mit etwas >Wesentlichem< und >Absolutem< auf Tuchfühlung gehen. Das Pendant zur gewaltigen Natur, der sich der Mann gegenübersieht, sind seine eigenen Kräfte. Es ist kein Zufall, dass diese Extremzone, in der die weiße Männlichkeit mit sich selbst ringt, eine >Welt von Eis und Schnee und damit in gleißendem Weiß gehalten ist. James Baldwin beschreibt die Gegebenheiten in den Schweizer Alpen als »white wilderness ${ }^{263}$ und spielt damit, wie ich in der Einleitung ausführe, nicht nur auf Schnee und Eis, sondern auch auf die Vorherrschaft eines weißen Wissensregimes an. In der Bergsteigerliteratur der 1950er Jahre wird der Himalaya zur Bühne einer weißen Männlichkeit, die ihre eigenen Grenzen erkundet. So wirbt der Film Mount Everest 1952 mit folgenden Worten: »Und man fühlt mit diesen Männern angesichts dieser Bergwelt die urtümlichen Triebkräfte, die sich aus der Verbindung von Angst und Kampfbegeisterung lösen. ${ }^{264}$ Damit ermöglicht die Todeszone eine bedeutsame Umkehrung von Geschlechterzuschreibungen: Steht der Mann im Bereich der Polis für Vernunft und Rationalität, darf er in der wilden Natur zum emotionalen Wesen werden. Denn die Everest-Berichterstattung zeigt nicht todesmutige Männer, die unbeirrt durch die Eiswüste zum Gipfel stürmen, sondern Männer, die mit sich ringen, zusammenbrechen, weinen, scheitern, weiterkämpfen, aufgeben und sich zwischen Tapferkeit, Hoffnung, Furcht und Verzweiflung bewegen.

Damit wird die Todeszone zu einem Ort, an dem extensiv und pausenlos über männliche Körper und Gefühle gesprochen werden kann. Während das Materielle und Stoffliche der Frau zugeschrieben und oftmals abgewertet oder unsichtbar gemacht wird, steht in diesem frauenlosen Raum der Körper des Mannes im Zentrum. Sein Kampf gegen den Zerfall, die Krankheit und den Tod stehen nicht im Gegensatz zu seiner

262 | Ebd.

263 | Baldwin 1963, 160.

264 | Werbung für den Film "Mount Everest 1952", in: Tages-Anzeiger, 20. Juli 1953. 
Männlichkeit, sondern lassen sie auf neue Weise hervortreten. Im Everest-Film heißt es dazu:

"Die unbehaglichen Symptome des Sauerstoffmangels treten häufiger und heftiger auf. Schlaflosigkeit, Kopfschmerzen, Schwindel, Muskelschwäche und vor allem Halsschmerzen. Der Himalajabesteiger ist ein Kranker, für dessen Leiden es nur ein Heilmittel gibt: Rückkehr in die Tiefe. Und doch, wie haben wir diesen Kampf gegen den Berg ersehnt. «265

Der Kampf des Bergsteigers mit dem Berg ist auch ein Kampf mit den Beschränkungen seines Körpers, mit seiner Lunge, mit seinem Kopf, mit seinen Muskeln, mit seinem Gleichgewichtssinn, mit seinem Schlafbedürfnis. Es ist ein riskanter Kampf an der Grenze des Lebens, aber auch einer, der den Mut und den Willen des Kämpfers sichtbar macht. Das Erklimmen des Berges wird zu einem Kampf des Subjekts mit sich selbst, dessen ethischer Wert das faktische Resultat weit übertrifft. Die Schweizerische Everest-Expedition, so die Werbung zum Film, endete »zwar nicht mit dem äußern Sieg der Bezwingung des höchsten Gipfels der Erde [...], aber mit einem inneren Sieg über die ungeheuren Gefahren dieser mörderischen Höhenzonen, die mit der drohenden Bergeuphorie wohl ihren tückischsten Triumph ausspielt. «266

Die Erwähnung der >Bergeuphorie< weist uns auf einen dritten Aspekt hin, der sich in der Todeszone umkehrt: Nicht nur wird der westliche und christliche Bergsteiger von Geistern und dem Abergläubischen heimgesucht, nicht nur wird der rationale Mann zu einem Schauplatz von Körperlichkeit und Gefühl - er wird auch Opfer eines Körpers, der sich der Willenskraft entzieht und sich als Einfallstor für den Wahnsinn erweist. Denn der >tückischste Triumph< der hohen Zonen besteht darin, dass der Bergsteiger seinen Verstand verlieren kann. Wyss-Dunant wird dazu 1952 in der Times folgendermaßen zitiert: »At those heights of dreams and illusions, [...] how can a climber judge the amount of energy remaining to him? Will he know the right time to turn back? How will he fare on the final, lifeless slopes of the mountain with his faculties of judgement

265 | Film "Mount Everest 1952", Archiv Alpines Museum der Schweiz (gesehen am 30. September 2012).

266 | Werbung für den Film "Mount Everest 1952", in: Tages-Anzeiger, 20. Juli 1953. 
blurred and dimmed? $\ll^{267}$ Die Todeszone stellt einen Raum dar, in dem sich der Mensch nicht mehr auf seinen Körper, seinen Intellekt oder seinen Instinkt verlassen und in der ihm jederzeit die Kontrolle über all das entgleiten kann, was ihn sonst als aktives selbstbewusstes und handelndes Subjekt befähigt.

Entsprechend schreibt die Times im Kontext der Schweizerischen Everest-Expedition über die Gefahr der »fearful lassitude with which the climber is overcome in the thinning air on the topmost ridges and couloirs - a lassitude that leaves his brain indifferent to danger and irresolute to meet it $\ll^{268}$. Die Todeszone ist der Ort, an dem Menschen pausenlos der physische Tod droht. Sie steht darüber hinaus für den Tod all dessen, was in der aufklärerischen Logik mit weißer bürgerlicher Männlichkeit assoziiert wird: Selbstkontrolle, Disziplin über den Körper, vernunftgesteuertes Handeln, Mut und Willenskraft als Schlüssel zum Erfolg. In die Todeszone bricht dasjenige unkontrolliert ein, was in der aufklärerischen Ordnung Frauen und rassifizierten Menschen zugeschrieben wird: die Gefühle, der Körper und der Wahnsinn. Lambert berichtet von einem "state of semi-hallucination ${ }^{269}$ und beschreibt, wie er und Norgay sich auf allen vieren vorwärts bewegten wie Hunde, die einem Geruch folgten, denn auch die konstitutive Grenze zwischen Mensch und Tier verliert in dieser Höhe ihre Bedeutung. ${ }^{270}$ Was heißt das nun für die Berge als »hypermasculine landscape «771? Stellt die Todeszone einen Raum dar, in dem Männlichkeit erodiert? Wie kann das In-Szene-Setzen von weinenden, erschöpften, kriechenden, umherirrenden, sich gegenseitig in den Armen liegenden, halb lebendigen und halb toten männlichen Körpern, von Männlichkeiten in der Krise, die die Berichterstattung so detailgetreu vor Augen führt, aus einer feministischen und postkolonialen Perspektive gelesen werden?

An dieser Stelle ist es hilfreich, auf Elahe Haschemi Yekanis Verständnis von Krise als Bestandteil weißer hegemonialer Männlichkeit

267 | 0.V.: "Everest Inviolate. Unsolved Problems of Rarefied Atmosphere", in: Times, 25. Juli 1952.

268 | O.V.: "Challenge to Everest. Departure of Swiss Expedition for Nepal", in: Times, 18. März 1952.

269 | Dittert, Chevalley und Lambert 1954, 151.

270 | Dittert, Chevalley und Lambert 1954, 152.

271 | Frohlick 1999, 83. 
zurückzugreifen. Haschemi Yekani bezieht sich in ihrer Analyse auf Judith Butlers Konzept des konstitutiven Außen als Bedingung moderner Subjektformation. Die Figur der Vernunft, so schreibt Butler in ihrer Auseinandersetzung mit Irigarays Lektüre von Platon, grenze sich von Anderen ab, die als weniger rational gelten - Frauen, Kinder, Sklav*innen. Der >Mann $<$ werde auf diese Weise erzeugt als jemand, der »der Notwendigkeit des Essens, des Ausscheidens, Lebens und Sterbens enthoben ist [...]. Es ist eine Figur der Körperlosigkeit, die aber dessen ungeachtet Figur eines Körpers ist, die Verkörperlichung einer vermännlichten Rationalität.« «72

Diese Figur rationaler Männlichkeit bedarf der ständigen Wiederholung derjenigen Ausschlüsse, die ihn als entkörperlichte Vernunft hervorbringen. In seiner konstitutiven Abhängigkeit von denjenigen, die das Körperliche signifizieren, befindet sich Männlichkeit in einer beständigen Krise, »denn dieser Körper der Vernunft ist selbst die phantasmatische Entmaterialisierung der Männlichkeit, die verlangt, dass Frauen und Sklaven, Kinder und Tiere der Körper sein sollen, dass sie die Körperfunktionen ausführen müssen, die er nicht ausführen wird « ${ }^{273}$. Butler verweist mit dieser Beschreibung auf die performative Arbeit, die geleistet werden muss, damit die Entkörperlichung der Männlichkeit über die Verkörperlichung von Anderen hergestellt und die Sicherung der Grenzen zwischen der hegemonialen Männlichkeit und dem konstitutiven Außen gewährleistet wird. Diese Männlichkeit, so Butler, ist eine »Figur in der Krise, eine Figur, die eine Krise inszeniert, die sie nicht völlig unter Kontrolle hat ${ }^{274}$.

Man könnte, wie Butler, die Bruchlinien aufzeigen, an denen die Herstellung einer hegemonialen Männlichkeit in die Krise gerät und ihr Konstruktionscharakter ersichtlich wird. Haschemi Yekani geht einen anderen Weg: Sie weist darauf hin, dass sich die Krise der hegemonialen Männlichkeit nicht nur an solchen gleichsam schlecht gekitteten diskursiven Bruchstellen ausmachen lässt, sondern dass sich Narrative von Männlichkeit auch explizit einer »Rhetorik der Krise « ${ }^{275}$ bedienen. Die Inszenierung und Sichtbarmachung der Krise lässt sich derart als

272 | Butler 1995, 76.

273 | Butler 1995, 76.

274 | Butler 1995, 76.

275 | Haschemi Yekani 2011, 19. 
Vorrecht einer hegemonialen weißen Männlichkeit lesen. Diejenigen Figuren hingegen, die als Andere des männlichen Subjekts figurieren, können keine fundamentale Krise verkörpern, weil ihnen der Platz in einer universalen Menschlichkeit verwehrt bleibt. Zwar gebe es durchaus Narrationen, in deren Zentrum Frauen oder marginalisierte Männer stehen, räumt Haschemi Yekani ein. Solchen Erzählungen fehle aber die >Grandeur<, welche mit der Universalität hegemonialer Krisen assoziiert werde: »[I]t is the normative and unmarked position of White masculinity that lends narratives of hegemonic masculinity in crisis such a cultural momentum of standing for the whole mankind. ${ }^{276}$ Durch die Narration der eigenen Krise wird das männliche Subjekt damit erneut ins Zentrum der Aufmerksamkeit gerückt: Weiße männliche Körper in der Krise vermögen universal menschliche Themen wie die Endlichkeit und das Ringen mit den Grenzen des Daseins zu verkörpern.

Vor dem Hintergrund dieser Überlegungen lässt sich der (drohende) Zusammenbruch der Männlichkeit in der Todeszone als Spielart einer weißen hegemonialen Männlichkeit lesen. Beschreibungen »that seem to lead away from an affirmation of >mountain masculinity< (including so-called >feminine< behaviour like crying, being afraid, or expressions of empathy) in fact reclaim any non-masculine action as an affirmation of true manhood « ${ }^{277}$, fasst Julie Rak diese scheinbar paradoxe Verbindung von weiblichen Verhaltensweisen und hegemonialer Männlichkeit zusammen. Der Kampf mit der Natur in der Todeszone wird zum Signum eines prometheischen Menschen, der weder Tod noch Wahnsinn scheut, um sich selbst zu ergründen.

Die Bedeutung der Todeszone in den 1950er Jahren kann aber auch in einem politischen Kontext situiert werden: Das Ringen weißer Männer in der durch und durch weißen Welt der Gletscher und Schneeberge liest sich wie die mit großem Aufwand durchgeführte phantasmatische Verschiebung einer Krise, welche die Dekolonisation für die imperiale Welt bedeutete. Während die weiße Vorherrschaft in den Niederungen der menschlichen Sozietät unumkehrbar infrage gestellt wurde, mutierte der Himalaya zum Schauplatz einer kolonialen Amnesie: Die Bergwelt wird zum menschenleeren Raum, in dem sich weiße Männer erfolgreich miteinander und mit den Urkräften der Natur messen. Allerdings wird

276 | Haschemi Yekani 2011, 16.

277 | Rak 2007, 117. 
auch diese Szenerie, wie die Rolle von Sherpa Tenzing Norgay zeigt, von kolonialen Umbrüchen erfasst.

\section{ÜBER \RASSENGRENZEN ' HINWEG: Tenzing Norgay Und Raymond Lambert}

Als die Mitglieder der erfolgreichen SSAF-Expedition von 1956, denen die Erstbesteigung des Lhotse und die zweite Besteigung des Everest gelang, in die Schweiz zurückkehrten, strahlte das nationale Radio Beromünster eine Sondersendung aus. Sie begann mit einem Rückblick auf die gelungene Erstbesteigung im Jahre 1953. Edmund Hillary würdigte in einem Interview die wichtige Vorarbeit der Schweizer Expedition ein Jahr zuvor. Ein Sprecher las dazu eine Passage aus einer kurz zuvor erschienen (kollaborativ verfassten) Autobiografie von Tenzing Norgay, in der beschrieben wird, wie dieser $195^{2}$ mit Raymond Lambert zum Gipfel aufsteigt und wenige hundert Meter unter dem Ziel umkehren muss. ${ }^{278}$

Die Lesung endete mit der Geschichte eines roten Schals, den der Sherpa auf der Expedition von Lambert erhalten hatte. Ein Jahr später, als er auf dem Gipfel des Everest stand, trug er diesen Schal und schickte ihn später seinem Freund Lambert nach Genf. Er sei tief berührt gewesen von Tenzings Geste, erzählte Lambert in der Radiosendung. Zwischen Tenzing und ihm habe sich eine profunde Freundschaft entwickelt. Auch wenn sie sich sprachlich nicht verständigen konnten, hätten sie sich auf eine andere Weise hervorragend verstanden. ${ }^{279}$ Bevor der Radiosprecher auf das eigentliche Ereignis des Tages einging, die Ankunft der erfolgreichen Bergsteiger am Flughafen Kloten am 9. Juli 1956, fügte er an: »Eine solche Freundschaft [...] zwischen zwei Männern, die verschiedenen Rassen angehören und verschiedene Sprachen sprechen, [...] kann ihren Ur-

278 | Vgl. Norgay und UlIman 1955.

279 | Lambert spricht von einer "très forte amitié bien qu'on ne se comprend pas avec les langues, mais on se comprend d'une autre manière; on se comprend parfaitement bien." (Radio Beromünster: "Zurück vom Dach der Welt", Radioreportage vom 8. Juli 1956, in: Archiv Schweizer Radio und Fernsehen SRF, gehört am 3. Juni 2015 in der Ausstellung "Himalaya Report. Bergsteigen im Medienzeitalter", Alpines Museum Bern). 
sprung nur in den Bergen finden. Das Seil ist ja das Symbol dieser tiefen Verbindung von Mensch zu Mensch. ${ }^{280}$

Die Erstbesteigung eines Achttausenders galt als Triumph für diejenige Nation, unter deren Flagge die Expedition stattgefunden hatte. Deshalb war es nicht erstaunlich, dass der nationale Radiosender die Zweitbesteigung des Everest zum Anlass nahm, an eine vorgängige Schweizer Expedition zu erinnern. Warum aber wurde die Freundschaft von Lambert und Tenzing in den Vordergrund gerückt? Warum kam der Geschichte eines roten Schals eine solche Bedeutung zu? Was symbolisierte die >Rassengrenzen überschreitende Beziehung zwischen zwei Männern im Jahr 1956, inmitten eines weltweiten Dekolonisierungsprozesses?

Die emotionale und physische Nähe zwischen Alpinisten ist ein gewichtiger Topos der Bergsteigerliteratur. Die Rede von der »Bruderschaft des Seils« (»brotherhood of the rope ${ }^{281}$ ), die diese Verbindung auf den Punkt bringt, wurde von Gaston Rébuffat geprägt, einem Mitglied der französischen Annapurna-Expedition von 1950. Das Seil, mit dem sich die Bergsteiger gegenseitig bei Stürzen sichern, symbolisiert dabei ihre existenzielle Verbundenheit und gegenseitige Abhängigkeit. Wie Rak bemerkt, kam die Metapher der Seilschaft auch zum Einsatz, um homoerotische Bindungen zwischen Männern anzudeuten, ohne diese explizit machen zu müssen: »It is a way of alluding to the homosocial bonding of men in climbing without having to call attention to the erotic nature of the bond. $\ll^{282}$

Ein solcher queerer Blick auf die Bergsteigerliteratur lässt sich etwa auf das Buch von Maurice Herzog richten, einem Mitglied der französischen Annapurna-Expedition, dessen Bericht unterschiedliche Momente dieser homoerotischen Intimität in den Fokus rückt. Als Herzog beim Abstieg vom Gipfel irreversible Erfrierungen erlitt, suchte er Trost bei Lionel Terray: »I howled and cried and sobbed in Terray's arms while he held me tight with all his strength. ${ }^{283}$ An einer anderen Stelle weinte Herzog, »while Terray soothed [him] with infinite gentleness « ${ }^{284}$. Herzog hatte gemeinsam mit Louis Lachenal als erster Mensch einen Achttausender bestiegen. In der Darstellung dieser heroischen Tat kam seiner physi-

280 | Ebd.

281 | Vgl. Rébuffat 1999, 104.

282 | Rak 2007, 117.

283 | Maurice Herzog, zitiert nach Rak 2007, 124.

284 | Rak 2007, 125. 
schen und emotionalen Schwäche eine zentrale Bedeutung zu. Die Überwindung seines Schmerzes und die Opferung seines gesunden Körpers für den Erfolg der Nation wurden zum Bestandteil eines französischen Heldennarrativs. Nach der deutschen Besatzung im Zweiten Weltkrieg ermöglichten es solche Geschichten, so Rak, die Größe und Bedeutung Frankreichs neu zu imaginieren. ${ }^{285}$

Bilder von männlicher Intimität, geteilter Verzweiflung, Freude oder Angst, von Männern, die sich in den Armen liegen, miteinander weinen und lachen, wurden nicht mit der Himalaya-Berichterstattung erfunden. Sie knüpften an homosoziale Darstellungen in Sport und Militär an. Über die Wahrnehmung von Soldaten-Kameradschaften in der Schweiz während des Zweiten Weltkriegs schreibt Dejung: »Nicht einmal Beschreibungen von körperlicher Nähe zwischen den Männern, die ansonsten den Verdacht der Homoerotik erregen würden, stellten die soldatische Männlichkeit infrage. Auch diese Körperkontakte wurden als Aspekte der militärischen Kameradschaft geschildert und so gegen eine kritische Hinterfragung immunisiert. ${ }^{286}$ Im hypermännlichen Raum des Militärs konnten weiblich konnotierte Verhaltensweisen weiterhin als männlich erscheinen. Und romantisch aufgeladene Formen der Zuneigung ließen sich als Bestandteil einer Kameradschaft lesen, die dazu verhalf, gemeinsam die Nation zu stärken und verteidigen.

Im Unterschied zu den schweizerischen Soldaten, die den Schutz der Nation garantieren sollten, und den französischen Bergsteigern, die einen symbolischen Kampf um das Ansehen Frankreichs führten, repräsentierten Lambert und Tenzing keine gemeinsame und auch keine westliche Nation. Auch trifft an dieser Stelle Slemons Analyse nicht zu, wonach die >brotherhood of the rope< auf dem Ausschluss von Anderen, insbesondere von Frauen und nicht-weißen Männern, beruht. ${ }^{287}$ Die Sendung im Schweizer Radio betont ja gerade die Freundschaft zwischen Lambert und Tenzing und damit »zwischen zwei Männern, die verschiedenen Rassen angehören und verschiedene Sprachen sprechen « ${ }^{288}$. Wie kann diese Darstellung gedeutet werden?

285 | Rak 2007, 123.

286 | Dejung 2006, 188.

287 | Slemon 2008, 241.

288 | Radio Beromünster: "Zurück vom Dach der Welt", Radioreportage vom 8. Juli 1956, in: Archiv Schweizer Radio und Fernsehen SRF (gehört am 3. Juni 
Lambert und Tenzing stellten im Mai 1952 die Gipfelgruppe der schweizerischen Everest-Expedition. Auf ihnen lastete die ganze Hoffnung auf eine erfolgreiche Erstbesteigung. Die beiden verbrachten eine kalte Nacht in eisiger Höhe, kämpften sich am kommenden Tag weiter und gaben weniger als 300 Höhenmeter unter dem Gipfel auf, um ihr Leben zu retten. Dieses Ereignis fand in der Presse und in der Bergsteigerliteratur großen Widerhall. Die Beziehung zwischen Lambert und Tenzing wurde in der Terminologie von Freundschaft und Liebe erfasst. Im Zentrum dieser Figuration einer Verbundenheit, die >Rassengrenzen < überschreitet, stand eine gemeinsame Intuition, die keiner sprachlichen Vermittlung bedurfte. In seinem Bericht schreibt Lambert: »Tensing interrupted my reflections. >Sahib, we ought to stay here tonight! < He indicated the tent he had been carrying since the start. I smiled, for our thoughts had been pursuing the same course. ${ }^{289}$ In Tenzings Autobiografie wird dieselbe Situation nahezu identisch beschrieben: »Als ich eine kleine, fast ebene Stelle entdeckte, auf der man das Zelt festmachen konnte, deutete ich darauf und sagte zu Lambert: >Sahib, wir sollten heute Nacht hierbleiben. Er lächelte mir zu, und ich wette, er hatte dasselbe gedacht. ${ }^{290}$ Beide betonten, wie sehr ihre Gedanken synchron verliefen und wie sich eine Art >geistige Verwandtschaft < zwischen ihnen eingestellt hatte, die ohne gemeinsame Sprache auskam.

Lamberts Schilderung des Gipfelversuchs enthält auch eine romantisch anmutende Szene, in der sich die beiden Bergsteiger auf 8.250 Meter unter einem leuchtenden Sternenhimmel befinden. Gemeinsam halten sie sich wach, um mit dem Schlaf nicht ihren Verstand zu verlieren: »This was the boundary between waking and sleeping. I dared not sleep, must not sleep. Tensing shook me and I awoke, and I shook him in turn. Amicably we beat one another and pressed close together throughout the night. In the sky the stars were so brilliant they filled me with fear. ${ }^{291}$ Der Zustand zwischen Wachheit und Schlaf, Leben und Tod, Freundschaft und Angst wird, wie bei den oben angeführten Schilderungen der französischen Annapurna-Expedition, auch hier als existenzielle Erfahrung des menschlichen Daseins beschrieben, welche die Männer im Angesicht

2015 in der Ausstellung "Himalaya Report. Bergsteigen im Medienzeitalter", Alpines Museum Bern).

289 | Dittert, Chevalley und Lambert 1954, 149.

290 | Norgay und UlIman 1955, $214 f$.

291 | Dittert, Chevalley und Lambert 1954, 151. 
des drohenden Todes und des zum Greifen nahen >Sieges erfahren. Dennoch unterscheidet sich die Szene am Everest 1952 maßgeblich von derjenigen an der Annapurna 1950.

Lambert und Tenzing überschritten eine konstitutive Grenze des modernen Bergsteigens, indem sie eine Gipfelgruppe bildeten, die aus einem weißen und einem nicht-weißen Bergsteiger bestand. Die Geschichte des roten Schals, die auch das Schweizer Radio aufnahm, wurde zum Sinnbild einer transracial love, einer Liebe zwischen heroischen Männern, deren Zuneigung und Kameradschaft bestehende Grenzen transzendierten. Lambert führt ihren Erfolg auf die Kooperation der ganzen Gruppe zurück: »L'ingéniosité, le courage, la patience et le magnifique esprit d'entraide de quelques dizaines d'hommes, de race et de mentalité combien différentes, ont voulu que tous deux, nous soyions portés - façon de parler - sur le Toit du Monde. « ${ }^{292}$ Tenzing und Lambert wurden zu Symbolfiguren eines Kollektivs, dessen Erfolg gerade darauf beruhte, dass es trotz der kolonial kodierten Unterschiede der Mitglieder einen Gemeinschaftssinn entwickeln konnte. Diese Vorstellung liest sich wie ein Idealbild für die nachkolonialen Verbindungen zwischen den ehemaligen Metropolen und Kolonien, die in Zeiten der Dekolonisation erst entwickelt und eingeübt werden mussten.

Wegweisend für diese neuen Bilder einer postkolonialen Intimität sind nicht nur die Texte, die beschreiben, wie sich ein weißer und ein nicht-weißer Mann unter einem leuchtenden Sternenhimmel halten und wärmen, sondern auch jene Stellen, die explizit die Auflösung von Machtverhältnissen artikulieren. Als Lambert beschreibt, wie er mit Tenzing durch den tiefen Schnee dem Gipfel entgegenstapft, kommt er auf ein >eigenartiges Gefühl zu sprechen: »Encore une fois, ce curieux sentiment m'envahit: suis-je le client? Est-ce Tensing le guide? Ou l'inverse. Je ne sais pas, mais l'impression est nouvelle. ${ }^{293}$ Diese Passage ist entscheidend, weil sie die Auflösung mehrerer Hierarchien vor Augen führt: diejenige zwischen Sahib und Sherpa, zwischen dem Bergsteiger und seinem Assistenten und zwischen einem weißen und einem nicht-weißen Mann. Vergessen ist an dieser Stelle, dass es ein Zufall war, der dazu führte, dass ein Sherpa der prestigeträchtigen Spitzengruppe angehören durfte: Die beiden Schweizer René Aubert und Léon Flory, auf die die Wahl als erstes

292 | Lambert 1953, 223.

293 | Lambert 1953, $225 f$. 
gefallen wäre, waren erschöpft und mussten umkehren. ${ }^{294}$ Damit wurde aus Tenzing, dem Assistenten, unverhofft ein Protagonist.

Warum beschreibt Lambert das Gefühl, das die Auflösung der Hierarchie innerhalb der Zweierseilschaft auslöst, als >neu<? Die Veränderung kann auf die Höhe zurückgeführt werden, die von Menschen bislang nicht erkundet worden war und in der ihnen mit der Kontrolle über den eigenen Körper auch diejenige über die soziale Ordnung entglitt. Sie kann aber auch im Kontext einer neuen transracial >brotherhood of the rope gelesen werden. Lamberts >neuer Eindruck « stellt dann eine Reaktion auf die Notwendigkeit dar, eine andere Sprache und andere Bilder für die Relationen zwischen weißen und nicht-weißen Männern zu finden. Dass die Auflösung von Intimitäts- und Hierarchiegrenzen zwischen den beiden Männern in der Todeszone stattfand, in einem Zustand der Halluzination und des nahen Wahnsinns, kann als Hinweis auf die Verwirrung eines imperialen Subjekts gelesen werden, das sich im Angesicht eines dekolonisierten Anderen, auf dessen Abwertung sein Selbstverständnis ganz wesentlich gründet, neu erfinden muss.

Die Intimität zwischen Lambert und Tenzing lässt sich auf diese Weise als Manifestation einer >Gleichheit in der Verschiedenheit< lesen und damit als eine mögliche Antwort auf die Herausforderung, neue Repräsentationen für eine dekolonisierte Welt zu finden. Es ist kein Widerspruch, dass diese Bilder kontinuierlich von orientalistischen und rassistischen Vorstellungen durchkreuzt werden. Vielmehr kündigt sich in solchen Darstellungen an, wie koloniale Bilder von Anderen umgeschrieben, umgearbeitet und in neue Register überführt werden konnten, ohne dass die Kolonialität der Macht dabei aufgelöst wurde. Für die Entwicklung einer neuen Ikonografie nachkolonialer Brüderlichkeit mag es hilfreich gewesen sein, dass die >rassenüberschreitendeく Liebesgeschichte unter dem Gipfel des höchsten Berges der Welt zwei Protagonisten involvierte, die Kolonie und Metropole zugeordnet wurden, gleichzeitig aber aus Ländern stammten, die weder Kolonialmacht noch Kolonie waren. Für das Bild des Schweizers als idealem Weggefährten des postkolonialen Anderen auf seinem langen Weg in die Moderne erwies sich allerdings noch ein weiterer Aspekt als entscheidend: die Darstellung der Schweiz als Ort technischer Expertise.

294 | Die Entscheidung zur Umkehr wurde selbstverständlich von den drei Sahibs getroffen, vgl. Norgay und Ullman 1955, 214. 


\section{SCHWEIZER ITECHNOKOLONIALISMUS,}

Im März 1952 veröffentlicht die Neue Zürcher Zeitung zwei Bilder zur geplanten Everest-Expedition. Das eine zeigt den >Everest-Battledress<, einen neuen Wärme-Anzug, der, wie es heißt, auf der Grundlage »der ausgedehnten Erfahrung im asiatischen und europäischen Hochgebirge und der Heranziehung arktiserprobten Materials« entwickelt worden war. ${ }^{295}$ Auf dem anderen Bild ist die sogenannte >Couchette Everest abgebildet, die von der SSAF zusammen mit der Deutschen Himalaya-Stiftung entwickelt und bei der Augsburger Ballonfabrik hergestellt worden war. Es handelte sich um ein fünf Kilo schweres Biwakzelt, das gleichzeitig als Kälteschutz und Schlafstätte diente. Der Artikel erklärt: »Dieses Mittelding zwischen Schlafsack und Zelt besteht aus einem aufblasbaren Gummitrog, in den ein Mann sich in voller Länge niederlegen kann. Nach oben wird diese >Couchette $<$ durch ein von aufgeblasenen Rippen getragenes Zeltgewölbe winddicht verschlossen. Durch eine eigenartige >Materialstrahlung< erfährt der Insasse eine fühlbare Erwärmung. ${ }^{296}$

Der Darstellung solcher technischer Hilfsmittel, ihrer Anwendung am Berg und ihrer wissenschaftlichen Entwicklung kam bei der Repräsentation der Everest-Expeditionen eine bedeutsame Rolle zu. Mehrere Zeitungsartikel widmeten sich dem Problem der Atmung in großer Höhe und diskutierten die Herstellung und Funktionsweise von Sauerstoffapparaten. ${ }^{297}$ Ein Inserat für die Schweizer Illustrierte Zeitung (vgl. Abbildung 24) zeigt die auch schon in der Neuen Zürcher Zeitung veröffentlichten Bilder vom >Everest-Battledress $<$ und von der >Couchette Everest und verspricht den Leser*innen, durch die Zeitungslektüre am »gigantische[n] Kampf einer Elite schweizerischer Bergsteiger gegen Kälte,

295 | O.V.: "Die Ausrüstung der Mount-Everest-Expedition 1952«, in: Neue Zürcher Zeitung, 20. März 1952.

296 | O.V.: "Die Ausrüstung der Mount-Everest-Expedition 1952«, in: Neue Zürcher Zeitung, 20. März 1952. Die Darstellungen der vermummten Figuren mit ihren Sauerstoffgeräten lassen sich auch als Vorläufer einer Ikonografie der Raumfahrt lesen, die wenige Jahre später mit dem Flug des Sputnik begann und die Vorstellung eines unentdeckten Territoriums über die höchsten Berge hinaus in den Weltraum erweiterte. Vgl. Polianski und Schwartz 2009.

297 | Siehe z.B. Gurtner, Othmar: "Höhensorgen am Everest», in: Neue Zürcher Zeitung, 4. März 1952. 
Eis, Schneestürme und Sauerstoffmangel« teilnehmen zu können. Der technische Fortschritt erschien in solchen Berichten als entscheidendes Element, um den unwirtlichen Lebensbedingungen in extremer Höhe trotzen zu können. Umgekehrt wurden die eisigen Zonen des Himalayas zu einem Schauplatz für technische Innovationen, die sich wirkmächtig mit kolonialen Fantasien verbanden; dieser Zusammenhang wird im Folgenden mit dem Begriff des >Technokolonialismus< beschrieben.

Abbildung 24: Inserat für die Schweizer Illustrierte Zeitung 1952

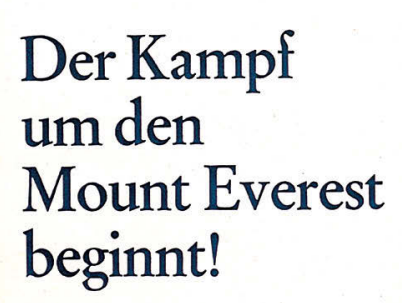

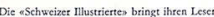
in Ersstvertiffentlichungstecht mehtrec spannend teils farbige Bildreportagen, eine Folge fesselnd «Froniberichte»" der gro Bangeclegten

schweizerischen MountEverest-Expedition 1952

Als Leser der "Schweeizer Illastrierten" efteben Sie jede Phase des gigantischicn Kampfes cincr Elite schweizerischet Bergsteiger gegen Kalte, Eis, Schneestimme und Sauerstoffmangel. Wird unscrer mutigen Equipe die Erstbesteciguag des 88 so m hohen Gipfels gelingen? Wic immer Eet Ausgang der Fxpecition zum "3. Pol der Mllustricrtenx ist mit dabeil
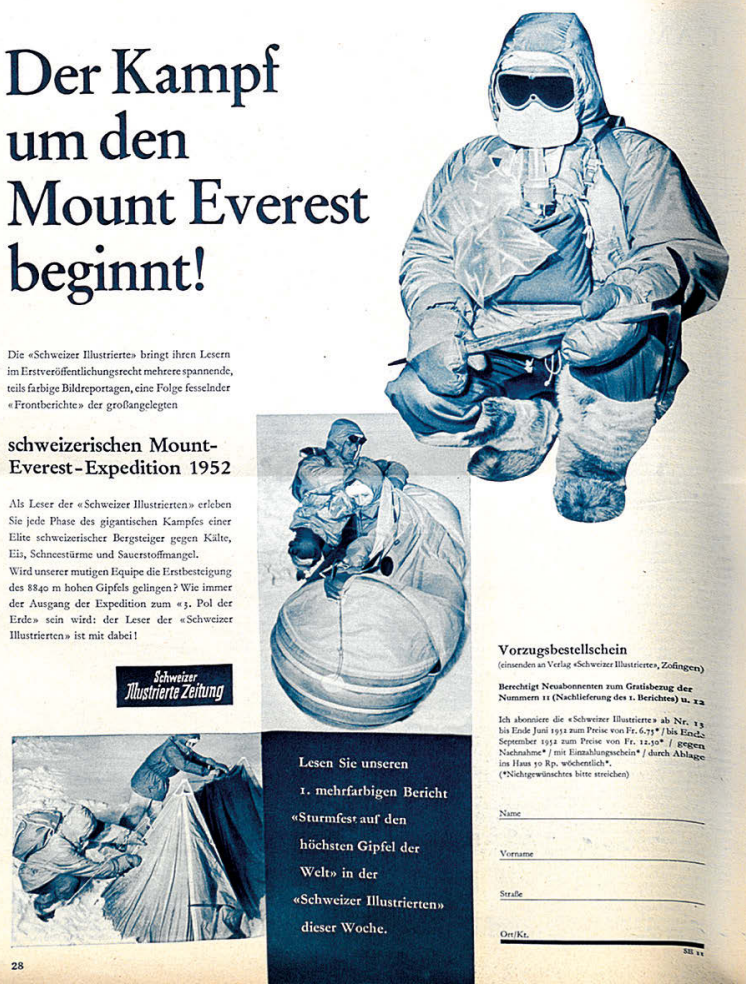

Quelle: Sie + Er 1952(11)

Technik umfasst dabei nicht nur Apparate (wie Waffen, Kameras, Karten oder Flugzeuge), sondern auch Mobilitätsregimes (durch die Verwendung von Autos, Flugzeugen, Schiffen und anderen Geräten zum Reisen und Entdecken, aber auch durch die Regulierung von Grenzen, Zulassungen 
und Bewilligungen), normative Konzepte (wie Fortschritt, Perfektion und Effizienz, aber auch kulturelle und rassische Überlegenheit) sowie Formen des Wahrnehmens, Kontrollierens, Messens, Speicherns, Strukturierens und Kontrollierens von Raum (durch Kartografie, Fotografie, Forschungsexpeditionen und Entdeckungsfahrten). Um die Bedeutung >technokolonialer< Fantasien für die Imagination der Schweiz und ihre unterschiedlichen Relationen zur Welt im 20. Jahrhunderts aufzuzeigen, wende ich mich zwei Figuren zu, die das >technokoloniale< Selbstverständnis exemplarisch zum Ausdruck bringen: der Alpinist Max Eiselin und der Pilot Walter Mittelholzer.

Im Jahr 1960 gelang es einer Gruppe von Bergsteigern unter der Leitung von Max Eiselin erstmalig, den Gipfel des Achttausenders Dhaulagiri zu erreichen (vgl. Abbildung 20). Als ehemaliges Mitglied einer Schweizerischen Dhaulagiri-Expedition, die im Jahre 1958 vergeblich versucht hatte, den Berg zu erklimmen, war Eiselin bereits mit dem Gelände vertraut und in ein europäisches Netzwerk von Bergsteigern eingebunden. Was Eiselins Expedition von allen vorherigen unterschied, war der Einsatz eines kleinen Flugzeugs, eines Pilatus Porter PC 6. Es war von den Stanser Pilatuswerken angefertigt worden, die sich seit ihrer Gründung im Jahre 1939 auf die Herstellung militärischer Flugzeuge spezialisiert hatten. ${ }^{298}$

Der Einsatz von Aviatik für das Höhenbergsteigen stellte ein Novum dar, das es ermöglichte, Abenteuernarrative auf neue Weise mit Technikvorstellungen zu verflechten. Das Flugzeug sollte den Transport von Nahrungsmitteln und Gepäck übernehmen, die Erkundung des Geländes und möglicher Routen erleichtern und durch den Transport der Bergsteiger die Zustiegsdauer verkürzen. In der Zeitschrift Die Alpen heißt es dazu: »Es ist das erste Mal, dass ein solches Flugzeug zum Einsatz gelangt, was die Materialtransporte sehr vereinfachen wird, da ein Großteil der Trägerkolonnen wegfällt. ${ }^{299}$ Gleichzeitig waren mit dem Einsatz des Pilatus Porters spektakuläre Erwartungen verknüpft, wie ein Artikel in der Neuen Zürcher Zeitung zeigt. Die Expedition hoffe, so ist dort zu le-

298 | Die Pilatuswerke gehörten zur Oerlikon-Bührle-Gruppe, die auf die Fabrikation von Maschinen und Gewehren spezialisiert war. Das Unternehmen geriet wegen Waffenlieferungen an das nationalsozialistische Deutschland vor und während des Zweiten Weltkriegs in die Kritik (Gmür 2010).

299 | M. Oe.: "Dhaulagiri«, in: Die Alpen 1960(36). 
sen, die Fragen nach der umstrittenen Existenz des Yeti »gerade dank der Möglichkeit fliegerischer Beobachtungen aufzuklären « ${ }^{300}$. Neben solchen enthusiastischen Kommentaren wurden auch die Risiken diskutiert, die der Einsatz des Kleinflugzeugs mit sich brachte, etwa das Starten und Landen auf schwierigem Terrain und in großer Höhe.

Die Schweizer Öffentlichkeit war Mitte des 20. Jahrhunderts bestens vertraut mit der Kombination von pionierhaften Taten, Aviatik und einer kolonialen Perspektive auf die Welt. Beispielhaft dafür sind die Reiseberichte des Schweizer Flugpioniers Walter Mittelholzer, die in den 1920er und 1930er Jahren erschienen und sich größter Beliebtheit erfreuten: Sie erreichten eine Gesamtauflage von 196.000 Exemplaren. ${ }^{301}$ Mittelholzers Bücher gehörten zum Genre der damals populären Abenteuerreportagen, die manchmal mit wissenschaftlichen Berichten verschränkt wurden, wie dies in den Schriften des bekannten Geologen Arnold Heim der Fall war. ${ }^{302}$

Mittelholzer unternahm als Pilot Expeditionsflüge zur Inselgruppe der Spitzbergen, nach Abessinien, nach Persien und in den Tschad und errang Weltberühmtheit mit der ersten Nord-Süd-Überquerung des afrikanischen Kontinents mit einem Wasserflugzeug im Jahre $1927 .{ }^{303}$ Er war nicht nur ein vorzüglicher Pilot und ein erfolgreicher Geschäftsmann, sondern auch ein guter Unterhalter. Während seiner Flüge fertige er zahlreiche Fotografien

$300 \mid$ | M. E.: "Schweizerische Dhaulagiri-Expedition 1960", in: Neue Zürcher Zeitung, 19. Februar 1960.

301 | Surber 2017, 20.

302 | Vgl. u.a. Heim 1934, Heim 1938, Heim 1953, Heim 1957. Heim war auch mit Mittelholzer unterwegs: Gemeinsam mit inm und René Couzy überquerte er den afrikanischen Kontinent mit einem Wasserflugzeug (vgl. Mittelholzer, Couzy und Heim 1927). Zudem war Heim an der geologischen Erforschung des Himalaya beteiligt (Heim 1950). Er führte zusammen mit August Gansser 1936 eine Forschungsreise in den indischen Garhwal durch und widmete sich im Jahre 1949 im Auftrag der SSAF in Nepal kartografischen Studien, welche die bergsteigerische Erschließung des Himalaya erleichtern sollten (Elmer 2012, 256). Vgl. auch www. alpinfo.ch/rueckblick/de/forschung/kartographie.html (Zugriff am 24. September 2018).

303 | Mittelholzer besuchte die Schweizer Schule für Militärpiloten, die von dem bekannten Aviatikpionier Oskar Bider geleitet wurde. Gemeinsam mit Alfred Comte gründete er 1919 die erste Fluggesellschaft der Schweiz, die Ad Astra Aero, aus der später die nationale Fluggesellschaft Swissair hervorging (Aeppli 2012). 
an, drehte Filme und publizierte aus dem Material später Bücher. 1924 beteiligte er sich an der Gründung der Filmgesellschaft Präsens Film AG. ${ }^{304}$ Seine Veröffentlichungen trafen einen Nerv der Zeit; sie befriedigten den Durst nach Abenteuergeschichten und exotischen Bildern und verbanden sie mit der Begeisterung für die Aviatik. Seine Berichte beinhalteten zudem melancholische Betrachtungen einer >primitiven $<$ und von der modernen Zivilisation scheinbar unberührten Welt. Mittelholzer inszenierte sich so als einer der letzten Zeugen eines angeblich ursprünglichen Lebens in der Natur.

In seinem Buch Kilimandjaro-Flug, das 1930 in Zürich erschien, beschreibt Mittelholzer den spektakulären ersten Überflug des höchsten Berges Afrikas, der ihm im Januar 1930 gelang. Nicht zufällig wurde die Vorführung einer neuen Rekordleistung in einer Landschaft inszeniert, die als unberührte Wildnis galt - so konnte der Kontrast von geschichtsloser Natur und modernster Technik aufgerufen werden. Im Folgenden untersuche ich drei Aspekte von Mittelholzers Bericht: erstens die Art und Weise, wie seine Narrative die Schweiz im Zentrum eines kolonialen Netzwerks platzierten, zweitens, wie Schweizer Männlichkeit in Abgrenzung zu nicht-weißen Anderen hergestellt und drittens, wie das Flugzeug als Zeichen und Vehikel eines kolonialen Schweizer Pioniergeistes eingesetzt wurde.

Der koloniale Charakter von Mittelholzers Reise war bereits durch das Setting des Buches vorgegeben: Der Wiener Bankier Louis de Rothschild, ein leidenschaftlicher Großwildjäger, bat Mittelholzer um seine Dienste als Pilot für die Jagd in der ostafrikanischen Serengeti, die damals unter britischer Kolonialherrschaft stand. Mittelholzer fand lobende Worte für die kolonialen Verhältnisse: So erwähnt er die »vorzügliche Kolonisationsarbeit der Deutschen« in der Kilimanjaro-Region, die auch »heute noch von den hier ansässigen Engländern gerühmt wird « ${ }^{305}$. In einem anderen Buch würdigt er die gute Zusammenarbeit mit der britischen Bürokratie, die Mittelholzers Projekt unterstützte und ihm zusicherte, er müsse auf britischem Territorium keine Probleme bei der Einfuhr von Waren, Munition und Fotomaterial befürchten. ${ }^{306}$ Mittelholzers Bücher thematisieren auch die Präsenz von Schweizer Unternehmern im kolonialen Afrika, auf die er bei seinen Zwischenlandungen jeweils traf. Er

\footnotetext{
304 | Aeppli 2012.

305 | Mittelholzer 1930, 79.

306 | Mittelholzer 1927, 14.
} 
zeichnet damit das Bild eines helvetischen Netzwerks, das über die unterschiedlichsten kolonialen Kontexte hinausreichte. So beschrieb er seine Besuche bei Schweizern in Alexandrien und Nairobi und begeisterte sich in Ägypten für die »die vorbildliche landwirtschaftliche Schöpfung eines Schweizer Grosskaufmanns « ${ }^{307}$.

Weiterhin bedient Mittelholzer das Bild des guten Kolonialherren, wenn er schreibt, dass die Arbeiter bei einem Aufstand gegen die europäischen Kolonisten 1919 den Schweizer Besitzer nicht angegriffen hatten, »so sehr verehren die ägyptischen Bauern trotz proklamierten Rassenhasses ihren Herrn ${ }^{308}$. Als Mittelholzer dessen Gut verließ, schrieb er: »Lustig flattert auf dem flachen Dach der Villa das weisse Kreuz im roten Feld. ${ }^{309}$ Über die Dokumentation der Schweizer Präsenz in Afrika hinaus machten Mittelholzers Schriften mit solchen Bildern ersichtlich, dass sich Schweizer*innen selbstverständlich als Teil der kolonialen Welt sahen und von den Vertretern der Kolonialmächte auch so wahrgenommen wurden. Kaspar Surber beschreibt die Wirkung solcher Darstellungen folgendermaßen: »Man flog hinaus in die Welt, in die Sonne, die Freiheit - und landete doch immer wieder in der Schweiz. ${ }^{310}$ Bezeichnend für diesen Ausgriff auf die Welt ist auch ein Titelbild der Schweizer Illustrierten Zeitung vom 10. Februar 1927. Es zeigt Mittelholzer in einer bekannten Inszenierung bürgerlicher Männlichkeit: Er sitzt in Hemd und Weste in einem Korbsessel auf einer Terrasse vor einer fremden Landschaft und macht sich Notizen. Auf dem Tisch vor ihm steht ein Blumenstrauß, aus dem eine Schweizer Fahne ragt. ${ }^{311}$ Die Legende unter dem Bild informiert darüber, dass sich Mittelholzer im ägyptischen Assuan befindet. Eine derartige Berichterstattung und Mittelholzers eigene Bücher und Filme spannten einen affektiven Horizont auf, der das Gefühl einer spezifisch schweizerischen Art der kolonialen Zugehörigkeit erzeugte. Sie leisteten damit einen wichtigen Beitrag zur Normalisierung kolonialer Verhältnisse in der Schweiz. Darüber hinaus verwoben sie Schweizer Identitätsvorstellungen auf selbstverständliche Weise mit dem kolonialen Anspruch, überall auf der Welt zu Hause sein und lokale Landschaft, Tiere

307 | Mittelholzer 1930, 30.

308 | Mittelholzer 1930, 31.

309 | Mittelholzer 1930, 31.

310 | Surber 2017, 14.

311 | Siehe Surber 2017, 14. 
und Menschen zur exotischen Kulisse für den eigenen Lebensstil machen zu können. ${ }^{312}$

Mittelholzers Texte bezeugten aber nicht nur die Möglichkeit, sich als Schweizer mit der europäischen Kolonialpolitik zu arrangieren und von deren Strukturen Gebrauch zu machen, sie dokumentierten auch koloniale Siedlerfantasien. So hält Mittelholzer fest, die Luftverbindungen würden Afrika näher an Europa rücken und damit neue Auswanderungspläne denkbar machen: »Das überbevölkerte Europa wird in den gesunden, hochgelegenen Gebieten Zentralafrikas ungeheure Besiedlungsflächen finden. Ostafrika [...] ist das Paradies der Weissen.« ${ }^{313}$ Der Autor verbindet in diesen Zeilen technischen Fortschritt, insbesondere im Bereich der Aviatik, mit neuen Möglichkeiten der Kolonisation und alternativen Territorien für europäische Auswanderer. Auf diese Weise erschienen die Schweizer Händler und Großgrundbesitzer, die er während seines Afrikafluges traf, als Vorläufer eines weißen Siedlerkolonialismus, der Schweizer Akteur*innen einschließen sollte. Bezeichnenderweise wendeten sich Mittelholzers koloniale Fantasien nicht einer staatlichen Okkupationspolitik zu, die für die Schweiz als kleines Binnenland keine ernsthafte Option darstellte. ${ }^{314}$ Sie setzten vielmehr bei kolonialen Auswanderungs- und Besiedlungspraktiken an, in die auch die Schweiz involviert war, wie Leo Schelbert bereits in den 1970er Jahren dargelegt hat. Schweizer Auswanderer, so schreibt er, »nahmen unter dem Schutz und als Gehilfen führender europäischer Nationen als Soldaten, Unternehmer, Berufsleute, Missionare und Siedler auf allen Kontinenten an der Unterwerfung, Verdrängung oder Dezimierung einheimischer Völkerschaften sowie am Aufbau neuer weißer Nationen in erstaunlichem Maße teil. Dadurch wurde und blieb der Kleinstaat Schweiz mit dem Wohl und Wehe, mit den Errungenschaften und Fraglichkeiten, den Groß- und Greuelta-

312 Bei der Exotisierung von Mittelholzers Berichten halfen auch die Redaktionen nach. So schreibt Kaspar Surber, Arnold Heim habe sich beim Orell-FüssliVerlag beklagt, "dass in einem Bericht in der Neuen Zürcher Zeitung über den Besuch in Abwong [wo er sich im Januar 1927 mit Mittelholzer aufhielt] rtaktlose Bemerkungen und Erfindungen، eingefügt worden seien. Etwa dass die Dorfbewohner ihre Zähne ,in seltenem Leuchten wie gezückte Dolche ' gefletscht hätten." (Surber 2017, 25).

313 | Mittelholzer 1930, 11. Siehe auch Minder 2011, 240.

314 | Vgl. Purtschert, Lüthi und Falk 2012b. 
ten des Abendlandes voll verflochten und ein integraler Bestandteil der nach Weltdominanz strebenden europäischen Ökumene. « ${ }^{315}$

Welche Geschlechterperspektive ging mit einem solchen Anspruch auf koloniale Teilhabe einher? Bei Mittelholzer erschien Afrika als Spielfeld für weiße Männer. Bis auf eine Ausnahme kommen weiße Frauen in Mittelholzers Bericht Kilimandjaro-Flug nicht vor. ${ }^{316}$ Anders Schwarze Frauen: Gegenüber der (inwendigen) Titelseite des Buches findet sich ein eingeklebtes koloriertes Bild einer Schwarzen jungen Frau mit unbedeckten Brüsten, untertitelt als »Waikoma-Mädchen«. Auch im Buch sind mehrere Abbildungen von halb nackten Frauen enthalten, die etwa als »Massai-Schöne $\ll^{317}$ bezeichnet werden. Mittelholzer nimmt damit einen Umgang mit Bildern auf, die insbesondere von der amerikanischen Zeitschrift National Geographic popularisiert wurden. Diese begann 1896, nahezu unbekleidete Frauen of color abzubilden. Die Kombination von Erotik und Exotik wurde zu einem konstitutiven Bestandteil der Bildpolitik von National Geographic. Lisa Bloom konnte nachweisen, dass die Haut einer abgebildeten polynesischen Frau dunkler koloriert wurde, damit sie stärker wie eine >Eingeborene und damit exotischer aussah. ${ }^{318} \mathrm{Wie}$ Bloom festhält, diente der Einsatz solcher Bilder dazu, eine imaginäre Verbindung zwischen den Entdeckern und ihren weißen heterosexuellen männlichen Lesern herzustellen: »The creation of such images of nonwhite women in sexually suggestive poses made it possible for male readers to experience through these photographs, albeit fictionally, a shared commonality with the wealthy and influential male writer-explorers of the National Geographic, thus creating a site for the possibility of a gendered community of readers. ${ }^{319}$ Dass Mittelholzers Buch mit dem Bild einer halb nackten afrikanischen Frau eröffnet wird, kann vor diesem Hintergrund als Angebot gelesen werden, sich mit dem Blick eines weißen heterosexuellen Protagonisten zu identifizieren und sich eine Welt anzueignen, die durch ihre Erotisierung und Exotisierung zugleich als fremd und verführerisch galt. Sie war dem Alltag weißer Schweizer Männer zugleich

315 | Schelbert 1976, 27.

316 | Mittelholzer erwähnt die amerikanische Filmemacherin Osa Johnson, die mit ihrem Mann unterwegs war. Vgl. Mittelholzer 1930, Bild 26, o.S.

317 | Mittelholzer 1930, Bild 39, o.S.

318 | Bloom 1993, 73.

319 | Bloom 1993, 76 [Hervorhebung im Original]. 
enthoben und durch die Vorstellung eines weißen Zugriffrechts auf die gesamte Welt dennoch imaginär mit diesem verbunden.

Während Schwarze Frauen in Mittelholzers Publikationen die Authentizität einer Kultur repräsentierten, die von der Moderne noch unberührt schien, wurden weiße Männer ständig in Bezug zur zivilisierten Welt gesetzt: Die Reisenden posierten in der Steppe neben einem Kleinflugzeug oder Auto, schrieben Notizen vor ihrem Zelt oder behandelten Einheimische mit westlicher Medizin. ${ }^{320}$ Die Abwesenheit von weißen Frauen und die Degradierung von Schwarzen Frauen zu exotischen Schönheiten, die mit der Flora und Fauna verschmolzen und damit als Bestandteil der Natur dargestellt wurden, führten dazu, dass die afrikanische Savannenlandschaft als » hypermasculine< landscape « ${ }^{321}$ erscheinen konnte, in der sich weiße Männer austoben, miteinander messen und großartige Abenteuer erleben konnten. Zu Mittelholzers >Porno-Tropics<, seiner Überblendung von kolonialer Geografie und sexualisierten Bildern von Schwarzen Menschen, gehörten neben Frauen auch exotisierte Männer. So beschreibt er den Löwentanz der Waikoma, ein »grandioser geräuschvoller Aufmarsch von braunen, hochgewachsenen Naturmenschen ${ }^{322}$ in einer homoerotisch aufgeladenen Körperästhetik als Spektakel einer kräftigen, gesunden und natürlichen Männlichkeit. ${ }^{323}$

Schwarze Männer erscheinen im Unterschied zu Frauen (und Kindern) in zweierlei Funktionen, nämlich als Verkörperung des natürlichen Menschen und als hybride Figuren mit Verbindungen zur modernen westlichen Welt. So erzählt Mittelholzer, wie alle Weißen auf der Jagd von ihren Assistenten begleitet werden: »Jeder von uns hat seinen Boy, der ihm die Wünsche von den Lippen abliest.« ${ }^{324}$ Solche erotisch kodierten Formulierungen finden sich immer wieder: Seinen eigenen Bediensteten beschreibt Mittelholzer als »mein anhänglicher Waikoma-Boy« ${ }^{325}$. Durchgängig werden Schwarze Männer, die für Weiße arbeiten, als unterwürfig charakterisiert: Wenn die weißen Männer von ihrem Flugabenteuer zurückkehren, servie-

320 | Mittelholzer 1930, Bild 48ff. und 70, o.S.

321 | Frohlick 1999.

322 | Mittelholzer 1930, 92.

323 | Mittelholzer 1930, 41 sowie Bild 27, 28, 29, 33, 78, o.S.

324 | Mittelholzer 1930, 63.

325 | Mittelholzer 1930, 96. 
ren ihnen die »braven Schwarzen ${ }^{326}$ das Essen. Weiße Männlichkeit wird in solchen Zeilen nicht nur im Kampf mit einer unberechenbaren Natur und wilden Tieren hergestellt, die gejagt und geschossen werden, sondern auch in der Differenz zu feminisierten (und manchmal sexualisierten) Schwarzen Männern, welche die Arbeiten übernehmen, die im europäischen Kontext den Frauen zugeschrieben werden.

Dazu gehören neben physischen Tätigkeiten wie Kochen oder Putzen auch emotionale Arbeiten: Der >Boy< kümmert sich um die Bedürfnisse des weißen Auftraggebers, er ist treu, anhänglich und fürsorglich. Mittelholzers Berichte beinhalten das, was Toni Morrison in ihrer Lektüre von Hemingway als »Aufgebot an hilfreichen schwarzen Krankenschwestern-AmmenMännern « ${ }^{327}$ beschreibt. Wie die Sherpas am Himalaya, so übernehmen in der frauenlosen Zone der afrikanischen Wildnis Schwarze Männer die Rolle der weißen Frauen, die weißen Männer zu nähren und zu umsorgen. Diese Figuren können sexuell und asexuell kodiert sein: Der >Boy< changiert, im Unterschied zum hypervirilen Wilden, zwischen einer geschlechtslosen Position und einer erotisch aufgeladenen Unterwürfigkeit.

Schließlich ist der koloniale Diskurs in Mittelholzers Texten eng verbunden mit der Inszenierung technischer Überlegenheit, die sich in der Bedeutung des Flugzeugs abbildet. Die Nationalisierung von Mittelholzers Reisen kam in seiner Namenspolitik zum Ausdruck: Seine Flugzeuge hießen oft >Switzerland<. Der symbolische Effekt dieser Namensgebung wird beispielsweise dann deutlich, wenn Mittelholzer beschreibt, wie er »dank den guten Flugeigenschaften unserer >Switzerland III < den Mount Kenya mühelos bezwungen ${ }^{328}$ habe.

Mittelholzers Unternehmungen galten als national bedeutsam. Das zeigt sich etwa daran, dass seinem Buch Abessinienflug von 1934 ein Vorwort des Bundesrates Marcel Pilet-Golaz vorangestellt wurde. ${ }^{329}$ Darin wird Mittelholzer als Abenteurer in einer exotischen Welt beschrieben, der das Nordkap und Spitzbergen »bezwang«, in Persien den »stolzen Demawend « überflog, vom »Mysterium des in den Himmel ragenden

326 | Mittelholzer 1930, 84.

327 | Morrison 1994, 115.

328 | Mittelholzer 1930, 51.

329 | Favez 2010. Pilet-Golaz hielt 1940 eine fragwürdige Rede an die Nation, die von einigen als Aufruf zur Annäherung an die nationalsozialistische Regierung in Deutschland interpretiert wurde. 
Kilimandjaro« gelockt wurde und dessen Flugzeug »seine majestätischen Kreise über dem Hochland des Negus von Aethiopien « zog. ${ }^{330}$ Seine Lobesrede schloss der Magistrat mit den Worten: »Und weiter ziehen Sie Ihre glorreiche Bahn, zur höchsten Ehre der schweizerischen Flügel.«331 An der Formulierung des Bundesrates lässt sich (trotz der schiefen Metaphern) erkennen, dass Mittelholzers Unternehmungen in eine nationale Repräsentationspolitik eingegliedert wurden, welche die Schweiz symbolisch mit der Aviatik und dem Erobern unbekannter Welten verband.

Eiselins Buch Erfolg am Dhaulagiri erschien 30 Jahre später, in einer Zeit also, in der die Welt durch den Zweiten Weltkrieg und die Dekolonisierungsbewegungen entscheidende Veränderungen erfuhr. Dennoch stellt es in mehrfacher Hinsicht eine Fortsetzung des stechnokolonialen Narrativs von Mittelholzer dar. ${ }^{332}$ Eiselins Reise nach Nepal enthält ebenfalls zahlreiche Geschichten einer eigenartigen und aus dem Rahmen der modernen Zeit gefallenen >orientalischen $<$ Welt. Ein zentraler Topos, der sich bei beiden Autoren findet, ist die angebliche Faszination nicht-weißer Anderer für das westliche Flugzeug. Über ihre Ankunft in Bagdad schreibt Eiselin: »Kaum auf dem Boden, sind wir auch schon von einem schnatternden Haufen Araber umringt, die sich offenbar an uns nicht satt sehen können. Neugierig wie Kinder untersuchen sie jede Ecke des >Yeti< [Name des Flugzeugs] und wollen alles betasten. ${ }^{333}$ Eine solche >koloniale Urszene der Aviatik< taucht auch bei Mittelholzer auf. In Kilimandjaro-Flug ist ein Bild seines Flugzeugs >Switzerland < abgedruckt, das von einheimischen Männern und Kindern umringt wird. Die Legende besagt: »Unser Fokker ist das große Ereignis der Eingeborenen.«334

Eiselins Buch enthält eine Fotografie mit ähnlichem Inhalt (vgl. Abbildung 25). Sie zeigt einen älteren und einen jüngeren Mann, die beide in die Kamera blicken. Sie stehen vor dem >Yeti<, dem Schweizer Kleinflugzeug (dessen Name in diesem Fall nicht die Schweiz repräsentiert,

330 | Pilet-Golaz 1934, 11.

331 | Pilet-Golaz 1934, 12.

332 | Flugabenteuer in Afrika waren nicht die einzige Schaubühne, auf der Schweizer Heroismus zur Aufführung kam. Wie Lea Pfäffli ausführt, hatten arktische Expeditionen zu Beginn des 20. Jahrhunderts ähnliche Möglichkeiten eröffnet (Pfäffli 2015).

333 | Eiselin 1960, 48.

334 | Mittelholzer 1930, 48. 
sondern die exotisierte Erwartung des Schweizer Publikums aufnimmt). Die Legende besagt: »Seit seiner Ankunft in Nepal wird der >Yeti< von den Einheimischen immer wieder angestaunt. ${ }^{335}$ Die beiden Personen im Vordergrund, ein älterer Mann auf der linken und ein junger auf der rechten Seite, schauen allerdings nicht zum Flugzeug, sondern zum Fotografen, und ihre Blicke bekunden eher Zurückhaltung als Staunen. Ein dritter Mann schaut von der Kamera weg Richtung Flugzeug, ohne dass klar wird, ob er die Maschine oder eine weitere Person fixiert, die sich ihm aus dem Hintergrund nähert. Der Widerspruch zwischen einem Text, der behauptet, dass das Flugzeug von den Einheimischen bewundert wird, und einem Bild, das sich schwerlich so lesen lässt, zeigt die Funktionsweise einer >technokolonialen $<$ Logik, die den Einheimischen immer schon Erstaunen, Begehren, Verwunderung und ein beinhahe übernatürliches Interesse für die technischen Geräte zuschreibt.

\section{Abbildung 25: Max Eiselins Bebilderung seiner Ankunft in Nepal}

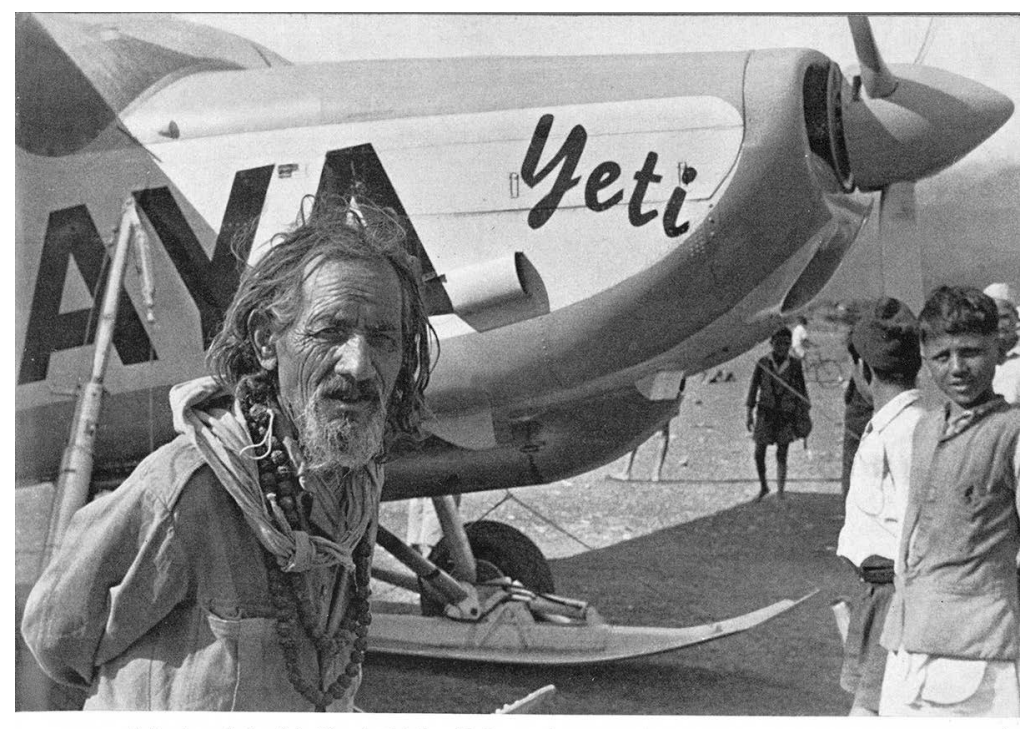

I Seit seiner Ankunft in Nepal wird der «Yeti» von den Einheimischen immer wieder angestaunt.

Quelle: Eiselin 1960, 16

335 | Eiselin 1960, 16. 
In der Schweiz war das Interesse an Eiselins Unternehmung groß; die Medien berichteten stolz vom neuen »Weltrekord $\aleph^{336}$ in der Höhenlandung und empathisch vom Absturz des >Yeti< in Nepal. Die Expedition mag auch darum auf großes Echo gestoßen sein, weil sie die Flugtechnik in den Vordergrund rückte. Denn der technische Fortschritt war in den 1950er Jahren ein populäres Thema. Zeitschriften brachten oftmals Bildreportagen über technische Projekte, die Kraft und Großartigkeit in den Mittelpunkt stellten. So erhielten die »Großbaustellen zur Stromproduktion überdurchschnittliche Beachtung: als Orte männlicher Wagemutigkeit, Entbehrungsbereitschaft und grosser Ingenieurskunst. [...] Mit der Glorifizierung der >Grande Dixence $<$, der damals höchsten Staumauer der Welt, avancierten Arbeiter und Techniker zu Heroen des Fortschritts «337, hält Joris fest. »Im Bild des zeitgenössischen Technikers schlechthin«, schreibt Melanie Rohner mit Blick auf die Figur des Ingenieurs Mitte des 2o. Jahrhunderts, »aktualisierten sich Männlichkeitsvorstellungen von Durchsetzungskraft, Freiheit und Individualität, die auch von europäischen Konquistadoren schon verkörpert wurden.«338 Die monumentale Gletscherwelt des Himalaya und die technische Pioniertätigkeit der Piloten und Bergsteiger konnte sich in diese Ästhetik einfügen. Sie stützten das Bild des heroischen technikaffinen Schweizers und verankerten es auf neue Weise in einer vertrauten kolonialen Weltsicht.

Der Einsatz eines Flugzeugs im Himalaya gab allerdings auch Anlass zu Kontroversen. Die Strategie, Bergsteiger direkt in das Basislager hochzufliegen, wurde infrage gestellt, insbesondere nachdem einige Mitglieder der Expedition mit Akklimatisierungsproblemen zu kämpfen hatten. So berichtete die Neue Zürcher Zeitung von einer Pressekonferenz, in der Norman Dyhrenfurth, der Mitglied der Unternehmung war, den Nutzen des Kleinflugzeugs für die Expedition in Zweifel zog. ${ }^{339}$ Eiselin widersprach dieser Einschätzung vehement. ${ }^{340}$ Die öffentlich ausge-

336 | 0.V.: "Weltrekord und Verlust des ,Yeti», in: Schweizer Illustrierte Zeitung 1960(21).

337 | Joris 2014, 249.

338 | Rohner 2015, 77.

339 | O.V.: „Die schweizerische Dhaulagiri-Expedition. Kritik am 'Yeti«, in: Neue Zürcher Zeitung, 12. Juni 1960.

340 | O.V.: "Abschluss der schweizerischen Dhaulagiri-Expedition", in: Neue Zürcher Zeitung, 15. Juni 1960. 
tragene Kontroverse spiegelte auch die ambivalente Wahrnehmung der Technik in der Gesellschaft wieder. Die zunehmende Erschließung und Verbauung der Alpen, gerade auch durch Kraftwerkprojekte, löste nicht nur Technikeuphorie aus, sondern befeuerte eine wachsende Angst vor dem Schwinden und einer irreversiblen Zerstörung der Natur. Diese Diskussionen fanden auch Eingang in alpinistische Kreise. Unter dem Titel »Bedenklicher Alpinismus« veröffentlichten Die Alpen 1960 einen Artikel, der den Einsatz von Flugzeugen in den Bergen heftig kritisierte. Besonnene Bergsteiger, so heißt es, »schüttelten den Kopf [...] über die Planung von alpinen Flugplätzen, um die Berge dem Lufttourismus und dem Lunch-Papiersack zu erschließen ${ }^{341}$.

Solche Debatten über Sinn und Unsinn, Möglichkeiten und Grenzen der Technik, über die nötige Nähe des Menschen zur Natur und die Frage, inwiefern die Technologie zu einer problematischen Entfremdung des Menschen von der Natur und sich selbst führte, wurden auch mit Bezug zum außereuropäischen Raum geführt. Technik-Enthusiasten wie Eiselin konnten ihr Fortschrittsnarrativ in dieser von Menschenhand scheinbar unberührten Umgebung anders zur Geltung bringen als es in der zunehmend als verbaut wahrgenommenen Schweiz möglich gewesen wäre. Im Himalaya wurde dem anachronistischen Bild des Pioniers und Entdeckers ein neuer Sinn verliehen. Konstitutiv für eine solche Sicht war aber nicht nur die koloniale Trope des Himalaya als leerer Raum, sondern auch die Konstruktion nicht-weißer Einheimischer, die den technischen Fortschritt bewunderten und begehrten.

Solche Bilder stützten das Selbstverständnis der Schweiz als einer technisch avancierten Nation und des Schweizers als eines Technikers, das für die Herstellung einer nationalen Identität im 20. Jahrhundert bedeutsam war. In einer Festschrift für das Eidgenössische Polytechnikum (die heutige ETH Zürich) von 1905 beschreibt der Historiker Wilhelm Oechsli die Schweiz als »Wunderland der Technik « ${ }^{342}$ und den Ingenieur als neue Verbindung der Schweiz zur Welt: »Wie einst der Schweizersoldat und Schweizeroffizier, so zieht heute der Schweizer Techniker neben dem Schweizer Kaufmann in alle Welt hinaus und bringt den Schweizernamen bis in die Berge Abessiniens zu Ehren. ${ }^{343}$ Nicht zufällig bezieht

341 | Fux, Adolf: "Bedenklicher Alpinismus", in: Die Alpen 1960(36).

342 | Oechsli 1905, 368.

343 | Oechsli 1905, 368. 
sich Oechsli auf einen anderen Schweizer, der in einem exotisch geltenden Kontext Berühmtheit erlangte, nämlich auf Alfred Ilg, der von 1879 bis 1906 für den abessinischen Herrscher Menelik II arbeitete und an der Planung und Realisierung einer Eisenbahnverbindung von Djibouti nach Addis Abeba beteiligt war. ${ }^{344}$ Wie gezeigt wurde, ist die Figur des Technikers als Botschafter der Schweiz allerdings kolonial gerahmt und gründet auf dem Othering von Frauen und nicht-weißen Menschen. Nicht zufällig beschreibt Eiselin, bevor er den >schnatternden Haufen Araber< erwähnt, wie dem Schweizer Piloten trotz starker Seitenwinde »eine fachmännische Landung $\ll^{345}$ gelang. Der überlegte und nervenstarke Umgang des Piloten mit dem Flugzeug kontrastiert auf aufsehenerregende Weise mit dem Bild arabischer Männer, die daraufhin, wie Eiselin schreibt, ohne Sinn und Verstand >jede Ecke< des Flugzeugs betasteten. Das Verhalten der nicht-weißen Anderen zeugte von ihrem fehlenden technischen Verständnis und konturierte so das Bild des weißen Piloten, der die Technik meisterhaft zu gebrauchen wusste.

Diese Figur des kolonialen Anderen, der die Technik nicht kennt, sie aber begehrt, ermöglicht erst die Darstellung des Schweizers als technisch herausragender Fachmann. Dieses stechnokoloniale< Othering strukturiert ein weiteres Narrativ, das insbesondere mit der Dekolonisierung bedeutsam wurde: die Vorstellung, dass männliche Schweizer dazu prädestiniert waren, postkoloniale Andere mit moderner Technik bekannt zu machen. Eine solche stechnische Hilfe< sollte es der Schweiz erlauben, die Umsetzung großer und ökonomisch gewichtiger Bauaufträge wie die Konstruktion von Brücken, Eisenbahnen oder Kraftwerken mit der humanitären Tradition der Schweiz zu verbinden. Die Idee eines technisch avancierten Landes in einer technisch unterentwickelten Welt wurde zu einem wichtigen Anknüpfungspunkt für die Erschließung neuer Märkte im Kontext der Entwicklungshilfe. Obwohl tief verbunden mit kolonial kodierten Leitbegriffen wie Fortschritt, Zivilisation und westlicher Vorherrschaft, wurde die Technik von den Erfindern der Schweizer Entwicklungshilfe als Bereich definiert, der sich scheinbar außerhalb der Politik befand und entsprechend mit der Schweizer Neutralitätsdoktrin zu vereinbaren war - abgesehen davon, dass sich der Technikexport als enorm rentable Wirtschaftsunternehmung erwies.

344 | Vgl. Eggimann Gerber 2009.

345 | Eiselin 1960, 48. 
Bergige Länder wie Nepal, Peru oder Ruanda galten wegen ihrer topografischen Ähnlichkeit als ideale Zielländer für die technische Hilfe der Schweiz, die zu Beginn stark von der Technischen Hochschule in Zürich geprägt worden war. ${ }^{346}$ Betont wurde auch die Bedeutung der Schweiz als Partnerin ohne koloniale Vergangenheit. Die helvetische Entwicklungshilfe versuchte sich auf diese Weise, so Elmer, positiv von den (ehemaligen) Kolonialmächten abzuheben: »Mit der Betonung des schweizerischen Fleißes, der Bescheidenheit und der neutralen Kleinstaatlichkeit grenzte man sich gerne vom imperialen Gebaren der Großmächte ab, was die Experten und Behörden als besonderen Vorteil im Wettlauf um die Entwicklungsländer betrachteten. ${ }^{347}$ Wie Lukas Zürcher zeigt, prägte die Selbstpositionierung des Schweizers als arbeitsam und beliebt, weil frei von kolonialer Schuld, die Figur des (männlichen) Entwicklungsexperten, die in dieser Zeit entstand. ${ }^{348}$ Sie zeigt auch, wie sehr das Schweizer Selbstverständnis nach der Dekolonisation von einer kolonialen Amnesie gezeichnet war. Während frühe stechnokoloniale in Mittelholzers Werk zu finden sind, eine affektive Verbundenheit der Schweiz mit der kolonialen Welt propagierten, wurden sie kurze Zeit später so umgedeutet, dass sich die Schweiz gerade deswegen als ideale Partnerin für die >technische Hilfe an unterentwickelte Länder< anbot, weil sie angeblich keine koloniale Vergangenheit besaß.

\section{Konklusion: 'Berg-Otheringı und Dekolonisation}

In der bestehenden Literatur zum Himalaya-Bergsteigen überwiegt die Vorstellung, die Schweizer hätten sich von britischen und anderen westlichen Bergsteigern durch die Abwesenheit von kolonialen Attitüden unterschieden. Ortner behauptet, die Schweizer Sahibs hätten den Sherpas in der Everest-Expedition von 1952 Respekt entgegengebracht und ihre Gefühlsäußerungen in schwierigen Situationen als »normal and human « ${ }^{349}$ beurteilt. Stewart meint, Tenzing Norgays Beziehung zu den Schweizern

346 | Vgl. Elmer 2012; Sanders 2015; Zürcher 2014.

347 | Elmer 2012, 257.

348 | Zürcher 2014, $200 f f$.

349 | Ortner 1997, 141. 
sei »empty [...] of imperial and Raj associations « gewesen. ${ }^{350}$ Auch Hansen gibt zu Protokoll, dass die Schweizer die Sherpas als Gleiche behandelt hätten. ${ }^{351}$ Tenzing Norgay selbst hält fest, die Schweizer hätten ihn wie einen Kameraden behandelt, »an equal, in a way that is not possible for the British « ${ }^{352}$. Gemeinhin wird den Schweizern damit, auch in der postkolonialen Geschichtsschreibung, die Rolle der >guten Sahibs < zugedacht.

Die vorliegende Studie zeigt, dass es so einfach nicht war. Es geht nicht darum, in Abrede zu stellen, dass britische und Schweizer Bergsteiger einen anderen Umgang mit den Sherpas gepflegt haben mögen und dass diese Unterschiede etwas mit den unterschiedlichen Rollen von britischen und Schweizer Akteur*innen im Kolonialismus zu tun hatten. Meine Analyse stellt vielmehr das simple Bild der >demokratisch veranlagten Schweizer infrage und zeigt, dass auch deren Sichtweise auf den Himalaya kolonial war und eine ganz spezifische und bislang ungeschriebene koloniale Geschichte des Bergsteigens hervorgebracht hat. Sie zeigt zudem, dass die Wahrnehmung der Berge als zentrale Signifikanten der Schweizer Nation nicht abgelöst werden kann von der kolonialen Imagination, in die der Alpinismus seit Anbeginn eingebettet ist. Damit wird eine Geschichte erkenntlich, in der die Figur des Bergsteigers dazu dient, die Zugehörigkeit zur Schweiz mit Männlichkeit und Weißsein engzuführen - ein Prozess, der auf einem kontinuierlichen Othering gegenüber Frauen und nicht-weißen Menschen (unterschiedlicher Geschlechter) gründet.

Hervorzuheben ist dabei das >Berg-Othering als eine spezifisch schweizerische Art und Weise, das Verhältnis von Nähe und Distanz zu den (post-)kolonialen Anderen in bestehenden Machtverhältnissen auszutarieren. Die Behauptung einer >ungleichen Ähnlichkeit< zwischen Bergnationen war bereits Ende des 19. Jahrhunderts bedeutsam, als der Alpenmythos zu einem zentralen Bestandteil des Schweizer Nationalismus mutierte. Missionare verwendeten positive Bilder vom einfachen Leben in den Bergen, um eine grundlegende Verbindung zwischen der Schweiz und ihren Missionsgebieten herzustellen: »Swiss missionary anthropologists had at their command a positive image of primitive communities that could be used to [...] incorporating African societies into a familiar

350 | Stewart 1995, 193.

351 | Hansen 1999, 227.

352 | Norgay und UlIman 1955, 204. 
system of explanation. Both Alpine and African worlds were populated by uncomplicated, small scale societies that seemed to reflect a primitive past of communitarian values, firm social hierarchies and authentic traditions «, ${ }^{353}$ hält Harries fest.

Die Konstruktion einer wesenhaften Ähnlichkeit zwischen einfach lebenden Menschen, die sich in der Figur des Bergbewohners verdichtete, fand sich ein halbes Jahrhundert später in den Arbeiten von René Gardi wieder, einem Reiseschriftsteller, Fotografen und Filmer, der das Schweizer Bild von Afrika nach dem Zweiten Weltkrieg maßgeblich prägte. Gardi, so zeigt Gaby Fierz, stand dem Kolonialismus keineswegs ablehnend gegenüber, bemühte sich in seinen Berichten aber um Distanz zur französischen Kolonialkultur. ${ }^{354}$ Entsprechend kennzeichnete der Kontrast zwischen >bescheidenen $<$ und >naturverbundenen $<$ Schweizer*innen auf der einen und >dekadenten der anderen Seite seine Berichterstattung. ${ }^{355}$ So schilderte er voller Befremdung den aufwendigen Lebensstil der colons, der Kolonialisten, mit denen er 1953 in Nordkamerun unterwegs war: »Es ging auch diesmal nicht ohne Tisch und Stühle, ohne die ganzen Popote, und zum Mittagessen hat Madame trotz unserem Protest Voressen, Huhn, Kartoffeln, Salat, Dessert, Kaffee bestellt.« ${ }^{356}$ Nicht zufällig verweist Gardi auf eine Französin, um seinen Unmut zu äußern; in misogyner Manier macht er sie zur Verkörperung der Verweichlichung und Dekadenz der französischen Kolonialkultur. Im Gegensatz dazu stilisieren viele von Gardis Reportagen die einfache, unprätentiöse und »männliche« Art des Reisens, Essens und Schlafens, die er und seine Schweizer Kollegen pflegten. Diese »inszenierte Bescheidenheit « ${ }^{357}$ sollte ihm auch einen direkteren Zugang zu den Einheimischen eröffnen. ${ }^{358}$ Gardi war mit allen Privilegien eines weißen Europäers ausgestattet und konnte auf die Unterstützung durch koloniale Netzwerke zählen. Gleichzeitig stellte er sich als einfacher Reisender dar, dem es angeblich gelang, eine Vertrautheit mit den Einheimischen aufzubauen, die den Kolonialherren verwehrt blieb.

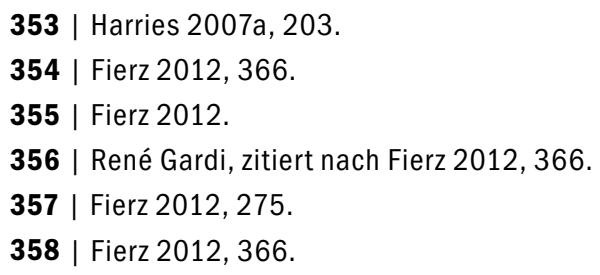


Wie ich in meinen Ausführungen gezeigt habe, ordnete eine solche Logik der >ungleichen Ähnlichkeit< nicht nur die Beziehungen zwischen Schweizer Akteuren und kolonialen sowie postkolonialen Anderen. Sie machte als >Berg-Othering « auch ein Strukturmoment der Binnenbeziehungen in der Schweiz aus. Die Identifikation mit (einem Idealbild) der alpinen Bevölkerung ermöglichte es den Angehörigen des Bürgertums, eine Nähe zur bäuerlichen und ländlichen Bevölkerung zu behaupten sowie im internationalen Kontext als Vertreter einer einfachen Alpennation aufzutreten. Entscheidend war, dass sich diese Gleichsetzung mit den bescheiden lebenden Anderen nach Bedarf in ein Verhältnis der Alterität kippen ließ. Schweizer Autor*innen der Alpendiskurse konnten sich jederzeit von der Bergbevölkerung distanzieren und als Mitglieder einer europäischen und kolonialen bürgerlichen Elite positionieren - ihre Zugehörigkeit zu eben dieser Elite belegten sie nicht zuletzt performativ durch das Schreiben über die >Primitiven<.

Schweizer >Berg-Othering $<$ ist demnach untrennbar mit der Kolonialität der Macht verbunden. Zum einen wurden die Alpen durch wissenschaftliche, militärische und sportliche Praktiken als kolonialer Raum kodiert und >erobert $<$. Zum anderen entstand das Bild der Alpen erst durch das ständige In-Beziehung-Setzen des nationalen Territoriums mit Landschaften in kolonialen Kontexten. Das >Berg-Othering < ermöglichte es ferner, asymmetrische Beziehungen zwischen Schweizern und kolonialen Anderen herzustellen, die auf der Vorstellung einer natürlichen Ähnlichkeit basierten. In kolonialen Kontexten legitimierten diese Alteritätsverhältnisse die missionarische Arbeit und ermöglichten eine Rhetorik der Proximität, die authentische Einsichten in das Leben der kolonialen Anderen versprach. Während der Dekolonisation erwies sich die >ungleiche Ähnlichkeit ‘ als attraktives Modell, um neue, vermeintlich egalitäre Beziehungen zwischen ehemaligen Kolonialmächten und vormaligen Kolonien denkbar zu machen.

Dieser Zusammenhang zeigt sich exemplarisch in der Berichterstattung zum Himalayabergsteigen. Aus helvetischer Sicht waren die Schweizer, die keine Kolonien besessen hatten, und die Nepalesen, die nie kolonisiert worden waren, prädestiniert dafür, eine neue, postkoloniale Ikonografie der Brüderlichkeit zu erschaffen. Die Berge wurden dabei als entpolitisierter und machtfreier Raum dargestellt, in dem sich Menschen über >Rassengrenzen < hinweg miteinander verbinden konnten, und das Bergsteigen als eine Tätigkeit, die auf Kooperation und Kameradschaft 
basierte und universelle menschliche Erfahrungen ermöglichte. Meine Untersuchung zeigt, dass die mediale Repräsentation des Höhenbergsteigens in der Schweiz trotz dieser Rhetorik der Gleichheit auf rassistischen Diskursen gründete und tiefgreifende koloniale Hierarchien perpetuierte. Dabei zeigt sich, dass Weißsein durch Figuren wie diejenige des Schweizer Bergsteigers auf ganz spezifische Weise hergestellt wird, nämlich durch die Errichtung eines verzerrten Spiegelverhältnisses zum kolonialen Anderen, der gleichzeitig enorm ähnlich ist und doch gänzlich verschieden bleibt. Die Vorstellung eines einfachen, naturnahen und bescheidenen Lebens in den Bergen verbindet Schweizer Bergsteiger und Sherpas und begründet den privilegierten Zugang der Schweizer zu den Nepalesen. Deren Situierung am Rand der Moderne und ihre Darstellung als un- und halbzivilisierte Menschen wiederum legitimieren die paternalistische Vorstellung von Schweizern, die die Nepalesen auf das Leben in der (technisch avancierten) Moderne vorbereiten. Der global bedeutsame Auftrag, den die Schweizer sich auf diese Weise selbst gaben und der im Himalaya-Bergsteigen der frühen Nachkriegszeit exemplarisch zum Ausdruck kam, nämlich bislang sunbekanntes< Land zu entdecken, $\mathrm{zu}$ durchschreiten, $\mathrm{zu}$ vermessen und zu kartografieren und die lokale Bevölkerung zu beschreiben, $\mathrm{zu}$ erforschen, zu erziehen, auszubilden und mit technischen Innovationen vertraut $\mathrm{zu}$ machen, reproduzierte die Vorstellung von tätigen, aktiven und gestaltenden Männern, neben denen Frauen nur eine verschwindend kleine (und immer auf die Männer ausgerichtete) Rolle spielen konnten. Als Verkörperung des idealen, mit militärischer Männlichkeit, kolonialer Expansionslust und technischer Versiertheit assoziierten weißen Staatsbürgers trugen die international erfolgreichen Schweizer Alpinisten damit auf ihre Weise dazu bei, den fortgesetzten Ausschluss der Frauen aus der Politik und aus den öffentlichen Tätigkeiten innerhalb der Schweiz zu begründen. 



\section{Nachwort}

In der vorliegenden Arbeit kommen zwei Perspektiven zur Anwendung, die für die Auseinandersetzung mit der Schweiz und ihrer Geschichte ungewöhnlich sind. Zum einen wird ein kulturwissenschaftlicher Zugang in der Tradition der britischen und US-amerikanischen Cultural Studies mobilisiert mit der Folge, dass die Schweizer Populärkultur ins Zentrum der Untersuchung rückt. Zum anderen bezieht sich die Studie auf Postkolonialismus, Dekolonisierungstheorien, Whiteness Studies, Geschlechterforschung und Queer Studies und thematisiert damit Kolonialismus und Rassismus sowie ihre intersektionalen Verflechtungen mit Nation, Geschlecht und Sexualität. Insbesondere die Kombination dieser Zugangsweisen ist, im Unterschied etwa zu Deutschland, ${ }^{1}$ in der Schweiz noch wenig erprobt. Das ist auch deshalb erstaunlich, weil die Verschränkung solcher Ansätze enorm produktiv ist, wenn es darum geht, die Komplexität gesellschaftlicher Machtverhältnisse in ihrer transnationalen Verflechtung und mit einer historischen Tiefenschärfe fassen zu können.

Ein häufig genannter Einwand gegen die postkoloniale Forschung auch in der Schweiz - besagt, dass die koloniale Weltsicht vor der Dekolonisation als unproblematisch galt und nicht ex post an ethischen Standards der heutigen Zeit gemessen werden dürfe. Ein solches Argument übersieht nicht nur die vielfältigen Formen von Kritik und Widerstand, die koloniale Herrschaft immer begleitet haben. Es impliziert auch, dass Erkenntnisse über die kolonialen Verflechtungen der Schweiz nicht von Bedeutung seien. Der Kolonialismus ist jedoch keine Fußnote der Schweizer Geschichte. Dass eine koloniale Weltsicht in der Schweiz hegemonial war (und es noch immer ist), bietet vielmehr Anlass zu Fragen:

1 | Vgl. Zantop 1997; Steyerl und Gutiérrez Rodriguez 2003; Eggers, Kilomba, Piesche und Arndt 2005; Tissberger, Dietze, Hrzan und Husmann-Kastein 2006; Ha, al-Samarai und Mysorekar 2007. 
Wie, warum und auf welche Weise wurde und wird koloniales Wissen in der Schweiz normalisiert? Wie ist es mit helvetischen Selbst- und Weltbildern verknüpft? Welche neuen Erkenntnisse sind möglich, wenn die koloniale Matrix der Schweizer Alltagskultur sichtbar und der Reflexion zugänglich gemacht wird? Diesen Fragen habe ich mich in der vorliegenden Arbeit anhand von zwei historischen Fallstudien angenommen.

\section{SWISS WaYs OF OtheRING: Die Hausfrau und der Bergsteiger}

Im ersten Kapitel dieser Arbeit wird die Entstehung der Schweizer Hausfrau als bedeutsames normatives Modell von Weiblichkeit in den 193oer Jahren untersucht. Für Großbritannien hat die postkoloniale Forschung gezeigt, dass die Beziehung zu den Kolonien für den Haushaltskult, der Ende des 19. Jahrhunderts entstand, konstitutiv war. ${ }^{2}$ In der Zeit, als der viktorianische Haushalt zur Schaubühne für die imperiale Kultur avancierte, wurde die Durchsetzung bürgerliche Familienverhältnisse in den Kolonien zu einer wichtigen Aufgabe der Zivilisationsmission. ${ }^{3}$ Diese Einsichten werden in der vorliegenden Arbeit in Bezug zur Schweiz gesetzt, indem die Entstehung der >Nur-Hausfrau ${ }^{4}$ aus einem postkolonialen Blickwinkel rekonstruiert wird. Der Rückgriff auf Ausstellungen, Illustrierte, Zeitungen und Werbung zeigt, dass koloniale Themen in der Schweiz der Zwischenkriegszeit allgegenwärtig waren. Diese imperiale Alltagskultur stellte nicht einfach eine historische Kulisse für die Aushandlung der Geschlechterverhältnisse dar. Vielmehr gründeten die diskursive Herstellung und die hegemoniale Durchsetzung neuer Geschlechternormen auf dem vielfältigen Einsatz von >kolonialen Fantasien<. Durch die Abgrenzung von nicht-weißen, als >primitiv< und rückständig apostrophierten Anderen konnte die Figur der Schweizer Hausfrau in einem imaginären Europa platziert werden, das Fortschritt und Zivilisiertheit symbolisierte, während es ein kontinuierliches Othering in Gang hielt.

2 | McClintock 1995.

3 | Comaroff und Comaroff 2013.

4 | Joris und Witzig 1986, 75. 
Der Blick auf die affektiven Dimensionen dieser Diskurse zeigt, wie die faktische Beschneidung weiblicher Partizipationsmöglichkeiten in Politik und Gesellschaft mithilfe kolonialer Bilder in eine Rhetorik des Glücks umgemünzt werden konnte. Das Othering erfüllte dabei unterschiedliche Funktionen: Die sprimitiven Anderen brachten die Fortschrittlichkeit der Hausfrau zum Vorschein, die unzivilisierten Anderen führten deren erzieherische Aufgabe in der mission civilisatrice vor Augen, die neidischen Anderen veranschaulichten ihr Hausfrauen-Konsum-Glück und die unterwürfigen Anderen rahmten den sozialen Aufstieg in die weiße Mittelschicht mit kolonialen Herrschaftsfantasien. Die Einschreibung des Schweizer Haushaltskults in eine imperiale Weltsicht erweist sich damit als bestimmendes Element eines Dispositivs, mit dem Frauen in der Schweiz seit Beginn des 20. Jahrhunderts an die häuslichen Tätigkeiten gebunden und auf sie reduziert wurden.

Allgemein innereuropäische und spezifisch schweizerische Konstruktionsprozesse haben sich dabei überschnitten und gegenseitig bedingt. Während die deutsche Firma Khasana oder das schwedische Unternehmen Electrolux Kolonialwerbung in die Schweiz brachten, entwickelten Schweizer Firmen wie Tobler oder Lindt koloniale Reklamen, die mit hoher Wahrscheinlichkeit auch im Ausland zirkulierten. Populäre Formen des Rassismus, die sich mit McClintock als Warenrassismus beschreiben lassen, spielten damit eine bedeutsame Rolle für die Entstehung und Durchsetzung neuer Geschlechterarrangements in der Schweiz des 20. Jahrhunderts - ein Aspekt, der sich erst mit einer postkolonialen Perspektive erschließen lässt und in der Forschung bislang gänzlich unberücksichtigt geblieben war.

Im zweiten Teil meiner Arbeit setze ich mich mit der Bedeutung heroischer Männlichkeitsbilder für die Herausbildung von Schweizer Identitätsvorstellungen auseinander. Ausgangspunkt ist die Einsicht der Geschlechterforschung, dass nationale Identitätskonzepte auf eine asymmetrische Weise vergeschlechtlicht werden: Männliche Figuren repräsentieren den konkreten Bürger, Frauen den abstrakten Staat. ${ }^{5}$ Politische Handlungsmacht wird auf diese Weise an männliche Körper gebunden, während Frauen diese Macht zwar legitimieren oder unterstützen, nie aber verkörpern können: Sie sind die verletzbaren Subjekte, die von männlichen Soldaten beschützt werden müssen oder die tatkräftige

5 | Sharp 1996, 99. 
Frau an der Seite des Helden. ${ }^{6}$ In meiner Arbeit fokussiere ich auf eine Figur des Bürgers, der mit der Entstehung des Nationalstaates als idealer Schweizer erfunden wird: auf den Bergsteiger und Bergführer. Zur Frage, wie Alpinisten seit dem späten 19. Jahrhunderts in der Schweiz eingesetzt wurden, um die Nation zu repräsentieren und ihr gleichzeitig ein Gesicht zu verleihen, liegen einschlägige Untersuchungen vor. Doch auch an dieser Stelle fehlt die Auseinandersetzung mit der Schweiz als Bestandteil eines imperialen Raumes.

Meine Untersuchungen zum außer-europäischen Bergsteigen der 1950er Jahre nehmen als Ausgangspunkt die erstaunliche Tatsache, dass Schweizer Bergsteiger im Wettrennen um die Erstbesteigung der höchsten Gipfel der Welt eine führende Position einnahmen. In einer im Zeitalter der Dekolonisation anachronistischen Inszenierung wurde der Himalaya zur imperialen Bühne erklärt, auf der die Entdeckung von unbekannten, gefährlichen und wilden Territorien noch einmal durchgespielt werden konnte. Bergsteigernarrative konstruierten aber nicht nur Bilder einer heroischen weißen Männlichkeit, sondern ermöglichten auch deren Umdeutung. ${ }^{7}$ Die Re-Interpretation von Männlichkeit, Rassifizierung und Nation wurde in den 1950er Jahren vordringlich, weil sich in dieser Zeit der Übergang von einem kolonialen zu einem nachkolonialen Zeitalter abzeichnete. Mit der Transformation der ehemaligen Kolonien in moderne und zumindest formal souveräne Staatsgebilde galt es, die Verbindungen zwischen >fortschrittlichen $<$ und >rückständigen $<$ Gebieten neu zu konfigurieren. Koloniale Hierarchien zwischen weißen und nicht-weißen Männern mussten umgedeutet und neu kalibriert werden - ein Prozess, der sich in den Bergsteigerberichten niederschlug und zu dem diese ihrerseits beitrugen. Die Schweiz als Land, das sich sowohl geografisch als auch ökonomisch im Zentrum der europäischen Metropole befand und dennoch keine formale Kolonialmacht war, eignete sich, um die neue Ikonografie einer >paternalistischen Partnerschaft $<\mathrm{zu}$ bedienen. Aus queerer Perspektive ist bemerkenswert, dass die Darstellungen

6 | Vgl. Kreis 2012a sowie Joris und Witzig 1986, 74f. Schließlich wurden Frauen als Gebärende symbolisch mit der Reproduktion der Nation in Verbindung gebracht, ohne selbst politische Handlungsmacht verkörpern zu können: "As mothers of the nation, they are precariously other to the nation ", hält Marie-Luise Pratt fest (Pratt 1990, 51). Vgl. auch McClintock 1993, 62 und Schutzbach 2014, 78 f. 7 | Frohlick 1999, 83. 
einer neuen, >rassenüberschreitenden Nähe und Intimität zwischen zwei Männern Anleihen bei einem Liebesdiskurs nahmen, während diese weiterhin als idealisierte Vertreter von (heteronormativ kodierten) Nationen erscheinen konnten. ${ }^{8}$

Die Inszenierung von Schweizer Bergsteigern als >gute Sahibs< beruhte auf einer langen Geschichte des Othering und wirkt, wie ich gezeigt habe, bis in die aktuelle Forschungsliteratur hinein. Die Entstehung des modernen Alpinismus in der Schweiz Mitte des 19. Jahrhunderts eröffnete ein komplexes und kolonial kodiertes Wechselspiel zwischen einem ländlichen, einfachen und naturverbundenen Leben in den Bergen und dem Anspruch einer europäischen Elite, das Bergsteigen als Realisierung einer bürgerlichen Männlichkeit zu praktizieren. Dabei wussten sich bürgerliche Männer in der Schweiz geschickt zwischen differenten Identifikationsmomenten in diesem >Berg-Othering $\mathrm{zu}$ bewegen. Koloniale Unterschiede wurden auf diese Weise strukturell in das Spiel von Gleichheit, Ähnlichkeit und Differenz eingebunden, das für die Herausbildung von Imaginationen der Schweiz im westlichen und globalen Kontext, aber auch für die Aushandlung von Binnendifferenzen entlang von Klasse, Milieu, Konfession, Region und Geschlecht innerhalb des Landes entscheidend war.

\section{DaS ihyperreale Europar Und die SchweIz}

Meine Untersuchung greift ein interdisziplinäres Forschungsverständnis auf, das die Schweiz nicht nur in Europa, sondern in einer globalisierten Welt zu verorten sucht. ${ }^{9}$ Das Land erweist sich als Beispiel für einen »Kolonialismus ohne Kolonien « ${ }^{10}$, weil ihm ohne Kolonien zwar ein herausragendes Zeichen europäischer Macht fehlte, seine Zugehörigkeit zur westeuropäischen Metropole aber dennoch nie infrage gestellt war.

8 | Während bis vor Kurzem heterosexuelle Arrangements und die Verwerfung von Homosexualität grundlegend für das Verständnis von Staatlichkeit waren, unterliegen die Ein- und Ausschlüsse entlang der Strukturkategorie Sexualität in jüngster Zeit starken Veränderungen. Vgl. Bargetz und Ludwig 2015 und für die Schweiz Mesquita 2011.

9 | Vgl. Schär 2016a.

10 | Purtschert, Falk und Lüthi 2015. 
In Übereinstimmung mit Susanne Zantops Befund für das vorkoloniale Deutschland kann festgehalten werden, dass nicht imperiale Feldzüge, sondern vielmehr »koloniale Fantasien «" ${ }^{11}$ für das Schweizer Selbstverständnis zentral waren. So räumt ein Artikel der Zeitschrift L'Afrique explorée et civilisée von 1883 bereitwillig ein, dass die Schweiz - anders als Portugal, England, Frankreich, Deutschland, Italien und Belgien - keinen bedeutsamen Beitrag zum >afrikanischen Werk leiste. Auch neben den Namen großer europäischer Entdecker würden diejenigen der Schweizer verblassen. Und weiter:

"Cependant, le ciel étoilé ne nous présente pas seulement des astres de première grandeur, et, quelque modeste que soit notre place dans le champ de l'exploration et de la civilisation de l'Afrique, il est intéressant de voir combien un peuple petit comme le nôtre, sans colonies sur la côte d'Afrique [...] a pu fournir de voyageurs et de missionnaires, pour concourir à la découverte de ce continent et au relèvement intellectuel et moral de ses habitants. ${ }^{12}$

Die Haltung, die diese Passage zum Ausdruck bringt, ist exemplarisch für das Schweizer Selbstverständnis in der Kolonialzeit: Bescheidenheit und Demut gegenüber den kolonialen Mächten verbindet sich mit unverhohlener Bewunderung für die imperiale Kultur. Sie gründet auf der Prämisse, dass die Schweiz Teil des kolonialen Projekts ist und, gemessen an ihrer Größe, eben doch einen substanziellen Beitrag dazu leistet. Ohne Frage wird die Schweiz in diesen Zeilen als Bestandteil der Metropole imaginiert. Dass die Schweiz zugleich ein intrinsisches Element von und eine exklusive Besonderheit des europäischen Projekts darstellt, eröffnet ein Spannungsverhältnis, das man mit Kristín Loftsdóttir und Lars Jensen als >colonial exceptionalism ${ }^{13}$ beschreiben kann. Eine solche Verortung der Schweiz in einer globalisierten - und das heißt imperialen - Welt hat zur Folge, dass die Diskussion um den >Sonderfall Schweiz ${ }^{14}$

11 Zantop 1997, 7.

12 | O.V., "La part des Suisses dans l'exploration et la civilisation de l'Afrique ", in: L'Afrique explorée et civilisée 1883, $215 f$.

13 | Loftsdóttir und Jensen 2012.

14 | Vgl. dazu Kreis 2012b. 
aus einer postkolonialen Perspektive neu aufgerollt werden muss. ${ }^{15}$ Wo kann ein solches Unterfangen ansetzen?

Dipesh Chakrabarty sieht moderne Nationalstaaten in ein Metanarrativ eingebettet, in dessen Zentrum sich stets Europa befindet, »a hyperreal >Europe <, a Europe constructed by the tales that both imperialism and nationalism have told the colonized ${ }^{16}$. Für die Geschichtsschreibung in Indien, die Gegenstand von Chakrabartys Erörterungen ist, resultiert daraus, dass Selbstrepräsentationen der indischen Nation mimetisch Europa verhaftet bleiben. Indem Europa gleichzeitig als historisches Beispiel und universeller Maßstab für die Herausbildung moderner Nationen fungiert, bleibt auch die kritischste Geschichtsschreibung von der Differenz zu Europa gezeichnet: Die Geschichte Indiens erscheint als Nachahmung Europas oder dokumentiert ein an Europa gemessenes Scheitern. Für die Ausgangslage von Historiker*innen in nicht-westlichen Staaten hält Chakrabarty grundlegende Einsichten bereit: Seine Analyse legt die eurozentrischen Parameter offen, die dazu führen, dass sich nicht-westliche Nationen gleichsam in einem »imaginary waiting room of history « ${ }^{17}$ vorfinden. Das shyperreale Europa< verweist dabei auf eine phantasmatische Dimension, in der Europa als Inbegriff von Moderne und Fortschritt erscheint. Der Begriff beschreibe, so Chakrabarty, »something like an imaginary entity that has some relation to the real but is also at the same time phantasmal and that, as I said, is part of everyday representations in a place like India ${ }^{18}$.

Mit Blick auf die postkoloniale Schweiz lässt sich daran die Frage anschließen, wie das hyperreale Europa innerhalb Europas als phantasmatischer Bezugsrahmen funktioniert. Obwohl Europa als Verkörperung von Fortschritt, Gleichheit und Demokratie gilt, geht diese Vorstellung auf komplexe Konstruktionsprozesse zurück, die beständig bestätigt und aufrechterhalten werden müssen, die von innen und außen angreifbar sind und zahlreiche Krisenmomente, Widersprüchlichkeiten und Gegenläufigkeiten aufweisen. Denn auch innerhalb eines europäischen Kontextes musste und muss die imaginäre Zugehörigkeit zu einem >hyperrealen Europa< kontinuierlich hervorgebracht werden. Dabei werden nicht nur

15 | Vgl. dazu Jain 2012, $187 \mathrm{ff}$.

16 | Chakrabarty 2002, 40.

17 | Chakrabarty 2002, 8.

18 | Chakrabarty 2008, 86. 
interne Andere wie Jenische, Sinti und Roma, Jüd*innen, die Sámi im Norden oder die irische Bevölkerung in Großbritannien hervorgebracht, die das Vormoderne, das Ahistorische oder das Fremde innerhalb eines Staates repräsentieren - Europa bleibt auch >hyperreal für jene Nationen, die angeblich das Zentrum Europas darstellen.

\section{FÜR EIN POST-MONOLITHISCHES VERSTÄNDNIS DES KOLONIALISMUS}

Diese Einsicht ist der Ausgangspunkt der transnationalen Studien von Kris Manjapra, mit denen er gegen eine monolithische Vorstellung von Europa anschreibt, die in der Globalgeschichte noch immer vorherrschend sei. ${ }^{19}$ Die Geschichte Deutschlands zeige, so Manjapra, dass es möglich war, eine europäische Kolonialmacht zu sein und sich dennoch für klein und minderwertig zu halten. ${ }^{20} \mathrm{Zu}$ Beginn des 19. Jahrhunderts wurden Bewohner*innen deutscher Staaten in den britischen ökonomischen Diskursen zudem oft als rückständig beschrieben: »Germans, in the early to mid-nineteenth century, were placed into the category of the Other by some western European thinkers. ${ }^{21}$ Eine Geschichtsschreibung, die diesen internen Marginalisierungen und Selbst-Marginalisierungen keine Beachtung schenke, übersehe »the internal fractures and asynchronies that defined state forms, sovereignties and political aspirations across the European continent ${ }^{22}$. Wenn nun Deutschland als >kleine Kolonialmacht ein ergiebiges Fallbeispiel für die Dekonstruktion des $>$ mythischen Bildes $<^{23}$ von Europa darstellt, eignen sich westeuropäische Staaten ohne Kolonien erst recht, um solche innereuropäischen Friktionen zu bestimmen.

So macht Kristín Loftsdóttir in der isländischen Nationalstaatsbildung ein ängstliches Bemühen aus, zur modernen Welt zu gehören und sich als weiße und zivilisierte Nation zu positionieren. ${ }^{24}$ Islands Kämpfe um

19 | Manjapra 2014b, 274ff.

20 | Manjapra 2014b, 285.

21 | Manjapra 2014b, 284.

22 | Manjapra 2014b, 286.

23 | Manjapra 2014b, 278.

24 | Loftsdóttir 2011, 18. 
eine europäische Zugehörigkeit waren, wie Loftsdóttir ausführt, einerseits durch die Vergangenheit als dänisches Schutzgebiet geprägt und andererseits durch die Wahrnehmung Islands als periphere Region, in der die Menschen von Armut gezeichnet waren und als Halbwilde galten. ${ }^{25}$ Anhand einer Analyse von Schulbüchern aus dem frühen 20. Jahrhundert zeigt die Autorin, wie die isländische Geschichte trotz dieser Ausgangslage so umgeschrieben wurde, dass sie sich in eine europäische Eroberungsgeschichte einfügte: »Textbooks on world history [...] locate Icelanders within stories of European explorers and subjectification of people in remote parts of the world. Icelanders are not represented as a subjected country, but more inserted in the collective and masculine >we<, which is modernising the world. ${ }^{26}$ Loftsdóttirs Analyse macht deutlich, dass die Zugehörigkeit zur Moderne Ende des 19. Jahrhunderts mit viel Aufwand hergestellt werden musste und dass den Bildern einer weißen kolonialen Männlichkeit in diesem Prozess eine zentrale Bedeutung zukam. Sie repräsentierten das Erobern, Entdecken, Unterwerfen und Regieren, das mit einem >hyperrealen Europa < verbunden war, und sollten so die Zeichen der eigenen Unterwerfung und Marginalisierung innerhalb Europas tilgen.

Meine Ergebnisse zur Schweiz stützen eine solche Analyse und ergänzen sie mit weiteren Einsichten. Die partielle Identifikation mit einer >primitiven Schweiz`war demnach für die bürgerliche Elite nicht nur nachteilig. Das >Berg-Othering< ermöglichte eine Selbst-Exotisierung der Schweiz und ihrer Bewohner*innen, die es dem Bürgertum erlaubte, sich je nach Bedarf mit einer >natürlichen < Lebensweise zu identifizieren, sich vom dekadenten Stil der Kolonialherren abzusetzen oder eine größere Nähe zu kolonialen Subjekten zu behaupten. Gerade während der Dekolonisation konnte Letzteres vorteilhaft eingesetzt werden: Schweizer, die angeblich frei waren von kolonialen Reminiszenzen und Attitüden, entwarfen sich als ideale Kooperationspartner der ehemaligen Kolonien.

Daraus lassen sich zwei zentrale Erkenntnisse gewinnen: Erstens wird deutlich, dass die Einbettung der Schweiz in einen imperialen Raum konstitutiv für das Verständnis dieses Landes ist. Entgegen der verbreiteten Annahme, Kolonialgeschichte könne entweder ganz vergessen oder als Randbemerkung abgehandelt werden, zeigt meine Forschung, dass sich Schweizer Geschichte mit Gewinn als Kolonialgeschichte betreiben

25 | Loftsdóttir 2011, 16; Loftsdóttir 2012, 600.

26 | Loftsdóttir 2012, 601. 
lässt und umgekehrt. ${ }^{27}$ Dieser Perspektivenwechsel hat zur Folge, dass die Schweiz als Teil einer (post-)kolonialen Weltordnung verstanden werden muss. Entgegen der bisherigen Praxis können Effekte und Nachwirkungen des Kolonialismus damit nicht mehr vom Standpunkt eines unbeteiligten Dritten aus betrachtet, sondern müssen aus einer Position des Involviertseins, der Betroffenheit und Verantwortung wahrgenommen werden. Zweitens macht meine Auseinandersetzung mit der Schweiz andere Modi kolonialer Macht denk- und sichtbar. Dies zeitigt Rückwirkungen auf die postkoloniale Forschung: Europa soll nicht nur »provinzialisiert ${ }^{28}$, sondern in den Worten von Bernhard Schär auch »pluralisiert « ${ }^{29}$ und dekonstruiert werden. Die spezifische Kolonialität, die sich im Schweizer Kontext herausbildete, beruht auf einer Funktionsweise kolonialer Macht, deren Kenntnisse grundlegend für ein post-monolithisches Verständnis des Kolonialismus sind. Dazu gehört die Distanzierung von der direkten politischen Macht durch Formen der indirekten Herrschaft. Nach dem kolonialen Zeitalter wurde Letztere durch ökonomische Abhängigkeiten, internationale Strukturanpassungsprogramme, Entwicklungshilfe sowie die fortgesetzte westliche Hegemonie im Bereich des Wissens, der Bildung und Kultur global etabliert. Das Studium eines »Colonialism on the Margins « ${ }^{30}$, der sich in der Schweiz exemplarisch zeigt, hilft die Entstehung, Wirkungsweise und Geschichte dieser Variation kolonialer Macht zu verstehen, und sie, wie Shalini Randeria vorschlägt, als Vorläufer heutiger neokolonialer Konstellationen zu begreifen. ${ }^{31}$ Die Auseinandersetzung mit der Schweiz dient damit auch der »Erkenntnis der Gegenwart, nämlich des heutigen Imperialismus ohne formalen Kolonialbesitz « ${ }^{32}$. Dazu gehört nicht zuletzt die Entwicklung wirkungsvoller diskursiver Strategien wie diejenige der >kolonialen Unschuld<, welche im nachkolonialen Zeitalter in vielen europäischen Kontexten aufgegriffen wurde. ${ }^{33}$

27 | Vgl. dazu auch Minder 2011; Zangger 2011; Purtschert, Lüthi und Falk 2012a; Schär 2015a; Purtschert und Fischer-Tiné 2015a.

28 | Vgl. Chakrabarty 2002.

29 | Schär 2015a, 329ff.

30 | Vgl. Purtschert und Fischer-Tiné 2015a.

31 | Vgl. dazu Randeria 2012.

32 | Randeria 2012, 11.

33 | Vgl. Wekker 2016. 


\section{WEITERFÜHRENDE ÜBERLEGUNGEN ZUR SCHWEIZER GeSChICHTE}

Schließlich möchte ich Schlaglichter auf zwei Aspekte werfen, die meines Erachtens für die weitere Forschung entscheidend sind. Der eine betrifft aktuelle Transformationen globaler Machtverhältnisse, der andere die Notwendigkeit, die nicht-weiße(n) Geschichte(n) der Schweiz zu rekonstruieren. Beide lassen sich in den >Vignetten < finden, die meine Kapitel eröffnet haben. Diese Verweise auf gegenwärtige Diskussionen zeigen, wie sehr die versprengten Spuren des Kolonialismus unsere aktuelle postkoloniale Gesellschaft kennzeichnen. ${ }^{34}$ Dies zeigt sich am Beispiel der Waschmittelwerbung, dessen >Pointe $<$ - das Weißwaschen eines nichtweißen Lebewesens - nur vor dem Hintergrund einer kolonialen Geschichte verstanden werden kann. Auch die Schweizer Berichterstattung zum Konflikt am Mount Everest, der sich 2013 zwischen nepalesischen Sherpas und westeuropäischen Extrembergsteigern entfacht hatte, macht ersichtlich, wie selbstverständlich in der Gegenwart koloniale Stereotype mobilisiert werden: Die Sherpas werden als >rückständige Schweizer< dargestellt oder als aggressiver und unkontrollierter >Mob<.

Über solche koloniale Kontinuitäten hinaus zeichnen sich aber auch neue diskursive Konstellationen ab: Dass sich der Protest gegen die Werbung für das Waschmittel >Total so schnell formierte, dass er sich auf Social-Media-Kanälen verbreiten konnte, dass anti-rassistische Kritiker*innen in verschiedenen Medien zu Wort kamen und vom verantwortlichen Großverteiler Migros zu einem Gespräch eingeladen wurden, weist darauf hin, dass die Frage des Rassismus gestellt wird und nicht einfach ungehört verhallt. Die Geschichte um das Waschmittel >Total macht die Präsenz und Agilität anti-rassistischer und insbesondere Schwarzer politischer Bewegungen wie etwa des CRAN sichtbar, sie zeigt aber auch, wie einfach Leitmedien wie die Neue Zürcher Zeitung oder führende Firmen wie Migros die wirklich schwierigen Fragen unter Berufung auf die koloniale Amnesie wieder fallenlassen können. Ähnliche Überlegungen schließen sich an die zweite Vignette an: So lässt sich die weiße Männlichkeit, die Ueli Steck repräsentierte, nicht ohne Weiteres mit den Kategorien der 1950 er Jahre fassen. Der Diskurs der Krise, in dem seine Erfahrungen dargestellt wurden, ist ein anderer als vor 60 Jahren: Stecks

34 | Vgl. dazu Stoler 2008. 
Tränen, Ängste und Alpträume wurden nicht in der Todeszone am Himalaya verortet, sondern in seinem Chalet im Berner Oberland, wo er sich im Gespräch mit Journalist*innen traf. ${ }^{35}$ Auch die Darstellung der amerikanischen Bergsteigerin Melissa Arnot weist auf solche Transformationen hin: Während der Topos der Sherpas, die vor der Macht einer weißen Memsahib parieren, einem kolonialen Drehbuch entstammen könnte, verweist die Vorstellung einer >weißen Frau, die weiße Männer vor braunen Männern rettet ${ }^{36}$ auf neuartige Konfigurationen von Geschlecht und Rassifizierung in der Gegenwart. Diese Transformationen sind in einen größeren Kontext eingebettet, in dem sich Machtverhältnisse global und lokal verschieben.

In seiner Arbeit zu Schweizer Repräsentationen von Indien zeichnet Rohit Jain solche Veränderungen detailliert nach, indem er zeigt, wie sich diese seit den 1990er Jahren, als das Land zunehmend zu einer ökonomischen Großmacht avancierte, gewandelt haben. In der Schweiz sei Indien zuvor entweder als armes und entwicklungsbedürftiges Land oder als mystisch verklärtes spirituelles Gegenmodell zur europäischen Moderne wahrgenommen worden. ${ }^{37}$ Nach der Marktöffnung des Subkontinents in den 1990er Jahren änderte sich diese Wahrnehmung. »Um Bollywood, indischen IT-Kapitalismus, Armut und Spiritualität arrangierte sich nun ein neuer Indiendiskurs «, stellt Jain fest. ${ }^{38}$ Bollywood, die Hindi-Filmindustrie mit Sitz in Mumbai, versinnbildlicht exemplarisch den Wandel des Repräsentationsregimes, der damit einherging: Nicht nur machten die Filme ein Indien sichtbar, das >traditionelle < und >moderne< Elemente im Kontext eines kapitalistischen Kosmopolitismus auf selbstverständliche Weise kombinieren konnte. Aus Schweizer Sicht war besonders von Belang, dass viele Bollywood-Streifen in den Alpen gedreht wurden und die Schweiz damit zu einem exotischen Setting für ein südasiatisches und globales Publikum mutierte. ${ }^{39}$

35 | Zur Transformation weißer Schweizer Männlichkeit im postkolonialen Bergsteigen vgl. auch meine Überlegungen in Purtschert 2015b.

36 | In Abwandlung des berühmten Diktums von Gayatri Spivak, vgl. Spivak 2008, 81 sowie meine Ausführungen in der Vignette, die dem zweiten Kapitel vorangestellt ist.

37 | Jain 2015, 138.

38 | Jain 2018, 176.

39 | Jain 2015, 140. 
Bollywoods verklärter Blick auf die Alpen löste einen Boom des indischen Tourismus in die Bergregionen der Schweiz aus. Das führte in einer ersten Phase zu Spannungen mit Unternehmen und Angestellten der Touristikbranche vor Ort, die sich über die >Respektlosigkeit< der indischen Gäste und über deren fehlendes Interesse an der Schweizer Kultur beschwerten. »However, as the unexpected Indian middle-class tourism secured the economic well-being of the region, politicians and tour operators began coaching employees and tourists to react sensitively to socalled >intercultural problems $<.{ }^{40}$ Schweizer mussten sich, so Jain, aus Geschäftsgründen an den >provinzialisierenden Blick der indischen Gäste gewöhnen, die in der Schweizer Bergwelt in vielen Fällen tatsächlich nichts anderes als die Bollywood-Kulisse sehen wollten. Diese Entwicklung eröffnete eine neue Phase des >Berg-Othering< in einem postkolonialen Kontext von sich wandelnden Macht- und Projektionsverhältnissen. Die Präsenz selbstbewusster und vermögender indischer Tourist*innen sowie einer wirkmächtigen indischen Populärkultur mit globaler Ausstrahlung stellt die Prämisse einer weißen Schweizer Überlegenheit infrage. Diese führt nicht zuletzt zur Ausbildung einer neuen »postkolonialen Ängstlichkeit« (»postcolonial anxiety«) $)^{41}$.

Jains Ausführungen sind zentral für eine postkoloniale Analyse der Schweizer Gegenwart. Wie er betont, werden rassistische Strukturen durch die aktuellen Transformationen globaler Machtverhältnisse nicht beseitigt, aber umgedeutet und neu konfiguriert. Mit anderen Worten: Rassistische Bilder von Schwarzen Männern verschwinden nicht durch Barack Obamas Präsidentschaft, aber ein Schwarzer Präsident der USA öffnet neue Aushandlungsmöglichkeiten für die Frage, wie Geschlecht, Rassifizierung und Macht miteinander verbunden sind und welche Handlungsräume sich dadurch für unterschiedlich rassifizierte (inklusive weiße) Subjekte ergeben. Bezogen auf die Schweiz heißt das: Wenn das Schicksal eines Bergtals im Kanton Uri vom ägyptischen Investor Samih Sawiris abhängt oder die zweitgrößte Schweizer Bank, die Credit Suisse, vom ivorischen Konzernleiter Tidjane Thiam repräsentiert wird, dann ändert sich auch die Art und Weise, wie Repräsentationen der Schweiz mit Weißsein und postkolonialem Othering verbunden werden.

40 | Jain 2015, 143.

41 | Jain 2015, 143. 
Der zweite Punkt, der von Bedeutung ist, betrifft die Rekonstruktion von Geschichten, die die weiße Hegemonie anfechten und aufbrechen. Auch darauf nehmen die Vignetten zu Beginn der Kapitel Bezug: So eröffnen die Aussagen von Tashi Sherpa eine alternative Sicht auf die Geschehnisse am Everest 2013. Die konzertierten Widerstandsaktionen gegen die Waschmittelwerbung der Migros 2014 wiederum zeigen, dass der Warenrassismus in der Schweiz nicht nur existiert, sondern immer auch auf Widerspruch stößt. Diese Gegenstimmen verweisen auf eine bedeutungsvolle Grenze einer Untersuchung wie der vorliegenden, die vorwiegend hegemoniale Artikulationen des Othering aufarbeitet. Rey Chow spricht in diesem Zusammenhang von der Gefahr, dominantes imperiales Wissen durch seine Kritik zu reproduzieren: »Insofar as it offers a means of showing the structural inevitability of >othering in all acts of domination, deconstructive criticism has collaborated with anti-imperialism in the most abstract sense. But it is not enough to know this inevitability structurally, for that remains, precisely, >knowledge from within the dominating stance. ${ }^{42}$ Obwohl es, wie Chow schreibt, kein Außen zum postkolonialen Wissen gibt, gilt es immer auch, dessen Ränder und Bruchstellen aufzusuchen und mögliche Gegendiskurse sichtbar zu machen.

Im Kontext der Schweiz wurden in den letzten Jahren wegweisende Arbeiten zu einer Schweizer Geschichte aus nicht-weißer Perspektive verfasst. So zeichnet Fischer-Tiné ein bislang unbekanntes Bild der Schweiz als Drehscheibe für anti-koloniale Aktivitäten. Anhand der Geschichte von Shyamji Krishnavarma, einem führenden anti-imperialen indischen Aktivisten, der die letzte Phase seines Lebens in den Jahren von 1914 bis 1930 in Genf verbracht hatte, gelingt es Fischer-Tiné, ein in der Schweiz lokalisiertes Netzwerk von Akteur*innen zu beleuchten, das Bestandteil einer globalen »anti-imperialen Ökumene « ${ }^{43}$ war. Der Autor kommt zum Schluss, »that representatives of three fringe groups had a particular inclination to cooperate [in anti-imperial activities]: socialists of various ideological orientations, >progressive $<$ women and the circles that could be dubbed >marginal<, >esoteric $<$ or völkisch Orientalists « ${ }^{44}$. Diese Einsicht eröffnet eine Reihe bedeutsamer neuer Forschungsfragen: Inwiefern en-

42 | Chow 1989, 160 f.

43 | Fischer-Tiné 2015, 243. Vgl. dazu auch Fischer-Tiné 2014.

44 | Fischer-Tiné 2015, 243 [Hervorhebung im Original]. 
gagierten sich Bewegungen mit einem emanzipatorischen Anspruch, also sozialistische, gewerkschaftliche, linke, kommunistische und andere Zusammenschlüsse, in der Schweiz für anti-imperialistische Kämpfe oder warum taten sie das nicht? Welche Netzwerke formierten sich dabei und welche Rolle spielte die Schweiz für transnationale anti-koloniale Befreiungsbewegungen?

Aus einer feministischen Perspektive interessieren insbesondere die Zusammenhänge zwischen Frauenrechtsbewegungen und anti-kolonialen Aktivitäten, die Fischer-Tinés Aufsatz ebenfalls belegt. ${ }^{45}$ In einer solchen Geschichtsschreibung, die die Schweiz als Ort anti-kolonialen Widerstands versteht, rücken in den Worten von Leela Gandhi auch »affective communities ${ }^{46}$ in den Horizont des Denkbaren, in denen anti-koloniale Kämpfer*innen mit Akteur*innen anderer Emanzipationsbewegungen gemeinsame Sache machten. Während Gandhi in der Freundschaft von anti-imperialen und queeren Subjekten ein Paradebeispiel für solche subversiven Zusammenschlüsse sieht, erinnert Schärs Tropenliebe allerdings daran, dass die Erfahrung der Marginalisierung keineswegs zur Solidarität mit anderen, namentlich anti-kolonialen Freiheitskämpfen führen muss: Die beiden Vettern Paul und Fritz Sarasin nutzten die Tropen im Fin de Siècle als entrückten Raum, in dem sie ihre illegitime Liebesbeziehung fernab von der Kontrolle durch das Basler Bürgertums leben und sich gleichzeitig an der imperialen Expeditionspraxis und der kolonialen Wissensproduktion beteiligen konnten. ${ }^{47}$ Schärs Befund erinnert daran, dass marginalisierte weiße Subjekte in Europa nicht zwingend anti-imperiale und intersektionale Koalitionen bildeten, sondern ebenso gut Herrschaftsbündnisse mit imperialen Machthabern eingehen konnten.

Shyamji Krishnavarmas Jahre in Genf und seine Tätigkeiten als Verleger, Autor und vor allem als gut vernetzter anti-imperialer Aktivist in der Schweiz des frühen 20. Jahrhunderts konstituieren eine Gegengeschichte zum gut dokumentierten Überfremdungsdiskurs und den harschen neuen Fremdengesetzgebungen, die in jener Zeit eingeführt wurden. Seine Geschichte zeigt, wie ein Einwanderer of color es verstand, sich das Schweizer Selbstverständnis anzueignen und für seine Zwecke dienstbar zu machen: »Swiss self-representations as an enclave of neutrality and

45 | Vgl. Fischer-Tiné 2015, 234ff.

46 | Gandhi 2006; vgl. Fischer-Tiné 2015, 221.

47 | Vgl. Schär 2015a. 
humanitarianism in the midst of Europe could be effectively utilized by members of the radical diaspora to suit their own designs and ends. « ${ }^{48}$ Dieser subversive Umgang mit den Schweizer Gegebenheiten führt exemplarisch vor Augen, wie wichtig es ist, die Geschichte von People of Color als inhärenten Bestandteil der Schweizergeschichte zu erforschen.

Allerdings ist Krishnavarma, der ein fleißiger Schreiber war und sich dank seines beachtlichen Vermögens die entsprechenden Kanäle für seine Publikationen sichern konnte, eine glückliche Ausnahme für eine solche alternative Geschichtsschreibung. In vielen Fällen ist die Quellenlage für eine Historiografie von People of Color in der Schweiz nämlich dünn oder sogar desolat. Wichtige Impulse für dafür, wie ein solche Forschung dennoch möglich wird, liefern Pintos Spurensuche für eine Geschichte Schwarzer Frauen in der Schweiz, Jains Arbeit zu den transnationalen Subjektivierungsprozessen von Inder*innen der zweiten Generation oder Michels ausführliche Dokumentation des Schwarzen Widerstands gegen die rassistische politische >Schäfchenkampagne< der letzten Jahre. ${ }^{49}$ Diese Arbeiten zeigen auf, wie die vorherrschende koloniale Amnesie durchbrochen werden kann, sei es, indem diskursive Lücken und Leerstellen aufgefunden und interpretiert, unorthodoxe Quellen beispielsweise über Oral History Forschung erschlossen oder bestehende Quellen, welche die Präsenz von People of Color in der Schweiz bezeugen, unter dieser Fragestellung neu gelesen werden.

Eine eindrückliche Re-Lektüre eines solchen Dokuments hat kürzlich Jovita dos Santos Pinto vorgelegt. Dabei gelingt es ihr, und das führt zu meiner abschließenden Beobachtung, das transformatorische Potenzial postkolonial-feministischer Ansätze für die Schweizer Geschichte vor Augen zu führen. Pinto wendet sich dafür der Biografie von Pauline Buisson $\mathrm{zu}$, die bereits in dem Buch Schwarze Geschäfte Erwähnung fand. ${ }^{50}$ Buisson, 1770 in der französischen Kolonie Saint-Domingue geboren, kam als sechsjähriges versklavtes Kind gemeinsam mit dem ebenfalls versklavten François Mida in die Schweiz. ${ }^{51}$ Ihr >Besitzer< war der Schweizer Handelsmann David-Philippe de Treytorrens, der durch koloniale Handelsgeschäfte zu großem Reichtum gekommen war. Buisson arbeitete fortan in Yverdon

48 | Fischer-Tiné 2015, 243.

49 | Vgl. Pinto 2013; Michel 2015; Jain 2018.

50 | Vgl. David, Etemad und Schaufelbuehl 2005.

51 | Die Rekonstruktion der Geschichte von Buisson basiert auf Pinto 2018. 
im Hause der Familie de Treytorrens, wo sie auch die Bekanntschaft des Rassenforschers Johann Friedrich Blumenbach machte und daraufhin in mehreren seiner Untersuchungen genannt wurde. Neben diesen Passagen wissen wir von Pauline Buisson wegen eines Disputs um die Frage, ob ihr Sohn Bürger von Yverdon werden kann oder nicht. Diese Angelegenheit führte zu einem jahrelangen Rechtsstreit zwischen der Familie de Treytorrens, die mit der Einbürgerung ihre Verantwortung für den jungen Samuel Hippolyte Buisson loswerden wollte, und den Behörden in Yverdon, Bern und Lausanne, die sich weigerten, die Einbürgerung zu vollziehen. Der Streit fand mit dem Tod des staatenlos gebliebenen Samuel Buissons in den frühen 183oer Jahren ein Ende. Pintos akribische Rekonstruktion des Falles wirft zahlreiche Fragen auf, von denen ich an dieser Stelle nur eine aufgreifen möchte: Der Fall um Pauline Buisson und ihren Sohn Samuel ist im Kern ein Streit um die Frage der Sklaverei und den Besitz von Menschen im Kontext der Schweiz. ${ }^{52}$ Pinto schreibt dazu: »Dass die versklavten Menschen in der Schweiz waren und eben nicht bloß auf entfernten Plantagenkolonien in Übersee und ihr Status [...] vor Ort dem Schweizer Liberalismus gegenübergestellt wurde, führt uns ins Zentrum postkolonialer Argumente, nämlich, dass für eine Reflexion über den modernen Liberalismus auch eine Auseinandersetzung mit der zeitgleichen Sklaverei stattfinden muss - vor Ort und in mehr als nur abstrakter Form. $\ll^{53}$

Diese Beobachtung birgt das Potenzial, das bisherige Bild der Schweizer Geschichte nachhaltig zu erschüttern. Dass die transatlantische Sklaverei für die Geschichte Brasiliens, Liberias, Ghanas, Nigerias, Haitis, Kubas oder auch der USA eine bedeutsame Rolle spielt, mag allgemein bekannt sein. Dass aber auch die Geschichte der Schweiz vor dem Hintergrund ihres Verhältnisses zur Sklaverei gedeutet werden muss, kommt einer unerhörten Einsicht gleich. Bedeutsam ist dabei insbesondere Pintos Forderung, die Auseinandersetzung mit der Sklaverei in der Schweizer Geschichte »vor Ort und in mehr als abstrakter Form« zu führen.

52 Dabei bedienen sich die weißen Akteur*innen nicht selten aus strategischen Gründen der Argumente der Gegenseite. So argumentierte die Familie de Treytorrens, deren Mitglied David-Philippe in Saint-Domingue Sklavenhalter war und der zwei versklavte Menschen in die Schweiz brachte, mit der Unmöglichkeit von Sklaverei auf Schweizer Boden, um die Einbürgerung von Samuel Buisson zu erwirken. Vgl. Pinto 2018.

53 | Pinto 2018, 0.S. 
Denn während sich unterschiedliche Vertreter der Behörden und der >Besitzer<-Familie über den Status von Samuel Buisson nicht einig werden konnten und die Frage der Sklaverei damit in einem Zustand der Unentschiedenheit verblieb, lebte Samuel Buisson de facto in einem rechtlich ungeregelten Zustand, der eine Folge von Sklaverei darstellte. Dass die Frage der Rassifizierung gleichzeitig zentral war und für die Aushandlung staatlicher Zugehörigkeit im Schweizer Staatenbund des frühen 19. Jahrhundert ungelöst blieb, zeigt sich noch expliziter bei Pauline Buisson und François Mida, in deren Fall die Familie de Treytorrens keine Anstrengungen unternahm, ihren versklavten Status in eine andere Form zu überführen. Mit anderen Worten: Während die Behörden und eine reiche Schweizer Familie darüber stritten, ob Samuel Buisson als Kind einer versklavten Schwarzen Frau eingebürgert werden konnte oder nicht, lebten drei Menschen über Jahrzehnte hinweg in rechtlich nicht geregelten Verhältnissen, die direkt aus der Sklaverei resultierten. Das wirft zum einen die Frage auf, was das für diese Menschen bedeutete, welche Formen des Zugriffs, der Macht und Gewalt ihr Leben prägten und inwiefern man in der Zeit zwischen Ancien Régime und dem Staatenbund von der Existenz faktischer Sklaverei in der >Schweiz< sprechen kann. Zum anderen lässt sich daran die Frage anschließen, wie die Sklaverei als global wirkmächtigste und radikalste Form der Objektivierung von Menschen mit anderen Formen der Enteignung menschlicher Freiheit in der jüngeren Geschichte der Schweiz zusammenhängt, mit Ausweisung und Haft, aber auch mit Verdingen, fürsorgerischen Zwangsmaßnahmen und der Versorgung in Heimen und Anstalten. ${ }^{54}$ Schließlich rücken diese drei Biografien, wie Pinto fordert, die Frage der Sklaverei ins Zentrum einer anderen Geschichte der liberalen Schweiz. Diese Geschichte ist noch ungeschrieben und dennoch zeichnen sich ihre möglichen Konturen ab: So treffen sich Pintos Überlegungen mit Bernhard Schärs Ansinnen, die kolonialen Verwicklungen der liberalen >Gründerväter < der Schweiz und Autoren der Verfassung von 1848 zu untersuchen, oder mit Noémi Michels kürzlich geäußerter Forderung, die haitianische Revolution als grundlegendes Element der Schweizer Demokratie zu verstehen. ${ }^{55}$ All diese Per-

54 | Vgl. Rietmann 2013 und 2017; Leuenberger und Seglias 2008.

55 | Vgl. Schär 2016b sowie Michels Beitrag zur Konferenz "Von der Kolonisierung zur Globalisierung" im April 2018, https://globaleschweiz.wordpress.com/ (Zugriff am 24. September 2018). 
spektiven machen deutlich, dass postkoloniale Forschung nicht nur eine Reihe neuer Randbemerkungen zur Schweizer Geschichte hervorbringt, sondern im Begriff steht, sie auf radikale Weise umzuschreiben. Dabei wird auch die Einschätzung davon, welche Ereignisse für eine Schweizer Geschichte zentral und welche bloß vernachlässigbare Anekdoten sind, tief greifend verändert.

Ähnliches lässt sich im Hinblick auf die Bedeutung von Migration aufzeigen, die im Zeitalter der Moderne immer auch mit Rassifizierungsprozessen verschränkt ist. In einer neuen Forschungsarbeit zur Schweiz belegt Francesca Falk, dass wichtige Modernisierungsschritte wie der Zugang von Frauen zu höherer Bildung, die Einführung des Frauenstimmrechts oder der Auf- und Ausbau einer außerhäuslichen Betreuungsstruktur wesentlich auf die Präsenz und die Aktivitäten von Migrant*innen und vor allem der Frauen unter ihnen zurückgehen. Dabei gelangt sie zu der wegweisenden Schlussfolgerung, dass es weniger einer Migrationsgeschichte der Schweiz bedürfe als vielmehr einer Migrantisierung der Schweizer Geschichte. ${ }^{56}$ Darunter versteht sie eine historische Rekonstruktionsarbeit, die Migration nicht als Herausforderung sieht, die von außen an zeitgenössische Gesellschaften herangetragen wird und von diesen gelöst werden muss, sondern als ein Phänomen, das ihnen inhärent ist und sie auf grundlegende Weise mit hervorbringt.

Die Kolonialität der Macht, das zeigen solche Ansätze, wird auch durch die Art und Weise infrage gestellt, wie wissenschaftliche Forschung verstanden und umgesetzt wird. Postkoloniale Forschung dokumentiert demnach nicht nur alternatives und subalternes Wissen, sondern stellt eine performative Praxis dar, die bestehendes Wissen auf eine neue Weise durchque(e)rt, liest, befragt, deutet, arrangiert, archiviert, dokumentiert, ins Gespräch bringt und kombiniert. Diese Praxis lässt nicht nur keinen Bereich des gängigen Geschichtsverständnisses unberührt, sie bringt auch beständig neue und mit bislang unbekannten Einsichten gesättigte Variationen des Satzes hervor, der James Baldwins Essay über seine Erfahrungen im Schweizer Dorf Leukerbad beschließt: »This world is white no longer and it will never be white again. ${ }^{57}$

Indem postkoloniale Geschichtsschreibung Weißsein als etwas erfasst, das ständig hergestellt und ausgehandelt werden muss, das eigen-

56 | Falk 2019.

57 | Baldwin 1963, 175. 
tümlich kontingent und gleichzeitig unheimlich wirkmächtig ist, das ständig umkämpft bleibt und auf vielfältige Formen des Widerstands stößt, zeigt sie darüber hinaus immer wieder, was ebenfalls durch jede einzelne von Baldwins Zeilen schimmert: Dass die Welt nicht mehr weiß ist und es auch nie wieder sein wird, bedeutet auch, dass sie niemals nur weiß war. 


\section{Danksagung}

Diese Forschungsarbeit wäre ohne die Anteilnahme vieler Menschen in meinem nahen und fernen Umfeld nie zustande gekommen. Als erstes bedanke ich mich bei den drei Gutachterinnen meiner Habilitation: Marianne Sommer hat meine Forschung während vieler Jahre bedingungslos unterstützt und es mir ermöglicht, die vorliegende Arbeit an der Universität Luzern als Habilitationsschrift einzureichen und damit die Venia Legendi in Kulturwissenschaften zu erhalten. Der Gastfreundschaft von Harald Fischer-Tiné ist es zu verdanken, dass ich einen großen Teil meiner Forschung im inspirierenden Umfeld am Lehrstuhl Geschichte der modernen Welt an der ETH Zürich durchführen konnte. Dankbar bin ich ihm zudem für die gemeinsame Arbeit zur Schweizer Kolonialgeschichte, die mir wichtige neue Zugänge zum Thema eröffnet hat. Mein Dank geht ferner an Gabriele Dietze für anregende Diskussionen und die wichtigen Denkanstöße, die ich ihren Arbeiten entnehmen konnte.

Brigitta Bernet, Francesca Falk, Sushila Mesquita und Bernhard Schär haben Teile der Arbeit gelesen und mir wertvolle inhaltliche Anregungen gegeben. Ganz besonders bedanke ich mich bei Elisabeth Joris für ihre präzise und erhellende Kommentierung des gesamten Manuskripts. Beim Lektorieren und Layouten der Habilitationsschrift und bei deren Umwandlung in ein Buch konnte ich auf tatkräftige Hilfe von Marie-Luise Hertkorn und Vanessa Näf bauen. Jovita dos Santos Pinto, Marina Lienhard und Lina Walti haben meine Forschungsarbeit an der ETH unterstützt und zahlreiche Recherchen für mich durchgeführt. Ein besonderer Dank geht dabei an Jovita dos Santos Pinto, die meine Arbeit auch an der Universität Bern begleitet und mir immer wieder geholfen hat, meine Erkenntnisse zu überdenken und genauer zu fassen. Bedanken möchte ich mich weiter bei Petra Schäfter für das sorgfältige Lektorat sowie beim Team des transcript Verlags für die produktive Zusammenarbeit. Anelis Kaiser bin ich dankbar für unzählige kitchen table-Gesprä- 
che über die theoretische und praktische Gestaltung meiner Forschung und für das Kunststück, den gemeinsamen feministischen Alltag zu bewältigen.

Während der Arbeit an dieser Studie stand ich in regem Austausch mit einem Kollektiv, das sich in den letzten Jahren im neuen und dynamischen Forschungsfeld zu Postkolonialismus, Migration und Rassismus in der Schweiz herausgebildet hat. Neben vielen inhaltlichen Einsichten verdanke ich diesen Forschungsnetzwerken wertvolle Erfahrungen zur Verbindung von wissenschaftlicher Arbeit mit politischem Aktivismus. Mein besonderer Dank geht an Serena O. Dankwa, Kijan Espahangizi, Francesca Falk, Hans Fässler, Rohit Jain, Anne Lavanchy, Barbara Lüthi, Sushila Mesquita, Noémi Michel, Tarek Naguib, Pamela Ohene-Nyako, Mélanie-Eveley Pétremont, Halua Pinto de Magalhães, Jovita dos Santos Pinto, Sarah Schilliger, Damir Skenderovic und Mohamed Wa Baile. Ein besonderer Dank geht an Bernhard C. Schär für unser nie abbrechendes Gespräch über die postkoloniale Schweiz. Noémi Michel danke ich besonders dafür, dass sie mir beigebracht hat, Race und die Schweiz zusammenzudenken.

Ferner bedanke ich mich bei den Mitgliedern des Zentrums Geschichte des Wissens Zürich und des Frankfurter Arbeitskreises für politische Theorie und Philosophie für zahlreiche anregende Diskussionen. Mein Dank geht weiter an die Teilnehmer*innen meiner Seminare an den Universitäten Zürich, Basel, Luzern und Bern, mit denen ich grundlegende Fragen des Postkolonialismus aus immer wieder neuen Blickwinkeln erörtern konnte. Ein riesiger Dank geht an das Team des Interdisziplinären Zentrums für Geschlechterforschung der Universität Bern, dem ich seit 2016 angehöre und das innerhalb der Universität einen wunderbaren feministischen Ort des Denkens, Forschens, Lehrens und Lebens geschaffen hat. Dem Schweizerischen Nationalfonds danke ich für die Unterstützung meiner Arbeit durch ein Ambizione-Forschungsprojekt und den großzügigen Zuschuss zu den Publikationskosten.

Zahlreiche Gespräche mit Freund*innen und Kolleg*innen haben es mir in den vergangenen Jahren ermöglicht, meine Gedanken zu entwickeln, zu erproben und zu schärfen. Neben den bereits genannten Personen danke ich besonders Michèle Amacker, Caroline Arni, Paola Bacchetta, Sabine Baier, Vasudha Bharadwaj, Stefanie Boulila, Tina Büchler, Judith Butler, Michelle Cottier, Erika Doucette, Dace Dzenovska, Rahel El-Maawi, Sara Elmer, Antke Engel, Barbara Fischer, Beate Fricke, Alex 
Gamma, Jonah Garde, Pascal Germann, Marianne Hänseler, Manuela Honegger, Annette Hug, Andrea Hungerbühler, Emil Kaiser, Nikolay Kamenov, Meral Kaya, Christoph Keller, Eva Keller, Ina Kerner, Robert Kramm-Masaoka, Gesine Krüger, Nina Kunz, Patrick Kupper, Katherine Lemons, Urs Lindner, Kristín Loftsdóttir, Isabell Lorey, Jonas Lüscher, Andrea Maihofer, Jon Mathieu, Manuel Menrath, Carmen Mörsch, Yv E. Nay, Margo Okazawa-Rey, Regula Ott, Lea Pfäffli, Katharina Pühl, Eva von Redecker, Lena Rérat, Tanja Rietmann, Angela Sanders, Franziska Schutzbach, Joan Scott, Cécile Stehrenberger, Ann L. Stoler, Brigitte Studer, Kaspar Surber, Jakob Tanner, Crispin Thurlow, Jana Tschurenev, Sophie Vögele, Janine Wilhelm und Yves Winter. 



\section{Abbildungsverzeichnis}

Abbildung 1: Werbung für die Weißwarenwoche im Warenhaus Globus 1933 | 71

Abbildung 2: Plakatwerbung der Migros für das Waschmittel >Total $\mid 72$

Abbildung 3: Filmstill aus der Migros-Werbung für das Waschmittel >Total< aus dem Jahr 2014 | 76

Abbildung 4: Wehmütige Gedanken an Suraja, Inserat für das Warenhaus Globus 1933 | 78

Abbildung 5: Serie von Werbeinseraten für das Warenhaus Globus 1933 (Teil 1 und 2) | 89

Abbildung 6: Serie von Werbeinseraten für das Warenhaus Globus 1933 (Teil 3 und 4) | 91

Abbildung 7: Serie von Werbeinseraten für das Warenhaus Globus 1933 (Teil 5) | 97

Abbildung 8: Inserat für Tobler-Schokolade 1932 | 124

Abbildung 9: Plakatwerbung für Tobler-Schokolade 1935| 126

Abbildung 10: Inserat für Lindt-Schokolade 1933|128

Abbildung 11: Inserat für das Warenhaus Globus 1935 | 134

Abbildung 12: Inserat für das Warenhaus Globus 1935 (Ausschnitt 1) | 135

Abbildung 13: Inserat für das Warenhaus Globus 1935 (Ausschnitt 2) | 137

Abbildung 14: Inserat der Firma Electrolux 1933| 142

Abbildung 15: Illustration des Artikels »Wasser im Haushalt« 1932 | 147

Abbildung 16: Inserat für Khasana-Kosmetik 1935 | 151

Abbildung 17: Inserat für Siko-Zahnpasta 1935 | 154

Abbildung 18: Inserat für Lux-Seife 1932 | 156

Abbildung 19: Inserat für Persil-Waschmittel 1934 | 168

Abbildung 20: Titelbild zum Artikel »Der Schweizer Sieg am Dhaulagiri« $1960 \mid 185$

Abbildung 21: Filmstill aus dem Dokumentarfilm High Tension 2013 | 190 
Abbildung 22: Hans Rudolf von Gunten mit Annullu und Pasang Phutar auf der Everest-Lhotse-Expedition | 254

Abbildung 23: Dawa Thondup und Raymond Lambert am Everest $\mid 256$

Abbildung 24: Inserat für die Schweizer Illustrierte Zeitung 1952 | 283

Abbildung 25: Max Eiselins Bebilderung seiner Ankunft in Nepal | 293 


\section{Literatur}

Aeppli, Felix (2012), »Walter Mittelholzer«, in: Historisches Lexikon der

Schweiz. Download unter: www.hls-dhs-dss.ch/textes/d/D9211.php (Zugriff am 15. Juli 2014).

Ahmed, Sara (2010), The Promise of Happiness, Durham: Duke University Press.

Alexander, M. Jacqui (1994), »Not Just (Any) Body Can Be a Citizen: The

Politics of Law, Sexuality and Postcoloniality in Trinidad and Tobago and the Bahamas«, in: Feminist Review, 48(1): 5-23.

Altermatt, Urs, Catherine Bosshard-Pfluger und Albert Tanner (Hg.) (1998), Die Konstruktion einer Nation. Nation und Nationalisierung in der Schweiz, 18.-20. Jahrhundert, Zürich: Chronos.

Amlinger, Fabienne (2017), Im Vorzimmer der Macht? Die Frauenorganisationen der SPS, FDP und CVP, 1971-1995, Zürich: Chronos.

Amstädter, Rainer (2000), »Hitler klettert mit«, in: Daniel Anker (Hg.), Eiger. Die vertikale Arena, Zürich: AS-Verlag, 220-225.

Anderson, Benedict (1983), Imagined Communities. Reflections on the Origin and Spread of Nationalism, London: Verso.

Anker, Daniel (1986), Oben statt unten. Der Schweizer Alpen-Club und die Politik, die Gesellschaft und die Ideologie der Berge, Universität Bern: unveröffentlichte Lizentiatsarbeit.

Appiah, Kwame A. und Amy Gutmann (1996), Color Conscious. The Political Morality of Race, Princeton: Princeton University Press.

Archer-Straw, Petrine (2000), Negrophilia. Avant-Garde Paris and Black Culture in the 1920s, London: Thames \& Hudson.

Arendt, Hannah (1986), Elemente und Ursprünge totaler Herrschaft, München: Piper.

Argast, Regula (2007), Staatsbürgerschaft und Nation. Ausschliessung und Integration in der Schweiz 1848-1933, Göttingen: Vandenhoeck \& Ruprecht. 
Ariès, Philippe (1978), Geschichte der Kindheit, München: dtv.

Arni, Caroline (2004), Entzweiungen. Die Krise der Ehe um 1900, Köln: Böhlau.

Arnold, David (2000), Science, Technology and Medicine in Colonial India, Cambridge: Cambridge University Press.

Arnold, David (2005), »Europe, Technology, and Colonialism in the 2oth Century«, in: History and Technology, 21(1): 85-106.

Badenberg, Nana (2004), »Die Bildkarriere eines kulturellen Stereotyps. 14. Juli 1894: Mohrenwäsche im Leipziger Zoo«, in: Alexander Honold und Klaus R. Scherpe (Hg.), Mit Deutschland um die Welt. Eine Kulturgeschichte des Fremden in der Kolonialzeit, Stuttgart: J.B. Metzler Verlag, 173-182.

Bähler, Anna (1996), »Die Veränderung des Arbeitsplatzes Haushalt durch das Eindringen der Haushalttechnik, 1930-1980«, in: Ulrich Pfister, Brigitte Studer und Jakob Tanner (Hg.), Arbeit im Wandel. Deutung, Organisation und Herrschaft vom Mittelalter bis zur Gegenwart, Zürich: Chronos, 171-192.

Baldwin, James (1963), »Stranger in a Village«, in: James Baldwin, Notes of a Native Son, Boston: Beacon Press, 159-175.

Baldwin, James und Raoul Peck (2017), I Am Not Your Negro, London: Penguin Classics.

Balibar, Étienne (1990), »Gibt es einen >Neo-Rassismus<?«, in: Étienne Balibar und Immanuel Wallerstein (Hg.), Rasse, Klasse, Nation. Ambivalente Identitäten, Hamburg: Argument Verlag, 23-38.

Balibar, Étienne (2005), »La Construction du Racisme«, in: Actuel Marx, 38(2): 11-28.

Ballantyne, Tony und Antoinette Burton (Hg.) (2005a), Bodies in Contact. Rethinking Colonial Encounters in World History, Durham: Duke University Press.

Ballantyne, Tony und Antoinette Burton (2005b), »Postscript: Bodies, Genders, Empires. Reimagining World Histories«, in: Tony Ballantyne und Antoinette Burton (Hg.), Bodies in Contact. Rethinking Colonial Encounters in World History, Durham: Duke University Press, 405-423.

Bargetz, Brigitte und Gundula Ludwig (2015), »Bausteine einer queerfeministischen politischen Theorie. Eine Einleitung«, in: Femina Politica, 24(1): 924 . 
Baumann, Alfred (1930), Das Schaufenster. Kurzgefasste Anleitung zur zeitgemässen Gestaltung und Dekoration, Zürich: Verlag Organisator.

Baxter, Janeen (2011), »Domestic Division of Labor«, in: Dale Southerton (Hg.), Encyclopedia of Consumer Culture, Thousand Oaks: Sage, 472474.

Beauvoir, Simone de (1994), Das andere Geschlecht. Sitte und Sexus der Frau, Reinbek bei Hamburg: Rowohlt.

Behrendt, Richard Fritz (1932), Die Schweiz und der Imperialismus. Die Volkswirtschaft des hochkapitalistischen Kleinstaates im Zeitalter des politischen und ökonomischen Nationalismus, Zürich: Rascher.

Bellwald, Waltraut (2003), Globi - ein Freund fürs Leben. Die Erfolgsgeschichte einer Reklamefigur, Zürich: Orell Füssli.

Bellwald, Waltraut und Ingrid Tomkowiak (2003), »Globi. Eine Reklamefigur wird zum Mythos«, in: René Ammann (Hg.), Globi und seine Zeit. Begegnung mit einem Schweizer Phänomen, Zürich: Globi-Verlag, 8-69.

Bendix, Regina (1993), »Of Mohrenköpfe and Japanesen: Swiss Images of the Foreign«, in: Journal of Folklore Research, 30(1): 15-28.

Benhabib, Seyla (1995), Selbst im Kontext, Frankfurt a.M.: Suhrkamp.

Bernet, Brigitta und Jakob Tanner (2015), »Ausser Betrieb. Metamorphosen der Arbeit in der Schweiz«, in: Brigitta Bernet und Jakob Tanner (Hg.), Ausser Betrieb. Metamorphosen der Arbeit in der Schweiz, Zürich: Limmat Verlag, 7-38.

Bernet, Peter (2006), »Arnold Glatthard«, in: Historisches Lexikon der Schweiz. Download unter: www.hls-dhs-dss.ch/textes/d/D48207.php (Zugriff am 21. Oktober 2015).

Bhabha, Homi K. (2007), Die Verortung der Kultur, Tübingen: Stauffenburg.

Bhambra, Gurminder K. (2007), Rethinking Modernity. Postcolonialism and the Sociological Imagination, Basingstoke: Palgrave Macmillan.

Bhambra, Gurminder K. (2009), »Postcolonial Europe. Or, Understanding Europe in Times of the Postcolonial«, in: Chris Rumford (Hg.), Handbook of European Studies, London: Sage, 69-86.

Blanchard, Pascal, Nicolas Bancel und Sandrine Lemaire (2008), »From Scientific Racism to Popular and Colonial Racism in France and the West«, in: Pascal Blanchard, Nicolas Bancel, Gilles Boëtsch, Eric Deroo, Sandrine Lemaire und Charles Forsdick (Hg.), Human Zoos. Sci- 
ence and Spectacle in the Age of Colonial Empires, Liverpool: Liverpool University Press, 104-113.

Blanchard, Pascal, Nicolas Bancel, Gilles Boëtsch, Eric Deroo und Sandrine Lemaire (2008), »Human Zoos. The Greatest Exotic Shows in the West«, in: Pascal Blanchard, Nicolas Bancel, Gilles Boëtsch, Eric Deroo, Sandrine Lemaire und Charles Forsdick (Hg.), Human Zoos. Science and Spectacle in the Age of Colonial Empires, Liverpool: Liverpool University Press, 1-49.

Blattmann, Lynn (1998), »Männerbund und Bundesstaat«, in: Lynn Blattmann und Irène Meier (Hg.), Männerbund und Bundesstaat. Über die politische Kultur der Schweiz, Zürich: Orell Füssli, 17-35.

Blattmann, Lynn (2011), »Geschlechterrollen«, in: Historisches Lexikon der Schweiz. Download unter: www.hls-dhs-dss.ch/textes/d/D15988.php (Zugriff am 17. September 2015).

Bloom, Lisa (1993), Gender on Ice. American Ideologies of Polar Expeditions, Minneapolis: University of Minneapolis Press.

Bloom, Lisa (2010), »Arctic Spaces. Politics and Aesthetics in >True North and >Gender on Ice«, in: Journal of Contemporary African Art, 26: 3037.

Bock, Gisela und Barbara Duden (1977), »Arbeit aus Liebe - Liebe als Arbeit: Zur Entstehung der Hausarbeit im Kapitalismus«, in: Gruppe Berliner Dozentinnen (Hg.), Frauen und Wissenschaft. Beiträge zur Berliner Sommeruniversität für Frauen, Berlin: Courage Verlag, 118-199.

Bott, Sandra, Janick Marina Schaufelbuehl und Sacha Zala (2011), »Die internationale Schweiz in der Zeit des Kalten Krieges. Eine Zwischenbilanz«, in: Sandra Bott, Janick Marina Schaufelbuehl, Sacha Zala (Hg.), Itinera 30, 5-16.

Boulila, Stefanie Claudine (2018), »Race and Racial Denial in Switzerland «, in: Ethnic and Racial Studies, DOI: 10.1080/01419870.2018.1493211.

Bourdieu, Pierre (2005), Die männliche Herrschaft, Frankfurt a.M.: Suhrkamp.

Boussoulas, Andrew Andriana (2011), »rassig«, in: Susan Arndt und Nadja Ofuatey-Alazard (Hg.), (K)Erben des Kolonialismus im Wissensarchiv deutsche Sprache. Ein kritisches Nachschlagewerk, Münster: Unrast Verlag, 665-666.

Brandes, Kerstin (2007), »Exotische Wilde - Grenzfiguren einer neoliberalen Bildpolitik?«, in: FKW - Zeitschrift für Geschlechterforschung und Visuelle Kultur, 44: 23-31. 
Brändle, Rea (2007), Nayo Bruce. Geschichte einer afrikanischen Familie in Europa, Zürich: Chronos.

Brändle, Rea (2013), Wildfremd, hautnah. Zürcher Völkerschauen und ihre Schauplätze 1835-1964, Zürich: Rotpunktverlag.

Brändli Blumenbach, Sibylle (2000), Der Supermarkt im Kopf. Konsumkultur und Wohlstand in der Schweiz nach 1945, Wien: Böhlau.

Braunschweig, Sabine (Hg.) (2014), >Als habe es die Frauen nicht gegeben<, Zürich: Chronos.

Buck-Morss, Susan (2011), Hegel und Haiti. Für eine neue Universalgeschichte, Berlin: Suhrkamp.

Burke, Nancy (Hg.) (1998), Gender \& Envy, New York: Routledge.

Burton, Antoinette M. (1990), »The White Woman's Burden. British Feminists and the Indian Woman, 1865-1915«, in: Women's Studies International Forum, 4(13): 295-308.

Butler, Judith (1991), Das Unbehagen der Geschlechter, Frankfurt a.M.: Suhrkamp.

Butler, Judith (1995), Körper von Gewicht. Die diskursiven Grenzen des Geschlechts, Berlin: Berlin Verlag.

Butler, Judith (2004), Undoing Gender, New York: Routledge.

Calmy-Rey, Micheline (2011), »Discours d'adieu«, 14. Dezember 2011. Download unter: http://kms1.isn.ethz.ch/.../20111214_Abschiedsrede ParlamentBern_2.pdf (Zugriff am 21. April 2015).

Castro Varela, María do Mar und Nikita Dhawan (2011), »Normative Dilemmas and the Hegemony of Counter-Hegemony«, in: María do Mar Castro Varela, Nikita Dhawan und Antke Engel (Hg.), Hegemony and Heteronormativity: Revisiting The Political in Queer Politics, Aldershot: Ashgate, 91-119.

Césaire, Aimé (2004), Discours sur le colonialisme, Paris: Présence Africaine.

Chakrabarty, Dipesh (2002), Provincializing Europe. Postcolonial Thought and Historical Difference, Princeton: Princeton University Press.

Chakrabarty, Dipesh (2008), »In Defense of >Provincializing Europe<. A Response to Carola Dietze«, in: History and Theory, 47(1): 85-96.

Cheng, Anne Anlin (2000), The Melancholy of Race, Oxford: Oxford University Press.

Chow, Rey (1989), »>It's You, and Not Me<. Domination and >Othering < in Theorizing the >Third World««, in: Elizabeth Weed (Hg.), Coming to Terms. Feminism, Theory, Politics, New York: Routledge, 152-161. 
Ciarlo, David (2011), Advertising Empire. Race and Visual Culture in Imperial Germany, Cambridge MA: Harvard University Press.

Cohen, Lizabeth (2003), A Consumer's Republic. The Politics of Mass Consumption in Postwar America, New York: Vintage Books.

Colombo Dougoud, Roberta und Lorin Wüscher (2008), »Marguerite Lobsiger-Dellenbach et les bambous kanak. Une femme, une passion, un peuple«, in: Roberta Colombo Dougoud (Hg.), Bambous kanak. Une passion de Marguerite Lobsiger-Dellenbach, Gollion: Infolio, 17-35.

Comaroff, John L. und Jean Comaroff (2013), »Hausgemachte Hegemonie«, in: Sebastian Conrad, Shalini Randeria und Regina Römhild (Hg.), Jenseits des Eurozentrismus. Postkoloniale Perspektiven in den Geschichts- und Kulturwissenschaften, Frankfurt a.M.: Campus, 267-300.

Connell, Robert W. (1999), Der gemachte Mann: Konstruktion und Krise von Männlichkeiten, Opladen: Leske + Budrich.

Conrad, Sebastian, Shalini Randeria und Regina Römhild (Hg.) (2013), Jenseits des Eurozentrismus. Postkoloniale Perspektiven in den Geschichtsund Kulturwissenschaften, Frankfurt a.M.: Campus.

Coulthard, Glen Sean (2014), Red Skin, White Masks. Rejecting the Colonial Politics of Recognition, Minneapolis: University of Minnesota Press.

Crais, Clifton und Pamela Scully (2009), Sara Baartman and the Hottentot Venus. A Ghost Story and a Biography, Princeton: Princeton University Press.

Crenshaw, Kimberlé (1989), »Demarginalizing the Intersection of Race and Sex: A Black Feminist Critique of Antidiscrimination Doctrine, Feminist Theory, and Antiracist Politics«, in: University of Chicago Legal Forum, 1: 139-67.

Cretton, Viviane (2018), »Performing whiteness: racism, skin colour, and identity in Western Switzerland«, in: Ethnic and Racial Studies 41(5): 842-859.

Dankwa, Serena Owusua (2011), »'The One who first says I love you<: Same-sex love and female masculinity in postcolonial Ghana«, in: Ghana Studies, 14: 223-264.

David, Thomas, Bouda Etemad und Janick Marina Schaufelbuehl (2005), Schwarze Geschäfte. Die Beteiligung von Schweizern an Sklaverei und Sklavenhandel im 18. und 19. Jahrhundert, Zürich: Limmat Verlag.

Davis, Angela (1983), Women, Race a Class, New York: Vintage Books. 
Degen, Bernard (2013), »Sozialdemokratische Partei (SP)«, in: Historisches Lexikon der Schweiz. Download unter: www.hls-dhs-dss.ch/textes/d/ D17393.php (Zugriff am 6. Mai 2015).

Dejung, Christof (2003), »Die höchste Potenz von Männlichkeit. Militär, Gesellschaft und Geschlechterordnung in der Schweiz, 1933-1945", in: Christof Dejung und Regula Stämpfli (Hg.), Armee, Staat und Geschlecht. Die Schweiz im internationalen Vergleich 1918-1945, Zürich: Chronos, 173-184.

Dejung, Christof (2006), Aktivdienst und Geschlechterordnung. Eine Kultur- und Alltagsgeschichte des Militärdienstes in der Schweiz 1939-1945, Zürich: Chronos.

Dejung, Christof (2012), »Zeitreisen durch die Welt. Temporale und territoriale Ordnungsmuster auf Weltausstellungen und schweizerischen Landessausstellungen während der Kolonialzeit«, in: Patricia Purtschert, Barbara Lüthi und Francesca Falk (Hg.), Postkoloniale Schweiz. Formen und Folgen eines Kolonialismus ohne Kolonien, Bielefeld: transcript, 333-354.

Dejung, Christof (2013), Die Fäden des globalen Marktes: Eine Sozial- und Kulturgeschichte des Welthandels am Beispiel der Handelsfirma Gebrüder Volkart 1851-1999, Köln: Böhlau.

Dejung, Christof und Regula Stämpfli (Hg.) (2003), Armee, Staat und Geschlecht. Die Schweiz im internationalen Vergleich 1918-1945. Zürich: Chronos.

Denneberg, Erwin (1937), Begriff und Geschichte des Warenhauses. Privatrechtliche Verhältnisse der schweizerischen Warenhäuser, Zürich: Oprecht.

Des Chene, Mary (2007), »Is Nepal in South Asia? The Condition of Non-Postcoloniality«, in: Studies in Nepali History and Society, 12(2): 207-223.

Dietze, Gabriele (2006), »Critical Whiteness Theory und Kritischer Okzidentalismus. Zwei Figuren hegemonialer Selbstreflexion«, in: Martina Tissberger, Gabriele Dietze, Daniela Hrzan und Jana Husmann-Kastein (Hg.), Weiss - Weisssein - Whiteness. Kritische Studien zu Gender und Rassismus, Frankfurt a.M.: Peter Lang, 219-247.

Dietze, Gabriele (2009), »Okzidentalismuskritik. Möglichkeiten und Grenzen einer Forschungsperspektivierung«, in: Gabriele Dietze, Claudia Brunner und Edith Wenzel (Hg.), Kritik des Okzidentalismus. 
Transdisziplinäre Beiträge zu (Neo-)Orientalismus und Geschlecht, Bielefeld: transcript, 23-54.

Dietze, Gabriele (2013), Weisse Frauen in Bewegung. Genealogien und Konkurrenzen von Race- und Genderpolitiken, Bielefeld: transcript.

Dittert, René, Gabriel Chevalley und Raymond Lambert (1954), Forerunners to Everest. The Story of Two Swiss Expeditions of 1952, London: Harper.

Dreesbach, Anne (2012), »Kolonialausstellungen, Völkerschauen und die Zurschaustellung des >Fremden««, in: Europäische Geschichte Online (EGO). Download unter: www.ieg-ego.eu/dreesbacha-2012-de (Zugriff am 25. Februar 2015).

Du Bois, William E. B. (2003), The Souls of Black Folks, New York: Barnes $\&$ Noble Classics.

Duden (2015), »Rasse«. Download unter www.duden.de/rechtschreibung/ Rasse (Zugriff am 16. April 2014).

Duncan, Nancy (Hg.) (1996), BodySpace. Destabilizing Geographies of Gender and Sexuality, London: Routledge.

Dyer, Richard (1997), White, London: Routledge.

Dyhrenfurth, Günter O. (1952), Zum dritten Pol, Zürich: Arche.

Dyhrenfurth, Hettie (1931), Memsahb im Himalaja, Leipzig: Verlag Deutsche Buchwerkstätten.

Dzenovska, Dace (2013), »Historical Agency and the Coloniality of Power in Postsocialist Europe«, in: Anthropological Theory, 13(4): 394-415.

Egger, Carl (Hg.) (1932a), Die Eroberung des Kaukasus, Basel: Schwabe.

Egger, Carl (1932b), »Die Belagerung des Dschailük«, in: Carl Egger (Hg.),

Die Eroberung des Kaukasus, Basel: Schwabe, 145-151.

Egger, Carl (1946), Pioniere der Alpen. 30 Lebensbilder der grossen Schweizer Bergführer von Melchior Anderegg bis Franz Lochmatter, 1827 bis 1933, Zürich: Herdeg \& Co.

Eggers, Maureen Maisha, Grada Kilomba, Peggy Piesche und Susan Arndt (Hg.) (2005), Mythen, Masken und Subjekte: Kritische Weissseinsforschung in Deutschland, Münster: Unrast.

Eggimann Gerber, Elisabeth (2009), »Alfred Ilg«, in: Historisches Lexikon der Schweiz. Download unter: http://www.hls-dhs-dss.ch/textes/d/ D31402.php (Zugriff am 3. September 2014).

Eggler, Albert (1956), Gipfel über den Wolken. Lhotse und Everest, Bern: Hallwag. 
Eiselin, Max (1960), Erfolg am Dhaulagiri. Die Erstbesteigung des Achttausenders durch die schweizerische Himalaya-Expedition 1960, Zürich: Orell Füssli.

Elmer, Sara (2012), »Postkoloniale Erschliessung ferner Länder? Die erste Schweizer Nepalmission und die Anfänge der stechnischen Hilfe an unterentwickelte Länder««, in: Patricia Purtschert, Barbara Lüthi und Francesca Falk (Hg.), Postkoloniale Schweiz. Formen und Folgen eines Kolonialismus ohne Kolonien, Bielefeld: transcript, 245-266.

Elmer, Sara (2014), Visions and Agents of Development in Twentieth Century Nepal, ETH Zürich, Unpublizierte Dissertation.

El-Tayeb, Fatima (2011), European Others. Queering Ethnicity in Postnational Europe, Minneapolis: University of Minnesota Press.

Eng, David (2001), Racial Castration. Managing Masculinity in Asian America, Durham: Duke University Press.

Espahangizi, Kijan (2015), »Von der Gesellschaftskritik zur Integrationsdienstleistung - und zurück? Einige Überlegungen zur Gegenwart und Zukunft antirassistischen Engagements in der Schweiz«, in: Freiplatzaktion Zürich (Hg.), 30 Jahre Freiplatzaktion Zürich. Zur Geschichte der Asylbewegung und der Schweizerischen Migrationspolitik 1985-2015, Zürich: Freiplatzaktion Zürich, 6-19.

Essed, Philomena (1991), Understanding Everyday Racism, Newbury Park: Sage.

Fabian, Johannes (1983), Time and the Other. How Anthropology Makes its Object, New York: Columbia University Press.

Falk, Francesca (2008), Grenzverwischer. >Jud Süss< und >Das Dritte Geschlecht<. Verschränkte Diskurse von Ausgrenzung, Innsbruck: Studienverlag.

Falk, Francesca (2011), Eine gestische Geschichte der Grenze. Wie der Liberalismus an der Grenze an seine Grenze kommt, München: Wilhelm Fink.

Falk, Francesca (2012), »Eine postkoloniale Perspektive auf die illegalisierte Immigration in der Schweiz. Über Ausschaffungen, den >Austausch mit Afrika<, Alltagsrassismus und die Angst vor der umgekehrten Kolonisierung«, in: Patricia Purtschert, Barbara Lüthi und Francesca Falk (Hg.), Postkoloniale Schweiz. Formen und Folgen eines Kolonialismus ohne Kolonien, Bielefeld: transcript, 201-224.

Falk, Francesca (2015), »Marignano da, Migration dort, Südafrika nirgends. Über eine gewollte Entkoppelung von Diskursen«, in: Traverse. Zeitschrift für Geschichte, 3: 155-166. 
Falk, Francesca (2019), Gender innovation and migration in Switzerland, Basingstoke: Palgrave Macmillan.

Fanon, Frantz (1980), Schwarze Haut, weisse Masken, Frankfurt a.M.: Suhrkamp.

Fanon, Frantz (1981), Die Verdammten dieser Erde, Frankfurt a.M.: Suhrkamp.

Fässler, Hans (2005), Reise in schwarz-weiss. Schweizer Ortstermine in Sachen Sklaverei, Zürich: Rotpunktverlag.

Favez, Jean-Claude (2010), »Marcel Pilet-Golaz«, in: Historisches Lexikon der Schweiz. Download unter: www.hls-dhs-dss.ch/textes/d/D4641. php (Zugriff am 15. Juli 2014).

Feuz, Ernst (1953), »Vorgeschichte und Vorbereitungen für die MountEverest-Expedition 1952«, in: Schweizerische Stiftung für Alpine Forschungen (Hg.), Berge der Welt, Zürich: Büchergilde Gutenberg, 39-42.

Fierz, Gaby (2012), »Das Making-of von Gardis Afrika«, in: Patricia Purtschert, Barbara Lüthi und Francesca Falk (Hg.), Postkoloniale Schweiz. Formen und Folgen eines Kolonialismus ohne Kolonien, Bielefeld: transcript, 355-378.

Fischer-Tiné, Harald (2009), Low and Licentious Europeans. Race, Class, and >White Subalternity< in Colonial India, New Delhi: Orient Blackswan.

Fischer-Tiné, Harald (2013), Pidgin-Knowledge. Wissen und Kolonialismus, Zürich: diaphanes.

Fischer-Tiné, Harald (2014), Shyamji Krishnavarma. Sanskrit, Sociology and Anti-Imperialism, New Delhi: Routledge.

Fischer-Tiné, Harald (2015), »The Other Side of Internationalism. Switzerland as a Hub of Militant Anti-Colonialism, c. 1910-1920«, in: Patricia Purtschert und Harald Fischer-Tiné (Hg.), Colonial Switzerland. Rethinking Colonialism from the Margins, Basingstoke: Palgrave Macmillan, 221-258.

Foucault, Michel (1978), Dispositive der Macht. Über Sexualität, Wissen und Wahrheit, Berlin: Merve.

Foucault, Michel (1992), Was ist Kritik?, Berlin: Merve.

Foucault, Michel (1994), Die Ordnung des Diskurses, Frankfurt a.M.: Fischer.

Frankenberg, Ruth (1993), White Women, Race Matters. The Social Construction of Whiteness, London: Routledge. 
Freud, Sigmund (1999a), »Drei Abhandlungen zur Sexualtheorie«, in: Gesammelte Werke, 5. Band, Frankfurt a.M.: Fischer, 27-145.

Freud, Sigmund (1999b), »Totem und Tabu«, Gesammelte Werke, 9. Band, Frankfurt a.M.: Fischer.

Freud, Sigmund (1999c), »Vorlesungen zur Einführung in die Psychoanalyse«, Gesammelte Werke, 11. Band, Frankfurt a.M.: Fischer.

Freud, Sigmund (1999d), »Das Unbehagen in der Kultur«, in: Gesammelte Werke, 14. Band, Frankfurt a.M.: Fischer, 419-506.

Frevert, Ute (1986), Frauen-Geschichte. Zwischen bürgerlicher Verbesserung und neuer Weiblichkeit, Frankfurt a.M.: Suhrkamp.

Friedan, Betty (2010), The Feminine Mystique, London: Penguin Books.

Frohlick, Susan (1999), »The >Hypermasculine< Landscape of High-Altitude Mountaineering «, in: Michigan Feminist Studies, 14: 83-106.

Furrer, Markus, Kevin Heiniger, Thomas Huonker, Sabine Jenzer und Anne-Françoise Praz (Hg.) (2014), »Fürsorge und Zwang: Fremdplatzierung von Kindern und Jugendlichen in der Schweiz 1850-1980«, Itinera 36 .

Gallop, Jane (Hg.) (2006), »Envy« (Special Issue of Women's Studies Quarterly), in: Women's Studies Quarterly, 34 (3\&4): 12-21.

Gandhi, Leela (2006), Affective Communities: Anticolonial Thought, Finde-Siècle Radicalism, and the Politics of Friendship, Durham: Duke University Press.

Gausemeier, Bernd, Staffan Müller-Wille und Edmund Ramsden (Hg.) (2013), Human Heredity in the Twentieth Century, Abingdon: Pickering \& Chatto.

Germann, Pascal (2013), »The Abandonment of Race. Researching Human Diversity in Switzerland, 1944-56«, in: Bernd Gausemeier, Staffan Müller-Wille und Edmund Ramsden (Hg.), Human Heredity in the Twentieth Century, Abingdon: Pickering \& Chatto, 85-99.

Germann, Pascal (2015), »Race in the Making. Colonial Encounters, Body Measurements and the Global Dimensions of Swiss Racial Science, 1900-1950«, in: Patricia Purtschert und Harald Fischer-Tiné (Hg.), Colonial Switzerland. Rethinking Colonialism from the Margins, Basingstoke: Palgrave Macmillan, 50-72.

Germann, Pascal (2016), Laboratorien der Vererbung. Rassenforschung und Humangenetik in der Schweiz, 1900-1970, Göttingen: Wallstein.

Ghosh, Durba und Dane Kennedy (Hg.) (2006), Decentring Empire. Britain, India and the Transcolonial World, London: Sangam Books. 
Gilroy, Paul (1993), The Black Atlantic. Modernity and Double Consciousness, Cambridge MA: Harvard University Press.

Gilroy, Paul (2005), Postcolonial Melancholia, New York: Columbia University Press.

Gmür, Thomas (2010), »Oerlikon-Bührle«, in: Historisches Lexikon der Schweiz. Download unter: www.hls-dhs-dss.ch/textes/d/D41808.php (Zugriff am 15. Juli 2015).

Goldberg, David Theo (2006), »Racial Europeanization«, in: Ethnic and Racial Studies, 29(2): 331-364.

Goltermann, Svenja (1998), »Doppelgänger ihrer selbst. Überlegungen zu Mimesis und Männlichkeit am Beispiel der deutschen Turnbewegung, 1860-1900«, in: Traverse. Zeitschrift für Geschichte, 1: 113-125.

Grabbe, Katharina (2012), »Gemeinschaften Roter Männer: Dakotas, Delawaren und DDR Bürger. >Der Indianer< als Figur eines deutschen Imaginären«, in: Katharina Grabbe, Sigrid G. Köhler und Martina Wagner-Egelhaaf (Hg.), Das Imaginäre der Nation. Zur Persistenz einer politischen Kategorie in Literatur und Film, Bielefeld: transcript, 163-188. Griffin, Ben (2014), The Politics of Gender in Victorian Britain. Masculinity, Political Culture and the Struggle for Women's Rights, New York: Cambridge University Press.

Gubar, Susan (1997), Racechanges. White Skin, Black Face in America, New York: Oxford University Press.

Gugerli, David und Daniel Speich (2002), Topographien der Nation. Politik, kartografische Ordnung und Landschaft im 19. Jahrhundert, Zürich: Chronos.

Gugglberger, Martina (2016), »>Mountain Femininity<. Selbstrepräsentation und Legitimierungsstrategien im Rahmen der ersten HimalayaFrauenexpedition 1955", in: Zeitgeschichte, 43(1): 5-20.

Guillaumin, Colette (2000), »Zur Bedeutung des Begriffs >Rasse««, in: Nora Räthzel (Hg.), Theorien über Rassismus, Hamburg: Argument Verlag, 34-42.

Gurtner, Othmar (1953), »Vorwort«, in: Schweizerische Stiftung für Alpine Forschungen (Hg.), Berge der Welt, Zürich: Büchergilde Gutenberg, 5-6.

Gutmann, Amy (1996), »Responding to Racial Injustice«, in: Kwame A. Appiah und Amy Gutmann, Color Conscious. The Political Morality of Race, Princeton: Princeton University Press, 106-178. 
Ha, Kien Nghi, Nicola Lauré al-Samarai, Sheila Mysorekar (Hg.) (2007), re/visionen. Postkoloniale Perspektiven von People of Color auf Rassismus, Kulturpolitik und Widerstand in Deutschland, Münster: Unrast.

Haas, Stefan (1995), »Die neue Welt der Bilder. Werbung und visuelle Kulturen der Moderne«, in: Peter Borscheid und Clemens Wischermann (Hg.), Bilderwelt des Alltags. Werbung in der Konsumgesellschaft des 19. und 20. Jahrhunderts, Stuttgart: Franz Steiner Verlag, 64-77.

Hall, Catherine, Keith McClelland und Jane Rendall (2000), Defining the Victorian Nation: Class, Race, Gender and the British Reform Act of 1867, Cambridge and New York: Cambridge University Press.

Hall, Stuart (1989), Ideologie, Kultur, Rassismus. Ausgewählte Schriften 1, Hamburg: Argument Verlag.

Hall, Stuart (1992), »The West and the Rest. Discourse and Power«, in: Stuart Hall und Bram Gieben (Hg.), Formations of Modernity, Cambridge: Polity Press, 275-320.

Hall, Stuart (1996), »The Question of Cultural Identity«, in: Stuart Hall, David Held, Don Hubert und Kenneth Thompson (Hg.), Modernity. An Introduction to Modern Societies, Oxford: Blackwell, 596-633.

Hall, Stuart (2000a), »Rassismus als ideologischer Diskurs«, in: Nora Räthzel (Hg.), Theorien über Rassismus, Hamburg: Argument Verlag, 7-16.

Hall, Stuart (2000b), »Who Needs >Identity<?«, in: Paul du Gay, Jessica Evans und Peter Redman (Hg.), Identity. A Reader, London: Sage, 15-30. Hall, Stuart (2004a), »Die Frage des Multikulturalismus«, in: Stuart Hall, Ideologie, Identität, Repräsentation. Ausgewählte Schriften 4, Hamburg: Argument Verlag, 188-227.

Hall, Stuart (2004b), »Die Konstruktion von >Rasse in den Medien«, in: Stuart Hall, Ideologie, Identität, Repräsentation. Ausgewählte Schriften 4, Hamburg: Argument Verlag, 150-171.

Hall, Stuart (2013), »Wann gab es >das Postkoloniale<? Denken an der Grenze«, in: Sebastian Conrad, Shalini Randeria und Regina Römhild (Hg.), Jenseits des Eurozentrismus. Postkoloniale Perspektiven in den Geschichts- und Kulturwissenschaften, Frankfurt a.M.: Campus, 197-223.

Haller-Dirr, Martina (2010), »Missionen«, in: Historisches Lexikon der Schweiz. Download unter: www.hls-dhs-dss.ch/textes/d/D11456.php (Zugriff am 24. Oktober 2018). 
Hansen, Peter H. (1995), »Albert Smith, the Alpine Club, and the Invention of Mountaineering in Mid-Victorian Britain«, in: The Journal of British Studies, 34(3): 300-324.

Hansen, Peter H. (1996), »The Dancing Lamas of Everest. Cinema, Orientalism, and Anglo-Tibetan Relations in the 1920s«, in: American Historical Review, 101(3): 712-747.

Hansen, Peter H. (1997), »Tenzing's Two Wrist-Watches. The Conquest of Everest and Late Imperial Culture in Britain 1921-1953«, in: Past Q Present, 157: 159-177.

Hansen, Peter H. (1999), »Partners: Guides and Sherpas in the Alps and Himalayas, 1850s-1950s«, in: Jas Elsner und Joan-Pau Rubiés (Hg.), Voyages and Visions. Towards a Cultural History of Travel, London: Reaktion Books, 210-231.

Hansen, Peter H. (2000), »Confetti of Empire. The Conquest of Everest in Nepal, India, Britain, and New Zealand«, in: Comparative Studies in Society and History, 42(2): 307-332.

Hansen, Peter H. (2013), The Summits of Modern Man. Mountaineering After Enlightenment, Cambridge MA: Harvard University Press.

Haritaworn, Jin (2015), Queer lovers and hateful others. Regenerating Violent Times and Places, London: Pluto Press.

Harries, Patrick (2007a), Butterflies \& Barbarians. Swiss Missionaries in South-East Africa, Oxford: James Currey.

Harries, Patrick (2007b), »From the Alps to Africa. Swiss Missionaries and Anthropology«, in: Helen Tilley und Robert J. Gordon (Hg.), Ordering Africa. Anthropology, European Imperialism, and the Politics of Knowledge, Manchester: Manchester University Press, 201-224.

Hartman, Saidiya (2007), Lose your Mother: A Journey Along the Atlantic Slave Route, New York: Farrar, Straus and Giroux.

Haschemi Yekani, Elahe (2011), The Privilege of Crisis. Narratives of Masculinities in Colonial and Postcolonial Literature, Photography and Film, Frankfurt a.M.: Campus.

Hausen, Karin (1976), »Die Polarisierung der >Geschlechtscharaktere <Eine Spiegelung der Dissoziation von Erwerbs- und Familienleben«, in: Werner Conze (Hg.), Sozialgeschichte der Familie in der Neuzeit Europas, Stuttgart: Ernst Klett Verlag, 363-395.

Heim, Arnold (1934), Negro Sahara. Von der Guineaküste zum Mittelmeer, Bern: Huber. 
Heim, Arnold (1938), Thron der Götter. Erlebnisse der ersten Schweizerischen Himalaya-Expedition, Zürich: Morgarten-Verlag.

Heim, Arnold (1950), »In den Zentralen Nepal-Himalaya 1949«, in: Schweizerische Stiftung für Alpine Forschungen (Hg.), Berge der Welt 5, Zürich: Büchergilde Gutenberg, 107-113.

Heim, Arnold (1953), Südamerika. Naturerlebnisse auf Reisen in Chile, Argentinien und Bolivien, Bern: Huber.

Heim, Arnold (1957), Wunderland Peru. Naturerlebnisse, Bern: Huber.

Hodel, Fabian (2010), »Pilatus Flugzeugwerke«, in: Historisches Lexikon der Schweiz. Download unter: www.hls-dhs-dss.ch/textes/d/D41935. php (Zugriff am 15. Juli 2014).

Hollenstein, Pia (2003), Interpellation 03.3014. Schweizer Beteiligungan Sklaverei und transatlantischem Handel mit Sklavinnen und Sklaven. Download unter:https://www.parlament.ch/de/ratsbetrieb/suche-curia-vista /geschaeft?AffairId=20033014 (Zugriff am 14. Juni 2016).

Honegger, Claudia (1991), Die Ordnung der Geschlechter: die Wissenschaften vom Menschen und das Weib, 1750-1850, Frankfurt a.M.: Campus.

hooks, bell (1992), Black Looks. Race and Representation, Boston: South End Press.

Horkheimer, Max und Theodor W. Adorno (2001), Dialektik der Aufklärung. Philosophische Fragmente, Frankfurt a.M.: Fischer.

Hund, Wulf D., Michael Pickering und Anandi Ramamurthy (2013), »Editorial«, in: Wulf D. Hund, Michael Pickering und Anandi Ramamurthy (Hg.), Colonial Advertising \& Commodity Racism, Zürich: LIT, 7-17.

Hungerbühler, Andrea (2009), »Hegemoniale Maskulinität im Bergführerberuf? Empirische Befunde und theoretische Implikationen«, in: Christa Binswanger, Margaret Bridges, Brigitte Schnegg und Doris Wastl-Walter (Hg.), Gender Scripts. Widerspenstige Aneignungen von Geschlechternormen, Frankfurt a.M.: Campus, 119-141.

Hungerbühler, Andrea (2013a), Könige der Alpen. Zur Kultur des Bergführerberufs, Bielefeld: transcript.

Hungerbühler, Andrea (2013b), »Vom >Ignoranten< zum Idealschweizer«, in: Daniel Anker (Hg.), Helvetia Club. 1863-2013, Bern: SAC Verlag, $82-85$.

Hunt, John (1954), »Preface«, in: René Dittert, Gabriel Chevalley und Raymond Lambert, Forerunners to Everest. The Story of Two Swiss Expeditions of 1952, London: Harper, o.S. 
Hunt, John (1984), »Dr Edouard Wyss-Dunant 1897-1983 (Hon. Member 1949)«, in: The Alpine Journal: 262-263.

Husmann-Kastein, Jana (2006), »Schwarz-Weiss. Farb- und Geschlechtssymbolik in den Anfängen der Rassenkonstruktionen«, in: Martina Tissberger, Gabriele Dietze, Daniela Hrzan und Jana Husmann-Kastein (Hg.), Weiss - Weisssein - Whiteness. Kritische Studien zu Gender und Rassismus, Frankfurt a.M.: Peter Lang, 43-6o.

Husmann-Kastein, Jana (2010), Schwarz-Weiß-Symbolik. Dualistische Denktraditionen und die Imagination von >Rasse<, Bielefeld: transcript.

Imhof, Kurt (2010). »Das Böse. Zur Weltordnung des Kalten Krieges in der Schweiz«, in: Juerg Albrecht, Georg Kohler und Bruno Mauerer (Hg.), Expansion der Moderne. Wirtschaftswunder - Kalter Krieg - Avantgarde - Populärkultur, Zürich: gta Verlag, 81-104.

Ingold, Niklaus (2015), Lichtduschen. Geschichte einer Gesundheitstechnik, 1890-1975, Zürich: Chronos.

Irigaray, Luce (1979), Das Geschlecht, das nicht eins ist, Berlin: Merve.

Irigaray, Luce (1980), Speculum. Spiegel des anderen Geschlechts, Frankfurt a.M.: Suhrkamp.

Iso, Isabel Miko (2008), »'Weiss - wie Schneewittchen««, in: Olympe, 27: 7-19.

Ittmann, Karl (1995), Work, gender and family in Victorian England, Basingstoke: Palgrave Macmillan.

Jacobs, Ingrid und Anna Weicker (2011), »Afrika«, in: Susan Arndt und Nadja Ofuatey-Alazard (Hg.), (K)Erben des Kolonialismus im Wissensarchiv deutsche Sprache. Ein kritisches Nachschlagewerk, Münster: Unrast Verlag, 200-214.

Jain, Rohit (2012), »Die Comedyfigur Rajiv Prasad in >Viktors Spätprogramm< - Post_koloniales Phantasma und die Krise des >Sonderfalls Schweiz««, in: Patricia Purtschert, Barbara Lüthi und Francesca Falk (Hg.), Postkoloniale Schweiz. Formen und Folgen eines Kolonialismus ohne Kolonien, Bielefeld: transcript, 175-199.

Jain, Rohit (2015), »Bollywood, Chicken Curry - and IT: The Public Spectacle of the Indian Exotic, and Postcolonial Anxieties in Switzerland«, in: Patricia Purtschert und Harald Fischer-Tiné (Hg.), Colonial Switzerland. Rethinking Colonialism from the Margins, Basingstoke: Palgrave Macmillan, 133-153. 
Jain, Rohit (2018), Kosmopolitische Pioniere. >Inder_innen der zweiten Generation aus der Schweiz zwischen Assimilation, Exotik und globaler Moderne, Bielefeld: transcript.

Jeannin-Jaquet, Isabelle (2008), »Tilo Frey«, in: Historisches Lexikon der Schweiz. Download unter: www.hls-dhs-dss.ch/textes/d/D6042.php (Zugriff am 21. Oktober 2015).

Jorio, Marco (2006), »Geistige Landesverteidigung«, in: Historisches Lexikon der Schweiz. Download unter: www.hls-dhs-dss.ch/textes/d/ D17426.php (Zugriff am 2. Oktober 2015).

Joris, Elisabeth (1990), »Die Schweizer Hausfrau«, in: Sebastian Brändli und Rudolf Braun (Hg.), Schweiz im Wandel. Studien zur neuen Gesellschaftsgeschichte, Basel: Helbing und Lichtenhahn, 99-116.

Joris, Elisabeth (2003), »Krieg, Propaganda und Geschlecht«, in: Christof Dejung und Regula Stämpfli (Hg.), Armee, Staat und Geschlecht. Die Schweiz im internationalen Vergleich 1918-1945. Zürich: Chronos, 229248.

Joris, Elisabeth (2012), »Dezenter Sexappeal - eklatante Diskriminierung. Weiblichkeits- und Männlichkeitsmythen in Zeiten von Textilrevolution und Kaltem Krieg«, in: Thomas Buomberger und Peter Pfrunder (Hg.), Schöner leben, mehr haben. Die 5oer Jahre in der Schweiz im Geiste des Konsums, Zürich: Limmat Verlag, 105-119.

Joris, Elisabeth (2014), »Die Fifties. Geschlechterimplikationen in den Fotoreportagen der 1950 er Jahre«, in: Sabine Braunschweig (Hg.), >Als habe es die Frauen nicht gegeben<, Zürich: Chronos, 245-262.

Joris, Elisabeth (2015), »Hausarbeit«, in: Historisches Lexikon der Schweiz. Download unter: www.hls-dhs-dss.ch/textes/d/D14072.php (Zugriff am 17. September 2015).

Joris, Elisabeth (2016), »Tunnelbau und Grossindustrie im Oberwallis: eine Geschichte von Männern und Frauen«, in: Luigi Lorenzetti und Nelly Valsangiacomo (Hg.), Alpi e patrimonio industriale. Cultura e memoria, XIX-XX sec./Alpes et patrimoine industriel. Culture et mémoire, XIXe-XXe siècles/Alpen und industrielles Erbe. Kultur und Erinnerung, 19.-20. Jahrhundert. Mendrisio: Mendrisio Academy Press, 23-53.

Joris, Elisabeth und Heidi Witzig (1986), Frauengeschichte(n). Dokumente aus zwei Jahrhunderten zur Situation der Frauen in der Schweiz, Zürich: Limmat Verlag.

Jost, Hans Ulrich (1998), Politik und Wirtschaft im Krieg. Die Schweiz 19381948, Zürich: Chronos. 
Kamis-Müller, Aaron (2000), Antisemitismus in der Schweiz, 1900-1930, Zürich: Chronos.

Kant, Immanuel (2006), Kritik der Urteilskraft, Hamburg: Felix Meiner Verlag.

Keller, Christoph (1995), Der Schädelvermesser: Otto Schlaginhaufen - Anthropologe und Rassenhygieniker. Eine biographische Reportage, Zürich: Limmat Verlag.

Keller, Erich (2006), »Das Herauskristallisieren der Rasse. Vom langsamen Verschwinden eines Phantoms am Anthropologischen Institut in Zürich«, in: Historische Anthropologie, 14(1): 46-67.

Kerner, Ina (2009), Differenzen und Macht. Zur Anatomie von Rassismus und Sexismus, Frankfurt a.M.: Campus.

Kerner, Ina (2012), Postkoloniale Theorien. Eine Einführung, Hamburg: Junius.

Kilomba, Grada (2009), »Das N-Wort«. Download unter: www.bpb.de/ge sellschaft/migration/afrikanische-diaspora/59448/das-n-wort? $\mathrm{p}=$ all (Zugriff am 14. Juni 2018).

Kohler, Georg (2012), »Konsumglück, Kalter Krieg und Zweite Moderne. Die Schweiz und die Fifties«, in: Thomas Buomberger und Peter Pfrunder (Hg.), Schöner leben, mehr haben. Die 5oer Jahre in der Schweiz im Geiste des Konsums, Zürich: Limmat Verlag, 7-19.

Komitee zur Gründung des SSAF (1972), »Aufruf - Schweizerische Auslandsexpeditionen«, in: Schweizerische Stiftung für Alpine Forschungen (Hg.), Schweizerische Stiftung für Alpine Forschungen 1939 bis 1970. Rückblick auf ihre 3ojährige Tätigkeit, Zürich: SSAF, 1-4.

König, Mario (2004), »Von der wahren Nationalität der Waren. Schweizerische Wirtschaftspropaganda im 20. Jahrhundert«, in: Elio Pellin und Elisabeth Ryter (Hg.), Weiss auf Rot. Das Schweizer Kreuz zwischen nationaler Identität und Corporate Identity, Zürich: Verlag Neue Zürcher Zeitung, 129-140.

König, Mario, Hannes Siegrist und Rudolf Vetterli (1985), Warten und Aufrücken. Die Angestellten in der Schweiz 1870-1950, Zürich: Chronos.

König, Wolfgang (2000), Geschichte der Konsumgesellschaft, Stuttgart: Franz Steiner Verlag.

Kreis, Georg (2012a), »Stauffacherin«, in: Historisches Lexikon der Schweiz. Download unter: www.hls-dhs-dss.ch/textes/d/D47808.php (Zugriff am 4. November 2015). 
Kreis, Georg (2012b), »Sonderfall«, in: Historisches Lexikon der Schweiz. Download unter: www.hls-dhs-dss.ch/textes/d/D49556.php (Zugriff am 28. November 2015).

Kreisky, Eva (2011), »Staatenlenker und Staatsdiener. Männlichkeiten im Bild des Staates«, in: Eva Kreisky, Marion Löffler und Sabine Zelger (Hg.), Staatsfiktionen. Denkbilder moderner Staatlichkeit, Wien: Facultas Verlag, 27-49.

Kury, Patrick (2003), Über Fremde reden. Überfremdungsdiskurs und Ausgrenzung in der Schweiz 1900-1945, Zürich: Chronos.

Kurz, Marcel (1950), »Chronologie der Himalaya-Expeditionen«, in: Schweizerische Stiftung für Alpine Forschungen (Hg.), Berge der Welt, Zürich: Büchergilde Gutenberg, 200-212.

Kurz, Marcel (1953), »Liste der Himalaya-Hochträger«, in: Journal der SSAF, 1(1): 1-20.

Lambert, Raymond (1953), A l'assault des >quatre mille<, 2. überarbeitete Auflage, Genf: Editions Jeheber.

Lambert, Raymond und Claude Kogan (1955), Record à l'Himalaya, Paris: Edition France Empire.

Lang, Karl (1932), »Die >faulen< N[...]«, in: Schweizer Monatshefte, 11(11/12): 622-624.

Laqueur, Thomas (1992), Auf den Leib geschrieben. Die Inszenierung der Geschlechter von der Antike bis Freud, Frankfurt a.M.: Campus.

Lavanchy, Anne (2015), »Glimpses into the Hearts of Whiteness: Institutions of Intimacy and the Desirable National«, in: Patricia Purtschert und Harald Fischer-Tiné (Hg.), Colonial Switzerland. Rethinking Colonialism from the Margins, Basingstoke: Palgrave Macmillan, 278-295.

Leuenberger, Marco und Loretta Seglias (Hg.) (2008), Versorgt und vergessen. Ehemalige Verdingkinder erzählen, Zürich: Rotpunktverlag.

Leuthard, Doris (2017), Visite à Ouidah: La Présidente Suisse Doris Leuthard se prononce sur l'histoire de l'esclavage. https://www.youtube. com/watch?v=ogMgptOuLLo (Zugriff am 24. Oktober 2018).

Levine, Philippa (Hg.) (2004), Gender and Empire, Oxford: Oxford University Press.

Liebeskind Sauthier, Ingrid (2013), »Warenhäuser«, in: Historisches Lexikon der Schweiz. Download unter: www.hls-dhs-dss.ch/textes/d/ D14037.php (Zugriff am 4. Februar 2015).

Linder, Wolf (2010), Swiss Democracy: Possible Solutions to Conflict in Multicultural Societies, Basingstoke: Palgrave Macmillan. 
Liver, Ricarda (2012), »Rätoromanisch«, in: Historisches Lexikon der Schweiz. Download unter: www.hls-dhs-dss.ch/textes/d/D24594.php (Zugriff am 12. November 2015).

Lobsiger-Dellenbach, Marguerite (1952), »Ethnologie«, in: Marguerite Lobsiger-Dellenbach, Augustin Lombard und Albert Zimmermann (Hg.), Himalaya du Nepal. Mission scientifique genevoise, Genève: Editions Jeheber, 41-44.

Lobsiger-Dellenbach, Marguerite (1953), »Contribution à l'étude anthropologique du Népal«, in: Archives Suisses d'anthropologie générale, 17(2): 97-113.

Loderer, Benedikt (2012), »Im Armeereformhaus. Das Sturmgewehr 57 als Fundament der Armee , in: Thomas Buomberger und Peter Pfrunder (Hg.), Schöner leben, mehr haben. Die 5oer Jahre in der Schweiz im Geiste des Konsums, Zürich: Limmat Verlag, 201-215.

Loftsdóttir, Kristín (2010), »The Loss of Innocence. The Icelandic Financial Crisis and Colonial Past«, in: Anthropology Today, 26(6): 9-13.

Loftsdóttir, Kristín (2011), »Negotiating White Icelandic Identity. Multiculturalism and Colonial Identity Formations«, in: Social Identities, 17(1): 11-25.

Loftsdóttir, Kristín (2012), »Colonialism at the Margins. Politics of Difference in Europe as seen through two Icelandic Crises«, in: Identities. Global Studies in Culture and Power, 19(5): 597-615.

Loftsdóttir, Kristín und Lars Jensen (2012), Whiteness and Postcolonialism in the Nordic Region: Exceptionalism, Migrant Others and National Identities, Farnham: Ashgate.

Lorey, Isabel (2006), »Der weisse Körper als feministischer Fetisch. Konsequenzen aus der Ausblendung des deutschen Kolonialismus«, in: Martina Tissberger, Gabriele Dietze, Daniela Hrzan und Jana Husmann-Kastein (Hg.), Weiss - Weisssein - Whiteness. Kritische Studien zu Gender und Rassismus, Frankfurt a.M.: Peter Lang, 291-299.

Lüdi, Georges und Iwar Werlen (2005), Sprachenlandschaft der Schweiz, Neuchâtel: Bundesamt für Statistik.

Lugones, María (2007), »Heterosexualism and the Colonial/Modern Gender System«, in: Hypatia, 22(1): 186-209.

Lugones, María (2010), »Toward a Decolonial Feminism«, in: Hypatia, 25(4): 742-759.

Lury, Celia (2011), Consumer Culture, Cambridge: Polity Press. 
Lüthi, Barbara, Francesca Falk und Patricia Purtschert (2016), »Colonialism without colonies: examining blank spaces in colonial studies«, in: Colonialism without Colonies: Examining Blank Spaces in Colonial Studies. Special Issue von National Identities, 18(1): 1-9.

Macleod, Roy M. und Deepak Kumar (Hg.) (1995), Technology and the Raj. Western Technology and Technical Transfers to India 1700-1947, New Delhi: Sage.

Maihofer, Andrea (1995), Geschlecht als Existenzweise. Macht, Moral, Recht und Geschlechterdifferenz, Frankfurt a.M.: Ulrike Helmer Verlag.

Maihofer, Andrea (2001), »Dialektik der Aufklärung. Die Entstehung der modernen Gleichheitsidee, des Diskurses der qualitativen Rassendifferenz und der Rassentheorien im 18. Jahrhundert«, in: Steffi Hobuss, Christina Schües, Nina Zimnik, Birgit Hartmann und Iulia Patrut (Hg.), Die andere Hälfte der Globalisierung. Menschenrechte, Ökonomie und Medialität aus feministischer Sicht, Frankfurt a.M.: Campus, 113132.

Maihofer, Andrea (2002), »Gender Studies. Von der Frauen- zur Geschlechterforschung «, in: Zeitschrift für schweizerische Archäologie und Kunstgeschichte, 59: 83-88.

Mailer, Norman (1957), The White Negro, San Francisco: City Lights Books.

Manjapra, Kris (2014a), Age of Entanglement. German and Indian Intellectuals Across Empire, Cambridge MA: Harvard University Press.

Manjapra, Kris (2014b), »Transnational Approaches to Global History. A View from the Study of German-Indian Entanglement«, in: German History, 32(2): 274-293.

Mann, Michael (2004), »>Torchbearer Upon the Path of Progress $<$. Britain's Ideology of a >Moral and Material Progress< in India«, in: Harald Fischer-Tiné und Michael Mann (Hg.), Colonialism as Civilizing Mission. Cultural Ideology in British India, London: Anthem Press, 1-26.

Marchal, Guy P. (1992), »Das >Schweizeralpenland<. Eine imagologische Bastelei«, in: Guy P. Marchal und Aram Mattioli (Hg.), Erfundene Schweiz. Konstruktionen nationaler Identität, Zürich: Chronos, 37-49.

Marchal, Guy P. und Aram Mattioli (Hg.) (1992), Erfundene Schweiz. Konstruktionen nationaler Identität, Zürich: Chronos.

Marti, Sybille (2015), »Den modernen Krieg simulieren. Imaginationen und Praxis totaler Landesverteidigung in der Schweiz«, in: David Eugster und Sybille Marti (Hg.), Das Imaginäre des Kalten Krieges. Beiträge zu einer Kulturgeschichte des Ost-West-Konfliktes in Europa. Frieden 
und Krieg. Beiträge zur Historischen Friedensforschung Band 21, Essen: Klartext, 243-268.

Martin, Charles D. (2002), The White African American Body. A Cultural and Literary Exploration, New Brunswick: Rutgers University Press.

Mathieu, Jon (2005), »Alpenwahrnehmung. Probleme der historischen Periodisierung«, in: Jon Mathieu und Simona Boscani Leoni (Hg.), Die Alpen! Zur europäischen Wahrnehmungsgeschichte seit der Renaissance, Bern: Peter Lang, 53-72.

Mathieu, Jon und Simona Boscani Leoni (Hg.) (2005a), Die Alpen! Zur europäischen Wahrnehmungsgeschichte seit der Renaissance, Bern: Peter Lang.

Mathieu, Jon und Simona Boscani Leoni (2005b), »Einführung und Zusammenfassungen «, in: Jon Mathieu und Simona Boscani Leoni (Hg.), Die Alpen! Zur europäischen Wahrnehmungsgeschichte seit der Renaissance, Bern: Peter Lang, 9-30.

Mattioli, Aram (1995), »Die intellektuelle Rechte und die Krise der demokratischen Schweiz. Überlegungen zu einem zeitgeschichtlichen Niemandsland«, in: Aram Mattioli (Hg.), Intellektuelle von rechts. Ideologie und Politik in der Schweiz 1918-1939, Zürich: Orell Füssli, 1-28.

Mbembe, Achille (2001), On the Postcolony, Berkeley: University of California Press.

Mbembe, Achille (2013), »Frankreich provinzialisieren?«, in: Sebastian Conrad, Shalini Randeria und Regina Römhild (Hg.), Jenseits des Eurozentrismus. Postkoloniale Perspektiven in den Geschichts- und Kulturwissenschaften, Frankfurt a.M.: Campus, 224-263.

Mbembe, Achille (2014), Kritik der schwarzen Vernunft, Berlin: Suhrkamp.

McClintock, Anne (1993), »Family Feuds. Gender, Nationalism and the Family«, in: Feminist Review, 44: 61-80.

McClintock, Anne (1995), Imperial Leather. Race, Gender and Sexuality in the Colonial Contest, New York: Routledge.

Meier, Marietta, Urs Germann, Brigitta Bernet und Roswitha Dubach (2007), Zwang zur Ordnung. Psychiatrie im Kanton Zürich, 1870-1970, Zürich: Chronos.

Meintel, Katja (2007), »Nachwort«, in: Abdourahman Waberi, In den Vereinigten Staaten von Afrika, Hamburg: Nautilus, 147-152.

Mesmer, Beatrix (1988), Ausgeklammert - Eingeklammert. Frauen und Frauenorganisationen in der Schweiz des 19. Jahrhunderts, Basel und Frankfurt a.M.: Helbing und Lichtenhahn. 
Mesquita, Sushila (2011), Ban Marriage. Ambivalenzen der Normalisierung aus queer-feministischer Perspektive, Wien: Zaglossus.

Mesquita, Sushila und Patricia Purtschert (2016), »Gay Governance: Challenges to Coalition Building against Homophobia in Postcolonial Switzerland «, in: Delphine Gardey und Cynthia Kraus (Hg.): Politics of Coalition. Thinking Collective Action with Judith Butler, Zürich: Seismo, 140-167.

Michel, Noémi (2014), Quand les mots et les images blessent. Postcolonialité, égalité et politique des actes de discours en Suisse et en France, Universität Genf: unveröffentlichte Doktorarbeit.

Michel, Noémi (2015), »Sheepology: The Postcolonial Politics of Raceless Racism in Switzerland «, in: Postcolonial Studies, 18(4) (Postcolonial Europe): $410-426$.

Michel, Noémi und Manuela Honegger (2010), »Thinking Whiteness in French and Swiss Cyberspaces«, in: Social Politics, 17(4): 423-449.

Mignolo, Walter D. (2009), »Epistemic Disobedience, Independent Thought and De-Colonial Freedom«, in: Theory, Culture a Society, 26(7/8): 1-23.

Minder, Patrick (2008), »Human Zoos in Switzerland«, in: Pascal Blanchard, Nicolas Bancel, Gilles Boëtsch, Eric Deroo, Sandrine Lemaire und Charles Forsdick (Hg.), Human Zoos. Science and Spectacle in the Age of Colonial Empires, Liverpool: Liverpool University Press, 328-340.

Minder, Patrick (2011), La Suisse coloniale? Les représentations de l'Afrique et des Africains en Suisse au temps des colonies (1880-1939), Bern: Peter Lang.

Mintz, Sidney (1987), Die süsse Macht. Kulturgeschichte des Zuckers, Frankfurt a.M.: Campus.

Mitchell, Timothy (2013), »Die Welt als Ausstellung«, in: Sebastian Conrad, Shalini Randeria und Regina Römhild (Hg.), Jenseits des Eurozentrismus. Postkoloniale Perspektiven in den Geschichts- und Kulturwissenschaften, Frankfurt a.M.: Campus, 438-465.

Mittelholzer, Walter (1927), Afrikaflug, Zürich: Orell Füssli.

Mittelholzer, Walter (1930), Kilimandjaro Flug, Zürich: Orell Füssli.

Mittelholzer, Walter (Hg.) (1934), Abessinienflug, Zürich: Verlag Schweizer Aero-Revue. 
Mittelholzer, Walter, René Couzy und Arnold Heim (1927), Afrika-Flug. Im Wasserflugzeug >Switzerland<von Zürich über den dunklen Erdteil nach dem Kap der guten Hoffnung, Zürich: Orell Füssli.

Morrison, Toni (1994), Im Dunkeln spielen. Weisse Kultur und literarische Imagination, Reinbek bei Hamburg: Rowohlt.

Morrison, Toni: »Making America White Again«, in: The New Yorker, 21. November 2016.

Mudimbe, Valentin Y. (1988), The Ivention of Africa. Gnosis, Philosophy, and the Order of Knowledge, Bloomington: Indiana University Press.

Mulinari, Diana, Suvi Keskinen, Sari Irni und Salla Tuori (2009), »Introduction. Postcolonialism and the Nordic Models of Welfare and Gender«, in: Suvi Keskinen, Salla Tuori, Sari Irni und Diana Mulinari (Hg.), Complying with Colonialism. Gender, Race and Ethnicity in the Nordic Region, Farnham: Ashgate, 1-16.

Müller-Wille, Staffan (2003), »Was ist Rasse? Die UNESCO-Erklärungen von 1950 und 1951«, in: Petra Lutz, Thomas Macho, Gisela Staupe und Heike Zirden (Hg.), Der (im-)perfekte Mensch. Metamorphosen von Normalität und Abweichung, Köln: Böhlau, 79-93.

N.N. (1883), »La part des Suisses dans l'exploration et la civilization de l'Afrique«, in: L'Afrique explorée et civilisée, 4: 21-29.

Nandy, Ashis (1983), The Intimate Enemy. Loss and Recovery of Self under Colonialism, Oxford: Oxford University Press.

Nenno, Nancy (1999), »Weiblichkeit - Primitivität - Metropole. Josephine Baker in Berlin«, in: Katharina von Ankum (Hg.), Frauen in der Großstadt. Herausforderung der Moderne?, Dortmund: Edition Ebersbach, 136-158.

Nickel, Andreas (2007), Günter, Hettie, Norman Dyhrenfurth. Zum dritten Pol, Zürich: AS-Verlag.

Nietzsche, Friedrich (1999), »Zur Genealogie der Moral«, in: Giorgio Colli und Mazzino Montinari (Hg.), Kritische Studienausgabe, Band 5, Berlin: de Gruyter, 245-412.

Norgay, Tenzing, und James Ramsey Ullman (1955), Der Tiger vom Everest. Die Autobiographie Sherpa Tenzings, Wiesbaden: Rheinische VerlagsAnstalt.

Oechsli, Wilhelm (1905), Geschichte der Gründung des Eidgenössischen Polytechnikums, Frauenfeld: Huber \& Co.

Opitz, May (1986), »Rassismus, Sexismus und vorkoloniales Afrikabild in Deutschland«, in: Katharina Oguntoye, May Opitz und Dagmar 
Schultz (Hg.), Farbe bekennen. Afro-deutsche Frauen auf den Spuren ihrer Geschichte, Frankfurt a.M.: Orlanda-Verlag, 17-64.

Ortner, Sherry B. (1997), »Thick Resistance. Death and the Cultural Construction of Agency in Himalayan Mountaineering«, in: Representations, 59: 135-162.

Ortner, Sherry B. (1999), Life and Death on Mt. Everest. Sherpas and Himalayan Mountaineering, Princeton: Princeton University Press.

Oyěwùmí, Oyèrónkẹ́ (I997), The Invention of Women. Making an African Sense of Western Gender Discourses, Minnesota: University of Minnesota Press.

Painter, Nell Irvin (2010), The History of White People, New York: Norton. Pasquier, Serge (2006), »Elektrifizierung«, in: Historisches Lexikon der Schweiz. Download unter: www.hls-dhs-dss.ch/textes/d/D13845.php (Zugriff am 28. September 2015).

Patterson, Orlando (1982), Slavery and Social Death. A Comparative Study, Cambridge MA: Harvard University Press.

Paumgarten, Nick (2013), »The Manic Mountain. Ueli Steck and the Clash on Everest«, in: The New Yorker, 3. Juni 2013. Download unter: www. newyorker.com/magazine/2013/06/03/the-manic-mountain (Zugriff am 14. Oktober 2015).

Peck, Raoul (2017), I am not your Negro, Switzerland, France, Belgium, USA, New York: Vintage Books.

Pfäffli, Lea (2015), »Diplomatie statt Heldentum. Robert Haefeli, die Schweizer Polarforschung und der Kalte Krieg«, in: Patrick Kupper und Bernhard C. Schär (Hg.), Die Naturforschenden. Auf der Suche nach Wissen über die Schweiz und die Welt, 1800 - 2015, Zürich: Chronos, 211-224.

Pfeisinger, Gerhard und Stefan Schennach (Hg.) (1989), Kolonialwaren. Die Schaffung der ungleichen Welt, Göttingen: Lamuv.

Pfenninger, Ernst (2007), Globus - das Besondere im Alltag. Das Warenhaus als Spiegel der Gesellschaft, Zürich: Verlag Neue Zürcher Zeitung. Piesche, Peggy und Susan Arndt (2011), »Weisssein. Die Notwendigkeit kritischer Weissseinsforschung «, in: Susan Arndt und Nadja OfuateyAlazard (Hg.), (K)Erben des Kolonialismus im Wissensarchiv deutsche Sprache. Ein kritisches Nachschlagewerk, Münster: Unrast Verlag, 192193. 
Pilet-Golaz, Marcel (1934), »Zum Geleit«, in: Mittelholzer, Walter, Abessinienflug. Mit dem dreimotorigen Fokker an den Hof des Negus Negesti, Zürich: Verlag Schweizer Aero-Revue, 11-12.

Pinto, Jovita dos Santos (2013), »Spuren. Eine Geschichte Schwarzer Frauen in der Schweiz«, in: Shelley Berlowitz, Elisabeth Joris und Zeedah Meierhofer-Mangeli (Hg.), Terra incognita? Der Treffpunkt Schwarzer Frauen in Zürich, Zürich: Limmat Verlag, 143-185.

Pinto, Jovita dos Santos (2014), >Oui, c'est un long chemin<. Tilo Frey, erste Schwarze Nationalrätin. Eine Spurensuche in Schweizer Medien, (19702011), Universität Zürich: unveröffentlichte Lizentiatsarbeit.

Pinto, Jovita dos Santos (2018), »Besitzen, s/exotisieren, vergessen - Sklaverei, Einbürgerung und Rassisierung um 1798«, Vortrag an der Tagung »Von der Kolonisierung zur Globalisierung. Weshalb wir Schweizer Geschichte neu denken sollten«, Universität Bern, 20. April 2018.

Pittard, Eugène und Marguerite Dellenbach (1931), L'augmentation de la stature en Suisse en cours de 25 ans, Bern: Stämpfli.

Polianski, Igor J. und Matthias Schwartz (Hg.) (2009), Die Spur des Sputnik. Kulturhistorische Expeditionen ins kosmische Zeitalter, Frankfurt a.M.: Campus.

Porrini, Andrea (2013), »Unsere Alpen, unsere Schweiz!«, in: Daniel Anker (Hg.), Helvetia Club. 1863-2013, Bern: SAC Verlag, 50-52.

Pous, Jacques (1979), Henry Dunant, l'Algérien ou le mirage colonial, Genf: Grounauer.

Pratt, Mary Louise (1985), »Scratches on the Face of the Country. Or, What Mr. Barrow Saw in the Land of the Bushmen«, in: Critical Inquiry, 12(1): 119-143.

Pratt, Mary Louise (1990), »Women, Literature, and National Brotherhood «, in: Seminar on Feminism and Culture in Latin America (Hg.), Women, Culture, and Politics in Latin America, Berkeley: University of California Press, 48-73.

Pratt, Mary Louise (1992), Imperial Eyes. Travel Writing and Transculturation, New York: Routledge.

Prodolliet, Simone (1987), Wider die Schamlosigkeit und das Elend der heidnischen Weiber. Die Basler Frauenmission und der Export des europäischen Frauenideals in die Kolonien, Zürich: Limmat Verlag.

Puar, Jasbir K. (2007), Terrorist Assemblages. Homonationalism in Queer Times. Durham, London: Duke University Press. 
Purtschert, Patricia (2006), Grenzfiguren. Kultur, Geschlecht und Subjekt bei Hegel und Nietzsche, Frankfurt a.M.: Campus.

Purtschert, Patricia (2008a), »Postkoloniale Diskurse in der Schweiz. >De Schorsch Gaggo reist uf Afrika««, in: Widerspruch, 28(54): 169-180.

Purtschert, Patricia (2008b), »)Heute bedankt sich Naresh Khan bei Silvia Hug für ihr Engagement<. Notizen zur postkolonialen Schweiz«, in: Olympe, 27: 76-87.

Purtschert, Patricia (2010a), »On the Limit of Spirit. Hegel's Racism Revisited «, in: Philosophy Q Social Criticism, 36(9): 1039-1051.

Purtschert, Patricia (2010b), Früh los. Im Gespräch mit Bergsteigerinnen über siebzig, Baden: hier + jetzt.

Purtschert, Patricia (2011a), »Chewing on Post_colonial Switzerland. Redigesting what has not yet been swallowed, Part $\mathrm{I} \ll$, in: Andrea Thal (Hg.), Chewing the Scenery 1, Zürich: Edition Fink, 173-176/199-202.

Purtschert, Patricia (2011b), »Chewing on Post_colonial Switzerland. Redigesting what has not yet been swallowed, Part II«, in: Andrea Thal (Hg.), Chewing the Scenery 2, Zürich: Edition Fink, 95-100/121-126/149154.

Purtschert, Patricia (2011c), »Chewing on Post_colonial Switzerland. Redigesting what has not yet been swallowed, Part III«, in: Andrea Thal (Hg.), Chewing the Scenery 3, Zürich: Edition Fink, 41-44/67-70.

Purtschert, Patricia (2012a), »>De Schorsch Gaggo reist uf Afrika<. Postkoloniale Konstellationen und diskursive Verschiebungen in Schweizer Kindergeschichten«, in: Patricia Purtschert, Barbara Lüthi und Francesca Falk (Hg.), Postkoloniale Schweiz. Formen und Folgen eines Kolonialismus ohne Kolonien, Bielefeld: transcript, 89-116.

Purtschert, Patricia (2012b), »Postkoloniale Philosophie. Die westliche Denkgeschichte gegen den Strich lesen«, in: Julia Reuter und Alexandra Karentzos (Hg.), Schlüsselwerke der Postcolonial Studies, Wiesbaden: Springer, 343-354.

Purtschert, Patricia (2012c), »Jenseits des Naturzustandes. Eine postkoloniale Lektüre von Hobbes und Rousseau«, in: Deutsche Zeitschrift für Philosophie, 6o(6): 861-882.

Purtschert, Patricia (2013), »Jenseits des Réduit: Die Schweiz und die Berge in Zeiten der Dekolonisierung«, in: Schweizerische Zeitschrift für Geschichte, 63(2): 250-268. 
Purtschert, Patricia (2014), »The Return of the Native. Racialised Space, Colonial Debris and the Human Zoo«, in: Identities: Global Studies in Culture and Power, 22(4): 508-523.

Purtschert, Patricia (2015a), »From >Native< Alpine Guides to Foreign >Sahibs< in the Himalayas. Swiss Identity Formation at the Moment of Decolonization«, in: Patricia Purtschert und Harald Fischer-Tiné (Hg.), Colonial Switzerland. Rethinking Colonialism from the Margins, Basingstoke: Palgrave Macmillan, 179-199.

Purtschert, Patricia (2015b), »Aviation Skills, Manly Adventures and Imperial Tears. The Dhaulagiri Expedition and Switzerland's Techno-Colonialism«, in: National Identities, 18(1): 53-69.

Purtschert, Patricia (2016), »Weisse Waren«, in: Kurjaković, Daniel, Franziska Koch und Lea Pfäffli (Hg)): The Air Will Not Deny You. Zürich im Zeichen einer anderen Globalität, Zürich, Berlin: diaphanes, 68-71.

Purtschert, Patricia (2018), »Weisse Fantasien von schwarzem Neid: Eine postkoloniale Affektstudie«, in: Maria Mesner und Sushila Mesquita (Hg.), Eine emotionale Geschichte: Geschlecht im Zentrum der Politik der Affekte, Wien: Zaglossus, 105-130.

Purtschert, Patricia (im Erscheinen), »Democratising Switzerland: Challenging Whiteness in the Public Space«, in: Damir Skenderovic und Barbara Lüthi (Hg.), Switzerland and Migration. Historical and Current Perspectives on a Changing Landscape. Basingstoke: Palgrave Macmillan.

Purtschert, Patricia und Gesine Krüger (2012), »Afrika in Schweizer Kinderbüchern. Hybride Helden in kolonialen Konstellationen«, in: Manuel Menrath (Hg.), Afrika im Blick. Afrikabilder im deutschsprachigen Europa, 1870-1970, Zürich: Chronos, 69-98.

Purtschert, Patricia und Harald Fischer-Tiné (Hg.) (2015a), Colonial Switzerland. Rethinking Colonialism from the Margins, Basingstoke: Palgrave Macmillan.

Purtschert, Patricia und Harald Fischer-Tiné (2015b), »The End of Innocence. Debating Colonialism in Switzerland«, in: Patricia Purtschert und Harald Fischer-Tiné (Hg.), Colonial Switzerland. Rethinking Colonialism from the Margins, Basingstoke: Palgrave Macmillan, 1-25.

Purtschert, Patricia, Barbara Lüthi und Francesca Falk (Hg.) (2012a), Postkoloniale Schweiz. Formen und Folgen eines Kolonialismus ohne Kolonien, Bielefeld: transcript. 
Purtschert, Patricia, Barbara Lüthi und Francesca Falk (2012b), »Eine Bestandesaufnahme der postkolonialen Schweiz«, in: Patricia Purtschert, Barbara Lüthi und Francesca Falk (Hg.), Postkoloniale Schweiz. Formen und Folgen eines Kolonialismus ohne Kolonien, Bielefeld: transcript, 13-63.

Purtschert, Patricia, Francesca Falk und Barbara Lüthi (2015), »Switzerland and >Colonialism Without Colonies<. Reflections on the Status of Colonial Outsiders «, in: Interventions. International Journal of Postcolonial Studies 18(2): 286-302.

Quijano, Anibal (2000), »Coloniality of Power, Eurocentrism, and Latin America«, in: Nepantla: Views from South, 1(3): 533-580.

Rak, Julie (2007), »Social Climbing on Annapurna. Gender in High-Altitude Mountaineering Narratives«, in: English Studies in Canada, 33(1/2): 109-146.

Randeria, Shalini (2012), »Verflochtene Schweiz. Herausforderungen eines Postkolonialismus ohne Kolonien«, in: Patricia Purtschert, Barbara Lüthi und Francesca Falk (Hg.), Postkoloniale Schweiz. Formen und Folgen eines Kolonialismus ohne Kolonien, Bielefeld: transcript, 7-12.

Rao, Rahul (2010), Third World Protest: Between Home and the World, Oxford: Oxford University Press.

Rébuffat, Gaston (1999), Starlight and Storm, New York: Modern Library.

Reich, David (2007), Direkte Demokratie in der Krise. Die Funktion des Notrechts in der Schweiz während Weltwirtschaftskrise und Zweitem Weltkrieg dargestellt am Beispiel des Warenhausbeschlusses 1933-1945, Basel: Helbing und Lichtenhahn.

Reznicek, Felicitas von (1967), Von der Krinoline zum sechsten Grad, Salzburg: Das Bergland-Buch.

Rietmann, Tanja (2013), >Liederlich $<$ und >arbeitsscheu<. Die administrative Anstaltsversorgung im Kanton Bern (1884-1981), Zürich: Chronos.

Rietmann, Tanja (2017), Fürsorgerische Zwangsmassnahmen. Anstaltsversorgungen, Fremdplatzierungen und Entmündigungen in Graubünden im 19. und 20. Jahrhundert, Chur: Quellen und Forschungen zur Bündner Geschichte.

Ritter, Sabine (2010), Facetten der Sarah Baartman. Repräsentationen und Rekonstruktionen der »Hottentottenvenus«, Münster: LIT.

Roca, René (2012), »Sonderbund«, in: Historisches Lexikon der Schweiz. Download unter: www.hls-dhs-dss.ch/textes/d/D17241.php (Zugriff am 24. Oktober 2018). 
Roch, André (1946), »Vorwort«, in: Schweizerische Stiftung für Alpine Forschungen (Hg.), Berge der Welt 1, 11-12.

Roch, André (1952), Everest 1952, Genf: Jeheber.

Rohner, Melanie (2015). Farbbekenntnisse. Postkoloniale Perspektiven auf Max Frischs »Stiller« und »Homo Faber«. Bielefeld: Aisthesis.

Rosenbaum, Heidi (1982), Formen der Familie. Untersuchungen zum Zusammenhang von Familienverhältnissen, Sozialstruktur und sozialem Wandel in der deutschen Gesellschaft des 19. Jahrhunderts, Frankfurt a.M.: Suhrkamp.

Rossfeld, Roman (2007a), Schweizer Schokolade: Industrielle Produktion und kulturelle Konstruktion eines nationalen Symbols 1840-1920, Baden: hier + jetzt.

Rossfeld, Roman (2007b), »Markenherrschaft und Reklameschwung. Die schweizerische Schokoladenindustrie zwischen Produktions- und Marketingorientierung, 1860-1914«, in: Hartmut Berghoff (Hg.), Marketinggeschichte. Die Genese einer modernen Sozialtechnik, Frankfurt a.M.: Campus, 87-119.

Rossfeld, Roman (2012), »Schweizer Schokolade: Zum Verhältnis von Identität, Alterität und der Genese eines nationalen Symbols um 1900«, in: Oliver Kühschelm, Franz Xaver Eder und Hannes Siegrist (Hg.), Konsum und Nation. Zur Geschichte nationalisierender Inszenierungen in der Produktkommunikation, Bielefeld: transcript, 47-79.

Roten, Iris von (1991), Frauen im Laufgitter. Offene Worte zur Stellung der Frau, Zürich: eFeF-Verlag.

Said, Edward (1994a), Orientalism, New York: Vintage Books.

Said, Edward (1994b), Culture and Imperialism, London: Vintage Books.

Sanders, Angela (2015), »'Wonderland< Peru. Migration and the Making of an Andean Switzerland«, in: Patricia Purtschert und Harald Fischer-Tiné (Hg.), Colonial Switzerland. Rethinking Colonialism from the Margins, Basingstoke: Palgrave Macmillan, 110-132.

Sarasin, Fritz (1936), »Die Anschauungen der Völker über den Albinismus«, in: Schweizerisches Archiv für Volkskunde, 34: 198-233.

Sarasin, Philipp (2001), Reizbare Maschinen. Eine Geschichte des Körpers 1765-1914, Frankfurt a.M.: Suhrkamp.

Sarasin, Philipp (2003), Geschichtswissenschaft und Diskursanalyse, Frankfurt a.M.: Suhrkamp. 
Sarasin, Philipp und Regina Wecker (Hg.) (1998), Raubgold, Réduit, Flüchtlinge. Zur Geschichte der Schweiz im Zweiten Weltkrieg, Zürich: Chronos.

Sassatelli, Roberta (2011), »Gender«, in: Dale Southerton (Hg.), Encyclopedia of Consumer Culture, Thousand Oaks: Sage, 629-637.

Schade, Sigrid und Silke Wenk (2011), Studien zur visuellen Kultur. Einführung in ein transdisziplinäres Forschungsfeld, Bielefeld: transcript.

Schaffer, Johanna (2008), Ambivalenzen der Sichtbarkeit. Über die visuellen Strukturen der Anerkennung, Bielefeld: transcript.

Schär, Bernhard C. (2007), Harmonie mit Biss. Zur Geschichte der Kieferorthopädie und der Zahnärzteschaft im schweizerischen Gesundheitswesen, Gümligen: Schweizerische Gesellschaft für Kieferorthopädie.

Schär, Bernhard C. (2008a), »>Nicht mehr Zigeuner, sondern Roma!<. Emanzipation, Forschung und Strategien der Repräsentation einer >Roma-Nation««, in: Historische Anthropologie, 16(2): 205-226.

Schär, Bernhard C. (2008b), »Karies, Kulturpessimismus und KVG. Zur Geschichte der Zahnmedizin in der Schweiz«, in: Traverse. Zeitschrift für Geschichte, 2: 99-116.

Schär, Bernhard C. (2012), »Bauern und Hirten reconsidered. Umrisse der >erfundenen< Schweiz im imperialen Raum«, in: Patricia Purtschert, Barbara Lüthi und Francesca Falk (Hg.), Postkoloniale Schweiz. Formen und Folgen eines Kolonialismus ohne Kolonien, Bielefeld: transcript, 315-331.

Schär, Bernhard C. (2015a), Tropenliebe. Schweizer Naturforscher und niederländischer Imperialismus in Südostasien um 1900, Frankfurt a.M.: Campus.

Schär, Bernhard C. (2015b), »On the Tropical Origins of the Alps: Science and the Colonial Imagination of Switzerland, 1700-1900«, in: Patricia Purtschert und Harald Fischer-Tiné (Hg.), Colonial Switzerland. Rethinking Colonialism from the Margins, Basingstoke: Palgrave Macmillan, 29-49.

Schär, Bernhard C. (2016a), »Global und intersektional. Prolegomena zu einer noch neueren Geschichte der Schweiz«, in: Didactica Historica. Schweizerische Zeitschrift für Geschichtsdidaktik, 2: 49-54.

Schär, Bernhard C. (2016b), Borneo und Bundesstaat: Geschichte für das 21. Jahrhundert, in: NZZ Geschichte Nr. 6, Juli 2016. 
Schär, Bernhard C. und Béatrice Ziegler (2014), Antiziganismus in der Schweiz und Europa. Geschichte, Kontinuitäten und Reflexionen, Zürich: Chronos.

Schelbert, Leo (1976), Einführung in die schweizerische Auswanderungsgeschichte der Neuzeit, Zürich: Stämpfli.

Schiebinger, Londa (1989), The Mind has no Sex? Women in the Origins of Modern Science, Cambridge MA: Harvard University Press.

Schiebinger, Londa (1993), Nature's Body. Gender in the Making of Modern Science, Boston: Beacon Press.

Schlatter, Helene (1935), »Unsere Mädchenschule in Agogo (Asante)«, in: Der Heidenbote, 2(108): 24-27.

Schmid, Thomas und Daniel Anker (2013), »Die 35 Oltner >Gründerväter«, in: Daniel Anker (Hg.), Helvetia Club. 1863-2013, Bern: SAC Verlag, 55-66.

Schmidt-Linsenhoff, Viktoria (2005), »Weiße Blicke. Bild- und Textlektüren zu Geschlechtermythen des Kolonialismus«, in: Viktoria SchmidtLinsenhoff, Karl Hölz und Herbert Uerlings (Hg.), Weiße Blicke. Geschlechtermythen des Kolonialismus, Marburg: Jonas Verlag, 8-18.

Schmidt-Linsenhoff, Viktoria (2014), Ästhetik der Differenz: Postkoloniale Perspektiven vom 16. bis 21. Jahrhundert, Marburg: Jonas Verlag.

Schmidt-Linsenhoff, Viktoria, Karl Hölz und Herbert Uerlings (Hg.) (2005), Weiße Blicke. Geschlechtermythen des Kolonialismus, Marburg: Jonas Verlag.

Schmidt-Ott, Gabriela (2005), »Carl Egger«, in: Historisches Lexikon der Schweiz. Download unter: www.hls-dhs-dss.ch/textes/d/D44272.php (Zugriff am 3. November 2015).

Schutzbach, Franziska (2014), »Bevölkerung, Krise, Nation. Koloniale Kontinuitäten in demografischen Fertilitätsdebatten«, in: Karin Hostettler und Sophie Vögele, Diesseits der imperialen Geschlechterordnung. (Post-) koloniale Reflexionen über den Westen, Bielefeld: trans-cript, 77-106.

Schweizerische Stiftung für Alpine Forschungen (1947), Himalaya. Schweizerische Expedition 1947 Lohner - Sutter, Zürich: Interverlag.

Schweizerische Stiftung für Alpine Forschungen (1948), Berge der Welt. Fremde Berge - ferne Ziele, Bern: Verbandsdruckerei AG.

Schweizerische Stiftung für Alpine Forschungen (1953a), Everest. Ein Bildbericht, München: Nymphenburger Verlagshandlung. 
Schweizerische Stiftung für Alpine Forschungen (1953b), »Vorwort«, in: Schweizerische Stiftung für Alpine Forschungen (Hg.), Berge der Welt, Zürich: Büchergilde Gutenberg, 9-10.

Schweizerische Stiftung für Alpine Forschungen (1972), Schweizerische Stiftung für Alpine Forschungen 1939 bis 1970. Rückblick auf ihre 3ojährige Tätigkeit, Zürich: SSAF.

Schweizerischen Stiftung für Alpine Forschung (SSAF) (Hg.) (1948), Fremde Berge - Ferne Ziele. Das Werk schweizerischer Forscher und Bergsteiger im Ausland, Bern: Verbandsdr. AG.

Scott, Joan W. (1996), Only Paradoxes to Offer. French Feminists and the Rights of Man, Cambridge MA: Harvard University Press.

Senger, Max (1945), Wie die Schweizer Alpen erobert wurden, Zürich: Büchergilde Gutenberg.

Senn, Hans (2010), »Réduit«, in: Historisches Lexikon der Schweiz. Download unter: http://www.hls-dhs-dss.ch/textes/d/D8696.php (Zugriff am 24. Oktober 2018).

Sharp, Joanne P. (1996), »Gendering Nationhood. A Feminist Engagement with Nation«, in: Nancy Duncan (Hg.), Bodyspace. Destabilizing Geographies of Gender and Sexuality, London: Routledge, 97-108.

Sill, Ulrike (2010), Encounters in Quest of Christian Womanhood. The Basel Mission in Pre- and Early Colonial Ghana, Leiden: Brill.

Simler, Theodor (2013), »Kreisschreiben«, in: Daniel Anker (Hg.), Helvetia Club. 1863-2013, Bern: SAC Verlag, 54.

Sinha, Mrinalini (1995), Colonial Masculinity. The >Manly Englishman< and the >Effeminate Bengali< in the Late Nineteenth Century, Manchester: Manchester University Press.

Skenderovic, Damir (2015a), »Fremdenfeindlichkeit«, in: Historisches Lexikon der Schweiz. Download unter: www.hls-dhs-dss.ch/textes/d/ D16529.php (Zugriff am 20. September 2015).

Skenderovic, Damir (2015b), »Schweizerische Volkspartei (SVP)«, in: Historisches Lexikon der Schweiz. Download unter: www.hls-dhs-dss.ch/ textes/d/D17389.php (Zugriff am 17. September 2015).

Slemon, Stephen (2000), »Climbing Mount Everest. Postcolonialism in the Culture of Ascent«, in: Rowland Smith (Hg.), Postcolonising the Commonwealth, Kitchener: Wilfried Laurier University Press, 51-73.

Slemon, Stephen (2008), »The Brotherhood of the Rope. Commodification and Contradiction in the >Mountaineering Community« «, in: Diana Brydon und William D. Coleman (Hg.), Renegotiating Community. 
Interdisciplinary Perspectives, Global Contexts, Vancouver: UBC Press, 234-245.

Sommer, Marianne (2005), »How Cultural is Heritage? Humanity's Black Sheep from Charles Darwin to Jack London«, in: Max-Planck-Institut für Wissenschaftsgeschichte (Hg.), A Cultural History of Heredity III: $19^{\text {th }}$ and Early $20^{\text {th }}$ Centuries, Berlin: Max-Planck-Institut, 233-253.

Sommer, Marianne (2007), Bones and Ochre. The Curious Afterlife of the Red Lady of Paviland, Cambridge MA: Harvard University Press.

Sommer, Marianne (2010), »>Wer sind Sie wirklich?< - Identität und Geschichte in der >Gensequenz««, in: L'Homme. Europäische Zeitschrift für Feministische Geschichtswissenschaft, 21(2): 51-70.

Sommer, Marianne (2015), Evolutionäre Anthropologie zur Einführung, Hamburg: Junius.

Speich Chassé, Daniel (2012), »Verflechtung durch Neutralität. Wirkung einer Schweizer Maxime im Zeitalter der Dekolonisation«, in: Patricia Purtschert, Barbara Lüthi und Francesca Falk (Hg.), Postkoloniale Schweiz. Formen und Folgen eines Kolonialismus ohne Kolonien, Bielefeld: transcript, 225-244.

Spivak, Gayatri Chakravorty (1985), »The Rani of Sirmur«, in: Francis Barker (Hg.), Europe and its Others. Proceedings of the Essex Conference on the Sociology of Literature, July 1984. Band 2, Colchester: University of Essex, 128-151.

Spivak, Gayatri Chakravorty (1999), A Critique of Postcolonial Reason. Toward a History of the Vanishing Present, Cambridge MA: Harvard University Press.

Spivak, Gayatri Chakravorty (2008), Can the Subaltern Speak? Postkolonialität und subalterne Artikulation, Wien: Turia + Kant.

Staehelin, Balthasar (1993), Völkerschauen im zoologischen Garten Basel, 1879-1935, Basel: Basler Afrika Bibliographien.

Stafford, Robert A. (1999), »Scientific Exploration and Empire«, in: Andrew Porter (Hg.), The Oxford History of the British Empire. Vol. 3, The Nineteenth Century, Oxford: Oxford University Press, 294-319.

Stalder, Anne-Marie (1984), »Die Erziehung zur Häuslichkeit: über den Beitrag des hauswirtschaftlichen Unterrichts zur Disziplinierung der Unterschichten im 19. Jahrhundert in der Schweiz«, in: Schweizerische Zeitschrift für Geschichte, 34: 370-384.

Stämpfli, Regula (2003), »Triumph der Geschlechtertrennung in der Schweiz 1918-1945«, in: Christof Dejung und Regula Stämpfli (Hg.), 
Armee, Staat und Geschlecht. Die Schweiz im internationalen Vergleich 1918-1945. Zürich: Chronos, 213-228.

Stearns, Peter N. (2010), Consumerism in World History. The Global Transformation of Desire, London: Routledge.

Steck, Ueli und Karin Steinbach (2016), Der nächste Schritt. Nach jedem Berg bin ich ein anderer, München: Malik Verlag.

Stephen, Leslie (1936), Der Tummelplatz Europas, München: Gesellschaft alpiner Bücherfreunde.

Stewart, Gordon T. (1980), »The British Reaction to the Conquest of Everest«, in: Journal of Sport History, 7: 21-39.

Stewart, Gordon T. (1995), »Tenzing's Two Wrist-Watches. The Conquest of Everest and Late Imperial Culture in Britain 1921-1953: Reply«, in: Past \& Present, 149(1): 178-190.

Steyerl, Hito und Encarnación Gutiérrez Rodriguez (Hg.) (2003), Spricht die Subalterne deutsch? Migration und postkoloniale Kritik, Münster: Unrast.

Stoler, Ann Laura (2008), »Imperial Debris: Reflections on Ruins and Ruination«, in: Cultural Anthropology, 23(2): 191-219.

Stoler, Ann Laura (2011), »Colonial Aphasia. Race and Disabled Histories in France«, in: Public Culture, 23(1): 121-156.

Stoler, Ann Laura und Frederick Cooper (1997), »Between Metropole and Colony. Rethinking a Research Agenda«, in: Frederick Cooper und Ann Laura Stoler (Hg.), Tensions of Empire. Colonial Cultures in a Bourgeois World, Berkeley: University of California Press, 1-56.

Studer, Brigitte (2001a), »Umschichtungen und Umstrukturierungen der weiblichen Erwerbstätigkeit in der Schweiz 1900-1960«, in: Regina Wecker, Brigitte Studer und Gaby Sutter (Hg.), Die >schutzbedürftige Frau<. Zur Konstruktion von Geschlecht durch Mutterschaftsversicherung, Nachtarbeitsverbot und Sonderschutzgesetzgebung, Zürich: Chronos, 7382 .

Studer, Brigitte (2001b), »Neue Grenzziehungen zwischen Frauenarbeit und Männerarbeit in den dreissiger Jahren und während des Zweiten Weltkriegs. Die Kampagne gegen das >Doppelverdienertum««, in: Regina Wecker, Brigitte Studer und Gaby Sutter (Hg.), Die >schutzbedürftige Frau<. Zur Konstruktion von Geschlecht durch Mutterschaftsversicherung, Nachtarbeitsverbot und Sonderschutzgesetzgebung, Zürich: Chronos, 83-106. 
Studer, Brigitte (2008), »Von einer exklusiven zu einer integrativen Bürgerrechtspolitik? 1934-2004«, in: Brigitte Studer, Gérald Arlettaz und Regula Argast (Hg.), Das Schweizer Bürgerrecht. Erwerb, Verlust, Entzug von 1848 bis zur Gegenwart, Zürich: Verlag Neue Zürcher Zeitung, 99-148.

Studer, Brigitte (2014a), »Das Frauenstimm- und -wahlrecht in der Schweiz 1848-1971. Ein >Fall< für die Geschlechtergeschichte«, in: Sabine Braunschweig (Hg.), >Als habe es die Frauen nicht gegeben<. Beiträge zur Frauen- und Geschlechtergeschichte. Zürich: Chronos, 179-195.

Studer, Brigitte (2014b), »Die Geschichte des Frauenstimm- und wahlrechts. Ein Misserfolgsnarrativ«, in: Georg Kreis (Hg.), Die Geschichte der Schweiz, Basel: Schwabe, 544-547.

Surber, Kaspar (2014), Eine fliegende Dunkelkammer - Walter Mittelholzers >Afrikaflüge< (1926-1934) als mediale Unternehmungen und die Gründung der Swissair, Universität Zürich, unveröffentlichte Lizentiatsarbeit.

Surber, Kaspar (2017), Walter Mittelholzer Revisited: Aus dem Fotoarchiv von Walter Mittelholzer, From the Walter Mittelholzer Photography Archive, Zürich: Scheidegger \& Spiess.

Sweeney, Carole (2004), From Fetish to Subject. Race, Modernism, and Primitivism 1919-1935, Westport: Praeger.

Tanner, Jakob (1997), »Diskurse der Diskriminierung. Antisemitismus, Sozialdarwinismus und Rassismus in den schweizerischen Bildungseliten«, in: Michael Graetz und Aram Mattioli (Hg.), Krisenwahrnehmungen im Fin de siècle. Jüdische und katholische Bildungseliten in Deutschland und der Schweiz, Zürich: Chronos, 323-340.

Tanner, Jakob (1999), »Switzerland and the Cold War: A Neutral Country between the >American Way of Life< and >Geistige Landesverteidigung «, in: Joy Charnley und Malcom Pender (Hg.), Switzerland and War, Bern: Peter Lang, 113-128.

Tanner, Jakob (2015), Geschichte der Schweiz im 20. Jahrhundert, München: C.H. Beck.

Tanner, Jakob und Brigitte Studer (2012), »Konsum und Distribution«, in: Patrick Halbeisen, Margrit Müller und Béatrice Veyrassat (Hg.), Wirtschaftsgeschichte der Schweiz im 20. Jahrhundert, Basel: Schwabe, 637-702.

Thode-Arora, Hilke (1989), Für fünfzig Pfennig um die Welt. Die Hagenbeckschen Völkerschauen, Frankfurt a.M.: Campus. 
Tinsley, Omise'eke Natasha (2008), »Black Atlantic, Queer Atlantic. Queer Imaginings of the Middle Passage «, in: GLQ: A Journal of Lesbian and Gay Studies, 14 (2/3): 191-215.

Tissberger, Martina, Gabriele Dietze, Daniela Hrzan und Jana Husmann-Kastein (Hg.) (2006), Weiss - Weisssein - Whiteness. Kritische Studien zu Gender und Rassismus, Frankfurt a.M.: Peter Lang, 219-247.

Tobler, Theodor (1917), Der Kakao, die Schweizer Schokolade-Industrie und ihre Verbreitung im Auslande, Bern: [ohne Verlagsangabe].

UNESCO (1969), »Four Statements on the Question of Race«, Paris: United Nations. Download unter: http://unesdoc.unesco.org/ images/0012/001229/122962eo.pdf (Zugriff am 17. September 2015).

Unsworth, Walt (1989), Everest, London: Grafton.

Unterweger, Claudia (2016), Talking Back. Strategien Schwarzer österreichischer Geschichtsschreibung, Wien: Zaglossus.

Valär, Rico Franc (2013), Weder Italiener noch Deutsche! Die rätoromanische Heimatbewegung 1863-1938, Baden: hier + jetzt.

Vergès, Françoise (2005), »Postface«, in: Aimé Césaire, Nègre je suis, nègre je resterai, Paris: Editions Albin Michel, 71-136.

Vuorela, Ulla (2009), »Colonial Complicity. The >Postcolonial< in a Nordic Context«, in: Suvi Keskinen, Salla Tuori, Sari Irni und Diana Mulinari (Hg.), Complying with Colonialism. Gender, Race and Ethnicity in the Nordic Region, Farnham: Ashgate, 19-33.

Waberi, Abdourahman (2007), In den Vereinigten Staaten von Afrika, Hamburg: Nautilus.

Walgenbach, Katharina (2005), »Die weisse Frau als Trägerin deutscher Kultur«. Koloniale Diskurse über Geschlecht, >Rasse und Klasse im Kaiserreich, Frankfurt a.M.: Campus.

Ward, Stuart (2001), British Culture and the End of Empire, Manchester: Manchester University Press.

Wekker, Gloria (2004), »Still Crazy After All Those Years... Feminism for the New Millenium«, in: European Journal of Women's Studies, 11(4): 487-500.

Wekker, Gloria (2014), »Diving into the Wreck. Intersections of Sexuality, $>$ Race $<$, Gender, and Class in the Dutch Cultural Archive«, in: Philomena Essed und Isabel Hoving (Hg.), Dutch Racism, Amsterdam: Rodophi, 159-178.

Wekker, Gloria (2016), White Innocence: Paradoxes of Colonialism and Race, Durham: Duke University Press. 
Westad, Odd Arne (2010), »The Cold War and the international history of the twentieth century«, in: Leffler, Melvyn P. und Odd Arne Westad (Hg.), The Cambridge History of the Cold War Volume I: Origins, Cambridge: Cambridge University Press, 1-19.

Whelpton, John (2005), A History of Nepal, Cambridge: Cambridge University Press.

Wirz, Tanja (2007), Gipfelstürmerinnen. Eine Geschlechtergeschichte des Alpinismus in der Schweiz 1840-1940, Baden: hier + jetzt.

Witzig, Heidi (1998), »Von der Mutter der Nation zur stummen Partnerin mit besonderen Aufgaben. Frauen in der Schweiz vor 1945«, in: Lynn Blattmann und Irène Meier (Hg.), Männerbund und Bundesstaat. Über die politische Kultur der Schweiz, Zürich: Orell Füssli, 177-197.

Wolf, Walter (2008), »Paul Lang«, in: Historisches Lexikon der Schweiz. Download unter: www.hls-dhs-dss.ch/textes/d/D28231.php (Zugriff am 29. September 2015).

Wollrad, Eske (2005), Weisssein im Widerspruch. Feministische Perspektiven auf Rassismus, Kultur und Religion, Königstein/Taunus: Ulrike Helmer Verlag.

Wolter, Stefanie (2005), Die Vermarktung des Fremden. Exotismus und die Anfänge des Massenkonsums, Frankfurt a.M.: Campus.

Wydler, Henry (2010), »Pionierjahre des Motorflugzeugs«, in: Historisches Lexikon der Schweiz. Download unter: www.hls-dhs-dss.ch/textes/d/ D26302.php (Zugriff am 15. Juli 2014).

Wyss, Hans A. (1933a), »Die jüdische Situation. Ein Beitrag zur Judenfrage, Teil 1«, in: Schweizer Monatshefte, 6: 274-282.

Wyss, Hans A. (1933b), »Die jüdische Situation. Ein Beitrag zur Judenfrage, Teil 3«, in: Schweizer Monatshefte, 8: 355-366.

Wyss-Dunant, Edouard (1952), »Introduction«, in: André Roch, Everest 1952, Genf: Editions Jeheber, 7-15.

Zala, Sacha (2014), »Wirtschaft und Politik in der Zwischenkriegszeit«, in: Georg Kreis (Hg.), Die Geschichte der Schweiz, Basel: Schwabe, 503514 .

Zangger, Andreas (2011), Koloniale Schweiz. Ein Stück Globalgeschichte zwischen Europa und Südostasien (1860-1930), Bielefeld: transcript.

Zantop, Susanne (1997), Colonial Fantasies. Conquest, Family and Nation in Precolonial Germany, 1770-1870, Durham: Duke University Press.

Ziegler, Béatrice (1996), » Kampf dem Doppelverdienertum!<. Die Bewegung gegen die Qualifizierung weiblicher Erwerbsarbeit in der Zwi- 
schenkriegszeit in der Schweiz«, in: Ulrich Pfister, Brigitte Studer und Jakob Tanner (Hg.), Arbeit im Wandel. Deutung, Organisation und Herrschaft vom Mittelalter bis zur Gegenwart, Zürich: Chronos, 85-104. Ziegler, Béatrice (1998). Der Bieler »Milchkrieg« 1930/1931 - Konsumentinnen organisieren sich, in: Jakob Tanner, Béatrice Veyrassat, Jon Mathieu, Hannes Siegrist und Regina Wecker (Hg.), Geschichte der Konsumgesellschaft. Märkte, Kultur und Identität (15-20.Jahrhundert)). Zürich: Chronos, 117-132.

Zimmer, Oliver (1998), »In Search of Natural Identity. Alpine Landscape and the Reconstruction of the Swiss Nation«, in: Society for the Comparative Study of Society and History, 40, 638-665.

Zurbriggen, Matthias (1937), Von den Alpen zu den Anden. Lebenserinnerungen eines Bergführers, Berlin: Roth.

Zürcher, Lukas (2014), Die Schweiz in Ruanda. Mission, Entwicklungshilfe und nationale Selbstbestätigung (1900-1975), Zürich: Chronos. 


\section{Kulturwissenschaft}
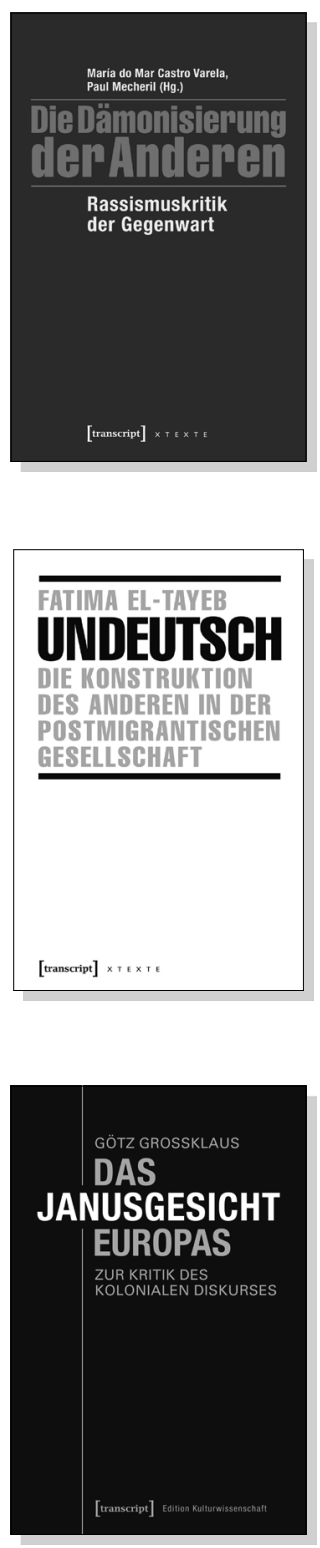

María do Mar Castro Varela, Paul Mecheril (Hg.) Die Dämonisierung der Anderen

Rassismuskritik der Gegenwart

2016, 208 S., kart.

$17,99 €(D E), 978-3-8376-3638-3$

E-Book

PDF: $15,99 €(D E)$, ISBN 978-3-8394-3638-7

EPUB: $15,99 €(D E)$, ISBN 978-3-7328-3638-3

Fatima El-Tayeb

\section{Undeutsch}

Die Konstruktion des Anderen

in der postmigrantischen Gesellschaft

2016, 256 S., kart.

$19,99 €(D E), 978-3-8376-3074-9$

E-Book: 17,99 € (DE), ISBN 978-3-8394-3074-3

Götz Großklaus

Das Janusgesicht Europas

Zur Kritik des kolonialen Diskurses

2017, 230 S., kart., z.T. farb. Abb.

$24,99 €(D E), 978-3-8376-4033-5$

E-Book: 21,99€ (DE), ISBN 978-3-8394-4033-9 


\section{Kulturwissenschaft}
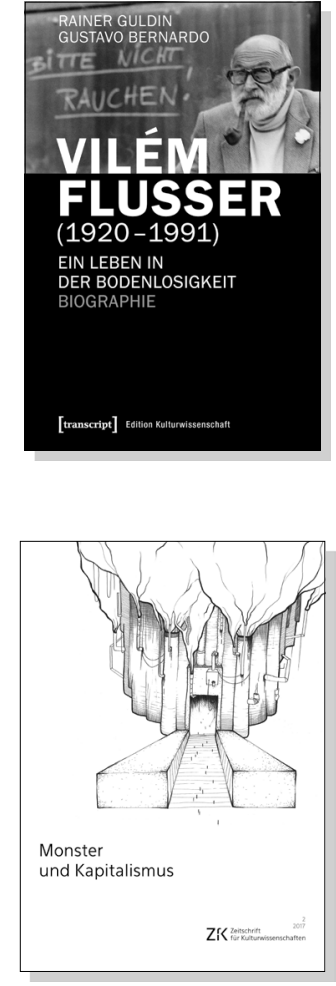

\section{POP}

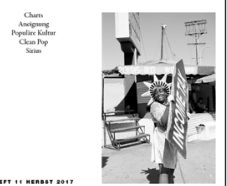

[transcript]
Rainer Guldin, Gustavo Bernardo

Vilém Flusser (1920-1991)

Ein Leben in der Bodenlosigkeit. Biographie

2017, 424 S., kart., zahlr. Abb.

$34,99 €(D E), 978-3-8376-4064-9$

E-Book: $34,99 €(D E)$, ISBN 978-3-8394-4064-3

Till Breyer, Rasmus Overthun,

Philippe Roepstorff-Robiano, Alexandra Vasa (Hg.)

Monster und Kapitalismus

Zeitschrift für Kulturwissenschaften, Heft 2/2017

2017, 136 S., kart.

$14,99 €(D E), 978-3-8376-3810-3$

E-Book: 14,99 € (DE), ISBN 978-3-8394-3810-7

Thomas Hecken, Moritz Baßler, Robin Curtis, Heinz Drügh, Mascha Jacobs, Nicolas Pethes, Katja Sabisch (Hg.)

POP

Kultur \& Kritik (Jg. 6, 2/2017)

2017, 176 S., kart., zahlr. Abb.

$16,80 €(D E), 978-3-8376-3807-3$

E-Book: $16,80 €(D E)$, ISBN 978-3-8394-3807-7 
